This item was submitted to Loughborough's Research Repository by the author.

Items in Figshare are protected by copyright, with all rights reserved, unless otherwise indicated.

\title{
Chemically vapour deposited a-alumina coatings on high speed steel cutting tools
}

PLEASE CITE THE PUBLISHED VERSION

PUBLISHER

(C) Zakia Naeem

LICENCE

CC BY-NC-ND 4.0

REPOSITORY RECORD

Naeem, Zakia. 2014. "Chemically Vapour Deposited A-alumina Coatings on High Speed Steel Cutting Tools". figshare. https://hdl.handle.net/2134/14130. 


\section{Loughborough University}

This item was submitted to Loughborough University as a PhD thesis by the author and is made available in the Institutional Repository

(https://dspace.lboro.ac.uk/) under the following Creative Commons Licence conditions.

\section{cc) creative}

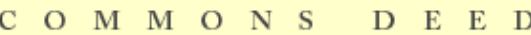

Attribution-NonCommercial-NoDerivs 2.5

You are free:

- to copy, distribute, display, and perform the work

Under the following conditions:

Attribution. You must attribute the work in the manner specified by the author or licensor.

Noncommercial. You may not use this work for commercial purposes.

No Derivative Works. You may not alter, transform, or build upon this work.

- For any reuse or distribution, you must make clear to others the license terms of this work.

- Any of these conditions can be waived if you get permission from the copyright holder.

Your fair use and other rights are in no way affected by the above.

This is a human-readable summary of the Leqal Code (the full license).

Disclaimer 민

For the full text of this licence, please go to: http://creativecommons.org/licenses/by-nc-nd/2.5/ 
LOUGHBOROUGH

UNIVERSITY OF TECHNOLOGY LIBRARY

AUTHOR/FILING TITLE

NAEEM,LZ

ACCESSION/COPY NO.

\begin{tabular}{|l|l} 
GrO & CLASS MARK \\
\hline VOL. NO. & LU A \\
\hline 25 JUN 1999 & LON CORY
\end{tabular}

- 6 DEC ISP

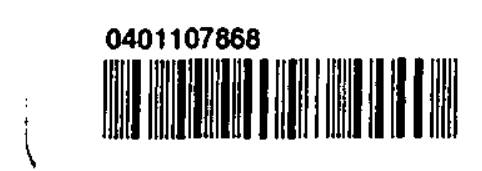




\title{
CHEMICALLY VAPOUR DEPOSITED $\alpha$ - ALUMINA COATINGS ON HIGH SPEED STEEL CUTTING TOOLS
}

by

\author{
Zakia Naeem, B.Sc.(Hons) \\ A Doctoral Thesis Submitted in Partial Fulfilment \\ of the requirements for the Award of \\ Doctor of Philosophy \\ of \\ Loughborough University of Technology
}

December 1994

Supervisor: Dr. A. B. Smith

Institute of Polymer Technology and Materials Engineering (IPTME)

Loughborough University of Technology, UK

(C) Zakia Naeem 1994 


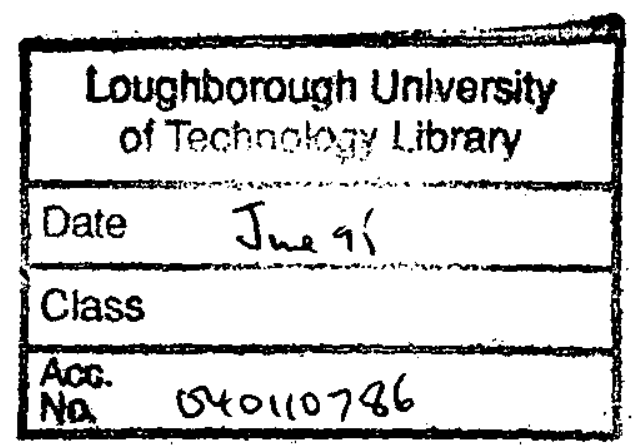


To my loving parents,

Sheikh Mohamed Maven and Mafia Maser for their devotion and encouragement over the years 


\section{ACKNOWLEDGEMENTS}

I would like to express my thanks to my research supervisor Dr A. B. Smith for his invaluable advice and encouragement throughout the course of the experimental work and during the writing of this thesis. I am indebted for his constant support and constructive criticism over the years and above all, inexhaustible patience. I wish to thank the European Union for their support within the EURAM project MA1E-0006-C(TT) and Loughborough University of Technology for the award of a University Studentship which enabled me to complete the research begun within the EURAM project. I would also like to thank Dr. D. R. Gabe, my Director of Research, and Dr. M. Gilbert, Director of the Institute of Polymer Technology and Materials Engineering, for the provision of research facilities.

Further, I would like to thank Edgar Allen Tools Limited, Sheffield, for the provision of the powder metallurgy high speed steel inserts and the use of their Plansee reactor for the chemical vapour deposition of the titanium carbonitride coatings. Thanks are also due to Diffusion Alloys Limited, Hatfield, for their assistance with aspects of the construction of the laboratory-scale CVD reactor.

I wish to thank the technical staff, particularly Mr. K. Ellison and Mr. C. Lines, and the departmental secretaries of the Institute of Polymer Technology and Materials Engineering for all their help and kindness shown to me during the course of this work. I am especially grateful to Mr. F. Page for his help in obtaining many of the SEM micrographs in this thesis.

Finally, I would like to thank my dear husband, Sajed, for all his patience, understanding and support throughout the writing of this thesis, without him I would not have achieved this goal. I am also grateful to Shumaila, Tayyauba, Iqbal and Samar whose cheerfulness made this aspect of the work enjoyable. 


\section{SYNOPSIS}

A detailed study has been made of the atmospheric pressure chemical vapour deposition (CVD) of aluminium oxide $\left(\mathrm{Al}_{2} \mathrm{O}_{3}\right)$ coatings on powder metallurgy (PM) BT42 grade high speed steel (HSS) indexable cutting tool inserts. To facilitate this, a laboratory-scale CVD reactor was initially designed and purpose-built.

The literature on the effect of process parameters on $\mathrm{Al}_{2} \mathrm{O}_{3}$ coatings chemically vapour deposited on cemented carbide substrates was comprehensively surveyed. With reference to deposition conditions quoted in this literature, a series of trial $\mathrm{Al}_{2} \mathrm{O}_{3}$ coating runs were then performed using uncoated and TiN, TiC and Ti(C,N) precoated PM HSS inserts. Concurrently, modifications to the laboratory-scale CVD reactor were made. Eventually, deposition conditions were established under which a preliminary $\alpha-\mathrm{Al}_{2} \mathrm{O}_{3}$ coating could be deposited on the PM HSS inserts and, in the case of the Ti(C,N) precoated inserts only, substantially retained during the obligatory post-coating HSS substrate heat treatment. The effect of the absence/presence and type of precoating on the CVD of $\mathrm{Al}_{2} \mathrm{O}_{3}$ coatings on the PM HSS inserts are discussed. Subsequent coating runs were carried out only on $\mathrm{Ti}(\mathrm{C}, \mathrm{N})$ precoated inserts.

The characteristics of the preliminary $\mathrm{Al}_{2} \mathrm{O}_{3}$ coating on the Ti(C,N) precoated PM HSS inserts were determined, both before and after the obligatory HSS substrate heat treatment, using an established characterisation procedure. This involved the following techniques: X-ray diffraction, Auger electron spectroscopy, optical microscopy, fractography, scanning electron microscopy, microhardness testing, profilometry and scratch-adhesion testing. Although many of the characteristics of the preliminary $\mathrm{Al}_{2} \mathrm{O}_{3}$ coating were found to be inferior to those presented in the literature, they were also established to be essentially unaffected by the post-coating HSS substrate heat treatment.

To improve upon the preliminary $\mathrm{Al}_{2} \mathrm{O}_{3}$ coating, the effect of two of the most important CVD process parameters quoted in the literature; $\mathrm{CO}_{2} / \mathrm{H}_{2}$ mole ratio and $\mathrm{AlCl}_{3}$ concentration, on the characteristics of $\mathrm{Al}_{2} \mathrm{O}_{3}$ coatings chemically vapour deposited on the $\mathrm{Ti}(\mathrm{C}, \mathrm{N})$ precoated PM HSS inserts was investigated. Both parameters were found to have a significant effect on $\mathrm{Al}_{2} \mathrm{O}_{3}$ coating characteristics. The reasons for this are discussed in detail. 


\subsection{EFFECT OF PROCESS PARAMETERS ON CHEMICALLY VAPOUR} DEPOSITED $\mathrm{Al}_{2} \mathrm{O}_{3}$ COATINGS - PREVIOUS WORK

2.1 Effect of Substrate

2.2 Effect of Deposition Time

2.3 Effect of Deposition Temperature ..................................................... 12

2.4 Effect of Total Pressure ...................................................................... 17

2.5 Effect of Reactant Gas Concentration .................................................. 19

2.5.1 Effect of Partial Pressure ........................................................... 20

2.5.2 Effect of Mole Ratio ..................................................................... 24

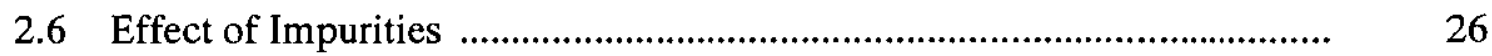

2.7 Effect of Other Process Variables ...................................................... 30

2.8 Characteristics of Commercial-Type CVD Al $\mathrm{O}_{3}$ Coatings ..................... 33

Figures 2.1 to 2.11

\subsection{DESIGN AND CONSTRUCTION OF LABORATORY-SCALE $\mathrm{Al}_{2} \mathrm{O}_{3}$} CVD REACTOR AND TRIAL $\mathrm{Al}_{2} \mathrm{O}_{3}$ COATING DEPOSITION .

3.1 Uncoated/Precoated PM HSS Inserts

3.2 Design and Basic Construction of Laboratory-Scale $\mathrm{Al}_{2} \mathrm{O}_{3}$ CVD Reactor

3.2.1 Design of laboratory-scale $\mathrm{Al}_{2} \mathrm{O}_{3}$ CVD reactor

3.2.2 Basic construction of laboratory-scale $\mathrm{Al}_{2} \mathrm{O}_{3} \mathrm{CVD}$ reactor

3.3 Trial $\mathrm{Al}_{2} \mathrm{O}_{3}$ Coating Runs and Reactor Modifications

3.3.1 Initial $\mathrm{Al}_{2} \mathrm{O}_{3}$ coating runs

3.3.2 Aluminide coating of 316 stainless steel reactor coating chamber parts

3.3.3 Replacement of aluminised 316 stainless steel reactor coating chamber parts with Inconel 600 
Figures 3.1 to 3.17

Tables 3.1 to 3.2

\subsection{EXPERIMENTAL WORK AND RESULTS (I)-CHARACTERISATION} OF PRELIMINARY CVD Al $\mathrm{O}_{3}$ COATINGS

4.1 Characterisation of Preliminary CVD $\mathrm{Al}_{2} \mathrm{O}_{3}$ Coatings on As-coated PM HSS Inserts

4.1.1 X-ray diffraction .................................................................... 52

4.1.2 Auger electron spectroscopy ....................................................... 55

4.1.3 Surface roughness assessment …................................................ 56

4.1.4 Optical microscopy - cross-section ….......................................... 56

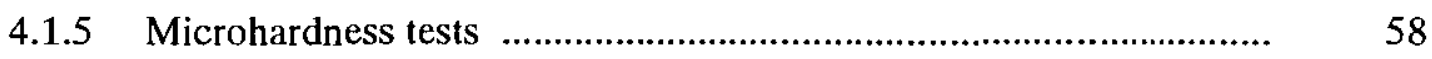

4.1.6 Optical microscopy - taper section ….......................................... 59

4.1.7 Fractography .......................................................................... 59

4.2 Characterisation of Preliminary CVD $\mathrm{Al}_{2} \mathrm{O}_{3}$ Coatings on Heat treated, Coated PM HSS inserts .................................................................... 60

4.3 Epilogue

Figures 4.1 to 4.24

Tables 4.1 to 4.11

5.0 EXPERIMENTAL WORK AND RESULTS (II)-EFFECT OF CO $/ \mathrm{H}_{2}$ MOLE RATIO AND $\mathrm{AlCl}_{3}$ CONCENTRATION ON CHARACTERISTICS OF CVD $\mathrm{Al}_{2} \mathrm{O}_{3}$ COATINGS

5.1 Effect of $\mathrm{CO}_{2} / \mathrm{H}_{2}$ Mole Ratio

5.1.1 Effect of $\mathrm{CO}_{2} / \mathrm{H}_{2}$ mole ratio on $\mathrm{Al}_{2} \mathrm{O}_{3}$ coating thickness

5.1.2 Effect of $\mathrm{CO}_{2} / \mathrm{H}_{2}$ mole ratio on preferred orientation and lattice parameter of $\mathrm{Al}_{2} \mathrm{O}_{3}$ coatings

5.1.3 Effect of $\mathrm{CO}_{2} / \mathrm{H}_{2}$ mole ratio on composition of $\mathrm{Al}_{2} \mathrm{O}_{3}$ coating and $\mathrm{Al}_{2} \mathrm{O}_{3}$ coating/Ti $(\mathrm{C}, \mathrm{N})$ precoating interface.

5.1.4 Effect of $\mathrm{CO}_{2} / \mathrm{H}_{2}$ mole ratio on surface roughness of $\mathrm{Al}_{2} \mathrm{O}_{3}$ coatings 
5.1.5 Effect of $\mathrm{CO}_{2} / \mathrm{H}_{2}$ mole ratio on peripheral thickness variation (and other features) of $\mathrm{Al}_{2} \mathrm{O}_{3}$ coatings

5.1.6 Effect of $\mathrm{CO}_{2} / \mathrm{H}_{2}$ mole ratio on $\mathrm{Al}_{2} \mathrm{O}_{3}$ coating microhardness

5.1.7 Effect of $\mathrm{CO}_{2} / \mathrm{H}_{2}$ mole ratio on microstructure of $\mathrm{Al}_{2} \mathrm{O}_{3}$ coating adjacent to interface with $\mathrm{Ti}(\mathrm{C}, \mathrm{N})$ precoating

5.1.8 Effect of $\mathrm{CO}_{2} / \mathrm{H}_{2}$ mole ratio on bulk and surface grain structures of $\mathrm{Al}_{2} \mathrm{O}_{3}$ coatings

5.1.9 Effect of $\mathrm{CO}_{2} / \mathrm{H}_{2}$ mole ratio on adhesion of $\mathrm{Al}_{2} \mathrm{O}_{3}$ coatings

5.2 Effect of $\mathrm{H}_{2}-1 / \mathrm{AlCl}_{3}$ Flow Rate $\left(\mathrm{AlCl}_{3}\right.$ Concentration)

5.2.1 Effect of $\mathrm{H}_{2}-1 / \mathrm{AlCl}_{3}$ flow rate on $\mathrm{Al}_{2} \mathrm{O}_{3}$ coating thickness

5.2.2 Effect of $\mathrm{H}_{2}-1 / \mathrm{AlCl}_{3}$ flow rate on preferred orientation and lattice parameter of $\mathrm{Al}_{2} \mathrm{O}_{3}$ coatings

5.2.3 Effect of $\mathrm{H}_{2}-1 / \mathrm{AlCl}_{3}$ flow rate on composition of $\mathrm{Al}_{2} \mathrm{O}_{3}$ coating and $\mathrm{Al}_{2} \mathrm{O}_{3}$ coating/Ti(C,N) precoating interface

5.2.4 Effect of $\mathrm{H}_{2}-1 / \mathrm{AlCl}_{3}$ flow rate on surface roughness of $\mathrm{Al}_{2} \mathrm{O}_{3}$ coatings

5.2.5 Effect of $\mathrm{H}_{2}-1 / \mathrm{AlCl}_{3}$ flow rate on peripheral thickness variation (and other features) of $\mathrm{Al}_{2} \mathrm{O}_{3}$ coatings

5.2.6 Effect of $\mathrm{H}_{2}-1 / \mathrm{AlCl}_{3}$ flow rate on $\mathrm{Al}_{2} \mathrm{O}_{3}$ coating microhardness ......

5.2.7 Effect of $\mathrm{H}_{2}-1 / \mathrm{AlCl}_{3}$ flow rate on microstructure of $\mathrm{Al}_{2} \mathrm{O}_{3}$ coating adjacent to interface with $\mathrm{Ti}(\mathrm{C}, \mathrm{N})$ precoating

5.2.8 Effect of $\mathrm{H}_{2}-1 / \mathrm{AlCl}_{3}$ flow rate on bulk and surface grain structures of $\mathrm{Al}_{2} \mathrm{O}_{3}$ coatings

5.2.9 Effect of $\mathrm{H}_{2}-1 / \mathrm{AlCl}_{3}$ flow rate on adhesion of $\mathrm{Al}_{2} \mathrm{O}_{3}$ coatings

Figures 5.1 to 5.55

Tables 5.1 to 5.17

6.0 DISCUSSION OF EXPERIMENTAL RESULTS

6.1 Characterisation of Preliminary CVD $\mathrm{Al}_{2} \mathrm{O}_{3}$ Coatings on PM HSS Inserts

6.1.1 Auger electron spectroscopy

6.1.2 X-ray diffraction

6.1.3 Optical microscopy - cross-section 
6.1.4 Optical microscopy - taper section ............................................. 82

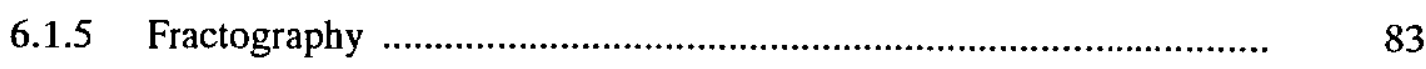

6.1.6 Surface roughness assessment ................................................... 85

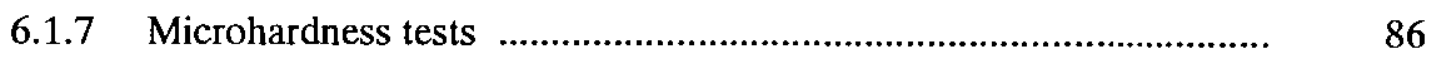

6.1.8 Adhesion test ........................................................................ 87

6.2 Effect of $\mathrm{CO}_{2} / \mathrm{H}_{2}$ mole ratio and $\mathrm{H}_{2}-1 / \mathrm{AlCl}_{3}$ flow rate on characteristics of $\mathrm{CVD} \mathrm{Al}_{2} \mathrm{O}_{3}$ coatings .................................................................. 89

6.2.1 Effect of $\mathrm{H}_{2}-1 / \mathrm{AlCl}_{3}$ flow rate $\left(\mathrm{AlCl}_{3}\right.$ concentration) …................... 89

6.2.1.1 Effect of $\mathrm{H}_{2}-1 / \mathrm{AlCl}_{3}$ flow rate on composition of $\mathrm{Al}_{2} \mathrm{O}_{3}$ coating and $\mathrm{Al}_{2} \mathrm{O}_{3}$ coating/ $\mathrm{Ti}(\mathrm{C}, \mathrm{N})$ precoating interface ......... $\quad 90$

6.2.1.2 Effect of $\mathrm{H}_{2}-1 / \mathrm{AlCl}_{3}$ flow rate on $\mathrm{Al}_{2} \mathrm{O}_{3}$ coating thickness ..... 97

6.2.1.3 Effect of $\mathrm{H}_{2}-1 / \mathrm{AlCl}_{3}$ flow rate on bulk and surface grain structures of $\mathrm{Al}_{2} \mathrm{O}_{3}$ coatings

6.2.1.4 Effect of $\mathrm{H}_{2}-1 / \mathrm{AlCl}_{3}$ flow rate on preferred orientation and lattice parameter of $\mathrm{Al}_{2} \mathrm{O}_{3}$ coatings

6.2.1.5 Effect of $\mathrm{H}_{2}-1 / \mathrm{AlCl}_{3}$ flow rate on $\mathrm{Al}_{2} \mathrm{O}_{3}$ coating microhardness

6.2.1.6 Effect of $\mathrm{H}_{2}-1 / \mathrm{AlCl}_{3}$ flow rate on peripheral thickness variation (and other features) of $\mathrm{Al}_{2} \mathrm{O}_{3}$ coatings

6.2.1.7 Effect of $\mathrm{H}_{2}-1 / \mathrm{AlCl}_{3}$ flow rate on surface roughness of $\mathrm{Al}_{2} \mathrm{O}_{3}$ coatings

6.2.1.8 Effect of $\mathrm{H}_{2}-1 / \mathrm{AlCl}_{3}$ flow rate on microstructure of $\mathrm{Al}_{2} \mathrm{O}_{3}$ coating adjacent to interface with $\mathrm{Ti}(\mathrm{C}, \mathrm{N})$ precoating ...

6.2.1.9 Effect of $\mathrm{H}_{2}-1 / \mathrm{AlCl}_{3}$ flow rate on $\mathrm{Al}_{2} \mathrm{O}_{3}$ coating adhesion ...... 106

6.2.2 Effect of $\mathrm{CO}_{2} / \mathrm{H}_{2}$ mole ratio

6.2.2.1 Effect of $\mathrm{CO}_{2} / \mathrm{H}_{2}$ mole ratio on composition of $\mathrm{Al}_{2} \mathrm{O}_{3}$ coating and $\mathrm{Al}_{2} \mathrm{O}_{3}$ coating/ $\mathrm{Ti}(\mathrm{C}, \mathrm{N})$ precoating interface

6.2.2.2 Effect of $\mathrm{CO}_{2} / \mathrm{H}_{2}$ mole ratio on $\mathrm{Al}_{2} \mathrm{O}_{3}$ coating thickness

6.2.2.3 Effect of $\mathrm{CO}_{2} / \mathrm{H}_{2}$ mole ratio on bulk and surface grain structures of $\mathrm{Al}_{2} \mathrm{O}_{3}$ coatings

6.2.2.4 Effect of $\mathrm{CO}_{2} / \mathrm{H}_{2}$ mole ratio on preferred orientation and lattice parameter of $\mathrm{Al}_{2} \mathrm{O}_{3}$ coatings

6.2.2.5 Effect of $\mathrm{CO}_{2} / \mathrm{H}_{2}$ mole ratio on $\mathrm{Al}_{2} \mathrm{O}_{3}$ coating microhardness 
6.2.2.6 Effect of $\mathrm{CO}_{2} / \mathrm{H}_{2}$ mole ratio on peripheral thickness variation (and other features) of $\mathrm{Al}_{2} \mathrm{O}_{3}$ coatings

6.2.2.7 Effect of $\mathrm{CO}_{2} / \mathrm{H}_{2}$ mole ratio on surface roughness of $\mathrm{Al}_{2} \mathrm{O}_{3}$ coatings

6.2.2.8 Effect of $\mathrm{CO}_{2} / \mathrm{H}_{2}$ mole ratio on microstructure of $\mathrm{Al}_{2} \mathrm{O}_{3}$ coating adjacent to interface with $\mathrm{Ti}(\mathrm{C}, \mathrm{N})$ precoating

6.2.2.9 Effect of $\mathrm{CO}_{2} / \mathrm{H}_{2}$ mole ratio on $\mathrm{Al}_{2} \mathrm{O}_{3}$ coating adhesion

6.3 Trial $\mathrm{Al}_{2} \mathrm{O}_{3}$ Coating Runs

7.0 MAJOR CONCLUSIONS AND SUGGESTIONS FOR FURTHER WORK

8.0 REFERENCES

APPENDIX 1 USING THE IDEAL GAS LAW TO OBTAIN THE RELATION BETWEEN GAS PARTIAL PRESSURE AND CONCENTRATION

APPENDIX 2 HANDLING/TRANSFERRING OF $\mathrm{AlCl}_{3}$

APPENDIX 3 EXPERIMENTAL PROCEDURE FOR C.V.D OF $\mathrm{Al}_{2} \mathrm{O}_{3}$

APPENDIX $4 \quad \mathrm{AlCl}_{3} \mathrm{BY}$-PASS RUNS

APPENDIX 5 DETERMINATION OF LATTICE PARAMETERS FOR HEXAGONAL SYSTEMS 
CHAPTER 1

INTRODUCTION 


\subsection{INTRODUCTION}

The patented cold compaction and direct vacuum sintering powder metallurgy (PM) route [1] has enabled the near nett-shape production of high speed steel (HSS) cutting tool inserts with an equivalent heat treatment response [2] and at least equivalent cutting properties [3] to cast and wrought HSS tools of similar composition. Edgar Allen Tools, Sheffield, employ this route for the industrial production of PM HSS cutting tool inserts [4]. The aptitude of such inserts to replace certain forms of conventional, solid HSS cutting tools is generally acknowledged [5]. Moreover, these inserts are particularly suitable for coating with thin layers of hard materials by the well-established chemical vapour deposition (CVD) process. They do not require regrinding and, as result of their more uniform metallurgical structure, are much less susceptible to size change and distortion during the obligatory post-coating heat treatment than cast and wrought high speed steels. Recognising the potential improvements in HSS insert cutting performance offered by such coatings, Edgar Allen Tools entered into a programme of collaborative research with Loughborough University of Technology in 1981, the aim of which was to investigate and develop the application of chemically vapour deposited hard material coatings to their PM (BT42 grade) HSS cutting tool inserts.

Initially, Whittle [6] investigated TiN coatings chemically vapour deposited on the PM HSS inserts at reduced pressure by Edgar Allen Tools. During the course of this work he developed a procedure for completely characterising the TiN coatings. This procedure has been used in all subsequent CVD coating studies at Loughborough University of Technology. It involves the use of various techniques including X-ray diffraction, Auger electron spectroscopy (AES), optical microscopy, fractography/scanning electron microscopy, profilometry, microhardness testing and scratch-adhesion testing in conjunction with energy dispersive $\mathrm{X}$-ray analysis on a scanning electron microscopy (SEM). With the exception of the latter technique it was applied by Whittle to the CVD TiN coated PM HSS inserts both before and after the obligatory post-coating HSS substrate heat treatment. It was found that this heat treatment did not have any significant effect on the characteristics of the TiN coatings. Whittle also investigated the effect of the CVD TiN coating on the cutting performance of the PM HSS inserts in a series of turning tests. From these tests it was established that the application of the TiN coating led to a significant overall improvement in the cutting performance of the PM HSS inserts at normal cutting speeds. This was characterised by an increase in tool life, a reduction in flank and crater wear, a decrease in tool forces and apparent coefficient of chip-tool friction, a reduction in built up edge (b.u.e) height and an improvement in workpiece surface finish [6-8].

Subsequently Abbas [9] studied the effect of three major CVD process parameters $\left(\mathrm{N}_{2} / \mathrm{TiCl}_{4}\right.$ mole ratio, deposition temperature and total flow rate) on the characteristics of TiN coatings chemically vapour deposited on the PM HSS inserts at atmospheric pressure by Edgar Allen 
Tools, and the effects of TiN coating characteristics on the cutting performance of the CVD TiN coated PM HSS inserts. It was established from this study that the $\mathrm{N}_{2} / \mathrm{TiCl}_{4}$ mole ratio, deposition temperature and total flow rate used during the CVD of the TiN coatings had a marked effect on the thickness, grain size and microhardness of the CVD TiN coatings. The tool life and tool wear of the CVD TiN coated PM HSS inserts were found to be significantly dependent on TiN coating grain size and thickness $[9,10]$.

Lewus [11] similarly investigated the effect of two major CVD process parameters $\left(\mathrm{CH}_{4} / \mathrm{TiCl}_{4}\right.$ mole ratio and deposition temperature) on the characteristics of titanium carbide ( $\mathrm{TiC}$ ) coatings chemically vapour deposited on the PM HSS inserts at atmospheric pressure by Edgar Allen Tools. It was established from this investigation that the $\mathrm{CH}_{4} / \mathrm{TiCl}_{4}$ mole ratio and deposition temperature used during the CVD of the TiC coatings had a marked effect not only on the characteristics of the coatings but also on the tool lives exhibited by the TiC coated PM HSS inserts. Lewus also carried out a detailed study of the effect of a CVD TiC coating, deposited under the optimum conditions identified, on the cutting performance of the PM HSS inserts. It was established that the presence of the TiC coating led to a marked overall improvement in the cutting performance of the PM HSS inserts at normal cutting speeds $[11-13]$.

Finally, Lamsehchi [14] established the optimum thickness (with regard to cutting performance) of single TiN and TiC coatings chemically vapour deposited on the PM HSS inserts at atmospheric pressure by Edgar Allen Tools. He then characterised these optimum thickness single layer coatings and multilayer TiN/TiC and TiC/TiN coatings of comparable thickness chemically vapour deposited on the PM HSS inserts at atmospheric pressure and compared their effect on the cutting performance of the PM HSS inserts on the basis of equal coating thickness. It was established that the optimum thickness single layer TiN coating afforded the greatest overall improvement in the cutting performance of the PM HSS inserts.

Aided by the collaboration research programme with Loughborough University of Technology, Edgar Allen Tools are manufacturing a range of CVD coated PM BT42 grade HSS cutting tool inserts. Since their introduction on the market, these inserts have been widely applied in industry to replace different forms of conventional, solid HSS cutting tools. Their use, in accordance with the laboratory research cutting tests results, has been characterised by significantly improved cutting performance. The inserts have even been found to outperform, and hence used to replace, cemented carbide cutting tool inserts in applications where the latter are being under-utilised, i.e at relatively low cutting speeds, or are prone to mechanical failure [13].

Despite its current pre-eminence, exemplified by the findings of the study carried out by Lamsehchi [14], TiN is not necessarily the optimum coating for HSS cutting tools: neither CVD nor PVD TiN coatings have been found to facilitate the desired increase in the usable 
cutting speed of HSS tools to span the existing cutting speed discontinuity between themselves and cemented carbides. In view of the above, it is desirable to begin to investigate the application of other CVD hard material coatings to PM HSS cutting tool inserts with a view to obtaining improvements in cutting performance, including increased usable cutting speed, beyond those afforded by single layer CVD TiN coatings.

Cemented carbide cutting tool inserts coated with thin layers of hard materials by CVD were introduced on to the market in 1969, much earlier than their HSS counterparts, initially with a single layer TiC coating [15]. Since then other types of CVD coatings have been developed. Currently the most important of these appears to be alumina $\left(\mathrm{Al}_{2} \mathrm{O}_{3}\right)$; now widely applied to cemented carbide inserts albeit, almost invariably, as one or more layers of a multilayer coating [16]. The relative properties of $\mathrm{Al}_{2} \mathrm{O}_{3}$ which account for its widespread application as a coating on cemented carbide inserts are its low thermal conductivity and its high chemical stability, resistance to oxidation and hardness at elevated temperatures $[17,18]$. These properties allow cemented carbide inserts with $\mathrm{Al}_{2} \mathrm{O}_{3}$ coatings to cut at higher speeds than afforded by coatings such as $\mathrm{TiN}[16]$ or $\mathrm{TiC}[16,17]$. However, particularly in comparison to $\mathrm{TiN}, \mathrm{Al}_{2} \mathrm{O}_{3}$ is a very difficult coating to CVD since it is very sensitive to deposition conditions and it does not adhere well to cemented carbide substrates without the presence of a precoating [16].

The aforementioned properties of $\mathrm{Al}_{2} \mathrm{O}_{3}$ make it an extremely attractive candidate coating material for application to HSS cutting tools, particularly with regard to raising their usable cutting speed range. Whilst the existing difficulties associated with the $\mathrm{CVD}$ of $\mathrm{Al}_{2} \mathrm{O}_{3}$ coatings on cemented carbides would be compounded in the case of their application to HSS tools, by the obligatory post-coating HSS substrate heat treatment, PVD does not as yet appear to be a realistic alternative [19-21]; a viewpoint shared by others [16,22]. Potentially, this leaves CVD as the most viable process for coating HSS cutting tools, particularly PM HSS inserts, with $\mathrm{Al}_{2} \mathrm{O}_{3}$.

As a consequence of the above, it was decided to study the CVD of an alumina coating on PM HSS cutting tool inserts. This study forms the subject matter of this thesis. No details could be found in the literature of $\mathrm{Al}_{2} \mathrm{O}_{3}$ coatings having previously been successfully chemically vapour deposited on HSS cutting tools, although the CVD of $\mathrm{Al}_{2} \mathrm{O}_{3}$ coatings on other steel substrates has recently been reported [23-25]. In the latter studies, however, post-coating heat treatment of the substrates was not carried out. Since access to a commercial alumina CVD reactor could not be arranged, it was decided that a laboratory-scale $\mathrm{Al}_{2} \mathrm{O}_{3}$ CVD reactor would be designed and constructed to facilitate the present study. Prior to this, extensive surveys of previous work on the effect of process parameters on chemically vapour deposited $\mathrm{Al}_{2} \mathrm{O}_{3}$ coatings (deposited, principally, on cemented carbide substrates) and on the characterisation and characteristics of commercial-type CVD $\mathrm{Al}_{2} \mathrm{O}_{3}$ coatings were 
undertaken. The former is presented in Chapter 2. Rather surprisingly, only a small amount of work concerned with the latter was found and it was therefore decided to deal with this work in an addendum to Chapter 2 . 


\section{CHAPTER 2}

EFFECT OF PROCESS PARAMETERS ON CHEMICALLY VAPOUR DEPOSITED $\mathrm{Al}_{2} \mathrm{O}_{3}$ COATINGS - PREVIOUS WORK 


\subsection{EFFECT OF PROCESS PARAMETERS ON CHEMICALLY VAPOUR DEPOSITED $\mathrm{Al}_{2} \mathrm{O}_{3}$ COATINGS- PREVIOUS WORK}

As mentioned in Chapter 1, this chapter is primarily concerned with previous investigations of the effect of process parameters on chemically vapour deposited $\mathrm{Al}_{2} \mathrm{O}_{3}$ coatings, but additionally contains, in the final section, the previous work on the characterisation and characteristics of commercial CVD $\mathrm{Al}_{2} \mathrm{O}_{3}$ coatings. The major CVD process parameters studied in previous work were found to be deposition time, deposition temperature, total pressure, gas reactant concentration (partial pressure and mole ratio) and trace impurities. Other minor process parameters, namely aluminium (Al) donor type and total gas flow rate have also been investigated, albeit to a lesser extent. These minor process parameters are considered together in a separate section. First, however, it is thought useful to consider the CVD reaction for $\mathrm{Al}_{2} \mathrm{O}_{3}$.

The CVD of $\mathrm{Al}_{2} \mathrm{O}_{3}$ involves the introduction of gaseous reactants, normally aluminium chloride $\left(\mathrm{AlCl}_{3}\right)$, hydrogen $\left(\mathrm{H}_{2}\right)$ and carbon dioxide $\left(\mathrm{CO}_{2}\right)$, into a chamber heated to approximately $1000^{\circ} \mathrm{C}(1273 \mathrm{~K})$ in which the substrates to be coated are situated. The $\mathrm{AlCl}_{3}$ is obtained by reacting chlorine $\left(\mathrm{Cl}_{2}\right)$ or hydrochloric acid $(\mathrm{HCl})$ with aluminium $(\mathrm{Al})$ metal at a temperature of $250^{\circ} \mathrm{C}$, or by heating $\mathrm{AlCl}_{3}$ powder at temperatures of about $200^{\circ} \mathrm{C}$ [26] and is normally transported into the coating chamber using $\mathrm{H}_{2}$ carrier gas. The reaction proceeds according to the following generally accepted chemical reactions.

$$
\begin{aligned}
& 3 \mathrm{H}_{2(g)}+3 \mathrm{CO}_{2(g)} \Longleftrightarrow 3 \mathrm{H}_{2} \mathrm{O}_{(g)}+3 \mathrm{CO}_{(g)} \\
& 2 \mathrm{AlCl}_{3(g)}+3 \mathrm{H}_{2} \mathrm{O}_{(g)}----\rightarrow \mathrm{Al}_{2} \mathrm{O}_{3(s)}+6 \mathrm{HCl}_{(g)}
\end{aligned}
$$

overall reaction:

$$
2 \mathrm{AlCl}_{3(g)}+3 \mathrm{H}_{2(s)}+3 \mathrm{CO}_{2(s)}---\rightarrow \mathrm{Al}_{2} \mathrm{O}_{3(s)}+3 \mathrm{CO}(s)+6 \mathrm{HCl}_{(8)}
$$

As is evident, the CVD of $\mathrm{Al}_{2} \mathrm{O}_{3}$ from an $\mathrm{AlCl}_{3}-\mathrm{H}_{2}-\mathrm{CO}_{2}$ gas mixture is based on the high temperature hydrolysis of $\mathrm{AlCl}_{3}$ by water (reaction (2)) from the reduction of $\mathrm{CO}_{2}$ by $\mathrm{H}_{2}$ (reaction (1)) [27]. When equilibrium is reached, $\mathrm{AlCl}_{3}$ is quantitatively reacted into $\mathrm{Al}_{2} \mathrm{O}_{3}$ as long as the initial gas mixture contains enough $\mathrm{H}_{2}$ and $\mathrm{CO}_{2}$ to form, at high temperatures $\left(>1100 \mathrm{~K}\left(827^{\circ} \mathrm{C}\right)\right)$, the required amount of water. Since reaction 1 is rather slow, even at temperatures as high as $1300 \mathrm{~K}\left(1027^{\circ} \mathrm{C}\right)$, reaction kinetics play an important role in the CVD of $\mathrm{Al}_{2} \mathrm{O}_{3}$ and reaction 1 can be considered to be rate controlling. 
One of the many difficulties associated with the CVD of $\mathrm{Al}_{2} \mathrm{O}_{3}$ from an $\mathrm{AlCl}_{3}-\mathrm{H}_{2}-\mathrm{CO}_{2}$ gas mixture is the ready nucleation in the gas phase and the tendency of the $\mathrm{Al}_{2} \mathrm{O}_{3}$ to form needles or other "odd" shaped crystals [28] on various substrates. It should be noted that in all the investigations cited in this chapter the $\mathrm{Al}_{2} \mathrm{O}_{3}$ coatings were chemically vapour deposited using the standard reaction shown above in reaction 3 .

\subsection{Effect of Substrate}

Although, strictly speaking, the substrate to be coated is not a process parameter, it was considered that it would be useful to review its effect on the chemically vapour deposited $\mathrm{Al}_{2} \mathrm{O}_{3}$ coatings in this section.

In their work on the CVD of $\mathrm{Al}_{2} \mathrm{O}_{3}$ coatings on cemented carbide inserts, Lindstrom and Johannesson [29] found that during initial heating in $\mathrm{H}_{2}$, prior to coating, the cobalt (Co) binder diffuses away causing voids to be left behind. They further established that the moisture which is inevitably present in the $\mathrm{H}_{2}$ gas slightly attacks the cemented carbide surface by oxidation, with the tungsten carbide (WC) phase being at least partially converted to carbide of the $\eta$-phase type $\left(\mathrm{Co}_{6} \mathrm{~W}_{6} \mathrm{C}\right)$. It was suggested that this deterioration of the substrate surface in $\mathrm{H}_{2}$ can result in poor adhesion of $\mathrm{Al}_{2} \mathrm{O}_{3}$ coatings chemically vapour deposited on cemented carbide substrates. According to Lindstrom and Johannesson, precoating with TiC helps to improve $\mathrm{Al}_{2} \mathrm{O}_{3}$ coating adhesion by preventing such deterioration of the cemented carbide substrate surface and further by giving an even density of $\mathrm{Al}_{2} \mathrm{O}_{3}$ nuclei and by isolating the Co and hence preventing it from interfering with nucleation and growth of the $\mathrm{Al}_{2} \mathrm{O}_{3}$ coating.

With regard to the latter, when chemically vapour depositing $\mathrm{Al}_{2} \mathrm{O}_{3}$ coatings directly onto cemented carbide substrates in a pilot plant scale reactor, Lindstrom and Johannesson found that difficulties can arise with $\mathrm{Al}_{2} \mathrm{O}_{3}$ nucleation and growth. They suggested that small amounts of Co from the substrate will be dissolved (probably as chlorides) into the formed $\mathrm{Al}_{2} \mathrm{O}_{3}$ layer and that this can cause the $\mathrm{Al}_{2} \mathrm{O}_{3}$ coating to develop a whisker-like morphology. In contrast, it was found that $\mathrm{Al}_{2} \mathrm{O}_{3}$ coatings chemically vapour deposited on cemented carbide substrates in a much smaller, laboratory-scale reactor exhibited columnar growth with grains mushrooming out to form voids. Lindstrom and Johannesson suggested that if $\mathrm{TiC}$ layers were used to protect the cemented carbide surface the former difficulty might be overcome.

As described in their patent, Lindstrom et al [30] found that when TiC coated cemented carbide substrates were coated with $\mathrm{Al}_{2} \mathrm{O}_{3}$ by CVD at a deposition temperature of $1100^{\circ} \mathrm{C}$ with a gas supply of $5 \% \mathrm{AlCl}_{3}, 5 \% \mathrm{CO}_{2}, 70 \% \mathrm{H}_{2}$ and $20 \% \mathrm{CO}$, at a gas flow rate of $3 \mathrm{~m} \mathrm{sec}^{-1}$ and a total pressure of 15 torr $(0.02 \mathrm{~atm})$ for a deposition time of 8 hours, a $2 \mu \mathrm{m}$ thick $\mathrm{Al}_{2} \mathrm{O}_{3}$ coating was formed. The bonding between this coating and the TiC intermediate layer was stated to be good and no embrittling $\eta$-phase was observed at the TiC coating/cemented carbide substrate interface. Under identical coating conditions, however, uncoated cemented carbide substrates 
of the same type were found to have been coated with a $15 \mu \mathrm{m}$ thick layer of $\mathrm{Al}_{2} \mathrm{O}_{3}$ which was both porous and poorly adhering. In addition, embrittling $\eta$-phase was found to be present at the $\mathrm{Al}_{2} \mathrm{O}_{3}$ coating/cemented carbide substrate interface. Lindstrom et al suggested that the superior $\mathrm{Al}_{2} \mathrm{O}_{3}$ coating deposited on the cemented carbide substrates precoated with $\mathrm{TiC}$ was due to the intermediate TiC layer impeding the diffusion of Co binder metal from the cemented carbide substrate into the formed oxide coating, and further that carbon diffusion was also considerably retarded. A similar effect was attributed to a TiN intermediate layer.

Funk et al [31] actually studied the CVD of $\mathrm{Al}_{2} \mathrm{O}_{3}$ coatings onto the constituents of cemented carbides (WC and $\mathrm{Co}$ ) as well as onto cemented carbide inserts precoated with layers of TiC, TiN and chromium $(\mathrm{Cr})$. On WC very adherent layers of $\alpha-\mathrm{Al}_{2} \mathrm{O}_{3}$ were obtained whereas on Co loose deposits of $\mathrm{Al}_{2} \mathrm{O}_{3}$ were formed. The presence of $\mathrm{TiC}$ and $\mathrm{TiN}$ intermediate layers was found to favour the adherence of $\mathrm{Al}_{2} \mathrm{O}_{3}$ coatings, whereas a $\mathrm{Cr}$ intermediate layer led to the formation of non-adherent deposits. This non-adherence of $\mathrm{Al}_{2} \mathrm{O}_{3}$ coatings on $\mathrm{Co}$ and $\mathrm{Cr}$ was suggested to be due to substrate attack, possibly by $\mathrm{HCl}$, resulting in disturbance of the nucleation and growth of the $\mathrm{Al}_{2} \mathrm{O}_{3}$ coatings.

In their work on $\mathrm{Al}_{2} \mathrm{O}_{3}$ coatings chemically vapour deposited at a deposition temperature of $1000^{\circ} \mathrm{C}$ and a total pressure of 50 torr $(0.066 \mathrm{~atm})$, with a gas composition of $0.6 \% \mathrm{AlCl}_{3}$, $0.9 \% \mathrm{CO}_{2}, 96.7 \% \mathrm{H}_{2}$ and $1.8 \% \mathrm{HCl}$, Kornmann et al [32] employed low angle electron diffraction to study the crystallographic structure of the $\mathrm{Al}_{2} \mathrm{O}_{3}$ coatings. They observed clusters of $\alpha-\mathrm{Al}_{2} \mathrm{O}_{3}$ on the polished surface of TiC coated cemented carbide substrates. These clusters were found to grow in size with time, their number remaining constant, until coalescence occurred. Occasionally the clusters were found to be aligned, indicative of nucleation being at least partly epitaxial. On the surface of uncoated cemented carbide substrate many very small $\mathrm{Al}_{2} \mathrm{O}_{3}$ clusters were observed in the centre of the carbide grains, resembling the nucleation found to occur on the polished surface of the TiC coated substrates. In addition, however, comparatively large patches of $\mathrm{Al}_{2} \mathrm{O}_{3}$ were observed which had grown preferentially from nucleation sites on the Co phase and on the grain boundaries between the carbide and Co phases. This lead Kornmann et al to conclude that the growth of $\mathrm{Al}_{2} \mathrm{O}_{3}$ coatings on $\mathrm{TiC}$ coated cemented carbide substrates is more uniform than on the uncoated cemented carbides.

Despite the difficulties associated with the CVD of $\mathrm{Al}_{2} \mathrm{O}_{3}$ coatings on uncoated cemented carbide substrates referred to in the work cited above, Hale [26] reports the successful CVD of a fully dense $\alpha-\mathrm{Al}_{2} \mathrm{O}_{3}$ layer, 1 to $20 \mu \mathrm{m}$ thick, on uncoated cemented carbide substrates consisting of either $\mathrm{WC}$ in a Co matrix or $\mathrm{TiC}$ in a nickel $(\mathrm{Ni})$ or iron (Fe) matrix. Between the $\mathrm{Al}_{2} \mathrm{O}_{3}$ coating and the substrate, a very thin (less than $1 \mu \mathrm{m}$ ) intermediate, non-metallic layer of $\mathrm{Co}(\mathrm{Fe}$ or $\mathrm{Ni})$ aluminate $\left(\mathrm{CoAl}_{2} \mathrm{O}_{4}\right)$ was present which, according to Hale, is necessary to achieve a good bond strength between the $\mathrm{Al}_{2} \mathrm{O}_{3}$ coating and the substrate. 
Using the following deposition conditions: deposition temperature 860 to $970^{\circ} \mathrm{C} ; \mathrm{AlCl}_{3}$ flow rate (using $\mathrm{H}_{2}$ as the carrier gas) $0.71 \mathrm{~min}^{-1}, \mathrm{CO}_{2}$ flow rate $1.71 \mathrm{~min}^{-1}, \mathrm{H}_{2}$ flow rate $2.51 \mathrm{~min}^{-1}$ and total pressure 760 torr (1 atm), Kuo et al [23, 24, 25] carried out two studies on the CVD of $\mathrm{Al}_{2} \mathrm{O}_{3}$ coatings on steel substrates. In the first of these [24], the effect of initial heating of the substrate in $\mathrm{H}_{2}$ (substrate pre-heating) prior to coating and of the $\mathrm{Cr}$ content of the substrates were investigated using two AISI tool steels: D2 (11 to $13 \% \mathrm{Cr}$ ) and $\mathrm{H} 13$ (4.5 to $5.5 \% \mathrm{Cr}$ ). They found that initial heating of the substrates in $\mathrm{H}_{2}$ led to the formation of a $(\mathrm{Cr}, \mathrm{Fe})_{2} \mathrm{O}_{3}$ film on the higher $\mathrm{Cr}$ content tool steel. For this tool steel, Kuo et al found that an increase in substrate pre-heating time over the range from 1.5 to 7.5 hours resulted in an increase in the $\mathrm{Al}_{2} \mathrm{O}_{3}$ coating microhardness from 1400 to $2000 \mathrm{HV}_{0.1}$, whereas for the tool steel having the lower $\mathrm{Cr}$ content the $\mathrm{Al}_{2} \mathrm{O}_{3}$ coating microhardness was found to be constant at $1575 \mathrm{HV}_{0.1}$. Kuo et al inferred from these results that the increase in microhardness of the $\mathrm{Al}_{2} \mathrm{O}_{3}$ coatings on the higher $\mathrm{Cr}$ content tool steel was related to the increase in thickness of the aforementioned $(\mathrm{Cr}, \mathrm{Fe})_{2} \mathrm{O}_{3}$ film. It should be noted that the microhardness values reflect both the $\mathrm{Al}_{2} \mathrm{O}_{3}$ coating ( 25 to $40 \mu \mathrm{m}$ thick) and the substrate. Kuo et al further established, from X-ray diffraction results, that with increasing substrate pre-heating time the crystallographic structure of the $\alpha-\mathrm{Al}_{2} \mathrm{O}_{3}$ coatings on the AISI-D2 tool steel, changed from being randomly oriented to exhibiting preferred orientation of the $(10 \overline{1} 4)$ and $(03 \overline{3} 0)$ planes. It was suggested that the formation of the $(\mathrm{Cr}, \mathrm{Fe})_{2} \mathrm{O}_{3}$ film on the substrate surface influences the nucleation and growth of the $\mathrm{Al}_{2} \mathrm{O}_{3}$ coating and can also enhance the adhesion between the $\mathrm{Al}_{2} \mathrm{O}_{3}$ coating and the steel substrate. It should, however, be noted that no results were presented to substantiate this latter statement.

In the second study, Kuo et al $[23,25]$ investigated the effect of substrate pre-heating time prior to coating and of the carbon $(C)$ content of the substrates on the $\mathrm{CVD}$ of $\mathrm{Al}_{2} \mathrm{O}_{3}$ coatings using two AISI carbon steels: $1045(0.45 \% \mathrm{C})$ and $\mathrm{W} 1(1.15 \% \mathrm{C})$. They found that for a pre-heating time of 1.5 hours, $\mathrm{Al}_{2} \mathrm{O}_{3}$ was deposited only on the steel substrate with the lower $\mathrm{C}$ content, whereas for substrate pre-heating times longer than 3.5 hours $\mathrm{Al}_{2} \mathrm{O}_{3}$ was found to be present on both steel substrates. From SEM examination it is evident that the grain size of the $\mathrm{Al}_{2} \mathrm{O}_{3}$ coatings deposited on the steel substrate with the higher $\mathrm{C}$ content is slightly larger that of the $\mathrm{Al}_{2} \mathrm{O}_{3}$ coatings deposited on the lower $\mathrm{C}$ content steel substrate. Kuo et al suggested that longer substrate pre-heating times resulted in substrate decarburisation and that nucleation or adhesion of $\mathrm{Al}_{2} \mathrm{O}_{3}$ was more effective on the steel with the lower $\mathrm{C}$ content. It was suggested that $\mathrm{C}$ in steels can cause a change in the lattice parameter of the substrate and this increases the mismatch in crystal lattices between the $\mathrm{Al}_{2} \mathrm{O}_{3}$ coating and the steel substrate resulting in a decrease in the nucleation rate. They also observed that the microhardness of the $\mathrm{Al}_{2} \mathrm{O}_{3}$ coating on the higher $\mathrm{C}$ content steel substrate was higher than that of the $\mathrm{Al}_{2} \mathrm{O}_{3}$ coating on the steel substrate having the lower $\mathrm{C}$ content. In addition, the microhardness of the $\mathrm{Al}_{2} \mathrm{O}_{3}$ coatings on both steel substrates was found to decrease with increasing substrate pre-heating time. Kuo et al suggested that decarburisation of the steel substrates was responsible for this. Again the microhardness values reflects both the $\mathrm{Al}_{2} \mathrm{O}_{3}$ coating (10 to $25 \mu \mathrm{m}$ thick) and the 
substrate. It was further suggested that steel substrates with a low $\mathrm{C}$ content (i.e. a lower yield strength) can improve the adhesion of $\mathrm{Al}_{2} \mathrm{O}_{3}$ coatings by decreasing the difference in coefficient of thermal expansion between the $\mathrm{Al}_{2} \mathrm{O}_{3}$ coating and the substrate. This is in direct contrast to findings in Sheih's work [23], in which it was stated that the deposition of $\mathrm{Al}_{2} \mathrm{O}_{3}$ is not feasible on steel substrates containing the lowest $\mathrm{C}$ content.

The effect of copper $(\mathrm{Cu})$ and $\mathrm{Cu}$-alloy substrates on $\mathrm{Al}_{2} \mathrm{O}_{3}$ coatings chemically vapour deposited has been investigated by Schachner et al [33]. In their work, transparent, smooth, amorphous $\mathrm{Al}_{2} \mathrm{O}_{3}$ coatings were obtained at a deposition temperature of $500^{\circ} \mathrm{C}$ and a total pressure of 0.6 torr $\left(7.9 \times 10^{-4} \mathrm{~atm}\right)$, with an $\mathrm{Al}_{2} \mathrm{Cl}_{6}$ partial pressure of 0.012 torr $\left(1.6 \times 10^{-5}\right.$ atm). They suggested that the adhesion of such amorphous $\mathrm{Al}_{2} \mathrm{O}_{3}$ coatings could be considerably enhanced by alloying the Cu substrate with $\mathrm{Al}$, manganese $(\mathrm{Mn})$ and zirconium $(\mathrm{Zr})$, i.e. metals exhibiting a high negative free energy of formation of the oxide. This lead Schachner et al to conclude that substrate attack i.e. oxidation was beneficial for the adhesion of their amorphous $\mathrm{Al}_{2} \mathrm{O}_{3}$ coatings. This may imply that either oxygen bridges or very thin oxide transition layers are formed between the metallic substrate and the $\mathrm{Al}_{2} \mathrm{O}_{3}$ coating, possibly due to oxidation by water vapour.

Schmitt et al [34] investigated the effect of different substrates on the growth morphology of $\mathrm{Al}_{2} \mathrm{O}_{3}$ coatings chemically vapour deposited under a range of deposition conditions: deposition temperature 300 to $1050^{\circ} \mathrm{C}$; gas composition 0.7 to $1.1 \% \mathrm{AlCl}_{3}, 3.5 \% \mathrm{CO}_{2} 95.5 \%$ $\mathrm{H}_{2}$; total pressure $65 \mathrm{mbar}(0.064 \mathrm{~atm})$ and deposition time 1 hour. Alumina, tungsten $(\mathrm{W})$, molybdenum (Mo), $\mathrm{Fe}, \mathrm{Ni}, \mathrm{Ni} / \mathrm{Cr}$ and $\mathrm{Cr}$ substrates were employed, the former as a reference substrate. In all their experiments, high levels of silicon (Si) impurity were present and it was observed that the $\alpha-\mathrm{Al}_{2} \mathrm{O}_{3}$ growth morphology was similar to that of $\mathrm{Al}_{2} \mathrm{O}_{3}$ coatings deposited on cemented carbide substrates under poorly controlled conditions.

They found that at low temperatures $\left(300\right.$ to $\left.950^{\circ} \mathrm{C}\right)$, where diffusion of elements from the substrate into the coating would be slow, the $\mathrm{Al}_{2} \mathrm{O}_{3}$ coatings on the different substrates showed very similar morphologies. Also both $\mathrm{Si}$ and $\mathrm{Cl}_{2}$ were found to be present in all the coatings (the former introduced through Si grease and the latter expected to be present from $\mathrm{AlCl}_{3}$ decomposition). For this temperature range, Schmitt et al concluded that the substrate has very little effect on the morphology of the $\alpha-\mathrm{Al}_{2} \mathrm{O}_{3}$ coatings.

At high temperatures $\left(>950^{\circ} \mathrm{C}\right)$ however, where significant diffusion can be expected to occur, they found that the substrate had a definite influence, based on the diffusion of substrate material through the coating to the coating/gas interface affecting growth. A great variety of crystal morphologies were observed on the alumina, $W$ and Mo substrates, with the latter two having a surprisingly strong influence on coating morphology; surprising since the high melting point of these metals preclude their rapid diffusion even at high temperatures. Although neither $\mathrm{W}$ nor Mo were detected in the $\mathrm{Al}_{2} \mathrm{O}_{3}$ coatings, Schmitt et al suggested that 
it was most likely that these elements, from the underlying substrates, had influenced $\mathrm{Al}_{2} \mathrm{O}_{3}$ coating morphology. The $\mathrm{Fe}, \mathrm{Ni}, \mathrm{Ni} / \mathrm{Cr}$ and $\mathrm{Cr}$ substrates caused less pronounced structural changes of the $\mathrm{Al}_{2} \mathrm{O}_{3}$ coatings than the $\mathrm{W}$ and Mo despite the fact that $\mathrm{Fe}, \mathrm{Cr}$ and $\mathrm{Ni}$ can be expected to diffuse rather rapidly in the temperature range considered. The coatings on these substrates were however still found to be different from that on the alumina reference substrate. Of the four substrates, $\mathrm{Fe}$ and $\mathrm{Cr}$ caused the most noticeable changes, both giving rise to coin-shaped and cauliflower-shaped $\mathrm{Al}_{2} \mathrm{O}_{3}$ crystals. Needle-shaped $\mathrm{Al}_{2} \mathrm{O}_{3}$ crystals were also observed on the $\mathrm{Cr}$ substrate. In addition, $\mathrm{Si}$ and $\mathrm{Cl}_{2}$ were found to be present in all the coatings on the $\mathrm{Fe}, \mathrm{Cr}, \mathrm{Ni} / \mathrm{Cr}$ and $\mathrm{Ni}$ substrates. Schmitt et al consequently suggested that the changes in the morphology of the $\mathrm{Al}_{2} \mathrm{O}_{3}$ coatings on these substrates could be the consequence of joint action among $\mathrm{Si}, \mathrm{Cl}_{2}$ and the substrate elements.

Colmet and Naslain [27] also investigated the effect of the substrate on the morphology of $\mathrm{Al}_{2} \mathrm{O}_{3}$ coatings chemically vapour deposited over a range of deposition conditions: deposition temperature 1173 to $1473 \mathrm{~K}\left(900-1200^{\circ} \mathrm{C}\right)$, gas composition $0.8 \% \mathrm{AlCl}_{3}, 49.6 \% \mathrm{CO}_{2}$ and $49.6 \% \mathrm{H}_{2}$, total gas flow rate $300 \mathrm{~cm}^{3} \mathrm{~min}^{-1}$ and total pressure 0.03 to $0.8 \mathrm{~atm}$. X-ray analysis confirmed that $\alpha-\mathrm{Al}_{2} \mathrm{O}_{3}$ coatings had been deposited on the cemented carbide substrates precoated with $4 \mu \mathrm{m}$ of $\mathrm{TiC}$ and on the sintered alumina and the alumina substrates, employed. It was found that the surface morphology of the $\mathrm{Al}_{2} \mathrm{O}_{3}$ coatings obtained varied markedly with each substrate type. Fine elongated protrusions of black $\mathrm{Al}_{2} \mathrm{O}_{3}$ (approximately $5 \mu \mathrm{m}$ long and $1 \mu \mathrm{m}$ in width) were visible on the TiC coated cemented carbide substrates, whilst on the sintered alumina substrates an $\mathrm{Al}_{2} \mathrm{O}_{3}$ coating with an equiaxed surface grain structure (grain size $\sim 1 \mu \mathrm{m}$ ) was observed. From examination of fracture surfaces, Colmet and Naslain reported that the grain size within the $\mathrm{Al}_{2} \mathrm{O}_{3}$ coating was smaller than that of the sintered alumina substrate itself. In contrast, the alumina substrates were found to be covered with an $\mathrm{Al}_{2} \mathrm{O}_{3}$ coating having surface grains $\sim 1$ to $2 \mu \mathrm{m}$ in diameter with some patches of finer grains $(<0.5 \mu \mathrm{m}$ in diameter).

In their work on the CVD of $\mathrm{Al}_{2} \mathrm{O}_{3}$ coatings on single and polycrystalline alumina substrates at a deposition temperature of $1050^{\circ} \mathrm{C}$, with an $\mathrm{AlCl}_{3} / \mathrm{CO}_{2} / \mathrm{H}_{2}$ gas ratio of $1 / 3.5 / 95.5$ and a total pressure of $65 \mathrm{mbar}(0.064 \mathrm{~atm})$, Altena et al [35] established that the crystal orientation of the alumina substrates had a definite influence on the growth rate of the $\mathrm{Al}_{2} \mathrm{O}_{3}$ coatings. They observed that $\mathrm{Al}_{2} \mathrm{O}_{3}$ grains growing epitaxially on the polycrystalline alumina substrates exhibited different growth rates depending on their respective orientations; planes with higher indices generally growing more rapidly than the low indexed faces. On the single and polycrystalline alumina substrates, epitaxial growth was observed only if highly polished surfaces were used. Altena et al further reported that nucleation of individual $\mathrm{Al}_{2} \mathrm{O}_{3}$ grains on the single crystal alumina substrate occurred only if lattice defects were present in the substrate. 


\subsection{Effect of Deposition Time}

Relatively little work has been carried out on the effect of this process parameter on chemically vapour deposited $\mathrm{Al}_{2} \mathrm{O}_{3}$ coatings.

In their work on $\mathrm{Al}_{2} \mathrm{O}_{3}$ coatings chemically vapour deposited on $\mathrm{TiC}$ coated cemented carbide substrates under the deposition conditions previously specified (see Section 2.1), Kornmann et al [32] found that the number of $\mathrm{Al}_{2} \mathrm{O}_{3}$ clusters was dependent on the deposition time. After 30 seconds the saturation density of $\mathrm{Al}_{2} \mathrm{O}_{3}$ clusters was $13.3 \times 10^{8} \mathrm{~cm}^{-2}$. In certain regions, clusters began to coalesce after only 2 minutes and after 15 minutes an $\mathrm{Al}_{2} \mathrm{O}_{3}$ layer was found to almost completely cover the surface. The saturation density of $\mathrm{Al}_{2} \mathrm{O}_{3}$ clusters after 2 minutes and 15 minutes respectively was $8.2 \times 10^{8} \mathrm{~cm}^{-2}$ and $9.8 \times 10^{8} \mathrm{~cm}^{-2}$.

Also for $\mathrm{Al}_{2} \mathrm{O}_{3}$ coatings chemically vapour deposited on $\mathrm{TiC}$ coated cemented carbide substrates, at a deposition temperature of $1000^{\circ} \mathrm{C}$ and a total pressure of 100 torr $(0.13 \mathrm{~atm})$, with a $\mathrm{CO}_{2} / \mathrm{H}_{2}$ mole ratio of 1 and an $\mathrm{AlCl}_{3}$ partial pressure of 0.5 torr $\left(6.6 \times 10^{-4} \mathrm{~atm}\right)$, Chun et al [36] established that the weight of $\mathrm{Al}_{2} \mathrm{O}_{3}$ deposited increased linearly with increase in deposition time (from 0 to 3 hours). This result is in good agreement with that determined by Colmet et al [37], who examined $\mathrm{Al}_{2} \mathrm{O}_{3}$ coatings chemically vapour deposited on cemented carbide substrates under a range of deposition conditions: deposition temperature $1323 \mathrm{~K}$ $\left(1050^{\circ} \mathrm{C}\right)$; gas composition $0.8 \% \mathrm{AlCl}_{3}, 49.6 \% \mathrm{CO}_{2}$ and $49.6 \% \mathrm{H}_{2}$; total gas flow rate 300 $\mathrm{cm}^{3} \mathrm{~min}^{-1}$ and total pressures of $0.06,0.5$ and $0.8 \mathrm{~atm}$. They found that at each total pressure the weight of $\mathrm{Al}_{2} \mathrm{O}_{3}$ deposited increased linearly with increase in deposition time (from 0 to 40 minutes).

For $\mathrm{Al}_{2} \mathrm{O}_{3}$ coatings chemically vapour deposited on AISID2 and $\mathrm{H} 13$ steel substrates, at a deposition temperature of $910^{\circ} \mathrm{C}$ and a substrate pre-heating time of 3.5 hours, the other deposition conditions employed being as previously specified in Section 2.1, Kuo et al [23] established that the weight of $\mathrm{Al}_{2} \mathrm{O}_{3}$ deposited increased with increase in deposition time (from 5 to 50 minutes). They found, however, that both the nucleation and the growth rate were greater for the $\mathrm{Al}_{2} \mathrm{O}_{3}$ coatings deposited on the D2 steel substrate which had the highest $\mathrm{Cr}$ content. Kuo et al concluded that the increase in $\mathrm{Al}_{2} \mathrm{O}_{3}$ nucleation rate with increasing deposition time was associated with the formation of a thick $(\mathrm{Cr}, \mathrm{Fe})_{2} \mathrm{O}_{3}$ film on this steel substrate, prior to $\mathrm{Al}_{2} \mathrm{O}_{3}$ coating deposition. They further established that for $\mathrm{Al}_{2} \mathrm{O}_{3}$ coatings chemically vapour deposited on AISI1045 and W1 steel substrates under the deposition conditions quoted above, the weight of $\mathrm{Al}_{2} \mathrm{O}_{3}$ deposited increased with increase in deposition time (from 5 to 50 minutes). However, the $\mathrm{Al}_{2} \mathrm{O}_{3}$ deposition rate was slightly greater for the $\mathrm{Al}_{2} \mathrm{O}_{3}$ coatings deposited on AISID2 the steel substrate which had the highest $\mathrm{C}$ content [23, 25]. 
Similarly, Silvestri et al [38] investigated the effect of deposition time on the rate of CVD of $\mathrm{Al}_{2} \mathrm{O}_{3}$ coatings on $\mathrm{Si}$ substrates over a range of deposition conditions: deposition temperature 730 to $915^{\circ} \mathrm{C}, \mathrm{AlCl}_{3}$ flow rate $2.4 \times 10^{-4}$ to $1.1 \times 10^{-3}$ mole $\mathrm{min}^{-1}, \mathrm{CO}_{2}$ flow rate $3.9 \times 10^{-4}$ to $6.2 \times 10^{-2}$ moles $\min ^{-1}$, and nitrogen $\left(\mathrm{N}_{2}\right)$ and $\mathrm{H}_{2}$ flow rates of $15.21 \mathrm{~min}^{-1}$ and $3.81 \mathrm{~min}^{-1}$ respectively, and found that the deposition rate was independent of deposition time under all the deposition conditions employed.

Using X-ray diffraction to investigate the effect of deposition time on $\mathrm{Al}_{2} \mathrm{O}_{3}$ coatings chemically vapour deposited on amorphous quartz substrates, at a deposition temperature of $1000^{\circ} \mathrm{C}$, with $\mathrm{AlCl}_{3}, \mathrm{CO}_{2}$ and $\mathrm{H}_{2}$ mole fractions of $2.2 \%, 6.3 \%$ and $91.5 \%$ respectively, a total pressure of 50 torr $(0.066 \mathrm{~atm})$ and a linear gas velocity of $25 \mathrm{~cm} \mathrm{~s}^{-1}$, Fredriksson and Carlsson [39] obtained diffraction peaks corresponding to $\kappa-\mathrm{Al}_{2} \mathrm{O}_{3}$ for deposition times less than 45 minutes, whereas for deposition times longer than 60 minutes, diffraction peaks corresponding to $\alpha-\mathrm{Al}_{2} \mathrm{O}_{3}$ were obtained. They found that a phase transformation from $\kappa$ to $\alpha-\mathrm{Al}_{2} \mathrm{O}_{3}$ occurred at longer deposition times, resulting in an $\alpha$ - layer on top of an initial $\kappa$ - layer.

According to Kalish and Peters [16], at long deposition times the kinetics of reaction leading to the formation of $\mathrm{Al}_{2} \mathrm{O}_{3}$ coatings tends to become unstable, resulting in non-uniform coating thickness and texture.

\subsection{Effect of Deposition Temperature}

A number of workers have investigated the effect of deposition temperature on $\mathrm{Al}_{2} \mathrm{O}_{3}$ coatings chemically vapour deposited on various substrates, paying particular attention to its effect on nucleation $[29,32,41]$, deposition rate $[31,36,37,42,43]$ surface morphology $[24,27,43$, $44,48]$, preferred orientation [43] and crystal structure [38, 45-47].

In their work, Lindstrom and Johannesson [29] studied the effect of deposition temperature on the nucleation of $\mathrm{Al}_{2} \mathrm{O}_{3}$ coatings chemically vapour deposited on cemented carbide and TiC coated cemented carbide substrates under the following, constant deposition conditions: total pressure $8 \mathrm{kPa}(0.099 \mathrm{~atm}), \mathrm{AlCl}_{3}$ and $\mathrm{CO}_{2}$ inlet gas pressures $0.16 \mathrm{kPa}$ and $0.24 \mathrm{kPa}$ (i.e. an $\mathrm{AlCl}_{3} / \mathrm{CO}_{2}$ mole ratio of 0.67$)$ and deposition time 60 seconds. They found that if the deposition temperature was decreased over the range from $1350 \mathrm{~K}\left(1077^{\circ} \mathrm{C}\right)$ to $1150 \mathrm{~K}\left(877^{\circ} \mathrm{C}\right)$ this resulted in an increase in the $\mathrm{Al}_{2} \mathrm{O}_{3}$ nuclei density from 50 to $140 \mu \mathrm{m}^{-2}$ and 120 to 130 $\mu \mathrm{m}^{-2}$ on the $\mathrm{TiC}$ coated cemented carbide and the $(\mathrm{Ti}, \mathrm{W}) \mathrm{C}$ phase in the cemented carbide substrates respectively. In the latter case, however, the observed increase in $\mathrm{Al}_{2} \mathrm{O}_{3}$ nuclei density with decreasing deposition temperature was not as consistent as in the former, since an overgrown $\mathrm{Al}_{2} \mathrm{O}_{3}$ coating layer was found to be present for deposition temperatures greater than $927^{\circ} \mathrm{C}$. According to Lindstrom and Johannesson, the observed increase in $\mathrm{Al}_{2} \mathrm{O}_{3}$ nuclei 
density was accompanied by an increase in the supersaturation of all the gaseous species present (Blocher [40] defines supersaturation as the excess of available reaction product in the gas relative to the concentration in equilibrium with the substrate surface).

In a similar investigation, Johannesson and Lindstrom [41] studied the effect of deposition temperature on the initial nucleation of $\mathrm{Al}_{2} \mathrm{O}_{3}$ coatings chemically vapour deposited on cemented carbide substrates under the following deposition conditions: deposition temperature 1180 to $1340 \mathrm{~K}$ (907 to $1067^{\circ} \mathrm{C}$ ); gas composition 0.5 to $4.5 \% \mathrm{AlCl}_{3}, 1.5$ to $13.5 \% \mathrm{CO}_{2}$ (i.e. an $\mathrm{AlCl}_{3} / \mathrm{CO}_{2}$ mole ratio of 0.33 ), balance $\mathrm{H}_{2}$; total pressure 2 to $18 \mathrm{kPa}(0.02$ to $0.18 \mathrm{~atm}$ ), and deposition time 60 seconds. They established the same relationship between deposition temperature and $\mathrm{Al}_{2} \mathrm{O}_{3}$ nuclei density as in the previous investigation cited, and also found that the density of $\mathrm{Al}_{2} \mathrm{O}_{3}$ nuclei was governed by the supersaturation of the gaseous reactants. In their experimental work, there was a relative shortage of $\mathrm{Al}$-donors $\left(\mathrm{AlCl}_{3} / \mathrm{CO}_{2}\right.$ mole ratio 0.33 ) and the $\mathrm{Al}_{2} \mathrm{O}_{3}$ nuclei density consequently varied with the supersaturation of the Al-donors. However, in the aforementioned experimental work, carried out by Lindstrom and Johannesson [29] there was a relative shortage of O-donors $\left(\mathrm{AlCl}_{3} / \mathrm{CO}_{2}\right.$ mole ratio 0.67 ) and consequently the $\mathrm{Al}_{2} \mathrm{O}_{3}$ nuclei density varied with the supersaturation of the O-donors $\left(\mathrm{CO}_{2}\right.$ and $\left.\mathrm{H}_{2} \mathrm{O}\right)$.

These results are corroborated by the results of work carried out by Kornmann et al [32], on the CVD of $\mathrm{Al}_{2} \mathrm{O}_{3}$ coatings on TiC coated cemented carbide substrates under the deposition conditions previously quoted (see Section 2.1 ). They also found that the saturation density of $\mathrm{Al}_{2} \mathrm{O}_{3}$ nuclei increased with decreasing deposition temperature. For $\mathrm{Al}_{2} \mathrm{O}_{3}$ coatings deposited at $1000^{\circ} \mathrm{C}$, the measured saturation density of $\mathrm{Al}_{2} \mathrm{O}_{3}$ clusters was found to be $5 \mathrm{x}$ $10^{7} \mathrm{~cm}^{-2}$ (at an $\mathrm{AlCl}_{3}$ supersaturation of $3.8 \times 10^{3}$ ) whilst for coatings deposited at $850^{\circ} \mathrm{C}$ (at an $\mathrm{AlCl}_{3}$ supersaturation of $10.3 \times 10^{3}$ ) the measured saturation density of $\mathrm{Al}_{2} \mathrm{O}_{3}$ clusters was found to be $3 \times 10^{9} \mathrm{~cm}^{-2}$. According to Kornmann et al, from work carried out at different deposition temperatures with different reactant gas compositions to those previously quoted, the saturation density of $\mathrm{Al}_{2} \mathrm{O}_{3}$ nuclei also increases with increasing $\mathrm{AlCl}_{3}$ supersaturation.

With regard to the effect of deposition temperature on the deposition rate of chemically vapour deposited $\mathrm{Al}_{2} \mathrm{O}_{3}$ coatings; in each of the five investigations cited below it was found that increasing deposition temperature caused an increase in deposition rate and, further, in four of these investigations an Arrhenius type relationship was found to exist between deposition rate and deposition temperature, i.e. graphs of $\ln$ (deposition rate) vs the reciprocal of deposition temperature (in $\mathrm{K}$ ) were found to be linear with a negative slope, from which values of activation energy were calculated.

Funk et al [31] investigated the effect of deposition temperature on the deposition rate of $\mathrm{Al}_{2} \mathrm{O}_{3}$ coatings chemically vapour deposited on cemented carbide substrates at deposition temperatures over the range from 750 to $1100^{\circ} \mathrm{C}$, at a total pressure of 50 torr $(0.066 \mathrm{~atm})$ 
with $\mathrm{AlCl}_{3}, \mathrm{CO}_{2}$ and $\mathrm{H}_{2}$ partial pressures of $0.2,24.9$ and 24.9 torr respectively and a linear gas velocity of $9.4 \mathrm{~cm}^{-1}$ at $200^{\circ} \mathrm{C}$. They found that the deposition rate increased rapidly with increasing deposition temperature and interpreted this as indicating that the deposition rate is controlled mainly by a chemical reaction step. An activation energy value of approximately $40 \mathrm{k} \mathrm{cal} \mathrm{mol}^{-1}$ was calculated from the results obtained. In their work on the CVD of $\mathrm{Al}_{2} \mathrm{O}_{3}$ coatings on cemented carbide substrates under the deposition conditions quoted earlier (see Section 2.2), Colmet et al [37] found a similar sharp increase in deposition rate with increase in deposition temperature above $1300 \mathrm{~K}\left(1027^{\circ} \mathrm{C}\right)$. Further, for deposition temperatures over the range from 800 to $1200^{\circ} \mathrm{C}$ and a total deposition pressure of $0.06 \mathrm{~atm}$, they obtained an activation energy of $31.2 \mathrm{k} \mathrm{cal} \mathrm{mol}^{-1}$. This activation energy value is in good agreement with the value obtained by Park et al [42] for $\mathrm{Al}_{2} \mathrm{O}_{3}$ coatings chemically vapour deposited on TiN coated cemented carbide substrates at an $\mathrm{AlCl}_{3}$ mole fraction of $2.0 \times 10^{-3}$ and a $\mathrm{CO}_{2} / \mathrm{H}_{2}$ mole ratio of 1 , with a gas flow rate of $11 \mathrm{~min}^{-1}$. For deposition temperatures over the range from 1000 to $1150^{\circ} \mathrm{C}$, Park et al calculated activation energy values of 36 and $35 \mathrm{k} \mathrm{cal} \mathrm{mol}^{-1}$ for total deposition pressures of 50 and 100 torr (0.066 and $0.13 \mathrm{~atm}$ ) respectively. Also in good agreement with the activation energies quoted above, Kim et al [43] obtained an activation energy value of $35 \mathrm{k} \mathrm{cal} \mathrm{mol}^{-1}$ for $\mathrm{Al}_{2} \mathrm{O}_{3}$ coatings chemically vapour deposited on TiN coated cemented carbide substrates at deposition temperatures over the range 900 to $1150^{\circ} \mathrm{C}$ at a total pressure of 100 torr $(0.13 \mathrm{~atm})$, with $\mathrm{AlCl}_{3}$ and $\mathrm{H}_{2}$ partial pressures of 1 and 50 torr respectively.

In their work on the CVD of $\mathrm{Al}_{2} \mathrm{O}_{3}$ coatings on TiC coated cemented carbide substrates under the deposition conditions quoted earlier (see Section 2.2), Chun et al [36] reported that an increase in deposition temperature over the range from 900 to $1150^{\circ} \mathrm{C}$ resulted in an increase in $\mathrm{Al}_{2} \mathrm{O}_{3}$ coating deposition rate from $\sim 0.5$ to $1.8 \mathrm{mg} \mathrm{hr}^{-1}$. They inferred from their results that the deposition reaction leading to the formation of $\mathrm{Al}_{2} \mathrm{O}_{3}$ coatings is controlled by chemical kinetics at temperatures $<1000^{\circ} \mathrm{C}$ and by mass transport at temperatures $>1000^{\circ} \mathrm{C}$. Similarly, Kuo et al [24] studied the effect of deposition temperature on the deposition rate of $\mathrm{Al}_{2} \mathrm{O}_{3}$ coatings chemically vapour deposited on AISID2 tool steel substrates under the deposition conditions quoted earlier (see Section 2.1). They found that, for a substrate pre-heating time of 3.5 hours, an increase in deposition temperature over the range from 860 to $970^{\circ} \mathrm{C}$ resulted in an increase in deposition rate of the $\mathrm{Al}_{2} \mathrm{O}_{3}$ coatings.

With regard to the effect of deposition temperature on the surface morphology of chemically vapour deposited $\mathrm{Al}_{2} \mathrm{O}_{3}$ coatings; in all the investigations cited below an increase in surface grain size was generally observed with increasing deposition temperature, accompanied by a change in the shape of the grains.

In their work, Kim et al [43] investigated the effect of deposition temperature on the surface morphology of $\mathrm{Al}_{2} \mathrm{O}_{3}$ coatings chemically vapour deposited on TiN coated cemented carbide substrates under the deposition conditions quoted earlier in this section. Using an SEM to 
examine the surface of the $\mathrm{Al}_{2} \mathrm{O}_{3}$ coatings, they established that increasing the deposition temperature over the range from 900 to $1150^{\circ} \mathrm{C}$ caused the surface grain structure to become coarser. From the SEM micrographs presented it is evident that surface grains $\sim 1$ to $2 \mu \mathrm{m}$ in size were present for the coatings deposited at a temperature of $900^{\circ} \mathrm{C}$, whilst the coatings deposited at $1150^{\circ} \mathrm{C}$ exhibited much larger surface grains $\sim 5$ to $10 \mu \mathrm{m}$ in size. X-ray analysis confirmed that, over the entire range of deposition temperatures employed, the coatings consisted of $\alpha-\mathrm{Al}_{2} \mathrm{O}_{3}$. In addition to the coarsening of the grain structure with increasing deposition temperature, Kim et al also observed a change in shape of the grains. The grains on the surface of the $\mathrm{Al}_{2} \mathrm{O}_{3}$ coatings deposited at 900 and $950^{\circ} \mathrm{C}$ were nodular in nature, but for deposition temperatures greater than $1027^{\circ} \mathrm{C}$ the grains became noticeably more faceted, exhibiting a pyramidal type structure. The coarsening of the surface grain structure with increasing deposition temperature observed was attributed by Kim et al to a decrease in the supersaturation of $\mathrm{H}_{2} \mathrm{O}$ and $\mathrm{AlCl}_{3}$ with increasing deposition temperature causing a decrease in the nucleation rate.

The experimental results obtained by Kim et al are in good agreement with those obtained by Park et al [44] and Colmet and Naslain [27] who respectively investigated the effect of deposition temperature on the surface morphology of $\mathrm{Al}_{2} \mathrm{O}_{3}$ coatings chemically vapour deposited on TiN coated and TiC coated cemented carbide substrates. Using a range of deposition conditions: deposition temperature 1000 to $1150^{\circ} \mathrm{C} ; \mathrm{AlCl}_{3}$ mol fraction $2.0 \times 10^{-3}$ to $3.0 \times 10^{-2} ; \mathrm{CO}_{2}$ mol fraction 0.1 to 0.9 ; gas flow rate 1 to $21 \mathrm{~min}^{-1}$; total pressure 50 to 400 torr $(0.066$ to $0.53 \mathrm{~atm})$ and deposition time 1 hour, Park et al found that the surface grains of the $\mathrm{Al}_{2} \mathrm{O}_{3}$ coatings deposited at $1150^{\circ} \mathrm{C}$ were coarser and more faceted than those of the coatings deposited at $1050^{\circ} \mathrm{C}$. They "explained" that the $\mathrm{Al}_{2} \mathrm{O}_{3}$ coating surface morphology is affected by the supersaturation of the reactants. Whilst the supersaturation of the Al-donor $\left(\mathrm{AlCl}_{3}\right)$ decreases as the deposition temperature increases, that of the O-donor $\left(\mathrm{H}_{2} \mathrm{O}\right.$ vapour from $\mathrm{CO}_{2}$ and $\mathrm{H}_{2}$ ) increases because the $\mathrm{H}_{2} \mathrm{O}$ inlet concentration is more sensitive to temperature than the $\mathrm{H}_{2} \mathrm{O}$ equilibrium concentration, the resulting exponentially increased growth rate accounting for the coarser grains found to exist at the higher deposition temperatures. It is pertinent to point out that whilst Park et al refer to an increase in the supersaturation of O-donor with increasing deposition temperature (in agreement with the findings of Johannesson and Lindstrom [41]) this is in direct contrast to the findings of Lindstrom and Johannesson [29] and Kim et al [43], according to whom the supersaturation of O-donors decreases with increasing deposition temperature. In their work Colmet and Naslain [27] observed that $\mathrm{Al}_{2} \mathrm{O}_{3}$ coatings deposited at a deposition temperature of $1173 \mathrm{~K}$ $\left(900^{\circ} \mathrm{C}\right.$ ) and a total pressure of $0.8 \mathrm{~atm}$, with the other deposition conditions as specified earlier in Section 2.1, were composed of nodules whilst coatings deposited at a temperature of $1323 \mathrm{~K}\left(1050^{\circ} \mathrm{C}\right)$ exhibited "well-shaped", pyramidal $\mathrm{Al}_{2} \mathrm{O}_{3}$ crystals. A somewhat similar increase in crystalline state with increase in deposition temperature from $1323 \mathrm{~K}\left(1050^{\circ} \mathrm{C}\right)$ to $1473 \mathrm{~K}\left(1200^{\circ} \mathrm{C}\right)$ was also observed for $\mathrm{Al}_{2} \mathrm{O}_{3}$ coatings deposited at a much lower total pressure $(0.03 \mathrm{~atm})$. For $\mathrm{Al}_{2} \mathrm{O}_{3}$ coatings chemically vapour deposited on AISID2 tool steel 
substrates under the deposition conditions specified in Section 2.1, Kuo et al [24] observed that, for a substrate pre-heating time of 1.5 hours, the surface grain size of the $\mathrm{Al}_{2} \mathrm{O}_{3}$ coatings deposited at a deposition temperature of $910^{\circ} \mathrm{C}$ was slightly larger than that of the $\mathrm{Al}_{2} \mathrm{O}_{3}$ coatings deposited at a temperature of $860^{\circ} \mathrm{C}$.

Using the deposition conditions quoted earlier in this section, Kim et al [43] also investigated the effect of deposition temperature on the preferred orientation of $\mathrm{Al}_{2} \mathrm{O}_{3}$ coatings chemically vapour deposited on TiN coated cemented carbide substrates. They found, from X-ray diffraction, that the crystallographic structure of the $\mathrm{Al}_{2} \mathrm{O}_{3}$ coatings changed from being randomly oriented to exhibiting (1014) preferred orientation with increasing deposition temperature, reflecting the columnar growth of the latter $\mathrm{Al}_{2} \mathrm{O}_{3}$ coating.

In his work on the CVD of $\mathrm{Al}_{2} \mathrm{O}_{3}$ single crystals, Schaffer [45] obtained epitaxial growth of $\alpha-\mathrm{Al}_{2} \mathrm{O}_{3}$ on ruby and sapphire substrates over a range of deposition temperature between 970 to $1800^{\circ} \mathrm{C}$. X-ray analyses of deposits formed at $970^{\circ} \mathrm{C}$ indicated that $\theta-\mathrm{Al}_{2} \mathrm{O}_{3}$ was the predominant crystalline form with lesser amounts of $\alpha, \kappa$ and $\eta-\mathrm{Al}_{2} \mathrm{O}_{3}$. In addition, homogeneous nucleation was obtained at temperatures below $1100^{\circ} \mathrm{C}$. In Wong and Robinson's [46] work on the effect of deposition temperature on the crystal structure of $\mathrm{Al}_{2} \mathrm{O}_{3}$ coatings chemically vapour deposited on sintered alumina substrates, different values of $\mathrm{CO}_{2}$, $\mathrm{H}_{2}$ and $\mathrm{Cl}_{2}$ volume flow rate were employed at a total pressure of 0.5 torr $\left(6.6 \times 10^{-4} \mathrm{~atm}\right)$. The metastable $\theta, \gamma$ and to a lesser extent $\kappa$ forms of $\mathrm{Al}_{2} \mathrm{O}_{3}$ were observed at a deposition temperature of $1000^{\circ} \mathrm{C}$, but at a deposition temperature to $1500^{\circ} \mathrm{C}$ the stable $\alpha$ phase was observed. For $\mathrm{Al}_{2} \mathrm{O}_{3}$ coatings chemically vapour deposited on $\mathrm{Si}$ substrates under the following deposition conditions: deposition temperature 400 to $1300^{\circ} \mathrm{C} ; \mathrm{AlCl}_{3}$ flow rate $21 \mathrm{~min}^{-1}, \mathrm{CO}_{2}$ flow rate $0.51 \mathrm{~min}^{-1}$ and $\mathrm{H}_{2}$ flow rate $131 \mathrm{~min}^{-1}$, Iida and Tsujide [47] reported that at a deposition temperature of $1000^{\circ} \mathrm{C}$ the diffraction peaks did not wholly correspond to $\alpha-\mathrm{Al}_{2} \mathrm{O}_{3}$, whereas at a temperature of $1300^{\circ} \mathrm{C}$ the diffraction peaks corresponded entirely to a stable $\alpha-\mathrm{Al}_{2} \mathrm{O}_{3}$ structure.

Iida and Tsujide further studied the effect of deposition temperature on the Cl content of their $\mathrm{Al}_{2} \mathrm{O}_{3}$ coatings using electron probe micro analysis (EPMA). They found that there was a decrease in the amount of $\mathrm{Cl}$ contained in the $\mathrm{Al}_{2} \mathrm{O}_{3}$ coatings with increasing deposition temperature. For $\mathrm{Al}_{2} \mathrm{O}_{3}$ coatings deposited at $470^{\circ} \mathrm{C}$ the $\mathrm{Cl}$ content was 10 to 21 at. $\%$ whereas for coatings deposited at $700^{\circ} \mathrm{C}$ the $\mathrm{Cl}$ content was about 2 at. \%, and a negligible amount of $\mathrm{Cl}$ was detected in the $\mathrm{Al}_{2} \mathrm{O}_{3}$ coatings deposited above $800^{\circ} \mathrm{C}$. The $\mathrm{Cl}$ in the coatings was also found to be eliminated by heat treatment at even higher temperatures. Iida and Tsujide concluded that the decomposition of $\mathrm{AlCl}_{3}$ at lower deposition temperatures is incomplete and the composition of $\mathrm{Al}_{2} \mathrm{O}_{3}$ film is affected by the "imperfections" of the reaction. This is consistent with the results of work by Silvestri et al [38] who assessed the Cl content of $\mathrm{Al}_{2} \mathrm{O}_{3}$ coatings, deposited at temperatures between 730 and $915^{\circ} \mathrm{C}$ with the remaining deposition conditions employed being as specified in Section 2.2. The $\mathrm{Cl}$ contents of the coatings 
deposited at 732 and $805^{\circ} \mathrm{C}$ were 0.008 and 0.0015 weight fractions respectively, whereas for the coatings deposited above $900^{\circ} \mathrm{C}$ the $\mathrm{Cl}$ content was below the detection limit of 0.0008 weight fraction.

Finally, for $\mathrm{Al}_{2} \mathrm{O}_{3}$ coatings deposited by the direct reaction of $\mathrm{AlCl}_{3}$ with $\mathrm{H}_{2} \mathrm{O}$, Mantyla et al [48] found, in agreement with the findings of previous investigations cited earlier, in this section, that the coating surface morphology, crystallinity and amount of impurities were all strongly dependent on the deposition temperature. $\mathrm{Al}_{2} \mathrm{O}_{3}$ coatings deposited at temperatures between 250 and $500^{\circ} \mathrm{C}$ at a total pressure of 4 mbar $\left(3.9 \times 10^{-3}\right.$ atm), with $\mathrm{AlCl}_{3}$ and $\mathrm{H}_{2} \mathrm{O}$ concentrations of 1.0 and $2.5 \%$ respectively, were mainly amorphous with a dome-like surface morphology. The amount of amorphous phase decreased with increasing deposition temperature and, between deposition temperatures of 750 and $800^{\circ} \mathrm{C}$, crystalline $\mathrm{Al}_{2} \mathrm{O}_{3}$ with an equiaxed, "rocky" surface morphology was observed. At $1000^{\circ} \mathrm{C}$ stable $\alpha-\mathrm{Al}_{2} \mathrm{O}_{3}$ was obtained. Chemical analysis of the low temperature $\mathrm{Al}_{2} \mathrm{O}_{3}$ coatings showed that they contained $\mathrm{Cl}$ as impurity, the amount of $\mathrm{Cl}$ decreasing with increasing deposition temperature.

\subsection{Effect of Total Pressure}

Investigations have been carried out into the effect of total pressure on the nucleation [29], deposition rate $[27,31,36,37,42]$, surface morphology $[27,42,44,46]$ and preferred orientation [44] of $\mathrm{Al}_{2} \mathrm{O}_{3}$ coatings chemically vapour deposited on various substrates.

In their work, Lindstrom and Johannesson [29] investigated the effect of total pressure on the nucleation of $\mathrm{Al}_{2} \mathrm{O}_{3}$ coatings chemically vapour deposited on $\mathrm{TiC}$ coated and uncoated cemented carbide substrates under the deposition conditions previously specified (see Section 2.3). They found that if the total pressure was decreased from $32 \mathrm{kPa}(0.32 \mathrm{~atm})$ to $2 \mathrm{kPa}$ $(0.02 \mathrm{~atm})$, this resulted in an increase in $\mathrm{Al}_{2} \mathrm{O}_{3}$ nuclei density on the TiC coated cemented carbide substrates (from 50 to $80 \mu \mathrm{m}^{-2}$ ) and on the (Ti,W)C phase in the cemented carbide substrates (from 50 to $110 \mu^{-2}$ ). This observed increase in $\mathrm{Al}_{2} \mathrm{O}_{3}$ nuclei density with decreasing total pressure was stated to have been caused by a concomitant increase in the supersaturation of $\mathrm{O}$-donors with decreasing total pressure, the supersaturation of Al-donors remaining relatively constant.

Colmet and Naslain [27] investigated the effect of total pressure on the deposition rate of $\mathrm{Al}_{2} \mathrm{O}_{3}$ coatings chemically vapour deposited on $\mathrm{TiC}$ coated cemented carbide substrates, under the deposition conditions previously specified (see Section 2.1). As shown in Figure 2.1, they found that the deposition rate increased linearly from 5 to $20 \mathrm{mg} \mathrm{hr}^{-1}$ with increase in total pressure from 0.2 to $1.0 \mathrm{~atm}$. Under their deposition conditions no significant nucleation in the gas phase was found to occur and no "soot" formation was observed. These findings are in agreement with the findings of Colmet et al [37]. The experimental results of Colmet and 
Naslain and Colmet et al are in stark disagreement with the findings of Funk et al [31] and, to a lesser extent, with those of Park et al [42]. Using a deposition temperature of $1050^{\circ} \mathrm{C}$ and a reactant gas composition of $0.4 \% \mathrm{AlCl}_{3}, 49.8 \% \mathrm{CO}_{2}$ and $49.8 \% \mathrm{H}_{2}$, with the remaining deposition conditions as previously specified in Section 2.3 , the former workers observed that the deposition rate of $\mathrm{Al}_{2} \mathrm{O}_{3}$ coatings chemically vapour deposited on cemented carbide substrates initially increased rapidly with increase in total pressure from close to 0 to 75 torr (from close to 0 to 0.099 atm respectively). Any further increase in total pressure however resulted in a rapid decrease in the deposition rate of the $\mathrm{Al}_{2} \mathrm{O}_{3}$ coatings, which fell to zero at a total pressure of 200 torr $(0.26 \mathrm{~atm})$, as evident from Figure 2.2. According to Funk et al, the decrease in deposition rate of the $\mathrm{Al}_{2} \mathrm{O}_{3}$ coatings at high total pressures might be due to undesirable homogeneous reactions leading to powder (i.e. soot) formation. From the results of the work carried out by Park et al, on the CVD of $\mathrm{Al}_{2} \mathrm{O}_{3}$ coatings on TiN coated cemented carbide substrates at deposition temperatures of 1050 and $1125^{\circ} \mathrm{C}$, with the other the deposition conditions as previously specified in Section 2.3 , it is evident that, at both temperatures, an increase in total pressure from close to 0 to 600 torr (from close to 0 to 0.79 atm respectively) caused an increase in the $\mathrm{Al}_{2} \mathrm{O}_{3}$ coating deposition rate from 0 to $13 \mu \mathrm{m}$ $\mathrm{hr}^{-1}$. At low total pressure (up to 200 torr $(0.26 \mathrm{~atm})$ ) Park et al found that the deposition rate increased almost linearly with increase in total pressure, but that with further increase in total pressure the increase in deposition rate was reduced. They suggested that this reduction was caused by depletion of the gaseous reactants by a homogeneous reaction, during which the reactant gases were transported to the substrate surface. They further suggested, that with increase in total pressure this homogeneous reaction was accelerated by the increase in the supersaturation of the reactants, leading to the formation of "soots" of $\mathrm{Al}_{2} \mathrm{O}_{3}$ at higher total pressures i.e. greater than or equal to 400 torr $(0.53 \mathrm{~atm})$. In contrast, for $\mathrm{Al}_{2} \mathrm{O}_{3}$ coatings chemically vapour deposited on cemented carbide substrates, at a deposition temperature of $1323 \mathrm{~K}\left(1050^{\circ} \mathrm{C}\right)$ and a gas composition of $0.8 \% \mathrm{AlCl}_{3}, 49.6 \% \mathrm{CO}_{2}$ and $49.6 \% \mathrm{H}_{2}$, Colmet et al [37] found that the $\mathrm{Al}_{2} \mathrm{O}_{3}$ coating deposition rate increased linearly (from $\sim 1$ to $23 \mathrm{mg}$ $\mathrm{hr}^{-1}$ ) with increase in the total pressure from close to 0 to 700 torr (close to 0 to $0.9 \mathrm{~atm}$ respectively). They also stated that no $\mathrm{Al}_{2} \mathrm{O}_{3}$ 'soot' was observed at the higher total pressures. Finally, in disagreement with all the previous investigations cited above, in the case of $\mathrm{Al}_{2} \mathrm{O}_{3}$ coatings chemically vapour deposited on $\mathrm{TiC}$ coated cemented carbide substrates under the following constant deposition conditions: deposition temperature $1050^{\circ} \mathrm{C}, \mathrm{CO}_{2} / \mathrm{H}_{2}$ mole ratio 1 and $\mathrm{AlCl}_{3}$ mole fraction 0.005 , Chun et al [36] established that, with an increase in total pressure over the range $\sim 50$ to 400 torr ( 0.066 to 0.5 atm respectively), the $\mathrm{Al}_{2} \mathrm{O}_{3}$ coating deposition rate increased linearly (from $\sim 9$ to $23 \mathrm{mg} \mathrm{hr}^{-1}$ ) with increase in (total pressure) ${ }^{1 / 2}$ as opposed to total pressure in the investigations cited above.

With regard to surface morphology; for $\mathrm{Al}_{2} \mathrm{O}_{3}$ coatings chemically vapour deposited on $\mathrm{TiC}$ coated cemented carbide substrates under the deposition conditions specified earlier (see Section 2.1), Colmet and Naslain [27] observed that the surface grain size of the coatings increased with increasing total pressure. The surface of the coatings deposited at low pressure 
(0.03 atm) was composed of small, equiaxed grains whereas that of the coatings deposited at a total pressure close to $1.0 \mathrm{~atm}$ consisted of large, irregular shaped $\mathrm{Al}_{2} \mathrm{O}_{3}$ grains. Colmet and Naslain commented that this modification in $\mathrm{Al}_{2} \mathrm{O}_{3}$ coating structure results in a decrease in coating strength and wear resistance, as shown by hardness and scratch tests respectively, and that the best results are obtained with $\mathrm{Al}_{2} \mathrm{O}_{3}$ coatings deposited at low total pressure, i.e. $0.06 \mathrm{~atm}$. This tendency to form more friable deposits of $\mathrm{Al}_{2} \mathrm{O}_{3}$ at high total pressures has also been observed by Park et al $[42,44]$ and Wong and Robinson [46] in their work on the CVD of $\mathrm{Al}_{2} \mathrm{O}_{3}$ coatings on TiN coated cemented carbide and sintered alumina substrates respectively. Park et al [42] observed $\mathrm{Al}_{2} \mathrm{O}_{3}$ powder on the surface of $\mathrm{Al}_{2} \mathrm{O}_{3}$ coatings deposited at a deposition temperature of $1125^{\circ} \mathrm{C}$ and a total pressure of 400 torr $(0.53 \mathrm{~atm})$, the other depositions conditions employed being as previously specified in Section 2.3, whereas Park et al [44] observed $\mathrm{Al}_{2} \mathrm{O}_{3}$ powder on the surface of the $\mathrm{Al}_{2} \mathrm{O}_{3}$ coatings deposited at total pressures of 200 and 400 torr ( 0.26 and 0.53 atm, respectively) with the other depositions conditions as quoted earlier in Section 2.3. Furthermore they noted that although the supersaturations of the $\mathrm{Al}$-donor species $\left(\mathrm{AlCl}_{3}\right.$ and $\left.\mathrm{Al}_{2} \mathrm{Cl}_{6}\right)$ stayed relatively constant with increasing total pressure, that of the O-donor species $\left(\mathrm{H}_{2} \mathrm{O}, \mathrm{CO}_{2}\right)$ was raised by a power of 0.5 causing vapour phase intermolecular collisions to increase, thereby giving rise to homogeneous "nucleation" (author's quotation marks) i.e. reaction of $\mathrm{Al}_{2} \mathrm{O}_{3}$ at higher total pressures. For a total pressure of 0.5 torr $\left(6.6 \times 10^{-4} \mathrm{~atm}\right)$, with the other deposition conditions employed being as previously quoted in Section 2.3 , Wong and Robinson observed the deposition of a porous $\theta-\mathrm{Al}_{2} \mathrm{O}_{3}$ coating (with possible $\kappa-\mathrm{Al}_{2} \mathrm{O}_{3}$ ). On increasing the total pressure to 5.0 torr $\left(6.6 \times 10^{-3} \mathrm{~atm}\right)$, low density, "fluffy" powder deposits of $\gamma-\mathrm{Al}_{2} \mathrm{O}_{3}$ were seen. Wong and Robinson state that the pressure range between 0.5 and 5.0 torr appears to be the critical transition region (for reaction of $\mathrm{AlCl}_{3}$ with both $\mathrm{H}_{2} \mathrm{O}$ and $\mathrm{CO}_{2}: \mathrm{H}_{2}$ ) in which $\gamma-\mathrm{Al}_{2} \mathrm{O}_{3}$ powder is formed in the gas phase with increasing total pressure.

Finally, Park et al [44] also investigated the effect of total pressure on the preferred orientation of $\mathrm{Al}_{2} \mathrm{O}_{3}$ coatings chemically vapour deposited on TiN coated cemented carbide substrates under the depositions conditions quoted earlier in Section 2.3. They found that increasing the total pressure from 100 to 400 torr ( 0.13 to 0.53 atm respectively) caused a reduction in the

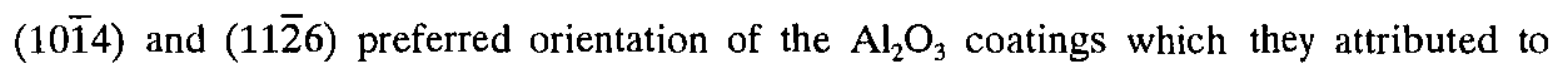
increased $\mathrm{O}$-donor supersaturation and the attachment of randomly oriented $\mathrm{Al}_{2} \mathrm{O}_{3}$ soots to the crystal surface.

\subsection{Effect of Reactant Gas Concentration}

Several workers have investigated the effect of reactant gas concentration on chemically vapour deposited $\mathrm{Al}_{2} \mathrm{O}_{3}$ coatings, in terms of either partial pressures or mole ratios, paying particular attention to the following: nucleation $[29,41]$, deposition rate $[31,36,37,38,42$, $43,44]$, surface morphology $[42,43,27]$ and preferred orientation [44]. This section is 
therefore divided into two parts; the first deals with the effect of partial pressure and the second with the effect of mole ratio. Since, as shown in Appendix 1, the partial pressure of any gas in a gas mixture is the total pressure of the gas mixture multiplied by the mole fraction of the gas in question, then the ratio of partial pressure to total pressure equals the mole fraction of the gas. It therefore follows that increasing or decreasing the concentration of a particular gaseous reactant by adjusting its partial pressure is the same as changing its concentration by adjusting its mole ratio.

\subsubsection{Effect of Partial Pressure}

In their work, Lindstrom and Johannesson [29] investigated the effect of $\mathrm{CO}_{2}$ and $\mathrm{AlCl}_{3}$ input partial pressures $\left(P_{\mathrm{CO}_{2}}\right.$ and $P_{\mathrm{AlCl}_{3}}$ respectively) on the nucleation of $\mathrm{Al}_{2} \mathrm{O}_{3}$ coatings chemically vapour deposited on $\mathrm{TiC}$ coated cemented carbide substrates and on the $(\mathrm{Ti}, \mathrm{W}) \mathrm{C}$ phase in cemented carbide substrates. The following constant deposition conditions were employed: deposition temperature $1250 \mathrm{~K}\left(977^{\circ} \mathrm{C}\right)$ and total pressure $8 \mathrm{kPa}(0.08 \mathrm{~atm})$, with the remaining deposition conditions as previously specified in Section 2.3. Lindstrom and Johannesson found that if $P_{\mathrm{CO}_{2}}$ was decreased over the range from $0.72 \mathrm{kPa}$ to $0.08 \mathrm{kPa}$ at a constant $P_{\mathrm{AlCl}_{3}}$ of $0.16 \mathrm{kPa}$, (i.e. a decrease in $\mathrm{P}_{\mathrm{CO}_{2}} / P_{\mathrm{AlCl}_{3}}$ ratio) this resulted in an increase in the $\mathrm{Al}_{2} \mathrm{O}_{3}$ nuclei density on the $\mathrm{TiC}$ coated cemented carbide substrates from 70 to $100 \mu \mathrm{m}^{-2}$. In contrast, for the $(\mathrm{Ti}, \mathrm{W}) \mathrm{C}$ phase in the cemented carbide substrates, an overgrown $\mathrm{Al}_{2} \mathrm{O}_{3}$ coating was observed at a $P_{\mathrm{CO}_{2}}$ of $0.72 \mathrm{kPa}$ whilst at $P_{\mathrm{CO}_{2}}$ values of $0.24 \mathrm{kPa}$ and $0.08 \mathrm{kPa}$ the $\mathrm{Al}_{2} \mathrm{O}_{3}$ nuclei densities were found to be 50 and $80 \mu \mathrm{m}^{-2}$ respectively. With decreasing $P_{\mathrm{CO}_{2}}$ Lindstrom and Johannesson reported an increase in the supersaturation of $\mathrm{O}$-donors and a decrease in the supersaturation of $\mathrm{Al}$-donors and stated that the $\mathrm{Al}_{2} \mathrm{O}_{3}$ nuclei density follows the former. In the case of the $\mathrm{TiC}$ coated cemented carbide substrates, an increase in $P_{\mathrm{AlCl}_{3}}$ from $0.053 \mathrm{kPa}$ to $0.16 \mathrm{kPa}$ at a constant $P_{\mathrm{CO}_{2}}$ value of $0.24 \mathrm{kPa}$ (i.e. a decrease in $P_{\mathrm{CO}_{2}} / P_{\mathrm{AlCl}_{3}}$ ratio) was found to cause a slight increase in the $\mathrm{Al}_{2} \mathrm{O}_{3}$ nuclei density from 50 to $80 \mu \mathrm{m}^{-2}$. Further increase in $P_{\mathrm{AICl}_{3}}$ to $0.48 \mathrm{kPa}$, however, caused a slight decrease in the $\mathrm{Al}_{2} \mathrm{O}_{3}$ nuclei density to $70 \mu \mathrm{m}^{-2}$. In contrast, at a $P_{\mathrm{AlCl}_{3}}$ of $0.053 \mathrm{kPa}$ an overgrown $\mathrm{Al}_{2} \mathrm{O}_{3}$ coating was observed on the $(\mathrm{Ti}, \mathrm{W}) \mathrm{C}$ phase in the cemented carbide substrates, whilst at $P_{\mathrm{AlCl}_{3}}$ values of 0.16 and $0.48 \mathrm{kPa} \mathrm{Al}_{2} \mathrm{O}_{3}$ nuclei densities of 50 and $90 \mu \mathrm{m}^{-2}$ respectively were obtained. Lindstrom and Johannesson suggested that with increasing $P_{\mathrm{AlCl}_{3}}$ the supersaturation of O-donors decreased whilst that of the Al-donors increased. The results from these two experiments are consistent with each other with regard to increasing $\mathrm{Al}_{2} \mathrm{O}_{3}$ nuclei density with decreasing $P_{\mathrm{CO}_{2}} / P_{\mathrm{AlCl}}$ ratio. It is, however, pertinent to note that there appears to be a contradiction between the tabulated data and the written text of Lindstrom and Johannesson's paper with regard to the effect of $P_{\mathrm{AlCl}_{3}}$ on the supersaturation of $\mathrm{O}$-donors.

For $\mathrm{Al}_{2} \mathrm{O}_{3}$ coatings chemically vapour deposited on cemented carbide substrates under the following deposition conditions: deposition temperature $1260 \mathrm{~K}\left(987^{\circ} \mathrm{C}\right)$ and total pressure $6 \mathrm{kPa}(0.059 \mathrm{~atm})$, with the remaining deposition conditions as previously quoted in Section 
2.3, Johannesson and Lindstrom [41] found that a decrease in $P_{\mathrm{CO}_{2}}$ over the range from 0.81 $\mathrm{kPa}$ to $0.09 \mathrm{kPa}$ at a constant $P_{\mathrm{AlCl} / 3}$ value of $0.90 \mathrm{kPa}$ (i.e. a decrease in $P_{\mathrm{CO}_{2}} / P_{\mathrm{AlCl}_{3}}$ ratio) resulted in a decrease in the $\mathrm{Al}_{2} \mathrm{O}_{3}$ nuclei density from 80 to $60 \mu \mathrm{m}^{-2}$. They associated this decrease with changes in the supersaturation of the O-donors and $\mathrm{Al}$-donors and in the total supersaturation. Johannesson and Lindstrom also observed that if $P_{\mathrm{AlCl}_{3}}$ was decreased over the range from $0.27 \mathrm{kPa}$ to $0.03 \mathrm{kPa}$ at a constant $P_{\mathrm{CO}_{2}}$ value of $0.27 \mathrm{kPa}$, (i.e. an increase in $P_{\mathrm{CO}_{2}} / P_{\mathrm{AlCl}_{3}}$ ratio) this resulted in an increase in the $\mathrm{Al}_{2} \mathrm{O}_{3}$ nuclei density from 50 to $60 \mu \mathrm{m}^{-2}$. This observed increase in $\mathrm{Al}_{2} \mathrm{O}_{3}$ nuclei density with decreasing $P_{\mathrm{AlCl}_{3}}$ was stated to be caused by a concomitant increase in the supersaturation of $\mathrm{Al}$-donors and in the total supersaturation, there being no correlation with the supersaturation of O-donors. It should be noted that although the results from the two experiments carried out by Johannesson and Lindstrom are in agreement with each other, i.e. the $\mathrm{Al}_{2} \mathrm{O}_{3}$ nuclei density decreasing with decreasing $P_{\mathrm{CO}_{2}} / P_{\mathrm{AlCl}_{3}}$ ratio, they are in direct contradiction to those in the aforementioned work carried out by Lindstrom and Johannesson [29], according to whom the $\mathrm{Al}_{2} \mathrm{O}_{3}$ nuclei density increases with decreasing $\mathrm{P}_{\mathrm{CO}_{2}} / P_{\mathrm{AlCl}_{3}}$ ratio.

In their work Funk et al [31] investigated the effect of partial pressures on the rate of deposition of $\mathrm{Al}_{2} \mathrm{O}_{3}$ coatings chemically vapour deposited on cemented carbide substrates under the following constant deposition conditions: deposition temperature $1000^{\circ} \mathrm{C}$, total pressure 50 torr $(0.066 \mathrm{~atm})$ and linear gas velocity $9.4 \mathrm{~cm}^{-1}$ at $200^{\circ} \mathrm{C}$. At a $P_{\mathrm{CO}_{2}} / P_{\mathrm{H}_{2}}$ ratio of 1 they found that an increase in $P_{\mathrm{AlCl}_{3}}$ from 0.2 to 1.5 torr caused a decrease in $\mathrm{Al}_{2} \mathrm{O}_{3}$ deposition rate from 10.4 to $7.2 \mathrm{mg} \mathrm{hr}^{-1}$. Funk et al also investigated the variation of $\mathrm{Al}_{2} \mathrm{O}_{3}$ deposition rate with $P_{\mathrm{CO}_{2}} / P_{\mathrm{H}_{2}}$ ratio at a constant $P_{\mathrm{AlCl}_{3}}$ value of 1.5 torr. As shown in Figure 2.3, they found that decrease in $P_{\mathrm{CO}_{2}} / P_{\mathrm{H}_{2}}$ ratio over the range from 22 to 1 caused only a slight decrease in $\mathrm{Al}_{2} \mathrm{O}_{3}$ deposition rate from 8 to $6 \mathrm{mg} \mathrm{hr}^{-1}$. Below a $P_{\mathrm{CO}_{2}} / P_{\mathrm{H}_{2}}$ ratio of 1 however the $\mathrm{Al}_{2} \mathrm{O}_{3}$ deposition rate was observed to decrease rapidly to $2 \mathrm{mg} \mathrm{hr}^{-1}$ at a $P_{\mathrm{CO}_{2}} / P_{\mathrm{H}_{2}}$ ratio of 0.05 (i.e. a $P_{\mathrm{H}_{2}} / P_{\mathrm{CO}_{2}}$ ratio of 20), further decrease in $P_{\mathrm{CO}_{2}} / P_{\mathrm{H}_{2}}$ ratio (i.e. increase in $P_{\mathrm{H}_{2}} / P_{\mathrm{CO}_{2}}$ ratio) having relatively little additional effect on $\mathrm{Al}_{2} \mathrm{O}_{3}$ deposition rate, as evident from Figure 2.3. Finally, at constant $P_{\mathrm{AlCl} 3}, P_{\mathrm{H}_{2}}$ and $P_{\mathrm{CO}_{2}}$ values of 0.2 torr, 24.9 torr and 12.5 torr respectively, i.e. a $P_{\mathrm{CO}_{2}} / P_{\mathrm{H}_{2}}$ ratio of $\sim 0.5\left(P_{\mathrm{H}_{2}} / P_{\mathrm{CO}_{2}}\right.$ ratio of $\left.\sim 2\right)$, Funk et al found that the addition of argon $\left(P_{\mathrm{Ar}} 12.5\right.$ torr) to the reactant gas mixture, led to an $\mathrm{Al}_{2} \mathrm{O}_{3}$ deposition rate of $10.9 \mathrm{mg} \mathrm{hr}^{-1}$ whereas the separate addition of the same amount of $\mathrm{CO}$ and $\mathrm{HCl}$ caused a decrease in $\mathrm{Al}_{2} \mathrm{O}_{3}$ deposition rate to 3.5 and $0.5 \mathrm{mg} \mathrm{hr}^{-1}$ respectively.

Colmet et al [37] have also investigated the effect of partial pressure on the rate of deposition of $\mathrm{Al}_{2} \mathrm{O}_{3}$ coatings chemically vapour deposited on cemented carbide substrates at a constant deposition temperature of $1323 \mathrm{~K}\left(1050^{\circ} \mathrm{C}\right)$ and a total pressure of $0.06 \mathrm{~atm}$. First, the variation of $\mathrm{Al}_{2} \mathrm{O}_{3}$ deposition rate with increasing $P_{\mathrm{AlCl}_{3}}$ was studied at $\alpha=P_{\mathrm{H}_{2 i \mathrm{n}}} / P_{\mathrm{CO}_{2 i \mathrm{n}}}$ (where "in" denotes initial) values of 1,12 and 30. As shown in Figure 2.4, Colmet et al found that at each value of $\alpha$ the $\mathrm{Al}_{2} \mathrm{O}_{3}$ deposition rate initially increased rapidly with increasing $P_{\mathrm{AlCl}_{3}}$, but then reached a limit, independent of $\alpha$, above which no further increase in deposition rate 
took place with increase in $P_{\mathrm{AlCl}_{3}}$. The experimental results obtained by Colmet et al are in good agreement with those obtained by Colmet and Naslain [27] in their work. However, the results obtained by Colmet et al and Colmet and Naslain [27] are in direct contradiction to the effect of $P_{\mathrm{AlCl}_{3}}$ on $\mathrm{Al}_{2} \mathrm{O}_{3}$ deposition rate observed by Funk et al [31]. Colmet et al also investigated the variation of $\mathrm{Al}_{2} \mathrm{O}_{3}$ deposition rate with $P_{\mathrm{CO}_{2 i \mathrm{n}}} / P_{\mathrm{H}_{2 i \mathrm{n}}}$ ratio at $P_{\mathrm{AlCl}}$ values of 5 $\times 10^{-4}$ and $2.4 \times 10^{-3} \mathrm{~atm}$. The results obtained are shown in Figure 2.5. In contrast to the situation with $P_{\mathrm{AlCl}_{3}}$, the effect of $P_{\mathrm{CO}_{2 i \mathrm{n}}} / P_{\mathrm{H}_{2 \mathrm{in}}}$ ratio on $\mathrm{Al}_{2} \mathrm{O}_{3}$ deposition rate established by Colmet et al is essentially the same as that found by Funk et al [31].

In addition to their experimental work described above, Colmet et al [37] carried out a thermodynamic study of the $\mathrm{CVD}$ of $\mathrm{Al}_{2} \mathrm{O}_{3}$, principally as a function of the initial composition of the gaseous reactants described on the basis of partial pressures $\left(P_{A C l_{3 i \mathrm{n}}}\right.$ and $P_{\mathrm{H}_{2 \mathrm{in}}} / P_{C \mathrm{CO}_{2 \mathrm{n}}}$ i.e. $\alpha$ ). Basically, they concluded from their study that for a given $P_{\mathrm{AlCl}_{3}}$ in the initial gas mixture, there are two limits of $P_{\mathrm{H}_{2 i \mathrm{n}}} / P_{C \mathrm{CO}_{2 \mathrm{i}}}$ namely $\alpha_{\mathrm{s}}$ and $\alpha_{\mathrm{i}}$ (s= superior, $\mathrm{i}=$ inferior), between which $\mathrm{AlCl}_{3}$ is completely converted into $\mathrm{Al}_{2} \mathrm{O}_{3}$. For $\alpha<\alpha_{\mathrm{i}}$ there is a lack of $\mathrm{H}_{2}$ and for $\alpha>\alpha_{\mathrm{s}}$ there is a lack of $\mathrm{CO}_{2}$. They further concluded, as shown in Figure 2.6, that the width of the $\alpha_{\mathrm{s}}$ to $\alpha_{\mathrm{i}}$ plateau (centre at $\alpha=1$ ) significantly increases as $P_{A l C l_{3}}$ decreases and that both $\alpha_{\mathrm{i}}$ and $\alpha_{s}$ appear to be only slightly dependent on other CVD parameters (deposition temperature and total pressure). The occurrence of a $100 \% \mathrm{Al}_{2} \mathrm{O}_{3}$ yield was concluded to be directly related to the existence of an excess of water in the water vapour phase at equilibrium. Colmet et al pointed out, however, that the main conclusions of their thermodynamic study were only partially corroborated by their experimental data, implying that dynamic factors such as mass transport in the vapour phase and/or kinetic considerations must play an important role in the CVD of $\mathrm{Al}_{2} \mathrm{O}_{3}$.

In their work, Chun et al [36] also reported on the effect of $P_{\mathrm{AlCl}_{3}}$ on the deposition rate of $\mathrm{Al}_{2} \mathrm{O}_{3}$ coatings chemically vapour deposited on $\mathrm{TiC}$ coated cemented carbide substrates under the following constant deposition conditions: deposition temperature $1050^{\circ} \mathrm{C}$, total pressure 100 torr $(0.13 \mathrm{~atm})$ and $\mathrm{CO}_{2} / \mathrm{H}_{2}$ mole ratio 1 . As shown in Figure 2.7 they established that up to a critical $P_{\mathrm{AlCl}_{3}}$ value of $\sim 1$ torr, the $\mathrm{Al}_{2} \mathrm{O}_{3}$ deposition rate increased with increasing $P_{\mathrm{AlCl}_{3}}$ but that above this critical $P_{\mathrm{ALCl}_{3}}$ value the deposition rate decreased with further increase in $P_{\mathrm{AlCl}_{3}}$. This decrease in $\mathrm{Al}_{2} \mathrm{O}_{3}$ deposition rate contradicts the findings of Colmet et al [37], (see Figure 2.2) since they found that with increase in $P_{A I C l_{3}}$ the $\mathrm{Al}_{2} \mathrm{O}_{3}$ deposition rate eventually reached a limit and then remains constant.

The effect of partial pressures on the rate of deposition of $\mathrm{Al}_{2} \mathrm{O}_{3}$ coatings chemically vapour deposited on TiN coated cemented carbide substrates has additionally been studied by Kim et al [43] under the following, constant deposition conditions: deposition temperature $1027^{\circ} \mathrm{C}$ and total pressure 100 torr $(0.13 \mathrm{~atm})$. Kim et al first investigated the effect of increasing $P_{\mathrm{AlCl}_{3}}$ on $\mathrm{Al}_{2} \mathrm{O}_{3}$ deposition rate at different constant $P_{\mathrm{H}_{2}}$ values between 10 and 90 torr, i.e. at $P_{\mathrm{H}_{2}} / P_{\mathrm{CO}_{2}}$ ratios between 0.1 and 10 . They found that an increase in $P_{\mathrm{AlCl}_{3}}$ over the range from 
0.5 to 1 torr, at a constant $P_{\mathrm{H}_{2}} / P_{\mathrm{CO}_{2}}$ ratio, caused an increase in the $\mathrm{Al}_{2} \mathrm{O}_{3}$ deposition rate. Further increase in $P_{\mathrm{AlCl}_{3}}$, however, was found to cause a decrease in deposition rate. These findings are in agreement with those of Chun et al [36]. Kim et al postulated that this decrease in $\mathrm{Al}_{2} \mathrm{O}_{3}$ deposition rate with increasing $P_{\mathrm{AlCl}_{3}}$ might be due to $\mathrm{HCl}$ gas by-products. $\mathrm{Kim}$ et al also investigated the effect of $P_{\mathrm{H}_{2}}$ on $\mathrm{Al}_{2} \mathrm{O}_{3}$ deposition rate at various constant $P_{\mathrm{AlCl}_{3}}$ values. The results obtained are shown in Figure 2.8. As is evident from this figure, Kim et al established that an increase in $P_{\mathrm{H}_{2}}$ from $\sim 2$ to $\sim 50$ torr (i.e. an increase in $P_{\mathrm{H}_{2}} / P_{\mathrm{CO}_{2}}$ ratio from 0.02 to 1 ) at a constant $P_{\mathrm{AlCl}_{3}}$ value, initially caused an increase in deposition rate, in disagreement with the findings of Funk et al [31] and Colmet et al [37] but that with further increase in $P_{\mathrm{H}_{2}}$ the deposition rate decreased, in agreement with the findings of Funk et al and Colmet et al. A similar trend was also observed at higher deposition temperatures. Kim et al inferred from these results that the maximum amount of $\mathrm{H}_{2} \mathrm{O}$ produced by reaction between $\mathrm{H}_{2}$ and $\mathrm{CO}_{2}$ can be attained when the $\mathrm{H}_{2} / \mathrm{CO}_{2}$ ratio is about unity and that the deposition rate of $\mathrm{Al}_{2} \mathrm{O}_{3}$ is limited by the formation of water vapour.

With regard to surface morphology, Kim et al [43] investigated the effect of partial pressures on the surface morphology of $\mathrm{Al}_{2} \mathrm{O}_{3}$ coatings chemically vapour deposited on TiN coated cemented carbide substrates at a constant deposition temperature of $1027^{\circ} \mathrm{C}(1300 \mathrm{~K})$ and a constant total pressure of 100 torr $(0.13 \mathrm{~atm})$. With an increase in $P_{\mathrm{AlCl}_{3}}$ over the range from 0.5 to 3.0 torr, at a constant a $P_{\mathrm{H}_{2}} / P_{\mathrm{CO}_{2}}$ ratio of 1 , they observed a slight decrease in $\mathrm{Al}_{2} \mathrm{O}_{3}$ coating surface grain size. From their accompanying thermodynamic calculations, Kim et al reported that the supersaturation of $\mathrm{H}_{2} \mathrm{O}$ increases with increasing $P_{\mathrm{AlCl}}$ whilst that of $\mathrm{AlCl}_{3}$ decreases. Noting the suggestion by Wong and Robinson [46] that the rate limiting step in the $\mathrm{Al}_{2} \mathrm{O}_{3}$ formation reaction is the production of water vapour from $\mathrm{CO}_{2}$ and $\mathrm{H}_{2}, \mathrm{Kim}$ et al suggested that the nucleation rate of $\mathrm{Al}_{2} \mathrm{O}_{3}$ coatings, and hence coating surface grain size, might be controlled by the supersaturation of $\mathrm{H}_{2} \mathrm{O}$. At a constant $P_{\mathrm{AlCl}_{3}}$ value of 1 torr, $\mathrm{Kim}$ et al also investigated the effect of increasing $P_{\mathrm{H}_{2}}$ over the range from 5 to 95 torr, i.e. increasing $P_{\mathrm{H}_{2}} / P_{\mathrm{CO}_{2}}$ ratio over the range from 0.05 to 24 . They found that the surface grains of the $\mathrm{Al}_{2} \mathrm{O}_{3}$ coatings deposited at $P_{\mathrm{H}_{2}}$ values of 50 and 65 torr, i.e. at $P_{\mathrm{H}_{2}} / P_{\mathrm{CO}_{2}}$ ratios of 1 and 2 respectively, were coarser that those of the coatings deposited at the other $P_{H_{2}}$ values. Since this corresponded closely to their calculated $\mathrm{H}_{2} \mathrm{O}$ supersaturations values, they concluded that the surface grain size of $\mathrm{Al}_{2} \mathrm{O}_{3}$ coatings was mainly affected by $\mathrm{H}_{2} \mathrm{O}$ supersaturation; i.e. an increase in $\mathrm{H}_{2} \mathrm{O}$ supersaturation results in a decrease in $\mathrm{Al}_{2} \mathrm{O}_{3}$ coating surface grain size, and further that grain size seems to be independent of $\mathrm{AlCl}_{3}$ supersaturation.

Colmet and Naslain [27] also investigated the effect of partial pressures on the surface morphology of $\mathrm{Al}_{2} \mathrm{O}_{3}$ coatings chemically vapour deposited on $\mathrm{TiC}$ coated cemented carbide substrates under the following constant deposition conditions: deposition temperature 1323 $\mathrm{K}\left(1050^{\circ} \mathrm{C}\right)$ and total pressure $0.03 \mathrm{~atm}$ with the remaining deposition conditions as specified earlier in Section 2.1. They observed different surface grain structures for coatings deposited at $P_{\mathrm{H}_{2}} / P_{\mathrm{CO}_{2}}$ ratios of 1 and 30 , the surface grains of the $\mathrm{Al}_{2} \mathrm{O}_{3}$ coatings deposited at the higher 
$P_{\mathrm{H}_{2}} / P_{\mathrm{CO}_{2}}$ ratio being noticeably more faceted than those of the $\mathrm{Al}_{2} \mathrm{O}_{3}$ coatings deposited at the lower ratio, which tended to be nodular. Colmet and Naslain noted that whilst the coatings were generally composed of black, non-stoichiometric $\alpha-\mathrm{Al}_{2} \mathrm{O}_{3}$, white $\alpha-\mathrm{Al}_{2} \mathrm{O}_{3}$ could be obtained, particularly at very low $P_{\mathrm{CO}_{2}}$ or very high $P_{\mathrm{ACl}_{3}}$ values, the crystals of white $\alpha-\mathrm{Al}_{2} \mathrm{O}_{3}$ being accicular. Colmet and Naslain stated that, as could be predicted from their crystal structure, the white $\alpha-\mathrm{Al}_{2} \mathrm{O}_{3}$ coatings were always very friable with "no" mechanical strength, hardness or wear resistance. According to Lindstrom and Johannesson [29], the occurrence of white $\alpha-\mathrm{Al}_{2} \mathrm{O}_{3}$ whiskers could be related to the existence of impurities at the substrate surface.

\subsubsection{Effect of Mole Ratio}

Using the following deposition conditions: deposition temperature $1150^{\circ} \mathrm{C}$, total pressure 100 torr $(0.13 \mathrm{~atm})$, gas flow rate $11 \mathrm{~min}^{-1}$ and $\mathrm{CO}_{2} / \mathrm{H}_{2}$ mole ratio 1 , Park et al [42] studied the effect of $\mathrm{AlCl}_{3}$ mole fraction on the deposition rate of $\mathrm{Al}_{2} \mathrm{O}_{3}$ coatings chemically vapour deposited on TiN coated cemented carbide substrates. An increase in $\mathrm{AlCl}_{3}$ mole fraction from close to 0 to $3 \times 10^{-3}$ was found to cause an initial increase in $\mathrm{Al}_{2} \mathrm{O}_{3}$ deposition rate but the rate then reached a peak between $\mathrm{AlCl}_{3}$ mole fractions of $3 \times 10^{-3}$ and $1 \times 10^{-2}$. Further increase in $\mathrm{AlCl}_{3}$ mole fraction was found to cause a slight decrease in the deposition rate. These findings are in agreement with those of Chun et al [36] and Kim et al [43], on the effect of $P_{A^{\prime C l} l_{3}}$ on the deposition rate of $\mathrm{Al}_{2} \mathrm{O}_{3}$ coatings. Park et al also investigated the effect of increasing $\mathrm{CO}_{2}$ mole fraction on $\mathrm{Al}_{2} \mathrm{O}_{3}$ coating deposition rate at a deposition temperature of $1027^{\circ} \mathrm{C}$, a total pressure of 100 torr $(0.13 \mathrm{~atm})$, a gas flow rate of $21 \mathrm{~min}^{-1}$ and various constant $\mathrm{AlCl}_{3}$ mole fractions between 1 and $3 \times 10^{-2}$. At each $\mathrm{AlCl}_{3}$ mole fraction, Park et al established that the deposition rate initially increased with increase in $\mathrm{CO}_{2}$ mole fraction from close to 0 to 0.45 , i.e. with increase in $\mathrm{CO}_{2} / \mathrm{H}_{2}$ mole ratio from close to 0 to 1 , in agreement with the findings of Funk et al [31] and Colmet et al [37], but then decreased with further increase in $\mathrm{CO}_{2}$ mole fraction, in disagreement with the findings of Funk et al and Colmet et al in their work on the effect of $P_{\mathrm{CO}_{2}} / P_{\mathrm{H}_{2}}$ ratio on the deposition rate of $\mathrm{Al}_{2} \mathrm{O}_{3}$ coatings. The trend obtained by Park et al, however, is in agreement with the trend obtained by Kim et al [43], in their work on the effect of $P_{\mathrm{H}_{2}} / \mathrm{P}_{\mathrm{CO}_{2}}$ ratio on the deposition rate of $\mathrm{Al}_{2} \mathrm{O}_{3}$ coatings. Noting the findings of Wong and-Robinson [46], Park et al suggested that $\mathrm{H}_{2} \mathrm{O}$ vapour, formed from $\mathrm{H}_{2}$ and $\mathrm{CO}_{2}$, is a more effective $\mathrm{O}$-donor than $\mathrm{CO}_{2}$ and at the higher $\mathrm{AlCl}_{3}$ mole fractions, the deposition reaction is mainly affected by the $\mathrm{H}_{2} \mathrm{O}$-forming reaction.

Silvestri et al [38] investigated the effect of $\mathrm{CO}_{2}$ and $\mathrm{AlCl}_{3}$ mole fractions (expressed in terms of mole flow rates) on the deposition rate of $\mathrm{Al}_{2} \mathrm{O}_{3}$ coatings chemically vapour deposited on Si substrates at a deposition temperature of $914^{\circ} \mathrm{C}$, with the other deposition conditions being as previously specified in Section 2.2. They first studied the effect of increasing $\mathrm{CO}_{2}$ mole flow rates on $\mathrm{Al}_{2} \mathrm{O}_{3}$ deposition rate at different constant $\mathrm{AlCl}_{3}$ mole flow rates between 5.6 
$\times 10^{-4}$ and $1.1 \times 10^{-3}$ moles $\mathrm{min}^{-1}$. It was found that if the $\mathrm{CO}_{2}$ mole flow rate was increased over the range from close to 0 to $6 \times 10^{-3}$ mole $\mathrm{min}^{-1}$, at a constant $\mathrm{AlCl}_{3}$ mole flow rate, i.e. an increase in $\mathrm{CO}_{2} / \mathrm{AlCl}_{3}$ mole ratio this resulted in an increase in the $\mathrm{Al}_{2} \mathrm{O}_{3}$ deposition rate, but that with further increase in $\mathrm{CO}_{2}$ mole flow rate, however, the deposition rate reached a constant value, determined by the $\mathrm{AlCl}_{3}$ mole flow rate. An increase in the $\mathrm{AlCl}_{3}$ mole flow rate from close to 0 to $1 \times 10^{-4}$ moles $\min ^{-1}$, at a constant $\mathrm{CO}_{2}$ mole flow rate, i.e. a decrease in $\mathrm{CO}_{2} / \mathrm{AlCl}_{3}$ mole ratio was found to cause an initial increase in the $\mathrm{Al}_{2} \mathrm{O}_{3}$ deposition rate, but at higher $\mathrm{AlCl}_{3}$ mole flow rates, the deposition rate reached a limit, governed by the $\mathrm{CO}_{2}$ mole flow rate. These findings are in agreement with those of Colmet et al [37] with regard to the effect of $P_{\mathrm{AlCl}_{3}}$ on the deposition rate of $\mathrm{Al}_{2} \mathrm{O}_{3}$ coatings. Silvestri et al further investigated the effect of $\mathrm{CO}_{2} / \mathrm{AlCl}_{3}$ mole ratio on the $\mathrm{Al}_{2} \mathrm{O}_{3}$ deposition rate at different constant $\mathrm{AlCl}_{3}$ mole flow rates (derived from the former experiment). They found that an increase in $\mathrm{CO}_{2} / \mathrm{AlCl}_{3}$ mole ratio over the range from $\sim 3$ to 10 , at a constant $\mathrm{AlCl}_{3}$ mole flow rate, caused an initial increase in the $\mathrm{Al}_{2} \mathrm{O}_{3}$ deposition rate, but then reached a limit, independent of $\mathrm{AlCl}_{3}$ flow rate, above which no further increase in deposition rate takes place with further increase in $\mathrm{CO}_{2} / \mathrm{AlCl}_{3}$ mole ratio. Silvestri et al concluded, that these findings indicated a complex chemical system with more than a single rate-limiting step.

In their work Park et al [44] investigated the effect of $\mathrm{AlCl}_{3}$ and $\mathrm{CO}_{2}$ mole fractions on the surface morphology and preferred orientation of $\mathrm{Al}_{2} \mathrm{O}_{3}$ coatings chemically vapour deposited on TiN coated cemented carbide substrates. They first investigated the effect of $\mathrm{AlCl}_{3}$ mole fraction at a deposition temperature of $1150^{\circ} \mathrm{C}$, a total pressure of 100 torr $(0.13 \mathrm{~atm})$, a gas flow rate of $11 \mathrm{~min}^{-1}$ and a $\mathrm{CO}_{2} / \mathrm{H}_{2}$ mole ratio of 1 . It was found that increasing the $\mathrm{AlCl}_{3}$ mole fraction from $1 \times 10^{-3}$ to $1 \times 10^{-2}$ caused the $\mathrm{Al}_{2} \mathrm{O}_{3}$ surface grain structure to become coarser and to exhibit preferred orientations of the $\{10 \overline{1} 4\}$ and $\{11 \overline{2} 6\}$ planes. Further increase in the $\mathrm{AlCl}_{3}$ mole fraction resulted in finer surface grains and a reduction in preferred orientation. From their supersaturation calculations, Park et al reported that the supersaturation of the $\mathrm{Al}$-donor decreases with increasing $\mathrm{AlCl}_{3}$ mole fraction whilst that of $\mathrm{O}$-donor increases. They suggested that up to an $\mathrm{AlCl}_{3}$ mole fraction value of $1 \times 10^{-2}$ the surface morphology is controlled by the supersaturation of the $\mathrm{Al}$-donor, with further increase in $\mathrm{AlCl}_{3}$ mole fraction the nucleation of $\mathrm{Al}_{2} \mathrm{O}_{3}$ is limited by the $\mathrm{O}$-donor, hence the grains become finer and preferred orientations are reduced. Using the following deposition conditions: deposition temperature $1027^{\circ} \mathrm{C}$, total pressure 100 torr $(0.13 \mathrm{~atm})$, gas flow rate $21 \mathrm{~min}^{-1}$ and $\mathrm{AlCl}_{3}$ mole fraction 1 $\mathrm{x} 10^{-2}$, Park et al then studied the effect of increasing the $\mathrm{CO}_{2}$ mole fraction over the range from 0.1 to 0.9 i.e. of increasing the $\mathrm{CO}_{2} / \mathrm{H}_{2}$ mole ratio from 0.1 to 24 . They found that the surface grains of the $\mathrm{Al}_{2} \mathrm{O}_{3}$ coatings deposited at a $\mathrm{CO}_{2}$ mole fraction value of 0.65 (i.e. a $\mathrm{CO}_{2} / \mathrm{H}_{2}$ mole ratio of 2) were coarser that those of the coatings deposited at the other $\mathrm{CO}_{2}$ mole fraction values, and clearly exhibited $\{10 \overline{1} 4\}$ and $\{11 \overline{2} 6\}$ preferred orientations. Since this corresponded closely to their calculated supersaturations of the O-donor values they concluded that the surface grain size of the $\mathrm{Al}_{2} \mathrm{O}_{3}$ coatings is mainly affected by $\mathrm{O}$-donor 
supersaturation. It should be noted that the results from the latter experiment are in agreement with the surface morphology results obtained by Kim et al [43] from their study of the effect of $P_{\mathrm{H}_{2}} / P_{\mathrm{CO}_{2}}$ ratio on the surface morphology of $\mathrm{Al}_{2} \mathrm{O}_{3}$ coatings.

\subsection{Effect of Impurities}

Although, strictly speaking, impurities are not a process parameter, a number of workers [49, $50,51,52,53,54]$ have carried out detailed investigations of the effect of impurities on the surface morphology of chemically vapour deposited $\mathrm{Al}_{2} \mathrm{O}_{3}$ coatings.

In their work, Altena et $\mathrm{Al}$ [49] investigated the effect of impurities on the surface morphology of $\mathrm{Al}_{2} \mathrm{O}_{3}$ coatings chemically vapour deposited on $\mathrm{TiC}$ coated cemented carbide and polycrystalline alumina substrates under the following deposition conditions: deposition temperature 980 to $1150^{\circ} \mathrm{C}$, total pressure $65 \mathrm{mbar}(0.064 \mathrm{~atm})$ and deposition time 2 hours. $\mathrm{Cr}, \mathrm{Fe}, \mathrm{Ni}, \mathrm{Ti}$ and gold (Au) (used as a reference) impurities were employed. They first investigated the effect of $\mathrm{Cr}, \mathrm{Ni}$, and $\mathrm{Fe}$ impurities using two different methods: rubbing the impurity on the surface of the substrate prior to $\mathrm{Al}_{2} \mathrm{O}_{3}$ coating deposition, and adding metal chlorides, in one instance at two different concentrations, during the deposition process. Rubbing with $\mathrm{Cr}$ and $\mathrm{Ni}$ impurities led to the formation of $\mathrm{Al}_{2} \mathrm{O}_{3}$ needles on both the $\mathrm{TiC}$ coated cemented carbide and polycrystalline alumina substrates, whereas rubbing with $\mathrm{Fe}$ was found to cause fine grained $\mathrm{Al}_{2} \mathrm{O}_{3}$ agglomerates on the former substrate with no results presented for the latter.

Low concentrations of chromium chloride $\left(\mathrm{CrCl}_{3}\right)$ during the deposition process, were found to cause coin-shaped $\mathrm{Al}_{2} \mathrm{O}_{3}$ crystals on the TiC coated cemented carbide substrates, whereas $\mathrm{Al}_{2} \mathrm{O}_{3}$ coatings deposited on the polycrystalline alumina substrates were observed to be composed of coarse grains. Nickel chloride was found to have no effect and iron chloride caused more pronounced homogeneous $\mathrm{Al}_{2} \mathrm{O}_{3}$ nucleation in the gas phase ("snowing") in the case of the TiC coated cemented carbide substrates. None of the three impurities were detected in the $\mathrm{Al}_{2} \mathrm{O}_{3}$ coatings. As $\mathrm{Cr}$ was found to cause the most noticeable changes, Altena et al additionally studied its effect at high concentration. They found that it led to the formation of needle-shaped $\mathrm{Al}_{2} \mathrm{O}_{3}$ crystals on both substrates. $\mathrm{CrCl}_{3}$ was also observed to damage the $\mathrm{TiC}$ precoating on the cemented carbide substrates and to form dark deposits of $\mathrm{CrCl}_{2}$ on certain areas of the $\mathrm{Al}_{2} \mathrm{O}_{3}$ crystals. $\mathrm{X}$-ray analysis confirmed the presence of $\mathrm{Cr}$ in the $\mathrm{Al}_{2} \mathrm{O}_{3}$ coatings.

Altena et al then studied the effect of Ti impurity by adding titanium tetrachloride $\left(\mathrm{TiCl}_{4}\right)$ during the deposition process. They obtained 7 to $10 \mu \mathrm{m}$ thick, black $\mathrm{Al}_{2} \mathrm{O}_{3}$ coatings consisting of coarse cubic grains on the $\mathrm{TiC}$ coated cemented carbide substrates, whereas on the polycrystalline alumina substrates 5 to $10 \mu \mathrm{m}$ thick, dark grey $\mathrm{Al}_{2} \mathrm{O}_{3}$ coatings consisting of 
coarse hexagonal grains were obtained. The dark colour of the $\mathrm{Al}_{2} \mathrm{O}_{3}$ coatings was stated to be due to the substitution of $\mathrm{Al}$ atoms by $\mathrm{Ti}$ atoms in the $\mathrm{Al}_{2} \mathrm{O}_{3}$ lattice. $\mathrm{X}$-ray analysis confirmed the presence of $\alpha-\mathrm{Al}_{2} \mathrm{O}_{3}$ for both substrates. Finally, Au sputtered on both the TiC coated cemented carbide and polycrystalline alumina substrates was found to cause an increase in the $\mathrm{Al}_{2} \mathrm{O}_{3}$ deposition rate accompanied by a breakdown of the continuous $\mathrm{Al}_{2} \mathrm{O}_{3}$ coating into needles. The transition in surface morphology was found to increase with increase in $\mathrm{Au}$ concentration and $\mathrm{Al}_{2} \mathrm{O}_{3}$ deposition time. Altena et al suggested that, at the high CVD temperatures where significant surface diffusion can be expected to occur, the effect of these impurities on $\mathrm{Al}_{2} \mathrm{O}_{3}$ coating morphology may be linked to their high mobility and mechanisms similar to vapour-liquid-solid (VLS) interactions, based not on liquid metals but on highly mobile thin solid films.

The effect of $\mathrm{Co}$ and $\mathrm{Si}$ impurities on the surface morphology of $\mathrm{Al}_{2} \mathrm{O}_{3}$ coatings chemically vapour deposited on TiC coated cemented carbide substrates has been investigated by Altena et al [50] at deposition temperatures of 980 and $1500^{\circ} \mathrm{C}$ and a total pressure of 65 mbar $(0.064$ atm) with a deposition time of 2 hours. They found that traces of either Co or Si impurities frequently caused the formation of $\mathrm{Al}_{2} \mathrm{O}_{3}$ whiskers and needles. Adding both impurities together was found to cause the formation of $\mathrm{Al}_{2} \mathrm{O}_{3}$ whiskers with rounded ends ("tops"). EDS analysis revealed the presence of $\mathrm{Al}, \mathrm{Si}$ and $\mathrm{Co}$ in the $\mathrm{Al}_{2} \mathrm{O}_{3}$ coatings and from X-ray diffraction revealed the presence of cobalt silicides ( $\mathrm{CoSi}$ and $\mathrm{Co}_{2} \mathrm{Si}$ ) in the ends of the whiskers. Altena et al suggested that $\mathrm{CoSi}$ and $\mathrm{Co}_{2} \mathrm{Si}$ together with other impurities, $\mathrm{Al}, \mathrm{Fe}$, $\mathrm{Ti}$ and $\mathrm{W}$ (i.e. impurities from reactor materials or the substrates), can form a liquid phase at the CVD temperatures and causes the formation of such $\mathrm{Al}_{2} \mathrm{O}_{3}$ whiskers by the VLS mechanism. The formation of such whiskers was also established to be associated with the thickness of the $\mathrm{TiC}$ precoating; during the $\mathrm{CVD}$ of $\mathrm{Al}_{2} \mathrm{O}_{3}$ coatings in a small-scale reactor, a decrease in $\mathrm{TiC}$ precoating thickness was found to cause an increase in the formation of $\mathrm{Al}_{2} \mathrm{O}_{3}$ whiskers. It was suggested that this was due to the diffusion of Co from the cemented carbide substrate through the thin $\mathrm{TiC}$ precoating and into the $\mathrm{Al}_{2} \mathrm{O}_{3}$ gas interface. The formation of $\mathrm{Al}_{2} \mathrm{O}_{3}$ whiskers on cemented carbide substrates without a $\mathrm{TiC}$ layer has been observed by Lindstrom and Johannesson [29], in their work on the CVD of $\mathrm{Al}_{2} \mathrm{O}_{3}$ coatings (see Section 2.1).

In their work Colombier et al [51] investigated the effect of $\mathrm{Cr}, \mathrm{Ni}, \mathrm{Fe}$ and $\mathrm{Co}$ impurities on the surface morphology of $\mathrm{Al}_{2} \mathrm{O}_{3}$ coatings chemically vapour deposited on uncoated and $\mathrm{TiC}$ coated cemented carbide substrates. Three different $\mathrm{Al}$ halogenides were used: $\mathrm{AlCl}_{3}$, aluminium bromide $\left(\mathrm{AlBr}_{3}\right)$ and aluminium iodide $\left(\mathrm{AlI}_{3}\right)$. The deposition conditions employed were as follows: deposition temperature $1050^{\circ} \mathrm{C}$, total pressure 65 mbar $(0.064 \mathrm{~atm})$, gas composition $1 \mathrm{~mol}^{2} \mathrm{AlX}_{3}$ (where $\mathrm{X}=\mathrm{Cl}, \mathrm{Br}, \mathrm{I}$ ), $3.5 \mathrm{~mol}^{2} \mathrm{CO}_{2}$ and $95.5 \mathrm{~mol}_{2} \mathrm{H}_{2}$, gas flow rate $25 \mathrm{Nl} \mathrm{hr}^{-1}$ (where $\mathrm{N}=$ normal temperature and pressure) and deposition time 2 hours. When $\mathrm{AlCl}_{3}$ was used in the gas mixture, $\mathrm{Cr}$ was found to have a strong influence, causing grain refinement of the $\alpha-\mathrm{Al}_{2} \mathrm{O}_{3}$ coatings, whereas traces of $\mathrm{Ni}$ and Co produced $\mathrm{Al}_{2} \mathrm{O}_{3}$ needles 
on the TiC coated cemented carbide substrates. Colombier et al found that these impurities caused less pronounced structural changes in the $\mathrm{Al}_{2} \mathrm{O}_{3}$ coatings when $\mathrm{AlBr}_{3}$ and $\mathrm{AlI}_{3}$ were used in the gas mixture. Adherent $\mathrm{Al}_{2} \mathrm{O}_{3}$ coatings were found to be deposited on only the cemented carbide substrates. When $\mathrm{AlCl}_{3}$ was used in the gas mixture, traces of $\mathrm{Fe}$ caused the formation of holes in the $\mathrm{Al}_{2} \mathrm{O}_{3}$ coating on both substrates, but on the TiC coated cemented carbide substrates the $\mathrm{Al}_{2} \mathrm{O}_{3}$ coating was observed to grow as separate single crystals. $\mathrm{A}$ similar $\mathrm{Al}_{2} \mathrm{O}_{3}$ coating morphology was observed when $\mathrm{AlCl}_{3}$ was replaced in the gas mixture by either $\mathrm{AlBr}_{3}$ or $\mathrm{AlI}_{3}$. These experimental findings were in direct contrast to thermodynamic calculations carried out by Colombier et al. Consequently it was suggested that the difference observed with the three different $\mathrm{Al}$ halogenide environments were due to different reaction rates between the $\mathrm{Al}$ halogenide and the metal impurities to form metal halogenides (i.e. the metal halogenide formation increases in the order $\mathrm{I}<\mathrm{Br}<\mathrm{Cl}$ ).

The effect of $\mathrm{O}_{2}$ and $\mathrm{H}_{2} \mathrm{O}$ trace impurities on the surface morphology of $\mathrm{Al}_{2} \mathrm{O}_{3}$ coatings chemically vapour deposited on cemented carbide substrates coated with a $6 \mu \mathrm{m}$ thick TiC coating has been investigated by Altena et al [52] at a deposition temperature of $1050^{\circ} \mathrm{C}$ and a total pressure of $65 \mathrm{mbar}(0.064 \mathrm{~atm})$ using an $\mathrm{AlCl}_{3}-\mathrm{CO}_{2}-\mathrm{H}_{2}$ gas mixture. Both $\mathrm{H}_{2}$ (of different purities) and $99.998 \%$ pure $\mathrm{CO}_{2}$ (containing less than $5 \mathrm{ppm} \mathrm{O}_{2}$ and $\mathrm{H}_{2} \mathrm{O}$ impurities) were used as carrier gases for the $\mathrm{AlCl}_{3}$. Using 99.993\% pure $\mathrm{H}_{2}$ gas, with less than $1 \mathrm{ppm}$ $\mathrm{O}_{2}$ and $\mathrm{H}_{2} \mathrm{O}$ impurities, Altena et al observed cubic-shaped grains, of 2 to $3 \mu \mathrm{m}$ in size, whereas with $99.999 \%$ pure $\mathrm{H}_{2}$, containing less than $25 \mathrm{ppm} \mathrm{O}_{2}$ and $\mathrm{H}_{2} \mathrm{O}$ impurities, pyramidal-shaped $\mathrm{Al}_{2} \mathrm{O}_{3}$ grains were observed. Altena et al also observed the deposition of amorphous $\mathrm{Al}(\mathrm{OH})_{\mathrm{x}} \mathrm{Cl}_{\mathrm{y}}$ reaction products on the inlet tubes of their reactor. Noting the suggestion by Wong and Robinson [46] that at temperatures of $\sim 1500^{\circ} \mathrm{C}$ the reaction rate of $\mathrm{AlCl}_{3}$ and pure $\mathrm{O}_{2}$ is very slow, Altena et al suggested that even at low temperatures $\left(180^{\circ} \mathrm{C}\right)$ small amounts of $\mathrm{O}_{2}$, caused either by leakages during the deposition process or from contaminated reactant gases, could rapidly transform to $\mathrm{H}_{2} \mathrm{O}$ and react with the $\mathrm{AlCl}_{3}$. Consequently an increase of the supersaturation of the reactants was found to cause gas phase nucleation leading to "snow".

As part of the same investigation, Altena et al then carried out further experiments whereby after a deposition time of 1 hour, the $\mathrm{Al}_{2} \mathrm{O}_{3}$ coated substrates were cooled to room temperature in three different gas environments: technical quality and $99.999 \%$ pure $\mathrm{H}_{2}, \mathrm{Ar}$ and humid air. The deposition process was then continued for another hour. Cooling in technical quality $\mathrm{H}_{2}$ containing $\sim 100$ to $500 \mathrm{ppm} \mathrm{O}_{2}$ and $\mathrm{H}_{2} \mathrm{O}$ impurities, was found to cause the breakdown of the primary continuous $\mathrm{Al}_{2} \mathrm{O}_{3}$ coating into irregular crystals on the TiC coated cemented carbide substrates whereas on the polycrystalline alumina substrates primary fine-grained $\mathrm{Al}_{2} \mathrm{O}_{3}$ coatings were observed. After the second deposition, however, $\mathrm{Al}_{2} \mathrm{O}_{3}$ coatings deposited on the latter were observed to be composed of needle-like crystals. When $99.999 \%$ pure $\mathrm{H}_{2}$ (containing less than 25pm $\mathrm{O}_{2}$ and $\mathrm{H}_{2} \mathrm{O}$ impurities) was used, a primary $\mathrm{Al}_{2} \mathrm{O}_{3}$ coating consisting of fine grains was found to be overgrown by arrays of irregular, faceted $\mathrm{Al}_{2} \mathrm{O}_{3}$ crystals on the $\mathrm{TiC}$ coated cemented carbide substrates. In the case of the polycrystalline 
alumina substrates, Altena et al observed growth of $\mathrm{Al}_{2} \mathrm{O}_{3}$ whiskers, which developed, after the second deposition, flat, lancet-like tops. When humid air was used, similar $\mathrm{Al}_{2} \mathrm{O}_{3}$ coating morphologies were obtained. Exposure to Ar was found to have much less influence on the $\mathrm{Al}_{2} \mathrm{O}_{3}$ coating morphology than that of $\mathrm{H}_{2}$. Altena et al stated that the $\mathrm{H}_{2} \mathrm{O}$ present in the gases reacted with $\mathrm{AlCl}_{\mathrm{x}}$ layers adsorbed on the solid/gas interface and formed amorphous $\mathrm{Al}(\mathrm{OH})_{\mathrm{x}} \mathrm{Cl}_{\mathrm{y}}$ compounds at low temperatures, during cooling. These compounds then prevented initiation of nucleation from new sites and growth from these sites, leading to the formation of whiskers and separated dendritic growth of $\mathrm{Al}_{2} \mathrm{O}_{3}$ crystals.

Finally, Altena et al carried out $\mathrm{Al}_{2} \mathrm{O}_{3}$ deposition process for 1 hour and then allowed only $\mathrm{H}_{2}(99.993 \%$ and $99.999 \%$ pure) to flow through the reactor at the deposition temperature of $1050^{\circ} \mathrm{C}$ for 1 hour after which the deposition process was resumed. With $99.993 \%$ pure $\mathrm{H}_{2}$, $\mathrm{Al}_{2} \mathrm{O}_{3}$ coatings deposited on the $\mathrm{TiC}$ coated cemented carbide substrates were observed to be composed of coarse grains which developed, after the second deposition, into faceted, isolated $\mathrm{Al}_{2} \mathrm{O}_{3}$ crystals. On the polycrystalline alumina substrates, however, the previously observed $\mathrm{Al}_{2} \mathrm{O}_{3}$ whiskers with flat, lancet-like tops were obtained again. With $99.999 \%$ pure $\mathrm{H}_{2}$, the previously observed $\mathrm{Al}_{2} \mathrm{O}_{3}$ coating morphologies for both substrates were obtained; obviously the growth of the $\mathrm{Al}_{2} \mathrm{O}_{3}$ coatings was not effected during the previous cooling and exposure of the coated substrate surface, to $99.999 \%$ pure $\mathrm{H}_{2}$.

In a further study, Altena et al [53] investigated the effect of $C$ on the surface morphology of $\mathrm{Al}_{2} \mathrm{O}_{3}$ coatings chemically vapour deposited on TiC coated cemented carbide substrates, using two different $\mathrm{C}$ compounds: methane $\left(\mathrm{CH}_{4}\right)$ and carbon disulphide $\left(\mathrm{CS}_{2}\right)$, at two different concentrations. The following deposition conditions were employed: deposition temperature $1050^{\circ} \mathrm{C}$, total pressure $65 \mathrm{mbar}(0.064 \mathrm{~atm})$, gas composition $0.8 \% \mathrm{AlCl}_{3}, 3.5 \% \mathrm{CO}_{2}$ and $95 \%$ $\mathrm{H}_{2}$ and deposition time 2 hours. At low concentrations of $\mathrm{CH}_{4}\left(2.5\right.$ vol\%), $2 \mu \mathrm{m}$ thick $\mathrm{Al}_{2} \mathrm{O}_{3}$ coatings with voids and crystal defects were observed, whereas the $\mathrm{Al}_{2} \mathrm{O}_{3}$ coatings $(\sim 5$ to 7 $\mu \mathrm{m}$ thick) deposited with $\mathrm{CS}_{2}$ (between 0.05 and 0.1 vol\%) exhibited fine grains and voids with large co-deposits of $\mathrm{C}(\sim 2$ to $10 \mu \mathrm{m}$ in size) additionally observed in the voids between the $\mathrm{Al}_{2} \mathrm{O}_{3}$ grains. Higher concentrations of $\mathrm{CH}_{4}(8 \mathrm{vol} \%)$ led to a significant reduction in the $\mathrm{Al}_{2} \mathrm{O}_{3}$ coating growth rate. In the case of $\mathrm{CS}_{2}(0.8$ vol\%), however, Altena et al obtained a black $\mathrm{Al}_{2} \mathrm{O}_{3}$ coating which exhibited a dome-like surface structure consisting of very fine grains of size 0.2 to $0.3 \mu \mathrm{m}$, surrounded by a of network of $\mathrm{C}$ films. X-ray analysis confirmed that the coating consisted of $\alpha-\mathrm{Al}_{2} \mathrm{O}_{3}$. They stated that the reduction in $\mathrm{Al}_{2} \mathrm{O}_{3}$ grain size was not associated with sulphur contamination but with $\mathrm{C}$ impurity.

Altena et al then studied the effect of sulphur on the surface morphology of $\mathrm{Al}_{2} \mathrm{O}_{3}$ coatings using sulphur dioxide. They obtained a dense $\mathrm{Al}_{2} \mathrm{O}_{3}$ coating, composed of coarse grains which was clearly different from the $\mathrm{Al}_{2} \mathrm{O}_{3}$ coatings obtained with the $\mathrm{CH}_{4}$ and $\mathrm{CS}_{2}$ additions. It was suggested that the difference in the $\mathrm{Al}_{2} \mathrm{O}_{3}$ coating morphology could be partially due to the presence of $\mathrm{S}$ but mainly due by the presence of excess $\mathrm{O}_{2}$. Altena et al suggested that $\mathrm{C}$ forms 
films, either adsorbed or chemically bonded, at the interface of growing $\mathrm{Al}_{2} \mathrm{O}_{3}$ crystal planes. They stated that these films change the nucleation and growth conditions and together with any subsequent crystal branching lead to $\mathrm{Al}_{2} \mathrm{O}_{3}$ coatings with a smaller grain size.

Finally, as a small part of a more detailed investigation, Colombier and Lux [54] also studied the effect of $\mathrm{CH}_{4}$ on the surface morphology of $\mathrm{Al}_{2} \mathrm{O}_{3}$ coatings chemically vapour deposited on cemented carbide substrates. The following deposition conditions were employed: deposition temperature $1050^{\circ} \mathrm{C}$, total pressure 65 mbar $(0.064 \mathrm{~atm})$, gas composition $3 \%$ $\mathrm{AlCl}_{3}, 1 \% \mathrm{CO}_{2}, 90 \% \mathrm{H}_{2}, 6 \% \mathrm{CH}_{4}$, gas flow rate $401 \mathrm{hr}^{-1}$ and deposition time 1 hour. They first carried out the coating deposition without any $\mathrm{CH}_{4}$ and obtained $\alpha-\mathrm{Al}_{2} \mathrm{O}_{3}$ needles on the cemented carbide substrates. In the presence of $\mathrm{CH}_{4}$, however, a compact $\mathrm{Al}_{2} \mathrm{O}_{3}$ coating was observed. X-ray analysis confirmed that the coating was of the $\mathrm{\kappa}$ form. Colombier and Lux suggested that the decomposition of $\mathrm{CH}_{4}$ increases the $\mathrm{C}$ activity in the Co-binder at an early stage in the CVD process. Since $W$ is also present in the Co-binder, a very thin protective layer of WC forms on the surface which hinders the reaction between the Co and the chlorides of the gas phase. In the former investigation, i.e. in the absence of $\mathrm{CH}_{4}$, the cobalt chloride $\left(\mathrm{CoCl}_{2}\right)$ influences the growth mode of the $\alpha$-phase leading to the formation of $\alpha-\mathrm{Al}_{2} \mathrm{O}_{3}$ needles.

\subsection{Effect of Other Process Variables}

In addition to the major process parameters dealt with previously in this chapter, the effect of total gas flow rate [42] and Al-donor type [28, 53, 55] on chemically vapour deposited $\mathrm{Al}_{2} \mathrm{O}_{3}$ coatings has also been investigated and will be dealt with here.

Park et al [42] investigated the effect of total gas flow rate on the deposition rate of $\mathrm{Al}_{2} \mathrm{O}_{3}$ coatings chemically vapour deposited on TiN coated cemented carbide substrates under the following deposition conditions: deposition temperature $1050^{\circ} \mathrm{C}$, total pressure 100 torr $(0.13$ atm), $\mathrm{CO}_{2} / \mathrm{H}_{2}$ mole ratio 1 and $\mathrm{AlCl}_{3}$ mole fraction $2 \times 10^{-3}$. They found that, up to a total gas flow rate of $0.8 \mathrm{I} \mathrm{min}^{-1}$, the deposition rate of the $\mathrm{Al}_{2} \mathrm{O}_{3}$ coatings increased with increasing total gas flow rate, but that with further increase in total gas flow rate the deposition rate remained constant. It was also established that below a total gas flow rate of $0.31 \mathrm{~min}^{-1}$ the deposition reaction did not take place. Park et al suggested that for a total gas flow rate above $0.81 \mathrm{~min}^{-1}$ the rate of deposition was limited by a surface chemical reaction whilst below a total gas flow rate of $0.81 \mathrm{~min}^{-1}$ the rate of deposition was limited by either diffusional transport of reactants to the substrate surface or by thermodynamic equilibrium. They concluded that in order to obtain a well developed, stable flow the total gas flow rate should be maintained above $0.81 \mathrm{~min}^{-1}$. 
The effect of $\mathrm{Al}$-donor type on $\mathrm{Al}_{2} \mathrm{O}_{3}$ coatings chemically vapour deposited on $\mathrm{TiC}$ coated cemented carbide substrates has been investigated by Pauer et al [55], using two $\mathrm{Al}$-alkoxides: aluminium triisopropylate $\left(\mathrm{Al}(\mathrm{O}-\mathrm{iPr})_{3}\right)$ and aluminium tributylate $\left(\mathrm{Al}(\mathrm{O}-\mathrm{tBu})_{3}\right)$, and two carrier gases: $\mathrm{Ar}$ and $\mathrm{H}_{2}$. Pauer et al pointed out that by using the $\mathrm{Al}$-alkoxides it was possible to significantly lower the deposition temperature and to obtain amorphous, fine grained $\mathrm{Al}_{2} \mathrm{O}_{3}$ coatings. However, although deposition temperatures greater than $300^{\circ} \mathrm{C}$ were established to be sufficient for thermal decomposition of the Al-alkoxides, temperatures greater than $900^{\circ} \mathrm{C}$ were found to be necessary for the deposition of $\alpha-\mathrm{Al}_{2} \mathrm{O}_{3}$ coatings. Pauer et al first investigated the use of the $\mathrm{Al}(\mathrm{O}-\mathrm{iPr})_{3} \mathrm{Al}$-donor, with $\mathrm{Ar}$ carrier gas, at a deposition temperature of $900^{\circ} \mathrm{C}$ and a gas flow rate of $40 \mathrm{Nl} \mathrm{hr}^{-1}$ with 0.04 to $0.3 \mathrm{~mol} \% \mathrm{Al}(\mathrm{O}-\mathrm{iPr})_{3}$. They obtained $\alpha-\mathrm{Al}_{2} \mathrm{O}_{3}$ coatings which exhibited a dome-like surface structure containing a fine sub-grain structure. In addition, variable amounts of $\mathrm{Al}_{2} \mathrm{O}_{3}$ dust were observed on the surfaces of the coatings and $\mathrm{C}$ was found to be present in the coatings. Increasing the total gas flow rate from 40 to 150 $\mathrm{Nl} \mathrm{hr}{ }^{-1}$ was found to produce a significant reduction in the amount of homogeneous nucleation in the gas phase and in the amount of $\mathrm{C}$ in the $\mathrm{Al}_{2} \mathrm{O}_{3}$ coatings. Coating thicknesses of 3 to 5 $\mu \mathrm{m}$ and $10 \mu \mathrm{m}$ (with a grain size of $0.3 \mu \mathrm{m}$ ) were respectively obtained on the surface and edges of the specimens. The increase in coating thickness at the edges of the specimens was attributed to the nature of the gas flow conditions and the rapid decomposition of the reactants leading to high local supersaturation. When $\mathrm{H}_{2}$ was used as the carrier gas, a similar $\mathrm{Al}_{2} \mathrm{O}_{3}$ coating morphology was obtained.

In the case of the $\mathrm{Al}(\mathrm{O}-\mathrm{tBu})_{3} \mathrm{Al}$-donor, Pauer et al found that the carrier gas had a significant influence on the morphology of the coatings. $\mathrm{Al}_{2} \mathrm{O}_{3}$ coatings deposited at a deposition temperature of $1000^{\circ} \mathrm{C}$ and a gas flow rate of $150 \mathrm{Nl} \mathrm{hr}^{-1}$ with 0.06 to $0.08 \mathrm{~mol} \% \mathrm{Al}(\mathrm{O}-\mathrm{tBu})_{3}$ using Ar carrier gas, were observed to be composed of faceted grains with a grain size of 1 $\mu \mathrm{m}$, whilst coatings deposited using $\mathrm{H}_{2}$ carrier gas exhibited dome-like structures consisting of fine sub-grains. For both carrier gases, coating thicknesses of 2 to $4 \mu \mathrm{m}$ and 7 to $10 \mu \mathrm{m}$ were respectively obtained on the surface and edges of the specimens. It was also found that the use of Ar carrier gas caused oxidation of the TiC precoating on the cemented carbide substrates which led to poor adhesion of the $\mathrm{Al}_{2} \mathrm{O}_{3}$ coatings. They suggested that the characteristic differences in $\mathrm{Al}_{2} \mathrm{O}_{3}$ coating surface morphologies observed with the $\mathrm{Ar}$ and $\mathrm{H}_{2}$ carrier gases was caused by the interaction of $\mathrm{H}_{2} \mathrm{O}$ with the $\mathrm{Al}$-alkoxides molecules. With $\mathrm{Ar}$, no $\mathrm{H}_{2} \mathrm{O}$ formation occurred and it was found that the excess oxygen from the decomposition of the $\mathrm{Al}(\mathrm{O}-\mathrm{tBu})_{3}$ caused oxidation of the $\mathrm{TiC}$ precoating. With $\mathrm{H}_{2}$, the presence of $\mathrm{H}_{2} \mathrm{O}$ led to partial hydrolysis followed by pyrolysis (thermal decomposition) of the $\mathrm{Al}$-alkoxide molecule, causing the change in $\mathrm{Al}_{2} \mathrm{O}_{3}$ crystal growth from a faceted to a dome-like morphology. Pauer et al also investigated the addition of $\mathrm{AlCl}_{3}$ to the $\mathrm{Al}(\mathrm{O}-\mathrm{tBu})_{3}$ $\mathrm{Al}$-donor, with Ar carrier gas. They found that this addition prevented oxidation of the $\mathrm{TiC}$ precoating and increased the thickness of the $\mathrm{Al}_{2} \mathrm{O}_{3}$ coating on the surface of the specimens to $5 \mu \mathrm{m}$. A coating surface grain size of 1 to $3 \mu \mathrm{m}$ was determined. It was suggested that the $\mathrm{AlCl}_{3}$ must have reacted with the excess $\mathrm{O}_{2}$ and hence prevented oxidation of the TiC 
precoating. When $\mathrm{H}_{2}$ was used as the carrier gas, however, the previously observed dome-like structure was again obtained. Pauer et al suggested that the addition of the $\mathrm{AlCl}_{3}$ could neither prevent the dome-like morphology nor influence the $\mathrm{Al}_{2} \mathrm{O}_{3}$ growth mode. The decomposition products from the $\mathrm{Al}(\mathrm{O}-\mathrm{tBu})_{3} \mathrm{Al}$-donor were stated to have poisoned the growth sites which are normally acting during the $\mathrm{AlCl}_{3}-\mathrm{CO}_{2}-\mathrm{H}_{2}$ reaction.

In their work, Altena et al [53] studied the use of an $\mathrm{Al}(\mathrm{O}-\mathrm{tBu})_{3} \mathrm{Al}$-donor together with an $\mathrm{AlCl}_{3}-\mathrm{CO}_{2}-\mathrm{H}_{2}$ gas mixture on the surface morphology of $\mathrm{Al}_{2} \mathrm{O}_{3}$ coatings chemically vapour deposited on $\mathrm{TiC}$ coated cemented carbide substrates. The deposition conditions employed were as follows: deposition temperature $1000^{\circ} \mathrm{C}$, total pressure $65 \mathrm{mbar}(0.064 \mathrm{~atm})$, gas composition $0.6 \% \mathrm{AlCl}_{3}, 2.2 \% \mathrm{CO}_{2}, 97.1 \% \mathrm{H}_{2}$ and $0.6 \% \mathrm{Al}(\mathrm{O}-\mathrm{tBu})_{3}$, gas flow rate $45 \mathrm{Nl} \mathrm{hr}^{-1}$ and deposition time 2 hours. The surface of the 3 to $4 \mu \mathrm{m}$ thick $\alpha-\mathrm{Al}_{2} \mathrm{O}_{3}$ coatings deposited was found to be mainly cap-like, exhibiting very fine sub-grains. Although small amounts of carbon were found to be present in the coatings, Altena et al associated the change in $\mathrm{Al}_{2} \mathrm{O}_{3}$ coating surface morphology with the excess $\mathrm{O}_{2}$ produced by the thermal decomposition of the $\mathrm{Al}(\mathrm{O}-\mathrm{tBu})_{3}$, which was stated to dominate the growth mode.

Colombier et al [28] studied the effect of $\mathrm{Al}$-donor type on the deposition rate and surface morphology of $\mathrm{Al}_{2} \mathrm{O}_{3}$ coatings chemically vapour deposited on $\mathrm{TiC}$ coated cemented carbide substrates, using three different $\mathrm{Al}$ halogenide donors: aluminium iodide $\left(\mathrm{AlI}_{3}\right)$, aluminium bromide $\left(\mathrm{AlB}_{3}\right)$ and $\mathrm{AlCl}_{3}$. The effect of the three $\mathrm{Al}$-donors on $\mathrm{Al}_{2} \mathrm{O}_{3}$ deposition rate was first investigated in a $\mathrm{CO}_{2} / \mathrm{H}_{2}$ gas mixture at a deposition temperature of $1050^{\circ} \mathrm{C}$ and a total pressure of 65 mbar $\left(0.064 \mathrm{~atm}\right.$ ) with a gas composition of $1 \% \mathrm{AlX}_{3}$ (where $\mathrm{X}=\mathrm{Cl}, \mathrm{Br}, \mathrm{I}$ ), $3.5 \% \mathrm{CO}_{2}$ and $95.5 \% \mathrm{H}_{2}$. It was found that the nature of the $\mathrm{Al}$ halogenide donor had no significant influence on the deposition rate of the $\mathrm{Al}_{2} \mathrm{O}_{3}$ coatings; this being suggested to be due to the slow rate of formation of the $\mathrm{O}$-donor $\left(\mathrm{H}_{2} \mathrm{O}\right)$ in the gas phase, which is the main rate determining deposition step. Colombier et al then investigated the direct reaction of the three $\mathrm{Al}$ halogenide donors with $\mathrm{CO}_{2}$ and $\mathrm{Ar}$, with a gas composition of $1 \% \mathrm{AlX}_{3}, 3.5 \% \mathrm{CO}_{2}$ and $89 \% \mathrm{Ar}$ and the remaining deposition conditions as quoted above. In agreement with their thermodynamical studies, they found that the nature of the $\mathrm{Al}$ halogenide donor had a marked influence on the deposition rate of the coatings. It was suggested that the reaction of $\mathrm{CO}_{2}$ with the $\mathrm{Al}$ halogenide donor was probably the rate determining step for these deposition reactions. Whilst the reaction of $\mathrm{AlI}_{3}$ with $\mathrm{CO}_{2}$ at $1050^{\circ} \mathrm{C}$ resulted in the deposition of $\mathrm{Al}_{2} \mathrm{O}_{3}$ coatings, that of $\mathrm{AlCl}_{3}$ with $\mathrm{CO}_{2}$ was found only to be feasible at higher deposition temperatures (greater than $1250^{\circ} \mathrm{C}$ ) and reactant concentrations. It was also established that dilution of the inlet gas mixtures with $\mathrm{Ar}$ was necessary for both the $\mathrm{AlBr}_{3}-\mathrm{CO}_{2}$ and $\mathrm{AlI}_{3}-\mathrm{CO}_{2}$ reactions. In addition, all three reactions were found to cause oxidation of the $\mathrm{TiC}$ precoating on the cemented carbide substrates. High deposition rates were established to be difficult to attain without nucleation gas phase or the formation of loose $\mathrm{Al}_{2} \mathrm{O}_{3}$ coatings. 
With regard to surface morphology, Colombier et al found that the $\mathrm{Al}_{2} \mathrm{O}_{3}$ coatings deposited, using the $\mathrm{AlX}_{3}-\mathrm{CO}_{2}-\mathrm{H}_{2}$ gas mixtures, had a columnar bulk structure and that the $\mathrm{Al}_{2} \mathrm{O}_{3}$ crystals exhibited an unusual fivefold pyramidal surface structure. In the case of the $\mathrm{AlX}_{3}-\mathrm{CO}_{2}-\mathrm{Ar}$ gas mixtures co-deposition of $\mathrm{C}$ or amorphous $\mathrm{Al}_{4} \mathrm{O}_{4} \mathrm{C}$ occurred with that $\mathrm{Al}_{2} \mathrm{O}_{3}$. The formation of $\mathrm{Al}_{4} \mathrm{O}_{4} \mathrm{C}$ was found to be greater in the case of the $\mathrm{AlI}_{3}-\mathrm{CO}_{2}-\mathrm{Ar}$ gas mixture than for either the $\mathrm{AlB}_{3}-\mathrm{CO}_{2}-\mathrm{Ar}$ or the $\mathrm{AlC}_{3}-\mathrm{CO}_{2}-\mathrm{Ar}$ mixtures. Further, with the $\mathrm{AlI}_{3}-\mathrm{CO}_{2}-\mathrm{Ar}$ gas mixture, $\mathrm{Al}_{2} \mathrm{O}_{3}$ coatings exhibiting cauliflower structures, typical of poorly crystallised deposits, were obtained. Colombier et al consequently suggested that the co-deposition of $\mathrm{C}$ or amorphous $\mathrm{Al}_{4} \mathrm{O}_{4} \mathrm{C}$ in $\mathrm{Al}_{2} \mathrm{O}_{3}$ coatings deposited using an $\mathrm{AlI}_{3}-\mathrm{CO}_{2}$ - $\mathrm{Ar}$ gas mixture, either initiates grain refinement or a dendritic mode of growth, depending on the degree of supersaturation.

\subsection{Characteristics of Commercial-Type $\mathrm{CVDAl} \mathrm{A}_{2} \mathrm{O}_{3}$ Coatings}

As mentioned in the introduction, this section is concerned with the characterisation and characteristics of commercial-type $\mathrm{CVD} \mathrm{Al}_{2} \mathrm{O}_{3}$ coatings reported in previous investigations. Extensive survey of the literature revealed that no work has previously been published on $\mathrm{Al}_{2} \mathrm{O}_{3}$ coatings chemically vapour deposited on HSS cutting tools. The characterisation techniques studied in previous work were found to be, AES, fractography, microhardness tests and scratch tests.

Several workers have employed AES $[20,56,57,58]$ to investigate compositional variations through the $\mathrm{Al}_{2} \mathrm{O}_{3}$ coating and coating/substrate interface, since this technique enables important light elements ( $\mathrm{C}, \mathrm{N}$ and $\mathrm{O}$ ) to be analysed and has a high spatial resolution. In two cases composition-depth profiles were obtained using AES by the sequential removal of surface layers using ion bombardment $[20,56]$. It is, however known that this bombardment can cause compositional artefacts to occur due to the preferential sputtering of one species, or by ion induced chemical decomposition [59]. Some workers have used other analytical techniques including, scanning Auger microprobe (SAM) [60], analytical electron microscopy (AEM) [61] and energy dispersive analysis (EDS) on either an SEM [61] or a scanning transmission electron microscopy (STEM) [58].

Results from elemental analysis of $\mathrm{Al}_{2} \mathrm{O}_{3}$ coatings $[20,56,58,61]$ chemically vapour deposited on $\mathrm{TiC}$ coated cemented carbide substrates all indicate substantial interdiffusion of $\mathrm{Al}_{2} \mathrm{O}_{3}$ coating and $\mathrm{TiC}$ precoating elements, which is hardly surprising given the elevated temperatures $\left(\sim 1000^{\circ} \mathrm{C}\right)$ at which the CVD of the coating is carried out. In the case of multilayer $\mathrm{Al}_{2} \mathrm{O}_{3}-\mathrm{TiN}-\mathrm{Al}_{2} \mathrm{O}_{3}-\mathrm{TiC}$ and $\mathrm{TiN}-\mathrm{Al}_{2} \mathrm{O}_{3}-\mathrm{TiC}$ coated cemented carbide substrates, both Layyous and Werthiem [57] and Mehrotro and Quinto [60], respectively, obtained composition-depth profiles through the $\mathrm{Al}_{2} \mathrm{O}_{3}$ coating and across the $\mathrm{Al}_{2} \mathrm{O}_{3}$ coating/TiN or TiC precoating interface, as shown in Figures 2.9 and 2.10. Whereas Mehrotro and Quinto 
observed relatively little diffusion of elements across this interface, with only $\mathrm{O}_{2}$ having diffused any appreciable amounts $(\sim 15$ at.\% at a distance of $\sim 3 \mu \mathrm{m}$ into the TiC precoating), Layyous and Werthiem noticed substantial diffusion of Ti, C and $\mathrm{N}$ into the $\mathrm{Al}_{2} \mathrm{O}_{3}$ coating.

In the case of $\mathrm{Al}_{2} \mathrm{O}_{3}$ coatings chemically vapour deposited on $\mathrm{TiC}$ coated cemented carbide substrates, Lhermitte-Sebire et al $[20,56]$ observed that post-deposition heat treatment of these substrates substantially increased the width of the interdiffusion zone between the $\mathrm{Al}_{2} \mathrm{O}_{3}$ coating and TiC precoating. They reported that the extent of such interdiffusion zones was important with regard to coating-substrate adhesion. Lhermitte-Sebire et al $[20,62]$ further, investigated the nature of diffusion layers formed between the $\mathrm{Al}_{2} \mathrm{O}_{3}$ coatings and cemented carbide substrates coated with preoxidised, prior to $\mathrm{Al}_{2} \mathrm{O}_{3}$ coating deposition, TiC coating. They observed the presence of a thin layer of titanium oxides and possibly aluminium titanate, in the $\mathrm{Al}_{2} \mathrm{O}_{3}$ coating at the $\mathrm{Al}_{2} \mathrm{O}_{3}$ coating/TiC precoating interface. It was proposed that the occurrence of such oxides could be a detrimental factor in coating/substrate adhesion. $\sim 10$ at. $\% \mathrm{Al}$ and $\sim 38$ at. $\% \mathrm{O}_{2}$ was detected at this interface.

In three of the investigations $[57,60,58]$ cited above, it was further observed that the composition of the $\mathrm{Al}_{2} \mathrm{O}_{3}$ coating was close to stoichiometric until the interface with the Ti-base precoating was approached. In contrast, Skogsmo and Norden [61] used atom probe field ion microscopy to analyse a $40 \mu \mathrm{m} \alpha-\mathrm{Al}_{2} \mathrm{O}_{3}$ coating on a $5 \mu \mathrm{m}$ TiC precoated cemented carbide substrates and found that the composition of the coating was $\mathrm{Al}_{2} \mathrm{O}_{1.5}$ to $\mathrm{Al}_{2} \mathrm{O}_{2}$, instead of the expected $\mathrm{Al}_{2} \mathrm{O}_{3}$. The composition of the coatings obtained by Lhermitte-Sebire et al $[20,62]$ was approximately $\mathrm{Al}_{4} \mathrm{O}_{3}$. It should be noted that, although Lhermitte-Sebire et al presented details on the nature of the $\mathrm{Al}_{2} \mathrm{O}_{3}$ coating/TiC precoating interface, no comment was made regarding the stoichiometry of the coatings i.e. the amount of excess $\mathrm{Al}$, clearly present in the coatings.

Due to the inherent difficulties with preparing polished and etched sections, through the $\mathrm{Al}_{2} \mathrm{O}_{3}$ coatings chemically vapour deposited on various hard material substrates, for optical examination, fractography has been used to examine the bulk grain structure of $\mathrm{Al}_{2} \mathrm{O}_{3}$ coatings. The bulk grain structure of such coatings has been determined by examination of the fracture surfaces using a SEM $[16,18,20,64,65]$. The procedure employed to prepare such fracture surfaces has not been described, unfortunately, in much of the literature. Although, the fractographs presented in the literature allow the identification of important structural features of the $\mathrm{Al}_{2} \mathrm{O}_{3}$ coatings, in some cases the investigators involved have not fully discussed the results.

Lux and Schachner [63] presented fractographs of $\mathrm{Al}_{2} \mathrm{O}_{3}$ coatings chemically vapour deposited on cemented carbide substrates, in which the $\mathrm{Al}_{2} \mathrm{O}_{3}$ coatings exhibited columnar characteristics. This is contrary to the findings of Werthiem et al [18] who presented a fractograph of an $\mathrm{Al}_{2} \mathrm{O}_{3}$ coating chemically vapour deposited on a cemented carbide substrate, 
showing a one grain thick $\mathrm{Al}_{2} \mathrm{O}_{3}$ coating with a grain size of $\sim 1$ to $1.5 \mu \mathrm{m}$. Fractographs of $\mathrm{Al}_{2} \mathrm{O}_{3}$ coatings on TiC precoated and TiN precoated cemented carbide substrates respectively, were presented by Kalish and Peters [16] and Lhermitte-Sebire et al [20] and both showed the $\mathrm{Al}_{2} \mathrm{O}_{3}$ coating to consist of coarse grains (much coarser than those of the TiC and TiN precoatings), exhibiting a tendency towards columnar growth. Layyous et al [64] presented fractographs of $\mathrm{Al}_{2} \mathrm{O}_{3}$ coatings chemically vapour deposited on multilayer cemented carbide substrates, in which the $\mathrm{Al}_{2} \mathrm{O}_{3}$ coatings also exhibited columnar characteristics. Although results presented for chemically vapour deposited $\mathrm{Al}_{2} \mathrm{O}_{3}$ coatings by Ellis [65], do not allow the coating structure to be clearly discerned, he has described the $\mathrm{Al}_{2} \mathrm{O}_{3}$ coating structure to consist of large and columnar grains.

Not surprisingly, given the extreme thinness of typical chemically vapour deposited $\mathrm{Al}_{2} \mathrm{O}_{3}$ coatings $[60,66,67]$, microhardness tests have been used exclusively to determine the coating hardness. Two types of indentor have been employed in these tests namely Knoop [67] and Vickers $[60,66]$. In their work on $\mathrm{TiN} / \mathrm{Al}_{2} \mathrm{O}_{3} / \mathrm{TiC}$ multilayer coated cemented carbide substrates Mehrotro and Quinto [60] noted the strong dependence of $\mathrm{Al}_{2} \mathrm{O}_{3}$ ( $\mathrm{TiC}$ and TiN) coating microhardness on temperature, as shown in Figure 2.11. The striking feature of Figure 2.11 , in addition to the relatively rapid decrease in $\mathrm{Al}_{2} \mathrm{O}_{3}$ coating microhardness (from $\sim 2400$ $\mathrm{kg} \mathrm{mm}^{-2}$ at $0^{\circ} \mathrm{C}$ ), and that of the $\mathrm{TiC}$ and TiN coatings, with increasing temperature, is that the $\mathrm{Al}_{2} \mathrm{O}_{3}$ coating exhibits the highest microhardness at $800^{\circ} \mathrm{C}$. Also, Hazra [66] has reported a similar microhardness value of $2800 \mathrm{~kg} \mathrm{~mm}^{-2}$ for an $\mathrm{Al}_{2} \mathrm{O}_{3}$ coating chemically vapour deposited on cemented carbide substrates. For $\mathrm{Al}_{2} \mathrm{O}_{3}$ coatings chemically vapour deposited on a "formulated" substrate, Bryant et al [67] determined $\mathrm{Al}_{2} \mathrm{O}_{3}$ coating microhardness values between 2170 and $2420 \mathrm{HK}_{0.1}$ and 1800 and $1950 \mathrm{HK}_{0.1}$ for $\mathrm{Al}_{2} \mathrm{O}_{3}$ coatings of thicknesses 0.7 $\mu \mathrm{m}$ and $\sim 3 \mu \mathrm{m}$, respectively.

Scratch tests have been exclusively employed to investigate the adhesion of $\mathrm{Al}_{2} \mathrm{O}_{3}$ coatings chemically vapour deposited on $\mathrm{TiC}[16,20,73]$ and on $\mathrm{TiN}[20]$ precoated cemented carbide substrates. The scratch test is based on work originally carried out by Heavens [68] and later developed by Benjamin and Weaver [69]. Essentially it consists of scratching a coated sample with a stylus (normally a diamond) of known tip radius at a given speed, under increasing normal load (either stepwise or continuously), until the coating is removed from the scratch channel. The lowest load at which this occurs, termed the critical load, can, in principle at least, be used to calculate the strength of coating/substrate adhesion. There are, however, problems associated with the scratch test; it has been found that the critical stylus load is also dependent on coating thickness [70,71] substrate hardness [71] and stylus tip radius [72]. In addition complete coating removal from the scratch channel during scratch testing can be preceded by other phenomena $[70,71,72]$ : partial removal of the coating from the scratch channel, flaking of the coating at the edges of the scratch channel, local coating spalling, 
cracking and loss of load bearing capacity. This has led to the application of various ancilliary techniques to facilitate critical load determination, including, acoustic emission $[16,20,73]$ and energy dispersive X-ray analysis on an SEM [73].

In their work Lhermitte-Sebire et al [20] investigated the adhesion of a 1 to $3 \mu \mathrm{m}$ thick $\mathrm{Al}_{2} \mathrm{O}_{3}$ coating chemically vapour deposited on cemented carbide substrates coated with a $30 \mu \mathrm{m}$ thick TiC coating. From SEM examination of the scratch channels they observed that close to the critical stylus load of $6.5 \mathrm{~kg}$ localised removal of the $\mathrm{Al}_{2} \mathrm{O}_{3}$ coating had occurred from within the channel accompanied by flaking from its sides. Complete coating removal from the scratch channel, accompanied by extensive flaking at edges of the scratch channels, was found to occur at a critical stylus load of $6.5 \mathrm{~kg}$. Lhermitte-Sebire et al suggested the mode of coating failure as being of the mixed adhesive/cohesive type (i.e. initiated by cracking at the $\mathrm{Al}_{2} \mathrm{O}_{3}$ coating/TiC precoating interface followed, initially, by propagation along this interface and then obliquely through the $\mathrm{Al}_{2} \mathrm{O}_{3}$ coating). They further investigated the adhesion of $\mathrm{Al}_{2} \mathrm{O}_{3}$ coatings chemically vapour deposited on cemented carbide substrates coated with a preoxidised TiC coating. As described earlier, a thin film of titanium oxides $\left(\mathrm{Ti}_{3} \mathrm{O}_{5}\right.$ and $\mathrm{TiO}_{2}$ ) was found to be present on the surface of the oxidised $\mathrm{TiC}$ precoating. For various thicknesses of these titanium oxide films, they observed that the $\mathrm{Al}_{2} \mathrm{O}_{3}$ coating was completely removed from the scratch channel, with almost no damage to the substrate, at a critical stylus load of $1 \mathrm{~kg}$. It was suggested that coating failure was of an almost pure adhesive type i.e. at the $\mathrm{Ti}_{3} \mathrm{O}_{5}$ and $\mathrm{TiO}_{2}$ film/ TiC precoating interface.

From scratch tests on a $1.5 \mu \mathrm{m}$ thick $\mathrm{Al}_{2} \mathrm{O}_{3}$ coating chemically vapour deposited on cemented carbide substrates coated with a $40 \mu \mathrm{m}$ thick TiN coating, Lhermitte-Sebire et al observed, from SEM micrographs, that coating failure was characterised by local cohesive loss (failure within the TiN coating) at stylus loads of $\sim 1 \mathrm{~kg}$. The cohesive failure was found to be related to the coarse microstructure of the thick TiN coating. Lhermitte-Sebire et al stated that a higher cohesive bond strength could be obtained if the $\mathrm{Al}_{2} \mathrm{O}_{3}$ coatings were deposited on a thinner TiN coating. Kalish and Peters [16] carried out scratch tests on two commercial $\mathrm{Al}_{2} \mathrm{O}_{3}$ coatings chemically vapour deposited on $\mathrm{TiC}$ precoated cemented carbide substrate. In one case, coating loss by adhesive failure at the $\mathrm{Al}_{2} \mathrm{O}_{3}$ coating/TiC precoating interface was found to occur at a stylus load of $3 \mathrm{~kg}$, whereas in the other case adhesive failure occurred at the $\mathrm{TiC}$ coating/substrate interface at a stylus load of $9 \mathrm{~kg}$. Finally from scratch tests on $\mathrm{Al}_{2} \mathrm{O}_{3}$ coatings chemically vapour deposited on TiC coated cemented carbide substrates, Boving et al [73] observed, from SEM examination, that $\mathrm{Al}_{2} \mathrm{O}_{3}$ coating failure was characterised by spalling of the $\mathrm{Al}_{2} \mathrm{O}_{3}$ coating at the $\mathrm{Al}_{2} \mathrm{O}_{3}$ coating/TiC precoating interface. From tungsten (W) X-ray maps, they also observed flaking of the TiC coating at the edges of the scratch channel (adhesive failure). 
No valid information was found in the literature relating the critical load during scratch testing to the thickness of chemically vapour deposited $\mathrm{Al}_{2} \mathrm{O}_{3}$ coatings. However, Lhermitte-Sebire et al [20] presented some results for $\mathrm{Al}_{2} \mathrm{O}_{3}$ coatings chemically vapour deposited on $\mathrm{TiC}$ coated cemented carbide substrates, which purported to show that the critical load increases with increasing $\mathrm{Al}_{2} \mathrm{O}_{3}$ coating thickness. 


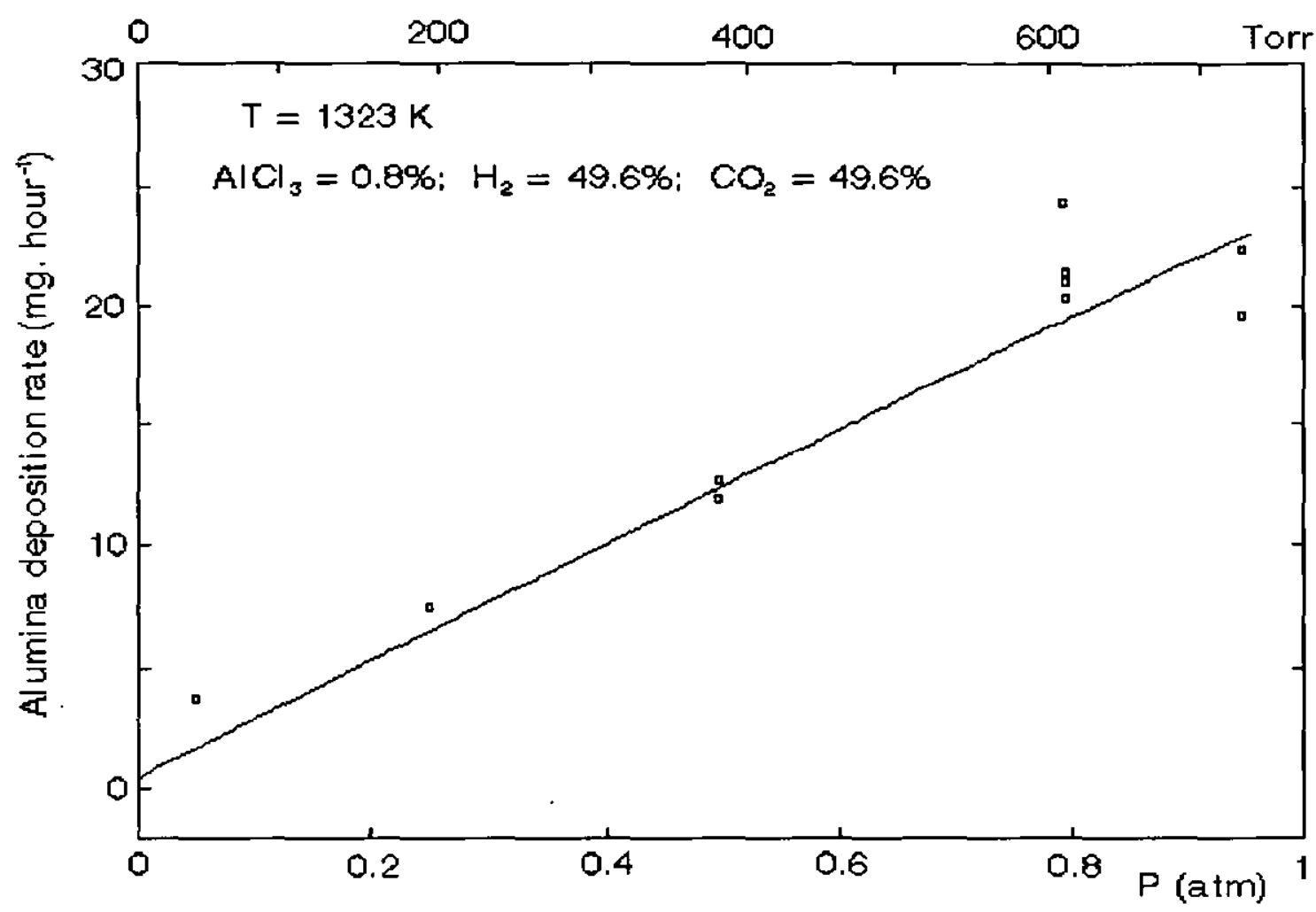

Figure 2.1 Effect of total pressure on deposition rate of chemically vapour deposited $\mathrm{Al}_{2} \mathrm{O}_{3}$ coatings [27]. (Diagram modified by author)

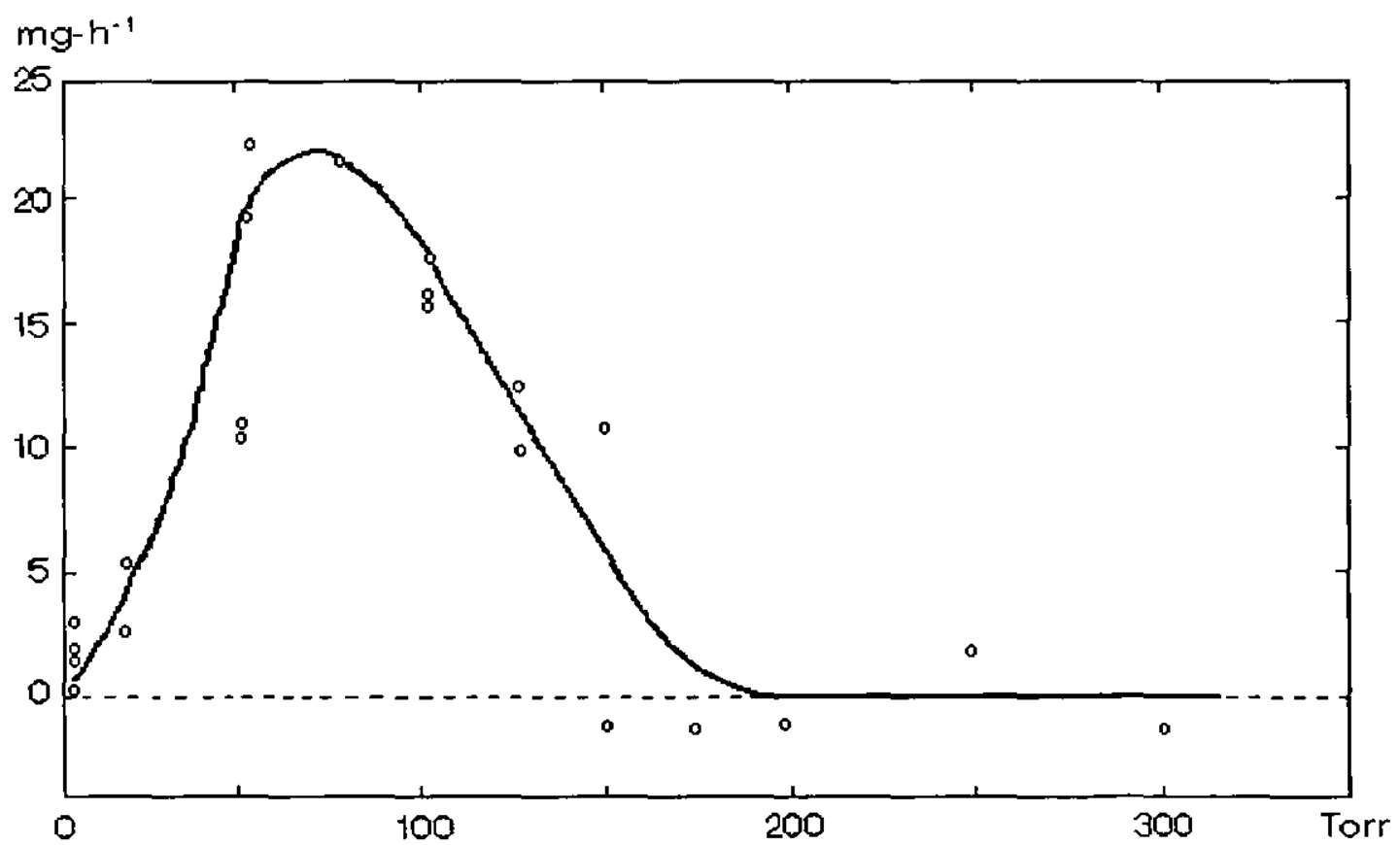

Figure 2.2 Effect of total pressure on deposition rate of chemically vapour deposited $\mathrm{Al}_{2} \mathrm{O}_{3}$ coatings [31]. 


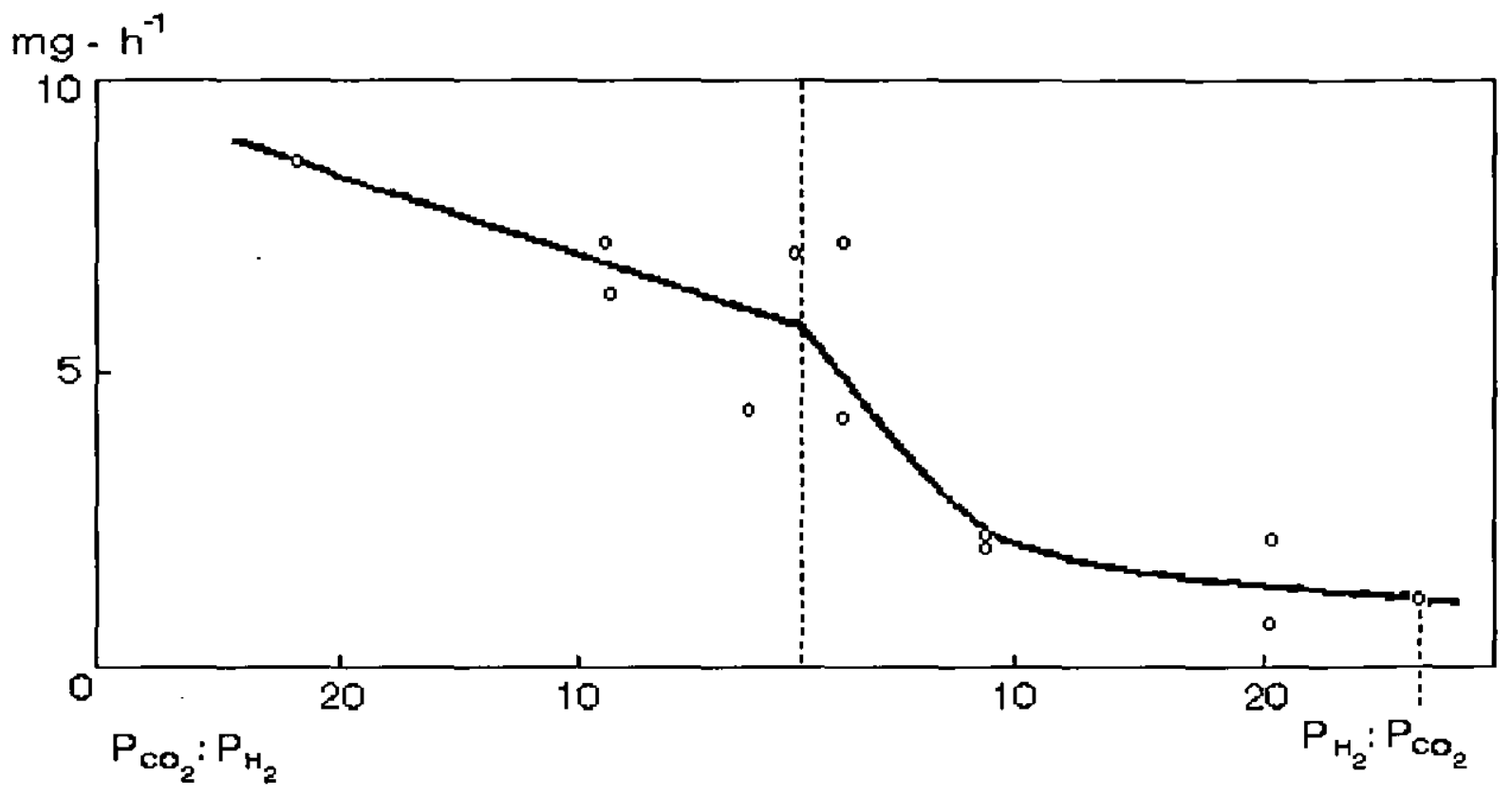

Figure 2.3 Effect of $P_{\mathrm{CO}_{2}} / P_{\mathrm{H}_{2}}$ and $P_{\mathrm{H}_{2}} / P_{\mathrm{CO}_{2}}$ on deposition rate of chemically vapour deposited $\mathrm{Al}_{2} \mathrm{O}_{3}$ coatings [31].

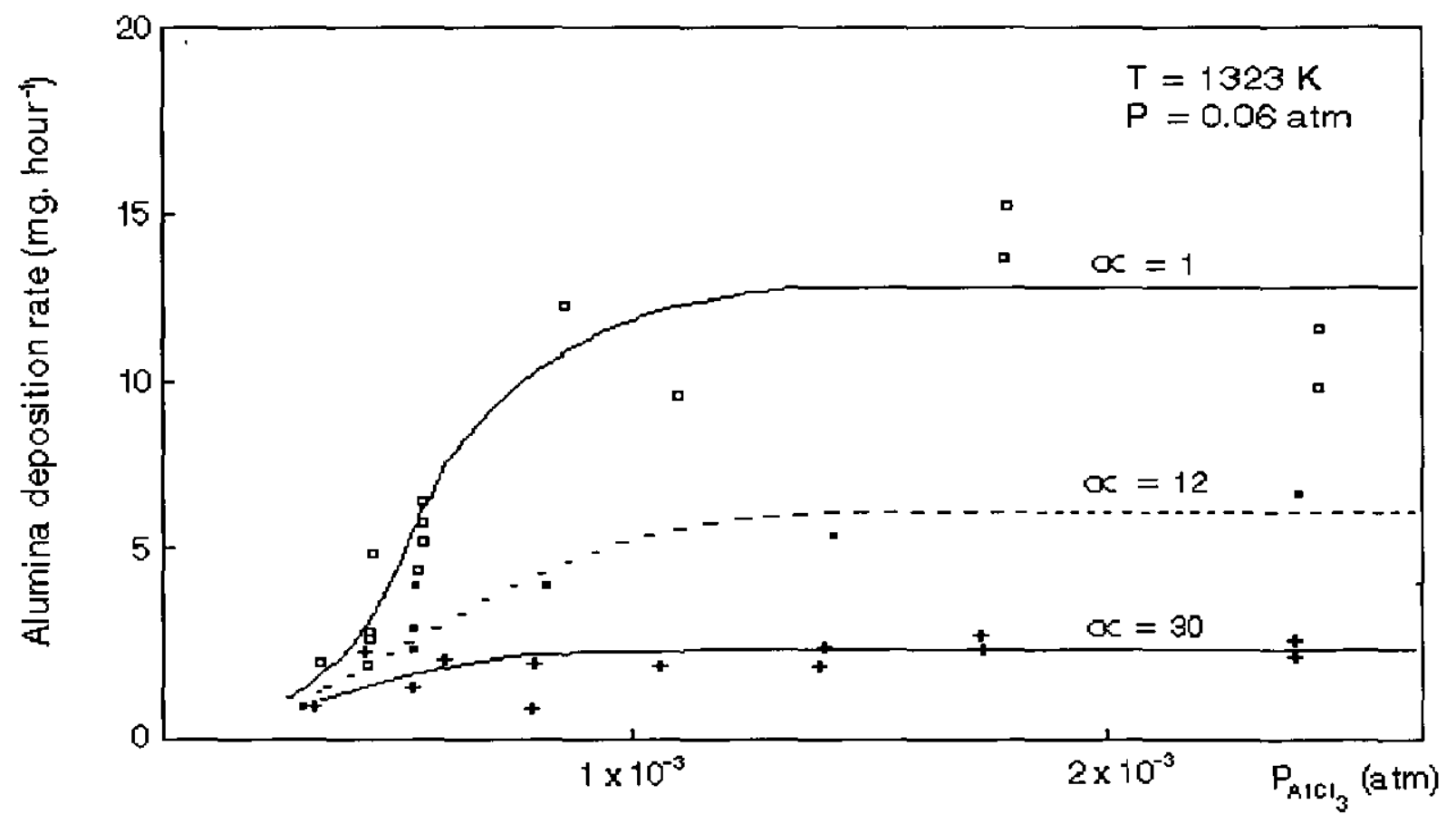

Figure 2.4 Variation of deposition rate of chemically vapour deposited $\mathrm{Al}_{2} \mathrm{O}_{3}$ coatings as a function of $P_{\mathrm{AlCl}_{3}}$ in the initial gas mixture for different values of $P_{\mathrm{H}_{2 \text { in }}} / P_{\mathrm{CO}_{2 \text { in }}}=$ $\alpha[37]$. 


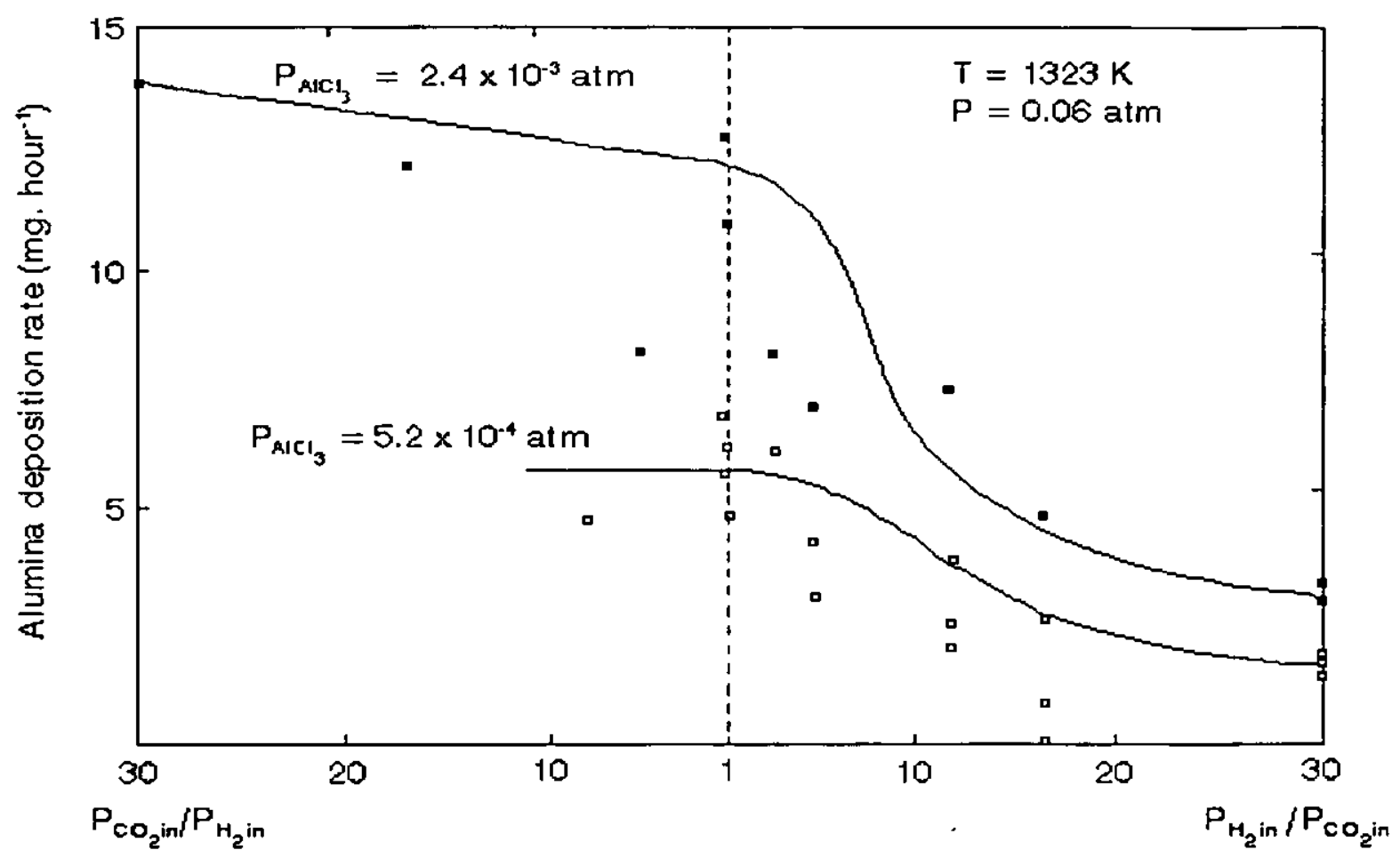

Figure 2.5 Effect of $\alpha$ or $1 / \alpha$ on deposition rate of chemically vapour deposited $\mathrm{Al}_{2} \mathrm{O}_{3}$ coatings for different values of $P_{\mathrm{ACCl}_{3}}$ [37].

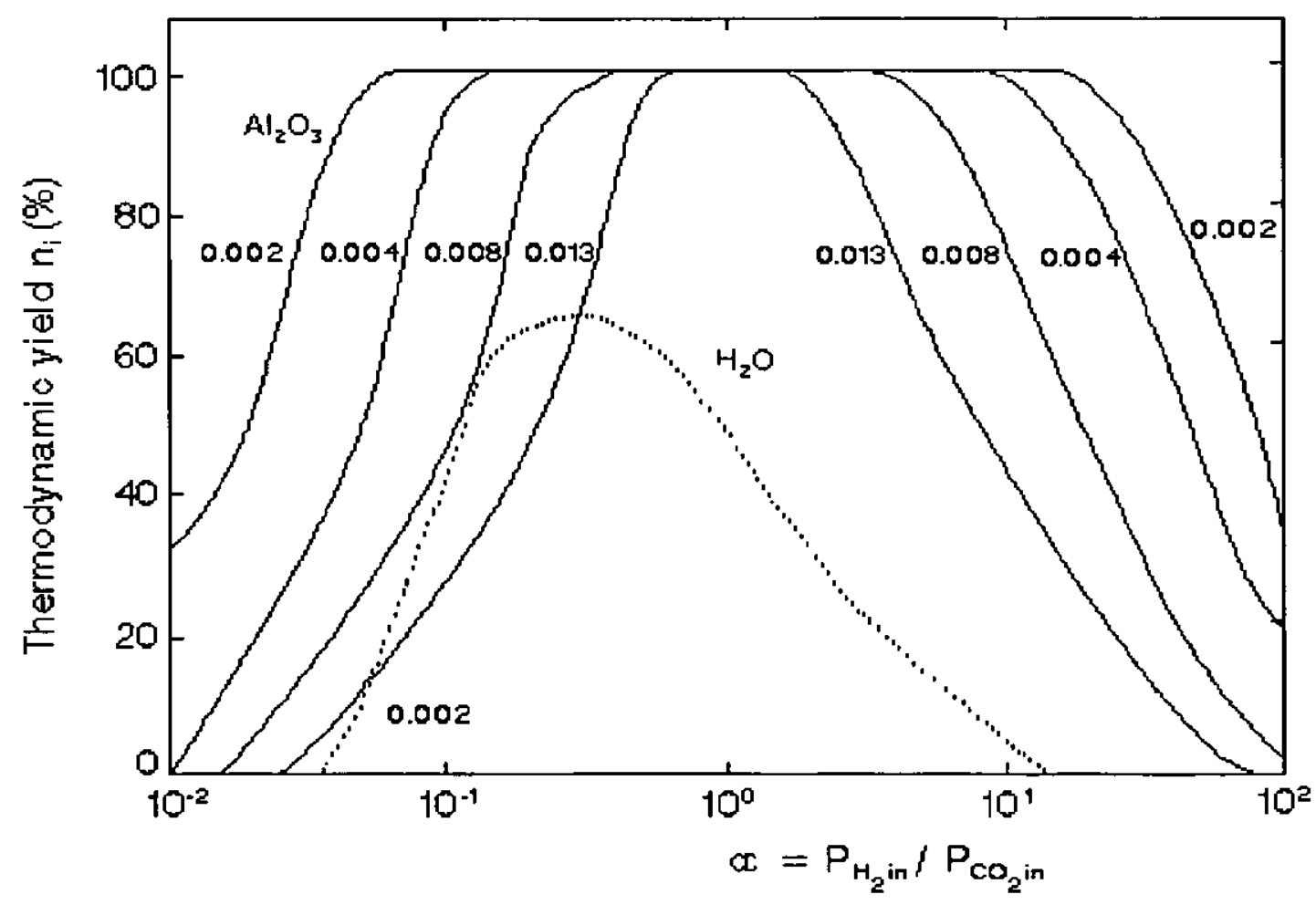

Figure 2.6 Effect of $\alpha$ on deposition rate of chemically vapour deposited $\mathrm{Al}_{2} \mathrm{O}_{3}$ coatings and formation of $\mathrm{H}_{2} \mathrm{O}$ for various values of $P_{A l C l}$ [37]. (Diagram modified by author) 


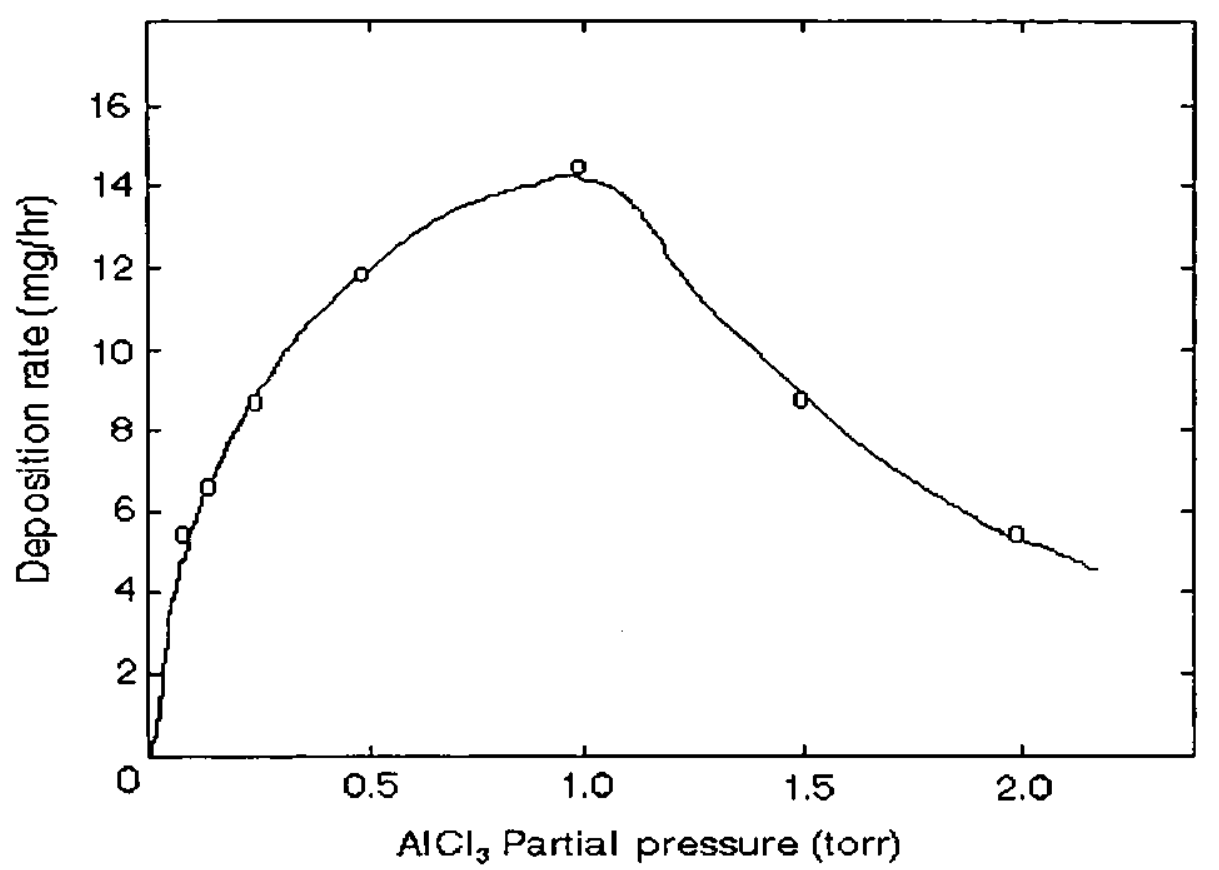

Figure 2.7 Effect of $P_{\mathrm{AlCl}_{3}}$ on deposition rate of chemically vapour deposited $\mathrm{Al}_{2} \mathrm{O}_{3}$ coatings [36].

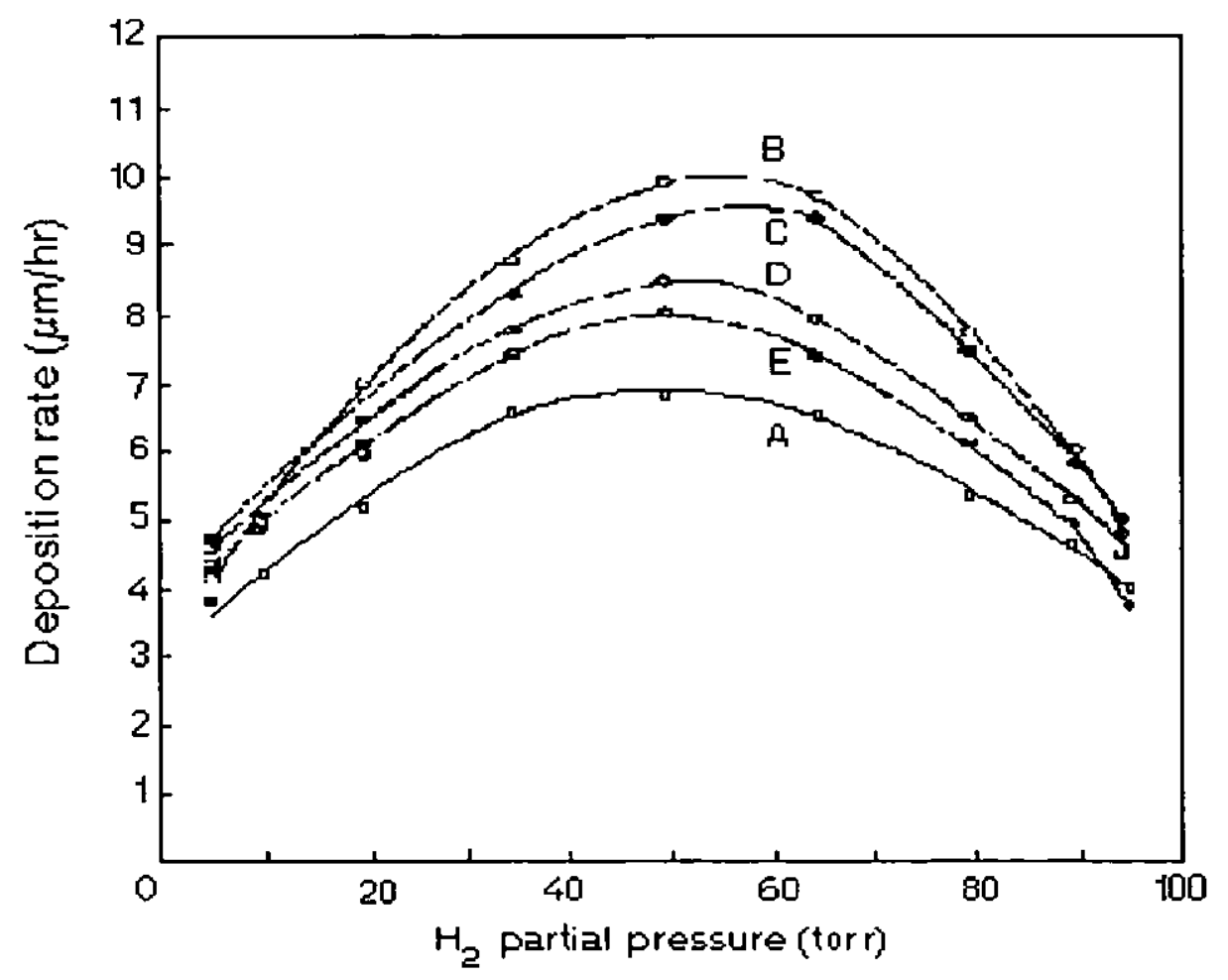

Figure 2.8 Effect of $P_{H_{2 i n}}$ on deposition rate of chemically vapour deposited $\mathrm{Al}_{2} \mathrm{O}_{3}$ for different values of $P_{\mathrm{AlCl}_{3}}$. Curve A, 0.5 torr; Curve B, 1.0 torr; Curve C, 1.5 torr; Curve D, 2.0 torr; Curve E, 3.0 torr [43]. 


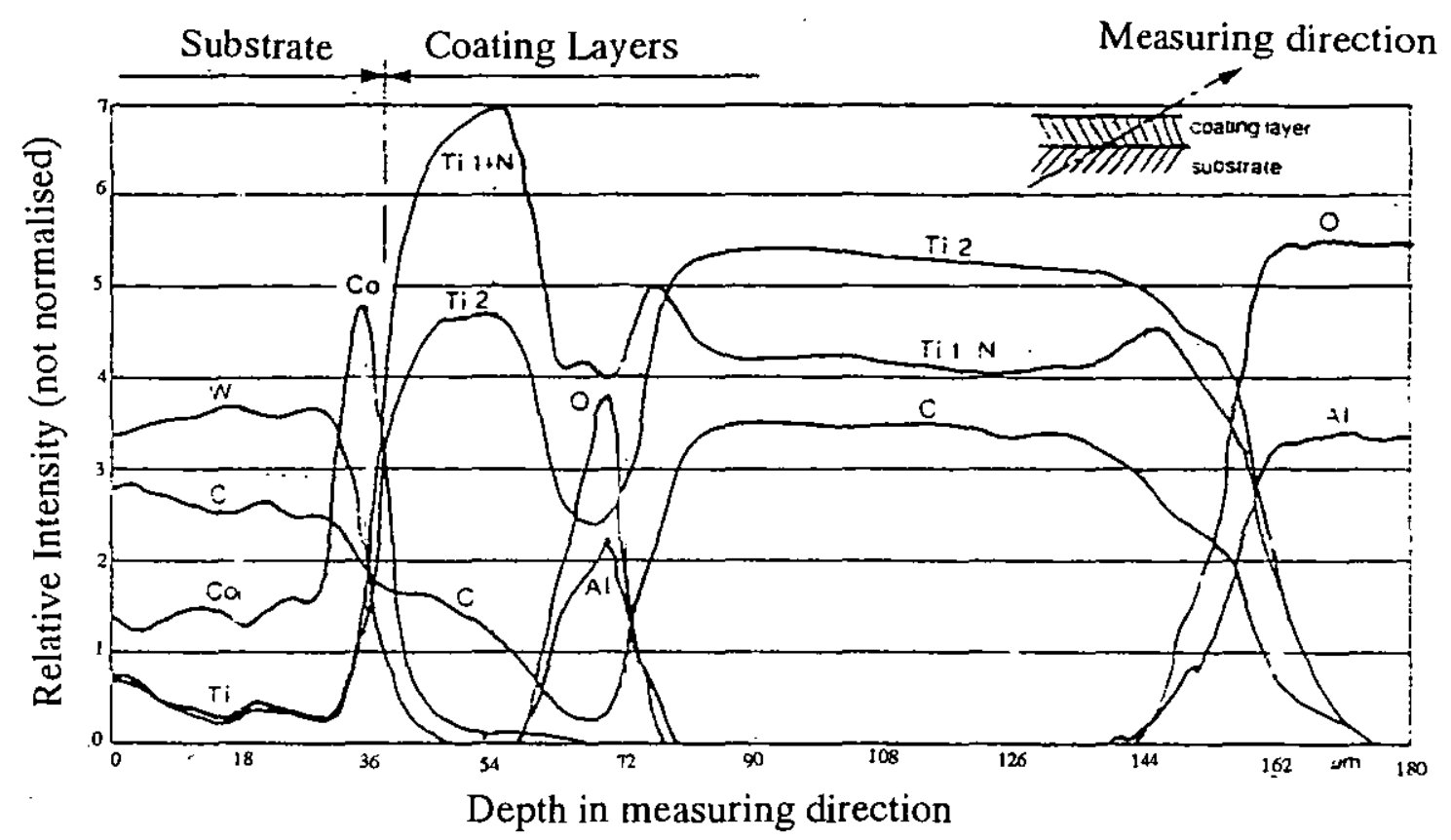

Figure 2.9 AES composition-depth profile of multilayer $\mathrm{Al}_{2} \mathrm{O}_{3}-\mathrm{TiN}-\mathrm{Al}_{2} \mathrm{O}_{3}-\mathrm{TiC}$ coated cemented carbide substrate [57].

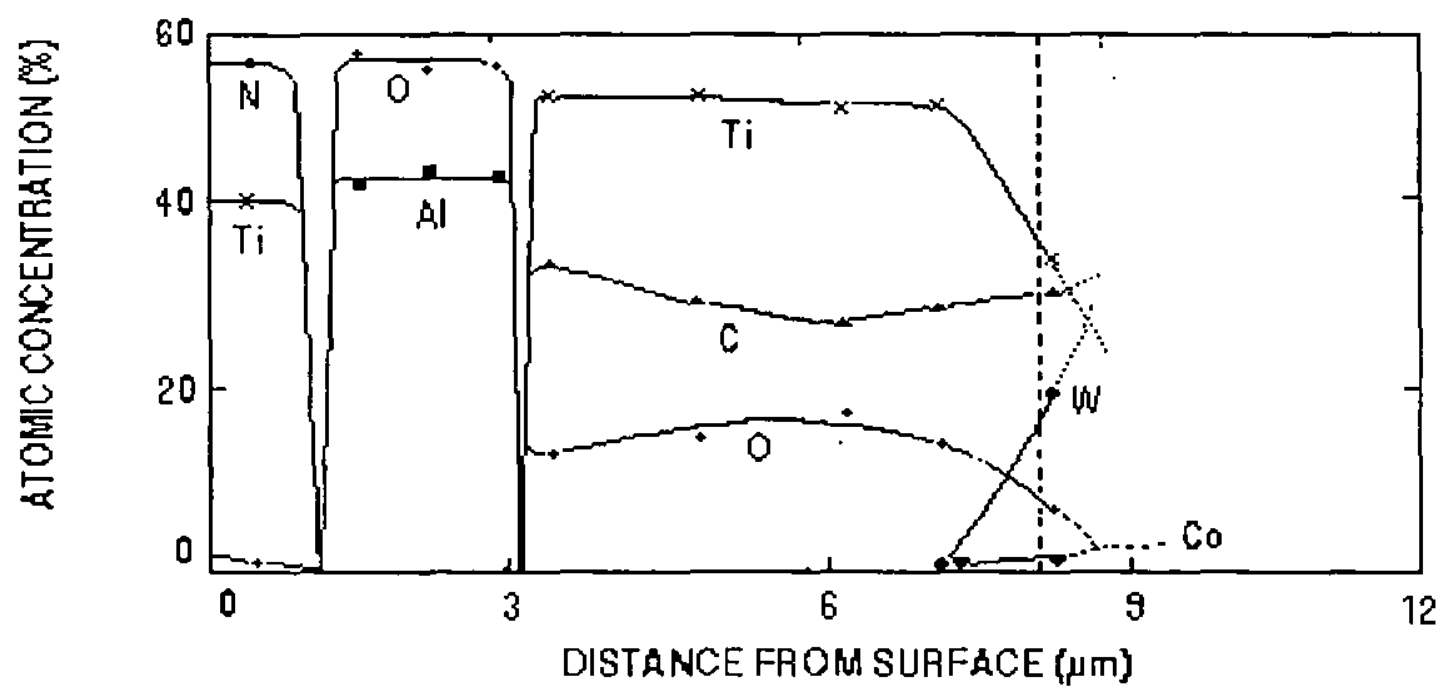

Figure 2.10 AES composition-depth profile of multilayer $\mathrm{TiC}-\mathrm{Al}_{2} \mathrm{O}_{3}-\mathrm{TiN}$ coated cemented carbide substrate [60]. 


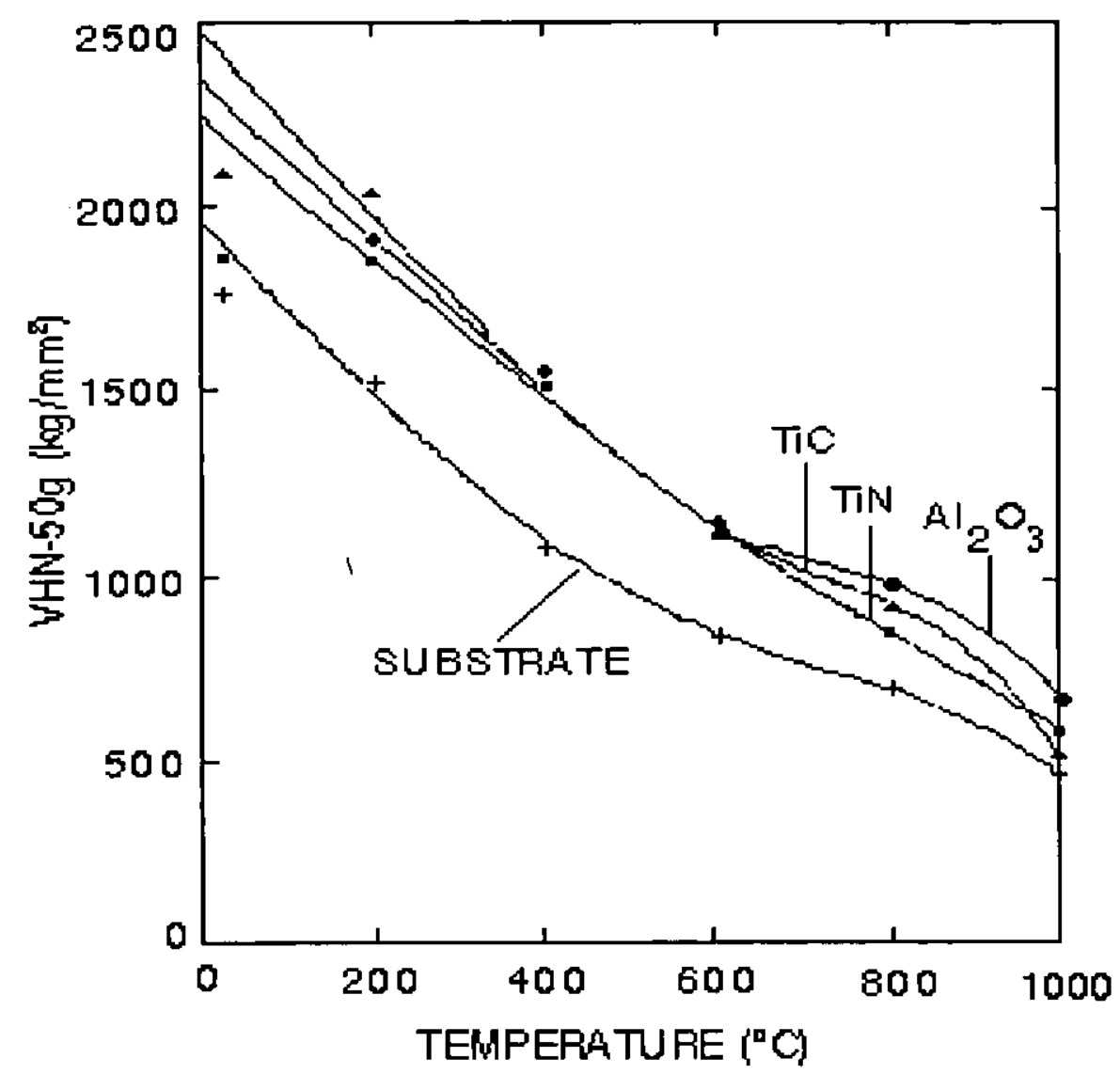

Figure 2.11 Effect of temperature on hardness of chemically vapour deposited $\mathrm{TiC}, \mathrm{Al}_{2} \mathrm{O}_{3}$ and TiN coatings and cemented carbide substrate [60]. 


\section{CHAPTER 3}

DESIGN AND CONSTRUCTION OF LABORATORY-SCALE REACTOR AND TRIAL $\mathrm{Al}_{2} \mathrm{O}_{3}$ COATING DEPOSITION 


\subsection{DESIGN AND CONSTRUCTION OF LABORATORY-SCALE $\underline{A l}_{2} \underline{O}_{3}$ CVD REACTOR AND TRIAL $\mathrm{Al}_{2} \underline{O}_{3}$ COATING DEPOSITION}

As previously described in Chapter 1 , since access to a commercial $\mathrm{Al}_{2} \mathrm{O}_{3} \mathrm{CVD}$ reactor could not be arranged, it was decided to design and construct a laboratory-scale reactor to facilitate the present work. Details are given in the second section of this chapter. Following completion of the basic construction of the laboratory-scale $\mathrm{Al}_{2} \mathrm{O}_{3} \mathrm{CVD}$ reactor, a series of trial coating runs were carried out, using deposition conditions derived from previous work, surveyed in Chapter 2. Concurrently, modifications to the laboratory-scale reactor were performed. Details of this work and the results obtained from it are presented in the last section of this chapter. First, however, relevant details of the PM HSS cutting tool inserts employed are presented.

\subsection{Uncoated/Precoated PM HSS Inserts}

The PM HSS cutting tool inserts employed throughout the present work were BT42 grade HSS indexable inserts, commercially manufactured by Edgar Allen Tools, Sheffield using their patented direct compaction and vacuum sintering PM route [1]. This route has been described in detail elsewhere $[6,9,11,14]$. It is not proposed to repeat that description here. The inserts, which had been surface ground on their rake, bottom and clearance faces after sintering, were $12.7 \mathrm{~mm}$ square and $3.18 \mathrm{~mm}$ thick, with $11^{\circ}$ clearance angles and $0.8 \mathrm{~mm}$ nose radii, as shown in Figure 3.1, conforming to ISO designation SPGN 120308 [74]. Their cutting edges were rounded with a radius of approximately $0.06 \mathrm{~mm}$. The chemical composition of BT42 grade HSS is given in Table 3.1 [75]. In addition to uncoated PM HSS inserts, inserts precoated with $\mathrm{TiN}, \mathrm{TiC}$ and titanium carbonitride $(\mathrm{Ti}(\mathrm{C}, \mathrm{N}))$ were employed in anticipation of problems with the adhesion of $\mathrm{Al}_{2} \mathrm{O}_{3}$ coatings chemically vapour deposited directly on to the former; comparable problems having previously been encountered in the case of uncoated cemented carbide inserts [16]. For all the trial coating runs but the last, TiN, $\mathrm{TiC}$ and $\mathrm{Ti}(\mathrm{C}, \mathrm{N})$ precoated PM BT42 grade HSS inserts remaining from previous work [9, $11,14,76]$ were employed. For the last trial coating run and subsequently, inserts precoated specifically for the present work were used. The $\mathrm{TiN}, \mathrm{TiC}$ and $\mathrm{Ti}(\mathrm{C}, \mathrm{N})$ precoatings were chemically vapour deposited on the PM BT42 grade HSS inserts by Edgar Allen Tools in their atmospheric pressure Plansee CVD reactor, utilising the standard reactions respectively defined below:

$$
\begin{aligned}
& 2 \mathrm{TiCl}_{4}+\mathrm{N}_{2}+4 \mathrm{H}_{2} \rightarrow 2 \mathrm{TiN}+8 \mathrm{HCl} \\
& \mathrm{TiCl}_{4}+\mathrm{CH}_{4} \rightarrow \mathrm{TiC}+4 \mathrm{HCl}
\end{aligned}
$$


$2 \mathrm{TiCl}_{4}+2 \mathrm{CH}_{4}+\mathrm{N}_{2} \rightarrow 2 \mathrm{TiCN}+8 \mathrm{HCl}$

The deposition conditions employed had been established in earlier work, $[9,11,14,76]$.

\subsection{Design and Basic Construction of Laboratory-Scale $\mathrm{Al}_{2} \underline{\mathrm{O}}_{3} \mathrm{CVD}$ Reactor}

Reference was made to relevant details of $\mathrm{Al}_{2} \mathrm{O}_{3} \mathrm{CVD}$ reactors described in the literature to facilitate the design and construction of the laboratory-scale $\mathrm{Al}_{2} \mathrm{O}_{3} \mathrm{CVD}$ reactor in the present work.

\subsubsection{Design of laboratory-scale $\mathrm{Al}_{2} \mathrm{O}_{3} \mathrm{CVD}$ reactor}

A schematic diagram showing the fundamental design of the laboratory-scale $\mathrm{Al}_{2} \mathrm{O}_{3} \mathrm{CVD}$ reactor is presented in Figure 3.2. As is evident from this figure, CVD of the $\mathrm{Al}_{2} \mathrm{O}_{3}$ coatings was to be effected from a normal $\mathrm{AlCl}_{3}-\mathrm{CO}_{2}-\mathrm{H}_{2}$ gas mixture via the standard reaction:

$$
2 \mathrm{AlCl}_{3(g)}+3 \mathrm{H}_{2(g)}+3 \mathrm{CO}_{2(g)}-----\rightarrow \mathrm{Al}_{2} \mathrm{O}_{3(s)}+3 \mathrm{CO}(g)+6 \mathrm{HCl}_{(g)}
$$

The design of the laboratory-scale reactor differs from that of the majority of commercial $\mathrm{Al}_{2} \mathrm{O}_{3} \mathrm{CVD}$ reactors and pilot-scale reactors used in previous work in two main respects. First, the $\mathrm{AlCl}_{3}$ was to be provided via the evaporation of $\mathrm{AlCl}_{3}$ powder as opposed to the normal reaction of $\mathrm{HCl}$ or $\mathrm{Cl}$ with $\mathrm{Al}$ chips $[27,29,31,42,43]$, and second, CVD of the $\mathrm{Al}_{2} \mathrm{O}_{3}$ coatings was to be carried out at atmospheric pressure as opposed to the reduced pressures normally employed (see Section 2.4). Both of these innovations were intended to simplify the CVD reactor and hence make the $\mathrm{Al}_{2} \mathrm{O}_{3}$ deposition process on the HSS inserts more amenable to eventual industrial exploitation. With regard to the total pressure, it has been stated [77] that whilst the CVD of $\mathrm{Al}_{2} \mathrm{O}_{3}$ coatings on cemented carbides is normally carried out at reduced pressures (typically $0.05 \mathrm{~atm}$ [20]), it can, in principle, also occur at atmospheric pressure. Although results apparently contradicting the last part of this statement have been presented (see Figure 2.2, Section 2.4) it is known that at least one CVD reactor used for coating cemented carbide inserts with $\mathrm{Al}_{2} \mathrm{O}_{3}$ operates at a total deposition pressure close to one atmosphere [78]. Given this, the decision to employ such a pressure for the CVD of the $\mathrm{Al}_{2} \mathrm{O}_{3}$ coatings in the present work was precipitated by the following facts:

All the conventional Ti-base hard material coatings applied to HSS cutting tools can be satisfactorily chemically vapour deposited at atmospheric pressure $[9,11,14,76]$. 
- The vacuum equipment required for reduced pressure CVD reactors is expensive and prone to damage by the corrosive by-products of the CVD deposition reaction.

- $\quad$ Atmospheric pressure CVD reactors are simpler and cheaper to build and cheaper to maintain.

As can be seen from Figure 3.2, the laboratory-scale CVD reactor for use in the present work was to consist, essentially, of five main parts:

1. Supply of $\mathrm{CO}_{2}, \mathrm{H}_{2}$ and $\mathrm{Ar}$ gases and flow control. It should be noted that two $\mathrm{H}_{2}$ sources were to be provided so that the $\mathrm{CO}_{2} / \mathrm{H}_{2}$ mole ratio could be varied independently of $\mathrm{AlCl}_{3}$ flow rate $\left(\mathrm{H}_{2}\right.$ was also to be used as the carrier gas for the $\left.\mathrm{AlCl}_{3}\right)$. Also $\mathrm{Ar}$ is not a reactant, but was to be used for by-passing the reactor coating chamber during heating up of the $\mathrm{AlCl}_{3}$ evaporator and also for use during deposition, if necessary, to reduce the number of intermolecular collisions and hence minimise the possibility of gas phase nucleation [16].

2. The $\mathrm{AlCl}_{3}$ evaporation unit and associated pipework, the latter heated to $\sim 200^{\circ} \mathrm{C}[16$, $27,46]$ to maintain the $\mathrm{AlCl}_{3}$ in gaseous form.

3. The gas mixing and delivery pipework systems, those downstream of the $\mathrm{AlCl}_{3}$ evaporation unit being heated to $\sim 200^{\circ} \mathrm{C}$.

4. The reactor coating chamber and the furnace to heat this chamber to a maximum temperature of $1100^{\circ} \mathrm{C}$.

5. The exhaust system to deal with unreacted $\mathrm{H}_{2}$ and the $\mathrm{HCl}$ and $\mathrm{CO}$ arising as by-products of the $\mathrm{Al}_{2} \mathrm{O}_{3}$ deposition reaction.

\subsubsection{Basic construction of laboratory-scale $\mathrm{Al}_{2} \underline{O}_{3}$ CVD reactor}

Views of the laboratory-scale reactor actually constructed are shown in Figures 3.3 to 3.9 and Figures 3.11 to 3.13. A schematic diagram of the reactor coating chamber is presented in Figure 3.10. To satisfy safety requirements the two gas cylinders for supplying the $\mathrm{H}_{2}$ gas had to be placed outside the building in which the CVD reactor is situated. As shown in Figure 3.3 , these cylinders were contained within a purpose-built cage. The $\mathrm{CO}_{2}$ and Ar gas cylinders were similarly contained. With reference to previous work on the effect of impurities on the CVD of $\mathrm{Al}_{2} \mathrm{O}_{3}$ coatings (see Section 2.6), commercial $\mathrm{CO}_{2}, \mathrm{H}_{2}$ and Ar gases of the following purities were obtained for use in the present work: $\mathrm{CO}_{2}-99.995 \%, \mathrm{H}_{2}-99.999 \%$ and $\mathrm{Ar}$ 99.998\%. As shown in Figure 3.4, flow control of the gases was to be effected using four 
Spectrol flowmeters with a borosilicate glass metering tube and glass and 316 stainless steel floats (g. and s.s. floats, respectively). The maximum and minimum flow rates attainable for the two $\mathrm{H}_{2}$ gases (designated $\mathrm{H}_{2}-1$ and $\mathrm{H}_{2}-2$ ) were $408 \mathrm{~cm}^{3} \min ^{-1}$ (s.s. float) and $2 \mathrm{~cm}^{3} \mathrm{~min}^{-1}$ (g. float) whilst those for the $\mathrm{CO}_{2}$ gas were $233 \mathrm{~cm}^{3} \mathrm{~min}^{-1}$ (s.s. float) and $5 \mathrm{~cm}^{3} \mathrm{~min}^{-1}$ (g. float). The maximum and minimum flow rates attainable for the Ar gas were $680 \mathrm{~cm}^{3} \mathrm{~min}^{-1}$ (s.s. float) and $4 \mathrm{~cm}^{3} \mathrm{~min}^{-1}$ (g. float). It should be noted that flash-back arrestors were installed on the two $\mathrm{H}_{2}$ gas lines, again to satisfy safety requirements. Also visible in the top right hand corner of Figure 3.4 is the Eurotherm 020 type temperature controller for the $\mathrm{AlCl}_{3}$ evaporation unit.

As previously indicated, the gaseous $\mathrm{AlCl}_{3}$ reactant was to be provided via the evaporation of $\mathrm{AlCl}_{3}$ powder at a temperature of $\sim 200^{\circ} \mathrm{C}$. $\mathrm{AlCl}_{3}$ powder (anhydrous) of $99.99 \%$ purity was obtained from Aldrich Chemicals Co. Ltd. for this purpose. The $\mathrm{H}_{2}-1$ was to be used as the carrier gas. Figure 3.5 shows a general view of the $\mathrm{AlCl}_{3}$ evaporation unit constructed. It is situated within a fume cupboard for safety reasons. As can be seen from Figure 3.5, the 316 stainless steel gas delivery and mixing pipework systems (6mm O.D. x $0.711 \mathrm{~mm}$ wall thickness) were constructed as an integral part of the evaporation unit. The valves evident on these pipes are Swagelok H series 316 stainless steel valves. The presence of the three blue heat guns visible in Figure 3.5 should be noted; reference will be made to them later in Section 3.3.1. A detailed top view of the evaporation unit is shown in Figure 3.6. As is evident from this figure (in which the lid of the evaporation unit has been removed) the unit itself consists of inner and outer parts, manufactured from 316 stainless steel, separated by $13 \mathrm{~mm}$ thick Fibrefrax ceramic fibre insulation. The lid of the unit is of similar construction. The Ar and $\mathrm{H}_{2}-1$ gas 316 stainless steel delivery pipes visible in Figure 3.6, were connected, respectively, to the $\mathrm{Ar}$ and $\mathrm{H}_{2}-1$ glass tubes on the evaporation vessel. The $\mathrm{Ar}$ and $\mathrm{H}_{2}-1$ glass tubes can be distinguished, respectively, by the general performance (blue) and high performance (red) Rotaflo stopcock valves evident in Figure 3.6. The valves can withstand temperatures up to a maximum of 150 and $200^{\circ} \mathrm{C}$, respectively.

A view inside the $\mathrm{AlCl}_{3}$ evaporation unit is presented in Figure 3.7. The upper part of the glass evaporation vessel, to contain the $\mathrm{AlCl}_{3}$ powder during evaporation, can be seen. Also visible are the glass tubes for carrying the $\mathrm{Ar}$ gas (at the front), the $\mathrm{H}_{2}-1$ gas (at the right hand side) and the $\mathrm{H}_{2}-1 / \mathrm{AlCl}_{3}$ gas mixture (in the centre) and the $\mathrm{Ar} / \mathrm{AlCl}_{3}$ by-pass glass tube (at the rear). The Quickfit plastic caps (with Quickfit silicone rubber rings and P.T.F.E. washers) used to attach these glass tubes to the glass evaporation vessel can also be seen. Silicone fluid (Dow Corning $210 \mathrm{H} / 100 \mathrm{cs}$ ), also visible in this figure, was employed as the heating medium for the glass evaporation vessel, heating of the silicone fluid being achieved by an immersion-type heater controlled by the aforementioned temperature controller visible in the top right-hand corner of Figure 3.5. The silicone fluid was additionally to be used to preheat the carrier, reactant and Ar gases by heating of the stainless steel pipes containing them. The stirrer motor assembly and propellor shown in Figure 3.6 (only the drive shaft of the latter is 
visible) were provided in an attempt to attain uniformity of temperature of the silicone fluid. Also evident in this figure are the heated and insulated $\mathrm{Ar} / \mathrm{AlCl}_{3}$ by-pass glass tube (vertical) and the heated and insulated $\mathrm{H}_{2}-1 / \mathrm{AlCl}_{3}$ glass tube (horizontal) and 316 stainless steel pipe (this pipe later joins the mixed gas delivery pipe), together with the high performance Rotaflo stopcock valves (red) on the glass tubes. Heating of the glass tubes was effected by the spiral application of Electrothermal type $\mathrm{HC} 103$ glass insulated heating cord, obviously carried out before they were insulated. Two types of insulation were employed: an inner $6 \mathrm{~mm}$ thick Fibrefrax ceramic fibre insulation (density $128 \mathrm{~kg} \mathrm{~m}^{-3}$ ), spirally wound between the heating cord, and an outer $13 \mathrm{~mm}$ thick PermaRock Rockwool insulation covering both the heating cord and the inner insulation. The outer surface of the insulated tubes/pipe was protected by $\mathrm{Al}$ foil tape. The heating cord on the $\mathrm{Ar} / \mathrm{AlCl}_{3}$ by-pass and the $\mathrm{H}_{2}-1 / \mathrm{AlCl}_{3}$ glass tubes was connected to an $\mathrm{RS} 0.5 \mathrm{~A}$ variable transformer to give the required temperature of approximately $200^{\circ} \mathrm{C}$ necessary to maintain the $\mathrm{AlCl}_{3}$ reactant in gaseous form.

Figure 3.8 shows the reactor coating chamber furnace (viewed from the inlet end) and associated control equipment. Heating of the chamber was to be effected by six Kanthal Crusilite heating elements. The control equipment consists of three units: a Eurotherm 090 type temperature controller connected to a platinum/platinum-13\% rhodium thermocouple with its junction adjacent to the furnace hot zone, a Eurotherm 024 type driver unit and a Eurotherm 032 type thyristor unit. Also visible in Figure 3.8 is the 316 stainless steel mixed gas delivery pipe ( $6 \mathrm{~mm}$ O.D $\times 0.711 \mathrm{~mm}$ wall thickness) to the reactor coating chamber. The presence of the two blue heat guns adjacent to this pipe should again be noted. This pipe (and the $\mathrm{H}_{2}-1 / \mathrm{AlCl}_{3}$ stainless steel pipe joined to it) was heated and insulated in the same manner as the $\mathrm{Ar} / \mathrm{AlCl}_{3}$ by-pass and $\mathrm{H}_{2}-1 / \mathrm{AlCl}_{3}$ glass tubes. The Electrothermal type $\mathrm{HC} 105$ glass insulated heating cord on the mixed gas delivery pipe was connected to an RS $8 \mathrm{~A}$ variable transformer and a BICC Pyronex temperature controller to maintain the desired temperature of $\sim 200^{\circ} \mathrm{C}$. The rotary pump assembly to be used to initially evacuate the coating chamber prior to the first stage of the coating cycle is also shown in Figure 3.8.

Figure 3.9 is a detailed view of the inlet end of the reactor coating chamber, showing the 316 stainless steel end cap, the heated and insulated mixed gas delivery pipe, the 316 stainless steel pipe connection to the rotary pump and the inlet end water-filled $\mathrm{Cu}$ cooling coils (to protect the O-ring inside the end cap - see later in this section). The inlet end cap also incorporates the 316 stainless steel sheath for the platinum/platinum-13\% rhodium thermocouple to be used to monitor the actual deposition temperature during coating. A schematic diagram of the CVD reactor coating chamber is shown in Figure 3.10. As is evident from this figure, the reactor coating chamber consists, essentially, of an outer recrystallised alumina tube and an inner 316 stainless steel tube, inside which the PM HSS inserts to be coated are to be located, supported in a $76 \mathrm{~mm}$ long 316 stainless steel holder with holes to accommodate up to eight inserts. It should be noted that the reason the former tube was not employed as the reactor coating chamber was that, the tensile stresses in the $\mathrm{Al}_{2} \mathrm{O}_{3}$ coating 
deposited on the alumina tube were liable to cause the tube to fracture. The 316 stainless steel inner tube was employed for two reasons: first to eliminate the aforementioned problem and second to withstand the corrosive by-products of the $\mathrm{Al}_{2} \mathrm{O}_{3}$ deposition reaction [79]. The stainless steel inner tube is located and supported in two 316 stainless steel cones connected, respectively, to the mixed gas delivery pipe at the inlet end and to the 316 stainless steel exhaust gas pipe (12 mm O.D. $x 0.911 \mathrm{~mm}$ wall thickness) at the outlet end of the reactor coating chamber. O-rings incorporated in the end caps (see Figure 3.10) have been used to seal each end of the recrystallised alumina tube (these O-rings were greased using Apeizon vacuum grease, prior to assembly). The actual reactor coating chamber stainless steel inner tube, stainless steel deposition temperature monitoring thermocouple sheath and stainless steel insert holder are shown in Figure 3.11.

Figure 3.12 shows the outlet end of the reactor coating chamber. The exhaust gas pipe connected to the 316 stainless steel outlet end cap was heated and insulated in the same manner as described earlier. The Electrothermal type $\mathrm{HC103}$ glass insulated heating cord on the exhaust gas pipe was connected to an RS 0.5A variable transformer to maintain the desired temperature. Even though all the by-products of the $\mathrm{Al}_{2} \mathrm{O}_{3}$ deposition reaction are gaseous (see the standard reaction in Section 3.2.1), the exhaust gas pipe was heated and insulated to prevent blockage arising from the accumulation of any "unreacted" $\mathrm{AlCl}_{3}$ and to prevent condensation of gaseous $\mathrm{HCl}$ by-product prior to the unheated vertical section of this pipe. As is evident from Figure 3.12 the exhaust gas pipe itself has two outlets; the smaller $(6 \mathrm{~mm}$ O.D. $x 0.711 \mathrm{~mm}$ wall thickness) horizontal outlet (with a Swagelok H series 316 stainless steel valve) was to be used to allow $\mathrm{H}_{2}$ to be burnt off during the heating stage of the coating cycle (see Section 3.3.3), whilst the larger vertical outlet $(12 \mathrm{~mm}$ O.D. x $0.911 \mathrm{~mm}$ wall thickness) is for the by-products of the $\mathrm{Al}_{2} \mathrm{O}_{3}$ deposition reaction. A Swagelok B series 316 stainless steel valve with a stellite stem was fitted on this pipe. Both outlets were situated inside the aforementioned fume cupboard (Figure 3.4) for safety reasons. Finally, Figure 3.13 is a view of the complete laboratory-scale $\mathrm{Al}_{2} \mathrm{O}_{3} \mathrm{CVD}$ reactor constructed, save for the gas cylinders (Figure 3.3).

After construction of the laboratory-scale reactor, the reactor coating chamber, was successfully heated to a temperature of $1000^{\circ} \mathrm{C}$ under a protective/reducing $\mathrm{H}_{2} / \mathrm{Ar}$ atmosphere to establish hot zone location and uniformity. A plot of the hot zone thus established is shown in Figure 3.14. As is evident, at $1000^{\circ} \mathrm{C}$ the temperature variation over the length of the aforementioned insert holder was less than $5^{\circ} \mathrm{C}$. Attention was then directed to establishing whether or not the $\mathrm{AlCl}_{3}$ powder could be successfully evaporated in the evaporation unit. As $\mathrm{AlCl}_{3}$ powder is hygroscopic and toxic, a standard procedure for handling/transferring the $\mathrm{AlCl}_{3}$ powder was devised. An atmosbag (filled with $\mathrm{N}_{2}$ ) was employed to ensure the safe transfer of the $\mathrm{AlCl}_{3}$ powder from the container in which it was supplied to the glass evaporation vessel. The glass evaporation vessel with the $\mathrm{AlCl}_{3}$ inside it (filled with $\mathrm{N}_{2}$ ) was then placed in the evaporation unit and the $\mathrm{N}_{2}$ replaced with Ar. It was subsequently established 
that the $\mathrm{AlCl}_{3}$ powder could be successfully evaporated in the evaporation unit constructed and that the optimum evaporation temperature was $190^{\circ} \mathrm{C}$. Full details of the standard procedure for handling/transferring the $\mathrm{AlCl}_{3}$ powder are given in Appendix 2 .

\subsection{Trial $\mathrm{Al}_{2} \mathrm{O}_{3}$ Coating Runs and Reactor Modifications}

All the trial $\mathrm{Al}_{2} \mathrm{O}_{3}$ coating runs carried out in the laboratory-scale $\mathrm{Al}_{2} \mathrm{O}_{3}$ CVD reactor and the results obtained from them are summarised in Table 3.2. The purpose of these runs was two fold: first to identify and solve any problems with the laboratory-scale reactor, and second to eventually determine deposition conditions under which a preliminary $\mathrm{Al}_{2} \mathrm{O}_{3}$ coating could be chemically vapour deposited on the PM HSS inserts.

With reference to the literature survey presented in Chapter 2, it was decided that throughout the present work the following deposition parameters would be held constant at the values stated: deposition temperature $1050^{\circ} \mathrm{C}$ and total flow rate of gaseous reactants $400 \mathrm{~cm}^{3} \mathrm{~min}^{-1}$. The coating cycle, planned for a deposition time of one hour, which was intended to be used in the present work is detailed below:

1. Evacuate reactor coating chamber using rotary pump (see Figure 3.8 ) to a starting vacuum of $8 \times 10^{-2}$ atm.

2. Heat reactor coating chamber (and the uncoated/precoated HSS inserts) to the deposition temperature under a reducing $\mathrm{H}_{2}$ atmosphere and equalise at the deposition temperature for one hour.

3. During the latter 30 minutes of stage 2 , heat the evaporation unit to the evaporation temperature.

4. Chemically vapour deposit the $\mathrm{Al}_{2} \mathrm{O}_{3}$ coatings on the uncoated/precoated HSS inserts using the standard reaction (as shown in Section 3.2), employing $\mathrm{Ar}$, if necessary.

5. Cool the reactor coating chamber and the coated inserts to room temperature, initially under a reducing $\mathrm{H}_{2}$ atmosphere, down to $160^{\circ} \mathrm{C}$, and finally under a protective $\mathrm{Ar}$ atmosphere.

\subsubsection{Initial $\mathrm{Al}_{2} \underline{\mathrm{O}}_{3}$ coating runs}

The following types of PM BT42 grade HSS inserts were employed in the initial coating runs: uncoated, TiN precoated, TiC precoated and $\mathrm{Ti}(\mathrm{C}, \mathrm{N})$ precoated. Prior to $\mathrm{Al}_{2} \mathrm{O}_{3}$ deposition, these inserts were ultrasonically cleaned in carbon tetrachloride $\left(\mathrm{CCl}_{4}\right)$. Two of each type of insert were then placed in the insert holder, in the following order from right to left (as shown 
in Figure 3.11): uncoated, $\mathrm{Ti}(\mathrm{C}, \mathrm{N})$ precoated, TiN precoated and $\mathrm{TiC}$ precoated. The loaded insert holder was then positioned in the centre of the hot zone of the reactor coating chamber, with the uncoated inserts towards the inlet end.

During the first six coating runs, only one major type of fault with the laboratory-scale reactor was identified, namely the existence of isolated cooler (i.e. less than $200^{\circ} \mathrm{C}$ ) regions of the $\mathrm{AlCl}_{3}$-carrying tubes/pipes, which led to $\mathrm{AlCl}_{3}$ solidification and hence tube/pipe blockage. These blockages were progressively eliminated by the strategic placement of the five blue heat guns referred to earlier in Section 3.2, as described below.

During the first coating run, $\mathrm{AlCl}_{3}$ solidification caused a blockage in the $\mathrm{H}_{2}-1 / \mathrm{AlCl}_{3}$ glass tube after a deposition time of less than 5 minutes. It was thought that this blockage was due to the $\mathrm{AlCl}_{3}$ evaporated during the heating-up of the evaporation unit (stage 3 of the coating cycle) prior to the start of coating deposition, accumulating in the glass evaporation vessel and a surge of $\mathrm{AlCl}_{3}$ occurring when the $\mathrm{H}_{2}-1 / \mathrm{AlCl}_{3}$ red valve (shown in Figure 3.6) was opened. It was therefore decided that, for the next and subsequent coating runs this accumulation of $\mathrm{AlCl}_{3}$ would be avoided by by-passing it through the $\mathrm{Ar} / \mathrm{AlCl}_{3}$ by-pass tube. However, when this was attempted, during the second coating run, the $\mathrm{Ar} / \mathrm{AlCl}$ by-pass tube became blocked during the heating-up of the evaporation unit and the coating run had to be abandoned without any deposition taking place. With reference to Figure 3.7, it was concluded that blockage of both the $\mathrm{H}_{2}-1 / \mathrm{AlCl}_{3}$ glass tube and the $\mathrm{Ar} / \mathrm{AlCl}_{3}$ by-pass glass tube was additionally due to the non-directly heated gap between the bottom of the heating cord on the glass tubes and the top of the silicone fluid in the evaporation unit. This non-directly heated gap was eliminated by the placement of a blue RS variable temperature heat gun (No.1) on the side of the evaporation unit (see Figure 3.5) with its nozzle protruding inside the unit (the nozzle of this heat gun is visible on the left hand side in Figure 3.7).

The placement of this heat gun appeared to have solved the aforementioned problems since there were no blockages in either the $\mathrm{H}_{2}-1 / \mathrm{AlCl}_{3}$ glass tube or the $\mathrm{Ar} / \mathrm{AlCl}_{3}$ by-pass glass tube during the third coating run. However, unfortunately, $\mathrm{AlCl}_{3}$ solidification caused a blockage in the connection (arrowed in Figure 3.6) between the $\mathrm{H}_{2}-1 / \mathrm{AlCl}_{3}$ glass tube and the stainless steel pipe after a deposition time of less than 5 minutes. To eliminate this blockage, a second heat gun (No.2) was placed near to this connection, with its nozzle being directed through the side of a 316 stainless steel box fitted around the connection (see Figure 3.5). The purpose of this box was to confine the heat from the heat gun. The placement of this heat gun and the fitting of the stainless steel box appeared to have solved the aforementioned problem, because during the fourth coating run no obstruction occurred in this location. Unfortunately, however, $\mathrm{AlCl}_{3}$ solidification did cause a blockage of the $\mathrm{H}_{2}-1 / \mathrm{AlCl}_{3}$ valve on the $\mathrm{H}_{2}-1 / \mathrm{AlCl}_{3}$ stainless steel pipe (valve number 6 - Figure 3.6) after a deposition time of less than 10 minutes. To eliminate this blockage a third heat gun (No.3) was located near to the $\mathrm{H}_{2}-1 / \mathrm{AlCl}_{3}$ valve, an extension to its nozzle terminating on the exposed side of the valve (see Figure 3.5). The 
placement of this heat gun appeared to have solved the aforementioned problem, since during the subsequent coating run no blockage of the $\mathrm{H}_{2}-1 / \mathrm{AlCl}_{3}$ valve on the $\mathrm{H}_{2}-1 / \mathrm{AlCl}_{3}$ stainless steel pipe occurred. However, $\mathrm{AlCl}_{3}$ solidification did cause a blockage of the stainless steel valve (arrowed in Figure 3.8) on the mixed gas delivery stainless steel pipe after a deposition time of 10 minutes. To eliminate this problem, a further heat gun (No.4) was placed adjacent to this valve, the nozzle of which terminated on the exposed side of the valve. During the sixth coating run, whilst there was no blockage of the stainless steel valve on the mixed gas delivery stainless steel pipe, somewhat surprisingly, $\mathrm{AlCl}_{3}$ solidification caused a blockage in the connection between the mixed gas delivery pipe and the inlet end cap (see Figure 3.10) after a deposition time of 35 minutes. To eliminate this blockage, a fifth heat gun (No.5) was fitted underneath the inlet end cap (see Figure 3.9) with its nozzle terminating on this connection. With the placement of this last heat gun, all the blockage problems with the $\mathrm{AlCl}_{3}$ carrying tubes/pipes appeared to have been solved, since the seventh coating run was successfully carried out for the planned total deposition time of one hour. It should be noted that the settings on the five heat guns referred to above were adjusted according to the nature of the region and material(s) being heated.

The initial seven coating runs were not only carried out to identify and solve any problems with the laboratory-scale reactor but also to begin to determine deposition conditions under which a preliminary $\mathrm{Al}_{2} \mathrm{O}_{3}$ coating could be chemically vapour deposited on the uncoated/precoated PM HSS inserts. With reference to the literature survey presented in Chapter 2, the first coating run was carried out at a $\mathrm{CO}_{2}$ flow rate of $200 \mathrm{~cm}^{3} \mathrm{~min}^{-1}$ and a total $\mathrm{H}_{2}\left(\mathrm{H}_{2}-1+\mathrm{H}_{2}-2\right)$ flow rate of $200 \mathrm{~cm}^{3} \mathrm{~min}^{-1}$, i.e. a $\mathrm{CO}_{2} / \mathrm{H}_{2}$ mole ratio of 1 [27, 36, 37, 42, 43]. The $\mathrm{H}_{2}-1 / \mathrm{AlCl}_{3}$ flow rate of $150 \mathrm{~cm}^{3} \mathrm{~min}^{-1}$ used was chosen arbitrarily. As can be seen from Table 3.2, the results obtained from run 1 were disastrous. External visual examination revealed that not only had no $\mathrm{Al}_{2} \mathrm{O}_{3}$ coating been deposited on the uncoated/precoated inserts but also that all the Ti-base precoatings on the PM HSS inserts were either completely removed or damaged through their thickness. This was thought to be due to the aforementioned surge of $\mathrm{AlCl}_{3}$ reactant at the start of coating deposition. Consequently, as previously described, in order to avoid this, it was therefore decided that for the next and subsequent coating runs the $\mathrm{AlCl}_{3}$ would be directed through the $\mathrm{Ar} / \mathrm{AlCl}_{3}$ by-pass tube, during the heating-up of the evaporation unit. The second coating run was then carried out under the same deposition conditions as the first. Unfortunately, as mentioned earlier, this run had to be abandoned due to the blockage in the $\mathrm{Ar} / \mathrm{AlCl}_{3}$ by-pass tube, prior to the start of deposition, caused by $\mathrm{AlCl}_{3}$ solidification. It was decided that the third coating run would be carried out using a $\mathrm{CO}_{2} / \mathrm{H}_{2}$ mole ratio of 1 , as before, but with a lower $\mathrm{H}_{2}-1 / \mathrm{AlCl}_{3}$ flow rate of $100 \mathrm{~cm}^{3} \mathrm{~min}^{-1}$, to mitigate against excess $\mathrm{AlCl}_{3}$ still being produced. Again, external visual examination of the uncoated/precoated inserts after this coating run revealed no $\mathrm{Al}_{2} \mathrm{O}_{3}$ coating and the Ti-base precoatings on the PM HSS inserts were again damaged through their thickness, by oxidation it was thought. Therefore, the next coating run (the fourth) was carried out at a lower $\mathrm{CO}_{2}$ flow rate of $100 \mathrm{~cm}^{3} \mathrm{~min}^{-1}$ and a total $\mathrm{H}_{2}$ flow rate of $200 \mathrm{~cm}^{3} \mathrm{~min}^{-1}$, i.e. a $\mathrm{CO}_{2} / \mathrm{H}_{2}$ mole ratio 
of $1 / 2$, with the same $\mathrm{H}_{2}-1 / \mathrm{AlCl}_{3}$ flow rate of $100 \mathrm{~cm}^{3} \mathrm{~min}^{-1}$ as used in the second run. To maintain the total gas flow rate at $400 \mathrm{~cm}^{3} \mathrm{~min}^{-1}$, Ar gas was also added to the reactant gaseous mixture. As can be seen from Table 3.2, this decrease in $\mathrm{CO}_{2} / \mathrm{H}_{2}$ mole ratio appeared to have caused an improvement in the sense that there was some evidence of intact $\mathrm{Ti}$-base precoatings on the PM HSS inserts. No $\mathrm{Al}_{2} \mathrm{O}_{3}$ coating was, however, obtained.

The fifth coating run was, therefore, carried out with a significantly lower $\mathrm{CO}_{2}$ flow rate of $25 \mathrm{~cm}^{3} \mathrm{~min}^{-1}$ and a total $\mathrm{H}_{2}$ flow rate of $200 \mathrm{~cm}^{3} \mathrm{~min}^{-1}$, i.e. a $\mathrm{CO}_{2} / \mathrm{H}_{2}$ mole ratio of $1 / 8$ and with a $\mathrm{H}_{2}-1 / \mathrm{AlCl}_{3}$ flow rate of $100 \mathrm{~cm}^{3} \mathrm{~min}^{-1}$ as in the previous two coating runs. The results obtained from this coating run were encouraging. Using the ball-cratering technique [80], it was visually established that, the Ti-base precoatings were present on the PM HSS inserts, although the TiC precoating exhibited some damage. Further, energy-dispersive X-ray analysis (EDX) on an SEM revealed the presence of some $\mathrm{Al}$ on the surface of the uncoated/precoated PM HSS inserts (it should be noted that EDX cannot detect elements of atomic number $<11$ ), but $\mathrm{Si}, \mathrm{Fe}$ and $\mathrm{Cr}$ contamination were also detected. The source of the Si contamination was thought to be the Apeizon vacuum grease applied to the end cap O-rings (see Section 3.2), whilst the source of the $\mathrm{Fe}$ and $\mathrm{Cr}$ contamination was thought to be $\mathrm{Cl}$ reaction [81] with the 316 stainless steel reactor coating chamber inner tube, due to an excess of $\mathrm{AlCl}_{3}$ reactant. The sixth coating run was, therefore, carried out at a $\mathrm{CO}_{2} / \mathrm{H}_{2}$ mole ratio of $1 / 8$, as before, but with a significantly lower $\mathrm{H}_{2}-1 / \mathrm{AlCl}_{3}$ flow rate of $25 \mathrm{~cm}^{3} \mathrm{~min}^{-1}$, having first removed all the vacuum grease from the O-rings. EDX analysis of the uncoated/precoated PM HSS inserts on an SEM after this coating run revealed the presence of significantly more $\mathrm{Al}$ on their surfaces and, apparently, the elimination of $\mathrm{Si}$ contamination, the virtual elimination of $\mathrm{Fe}$ contamination and some reduction of $\mathrm{Cr}$ contamination. Further, ball-cratering revealed that all the Ti-base precoatings were again present although the $\mathrm{TiC}$ precoating exhibited some signs of damage. SEM examination of the surface of the $\mathrm{Al}$-containing layer on each insert revealed that it was polycrystalline in nature. In an attempt to completely eliminate $\mathrm{Cr}$ contamination, the next coating run (the seventh) was carried out at the same $\mathrm{CO}_{2} / \mathrm{H}_{2}$ mole ratio as before, but using an even lower $\mathrm{H}_{2}-1 / \mathrm{AlCl}_{3}$ flow rate of 10 $\mathrm{cm}^{3} \mathrm{~min}^{-1}$. As can be seen from Table 3.2, the results obtained were disastrous. Not only were the Ti-base precoatings either partially or completely removed from the PM HSS inserts, extensive flaking was also evident on the inserts and on the 316 stainless steel reactor coating chamber inner tube and insert holder. A leak was suspected.

\subsubsection{Aluminide coating of 316 stainless steel reactor coating chamber parts}

As an alternative method of reducing $\mathrm{Cr}$ contamination, the 316 stainless steel reactor coating chamber inner tube and insert holder were given an aluminide coating by Diffusion Alloys Limited, Hatfield. The eighth coating run was then carried out under the same deposition conditions as the sixth run. As in the initial coating runs, uncoated, Ti(C,N) precoated, TiN 
precoated and TiC precoated PM BT42 grade HSS inserts were employed. Ball-cratering results were encouraging; not only were all the Ti-base precoatings established to be present on the PM HSS inserts, EDX analysis on an SEM revealed the presence of Al on the surface of all the inserts although $\mathrm{Cr}$ was also detected. The best results (maximum $\mathrm{Al}$ and minimum $\mathrm{Cr}$ ) were obtained on the $\mathrm{Ti}(\mathrm{C}, \mathrm{N})$ precoated HSS inserts. It is relevant to note at this point that the ball-cratering technique also provides a reasonably, accurate, convenient "non-destructive" method of determining coating thickness (experimental details on the application of this technique are given in Chapter 4). The ball-cratering technique was used to determine the thickness of the Al-containing coating layer; a value of $2.75 \mu \mathrm{m}$ being obtained for the latter inserts.

As a consequence of the above, the ninth coating run was carried out under the same deposition conditions as the eighth, but with eight $\mathrm{Ti}(\mathrm{C}, \mathrm{N})$ precoated inserts of coating thickness $9 \mu \mathrm{m}$ (remaining from previous work [76], deposited using an $\mathrm{N}_{2} / \mathrm{CH}_{4}$ mole ratio of 8:1) placed in the insert holder. Ball-cratering of the inserts after this coating run revealed the presence of a distinct coating layer on top of the Ti-base precoatings, the thickness of this distinct coating layer on the $\mathrm{Ti}(\mathrm{C}, \mathrm{N})$ precoated inserts located towards the inlet end of the reactor coating chamber being established to be between 4 and $5 \mu \mathrm{m}$. It was decided to identify the structure of the distinct coating layer on the rake face of these inserts using $\mathrm{X}$-ray diffraction (experimental details on the application of this technique are given in Chapter 4). From the $\mathrm{X}$-ray diffraction results obtained, shown in Figure 3.15, it was established that not only was this coating $\mathrm{Al}_{2} \mathrm{O}_{3}$ but that it was, in fact, the $\alpha$ type of $\mathrm{Al}_{2} \mathrm{O}_{3}$ as desired. As is also evident from Figure 3.15, the relative intensities for the $\mathrm{Al}_{2} \mathrm{O}_{3}$ coating correspond closely to those quoted for $\alpha-\mathrm{Al}_{2} \mathrm{O}_{3}$ in the ASTM powder diffraction file (card No. 10-173 [82]). Finally electrical conductivity tests revealed the $\alpha-\mathrm{Al}_{2} \mathrm{O}_{3}$ coating to be an electrical (and hence thermal) insulator. Although these results were encouraging, the PM HSS substrate had yet to be subjected to the obligatory post-coating heat treatment and there was found to be a significant difference in the thickness of the $\mathrm{Al}_{2} \mathrm{O}_{3}$ coatings deposited on the precoated inserts located towards the inlet end of the reactor coating chamber (4-5 $\mu \mathrm{m})$ and those located towards the outlet end of the reactor coating chamber $(2-2.5 \mu \mathrm{m})$. It was thought that the latter might be due to unwanted reaction of the reactant gases with the aluminised 316 stainless steel reactor coating chamber inner tube.

\subsubsection{Replacement of aluminised 316 stainless steel reactor coating chamber parts with Inconel 600}

In an attempt to solve the above problem once and for all, the existing aluminised 316 stainless steel reactor coating chamber inner tube and insert holder (and the 316 stainless steel thermocouple sheath) were replaced by new ones made from Inconel 600 . In addition, since the best results from the previous runs had been obtained on the Ti(C,N) precoated PM HSS 
inserts, a batch of 50 PM BT42 grade HSS inserts coated with Ti(C,N) (using a $\mathrm{N}_{2} / \mathrm{CH}_{4}$ mole ratio of $6: 1$ ) by CVD were specially produced for the next and subsequent coating runs by Edgar Allen Tools, Sheffield. The thickness of these $\mathrm{Ti}(\mathrm{C}, \mathrm{N})$ precoatings were within the range $2.0 \pm 0.5 \mu \mathrm{m}$.

It was also decided to begin to determine the amount of $\mathrm{AlCl}_{3}$ used during the coating runs, since a deposition time of one hour had now been achieved, an $\mathrm{Al}_{2} \mathrm{O}_{3}$ coating procedure had been established and encouraging results were beginning to be obtained. This procedure is detailed in Appendix 3. The amount of $\mathrm{AlCl}_{3}$ used during each coating run was to be determined by weighing before and after the run and then subtracting the amount of $\mathrm{AlCl}_{3}$ by-passed during the heating-up of the evaporation unit, prior to the start of coating deposition. In order to determine the amount of $\mathrm{AlCl}_{3}$ by-passed, special runs known as $\mathrm{AlCl}_{3}$ by-pass run were carried out, these are outlined below and detailed in Appendix 4.

The $\mathrm{AlCl}_{3}$ powder was placed in the glass evaporation vessel using the $\mathrm{AlCl}_{3}$ powder handling/transferring procedure presented in Section 3.2.2. The glass evaporation vessel with the $\mathrm{AlCl}_{3}$ inside it (filled with $\mathrm{N}_{2}$ ) was then placed in the evaporation unit and the $\mathrm{N}_{2}$ replaced with $\mathrm{H}_{2}$. The vessel (and its contents) were then removed from the evaporation unit, weighed and placed back in the unit. Finally the $\mathrm{H}_{2}$ inside the evaporation vessel was replaced by Ar. The $\mathrm{AlCl}_{3}$ powder was then heated to the evaporation temperature in the evaporation unit and during this heating-up the evaporated $\mathrm{AlCl}_{3}$ was by-passed through the $\mathrm{Ar} / \mathrm{AlCl}_{3}$ by-pass tube for the same period of time as allocated prior to the start of coating deposition. The evaporation unit was then allowed to cool to room temperature and the glass evaporation vessel back-filled with Ar. The Ar was then replaced by $\mathrm{H}_{2}$. The vessel (and its contents) were then removed from the evaporation unit, weighed and placed back in the unit. The weight of the $\mathrm{AlCl}_{3}$ by-passed was then determined by subtracting the weight of $\mathrm{AlCl}_{3}$ determined before and after the by-pass run. Three $\mathrm{AlCl}_{3}$ by-pass runs were carried out and an average value of $4.7 \mathrm{~g}$ of $\mathrm{AlCl}_{3}$ was established. It was noted that, for the latter two coating runs (the eighth and the ninth), between 30 and $35 \mathrm{~g}$ of the $\mathrm{AlCl}_{3}$ powder had been placed in the glass evaporation vessel. It was decided to use the same amount for the next and subsequent coating runs.

As can be seen from Table 3.2, the tenth coating run was then carried out under the same deposition conditions as the ninth run (i.e. at a $\mathrm{CO}_{2} / \mathrm{H}_{2}$ mole ratio of $1 / 8$ and with a $\mathrm{H}_{2}-1 / \mathrm{AlCl}_{3}$ flow rate of $25 \mathrm{~cm}^{3} \mathrm{~min}^{-1}$ ) using eight $\mathrm{Ti}(\mathrm{C}, \mathrm{N})$ precoated PM HSS inserts from the specially prepared batch. One of the precoated inserts was then examined by X-ray diffraction and from the results obtained it was revealed that the insert had been successfully coated with $\alpha-\mathrm{Al}_{2} \mathrm{O}_{3}$. The thickness of the $\mathrm{Al}_{2} \mathrm{O}_{3}$ coatings deposited on the inserts located towards the inlet end of the reactor coating chamber $(3.59 \mu \mathrm{m})$ and those located towards the outlet end of the reactor coating chamber $(1.93 \mu \mathrm{m})$ was found to be much more uniform. It therefore appeared that the new Inconel 600 parts had achieved the desired effect. The weight of $\mathrm{AlCl}_{3}$ used during this coating run was $6.8 \mathrm{~g}$. 


\subsubsection{Heat treatment of as-coated inserts}

Since a more a uniform $\mathrm{Al}_{2} \mathrm{O}_{3}$ coating thickness had been obtained, it was decided to heat treat some of the as-coated PM BT42 grade HSS inserts to ascertain if the $\mathrm{Al}_{2} \mathrm{O}_{3}$ coating could be retained during the obligatory post-coating HSS substrate heat treatment. The four as-coated PM HSS inserts from the right-hand side of the insert holder were selected. Heat treatment of these as-coated inserts (hereafter as-coated inserts will be identified by the acronym $a c$ ) was carried out in-house using the $\mathrm{MJ}$ Engineering type VF 1515 vacuum heat treatment furnace with over pressure $\mathrm{N}_{2}$ gas quenching facility shown in Figure 3.16. The heat treatment procedure employed is detailed below:

1. Preheat at $850^{\circ} \mathrm{C}$ for 10 minutes.

2. Second preheat at $1050^{\circ} \mathrm{C}$ for 10 minutes.

3. Austenitise at $1200^{\circ} \mathrm{C}$ for 7 minutes.

4. Quench to $50^{\circ} \mathrm{C}$ within 25 minutes.

5. Double temper $(2 \times 1.5$ hours $)$ at $550^{\circ} \mathrm{C}$, quenching to $50^{\circ} \mathrm{C}$ after the first temper and to room temperature after the second.

Following heat treatment the HSS substrate hardnesses were determined from Vickers hardness tests preformed on the area of HSS substrate previously exposed by ball-cratering. The substrate hardnesses were found to be within the range $900 \pm 20 \mathrm{HV} 30$. In order that inserts at this stage may be discriminated from the $a c$ inserts previously defined, they will be referred to as "heat treated, coated" inserts and, hereafter such inserts will be identified by the acronym, $h c$.

Although, on the two hc PM HSS inserts which had been located towards the outlet end of the reactor coating chamber during coating deposition, subsequent visual examination revealed evidence of partial detachment of the $\alpha-\mathrm{Al}_{2} \mathrm{O}_{3}$ coating, on the remaining two $h c$ PM HSS inserts (which had been located towards the inlet end of the reactor coating chamber during coating deposition), the $\alpha-\mathrm{Al}_{2} \mathrm{O}_{3}$ coating appeared to have remained intact. Photograph showing external appearances of the $a c$ and $h c$ inserts from the tenth coating run is presented in Figure 3.17. On the basis of these and previous characterisation results, it was concluded that the desired preliminary $\alpha-\mathrm{Al}_{2} \mathrm{O}_{3}$ coating had been obtained. It was therefore decided to carry out a detailed characterisation of this preliminary CVD $\mathrm{Al}_{2} \mathrm{O}_{3}$ coating on the PM BT42 grade HSS inserts, both before and after the obligatory HSS substrate heat treatment, in order 
to determine whether this heat treatment had any effect on the characteristics of the $\mathrm{Al}_{2} \mathrm{O}_{3}$ coating, in addition to its desired effect on the HSS substrate. This work is presented in Chapter 4. 


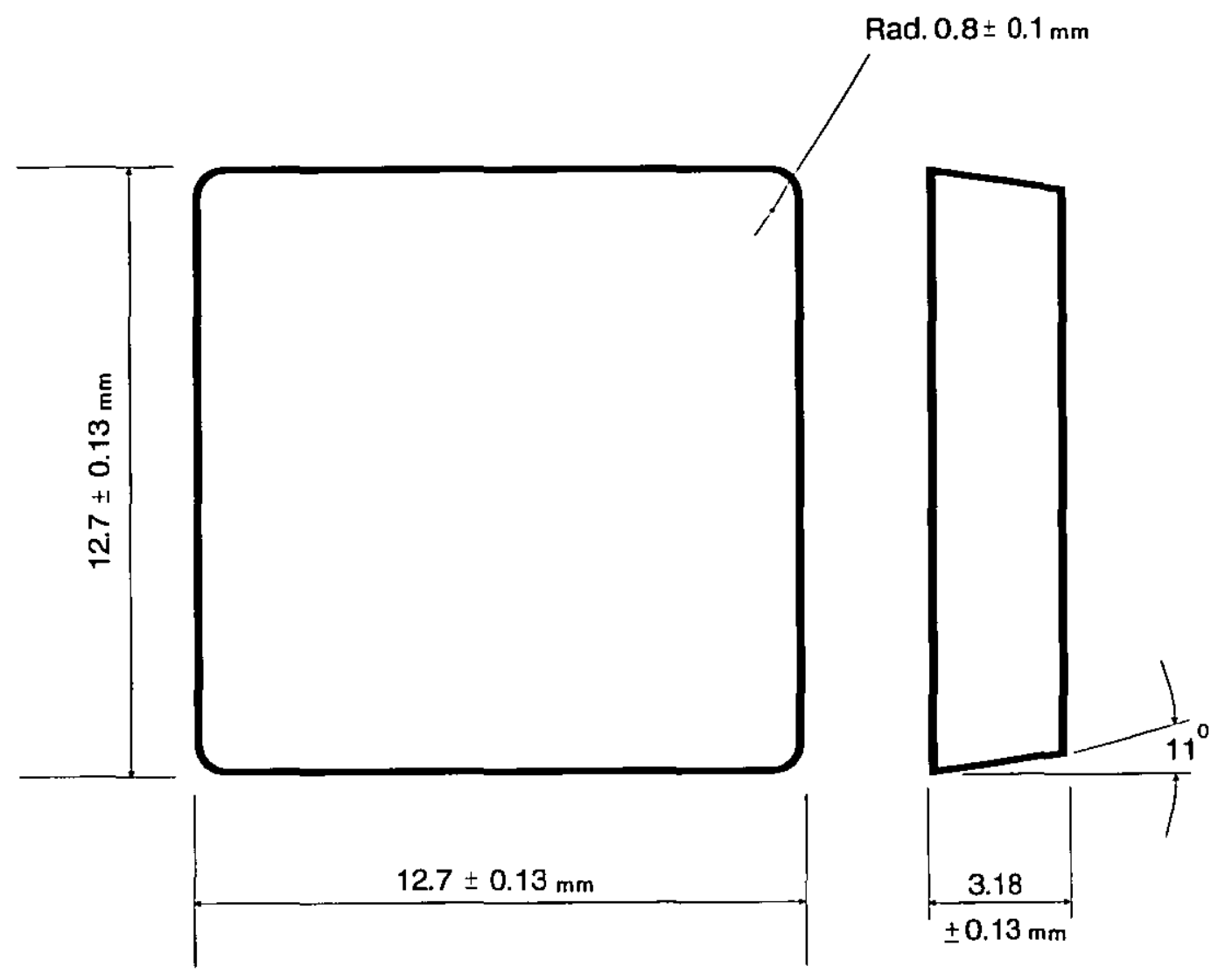

Figure 3.1 Dimensions of SPUN 120308 inserts [74]. 


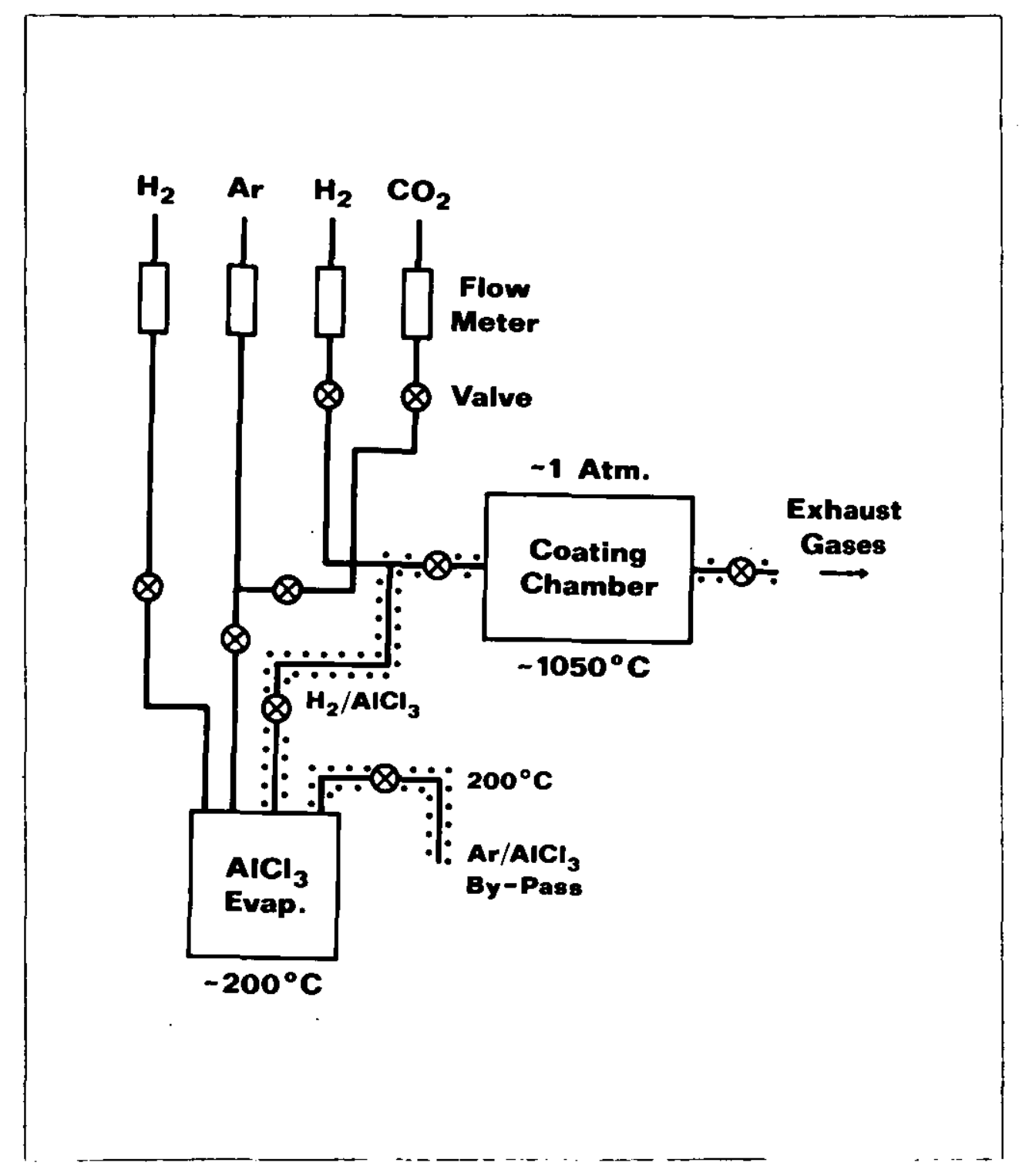

Figure 3.2 Schematic diagram showing fundamental design of laboratory-scale $\mathrm{Al}_{2} \mathrm{O}_{3} \mathrm{CVD}$ reactor 


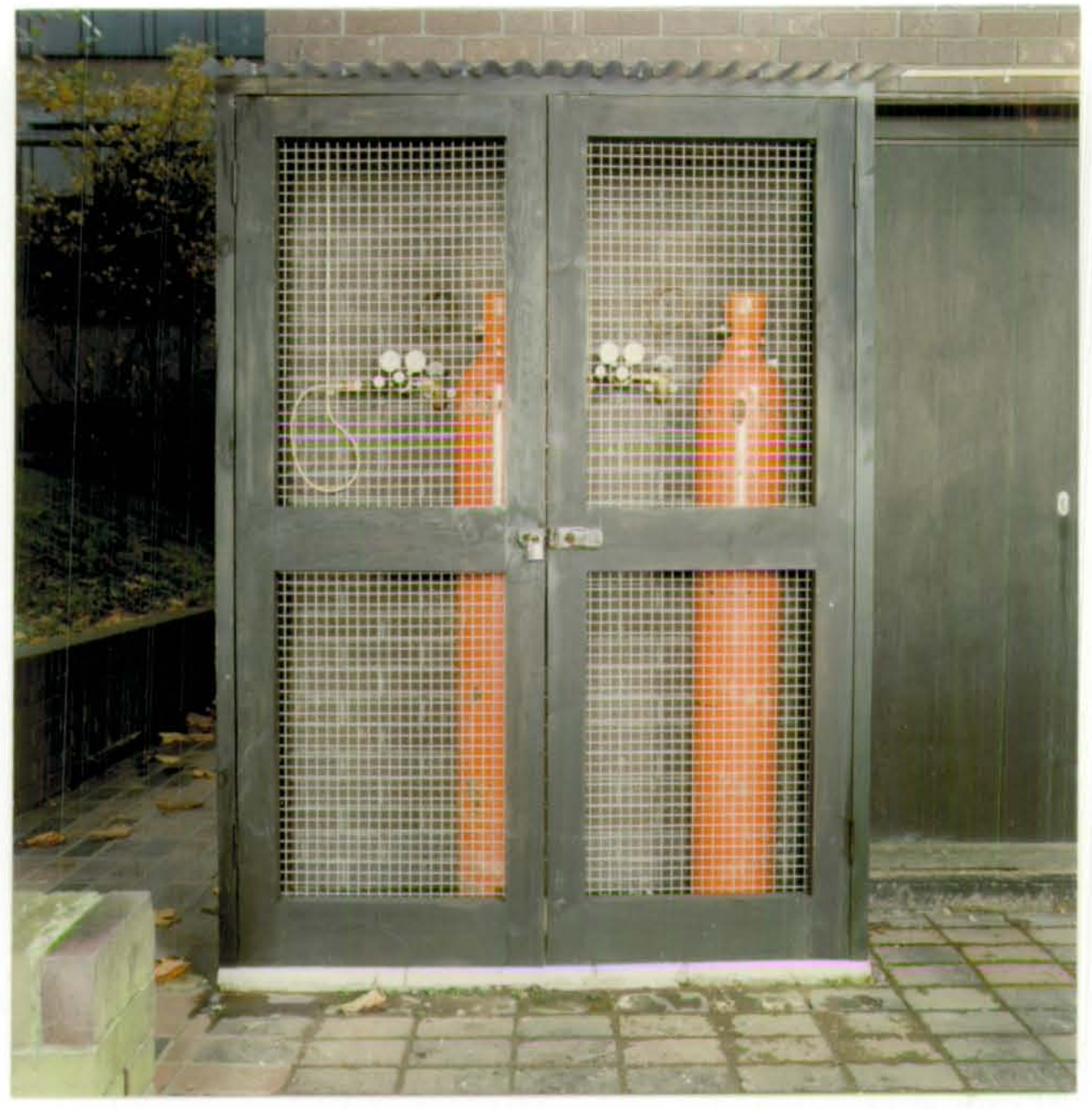

Figure $3.3 \quad \mathrm{H}_{2}$ gas supply

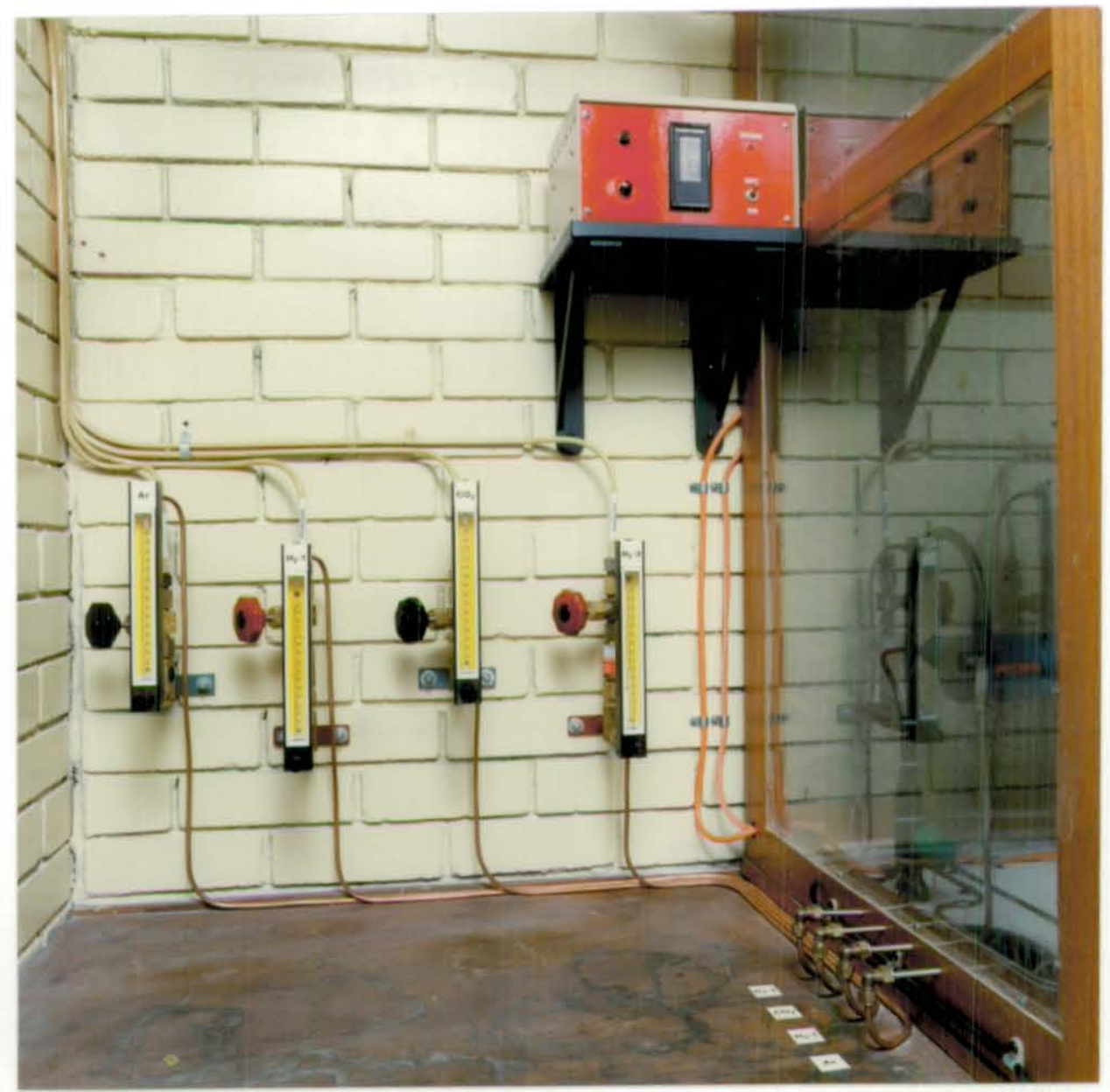

Figure 3.4 Flowmeters for gases 


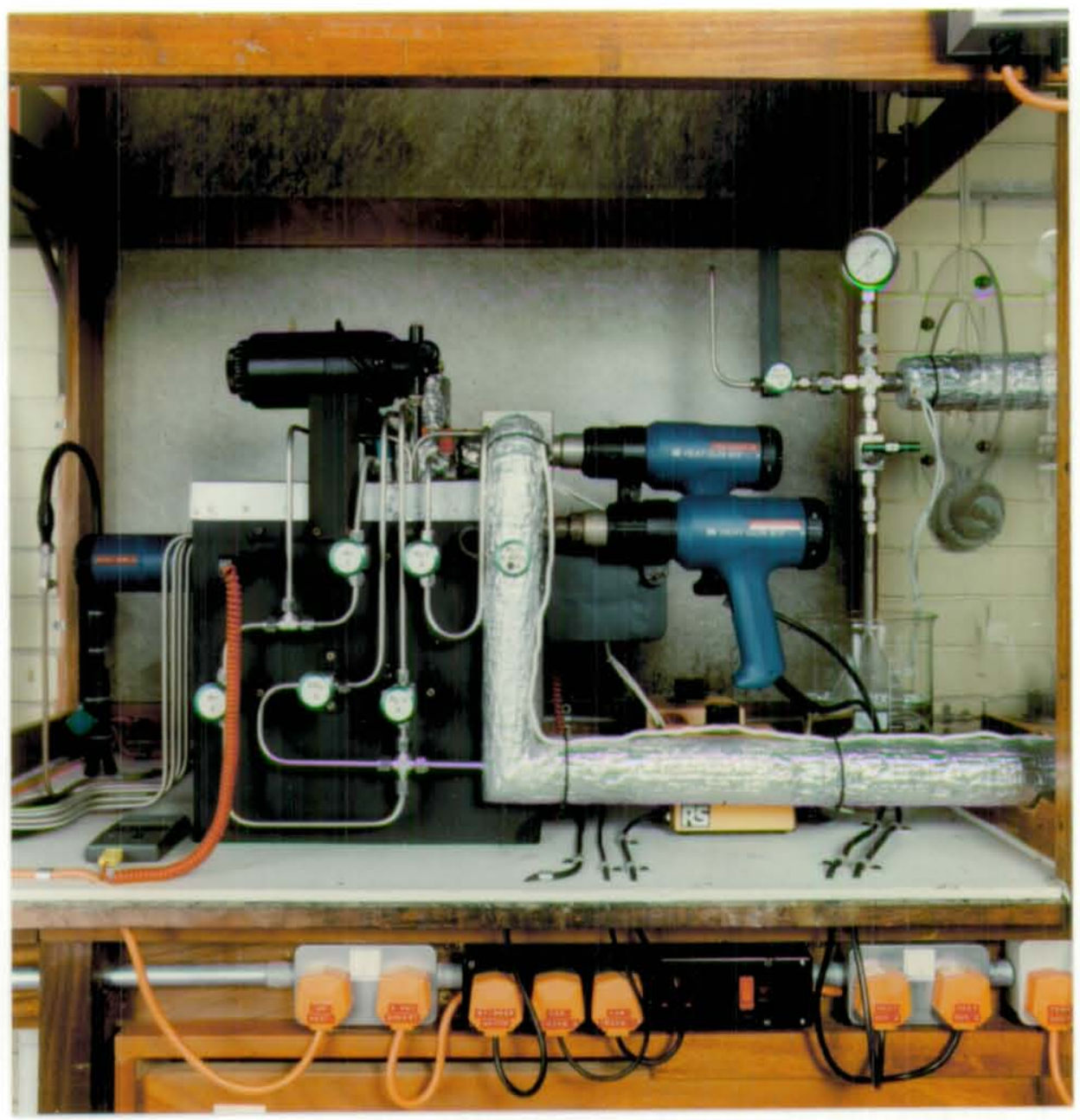

Figure $3.5 \quad \mathrm{AlCl}_{3}$ evaporation unit - general view

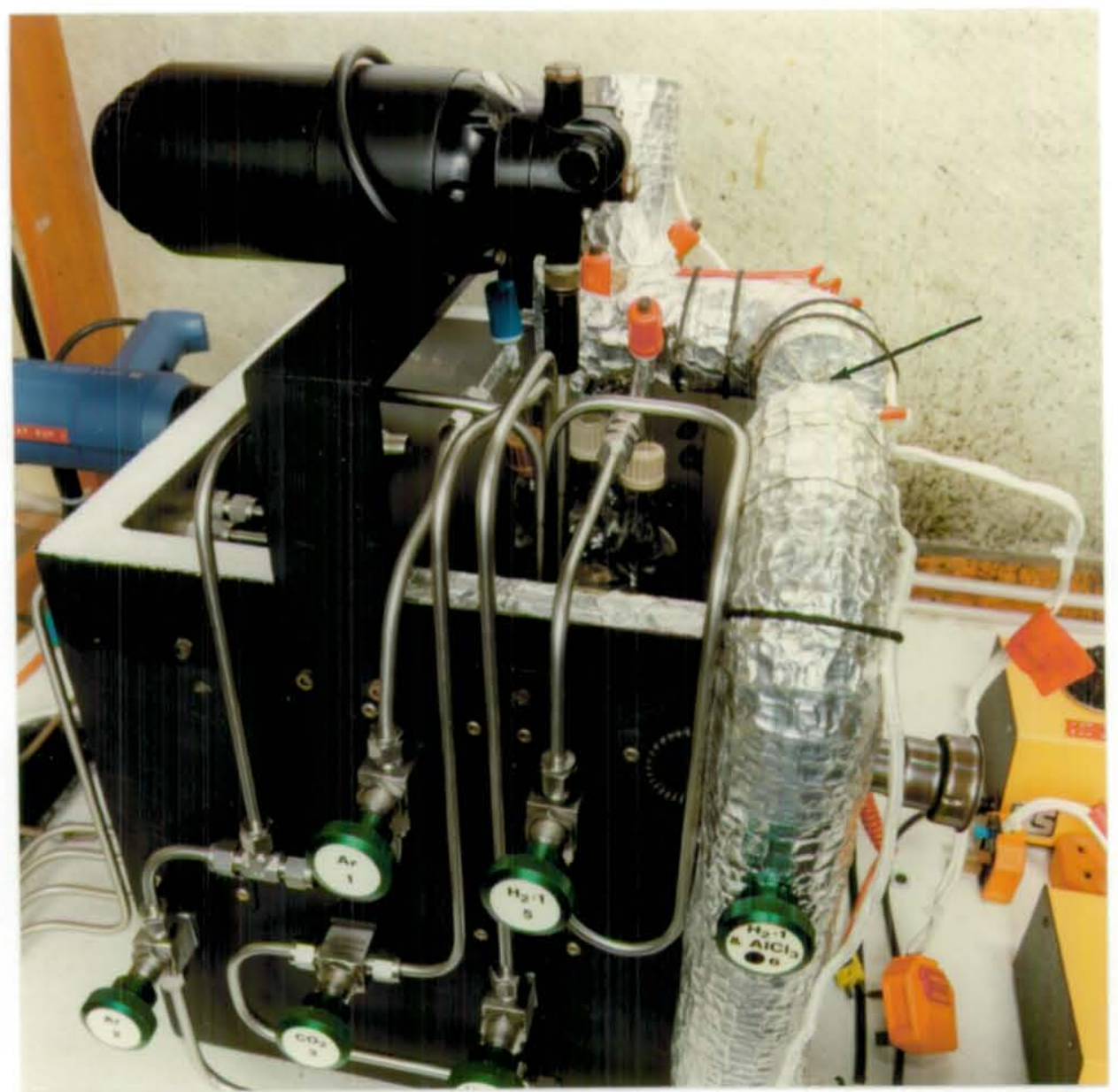

Figure $3.6 \quad \mathrm{AlCl}_{3}$ evaporation unit - detailed top view 


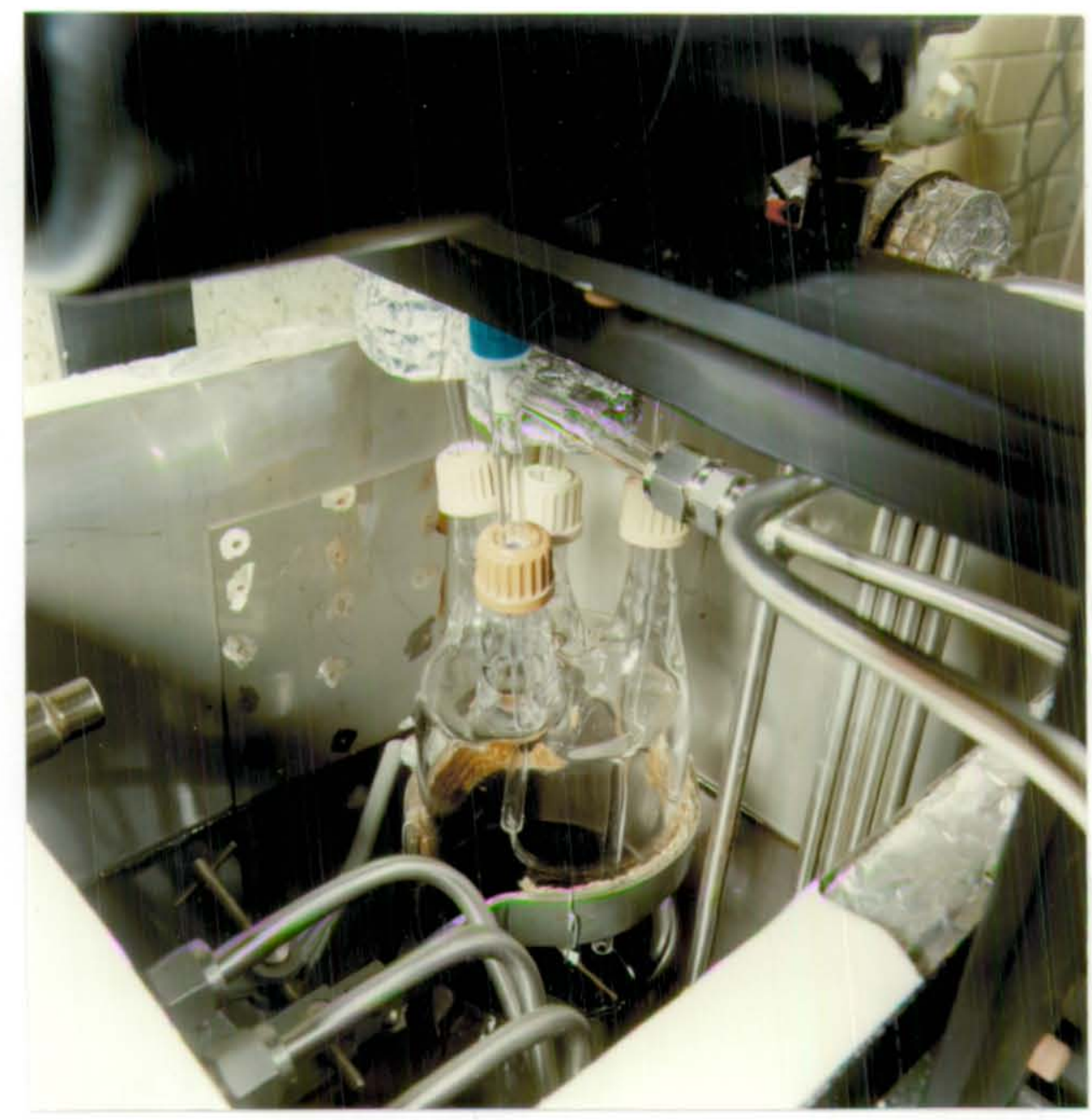

Figure 3.7 View inside $\mathrm{AlCl}_{3}$ evaporation unit

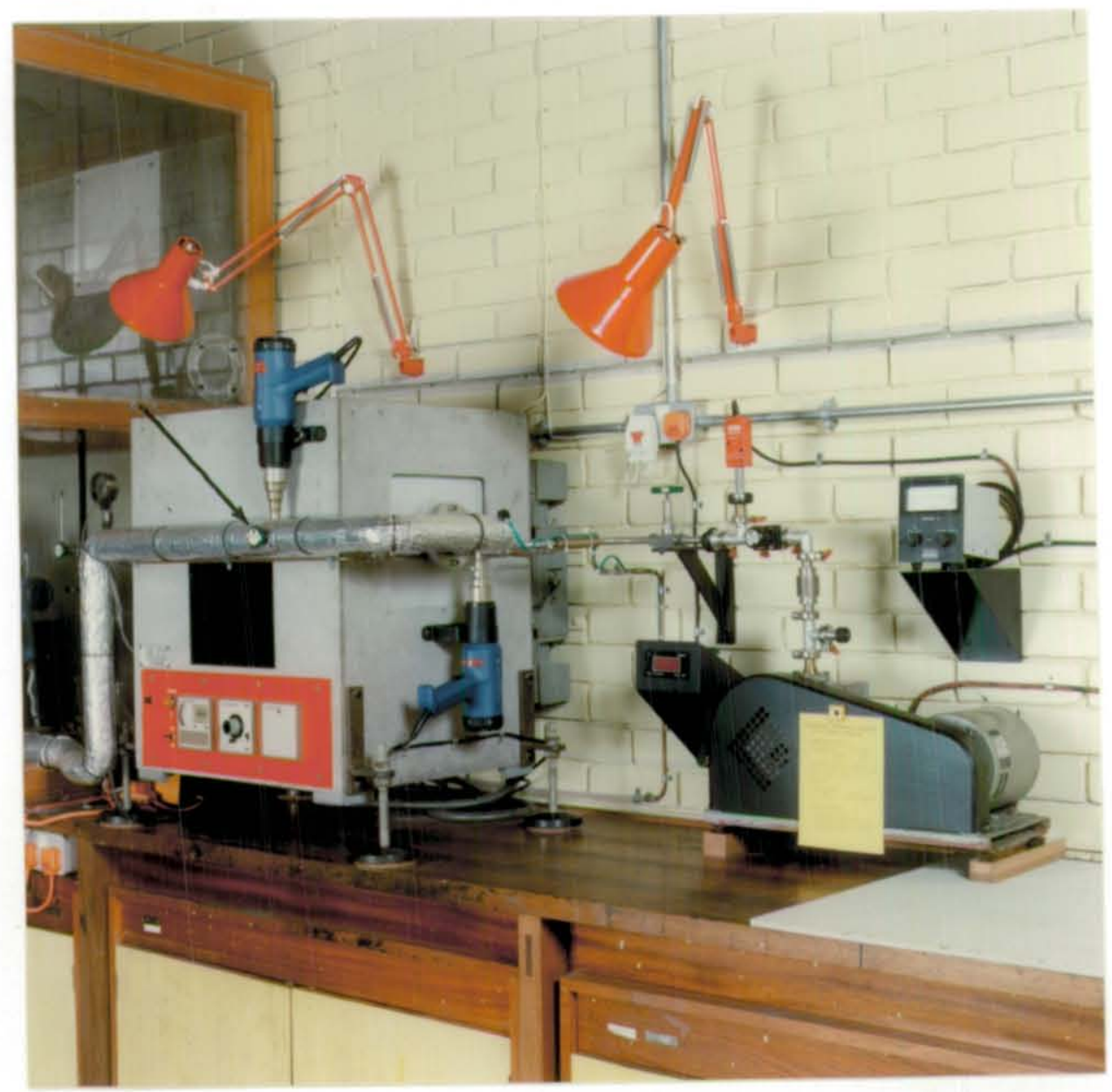

Figure 3.8 Reactor coating chamber furnace (viewed from inlet end) and associated control equipment 


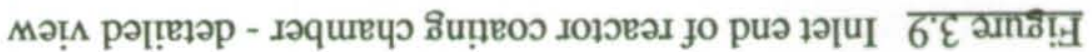

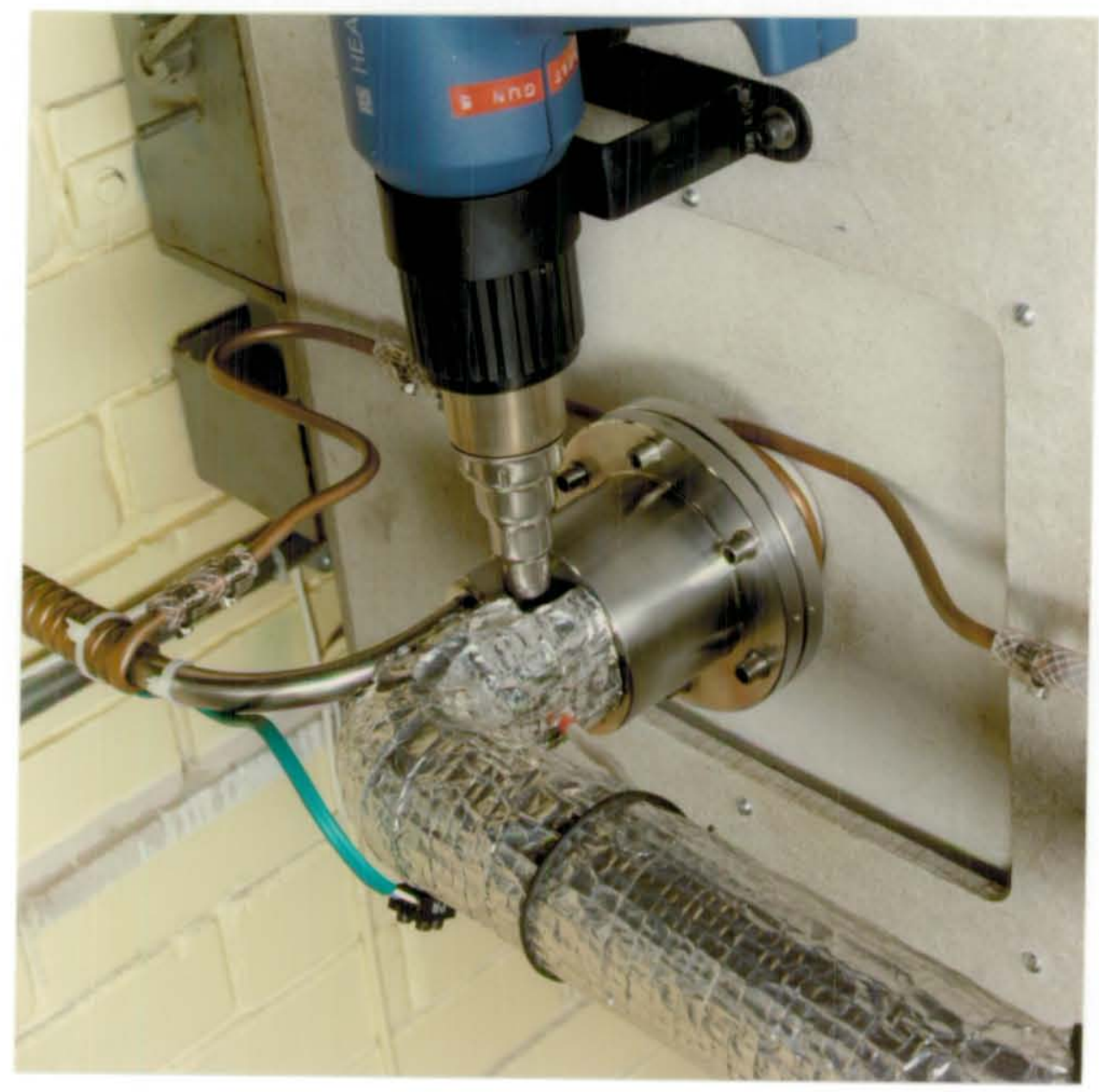




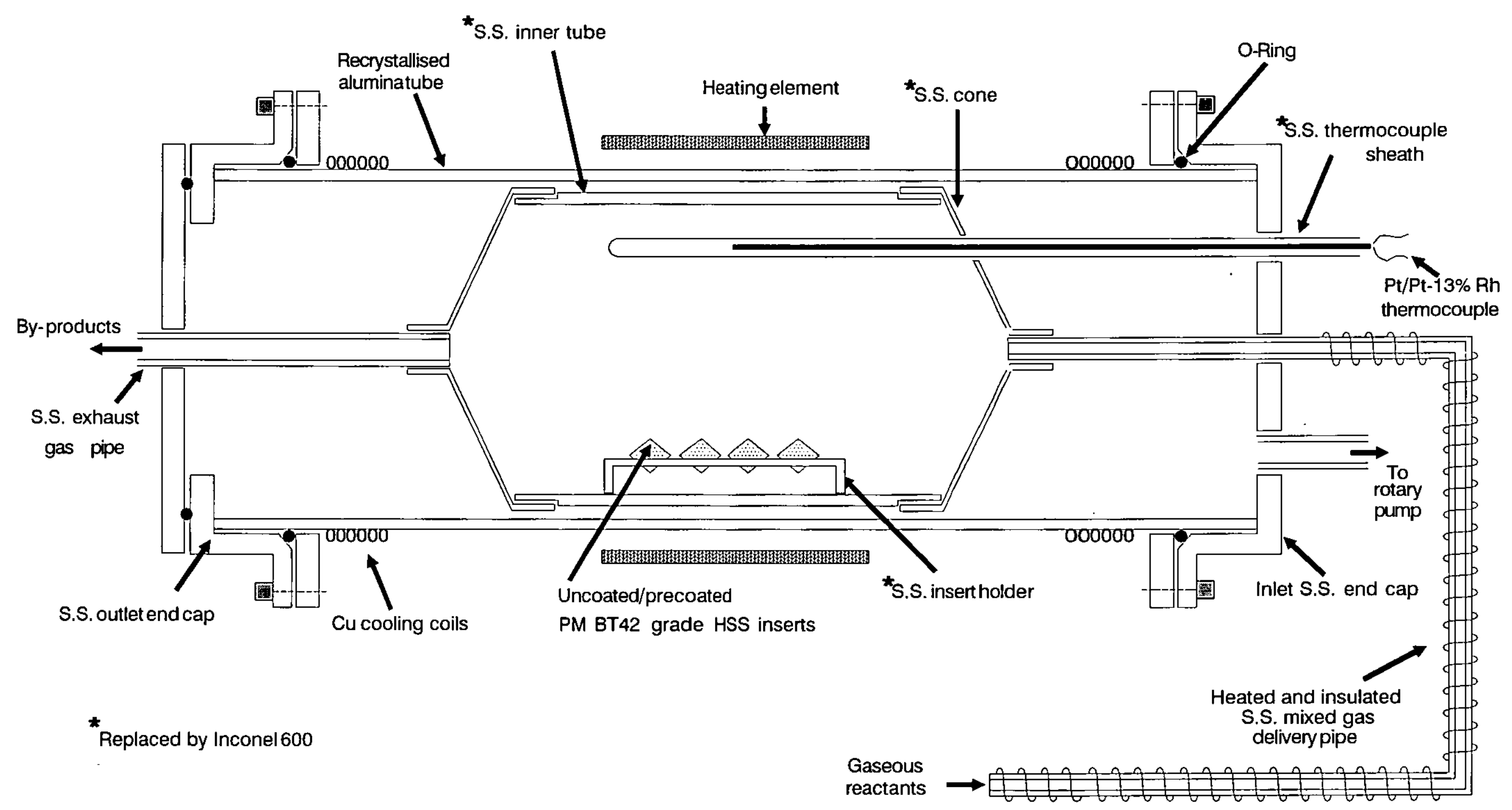

Figure 3.10 Schematic diagram of reactor coating chamber 


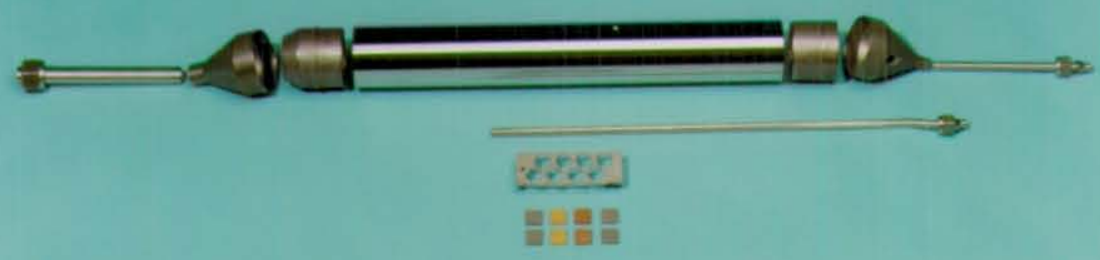

Figure 3.11 Reactor coating chamber inner tube and associated parts

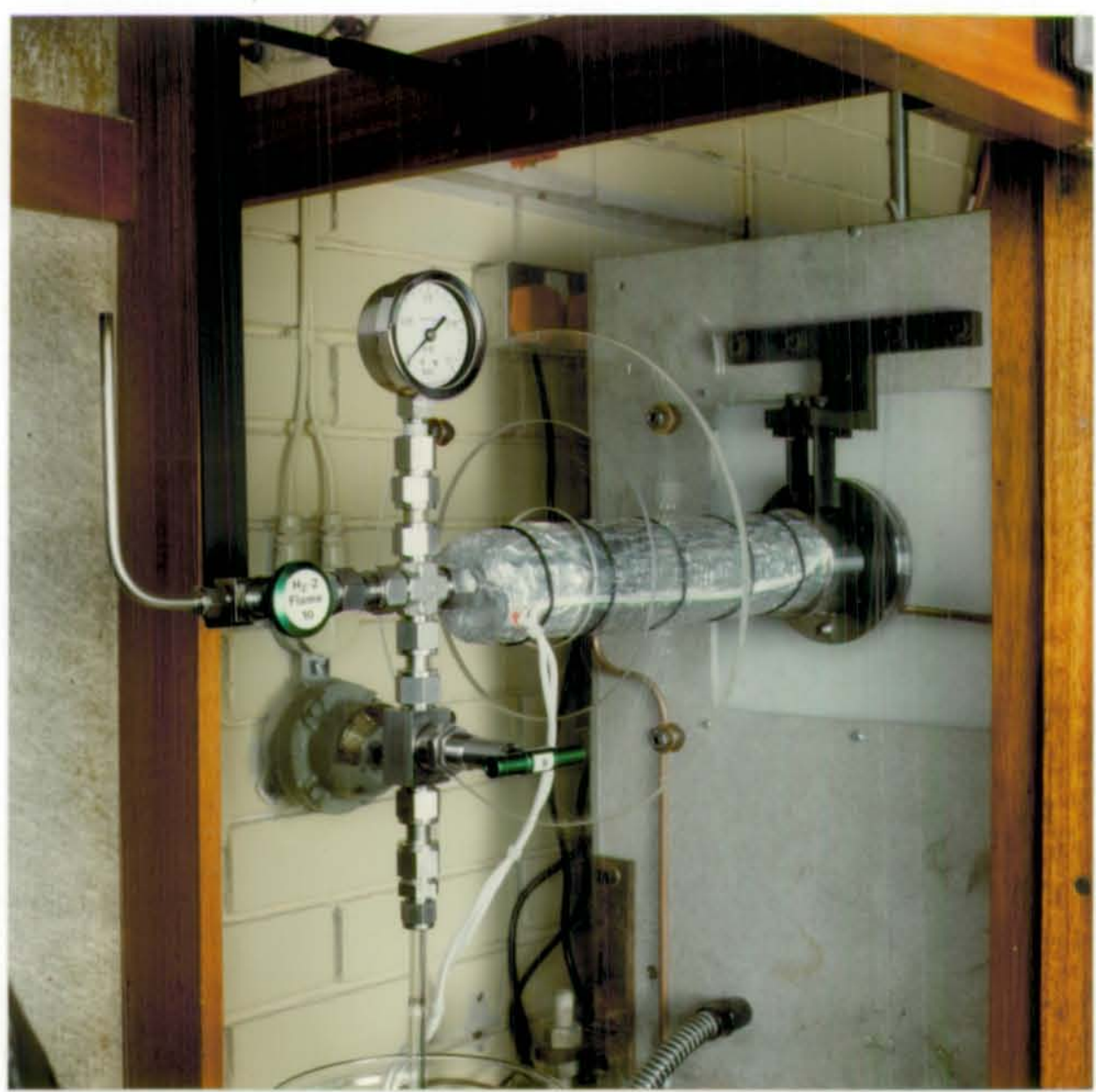

Figure 3.12 Outlet end of reactor coating chamber 


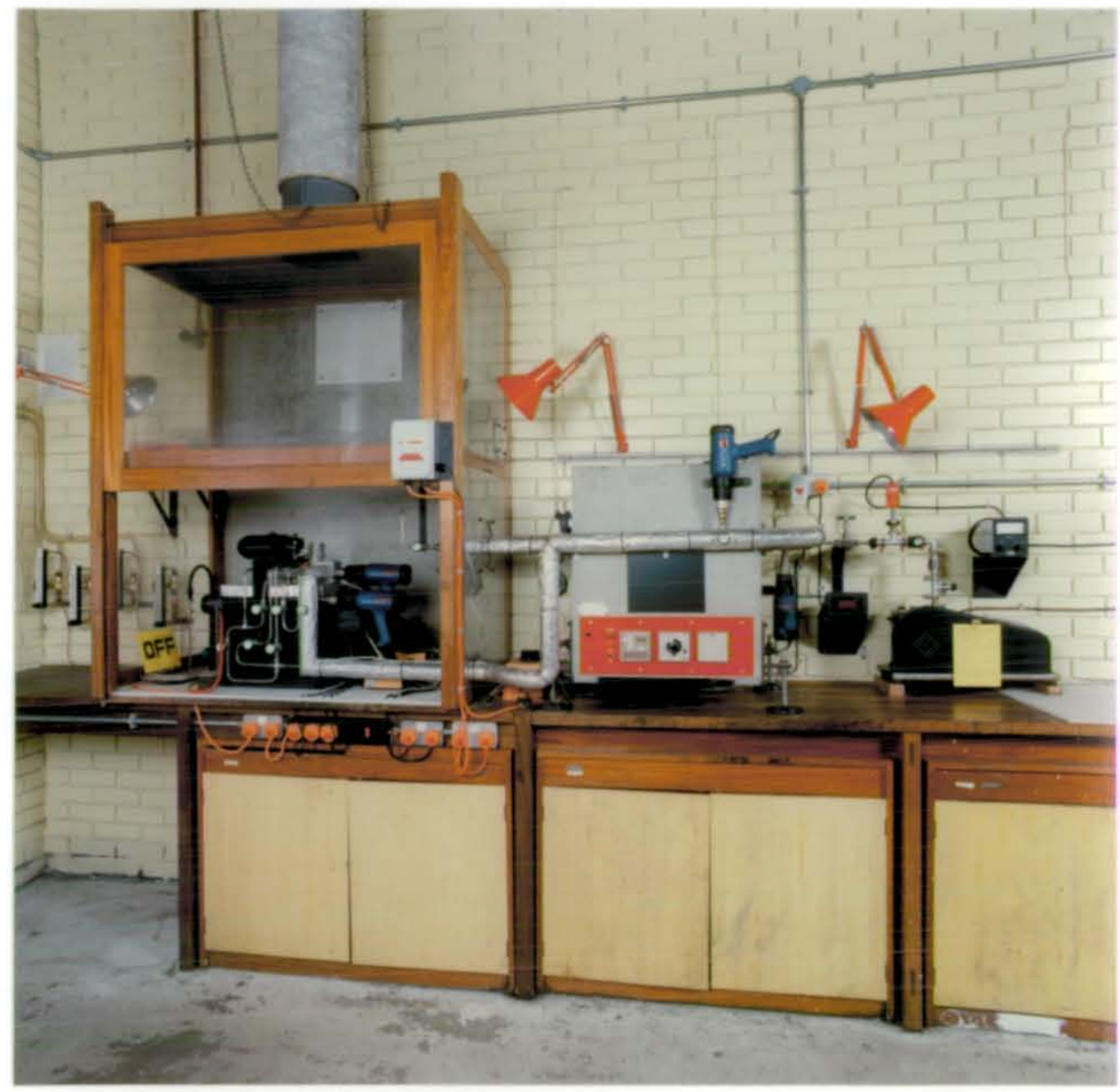

Figure 3.13 View of complete laboratory-scale $\mathrm{Al}_{2} \mathrm{O}_{3} \mathrm{CVD}$ reactor 


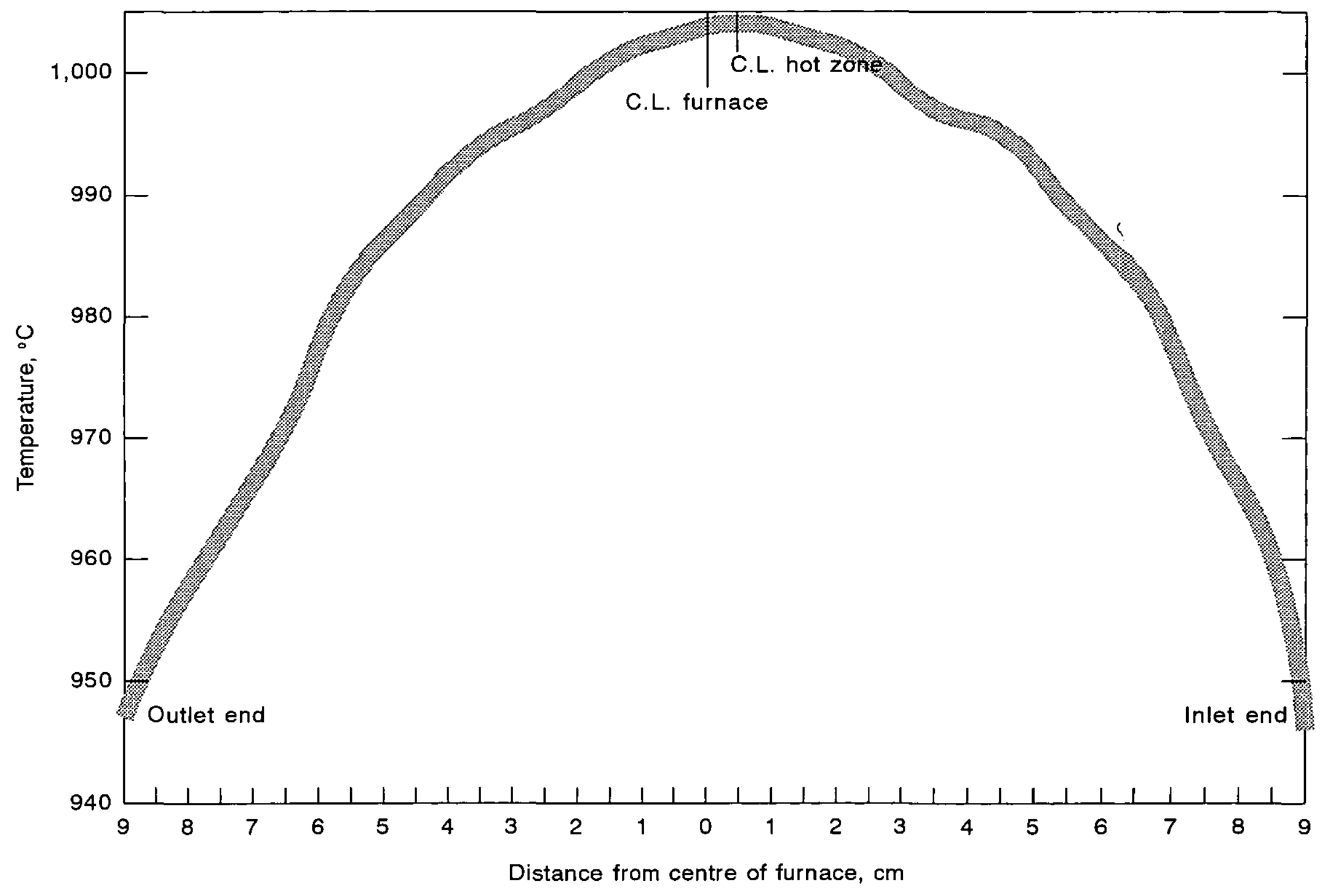

Figure 3.14 Reactor coating chamber hot zone plot. 


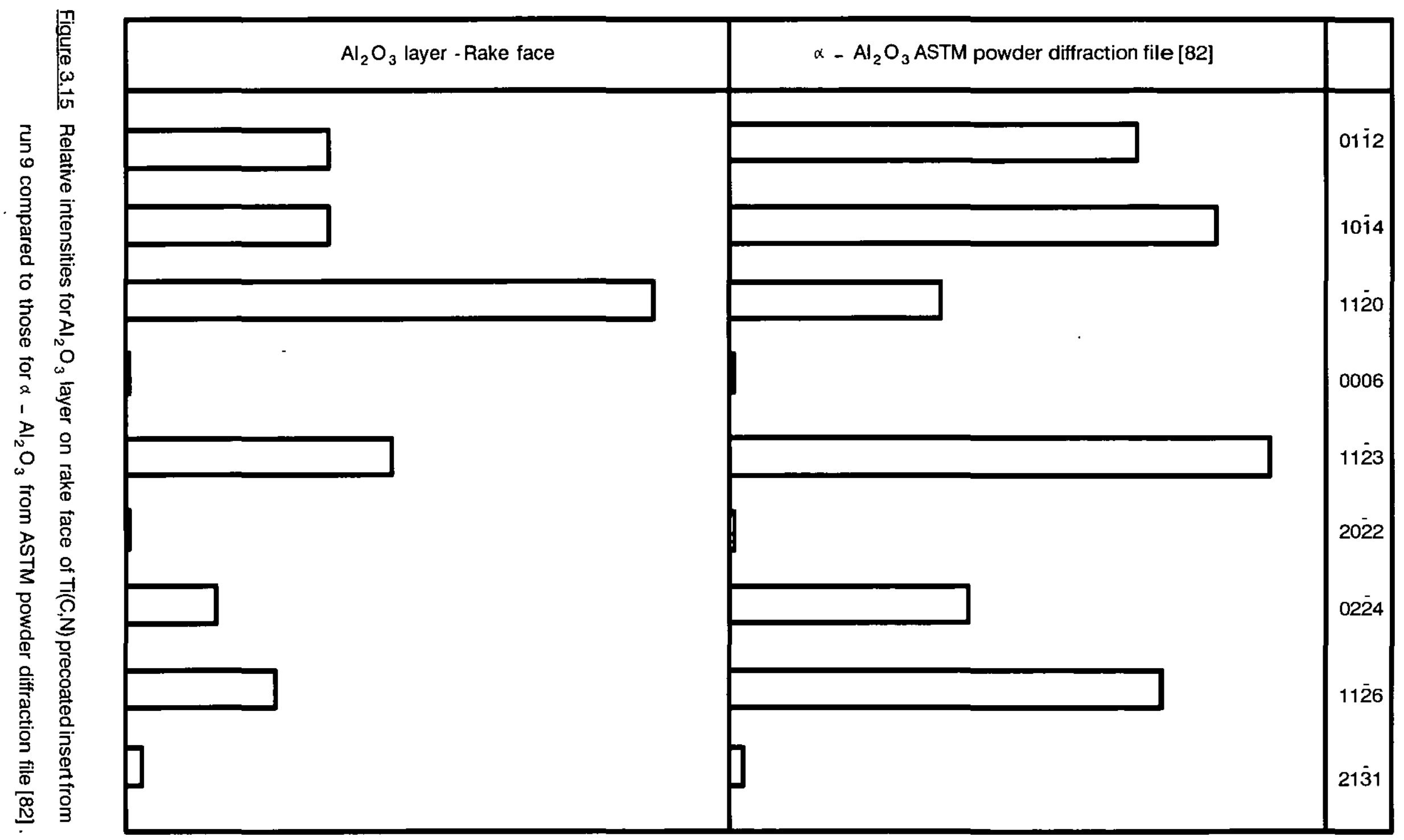




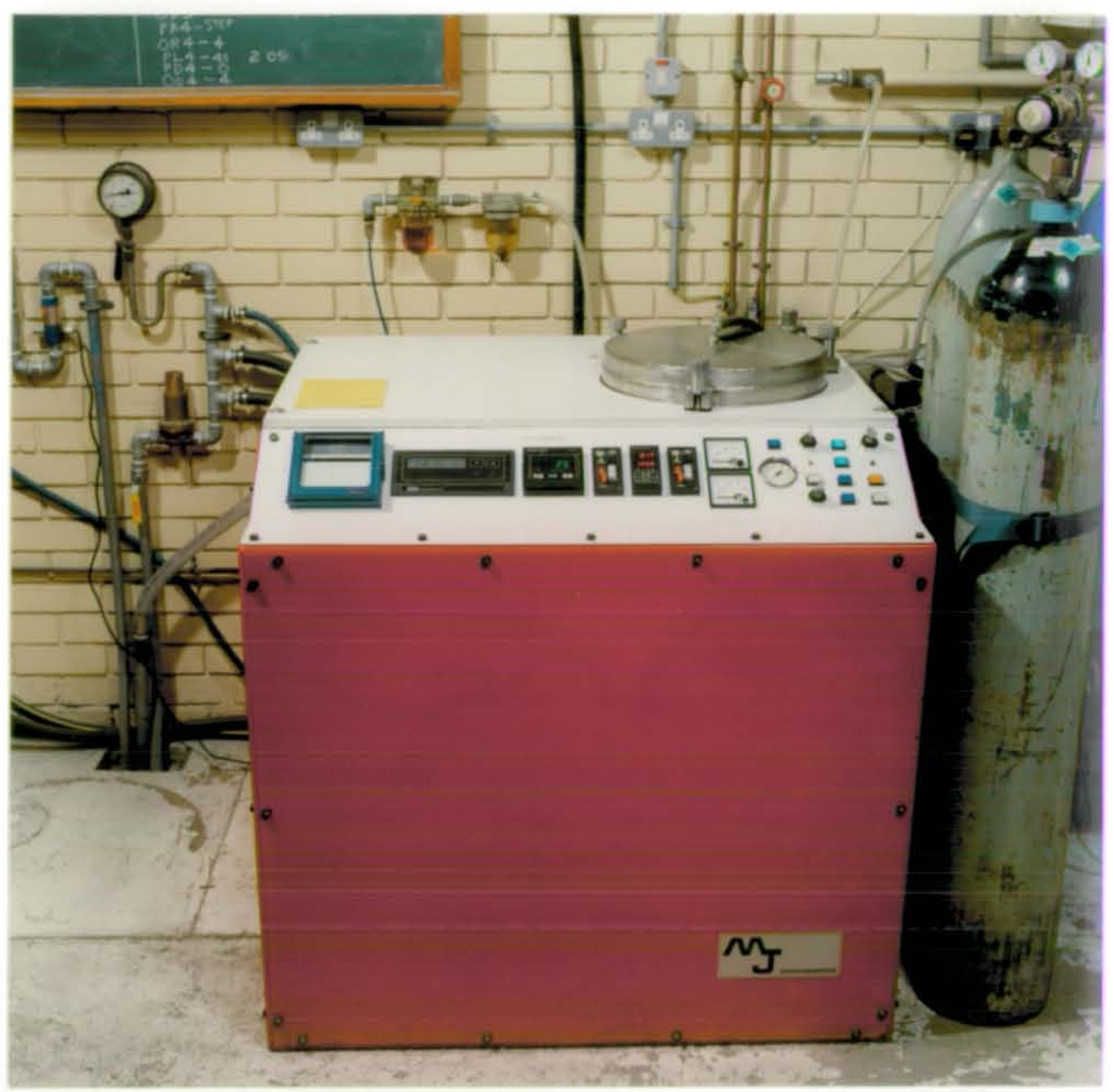

Figure 3.16 Vacuum heat treatment furnace 


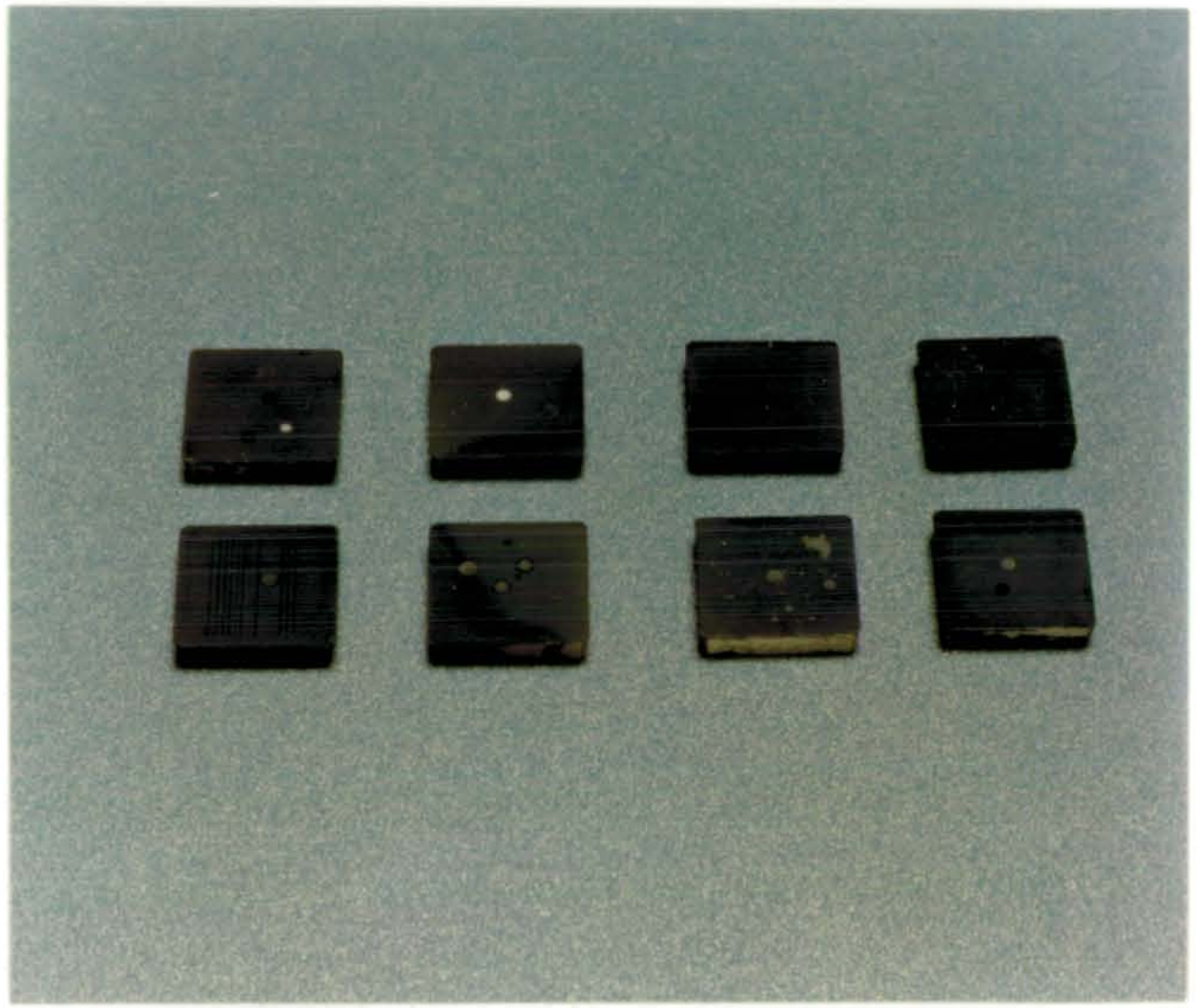

Figure 3.17 External appearance of $a c$ (upper) and $h c$ (lower) inserts from tenth run. 
Table 3.1 Composition of BT42 grade HSS [75]

Chemical compositions, wt.\%

\begin{tabular}{cccccccc}
\hline $\mathrm{C}$ & $\mathrm{Si}$ & $\mathrm{Mn}$ & $\mathrm{Cr}$ & $\mathrm{Mo}$ & $\mathrm{W}$ & $\mathrm{V}$ & Co \\
\hline $1.25-1.40$ & $0.40 \mathrm{max}$. & $0.40 \mathrm{max}$. & $3.75-4.50$ & $2.75-3.50$ & $8.50-9.50$ & $2.75-3.25$ & $9.0-10.0$ \\
\hline
\end{tabular}

Table 3.2 Summary of trial $\mathrm{Al}_{2} \mathrm{O}_{3}$ coating runs

\begin{tabular}{|c|c|c|c|c|c|c|c|c|}
\hline $\begin{array}{l}\text { Run } \\
\text { No. }\end{array}$ & $\mathrm{CO}_{2}$ & $\begin{array}{r}\mathrm{Gas} \text { flo } \\
\left(\mathrm{cm}^{3} \mathrm{n}\right. \\
\mathrm{H}_{2}-1 / \\
\mathrm{AlCl}_{3}\end{array}$ & $\begin{array}{l}\text { rate } \\
\left.\text { in }^{-1}\right) \\
\mathrm{H}_{2}-2\end{array}$ & $\mathrm{Ar}$ & $\begin{array}{c}\mathrm{CO}_{2} / \mathrm{H}_{2} \\
\text { mole } \\
\text { ratio }\end{array}$ & $\begin{array}{l}\text { Dep. } \\
\text { time } \\
(\mathrm{min})\end{array}$ & $\begin{array}{l}\text { PM HSS } \\
\text { inserts }\end{array}$ & Results \\
\hline \multicolumn{9}{|c|}{ Initial $\mathrm{Al}_{2} \mathrm{O}_{3}$ coating runs } \\
\hline 1 & 200 & 150 & 50 & 0 & 1 & $<5$ & \multirow{7}{*}{$\begin{array}{l}\text { Uncoated, } \\
\text { Ti(C,N), } \\
\text { TiN, and TiC } \\
\text { precoated }\end{array}$} & $\begin{array}{l}\text { Disastrous. } \mathrm{No} \mathrm{Al}_{2} \mathrm{O}_{3} \text { coating. } \\
\text { Ti-base precoatings completely } \\
\text { removed/damaged through } \\
\text { thickness. }\end{array}$ \\
\hline 2 & 200 & 150 & 50 & 0 & 1 & 0 & & $\begin{array}{l}\text { No } \mathrm{Al}_{2} \mathrm{O}_{3} \text { coating. } \mathrm{Ar} / \mathrm{AlCl}_{3} \\
\text { by-pass glass tube blocked, prior } \\
\text { to deposition. }\end{array}$ \\
\hline 3 & 200 & 100 & 100 & 0 & 1 & $<5$ & & 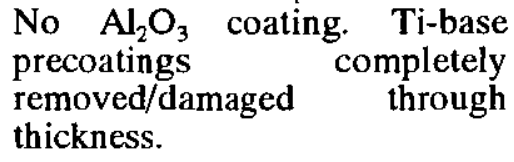 \\
\hline 4 & 100 & 100 & 100 & 100 & $1 / 2$ & $<10$ & & $\begin{array}{l}\mathrm{No} \mathrm{Al}_{2} \mathrm{O}_{3} \text {. Some evidence of } \\
\text { intact Ti-base precoatings. }\end{array}$ \\
\hline 5 & 25 & 100 & 100 & 175 & $1 / 8$ & 10 & & $\begin{array}{l}\text { Ti-base precoatings present. } \\
\text { EDX analysis: some } \mathrm{Al} \text {, but } \mathrm{Si} \text {, } \\
\mathrm{Fe} \text { and } \mathrm{Cr} \text { contamination }\end{array}$ \\
\hline 6 & 25 & 25 & 175 & 175 & $1 / 8$ & 35 & & $\begin{array}{l}\text { EDX analysis: more } \\
\text { elimination of } \mathrm{Al} \text {, } \mathrm{Si} \text { and } \mathrm{Fe} \text {, } \\
\text { reduction of } \mathrm{Cr} \text {. }\end{array}$ \\
\hline 7 & 25 & 10 & 190 & 175 & $1 / 8$ & 60 & & $\begin{array}{l}\text { Disastrous. Ti-base } \\
\text { precoatings-partly/completely } \\
\text { removed. Flaking of inserts and } \\
\text { chamber inner tube. Leak } \\
\text { suspected. }\end{array}$ \\
\hline \multicolumn{9}{|c|}{ Chamber inner tube and insert holder - aluminide coating } \\
\hline 8 & 25 & 25 & 175 & 175 & $1 / 8$ & 60 & As above & $\begin{array}{l}\text { Ti-base precoatings present. } \\
\text { EDX analysis: } \mathrm{Al} \text { on all inserts, } \\
\text { best results with Ti(C,N) } \\
\text { precoating. }\end{array}$ \\
\hline 9 & 25 & 25 & 175 & 175 & $1 / 8$ & 60 & $\begin{array}{c}9 \mu \mathrm{m} \\
\text { Ti(C,N) } \\
\text { precoated. }\end{array}$ & $\begin{array}{l}\text { Promising } \mathrm{Al}_{2} \mathrm{O}_{3} \text { coatings - } \\
\mathrm{X} \text {-ray results. }\end{array}$ \\
\hline \multicolumn{9}{|c|}{ Chamber inner tube, insert holder and thermocouple sheath - Inconel 600} \\
\hline 10 & 25 & 25 & 175 & 175 & $1 / 8$ & 60 & $\begin{array}{c}2 \mu \mathrm{m} \\
\text { Ti(C,N) } \\
\text { precoated. }\end{array}$ & $\begin{array}{l}\mathrm{All} \mathrm{Al}_{2} \mathrm{O}_{3} \text { coated. More uniform } \\
\text { coating thickness. Evidence of } \\
\text { intact } \mathrm{Al}_{2} \mathrm{O}_{3} \text { coatings after heat } \\
\text { treatment. }\end{array}$ \\
\hline
\end{tabular}




\section{CHAPTER 4}

EXPERIMENTAL WORK AND RESULTS (I)-CHARACTERISATION OF PRELIMINARY CVD $\mathrm{Al}_{2} \mathrm{O}_{3}$ COATINGS 


\subsection{EXPERIMENTAL WORK AND RESULTS (I)-CHARACTERISATION OF PRELIMINARY CVD Al $\underline{2}_{3}$ COATINGS}

As mentioned at the end of Chapter 3 and for reasons given there, it was decided to carry out a detailed characterisation of the preliminary $\mathrm{CVD} \mathrm{Al}_{2} \mathrm{O}_{3}$ coatings on both the $a c$ and the $h c$ PM BT42 grade HSS inserts, i.e. both before and after the obligatory HSS substrate heat treatment. The work carried out and the results obtained from it are presented in this chapter. The coating characterisation techniques employed were chosen with reference to those used by Whittle in his work on CVD TiN coated PM HSS inserts [6]; the coating characteristics actually investigated were selected with reference to those previously determined for CVD $\mathrm{Al}_{2} \mathrm{O}_{3}$ coatings (see Section 2.8).

\subsection{Characterisation of Preliminary $\mathrm{CVD} \mathrm{Al}_{2} \mathrm{O}_{3}$ Coatings on As-coated PM HSS Inserts}

\subsubsection{X-ray diffraction}

X-ray diffraction was first used to determine the preferred orientation and lattice parameters of the preliminary $\mathrm{Al}_{2} \mathrm{O}_{3}$ coating on the rake face of all the ac inserts to be studied in the present characterisation work. This was done to determine whether there were any significant differences in the crystal structure of the $\mathrm{Al}_{2} \mathrm{O}_{3}$ coating on each insert which could affect the results subsequently obtained by the other characterisation techniques. The X-ray work reported here, and that referred to previously and reported subsequently, was carried out on a Philips X-ray set using a diffractometer. A crystal monochromater was employed to ensure that only the $\mathrm{CuK} \alpha_{1}$ radiation from the $\mathrm{Cu}$ target was present at the detector.

In the previous work on $\mathrm{CVD} \mathrm{Al}_{2} \mathrm{O}_{3}$ coatings surveyed, preferred orientations had been obtained by comparing the relative intensities of the reflections from the coatings to those quoted for $\mathrm{Al}_{2} \mathrm{O}_{3}$ in the ASTM powder file $[36,43,44]$. In the present work, it was decided that an $\alpha-\mathrm{Al}_{2} \mathrm{O}_{3}$ powder, supplied by Aldrich Chemical Company Limited, would be used to facilitate this comparison. The purity of this $\alpha-\mathrm{Al}_{2} \mathrm{O}_{3}$ powder is shown in Table 4.1. The $\alpha-\mathrm{Al}_{2} \mathrm{O}_{3}$ powder samples for $\mathrm{X}$-ray diffraction were prepared by suspending the powder in vaseline in the proportion $4: 1$ by weight. For TiN [6,9] and TiC [11] powder samples, it has previously been determined that this ratio is well in excess of the ratio of powder:vaseline at which the amount of powder present becomes so low as to have an effect. X-ray spectra for the $\alpha-\mathrm{Al}_{2} \mathrm{O}_{3}$ powder samples were then obtained using a $1^{\circ}$ incident slit and a $1^{\circ}$ receiving slit, the spectra obtained then being analysed. The integrated intensity of reflection for each family of planes was first determined by measuring the area under the corresponding peak 
using a planimeter. The integrated intensity for the strongest reflection (the $\{1 \overline{12} 3\}$ planes) was then assigned a value of 100 , as in the ASTM powder diffraction file (card no. 10-173 [82]). The relative intensities for the other families of planes were then obtained by dividing the area under the peak corresponding to the family of planes under consideration by the area under the peak corresponding to the $\{11 \overline{2} 3\}$ planes and then multiplying by 100 . As shown in Figure 4.1, the relative intensities thus obtained for the $\alpha-\mathrm{Al}_{2} \mathrm{O}_{3}$ powder samples corresponded very well indeed with those quoted for $\alpha-\mathrm{Al}_{2} \mathrm{O}_{3}$ in the ASTM powder file [82].

$\mathrm{X}$-ray spectra for the $\mathrm{Al}_{2} \mathrm{O}_{3}$ coating on the rake face of all the ac inserts were obtained separately using the slit arrangement referred to earlier. From the spectra obtained for the coating on a particular insert, the integrated intensity of reflection for each family of planes was first determined, as for the powder sample, by measuring the area under the corresponding peak. Relative intensities were then obtained by dividing the area under the peak corresponding to a particular family of planes by the area under the peak corresponding to the $\{11 \overline{2} 3\}$ planes of the $\alpha-\mathrm{Al}_{2} \mathrm{O}_{3}$ powder sample and then multiplying by 100 . Finally, preferred orientation in each coating was identified by comparing the relative intensities thus obtained to those of the randomly oriented powder sample. Figure 4.2 shows the relative intensities thus determined for the coating on one of the ac inserts, compared to those for the powder sample. The relative intensities determined for the $\mathrm{Al}_{2} \mathrm{O}_{3}$ coating on the other $a c$ inserts did not differ significantly from those shown in Figure 4.2.

Only three reflections in the X-ray spectra obtained for the $a c$ inserts were identified as originating from the $\mathrm{Ti}(\mathrm{C}, \mathrm{N})$ precoating, but they did not interfere with any of the reflections from the $\mathrm{Al}_{2} \mathrm{O}_{3}$ coating itself. However, as is evident from Figure 4.2, the magnitudes for the relative intensities of the $\mathrm{Al}_{2} \mathrm{O}_{3}$ coating on the rake face of all the $a c$ inserts were considerably smaller than those for the $\alpha-\mathrm{Al}_{2} \mathrm{O}_{3}$ powder. Before proceeding further, it was consequently thought best to investigate the source of the smaller relative intensities obtained for the $\mathrm{Al}_{2} \mathrm{O}_{3}$ coatings. A theoretical analysis was made of the depth of X-ray penetration through $\mathrm{Al}_{2} \mathrm{O}_{3}$ using the formula [83]

$$
\frac{2 \mu x}{\sin \theta}=\ln \left(\frac{1}{1-G_{x}}\right)
$$

where $G_{x}$ is the fraction of the total diffracted intensity contributed by a surface layer of depth $\mathrm{x}, \mu$ is the linear absorption factor for the material (calculated to be $126 \mathrm{~cm}^{-1}$ for stoichiometric $\mathrm{Al}_{2} \mathrm{O}_{3}$ [83]) and $\theta$ is the Bragg angle. Using this formula, a curve of $\mathrm{G}_{\mathrm{x}}$ versus $\mathrm{x}$ was derived and plotted for the $\{11 \overline{2} 3\}$ planes of $\mathrm{Al}_{2} \mathrm{O}_{3}$ exhibiting the maximum relative intensity. This is shown in Figure 4.3. From this figure it is evident that for a typical preliminary $\mathrm{Al}_{2} \mathrm{O}_{3}$ 
coating thickness of $2.5-3 \mu \mathrm{m}$, only $15 \%$ of the total possible diffracted intensity is being obtained from the preliminary $\mathrm{Al}_{2} \mathrm{O}_{3}$ coating. Clearly, therefore, the low relative intensities obtained for the preliminary $\mathrm{Al}_{2} \mathrm{O}_{3}$ coatings are related to coating thickness.

Lattice parameter values for the preliminary $\mathrm{Al}_{2} \mathrm{O}_{3}$ coating were determined using the following formula for hexagonal systems [83]:

$$
d_{h k l}=\left[\frac{4}{3 a^{2}}\left(h^{2}+k^{2}+h k\right)+\frac{l^{2}}{c^{2}}\right]^{-\frac{1}{2}}
$$

where a and $c$ are lattice parameters, h,k,l are the Miller indices and $d_{h k l}$ is the interplanar spacing. It can be shown (see Appendix 5) that equation 4.2 can be rewritten as:

$$
\begin{gathered}
\frac{x}{a^{2}}+\frac{y}{c^{2}}=1 \\
\text { where, } x=\frac{4}{3}\left(h^{2}+k^{2}+h k\right)\left(d_{h k l}\right)^{2} \quad \text { and } \quad y=l^{2}\left(d_{h k l}\right)^{2}
\end{gathered}
$$

Lattice parameter values for both the $\alpha-\mathrm{Al}_{2} \mathrm{O}_{3}$ powder and the $\alpha-\mathrm{Al}_{2} \mathrm{O}_{3}$ coating on the rake face of all the $a c$ inserts were from the Bragg angle $\theta$ for each reflection (hkl) on the spectra for a particular sample by first using Bragg's Law to calculate values of $d_{h k l}$. Values of $x$ and ' $y$ were then calculated using equation 4.4 and a graph of $y$ against $x$ plotted. This was actually carried out on an IBM compatible PC. A linear regression analysis program was then employed to fit the best straight line to the experimental data, this line being extrapolated to determine the $y$ intercept at $x=0$ and hence the value of $c$ (equation 4.3). Further, the gradient of this line is equal to $-c^{2} / a^{2}$ hence, using this gradient and the value of $c$ determined, the corresponding $a$ value was calculated. The values of the $a$ and c lattice parameters thus calculated for the $\alpha-\mathrm{Al}_{2} \mathrm{O}_{3}$ powder sample and the $\alpha-\mathrm{Al}_{2} \mathrm{O}_{3}$ coating on the rake face of all the $a c$ inserts are detailed in Table 4.2, together with the values for $\alpha-\mathrm{Al}_{2} \mathrm{O}_{3}$ quoted in the ASTM powder file [82].

Before going on to describe the rest of the characterisation work, it is clear from Table 4.2 and from the relative intensities obtained for the $\alpha-\mathrm{Al}_{2} \mathrm{O}_{3}$ coatings that there are no significant differences in the crystal structure of the $\mathrm{Al}_{2} \mathrm{O}_{3}$ coating on each of the $a c$ inserts and hence that these inserts can be validly employed in the characterisation study. 


\subsubsection{Auger electron spectroscopy}

AES was employed to obtain a composition-depth profile through the $\mathrm{Al}_{2} \mathrm{O}_{3}$ coating, across the $\mathrm{Al}_{2} \mathrm{O}_{3}$ coating/Ti(C,N) precoating interface, through the Ti(C,N) precoating and across the $\operatorname{Ti}(\mathrm{C}, \mathrm{N})$ precoating/HSS substrate interface of one of the $a c$ inserts. The ball-cratering technique [80] was used to eliminate the problems associated with the sequential removal of surface layers by Ar-ion bombardment (see Section 2.8). This technique basically involves a rotating, spherical steel ball coated in fine diamond paste being used to grind a crater in the surface of a loaded sample. The ball is lightly loaded and hence the depth of the abrasive wear marks produced in the crater are generally less than the diameter of the diamond paste used. This is important since the final surface roughness determines the depth resolution subsequently attainable.

A schematic diagram of a ball crater in the surface of an $\mathrm{Al}_{2} \mathrm{O}_{3} / \mathrm{Ti}(\mathrm{C}, \mathrm{N})$ precoated insert is shown in Figure 4.4. With reference to this figure, since the radius of the ball $(R)$ determines the curvature of the crater, its total depth (d) can be simply calculated using the formula:

$$
d=\frac{D_{3}^{2}}{8 R}
$$

where $\mathrm{D}_{3}$ is the diameter of the crater on the surface of the $\mathrm{Al}_{2} \mathrm{O}_{3}$ coating. Again with reference to Figure 4.4, it can be shown using simple geometry that the thickness of the $\mathrm{Al}_{2} \mathrm{O}_{3}$ coating $(t)$ is given by the expression:

$$
t=\frac{D_{3}{ }^{2}-D_{2}{ }^{2}}{8 R}
$$

and that the thickness of the $\operatorname{Ti}(\mathrm{C}, \mathrm{N})$ precoating $\left(\mathrm{t}_{1}\right)$ is given by the expression:

$$
t_{1}=\frac{D_{2}{ }^{2}-D_{1}{ }^{2}}{8 R}
$$

where $\mathrm{D}_{2}$ is the diameter of the $\mathrm{Al}_{2} \mathrm{O}_{3} / \mathrm{Ti}(\mathrm{C}, \mathrm{N})$ precoating interface, $\mathrm{D}_{1}$ is the diameter of the exposed substrate surface and the other symbols are as previously defined.

In the present work, a $30 \mathrm{~mm}$ diameter steel ball coated in $1 \mu \mathrm{m}$ diamond paste was used to produce a crater approximately $10 \mu \mathrm{m}$ deep on the rake face of the $a c$ insert to be analysed. After ball-cratering the insert was cleaned in acetone followed by methanol. It was then 
mounted in a $10 \mathrm{keV}$ Varian Scanning Auger Electron Spectrometer and its surface again cleaned, this time by Ar ions, to remove any residual atmospheric contamination and oxidation. The electron analyser was then tuned to the Auger peak of a particular element (e.g. $\mathrm{Al}, \mathrm{O}$ ) the incident electron beam moved across the crater, and the variation of the particular Auger peak chosen, with position, recorded. Line scans were taken for these elements in order to accurately locate the edge of the crater, this being located by the change in amplitude of the secondary electron current which occurs at the crater edge due to the change in curvature. In addition, line scans were taken for several other elements (e.g. Ti, C, $\mathrm{N}, \mathrm{Cr}, \mathrm{Fe}$ ), in order, together with the previous scans, to locate the $\mathrm{Al}_{2} \mathrm{O}_{3}$ coating $/ \mathrm{Ti}(\mathrm{C}, \mathrm{N})$ precoating interface and the $\mathrm{Ti}(\mathrm{C}, \mathrm{N})$ precoating/HSS substrate interface. The length of the relevant part of the line-scans was then correlated with crater depth using the expression:

$$
y=d-R+\left(R^{2}-\frac{1}{4}\left(D_{3}-2 x\right)^{2}\right)^{1 / 2}
$$

where $y$ is the depth of the crater at lateral distance $\mathrm{x}$ from its edge and the other symbols are as defined previously. This enabled various points along the line-scans, corresponding to different crater depths, to be selected for analysis. Full-spectrum analysis was subsequently carried out at each of these points (i.e. depths) with simultaneous Ar-ion bombardment at a slow erosion rate to prevent the adsorption of water vapour from the residual gases in the vacuum system. The results thus obtained for one of the $a c$ inserts are presented in Figure 4.5 .

\subsubsection{Surface roughness assessment}

Profilometry was employed to assess the surface roughness of the preliminary $\mathrm{Al}_{2} \mathrm{O}_{3}$ coating on the rake face of one of the $a c$ inserts using a Talysurf 10 . Two $\mathrm{R}_{\mathrm{a}}$ (roughness average) readings were taken on each of five evenly divided sampling lengths parallel to one of the cutting edges and on five similar lengths perpendicular to the former five sampling lengths. The reason for taking so many readings was to determine the consistency of the surface roughness of the $\mathrm{Al}_{2} \mathrm{O}_{3}$ coating. The $\mathrm{R}_{\mathrm{a}}$ values thus obtained are summarised in Table 4.3. In addition a typical Talysurf trace of the surface of the $\mathrm{Al}_{2} \mathrm{O}_{3}$ coating on the rake face of the $a c$ insert studied is shown in Figure 4.6.

\subsubsection{Optical microscopy - cross-section}

Optical microscopy was employed principally to determine whether the preliminary $\mathrm{Al}_{2} \mathrm{O}_{3}$ coating on one of the $a c$ inserts was present all around its periphery, and, if so, to determine the thickness of the $\mathrm{Al}_{2} \mathrm{O}_{3}$ coating on the rake and flank faces and on the corners (i.e. cutting 
edges) of the insert. It was further used to check for the presence of defects in the $\mathrm{Al}_{2} \mathrm{O}_{3}$ coating, to examine the $\mathrm{Al}_{2} \mathrm{O}_{3}$ coating/Ti(C,N) precoating interface and the $\mathrm{Ti}(\mathrm{C}, \mathrm{N})$ precoating/HSS substrate interface and to investigate the microstructure of the PM BT42 grade HSS substrate adjacent to and remote from the latter interface.

To this end, one of the $a c$ inserts was first sectioned using a diamond impregnated slitting saw and the two halves obtained were ultrasonically cleaned in acetone followed by methanol. One half of the sectioned $a c$ insert was then mounted in Buehler "Epomet" (a proprietary mounting medium containing hard particles, designed to give a good edge definition and flatness) and successively polished on five cast iron lapping plates impregnated with 15,9 , 6 and $3 \mu \mathrm{m}$ diamond compound respectively, for a period of at least one hour per plate under a load of $\sim 2 \mathrm{~kg}$. When a reasonable polished section had been achieved on the $3 \mu \mathrm{m}$ lap the sample was vibratory polished on a napless nylon cloth impregnated with $1 \mu \mathrm{m}$ diamond compound, until all the surface damage remaining from the final lapping operation had been removed, this stage normally taking 80-90 hours. It was then given a final polish on a Selvyt cloth using a suspension of $0.05 \mu \mathrm{m} \gamma$-alumina powder in water.

The polished cross-section thus produced was then etched in $2 \%$ nital and a relatively high magnification optical examination made on a Reichert MeF2 microscope; this microscope being used for all the optical microscopy carried out in the present work. First the periphery of the sectioned insert was examined at relatively high magnification to check for the presence of the $\mathrm{Al}_{2} \mathrm{O}_{3}$ coating. The coating was established to be present all around the periphery of the $a c$ insert. However, it was observed that although the thickness of the $\mathrm{Al}_{2} \mathrm{O}_{3}$ coating was fairly uniform on the rake face of the $a c$ insert, on one flank face and corner of the insert the $\mathrm{Al}_{2} \mathrm{O}_{3}$ coating was very thin and on the other flank face and corner it was much thicker. The thickness of the $\mathrm{Al}_{2} \mathrm{O}_{3}$ coating on the rake and flank faces and at the corners of the $a c$ insert was subsequently measured optically, using the micrometer eyepiece normally used for microhardness testing on the Reichert MeF2. Twenty readings on the rake face, ten readings on each of the two flank faces ( 1 and 2$)$ and five readings on each of the two corners ( 1 and 2) were taken. The results obtained are summarised in Table 4.4.

The $\mathrm{Al}_{2} \mathrm{O}_{3}$ coating itself, the $\mathrm{Al}_{2} \mathrm{O}_{3}$ coating/Ti(C,N) precoating interface and the $\mathrm{Ti}(\mathrm{C}, \mathrm{N})$ precoating/HSS substrate interface on the $a c$ insert were then examined together with the microstructure of the PM BT42 grade HSS substrate adjacent to and remote from the latter. With the exception of isolated porosity, no major defects were observed in the $\mathrm{Al}_{2} \mathrm{O}_{3}$ coating and both the $\mathrm{Al}_{2} \mathrm{O}_{3}$ coating/Ti(C,N) precoating and the $\mathrm{Ti}(\mathrm{C}, \mathrm{N})$ precoating/HSS substrate interfaces were observed to be continuous, although there was some isolated porosity in the HSS substrate adjacent to the latter. The substrate microstructure adjacent to and remote from the $\mathrm{Ti}(\mathrm{C}, \mathrm{N})$ precoating/HSS substrate interface did not differ significantly. Typical optical cross-sections through the rake and flank faces of the ac insert are presented in Figure 4.7. As is just evident from these optical cross-sections, particularly that through the flank face 
of the $a c$ insert, a thin band is just discernible at the $\mathrm{Al}_{2} \mathrm{O}_{3}$ coating/Ti(C,N) precoating interface. It was decided to examine this band at higher magnification on an SEM using a back-scattered detector in order to obtain atomic number contrast, and hence allow this band to be more easily delineated. Somewhat surprisingly, insufficient contrast at the higher magnification employed precluded this.

\subsubsection{Microhardness tests}

Microhardness tests were employed to determine the hardness of the preliminary $\mathrm{Al}_{2} \mathrm{O}_{3}$ coating. They have also previously been used to determine the hardness of $\mathrm{CVD} \mathrm{Al}_{2} \mathrm{O}_{3}$ coatings (see Section 2.8). As described in Section 2.8, two types of indentor have previously been employed to determine the microhardness of $\mathrm{CVD} \mathrm{Al}_{2} \mathrm{O}_{3}$ coatings, namely Knoop and Vickers; the former, since it produces a much shallower indentation than the latter under the same load, generally giving more accurate microhardness values. Unfortunately, only a Vickers indentor was available for use in the present work. Two methods have, however, previously been employed to reduce the errors associated with the greater relative depth of a Vickers indentation; increasing coating thickness specifically to facilitate microhardness measurements [70], and producing low-angle taper sections to "mechanical magnify" the area of the sectioned coating [6]. The latter method was used in the present work.

One of the $a c$ inserts was first sectioned using the diamond impregnated slitting saw referred to earlier (see Section 4.1.4). One half of the sectioned insert was then ultrasonically cleaned in acetone followed by methanol and mounted in Buehler "Epomet" with its rake face at an angle of $5.6^{\circ}$ to the base of the mount. The mount was then ground parallel to its base, thus obliquely sectioning the coating and "mechanically magnifying" its thickness by a factor of 10. This preparation sequence is illustrated schematically in Figure 4.8. The low-angle taper section thus produced was then lapped and polished using the procedure previously detailed in Section 4.1.4. Microhardness tests were carried out on the Reichert MeF2 microscope previously employed in the optical microscopy work, using a Vickers indentor with a load of $25 \mathrm{~g}$ applied for a duration of 6 seconds. An investigation of the variation in microhardness of the $\mathrm{Al}_{2} \mathrm{O}_{3}$ coating on the taper-sectioned ac insert with distance from the $\mathrm{Al}_{2} \mathrm{O}_{3}$ coating/Ti(C,N) precoating interface was first carried out to locate the region in which truly representative microhardness values could be obtained. The measured variation in microhardness of the $\mathrm{Al}_{2} \mathrm{O}_{3}$ coating thus determined is shown in Figure 4.9. It can be seen that once a certain distance from the $\mathrm{Al}_{2} \mathrm{O}_{3}$ coating/Ti(C,N) precoating interface is reached, a plateau exists on which the microhardness does not vary significantly. Consequently, twenty five microhardness measurements were subsequently taken in the centre of this plateau along the length of the $\mathrm{Al}_{2} \mathrm{O}_{3}$ coating, in order to determine the microhardness of the $\mathrm{Al}_{2} \mathrm{O}_{3}$ coating. The results thus obtained are summarised in Table 4.5 . 


\subsubsection{Optical microscopy - taper section}

As previously described in Section 4.1.4 on the optical cross-sections through the rake and flank faces of one of the $a c$ inserts, particularly the latter, a thin band was just discernible at the $\mathrm{Al}_{2} \mathrm{O}_{3}$ coating/Ti(C,N) precoating interface. An attempt to examine this band in greater detail at high magnification on an SEM using a back-scattered detector to obtain atomic number contrast unfortunately proved unsuccessful. However, it was noted during the microhardness tests that the low-angle $\left(5.6^{\circ}\right)$ taper section through the rake face of the $a c$ insert afforded a much clearer view of the band. It was therefore decided to employ the taper-sectioned insert to carry out a proper relatively high magnification optical examination of this band on the Reichert MeF2 microscope. To facilitate this, the low-angle taper section previously produced was re-lapped on the cast iron plate impregnated with $3 \mu \mathrm{m}$ diamond paste and then re-polished using the procedure previously detailed in Section 4.1.4. The typical appearance of the thin band at the $\mathrm{Al}_{2} \mathrm{O}_{3}$ coating/Ti(C,N) precoating interface on this taper section is illustrated in Figure 4.10.

\subsubsection{Fractography}

Fractography was employed to examine the bulk grain structure of the preliminary $\mathrm{Al}_{2} \mathrm{O}_{3}$ coating. This technique has similarly been used in previous work on $\mathrm{CVD} \mathrm{Al}_{2} \mathrm{O}_{3}$ coatings (see Section 2.8). The remaining half of the $a c$ insert previously slit for micro-examination in the present work (see Section 4.1.4) was employed for the fractography study. Following the method devised by Whittle [6], the diamond impregnated slitting saw referred to earlier (Section 4.1.4) was first used to cut a deep $(-2.9 \mathrm{~mm})$ central slit in the bottom of the ac insert to be examined. The insert was then ultrasonically cleaned in acetone followed by methanol and then fractured using a specially designed fixture, in which the lower half of the insert was clamped whilst a uniformly distributed load was applied to its upper half, causing fracture to occur evenly along the central slit (the use of this fixture generally, although not always, lead to the attainment of consistent coating fracture surfaces). The two pieces of fractured insert were then sputtered with gold and their rake face coating fracture surfaces examined on an SEM. It was found that the bulk grain structure of the $\mathrm{Al}_{2} \mathrm{O}_{3}$ coating was essentially uniform along its length, Figure 4.11 showing the typical $\mathrm{Al}_{2} \mathrm{O}_{3}$ coating bulk grain structure observed on the $a c$ insert. The surface grain structure of the $\mathrm{Al}_{2} \mathrm{O}_{3}$ coating on the rake face of the $a c$ insert was then determined by direct SEM observation. Figure 4.12 shows the typical $\mathrm{Al}_{2} \mathrm{O}_{3}$ coating surface grain structure observed. 


\subsection{Characterisation of Preliminary $\mathrm{CVD} \mathrm{Al} \mathrm{O}_{3}$ Coatings on Heat treated, Coated PM HSS inserts}

With the exception of scratch-adhesion testing (hereafter referred to simply as scratch testing), the characterisation of the preliminary $\mathrm{Al}_{2} \mathrm{O}_{3}$ coating on the four $h c$ inserts was carried out using the same characterisation techniques and procedures as previously employed in the case of the $a c$ inserts. Since these have been described in detail in the preceding section, it is not thought necessary to repeat their description here. The scratch tests will, of course, be described in full. The results obtained from the characterisation of the preliminary $\mathrm{Al}_{2} \mathrm{O}_{3}$ coating on the $h c$ inserts (with the exception of the scratch tests results) are presented in Figures 4.13 to 4.20 and in Tables 4.6 to 4.9 .

Scratch tests have previously been employed to assess the adhesion of $\mathrm{Al}_{2} \mathrm{O}_{3}$ coatings chemically vapour deposited on $\mathrm{TiC}[16,20,73]$ and on $\mathrm{TiN}[20]$ precoated cemented carbide substrates using testers similar to that employed in the present work (see Section 2.8). The scratch tester actually employed in the present work has been described in detail elsewhere [6] hence it is not proposed to repeat that description here other than to say that, in common with other scratch testers, the stylus used was a Rockwell C-scale diamond indentor with a tip radius of $0.2 \mathrm{~mm}$. For TiN coatings physically vapour deposited on steel substrates, the critical load during scratch testing has been found to increase with both increasing coating thickness $[70,71]$ and substrate hardness [71]. In view of these findings, it seemed prudent, prior to scratch testing of the $h c$ insert in the present work, to actually determine the thickness of the $\mathrm{Al}_{2} \mathrm{O}_{3}$ coating (and the $\mathrm{Ti}(\mathrm{C}, \mathrm{N})$ precoating) and the hardness of the PM HSS substrate of the $h c$ insert to be employed. As shown in Table 4.10, the values thus determined were, respectively, $1.44 \mu \mathrm{m}, 1.93 \mu \mathrm{m}$ and $912 \mathrm{HV} 30$. The direction in which the rake face of the $h c$ insert had originally been surface ground was then determined using optical microscopy, after which scratch tests were performed on the insert using the procedure described below.

The $h c$ insert to be tested was first located and clamped on the scratch tester table such that the scratches would be made in the same direction as that in which its rake face had originally been surface ground. Scratch tests were then carried out at a scratch speed of $10 \mathrm{~mm} \mathrm{~min}$, under stylus loads increasing in $0.5 \mathrm{~kg}$ increments from $1 \mathrm{~kg}$ to $10 \mathrm{~kg}$. After scratch testing, the $h c$ insert was ultrasonically cleaned in acetone followed by methanol. With reference to the ancillary techniques employed by Whittle [6], the scratches produced on the $h c$ insert in the present work were first examined on an optical microscope, beginning with the scratch channel produced at the stylus load of $1 \mathrm{~kg}$ and proceeding to those produced at higher stylus loads. Flaking was clearly observed at the edges of scratch channels produced at stylus loads of $3 \mathrm{~kg}$ and above. It was also observed that the scratch channels produced at stylus loads up to and including $5 \mathrm{~kg}$ were of a uniform dark purple appearance but that at a stylus load of 6 $\mathrm{kg}$ some orange/silvery areas were visible. At stylus loads of $7 \mathrm{~kg}$ and above, however, virtually the whole of the scratch channels was silvery in appearance. The latter contrasted starkly with 
the dark purple colour of the $\mathrm{Al}_{2} \mathrm{O}_{3}$ coating visible beyond their edges. However, this optical examination did not allow identification of the type of flaking observed nor the unequivocal determination of the critical stylus load, (i.e. the stylus load at which extensive coating removal from the scratch channel occurs). Consequently, it was decided to examine the scratch channels on an SEM fitted with an EDX analyser.

The $h c$ insert was first ultrasonically cleaned in acetone followed by methanol and then given an evaporated $C$ coating. The scratch channels on the insert were then examined on the SEM. Beginning with the examination of the edges of the scratch channels on the insert, it was determined that the lowest stylus load at which flaking of the coating actually occurred was $3 \mathrm{~kg}$, corroborating the earlier optical observation. A typical instance of this flaking together with the corresponding $\mathrm{Al}, \mathrm{Ti}$ and $\mathrm{Fe} K_{\alpha} \mathrm{X}$-ray maps is shown in Figure 4.21, allowing identification of the type of flaking observed. The scratch channels on the $h c$ insert corresponding to stylus loads of 5,6 and $7 \mathrm{~kg}$ were then studied. SEM micrographs of a typical region of each of these channels, together with the corresponding $\mathrm{Al}, \mathrm{Ti}$ and $\mathrm{Fe} K_{\mathrm{a}} \mathrm{X}$-ray maps are shown in Figures 4.22 to 4.24 .

It should be noted that the reason scratch tests were not carried out on the $a c$ as well as the $h c$ inserts was that, as mentioned earlier in this section, the critical load during scratch testing has previously been found to increase with increasing substrate hardness. The difference in hardness of the HSS substrate of the $a c$ and $h c$ inserts (see Table 4.11) would therefore have precluded any meaningful comparison of scratch test behaviour.

\subsection{Epilogue}

Although the results presented in this chapter will be fully discussed in Chapter 6 , with the relevant conclusions summarised in Chapter 7 , it is pertinent at this point to pause to briefly consider their significance. First, by comparison of the characteristics determined for the preliminary $\mathrm{Al}_{2} \mathrm{O}_{3}$ coating on the $a c$ inserts and on the $h c$ inserts, it can be deduced that the post-coating heat treatment of the HSS substrate of the inserts has not significantly affected the characteristics of the preliminary $\mathrm{Al}_{2} \mathrm{O}_{3}$ coatings. This is important since it allows any further characterisation work to be conducted on inserts in their $a c$ as well as in their $h c$ condition. Second, comparison of the characteristics of the preliminary $\mathrm{Al}_{2} \mathrm{O}_{3}$ coating deposited in the present work with those previously determined for $\mathrm{CVD} \mathrm{Al}_{2} \mathrm{O}_{3}$ coatings on cemented carbide substrates by other investigators (see Chapter 2), clearly reveals the former to be inferior in several respects. These will be identified and fully discussed in Chapter 6 . As described in detail in Sections 2.1 to 2.5, it has previously been established that the process parameters employed during the CVD of $\mathrm{Al}_{2} \mathrm{O}_{3}$ coatings (on to substrates other than HSS; principally cemented carbide) have a significant effect on coating characteristics. Consequently, in order, ultimately, to improve upon the characteristics of the preliminary 
$\mathrm{Al}_{2} \mathrm{O}_{3}$ coating obtained in the present work, it was decided to continue the experimental work of this thesis by carrying out a major study of the effect of two of the most significant CVD process parameters, namely $\mathrm{CO}_{2} / \mathrm{H}_{2}$ mole ratio and $\mathrm{AlCl}_{3}$ reactant gas concentration (analogous to $\mathrm{AlCl}_{3}$ partial pressure), on the characteristics of $\mathrm{Al}_{2} \mathrm{O}_{3}$ coatings chemically vapour deposited on the PM BT42 grade HSS inserts. This work is presented in the following chapter. 


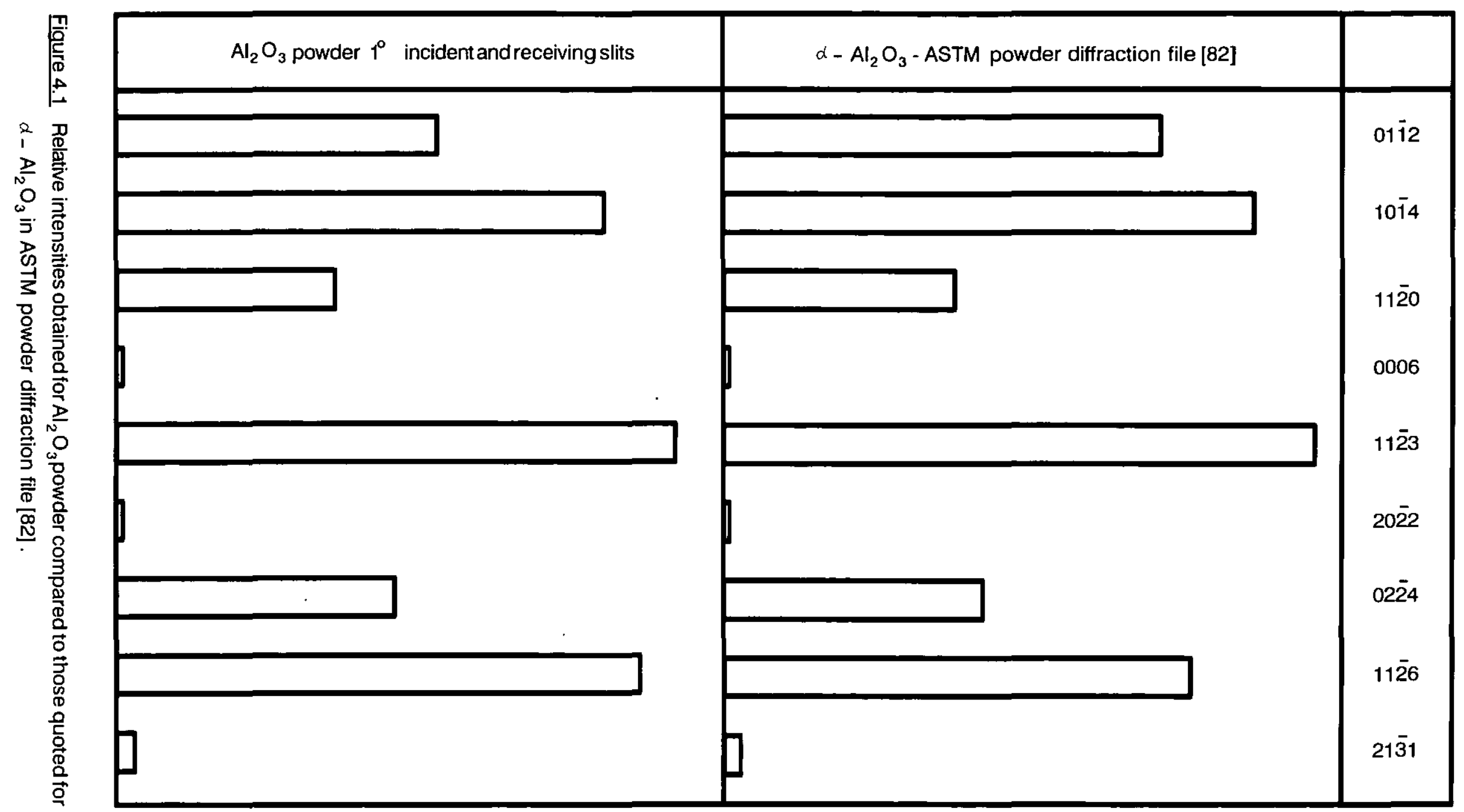




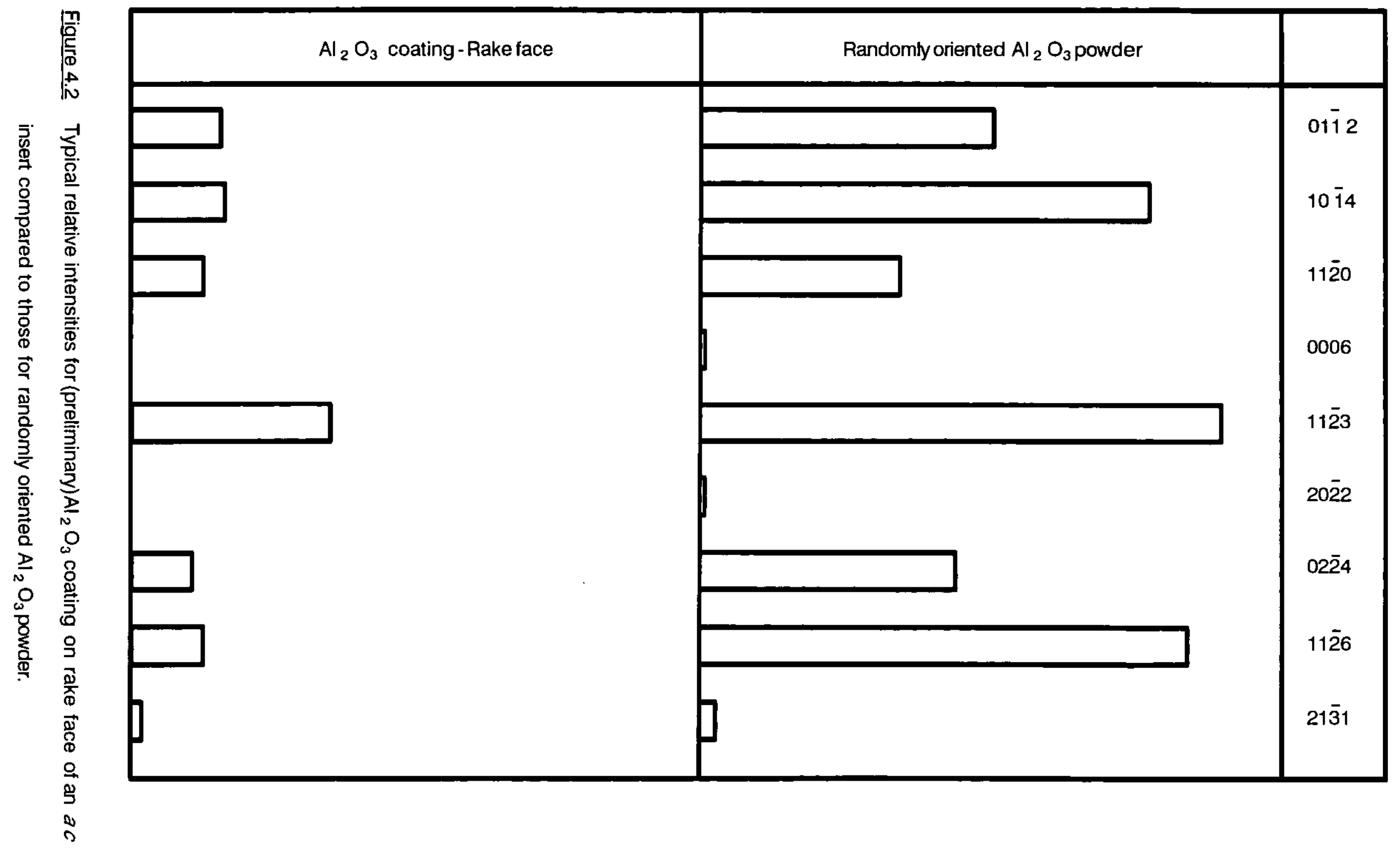




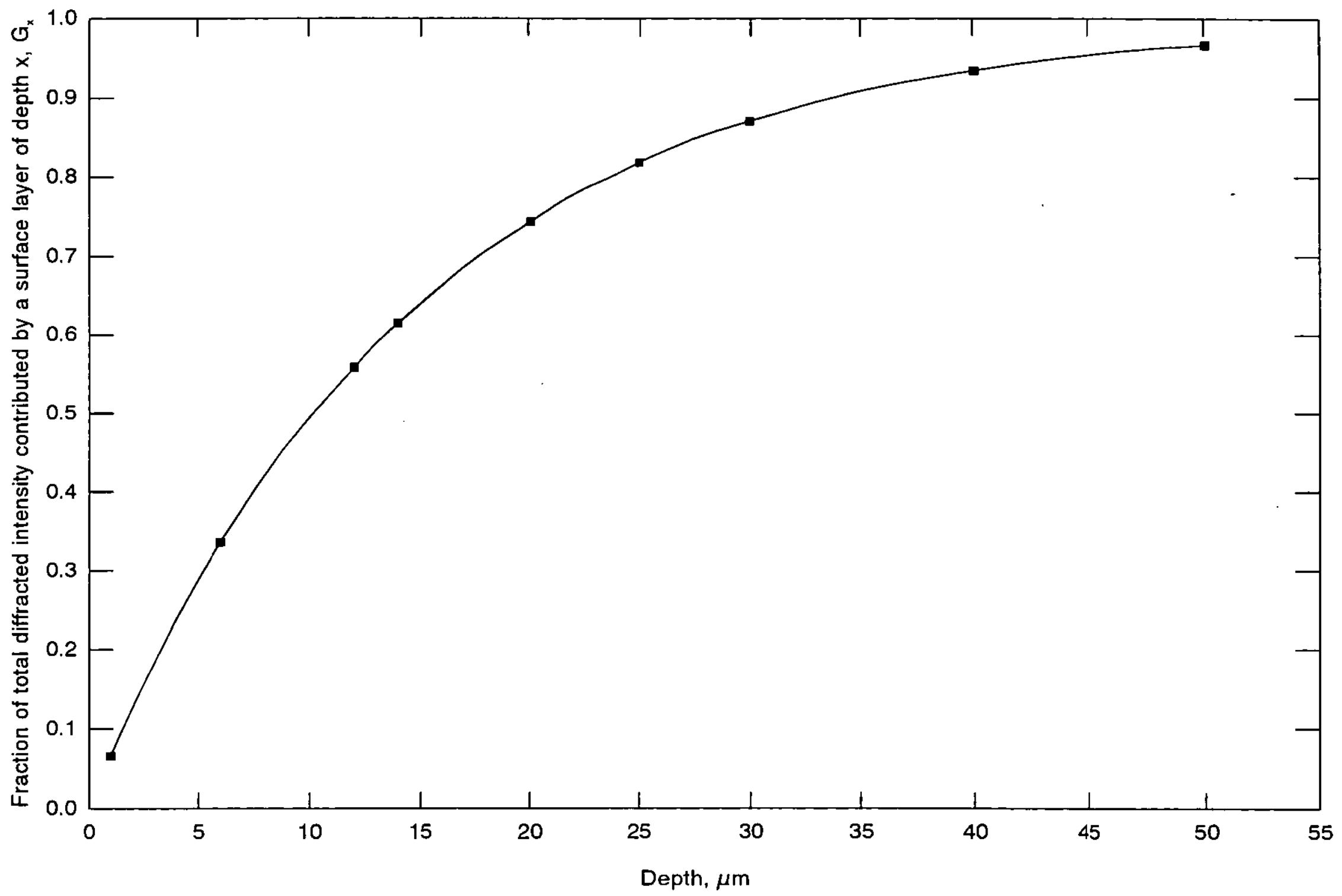

Figure 4.3 Graph of $\mathrm{G}_{x}$ versus $x$ for (112̄3) planes in stoichiometric $\mathrm{Al}_{2} \mathrm{O}_{3}$. 


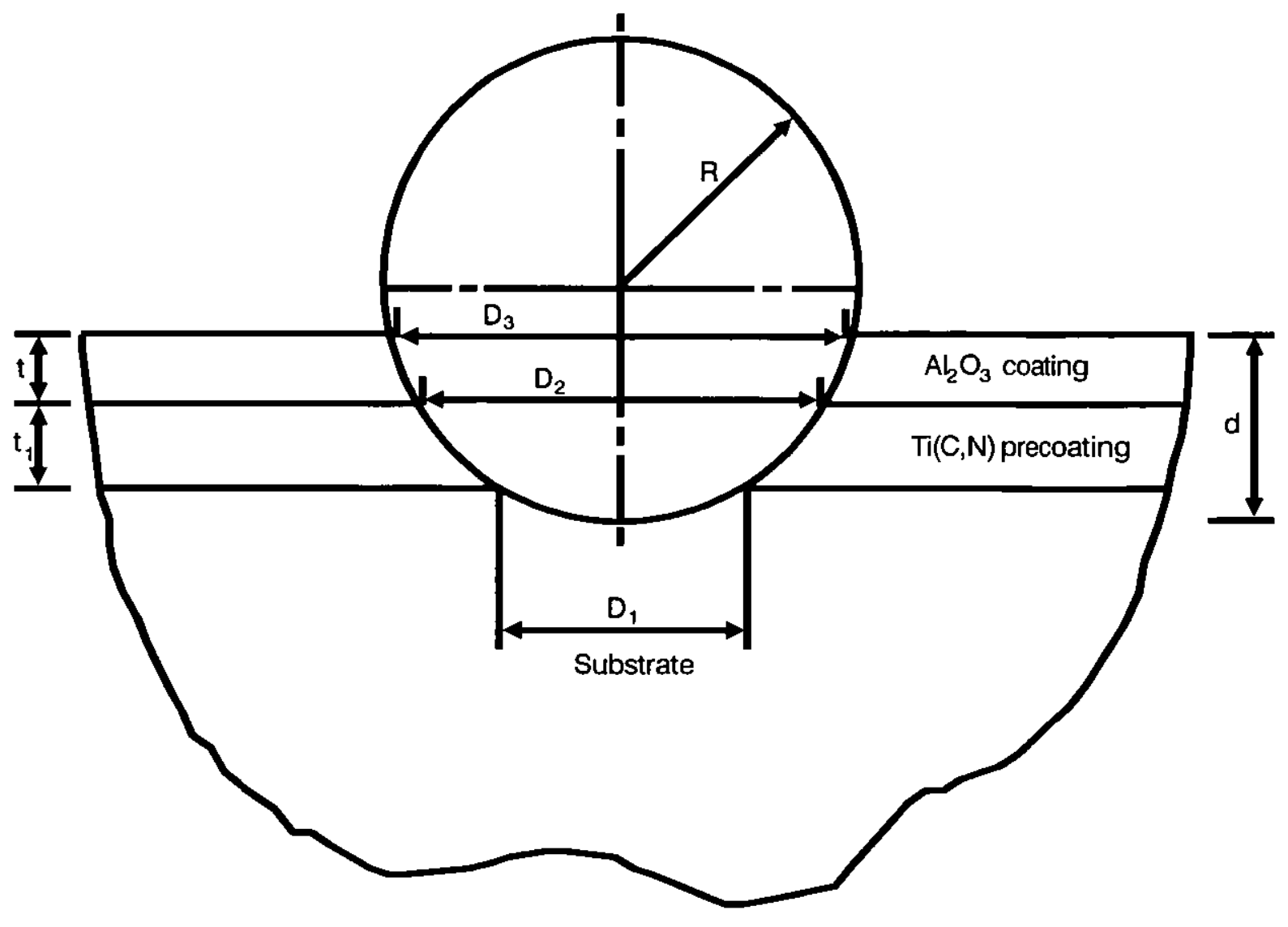

Figure 4.4 Schematic diagram of ball-crater in surface of an $\mathrm{Al}_{2} \mathrm{O}_{3} / \mathrm{Ti}(\mathrm{C}, \mathrm{N})$ precoated sample. 


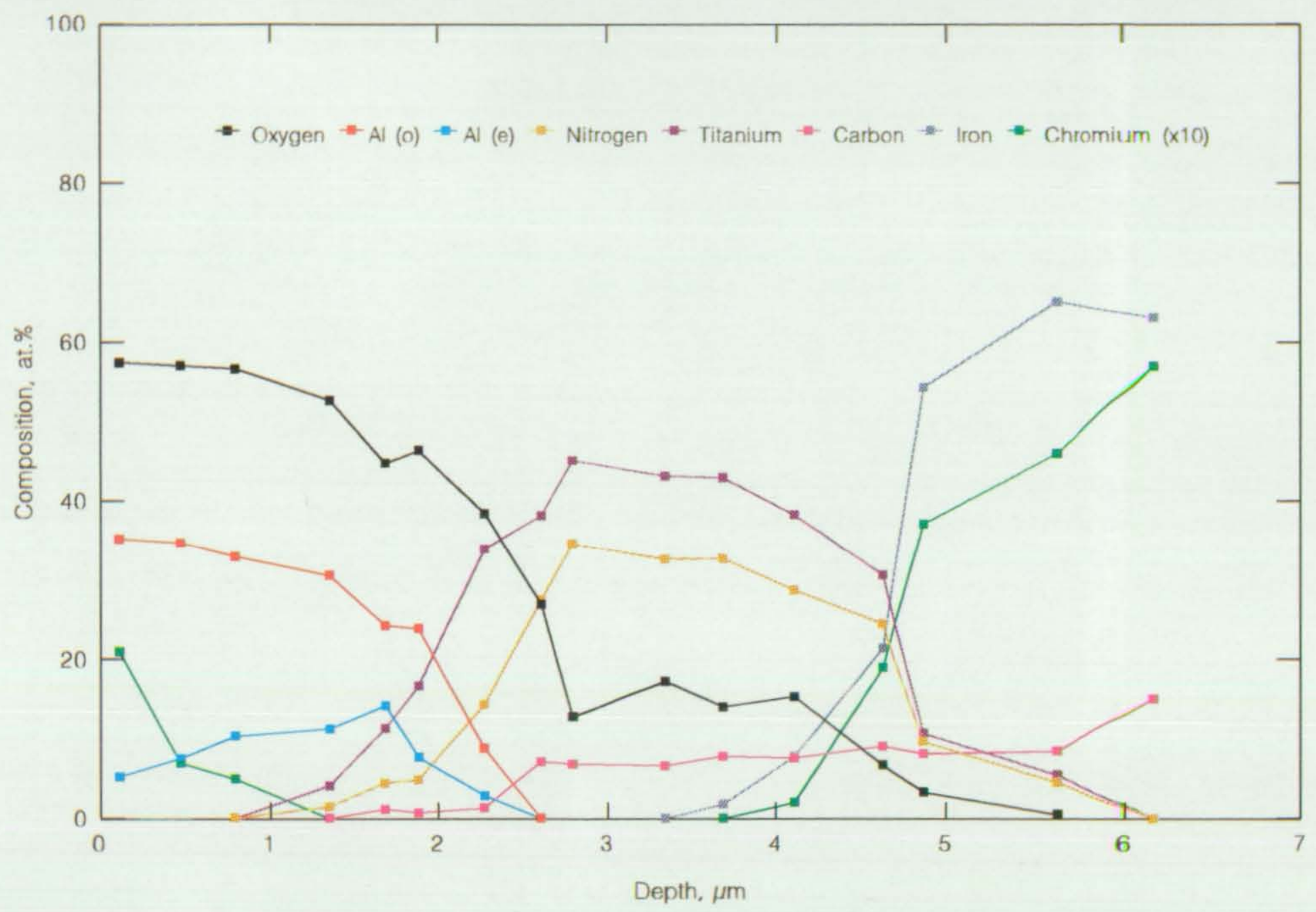

Figure 4.5 Composition-depth profile through (preliminary) $\mathrm{Al}_{2} \mathrm{O}_{3}$ coating and $\mathrm{Al}_{2} \mathrm{O}_{3}$ coating/Ti(C.N) precoating interface (extending through $\mathrm{Ti}(\mathrm{C}, \mathrm{N})$ precoating and Ti (C,N) precoating/HSS substrate interface) of an ac insert. 


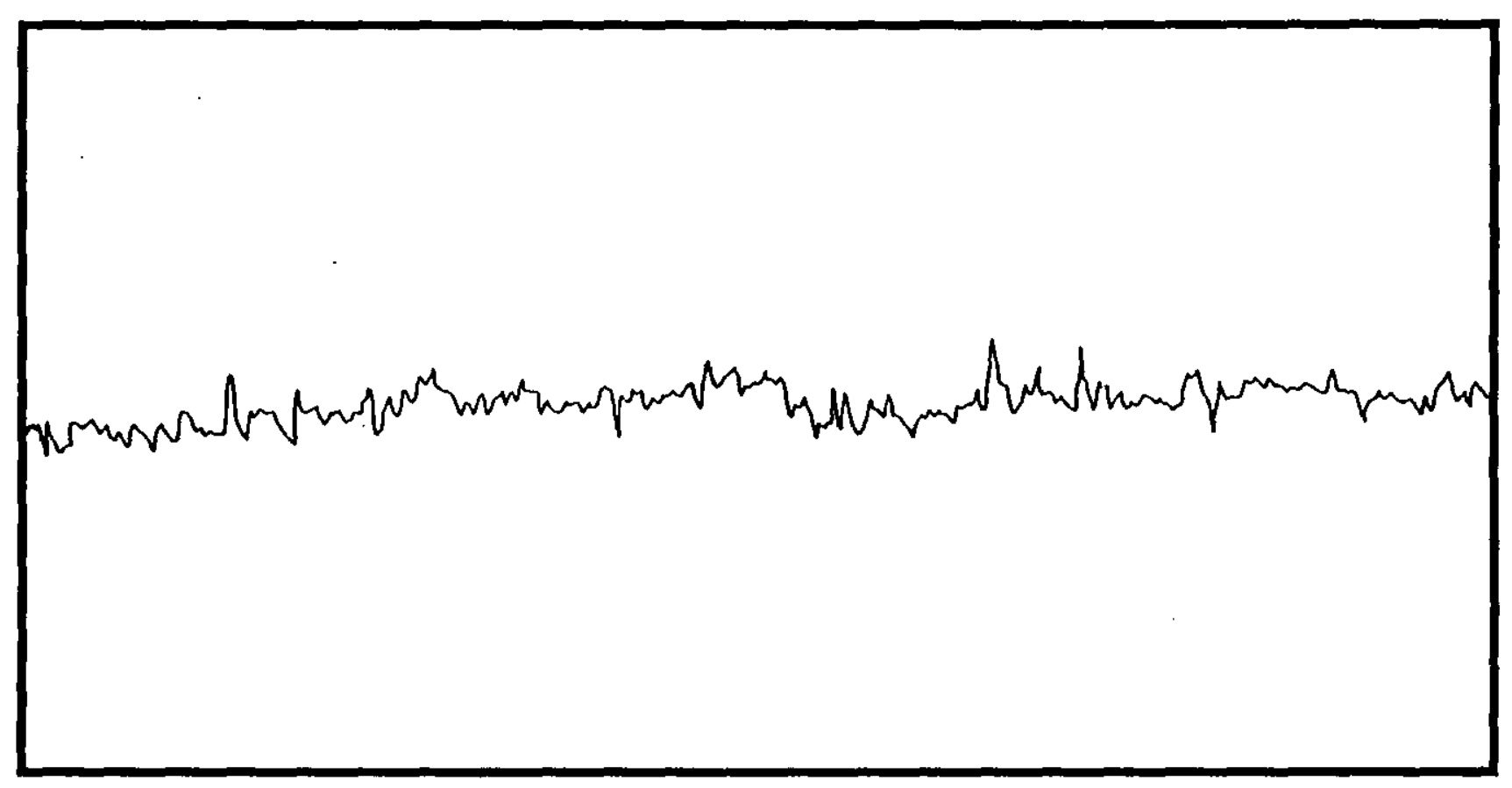

Figure 4.6 Typical Talysurf trace of preliminary $\mathrm{Al}_{2} \mathrm{O}_{3}$ coating on an $a c$ insert. 


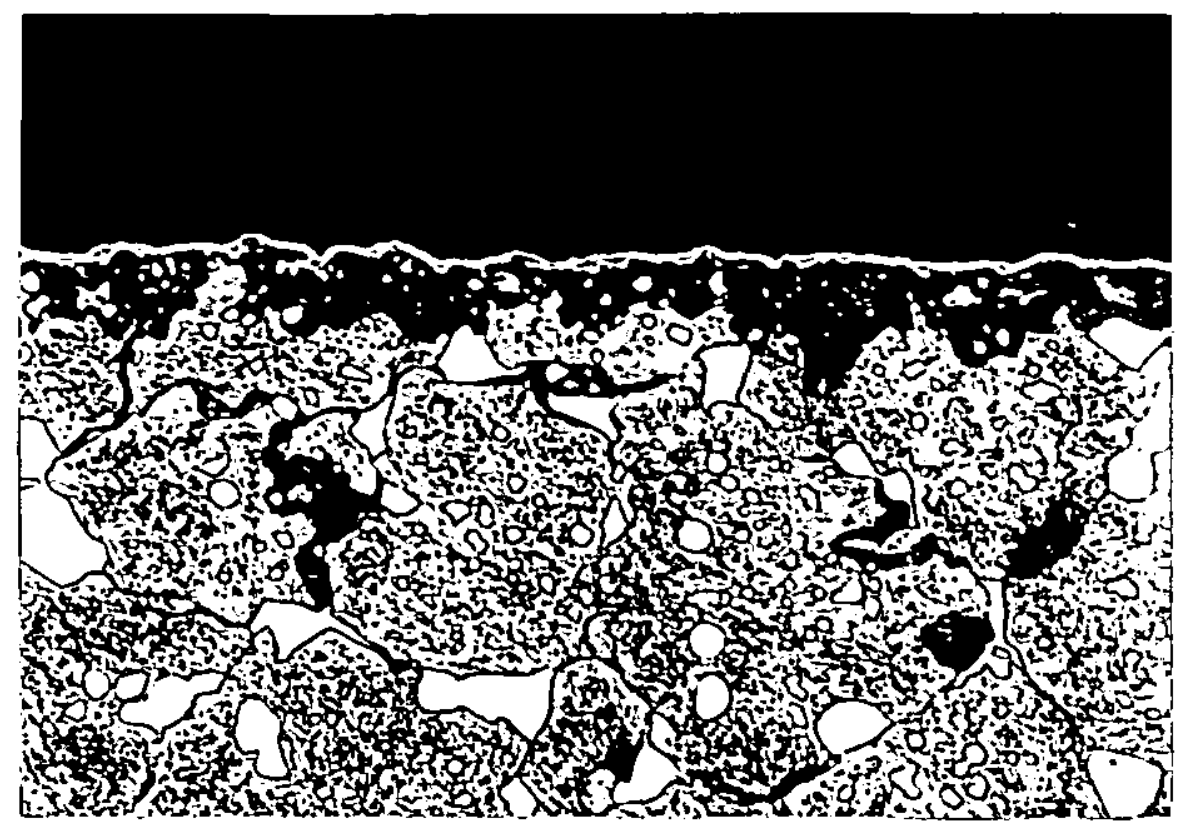

(a) Rake surface

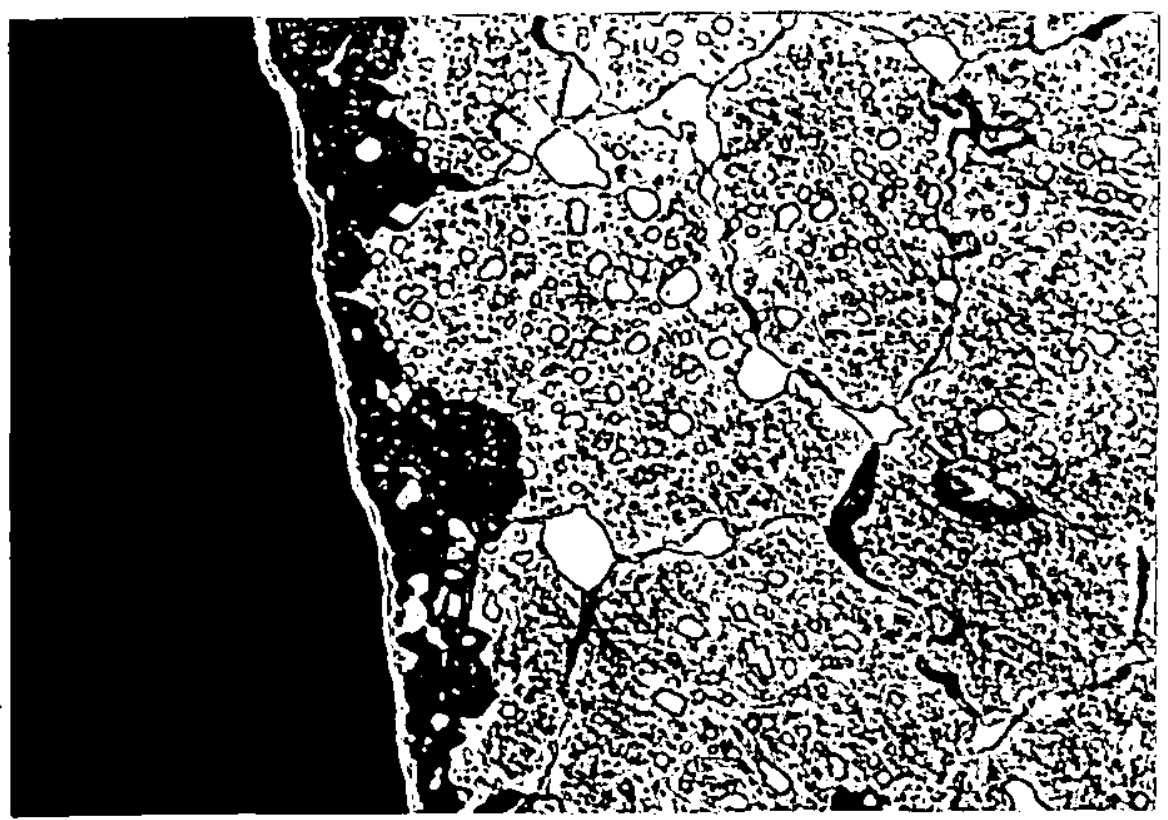

(b) Flank surface

Eigure 4.7 Optical cross-sections through rake and flank faces of an $a c$ insert. Etchant $2 \%$ nital, $\mathbf{x} 1000$. 


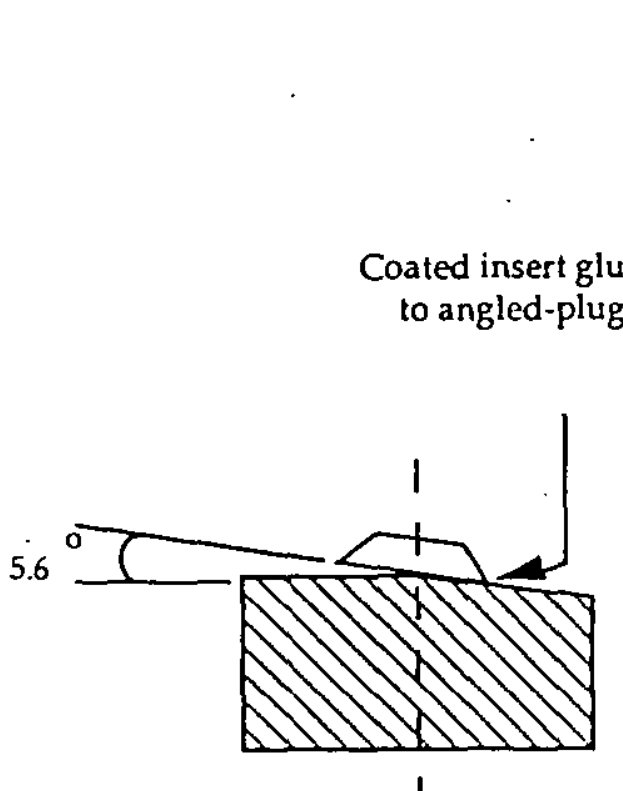

(a)

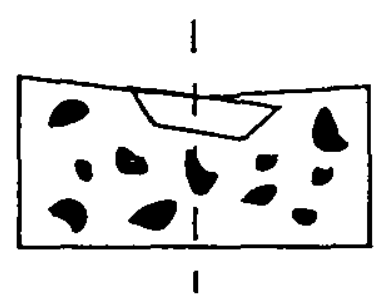

(c)

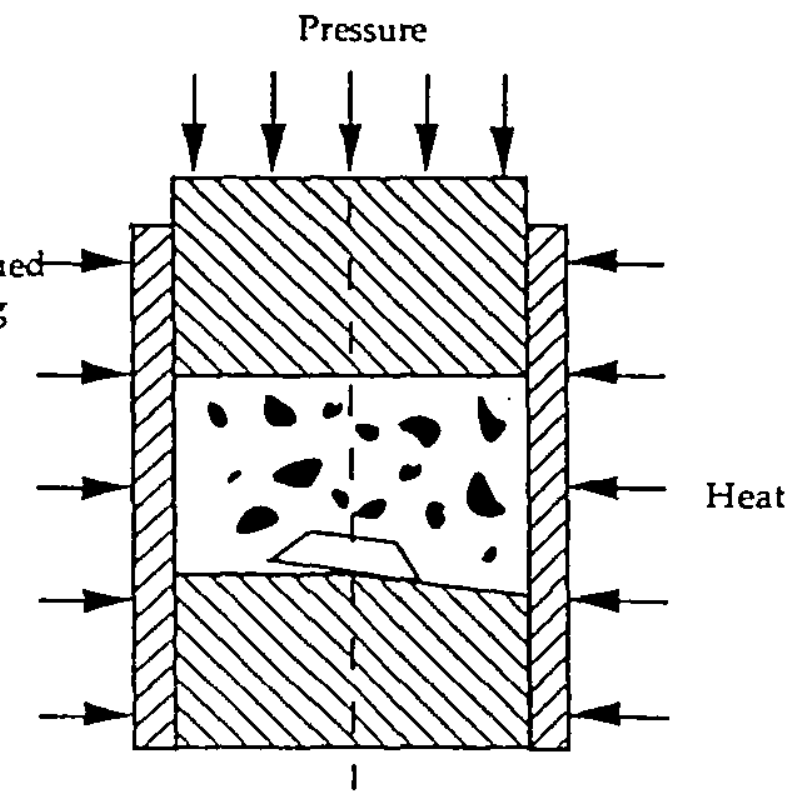

(b)

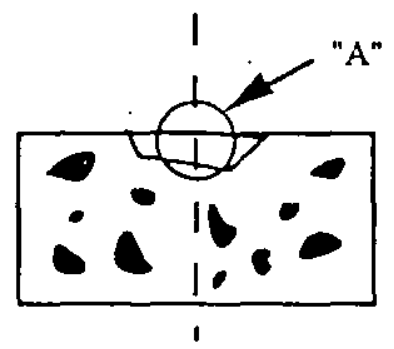

(d)

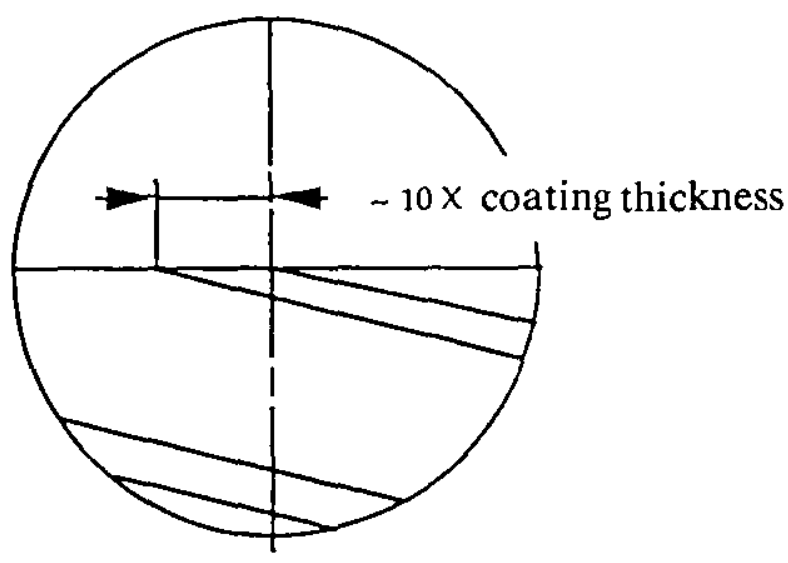

(e)

Figure 4.8 Preparation of a low-angle taper section (schematic) [ 6].

(a) Rake face of coated insert glued to angled-plug.

(b) Coated insert mounted in Buehler "Epomet".

(c) Resulting mount.

(d) Mount ground parallel to its base.

(e) Magnified view of region " $\mathrm{A}$ " showing taper-sectioned coating. 


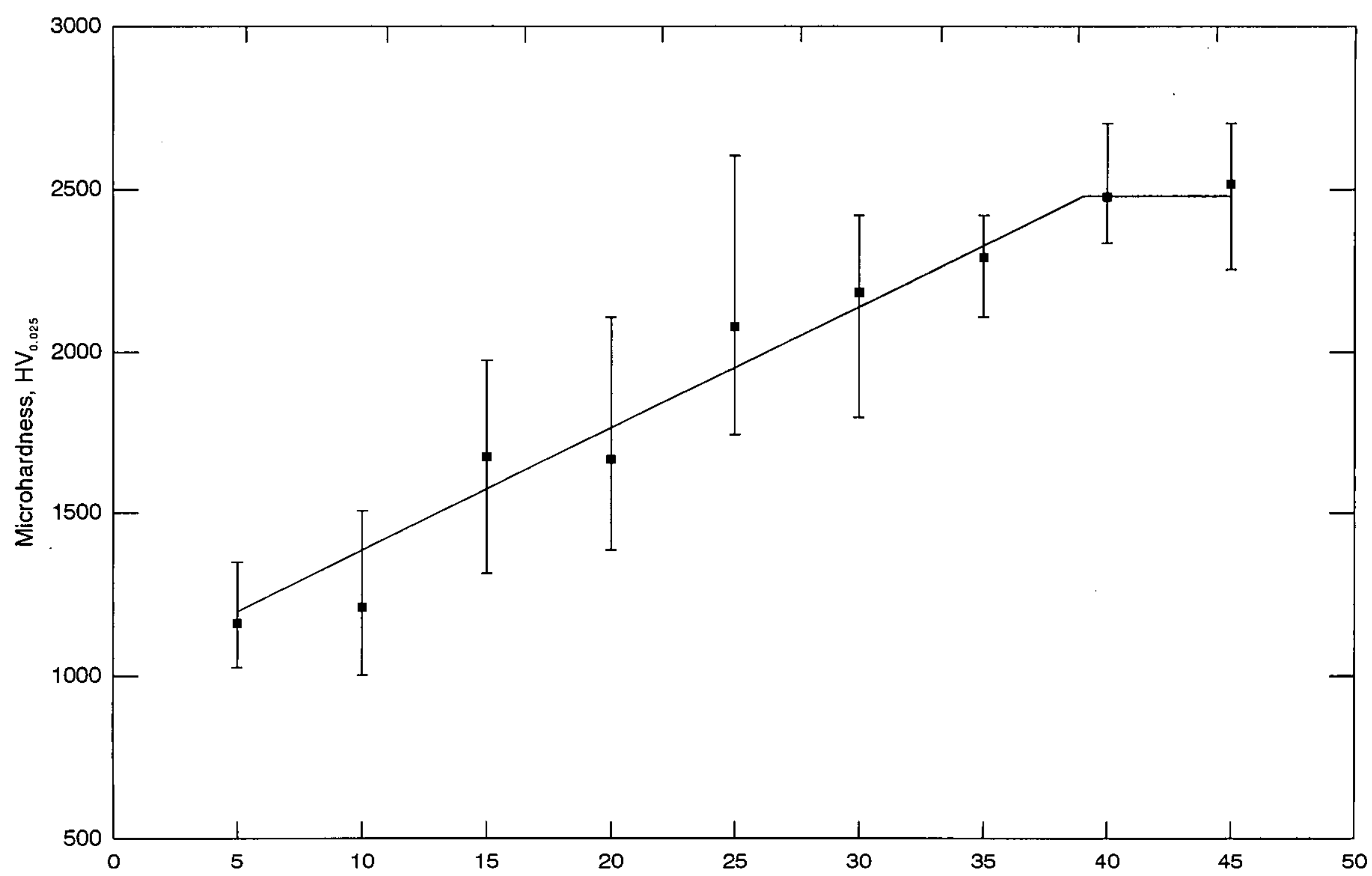

Distance from $\mathrm{Al}_{2} \mathrm{O}_{3}$ coating/Ti(C,N) precoating interface, $\mu \mathrm{m}$

Figure 4.9 Measured variation in microhardness of (preliminary) $\mathrm{Al}_{2} \mathrm{O}_{3}$ coating on a taper-sectioned, ac insert with distance from $\mathrm{Al}_{2} \mathrm{O}_{3}$ coating/Ti(C,N) precoating interface. 


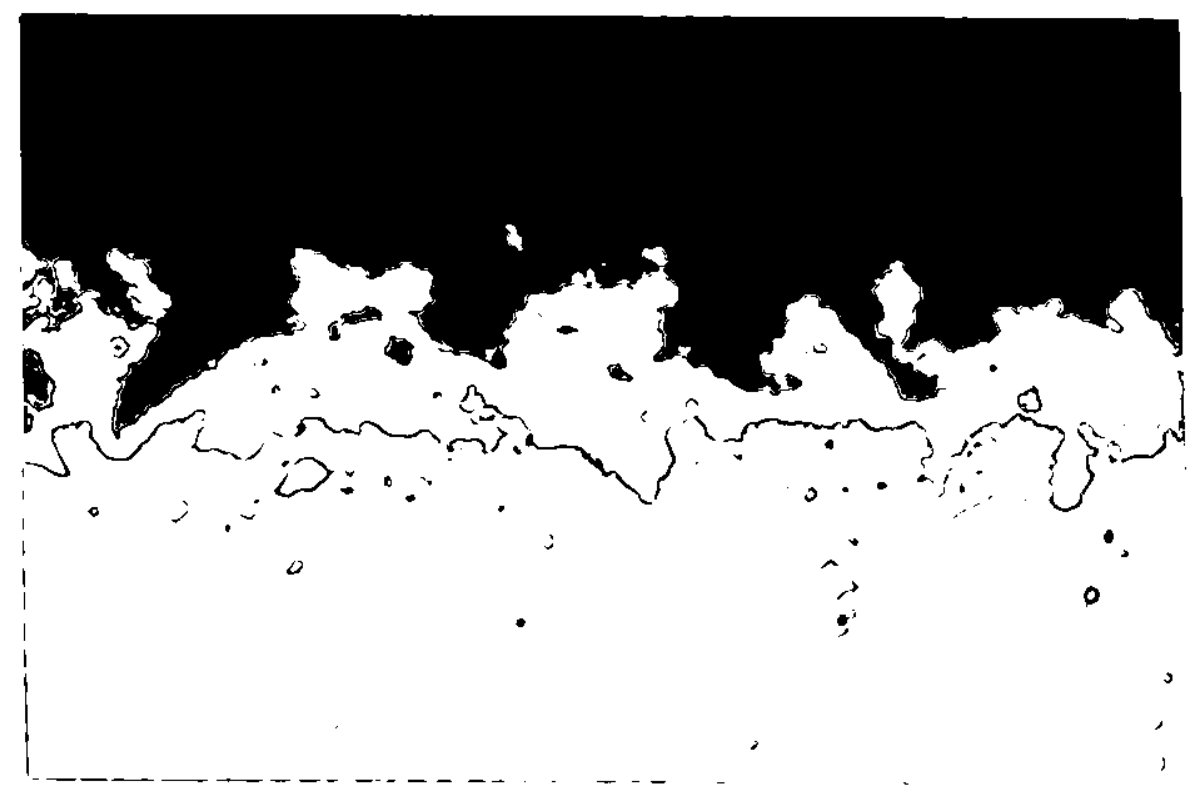

Figure 4.10 Low-angle (5.6 $)$ optical taper-section through (preliminary) $\mathrm{Al}_{2} \mathrm{O}_{3}$ coating $/ \mathrm{Ti}(\mathrm{C}, \mathrm{N})$ precoating interface on an ac insert. $\mathrm{x} 1000$.

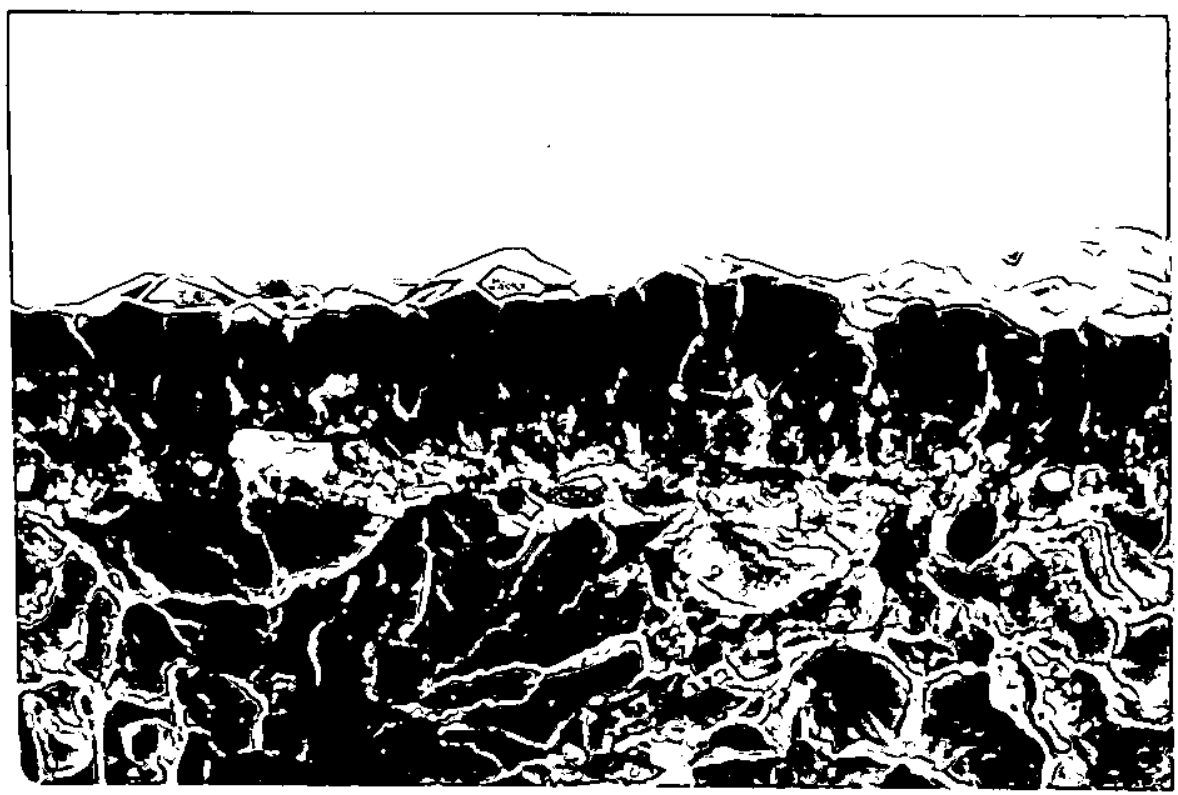

Eigure 4.11 Bulk grain structure of (preliminary) $\mathrm{Al}_{2} \mathrm{O}_{3}$ coating on an $a c$ insert. $\times 5000$.

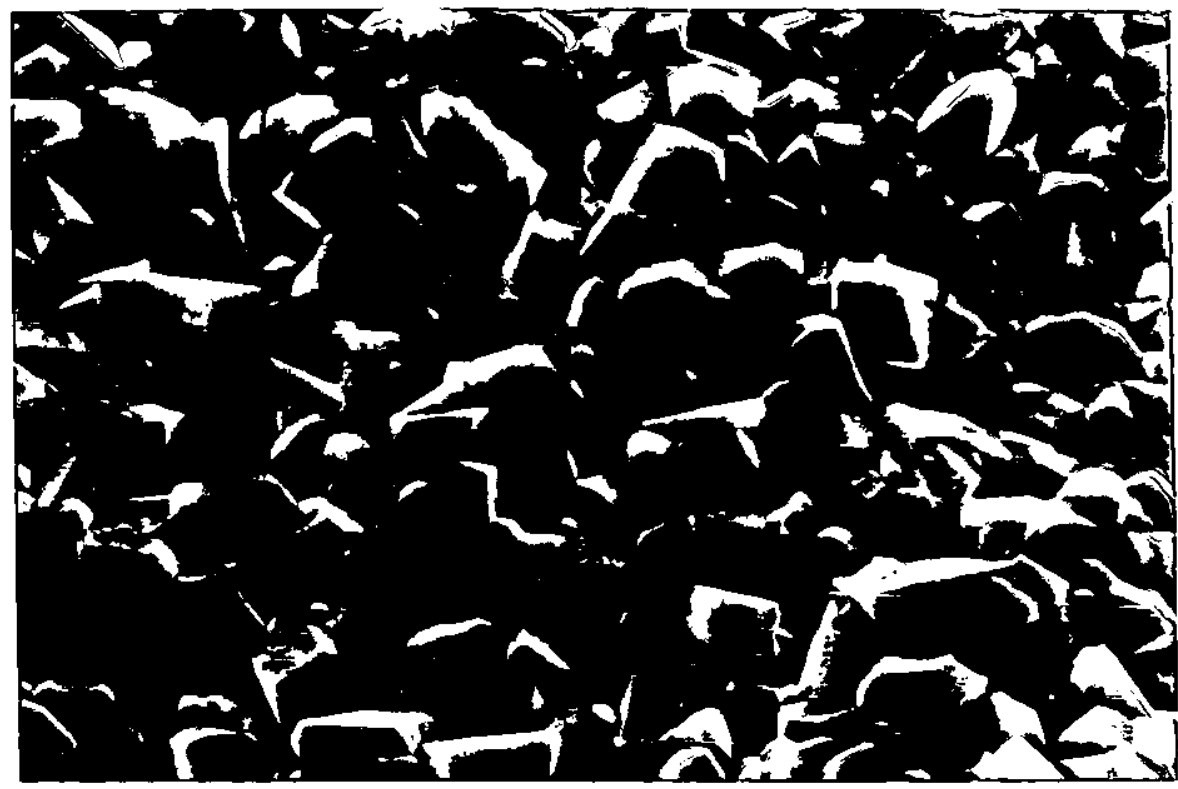

Figure 4.12 Surface grain structure of (preliminary) $\mathrm{Al}_{2} \mathrm{O}_{3}$ coating on an ac insert. $\times 5000$. 


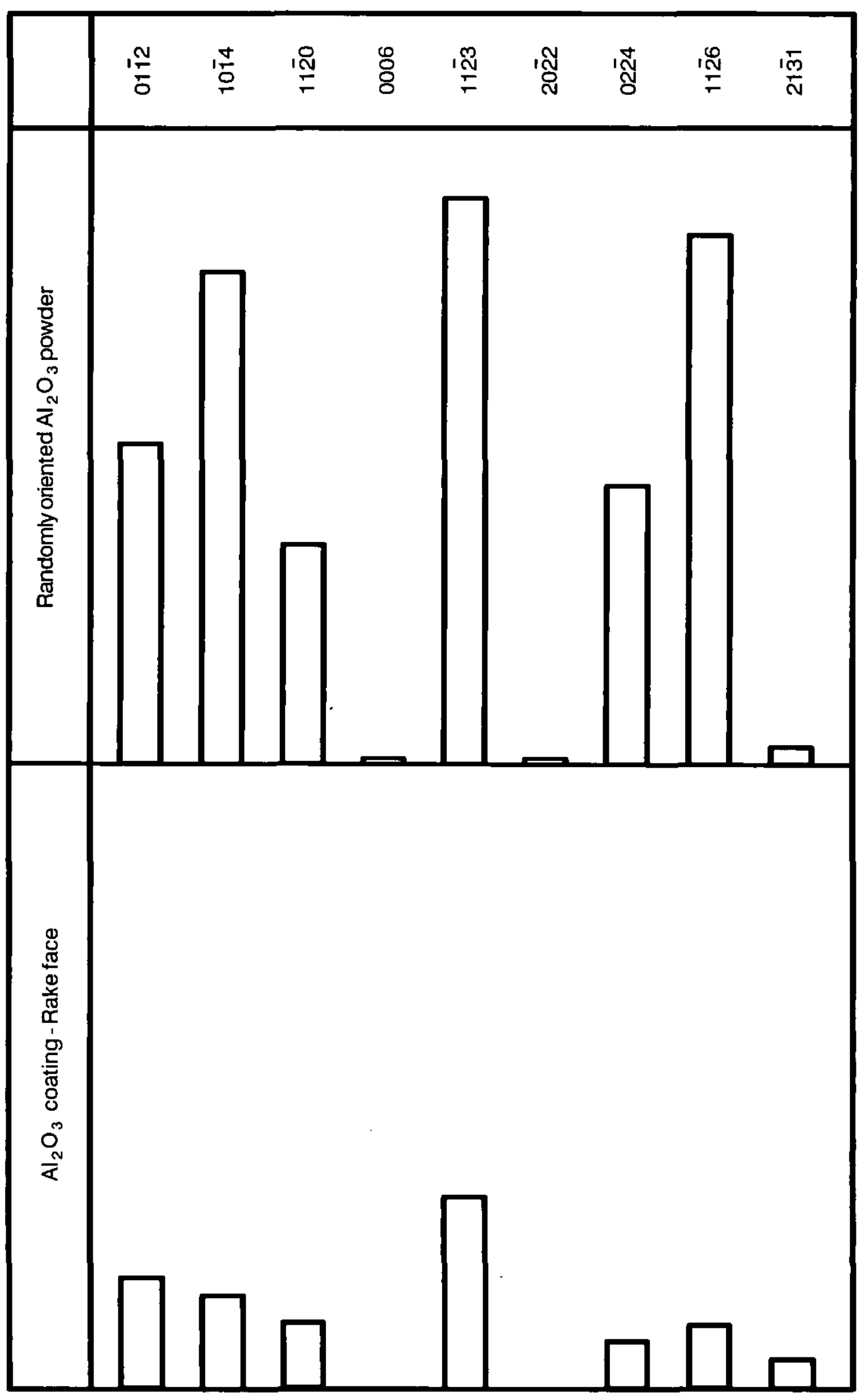

Figure 4.13 Typical relative intensities for (preliminary) $\mathrm{Al}_{2} \mathrm{O}_{3}$ coating on rake face of a $h C$ insert compared to those for randomlyoriented $\mathrm{Al}_{2} \mathrm{O}_{3}$ powder. 


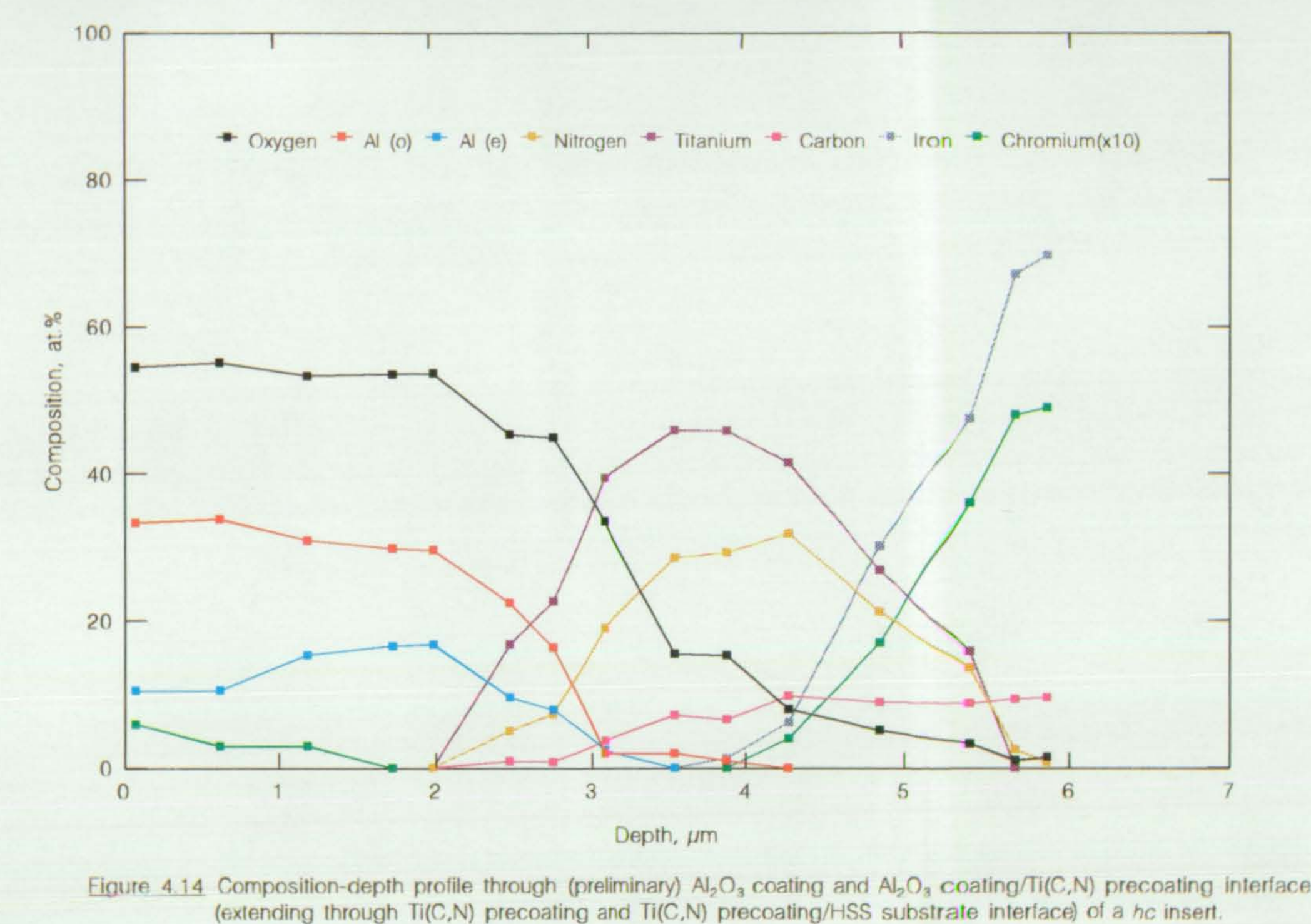




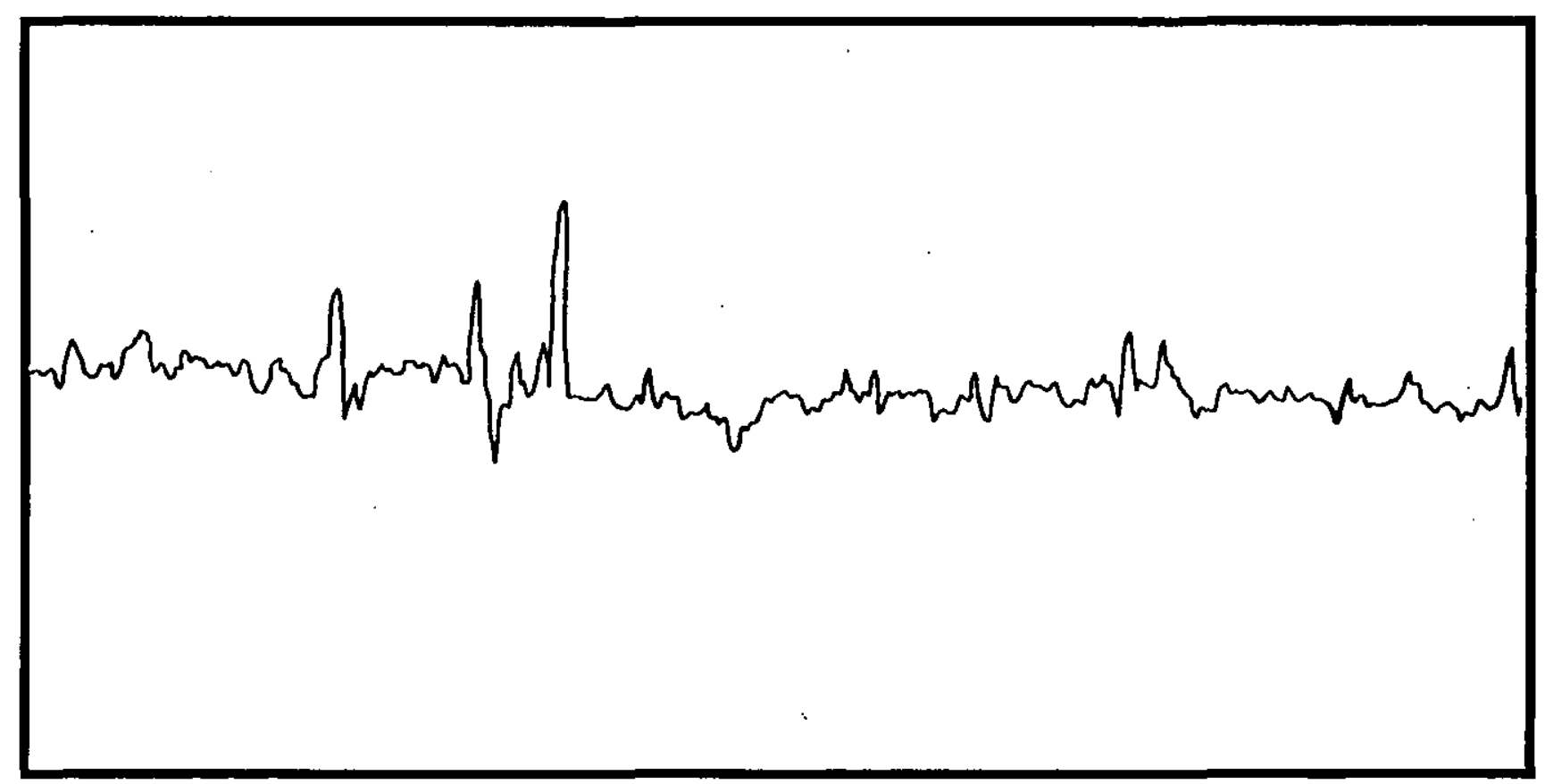

Eigure 4.15 Typical Talysurf trace of preliminary $\mathrm{Al}_{2} \mathrm{O}_{3}$ coating on a. $h c$ insert. 


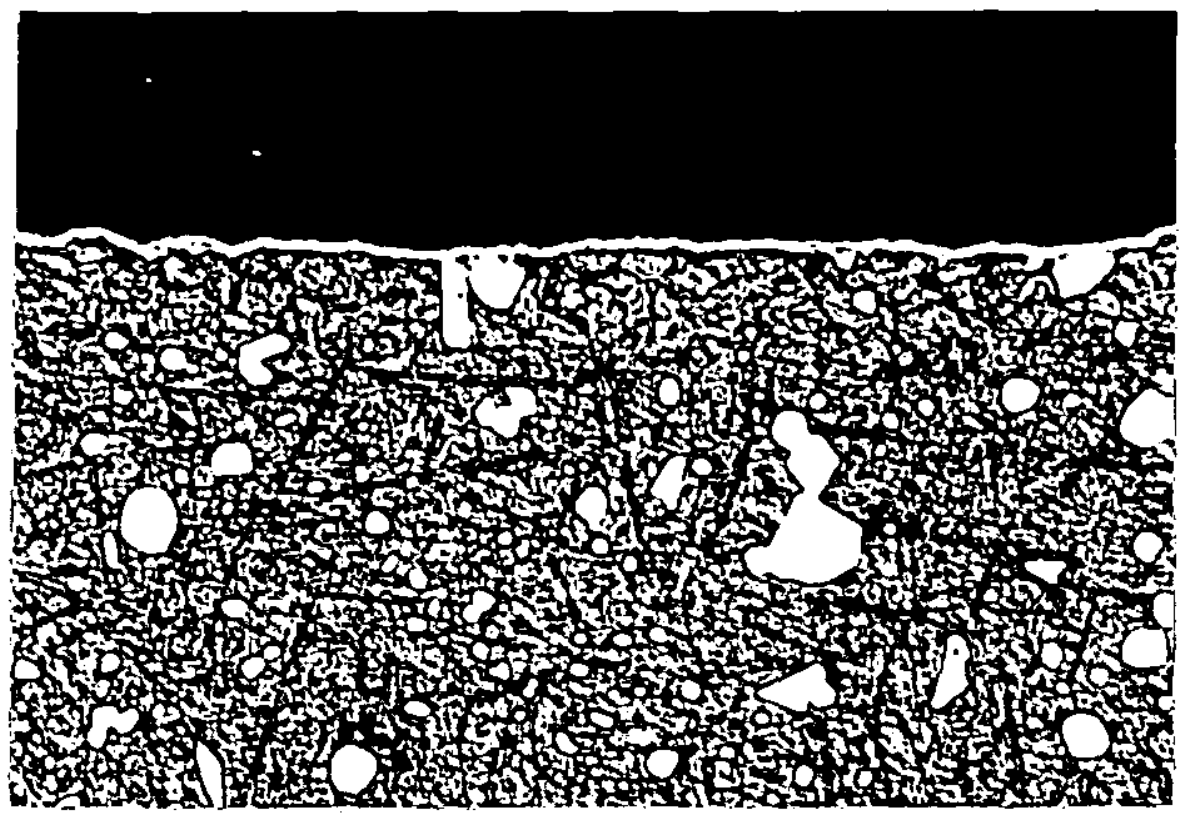

(a) Rake surface

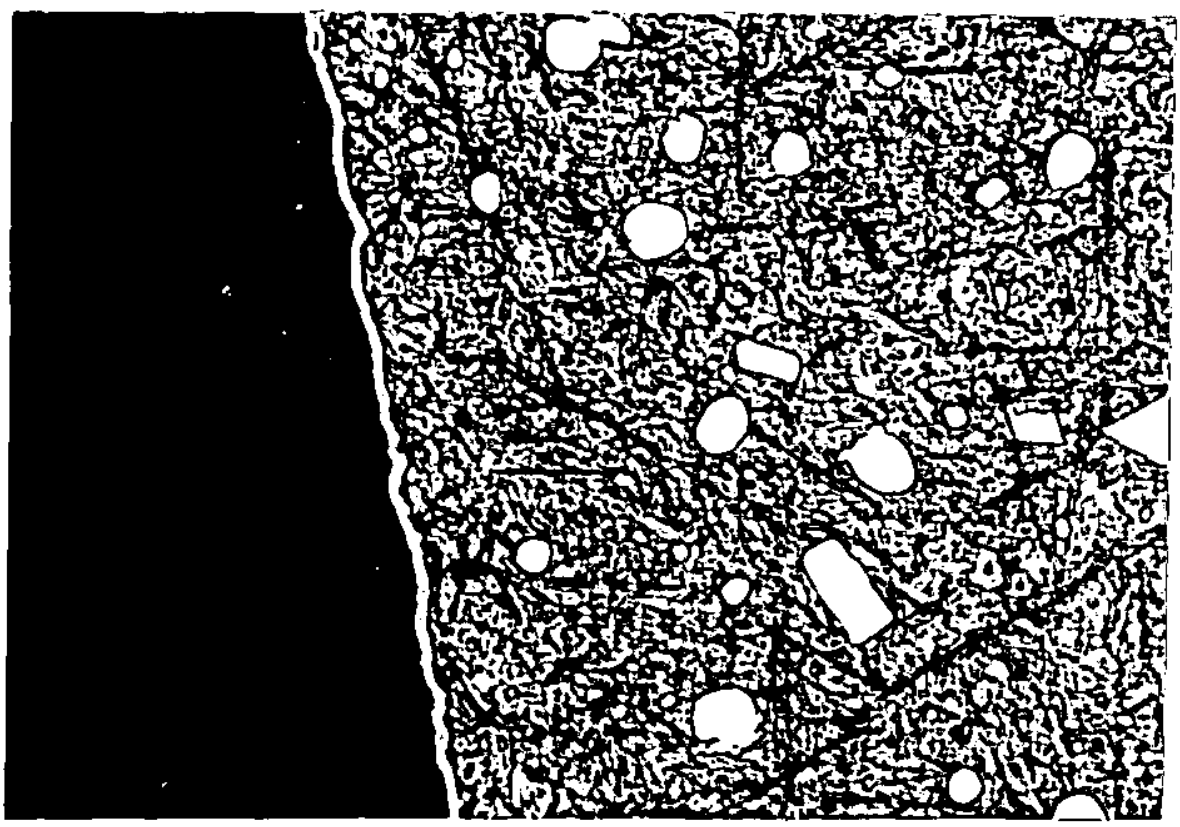

(b) Flank surface

Figure 4.16 Optical cross-sections through rake and flank faces of a $h c$ insert. Etchant $2 \%$ nital, $x 1000$. 


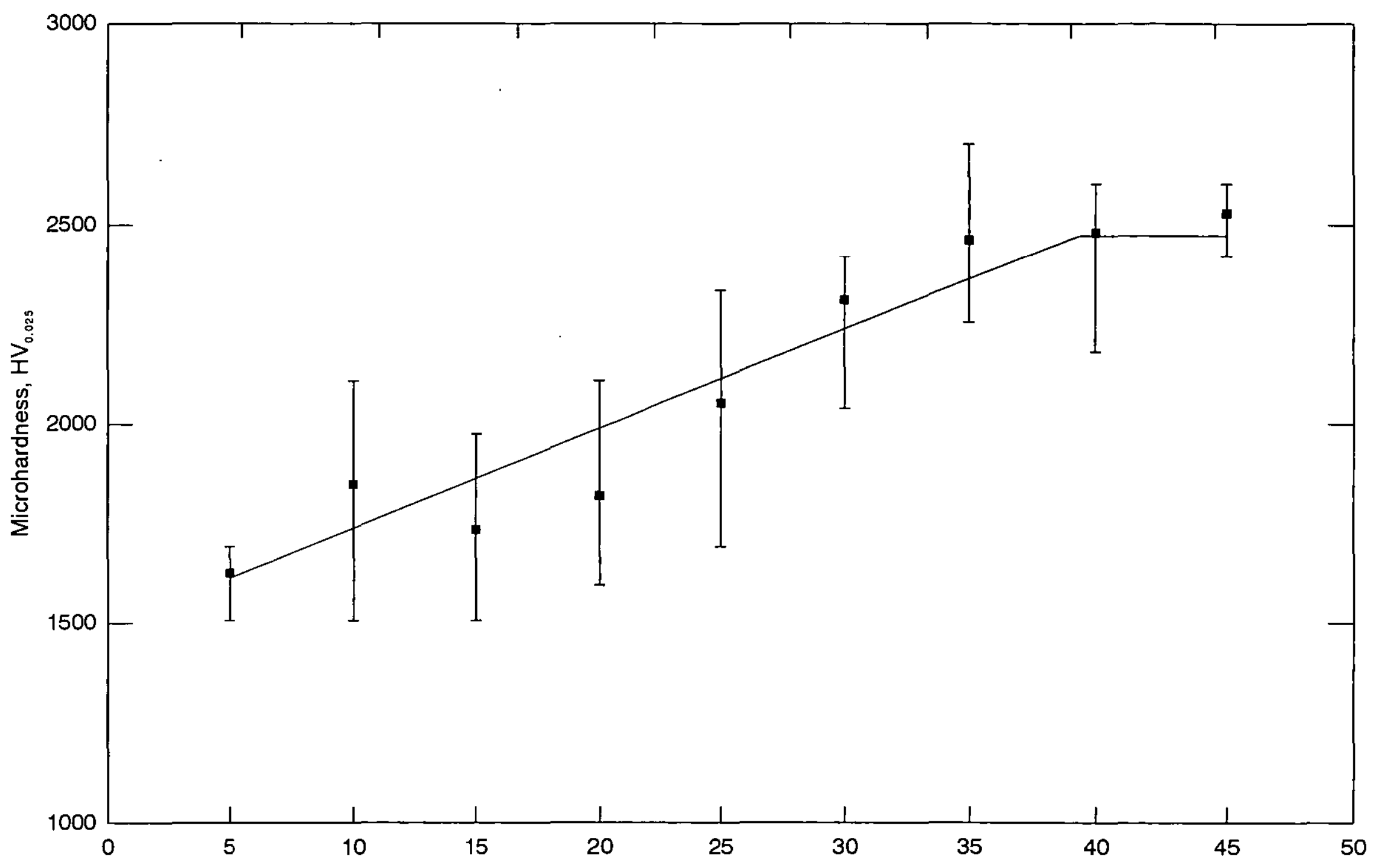

Distance from $\mathrm{Al}_{2} \mathrm{O}_{3}$ coating/Ti(C,N) precoating interface, $\mu \mathrm{m}$

Fiqure 4.17 Measured variation in microhardness of (preliminary) $\mathrm{Al}_{2} \mathrm{O}_{3}$ coating on a taper-sectioned, $h c$ insert with distance from $\mathrm{Al}_{2} \mathrm{O}_{3}$ coating/Ti(C,N) precoating interface. 


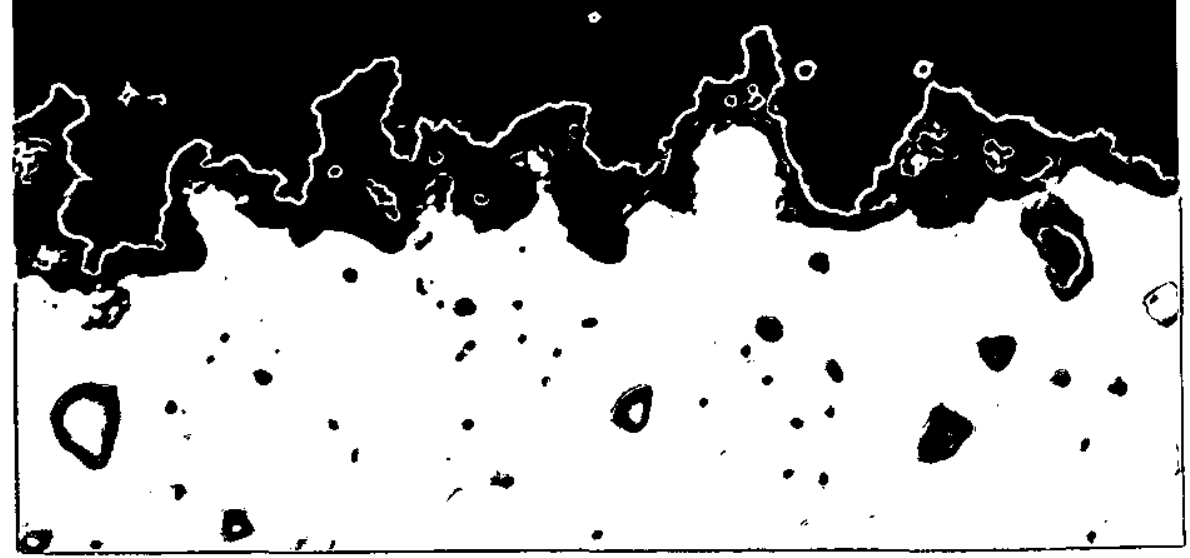

Figure 4.18 Low-angle (5.6 $)$ optical taper-section through (preliminary) $\mathrm{Al}_{2} \mathrm{O}_{3}$ coating $T i(C, N)$ precoating interface on a $h c$ insert. $x 1000$.

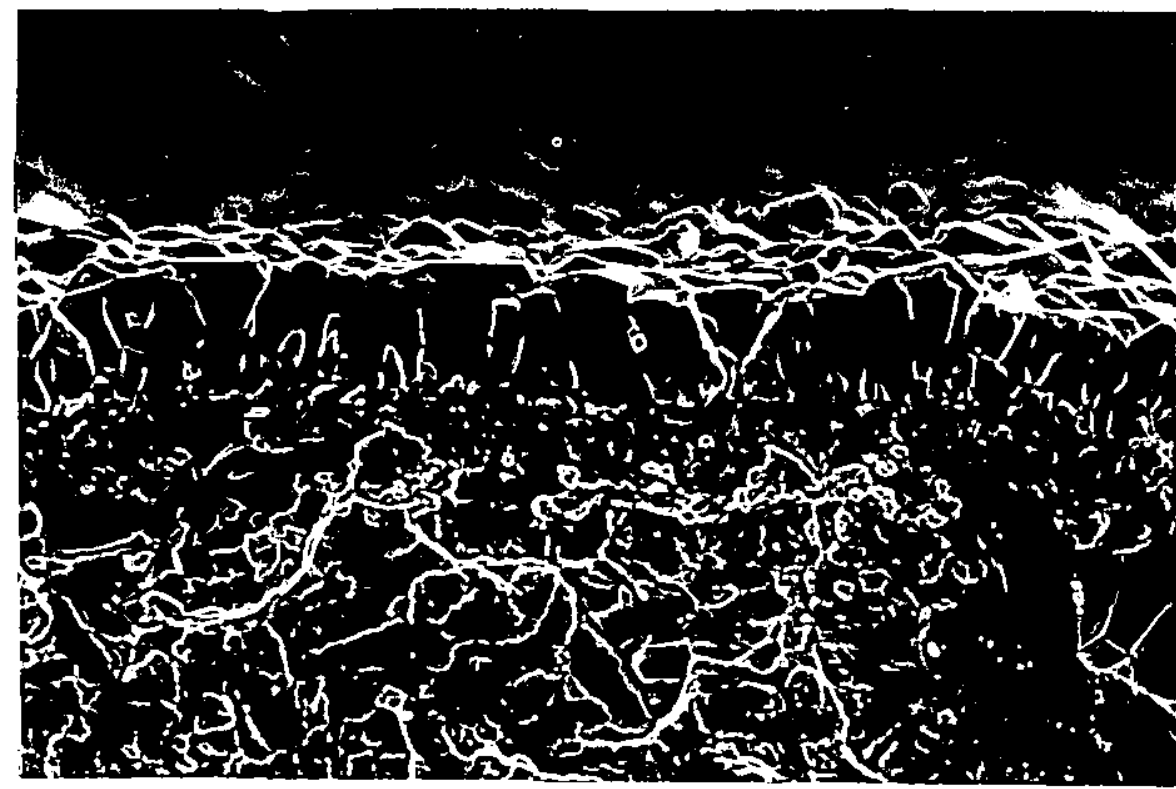

Figure 4.19 Bulk grain structure of (preliminary) $\mathrm{Al}_{2} \mathrm{O}_{3}$ coating on a $h c$ insert. $\times 5000$.

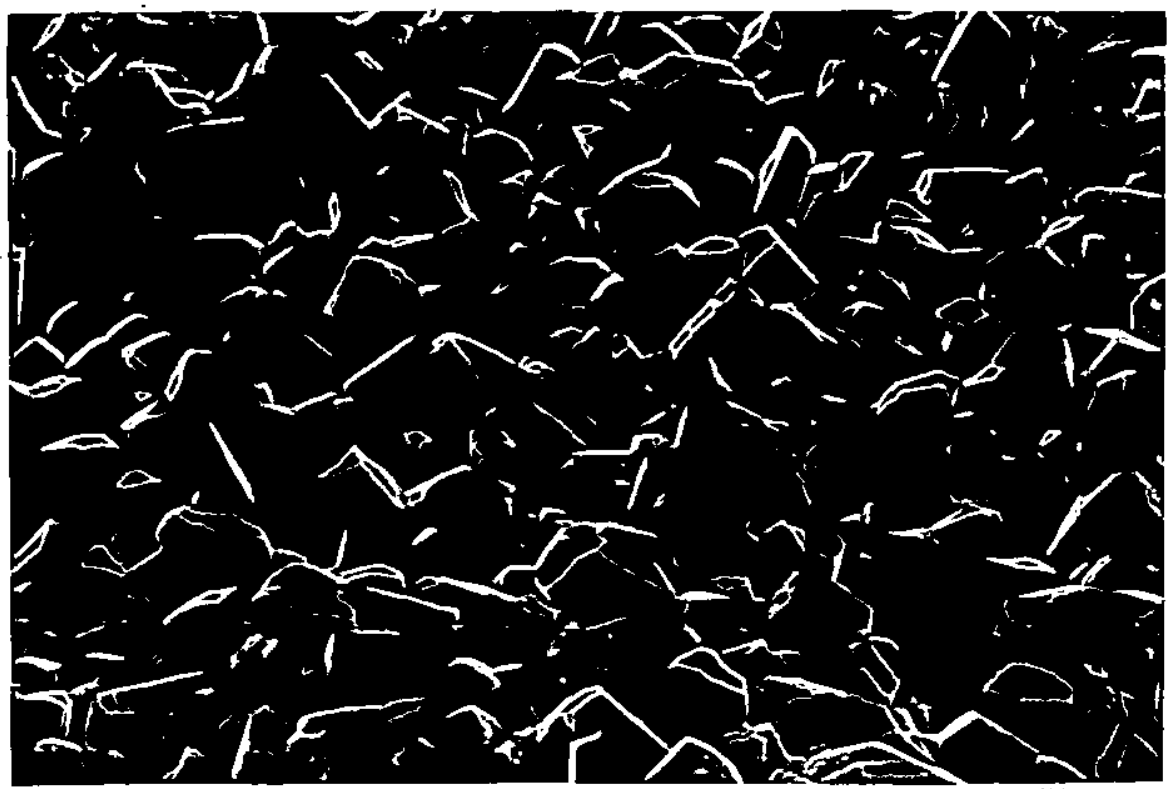

Figure 4.20 Surface grain structure of (preliminary) $\mathrm{Al}_{2} \mathrm{O}_{3}$ coating on a $h c$ insert. $\mathrm{x} 5000$. 


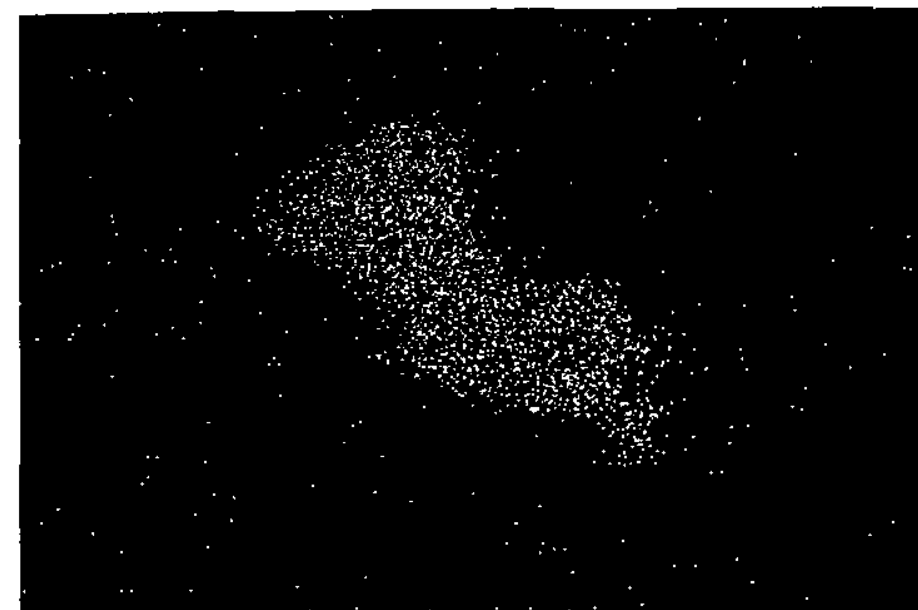

(c)

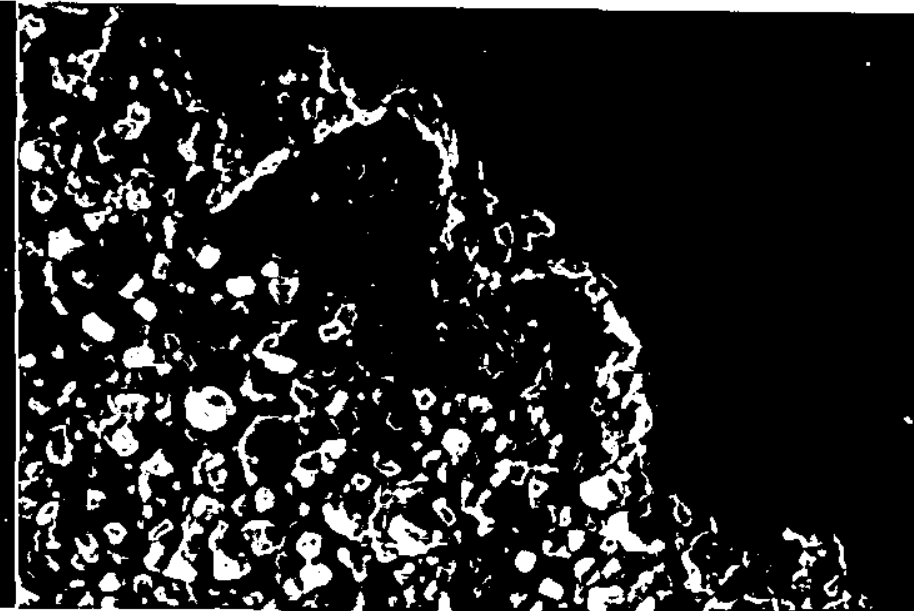

(a)

Figure 4.21 (a) SEM micrograph of flaking at edge of scratch channel on a $h c$ insert. Stylus load $=3 \mathrm{~kg} . \times 1200$.

(b) Al $K_{\alpha}$ elemental scan of area shown in (a)

(c) Ti $K_{\alpha}$ elemental scan of area shown in (a)

(d) Fe $K_{\mathrm{\alpha}}$ elemental scan of area shown in (a). 


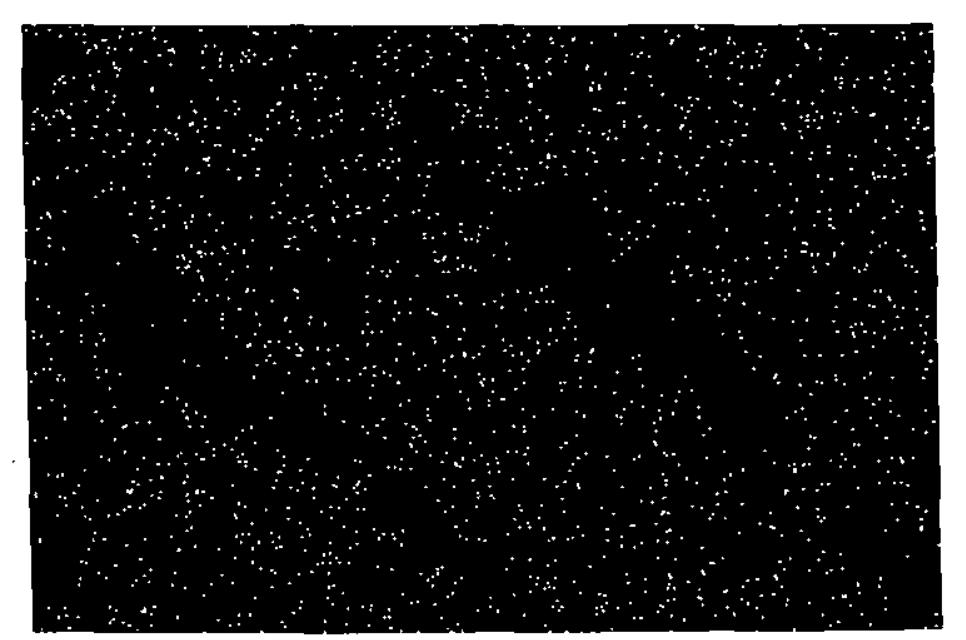

(b)
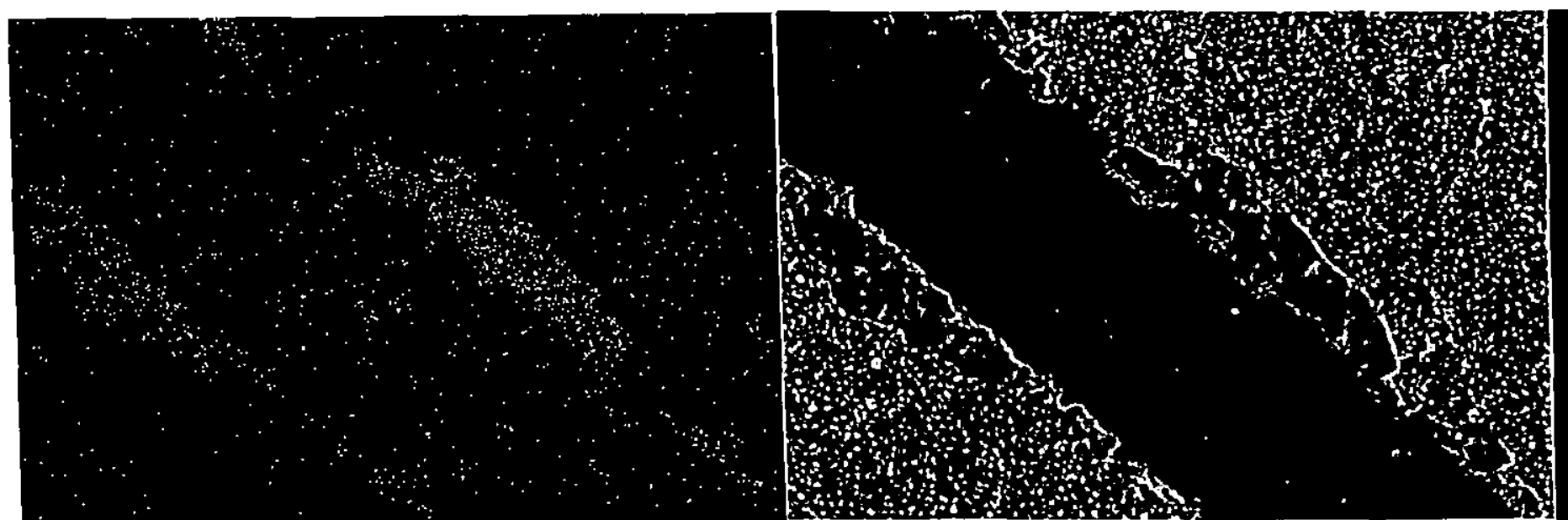

(c)

(a)

(d)

Eigure 4.22 (a) SEM micrograph of scratch channel on a $h c$ insert. Stylus load $=5 \mathrm{~kg}, \times 300$.

(b) Al $K_{\alpha}$ elemental scan of area shown in (a).

(c) Ti $K_{\alpha}$ elemental scan of area shown in (a).

(d) Fe $K_{\mathrm{a}}$ elemental scan of area shown in (a). 


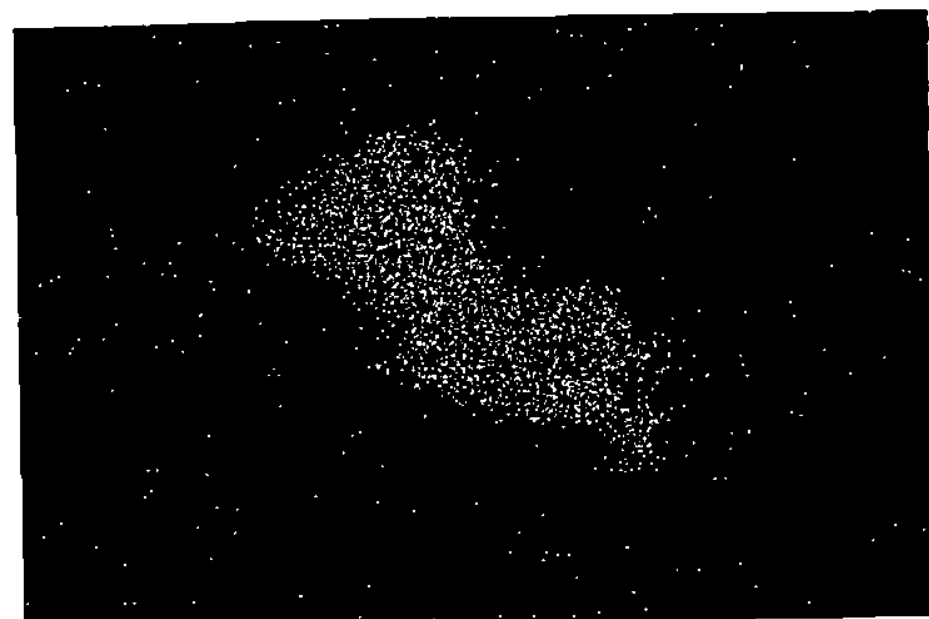

(c)

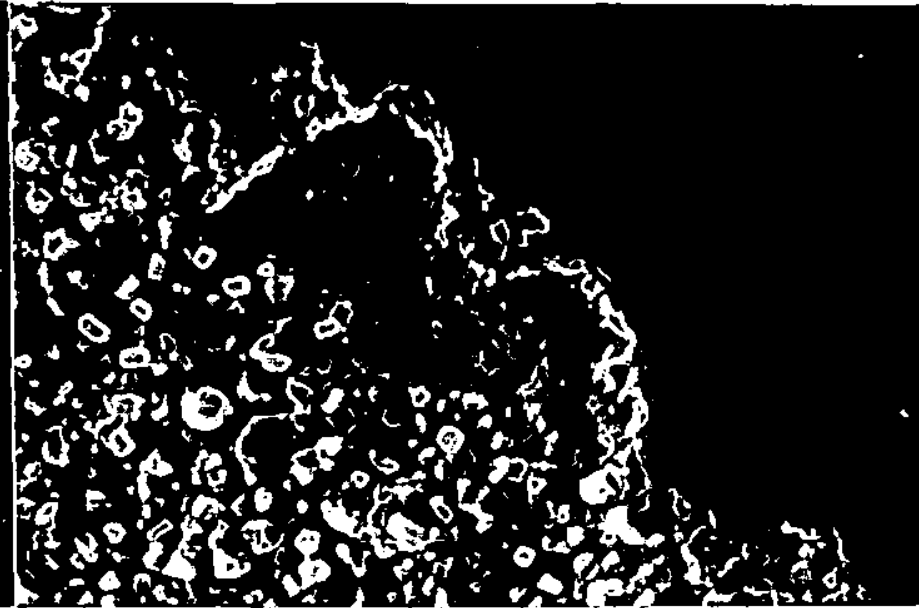

(a)

Figure 4.21 (a) SEM micrograph of flaking at edge of scratch channel on a he insert. Stylus load $=3 \mathrm{~kg} . \times 1200$.

(b) Al $K_{\mathrm{a}}$ elemental scan of area shown in (a)

(c) Ti $K_{\mathrm{a}}$ elemental scan of area shown in (a)

(d) Fe $K_{\alpha}$ elemental scan of area shown in (a). 


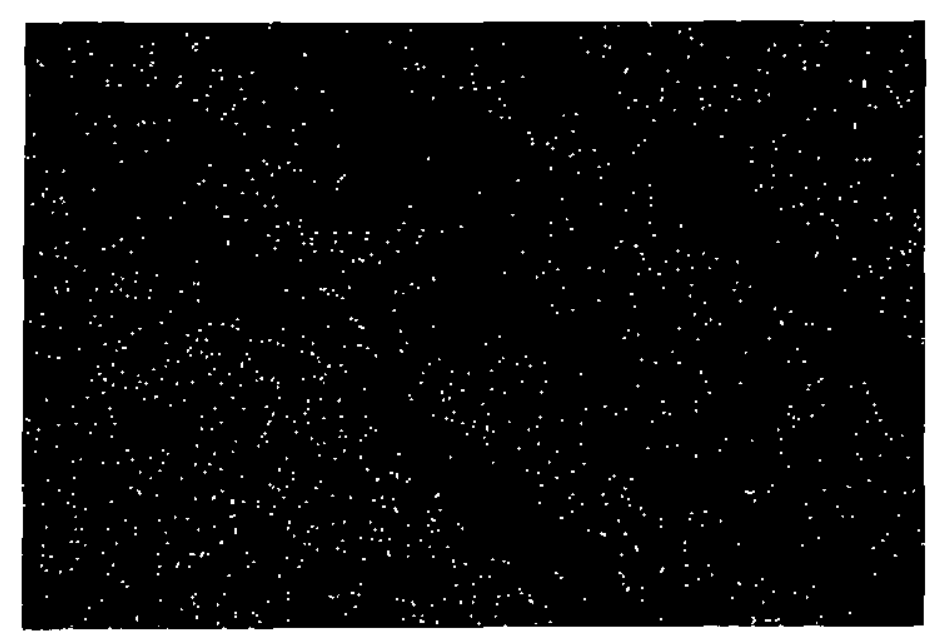

(b)

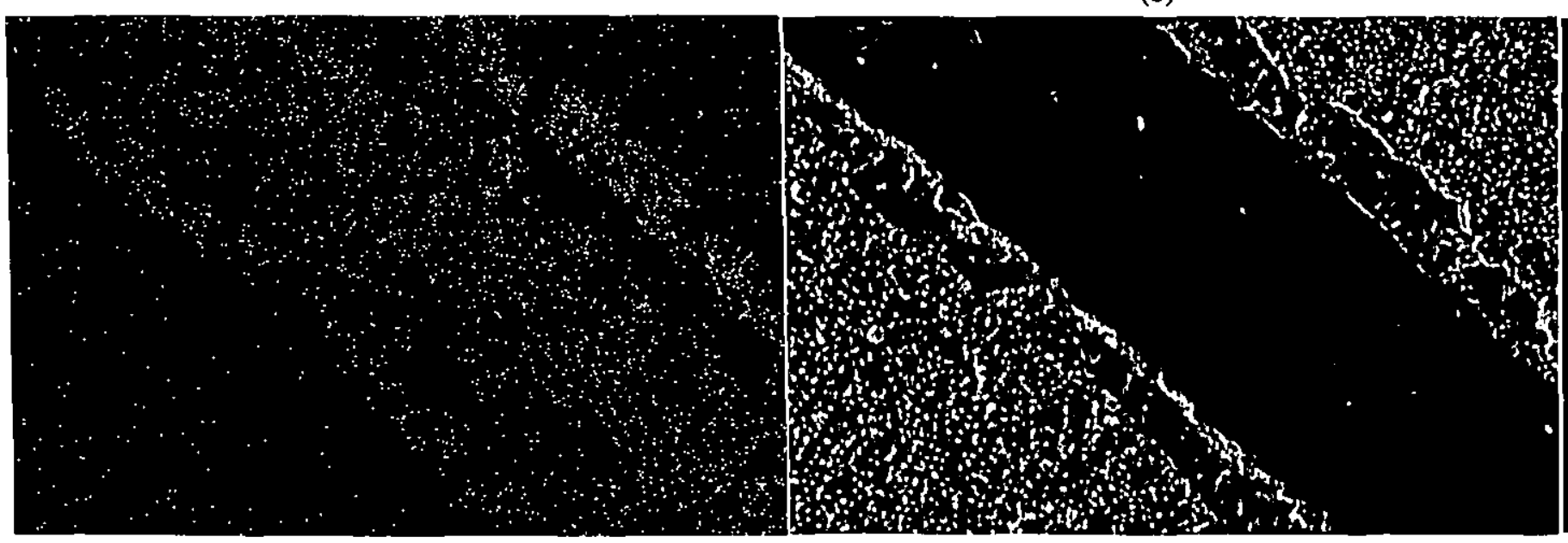

(c)

(a)

(d)

Eigure 4.23 (a) SEM micrograph of scratch channel on a $h c$ insert. Stylus load $=6 \mathrm{~kg}, \times 300$.

(b) $\mathrm{Al} K_{\alpha}$ elemental scan of area shown in (a).

(c) Ti $K_{\alpha}$ elemental scan of area shown in (a).

(d) Fe $K_{\alpha}$ elemental scan of area shown in (a). 
(b)

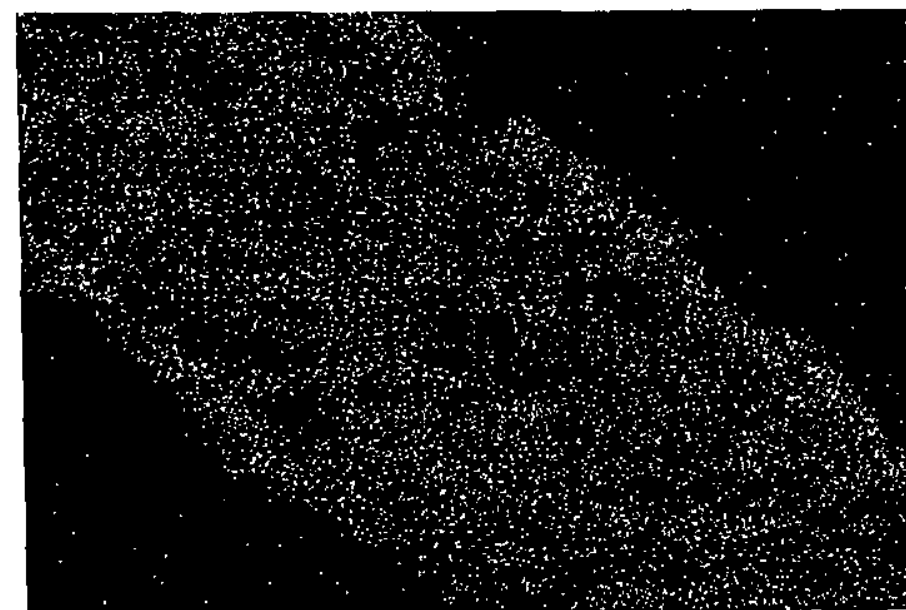

(c)

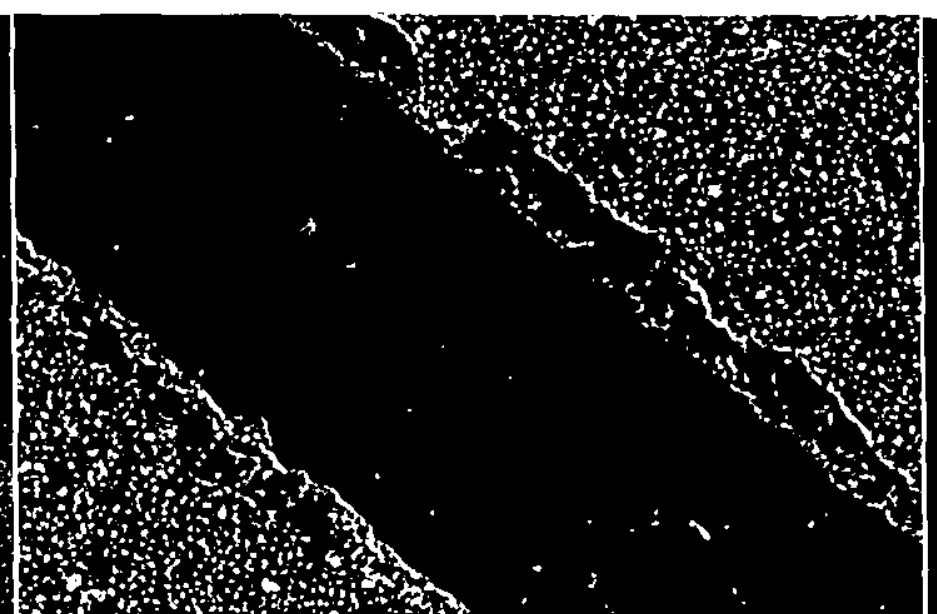

(a) (d)

Figure 4.24 (a) SEM micrograph of scratch channel on a $h c$ insert. Stylus load $=7 \mathrm{~kg}, \times 300$.

(b) Al $K_{\alpha}$ elemental scan of area shown in (a).

(c) Ti $K_{\alpha}$ elemental scan of area shown in (a).

(d) Fe $K_{a}$ elemental scan of area shown in (a). 
Table 4.1 Purity of $\alpha-\mathrm{Al}_{2} \mathrm{O}_{3}$ powder used in $\mathrm{X}$-ray diffraction work

\begin{tabular}{|c|c|c|c|}
\hline \multicolumn{4}{|c|}{ Composition, wt.\% } \\
\hline \hline $\mathrm{Al}_{2} \mathrm{O}_{3}$ & $\mathrm{Fe}$ & $\mathrm{Na}$ & $\mathrm{Cl}$ \\
\hline 99.2 & 0.009 & 0.2 & $<0.005$ \\
\hline
\end{tabular}

Table 4.2 Lattice parameter values quoted for $\alpha-\mathrm{Al}_{2} \mathrm{O}_{3}$ in ASTM diffraction file and values determined for $\alpha-\mathrm{Al}_{2} \mathrm{O}_{3}$ powder and (preliminary) $\mathrm{Al}_{2} \mathrm{O}_{3}$ coating on rake face of $a c$ inserts

\begin{tabular}{|c|c|c|}
\cline { 2 - 3 } & \multicolumn{2}{c|}{ Lattice parameter, $\AA$} \\
\cline { 2 - 3 } & $\mathrm{a}$ & $\mathrm{c}$ \\
\hline $\mathrm{Al}_{2} \mathrm{O}_{3}$ (ASTM) & 4.758 & 12.991 \\
\hline $\mathrm{Al}_{2} \mathrm{O}_{3}$ powder (average) & 4.753 & 12.974 \\
\hline $\mathrm{Al}_{2} \mathrm{O}_{3}$ coating (insert 1) & 4.757 & 13.004 \\
\hline $\mathrm{Al}_{2} \mathrm{O}_{3}$ coating (insert 2) & 4.754 & 13.004 \\
\hline $\mathrm{Al}_{2} \mathrm{O}_{3}$ coating (insert 3) & 4.753 & 12.987 \\
\hline $\mathrm{Al}_{2} \mathrm{O}_{3}$ coating (insert 4) & 4.752 & 12.983 \\
\hline
\end{tabular}

Table 4.3 Surface roughness values for (preliminary) $\mathrm{Al}_{2} \mathrm{O}_{3}$ coating on rake face of an $a c$ insert

\begin{tabular}{|c|c|}
\cline { 2 - 2 } \multicolumn{1}{c|}{} & Roughness average $\mathrm{R}_{\mathrm{a}}, \mu \mathrm{m}$ \\
\hline Average & 0.45 \\
\hline Maximum & 0.68 \\
\hline Minimum & 0.34 \\
\hline Standard dev. & 0.11 \\
\hline
\end{tabular}


Table 4.4 Thickness of (preliminary) $\mathrm{Al}_{2} \mathrm{O}_{3}$ coating on rake and flank faces and corner of an $a c$ insert

\begin{tabular}{|c|c|c|c|c|c|}
\hline \multirow{2}{*}{$\mathrm{Al}_{2} \mathrm{O}_{3}$ coating thickness, $\mu \mathrm{m}$} & \multirow{2}{*}{ Rake } & \multicolumn{2}{|c|}{ Flank } & \multicolumn{2}{c|}{ Corner } \\
\cline { 3 - 6 } & & 1 & 2 & 1 & 2 \\
\hline \hline Average & 4.42 & 5.41 & $\begin{array}{c}\text { very thin } \\
\text { coating }\end{array}$ & 9.14 & $\begin{array}{c}\text { very thin } \\
\text { coating }\end{array}$ \\
\hline Maximum & 5.31 & 8.67 & - & 10.0 & - \\
\hline Minimum & 2.03 & 3.59 & - & 8.36 & - \\
\hline Standard Dev. & 1.22 & 1.5 & - & 0.66 & - \\
\hline
\end{tabular}

Table 4.5 Microhardness of (preliminary) $\mathrm{Al}_{2} \mathrm{O}_{3}$ coating on an $a c$ insert

\begin{tabular}{|c|c|}
\cline { 2 - 2 } \multicolumn{1}{c|}{} & Microhardness, $\mathrm{HV}_{0.025}$ \\
\hline Average & 2374 \\
\hline Maximum & 2702 \\
\hline Minimum & 1975 \\
\hline
\end{tabular}

Table 4.6 Lattice parameter values determined for $\mathrm{Al}_{2} \mathrm{O}_{3}$ powder and (preliminary) $\mathrm{Al}_{2} \mathrm{O}_{3}$ coating on rake face of $h c$ inserts

\begin{tabular}{|c|c|c|}
\hline & \multicolumn{2}{|c|}{ Lattice parameter, $\AA$} \\
\hline & a & $\mathrm{c}$ \\
\hline $\mathrm{Al}_{2} \mathrm{O}_{3}$ coating (insert 1 ) & 4.757 & 13.004 \\
\hline $\mathrm{Al}_{2} \mathrm{O}_{3}$ coating (insert 2 ) & 4.754 & 13.004 \\
\hline $\mathrm{Al}_{2} \mathrm{O}_{3}$ coating (insert 3 ) & 4.753 & 12.987 \\
\hline $\mathrm{Al}_{2} \mathrm{O}_{3}$ coating (insert 4) & 4.752 & 12.983 \\
\hline
\end{tabular}


Table 4.7 Surface roughness values for (preliminary) $\mathrm{Al}_{2} \mathrm{O}_{3}$ coating on rake face of a $h c$ insert

\begin{tabular}{|c|c|}
\cline { 2 - 2 } \multicolumn{1}{c|}{} & Roughness average $\mathrm{R}_{\mathrm{a}}, \mu \mathrm{m}$ \\
\hline Average & 0.45 \\
\hline Maximum & 0.68 \\
\hline Minimum & 0.3 \\
\hline Standard dev. & 0.08 \\
\hline
\end{tabular}

Table 4.8 Thickness of (preliminary) $\mathrm{Al}_{2} \mathrm{O}_{3}$ coating on rake and flank faces and corner of a $h c$ insert

\begin{tabular}{|c|c|c|c|c|c|}
\hline \multirow[t]{2}{*}{$\mathrm{Al}_{2} \mathrm{O}_{3}$ coating thickness, $\mu \mathrm{m}$} & \multirow[t]{2}{*}{ Rake } & \multicolumn{2}{|c|}{ Flank } & \multicolumn{2}{|c|}{ Corner } \\
\hline & & 1 & 2 & 1 & 2 \\
\hline Average & 4.17 & 3.56 & $\begin{array}{l}\text { very thin } \\
\text { coating }\end{array}$ & 4.17 & $\begin{array}{l}\text { very thin } \\
\text { coating }\end{array}$ \\
\hline Maximum & 6.88 & 7.42 & - & 5.47 & - \\
\hline Minimum & 2.81 & 2.5 & - & 3.44 & - \\
\hline Standard Dev. & 0.83 & 1.5 & - & 0.83 & - \\
\hline
\end{tabular}

Table 4.9 Microhardness of (preliminary) $\mathrm{Al}_{2} \mathrm{O}_{3}$ coating on a $h c$ insert

\begin{tabular}{|c|c|}
\cline { 2 - 2 } & Microhardness, $\mathrm{HV}_{0.025}$ \\
\hline Average & 2333 \\
\hline Maximum & 2742 \\
\hline Minimum & 2040 \\
\hline
\end{tabular}


Table 4.10 Thickness of (preliminary) $\mathrm{Al}_{2} \mathrm{O}_{3}$ coating and Ti(C,N) precoating and hardness of HSS substrate of $h c$ insert used in scratch tests

\begin{tabular}{|c|c|c|}
\hline \multicolumn{2}{|c|}{ Coating thickness, $\mu \mathrm{m}$} & \\
\cline { 1 - 2 } $\mathrm{Al}_{2} \mathrm{O}_{3}$ coating & $\begin{array}{r}\mathrm{Ti}(\mathrm{C}, \mathrm{N}) \\
\text { precoating }\end{array}$ & \\
\hline \hline 1.44 & 1.93 & Substrate hardness, HV30 \\
\hline \hline
\end{tabular}

Table 4.11 Hardness of HSS substrate of $a c$ and $h c$ inserts used in preliminary $\mathrm{Al}_{2} \mathrm{O}_{3}$ coating run

\begin{tabular}{|c|c|c|}
\hline Substrate hardness, HV30 & \multicolumn{2}{|c|}{ Insert } \\
\hline & $a c$ & $h c$ \\
\hline \hline Average & 534 & 935 \\
\hline Maximum & 579 & 950 \\
\hline Minimum & 514 & 912 \\
\hline
\end{tabular}




\section{CHAPTER 5}

EXPERIMENTAL WORK AND RESULTS (II)-EFFECT OF $\mathrm{CO}_{2} / \mathrm{H}_{2}$ MOLE RATIO AND $\mathrm{AlCl}_{3}$ CONCENTRATION ON CHARACTERISTICS OF CVD Al ${ }_{2} \mathrm{O}_{3}$ COATINGS 


\subsection{EXPERIMENTAL WORK AND RESULTS (II)-EFFECT OF $\mathrm{CO}_{2} / \mathrm{H}_{2}$ MOLE RATIO AND AICl${ }_{3}$ CONCENTRATION ON CHARACTERISTICS OF CVD Al ${ }_{2} \underline{O}_{3}$ COATINGS}

For the reasons previously identified in Section 4.3, this chapter is concerned with a major study of the effect of $\mathrm{CO}_{2} / \mathrm{H}_{2}$ mole ratio and $\mathrm{AlCl}_{3}$ concentration (analogous to $\mathrm{AlCl}_{3}$ partial pressure) on the characteristics of $\mathrm{Al}_{2} \mathrm{O}_{3}$ coatings chemically vapour deposited on the $\mathrm{Ti}(\mathrm{C}, \mathrm{N})$ precoated PM BT42 grade HSS inserts. The effect of $\mathrm{CO}_{2} / \mathrm{H}_{2}$ mole ratio will be dealt with first.

\subsection{Effect of $\mathrm{CO}_{2} / \mathrm{H}_{2}$ Mole Ratio}

With reference to previous work on the CVD of $\mathrm{Al}_{2} \mathrm{O}_{3}$ coatings (see Sections 2.1 to 2.5) and to the trial $\mathrm{Al}_{2} \mathrm{O}_{3}$ coating runs carried out in the present work, $\mathrm{CO}_{2} / \mathrm{H}_{2}$ mole ratios of $1 / 6,1 / 10$, $1 / 12$ and $1 / 14$ were selected for study in the present work, at a constant $\mathrm{AlCl}_{3}$ evaporation temperature of $190^{\circ} \mathrm{C}$, a deposition temperature of $1050^{\circ} \mathrm{C}$, an $\mathrm{H}_{2}-1 / \mathrm{AlCl}_{3}$ flow rate of $25 \mathrm{~cm}^{3}$ $\mathrm{min}^{-1}$, a total flow rate of $400 \mathrm{~cm}^{3} \mathrm{~min}^{-1}$ and a deposition time of 1 hour. With regard to the $\mathrm{CO}_{2} / \mathrm{H}_{2}$ mole ratio of $1 / 8$ missing from the sequence above; the characteristics of an $\mathrm{Al}_{2} \mathrm{O}_{3}$ coating deposited on the specially prepared Ti(C,N) precoated PM BT42 grade HSS inserts under the latter conditions and at a $\mathrm{CO}_{2} / \mathrm{H}_{2}$ mole ratio of $1 / 8$, have already been determined (run number 10 - preliminary $\mathrm{Al}_{2} \mathrm{O}_{3}$ coating) and presented (see Chapter 4). In order to facilitate identification of trends in the effect of $\mathrm{CO}_{2} / \mathrm{H}_{2}$ mole ratio on $\mathrm{Al}_{2} \mathrm{O}_{3}$ coating characteristics, however, they will be re-presented in the relevant places of this chapter.

It was concluded that the above, desired range of $\mathrm{CO}_{2} / \mathrm{H}_{2}$ mole ratios could most simply and easily be achieved by maintaining the flow rate of the $\mathrm{CO}_{2}$ (and the $\mathrm{H}_{2}-1 / \mathrm{AlCl}_{3}$ ) at a constant level whilst changing that of the $\mathrm{H}_{2}$-2 i.e. the $\mathrm{H}_{2}$ which is not passed through the $\mathrm{AlCl}_{3}$ glass evaporation vessel (see Section 3.2). On their own, however, changes in the $\mathrm{H}_{2}-2$ flow rate would cause changes in the total flow rate of the reactant plus carrier gases, the effect of which on the CVD of $\mathrm{Al}_{2} \mathrm{O}_{3}$ coatings has not been established. Consequently, it was decided that the flow rates of the $\mathrm{H}_{2}-2$ and the Ar would be set so as to not only achieve the desired $\mathrm{CO}_{2} / \mathrm{H}_{2}$ mole ratios but also to ensure that the total flow rate remained constant at the required value of $400 \mathrm{~cm}^{3} \mathrm{~min}^{-1}$. The $\mathrm{H}_{2}-2$ and $\mathrm{Ar}$ flow rates thus calculated for the $\mathrm{CO}_{2} / \mathrm{H}_{2}$ mole ratio coating runs are shown in Table 5.1, together with the other deposition conditions.

The Ti(C,N) precoated PM BT42 grade HSS inserts employed in this study of the effect of $\mathrm{CO}_{2} / \mathrm{H}_{2}$ mole ratio were taken from the batch specially prepared for the present work (see Section 3.3.3). Prior to $\mathrm{Al}_{2} \mathrm{O}_{3}$ deposition, the precoated inserts were ultrasonically cleaned in $\mathrm{CCl}_{4}$. Eight inserts were then coated with $\mathrm{Al}_{2} \mathrm{O}_{3}$, in four coating runs at $\mathrm{CO}_{2} / \mathrm{H}_{2}$ mole ratios of $1 / 6,1 / 10,1 / 12$ and $1 / 14$ using the relevant deposition conditions specified in Table 5.1. 
All the coating runs were carried out using the standard coating procedure defined in Appendix 3. During each coating run, readings were taken at 5 minute intervals of $\mathrm{CO}_{2}, \mathrm{H}_{2}-2, \mathrm{H}_{2}-1 / \mathrm{AlCl}_{3}$ and $\mathrm{Ar}$ gas flow rates; $\mathrm{AlCl}_{3}$ evaporation unit temperature and deposition temperature. If any deviation from the desired values was noted, it was immediately compensated for. At the end of each coating run the amount of $\mathrm{AlCl}_{3}$ which had been used was determined using the procedure defined in Appendix 4. These amounts are included in Table 5.1.

As was the case with the ac inserts from run 10 , i.e. $\mathrm{CO}_{2} / \mathrm{H}_{2}$ mole ratio $1 / 8$ (see Section 3.3.4), after each of the above four $\mathrm{CO}_{2} / \mathrm{H}_{2}$ mole ratio coating runs, the four ac inserts from the right-hand side of the insert holder were heat treated to harden and temper their PM HSS substrates, using the procedure previously described in Section 3.3.4. The $a c$ and $h c$ inserts from the four $\mathrm{CO}_{2} / \mathrm{H}_{2}$ mole ratio coating runs were then characterised, using essentially the same characterisation techniques and procedures as previously employed in the case of the $a c$ and $h c$ inserts from run 10 , i.e. $\mathrm{CO}_{2} / \mathrm{H}_{2}$ mole ratio $1 / 8$, in order to determine the effect of $\mathrm{CO}_{2} / \mathrm{H}_{2}$ mole ratio on coating characteristics. Since these techniques and procedures have been described in detail in the preceding chapter, it is not thought necessary to repeat their description here. Since only four $a c$ and four $h c$ inserts, were available from each coating run, the characterisation techniques were judiciously allocated to them as indicated in Table 5.2. It should be noted that this allocation is compatible with the characterisation of the $a c$ and $h c$ inserts from run $10\left(\mathrm{CO}_{2} / \mathrm{H}_{2}\right.$ mole ratio $\left.1 / 8\right)$. For purpose of identification, the left-hand side and right-hand side of the insert holder will hereafter be designated either as left, right or L, R. After scratch testing, but before any other characterisation, photographs of the ac and $h c$ inserts from the four $\mathrm{CO}_{2} / \mathrm{H}_{2}$ mole ratio coating runs were taken to compare their external appearances. These photographs are presented in Figure 5.1, together with the corresponding photographs of the inserts from run $10\left(\mathrm{CO}_{2} / \mathrm{H}_{2}\right.$ mole ratio $\left.1 / 8\right)$ obtained earlier (see Figure 3.17).

\subsubsection{Effect of $\mathrm{CO}_{2} / \mathrm{H}_{2}$ mole ratio on $\mathrm{Al}_{2} \underline{\mathrm{O}}_{3}$ coating thickness}

The thickness of the $\mathrm{Al}_{2} \mathrm{O}_{3}$ coating on the rake face of all eight inserts from each coating run was first determined utilising the ball-cratering technique previously described in Section 4.1.2. The $\mathrm{Al}_{2} \mathrm{O}_{3}$ coating thickness values thus determined are shown in Table 5.3.

\subsubsection{Effect of $\mathrm{CO}_{2} / \mathrm{H}_{2}$ mole ratio on preferred orientation and lattice parameter of} $\mathrm{Al}_{2} \underline{\mathbf{O}}_{3}$ coatings

$\mathrm{X}$-ray diffraction was used to determine the preferred orientation and lattice parameters of the $\mathrm{Al}_{2} \mathrm{O}_{3}$ coating on the rake face of the six designated inserts from each of the $\mathrm{CO}_{2} / \mathrm{H}_{2}$ mole ratio coating runs which were to be employed in the further characterisation work. This was done to determine, for each coating run, whether there were any significant differences in the 
crystal structure of the $\mathrm{Al}_{2} \mathrm{O}_{3}$ coatings on the rake face of the six inserts which could affect the results subsequently obtained by the other characterisation techniques. Typical relative intensities obtained for the $\mathrm{Al}_{2} \mathrm{O}_{3}$ coating on the rake face of one of the ac inserts (number 2 L) from each $\mathrm{CO}_{2} / \mathrm{H}_{2}$ mole ratio coating run are shown in Figure 5.2, in comparison to those for the randomly oriented $\mathrm{Al}_{2} \mathrm{O}_{3}$ powder. The corresponding coating lattice parameter values are presented plotted against $\mathrm{CO}_{2} / \mathrm{H}_{2}$ mole ratio in Figure 5.3. In addition, all the lattice parameter values obtained for the coatings on the six inserts from each of the $\mathrm{CO}_{2} / \mathrm{H}_{2}$ mole ratio coating runs are defined in Table 5.4. As is evident from this table, the lattice parameter values determined for the coatings on all the inserts from a particular coating run did not differ significantly. This was also the case for coating preferred orientation. It can thus be concluded, for each coating run, that there are no significant differences in the crystal structure of the $\mathrm{Al}_{2} \mathrm{O}_{3}$ coating on each of the inserts and hence that these inserts can be validly employed in the subsequent characterisation work.

\subsubsection{Effect of $\mathrm{CO}_{2} / \mathrm{H}_{2}$ mole ratio on composition of $\mathrm{Al}_{2} \underline{\mathrm{O}}_{3}$ coating and $\mathrm{Al}_{2} \underline{\mathrm{O}}_{3}$ coating/Ti(C,N) precoating interface}

AES was employed to obtain a composition-depth profile through the $\mathrm{Al}_{2} \mathrm{O}_{3}$ coating, the $\mathrm{Al}_{2} \mathrm{O}_{3}$ coating/Ti(C,N) precoating interface, the $\mathrm{Ti}(\mathrm{C}, \mathrm{N})$ precoating and the $\mathrm{Ti}(\mathrm{C}, \mathrm{N})$ precoating/HSS substrate interface for one of the ac inserts from each of the $\mathrm{CO}_{2} / \mathrm{H}_{2}$ mole ratio coating runs. The results obtained are shown in Figure 5.4.

\subsubsection{Effect of $\mathrm{CO}_{2} \mathrm{H}_{2}$ mole ratio on surface roughness of $\underline{\mathrm{Al}}_{2} \underline{\mathrm{O}}_{3} \underline{\text { coatings }}$}

A Talysurf 10 was used to investigate the surface roughness of the $\mathrm{Al}_{2} \mathrm{O}_{3}$ coating on the rake face of one $a c$ insert from each of the $\mathrm{CO}_{2} / \mathrm{H}_{2}$ mole ratio coating runs. The roughness average $\left(R_{a}\right)$ values obtained are summarised in Table 5.5. In addition, typical Talysurf traces recorded for the surface of the $\mathrm{Al}_{2} \mathrm{O}_{3}$ coating on the insert from each coating run studied are presented in Figure 5.5, visually illustrating the effect of $\mathrm{CO}_{2} / \mathrm{H}_{2}$ mole ratio on the surface roughness of the $\mathrm{Al}_{2} \mathrm{O}_{3}$ coatings.

\subsubsection{Effect of $\mathrm{CO}_{2} / \mathrm{H}_{2}$ mole ratio on peripheral thickness variation (and other features) of $\mathrm{Al}_{2} \underline{\mathrm{O}}_{3}$ coatings}

Optical examination of a polished and etched cross-section through one of the ac inserts from each of the $\mathrm{CO}_{2} / \mathrm{H}_{2}$ mole ratio coating runs was employed principally to determine whether the $\mathrm{Al}_{2} \mathrm{O}_{3}$ coating was present all around the periphery of the insert, and, if so, to determine the thickness of the $\mathrm{Al}_{2} \mathrm{O}_{3}$ coating on the rake and flank faces and at the corners (i.e. cutting edges) of the insert. These thicknesses were determined using the micrometer eyepiece normally used for microhardness testing on the Reichert MeF2. Twenty readings on the rake 
face, ten readings on each of the two flank faces (1 and 2) and five readings on each of the two corners ( 1 and 2 ) were taken. The thicknesses thus determined are summarised in Table 5.6 together with, for purposes of comparison, the corresponding average rake face coating thicknesses previously determined by ball-cratering. The average rake face coating thicknesses determined by optical measurement are also presented in Figure 5.6 plotted against $\mathrm{CO}_{2} / \mathrm{H}_{2}$ mole ratio together with the corresponding average, maximum and minimum rake face coating thicknesses determined by ball-cratering, again for comparison purposes.

The cross-sections were then examined optically on the Reichert MeF2 to check for the presence of any defects in the $\mathrm{Al}_{2} \mathrm{O}_{3}$ coating, to examine the $\mathrm{Al}_{2} \mathrm{O}_{3}$ coating/Ti(C,N) precoating interface and the $\mathrm{Ti}(\mathrm{C}, \mathrm{N})$ precoating/HSS substrate interface and to investigate the microstructure of the PM BT42 grade HSS substrate adjacent to and remote from the latter interface. Typical optical cross-sections through the rake face of the inserts from each $\mathrm{CO}_{2} / \mathrm{H}_{2}$ mole ratio coating run are shown in Figure 5.7. As is just evident from these optical cross-sections, particularly that through the rake face of the inserts corresponding to $\mathrm{CO}_{2} / \mathrm{H}_{2}$ mole ratios of $1 / 6,1 / 14$ and of course $1 / 8$, a thin band is just discernible at the $\mathrm{Al}_{2} \mathrm{O}_{3}$ coating/Ti(C,N) precoating interface.

\subsubsection{Effect of $\mathrm{CO}_{2} / \mathrm{H}_{2}$ mole ratio on $\mathrm{Al}_{2} \underline{O}_{3}$ coating microhardness}

Microhardness tests were employed to determine the hardness of the $\mathrm{Al}_{2} \mathrm{O}_{3}$ coating on one of the $a c$ inserts from each of the $\mathrm{CO}_{2} / \mathrm{H}_{2}$ mole ratio coating runs. Using the procedure described in Section 4.1.5, low angle $\left(5.6^{\circ}\right)$ taper sections through the rake face of the insert selected from each coating run were first produced. An investigation of the variation in microhardness of the $\mathrm{Al}_{2} \mathrm{O}_{3}$ coating on each taper-sectioned insert with distance from the $\mathrm{Al}_{2} \mathrm{O}_{3}$ coating/ $\mathrm{Ti}(\mathrm{C}, \mathrm{N})$ precoating interface was then carried out to locate the region in which truly representative microhardness values could be obtained. The measured variations in microhardness of the $\mathrm{Al}_{2} \mathrm{O}_{3}$ coatings deposited at the different $\mathrm{CO}_{2} / \mathrm{H}_{2}$ mole ratios thus determined are shown in Figure 5.8. As can be seen, in each case, once a certain distance from the $\mathrm{Al}_{2} \mathrm{O}_{3}$ coating/Ti(C,N) precoating interface is reached, a plateau exists on which the microhardness of the $\mathrm{Al}_{2} \mathrm{O}_{3}$ coating does not vary significantly. Consequently, on each taper-sectioned insert, twenty five microhardness measurements were subsequently taken along the length of the rake face $\mathrm{Al}_{2} \mathrm{O}_{3}$ coating in the centre of this plateau in order to determine the microhardness of the $\mathrm{Al}_{2} \mathrm{O}_{3}$ coating. The microhardness values thus obtained are summarised in Table 5.7 and also presented in Figure 5.9 plotted against $\mathrm{CO}_{2} / \mathrm{H}_{2}$ mole ratio. 


\subsubsection{Effect of $\mathrm{CO}_{2} / \mathrm{H}_{2}$ mole ratio on microstructure of $\mathrm{Al}_{2} \mathrm{O}_{3}$ coating adjacent to interface with Ti(C,N) precoating}

As previously described in Section 5.1.5, on the optical cross-sections through the rake face of some of the $\mathrm{Al}_{2} \mathrm{O}_{3}$ coated inserts from the $\mathrm{CO}_{2} / \mathrm{H}_{2}$ mole ratio coating runs, a thin band was just discernible at the $\mathrm{Al}_{2} \mathrm{O}_{3}$ coating/Ti(C,N) precoating interface. As previously described in Section 4.1.6 for the $\mathrm{Al}_{2} \mathrm{O}_{3}$ coated insert from run $10\left(\mathrm{CO}_{2} / \mathrm{H}_{2}\right.$ mole ratio $\left.1 / 8\right)$, the taper-sectioned inserts from each of the $\mathrm{CO}_{2} / \mathrm{H}_{2}$ mole ratio coating runs were employed to facilitate a proper, relatively high magnification optical examination of these bands on the Reichert MeF2 microscope. To this end, the taper-sectioned $a c$ inserts were re-lapped on the cast iron plate impregnated with $3 \mu \mathrm{m}$ diamond paste and then re-polished using the procedure previously detailed in Section 4.1.4. Figure 5.10 shows the resulting low-angle optical taper-sections through the $\mathrm{Al}_{2} \mathrm{O}_{3}$ coating and the $\mathrm{Al}_{2} \mathrm{O}_{3}$ coating/Ti $(\mathrm{C}, \mathrm{N})$ precoating interface for the $\mathrm{Al}_{2} \mathrm{O}_{3}$ coated inserts from each of the $\mathrm{CO}_{2} / \mathrm{H}_{2}$ mole ratio coating runs.

\subsubsection{Effect of $\mathrm{CO}_{2} / \mathrm{H}_{2}$ mole ratio on bulk and surface grain structures of $\mathrm{Al}_{2} \underline{\mathrm{O}}_{3}$ coatings}

Fractography was employed to determine the bulk grain structure of the $\mathrm{Al}_{2} \mathrm{O}_{3}$ coatings deposited at the different $\mathrm{CO}_{2} / \mathrm{H}_{2}$ mole ratios. One $h c$ insert from each $\mathrm{CO}_{2} / \mathrm{H}_{2}$ coating run was notched and fractured; it having previously been found (see Section 4.1.7) that $\mathrm{Al}_{2} \mathrm{O}_{3}$ coating bulk grain structure was more clearly defined in the case of an $h c$ insert than in the case of an $a c$ insert (see Figures 4.19 and 4.11). The two pieces of each fractured $h c$ insert were then sputtered with gold and their rake face coating fracture surfaces examined on an SEM. It was observed that the bulk grain structure of the $\mathrm{Al}_{2} \mathrm{O}_{3}$ coating on the hc insert from each $\mathrm{CO}_{2} / \mathrm{H}_{2}$ mole ratio coating run was uniform along its length. Typical bulk grain structures of the $\mathrm{Al}_{2} \mathrm{O}_{3}$ coatings deposited at the different $\mathrm{CO}_{2} / \mathrm{H}_{2}$ mole ratios are thus presented in Figure 5.11. The corresponding surface grain structures of the $\mathrm{Al}_{2} \mathrm{O}_{3}$ coatings were then determined by direct $\mathrm{SEM}$ observation. Figure 5.12 shows the typical $\mathrm{Al}_{2} \mathrm{O}_{3}$ coating surface grain structures observed.

\subsubsection{Effect of $\mathrm{CO}_{2} / \mathrm{H}_{2}$ mole ratio on adhesion of $\mathrm{Al}_{2} \mathrm{O}_{3}$ coatings}

The scratch test was used to investigate the effect of $\mathrm{CO}_{2} / \mathrm{H}_{2}$ mole ratio on the adhesion of the $\mathrm{Al}_{2} \mathrm{O}_{3}$ coatings to the $\mathrm{Ti}(\mathrm{C}, \mathrm{N})$ precoated PM HSS inserts. For the reasons previously explained in Section 4.2, prior to scratch testing of the $h c$ inserts from the different $\mathrm{CO}_{2} / \mathrm{H}_{2}$ mole ratio coating runs, the thickness of the $\mathrm{Al}_{2} \mathrm{O}_{3}$ coating (and of the $\mathrm{Ti}(\mathrm{C}, \mathrm{N})$ precoating) and the hardness of the PM HSS substrate of each of the $h c$ inserts to be employed were 
determined. These values are shown in Table 5.8. The direction in which the rake face of each $h c$ insert had originally been surface ground was then determined using optical microscopy, after which scratch tests were performed on each insert.

Following the procedure described in detail in Section 4.2, the $h c$ insert selected from each $\mathrm{CO}_{2} / \mathrm{H}_{2}$ mole ratio coating run was scratch tested. The scratch channels produced were then examined on an optical microscope. First, the edges of the scratch channels on each of the inserts were examined to determine if any coating flaking had occurred at this location and, if so, the minimum stylus load at which it had occurred. Next, the effect of increasing stylus load on the appearance of the scratch channels was studied. It was observed, on each insert, that up to a particular stylus load, the scratch channels had a uniform dark purple appearance but that as the stylus load was further increased some orange/silvery areas were visible. At even higher stylus loads virtually the whole of the scratch channels was silvery in appearance. For each insert, the stylus load at which the latter was first observed, together with the minimum stylus load at which flaking was observed were noted. Following this, the scratch channels on the $h c$ insert from each $\mathrm{CO}_{2} / \mathrm{H}_{2}$ mole ratio coating run were examined on an SEM fitted with an EDX analyser. As before, the edges of the scratch channels on each insert were first examined to corroborate (or otherwise) the optically determined minimum stylus load at which coating flaking had occurred. SEM micrographs of a typical instance of this flaking on each insert at the minimum stylus load determined, together with the corresponding $\mathrm{Al}$, $\mathrm{Ti}$ and $\mathrm{Fe} K_{\alpha} \mathrm{X}$-ray maps, are shown in Figures 5.13 to 5.17 allowing identification of the type of flaking observed. The degree of flaking observed was also noted. The scratch channel on each of the $h c$ inserts corresponding to the optically determined stylus load at which virtually the whole of the scratch channel became silvery in appearance was then studied, together with scratch channels produced by stylus loads lower than this, in order to determine the critical stylus load corresponding to extensive removal of the $\mathrm{Al}_{2} \mathrm{O}_{3}$ coating from the scratch channel. SEM micrographs of a typical region of the relevant scratch channels on each of the $h c$ inserts, together with the corresponding $\mathrm{Al}$, Ti and $\mathrm{Fe} K_{\alpha} \mathrm{X}$-ray maps are shown in Figures 5.18 to 5.28. A summary of the scratch test results obtained is provided in Table 5.9 , listing the minimum stylus loads at which coating flaking was observed at the edges of the scratch channels, together with the type and degree of flaking, and the critical stylus load at which extensive $\mathrm{Al}_{2} \mathrm{O}_{3}$ coating removal occurred from the scratch channel.

With reference to Figures 5.1 to 5.28 and Tables 5.3 to 5.9 , it is the author's opinion that the best $\mathrm{Al}_{2} \mathrm{O}_{3}$ coating characteristics have been obtained at a $\mathrm{CO}_{2} / \mathrm{H}_{2}$ mole ratio of $1 / 10$. Consequently, it was decided to carry out the study of the effect of $\mathrm{AlCl}_{3}$ concentration on the characteristics of $\mathrm{Al}_{2} \mathrm{O}_{3}$ coatings chemically vapour deposited on the $\mathrm{Ti}(\mathrm{C}, \mathrm{N})$ precoated PM BT42 grade HSS inserts at a constant $\mathrm{CO}_{2} / \mathrm{H}_{2}$ mole ratio of $1 / 10$. This study is presented in the following section. 


\subsection{Effect of $\mathrm{H}_{2}-1 / \mathrm{AlCl}_{3}$ Flow Rate (AlCl${ }_{3}$ Concentration)}

It was considered that, of the options available, $\mathrm{AlCl}_{3}$ concentration (analogous to $\mathrm{AlCl}_{3}$ partial pressure) could most readily be varied simply by changing the $\mathrm{H}_{2}-1 / \mathrm{AlCl}_{3}$ flow rate, hence the title of this section. With reference to previous work on the CVD of $\mathrm{Al}_{2} \mathrm{O}_{3}$ coatings (see Sections 2.1 to 2.5) and to the trial $\mathrm{Al}_{2} \mathrm{O}_{3}$ coating runs carried out in the present work (see Section 3.3), $\mathrm{H}_{2}-1 / \mathrm{AlCl}_{3}$ flow rates of $10,15,20,25$ and $30 \mathrm{~cm}^{3} \mathrm{~min}^{-1}$ were selected for study in the present work, at a constant $\mathrm{AlCl}_{3}$ evaporation temperature of $190^{\circ} \mathrm{C}$, a deposition temperature of $1050^{\circ} \mathrm{C}$, a total flow rate of $400 \mathrm{~cm}^{3} \mathrm{~min}^{-1}$, a deposition time of 1 hour and, as already quoted, a $\mathrm{CO}_{2} / \mathrm{H}_{2}$ mole ratio of $1 / 10$. It was further considered that the constant total flow rate and $\mathrm{CO}_{2} / \mathrm{H}_{2}$ mole ratio desired could most simply and easily be obtained by maintaining the flow rate of the $\mathrm{CO}_{2}$ and the $\mathrm{Ar}$ at constant levels and compensating for the changes in $\mathrm{H}_{2}-1$ flow rate by adjusting that of the $\mathrm{H}_{2}-2$, i.e. the $\mathrm{H}_{2}$ which is not passed through the $\mathrm{AlCl}_{3}$ glass evaporation vessel (see Section 3.2). The $\mathrm{H}_{2}-2$ flow rates thus calculated for the $\mathrm{H}_{2}-1 / \mathrm{AlCl}_{3}$ flow rate coating runs are shown in Table 5.10, together with the other deposition conditions.

As there were insufficient $\mathrm{Ti}(\mathrm{C}, \mathrm{N})$ precoated PM BT42 grade HSS inserts remaining from the specially prepared batch to complete the $\mathrm{H}_{2}-1 / \mathrm{AlCl}_{3}$ flow rate study, a new batch of 50 PM BT42 grade HSS inserts coated with Ti(C,N) by CVD were produced by Edgar Allen Tools for this study, using exactly the same deposition conditions as before (see Section 3.3.3). As anticipated, the thickness of these $\mathrm{Ti}(\mathrm{C}, \mathrm{N})$ precoatings was within the desired range of $2.0 \pm 0.5 \mu \mathrm{m}$, but their colour was slightly darker than that of the previously deposited precoatings, possibly indicating a minor compositional difference. In order to guard against any effects of this on $\mathrm{Al}_{2} \mathrm{O}_{3}$ coating characteristics, it was decided that the $\mathrm{Al}_{2} \mathrm{O}_{3}$ coating run previously carried out during the $\mathrm{CO}_{2} / \mathrm{H}_{2}$ mole ratio study at an $\mathrm{H}_{2}-1 / \mathrm{AlCl}_{3}$ flow rate of 25 $\mathrm{cm}^{3} \mathrm{~min}^{-1}$ and a $\mathrm{CO}_{2} / \mathrm{H}_{2}$ mole ratio of $1 / 10$ (i.e. deposition conditions also common to the $\mathrm{H}_{2}-1 / \mathrm{AlCl}_{3}$ flow rate study) should be repeated for the $\mathrm{H}_{2}-1 / \mathrm{AlCl}_{3}$ flow rate study using $\mathrm{Ti}(\mathrm{C}, \mathrm{N})$ precoated inserts from the newly prepared batch.

Prior to $\mathrm{Al}_{2} \mathrm{O}_{3}$ deposition the $\mathrm{Ti}(\mathrm{C}, \mathrm{N})$ precoated inserts were ultrasonically cleaned in $\mathrm{CCl}_{4}$. Eight inserts were then coated with $\mathrm{Al}_{2} \mathrm{O}_{3}$ in five coating runs at $\mathrm{H}_{2}-1 / \mathrm{AlCl}_{3}$ flow rates of 10 , $15,20,25$ and $30 \mathrm{~cm}^{3} \mathrm{~min}^{-1}$ using the relevant deposition conditions specified in Table 5.10. All the coating runs were carried out using the standard coating procedure defined in Appendix 3. During each coating run, readings were taken at 5 minute intervals of $\mathrm{CO}_{2}, \mathrm{H}_{2}-2, \mathrm{H}_{2}-1 / \mathrm{AlCl}_{3}$ and $\mathrm{Ar}$ gas flow rates; $\mathrm{AlCl}_{3}$ evaporation unit temperature and deposition temperature. If any deviation from the desired values was noted, it was immediately compensated for. At the end of each coating run the amount of $\mathrm{AlCl}_{3}$ which had been used was determined using the procedure defined in Appendix 3. These amounts are included in Table 5.10. 
As was the case with the ac inserts from the $\mathrm{CO}_{2} / \mathrm{H}_{2}$ mole ratio coating runs (see Section 5.1), after each of the above five $\mathrm{H}_{2}-1 / \mathrm{AlCl}_{3}$ flow rate coating runs, the four ac inserts from the right-hand side of the insert holder were heat treated to harden and temper their PM HSS substrates, using the procedure previously described in Section 3.3.4. The $a c$ and $h c$ inserts from the five $\mathrm{H}_{2}-1 / \mathrm{AlCl}_{3}$ flow rate coating runs were then characterised, using the same characterisation techniques and procedures as previously employed in the case of the $a c$ and $h c$ inserts from the earlier $\mathrm{CO}_{2} / \mathrm{H}_{2}$ mole ratio study, in order to determine the effect of $\mathrm{H}_{2}$-1/AlCl 3 flow rate on coating characteristics. Since these techniques and procedures have been described in detail in the preceding chapter, it is not thought necessary to repeat their description here. The characterisation techniques were allocated to the $a c$ and $h c$ inserts from the $\mathrm{H}_{2}-1 / \mathrm{AlCl}_{3}$ flow rate coating runs in exactly the same way as to the $a c$ and $h c$ inserts from the $\mathrm{CO}_{2} / \mathrm{H}_{2}$ mole ratio coating runs (see Table 5.2). After scratch testing, but before any other characterisation, photographs of the $a c$ and $h c$ inserts from the five $\mathrm{H}_{2}-1 / \mathrm{AlCl}_{3}$ flow rate coating runs were taken to compare their external appearances. These photographs are presented in Figure 5.29.

\subsubsection{Effect of $\mathrm{H}_{2}-1 / \mathrm{AlCl}_{3}$ flow rate on $\mathrm{Al}_{2} \underline{\mathrm{O}}_{3}$ coating thickness}

The thickness of the $\mathrm{Al}_{2} \mathrm{O}_{3}$ coating on the rake face of all eight inserts from each coating run was first determined utilising the ball-cratering technique previously described in Section 4.1.2. The $\mathrm{Al}_{2} \mathrm{O}_{3}$ coating thickness values thus determined are shown in Table 5.11

\subsubsection{Effect of $\mathrm{H}_{2}-1 / \mathrm{AlCl}_{3}$ flow rate on preferred orientation and lattice parameter of $\mathrm{Al}_{2} \underline{\mathrm{O}}_{3}$ coatings}

$\mathrm{X}$-ray diffraction was used to determine the preferred orientation and lattice parameters of the $\mathrm{Al}_{2} \mathrm{O}_{3}$ coating on the rake face of the six designated inserts from each of the $\mathrm{H}_{2}-1 / \mathrm{AlCl}_{3}$ flow rate coating runs which were to be employed in the further characterisation work. This was done to determine, for each coating run, whether there were any significant differences in the crystal structure of the $\mathrm{Al}_{2} \mathrm{O}_{3}$ coatings on the rake face of the six inserts which could affect the results subsequently obtained by the other characterisation techniques. Typical relative intensities obtained for the $\mathrm{Al}_{2} \mathrm{O}_{3}$ coating on the rake face of one of the ac inserts (number $2 \mathrm{~L}$ ) from each $\mathrm{H}_{2}-1 / \mathrm{AlCl}_{3}$ flow rate coating run are shown in Figure 5.30 , in comparison to those for the randomly oriented $\mathrm{Al}_{2} \mathrm{O}_{3}$ powder. The corresponding coating lattice parameter values are presented plotted against $\mathrm{H}_{2}-1 / \mathrm{AlCl}_{3}$ flow rate in Figure 5.31. In addition, all the lattice parameter values obtained for the coatings on the six inserts from each of the $\mathrm{H}_{2}-1 / \mathrm{AlCl}_{3}$ flow rate coating runs are defined in Table 5.12. As is evident from this table, for a particular coating run, the lattice parameter values determined for the coatings on all the inserts did not differ significantly. This was also the case for coating preferred 
orientation. It can thus be concluded, for each coating run, that there are no significant differences in the crystal structure of the $\mathrm{Al}_{2} \mathrm{O}_{3}$ coating on each of the inserts and hence that these inserts can be validly employed in the subsequent characterisation work.

\subsubsection{Effect of $\mathrm{H}_{2}-1 / \mathrm{AlCl}_{3}$ flow rate on composition of $\mathrm{Al}_{2} \underline{\mathrm{O}}_{3}$ coating and $\mathrm{Al}_{2} \underline{\mathrm{O}}_{3}$ coating/Ti(C,N) precoating interface}

AES was employed to obtain a composition-depth profile through the $\mathrm{Al}_{2} \mathrm{O}_{3}$ coating, the $\mathrm{Al}_{2} \mathrm{O}_{3}$ coating/Ti(C,N) precoating interface, the $\mathrm{Ti}(\mathrm{C}, \mathrm{N})$ precoating and the $\mathrm{Ti}(\mathrm{C}, \mathrm{N})$ precoating/HSS substrate interface for one of the $a c$ inserts from each of the $\mathrm{H}_{2}-1 / \mathrm{AlCl}_{3}$ flow rate coating runs. The results obtained are shown in Figure 5.32.

\subsubsection{Effect of $\mathrm{H}_{2}-1 / \mathrm{AlCl}_{3}$ flow rate on surface roughness of $\mathrm{Al}_{2} \underline{\mathrm{O}}_{3}$ coatings}

A Talysurf 10 was used to investigate the surface roughness of the $\mathrm{Al}_{2} \mathrm{O}_{3}$ coating on the rake face of one $a c$ insert from each of the $\mathrm{H}_{2}-1 / \mathrm{AlCl}_{3}$ flow rate coating runs. The roughness average $\left(R_{a}\right)$ values obtained are summarised in Table 5.13. In addition, typical Talysurf traces recorded for the surface of the $\mathrm{Al}_{2} \mathrm{O}_{3}$ coating on the insert from each coating run studied are presented in Figure 5.33, visually illustrating the effect of $\mathrm{H}_{2}-1 / \mathrm{AlCl}_{3}$ flow rate on the surface roughness of the $\mathrm{Al}_{2} \mathrm{O}_{3}$ coatings.

\subsubsection{Effect of $\mathrm{H}_{2}-1 / \mathrm{AlCl}_{3}$ flow rate on peripheral thickness variation (and other features) of $\mathrm{Al}_{2} \underline{\mathrm{O}}_{3}$ coatings}

Optical examination of a polished and etched cross-section through one of the $a c$ inserts from each of the $\mathrm{H}_{2}-1 / \mathrm{AlCl}_{3}$ flow rate coating runs was employed principally to determine whether the $\mathrm{Al}_{2} \mathrm{O}_{3}$ coating was present all around the periphery of the insert, and, if so, to determine the thickness of the $\mathrm{Al}_{2} \mathrm{O}_{3}$ coating on the rake and flank faces and at the corners (i.e. cutting edges) of the insert. These thicknesses were determined using the micrometer eyepiece normally used for microhardness testing on the Reichert MeF2. Twenty readings on the rake face, ten readings on each of the two flank faces (1 and 2) and five readings on each of the two corners ( 1 and 2 ) were taken. The thicknesses thus determined are summarised in Table 5.14 together with, for purposes of comparison, the corresponding average rake face coating thicknesses previously determined by ball-cratering. The average rake face coating thicknesses determined by optical measurement are also presented in Figure 5.34 plotted against $\mathrm{H}_{2}-1 / \mathrm{AlCl}_{3}$ flow rate together with the corresponding average, maximum and minimum rake face coating thicknesses determined by ball-cratering, again for comparison purposes. 
The cross-sections were then examined optically on the Reichert MeF2 to check for the presence of any defects in the $\mathrm{Al}_{2} \mathrm{O}_{3}$ coating, to examine the $\mathrm{Al}_{2} \mathrm{O}_{3}$ coating/Ti(C,N) precoating interface and the $\mathrm{Ti}(\mathrm{C}, \mathrm{N})$ precoating/HSS substrate interface and to investigate the microstructure of the PM BT42 grade HSS substrate adjacent to and remote from the latter interface. Typical optical cross-sections through the rake face of the inserts from each $\mathrm{H}_{2}-1 / \mathrm{AlCl}_{3}$ flow rate coating run are shown in Figure 5.35. As is just evident from these optical cross-sections, particularly that through the rake face of the inserts corresponding to $\mathrm{H}_{2}-1 / \mathrm{AlCl}_{3}$ flow rates of 25 and $30 \mathrm{~cm}^{3} \mathrm{~min}^{-1}$, a thin band is just discernible at the $\mathrm{Al}_{2} \mathrm{O}_{3}$ coating/Ti(C,N) precoating interface.

\subsubsection{Effect of $\mathrm{H}_{2}-1 / \mathrm{AlCl}_{3}$ flow rate on $\mathrm{Al}_{2} \underline{\mathrm{O}}_{3}$ coating microhardness}

Microhardness tests were employed to determine the hardness of the $\mathrm{Al}_{2} \mathrm{O}_{3}$ coating on one of the ac inserts from each of the $\mathrm{H}_{2}-1 / \mathrm{AlCl}_{3}$ flow rate coating runs. Using the procedure described in Section 4.1.5, low angle $\left(5.6^{\circ}\right)$ taper sections through the rake face of the insert selected from each coating run were first produced. An investigation of the variation in microhardness of the $\mathrm{Al}_{2} \mathrm{O}_{3}$ coating on each taper-sectioned insert with distance from the $\mathrm{Al}_{2} \mathrm{O}_{3}$ coating/Ti(C,N) precoating interface was then carried out to locate the region in which truly representative microhardness values could be obtained. The measured variations in microhardness of the $\mathrm{Al}_{2} \mathrm{O}_{3}$ coatings deposited at the different $\mathrm{H}_{2}-1 / \mathrm{AlCl}_{3}$ flow rates thus determined are shown in Figure 5.36. As can be seen, in each case, once a certain distance from the $\mathrm{Al}_{2} \mathrm{O}_{3}$ coating/Ti(C,N) precoating interface is reached, a plateau exists on which the microhardness of the $\mathrm{Al}_{2} \mathrm{O}_{3}$ coating does not vary significantly. Consequently, on each taper-sectioned insert, twenty five microhardness measurements were subsequently taken along the length of the rake face $\mathrm{Al}_{2} \mathrm{O}_{3}$ coating in the centre of this plateau in order to determine the microhardness of the $\mathrm{Al}_{2} \mathrm{O}_{3}$ coating. The microhardness values thus obtained are summarised in Table 5.15 and also presented in Figure 5.37 plotted against $\mathrm{H}_{2}-1 / \mathrm{AlCl}_{3}$ flow rate.

\subsubsection{Effect of $\mathrm{H}_{2}-1 / \mathrm{AlCl}_{3}$ flow rate on microstructure of $\mathrm{Al}_{2} \underline{\mathrm{O}}_{3}$ coating adjacent to interface with $\mathrm{Ti}(\mathrm{C}, \mathrm{N})$ precoating}

As previously described in Section 5.2.5, on the optical cross-sections through the rake face of some of the $\mathrm{Al}_{2} \mathrm{O}_{3}$ coated inserts from the $\mathrm{H}_{2}-1 / \mathrm{AlCl}_{3}$ flow rate coating runs, a thin band was just discernible at the $\mathrm{Al}_{2} \mathrm{O}_{3}$ coating/Ti(C,N) precoating interface. As previously described in Section 5.1.7 for the $\mathrm{Al}_{2} \mathrm{O}_{3}$ coated inserts from the $\mathrm{CO}_{2} / \mathrm{H}_{2}$ mole ratio coating runs, the taper-sectioned inserts from each of the $\mathrm{H}_{2}-1 / \mathrm{AlCl}_{3}$ flow rate coating runs were employed to facilitate a proper, relatively high magnification optical examination of these bands on the Reichert MeF2 microscope. To this end, the taper-sectioned ac inserts were re-lapped on the cast iron plate impregnated with $3 \mu \mathrm{m}$ diamond paste and then re-polished using the procedure 
previously detailed in Section 4.1.4. Figure 5.38 shows the resulting low-angle optical taper-sections through the $\mathrm{Al}_{2} \mathrm{O}_{3}$ coating and the $\mathrm{Al}_{2} \mathrm{O}_{3}$ coating/Ti(C,N) precoating interface for the $\mathrm{Al}_{2} \mathrm{O}_{3}$ coated inserts from each of the $\mathrm{H}_{2}-1 / \mathrm{AlCl}_{3}$ flow rate coating runs.

\subsubsection{Effect of $\mathrm{H}_{2}-1 / \mathrm{AlCl}_{3}$ flow rate on bulk and surface grain structures of $\mathrm{Al}_{2} \mathrm{O}_{3}$ coatings}

Fractography was employed to determine the bulk grain structure of the $\mathrm{Al}_{2} \mathrm{O}_{3}$ coatings deposited at the different $\mathrm{H}_{2}-1 / \mathrm{AlCl}_{3}$ flow rates. One $h c$ insert from each $\mathrm{H}_{2}-1 / \mathrm{AlCl}_{3}$ flow rate coating run was notched and fractured. The two pieces of each fractured $h c$ insert were then sputtered with gold and their rake face coating fracture surfaces examined on an SEM. It was observed that the bulk grain structure of the $\mathrm{Al}_{2} \mathrm{O}_{3}$ coating on the $h c$ insert from each $\mathrm{H}_{2}-1 / \mathrm{AlCl}_{3}$ flow rate coating run was uniform along its length. Typical bulk grain structures of the $\mathrm{Al}_{2} \mathrm{O}_{3}$ coatings deposited at the different $\mathrm{H}_{2}-1 / \mathrm{AlCl}_{3}$ flow rates are thus presented in Figure 5.39. The corresponding surface grain structures of the $\mathrm{Al}_{2} \mathrm{O}_{3}$ coatings were then determined by direct SEM observation. Figure 5.40 shows the typical $\mathrm{Al}_{2} \mathrm{O}_{3}$ coating surface grain structures observed.

\subsubsection{Effect of $\mathrm{H}_{2}-1 / \mathrm{AlCl}_{3}$ flow rate on adhesion of $\mathrm{Al}_{2} \underline{\mathrm{O}}_{3}$ coatings}

The scratch test was used to investigate the effect of $\mathrm{H}_{2}-1 / \mathrm{AlCl}_{3}$ flow rate on the adhesion of the $\mathrm{Al}_{2} \mathrm{O}_{3}$ coatings to the $\mathrm{Ti}(\mathrm{C}, \mathrm{N})$ precoated PM HSS inserts. For the reasons previously explained in Section 4.2, prior to scratch testing of the $h c$ inserts from the different $\mathrm{H}_{2}-1 / \mathrm{AlCl}_{3}$ flow rate coating runs, the thickness of the $\mathrm{Al}_{2} \mathrm{O}_{3}$ coating (and of the $\mathrm{Ti}(\mathrm{C}, \mathrm{N}$ ) precoating) and the hardness of the PM HSS substrate of each of the $h c$ inserts to be employed were determined. These values are shown in Table 5.16. The direction in which the rake face of each $h c$ insert had originally been surface ground was then determined using optical microscopy, after which scratch tests were performed on each insert.

Following the procedure described in detail in Section 4.2, the $h c$ insert selected from each $\mathrm{H}_{2}-1 / \mathrm{AlCl}_{3}$ flow rate coating run was scratch tested. The scratch channels produced were then examined on an optical microscope. First, the edges of the scratch channels on each of the inserts were examined to determine if any coating flaking had occurred at this location and, if so, the minimum stylus load at which it had occurred. Next, the effect of increasing stylus load on the appearance of the scratch channels was studied. It was observed, on each insert, that up to a particular stylus load, the scratch channels had a uniform dark purple appearance but that as the stylus load was further increased some orange/silvery areas were visible. At even higher stylus loads virtually the whole of the scratch channels was silvery in appearance. For each insert, the stylus load at which the latter was first observed, together with the minimum stylus load at which flaking was observed were noted. Following this, the scratch 
channels on the $h c$ insert from each $\mathrm{H}_{2}-1 / \mathrm{AlCl}_{3}$ flow rate coating run were examined on an SEM fitted with an EDX analyser. As before, the edges of the scratch channels on each insert were first examined to corroborate (or otherwise) the optically determined minimum stylus load at which coating flaking had occurred. SEM micrographs of a typical instance of this flaking, on each insert at the minimum stylus load determined, together with the corresponding $\mathrm{Al}$, Ti and $\mathrm{Fe} K_{\alpha} \mathrm{X}$-ray maps, are shown in Figures 5.41 to 5.45 allowing identification of the type of flaking observed. The degree of flaking observed was also noted. The scratch channel on each of the $h c$ inserts corresponding to the optically determined stylus load at which virtually the whole of the scratch channel became silvery in appearance was then studied, together with scratch channels produced by stylus loads lower than this, in order to determine the critical stylus load corresponding to extensive removal of the $\mathrm{Al}_{2} \mathrm{O}_{3}$ coating from the scratch channel. SEM micrographs of a typical region of the relevant scratch channels on each of the $h c$ inserts, together with the corresponding $\mathrm{Al}$, Ti and $\mathrm{Fe} K_{\alpha} \mathrm{X}$-ray maps are shown in Figures 5.46 to 5.55. A summary of the scratch test results obtained is provided in Table 5.17 , listing the minimum stylus loads at which coating flaking was observed at the edges of the scratch channels together with the type and degree of flaking, and the critical stylus load at which extensive $\mathrm{Al}_{2} \mathrm{O}_{3}$ coating removal occurred from the scratch channel. 


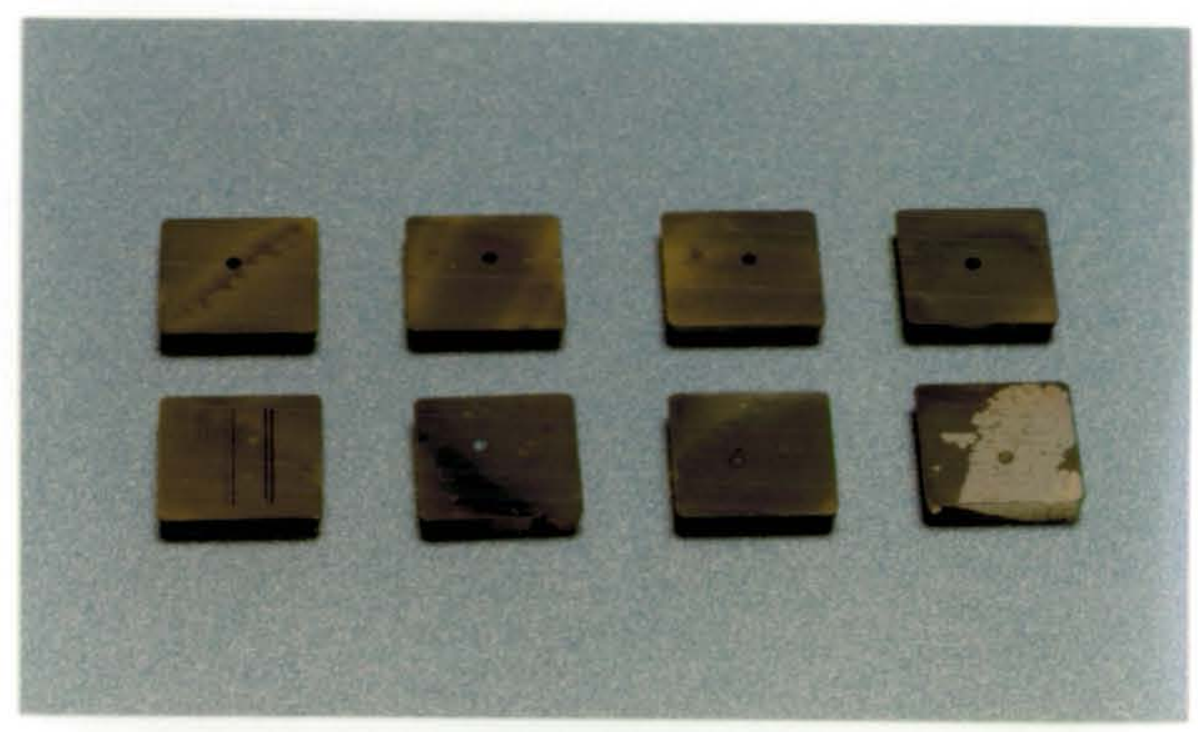

(a) $\mathrm{CO}_{2} / \mathrm{H}_{2}$ mole ratio $=1 / 6$

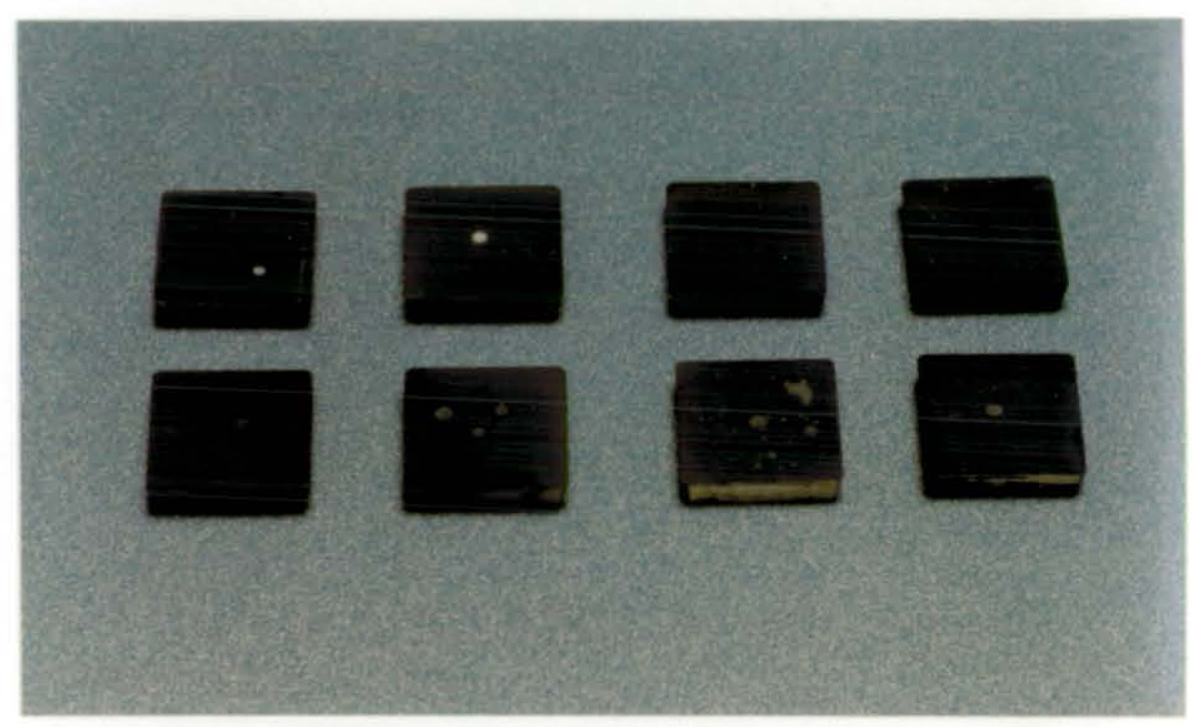

(b) $\mathrm{CO}_{2} / \mathrm{H}_{2}$ mole ratio $=1 / 8$

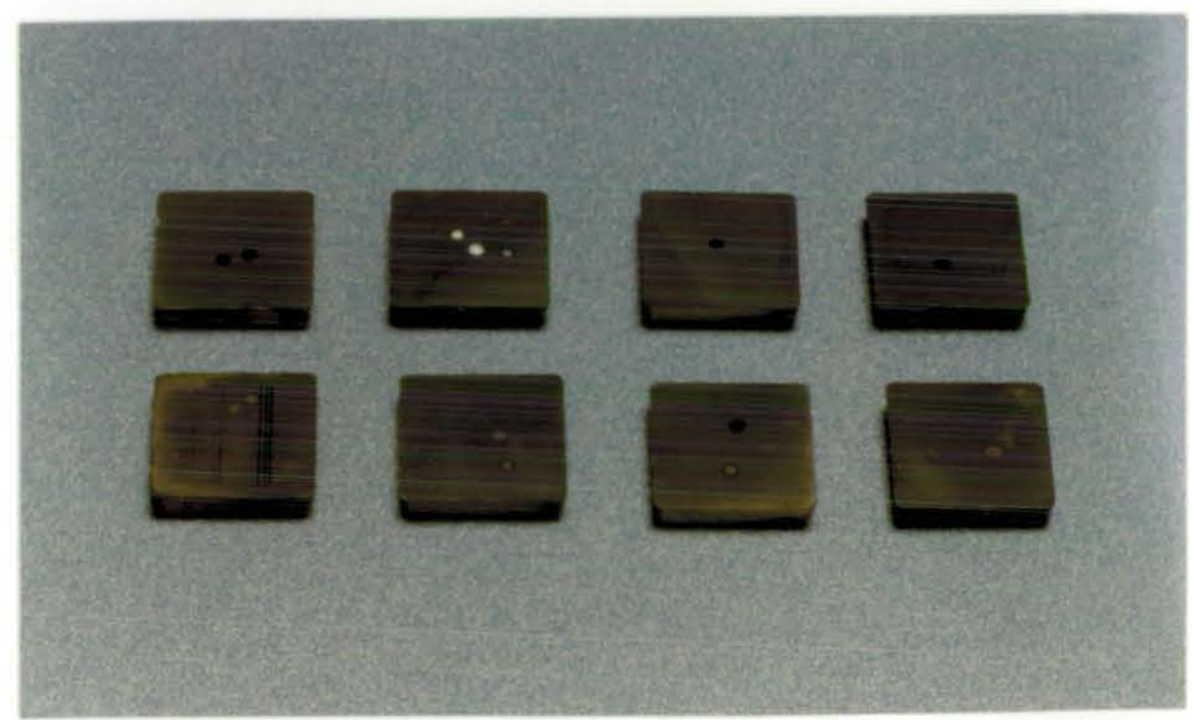

(c) $\mathrm{CO}_{2} / \mathrm{H}_{2}$ mole ratio $=1 / 10$

Figure 5.1 External appearance of $a c$ (upper) and $h c$ (lower) inserts from $\mathrm{CO}_{2} / \mathrm{H}_{2}$ mole ratio coating runs. 


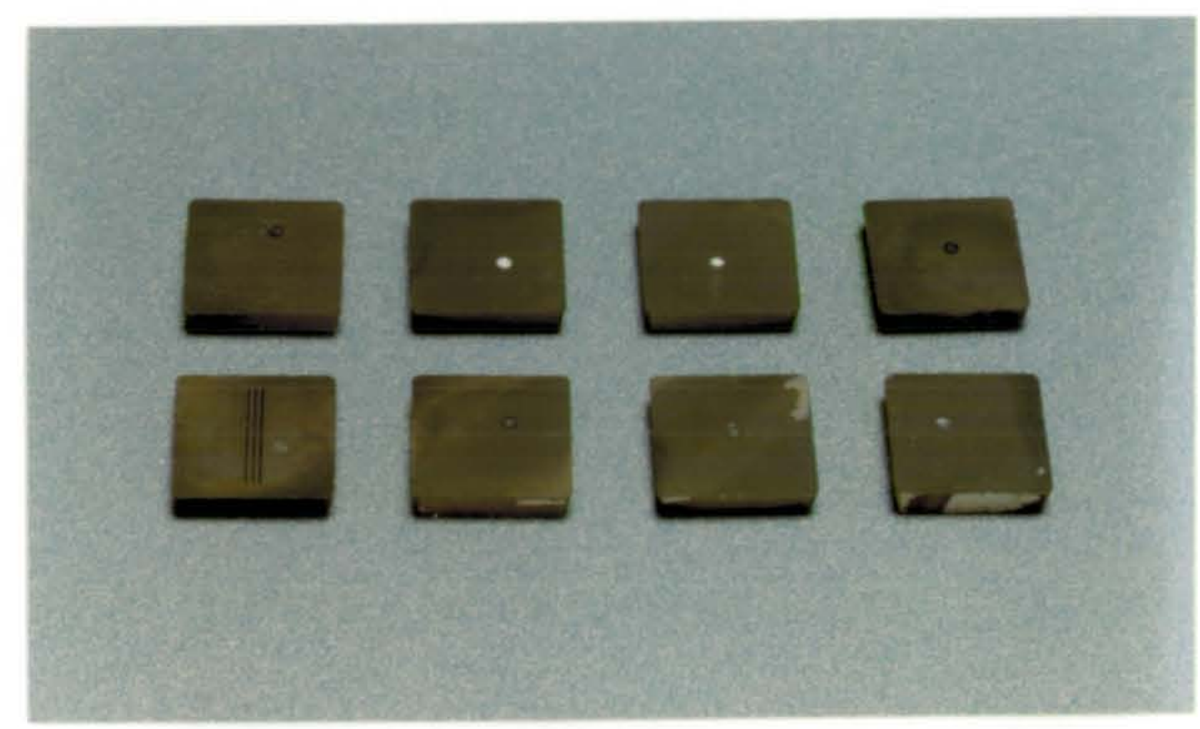

(d) $\mathrm{CO}_{2} / \mathrm{H}_{2}$ mole ratio $=1 / 12$

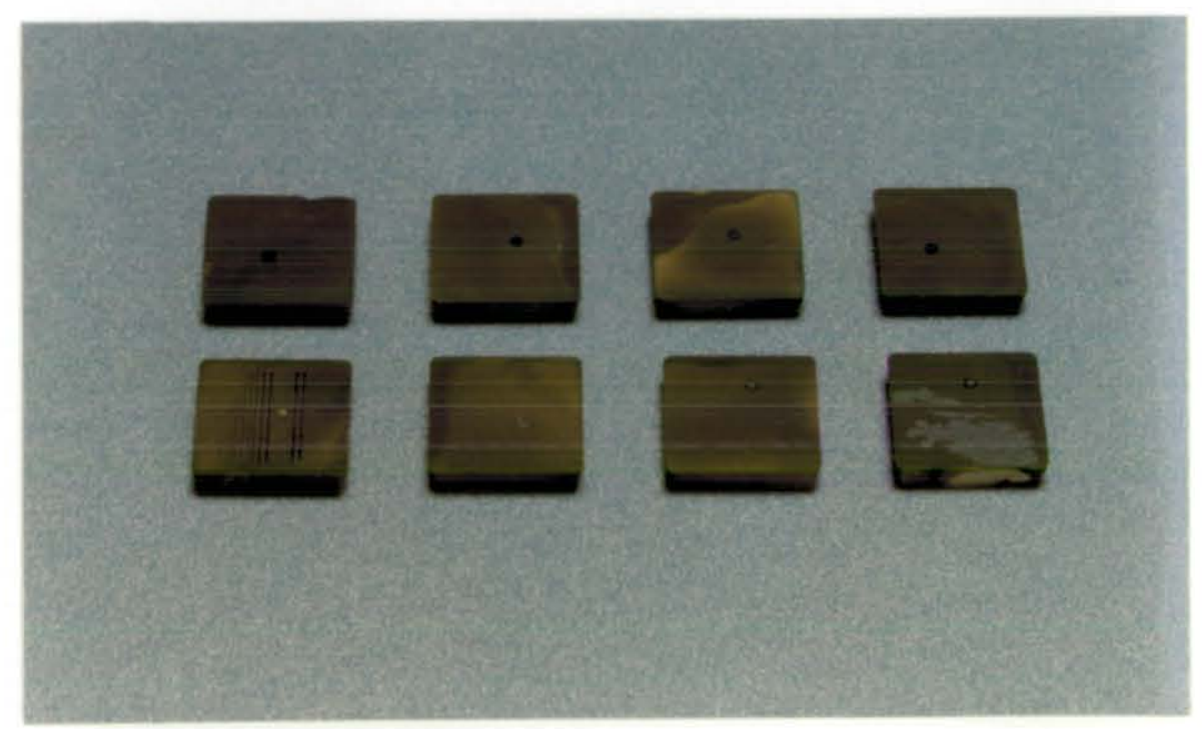

(e) $\mathrm{CO}_{2} / \mathrm{H}_{2}$ mole ratio $=1 / 14$

Figure 5.1 External appearance of $a c$ (upper) and $h c$ (lower) inserts from $\mathrm{CO}_{2} / \mathrm{H}_{2}$ mole ratio coating runs. 


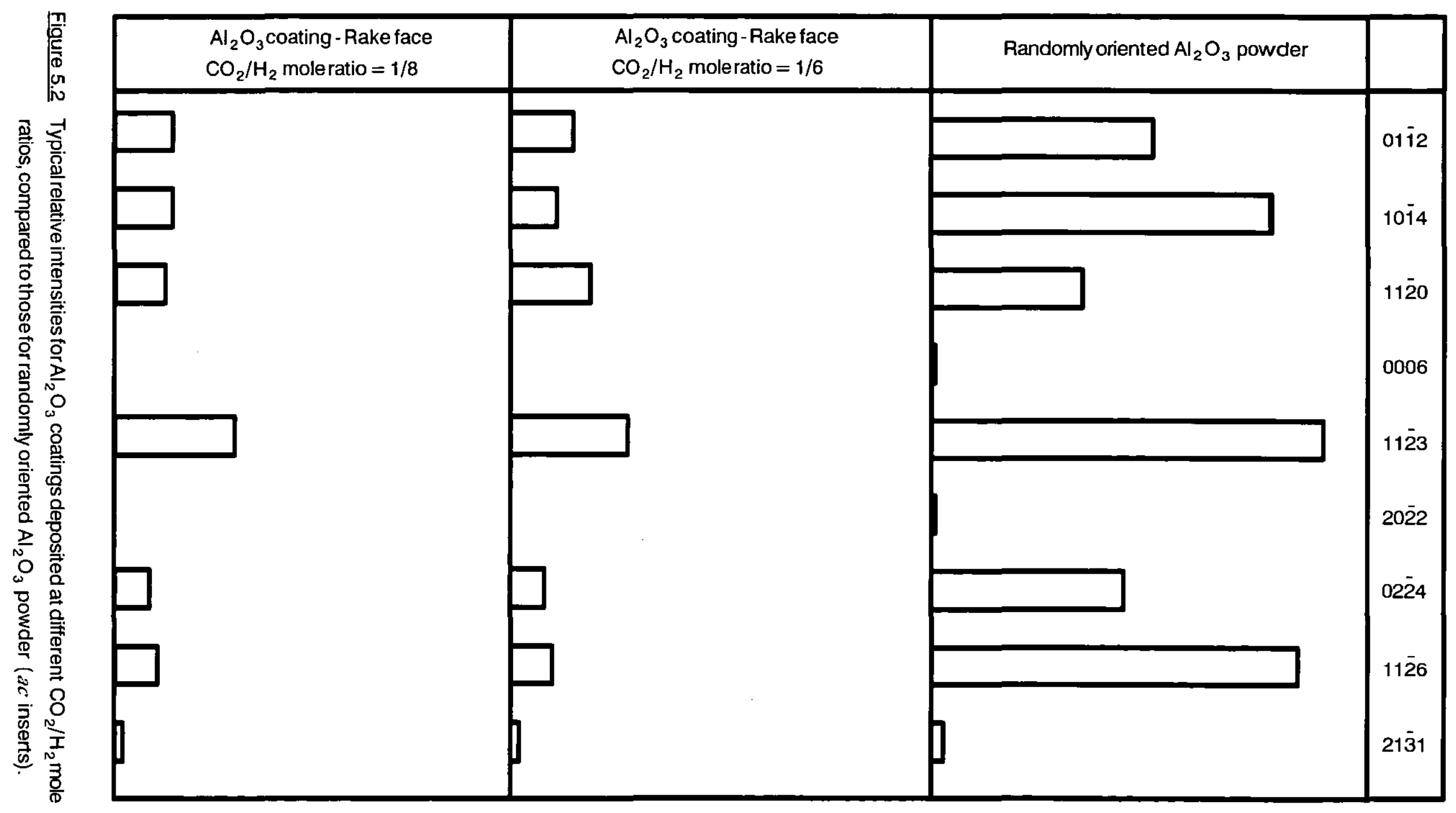




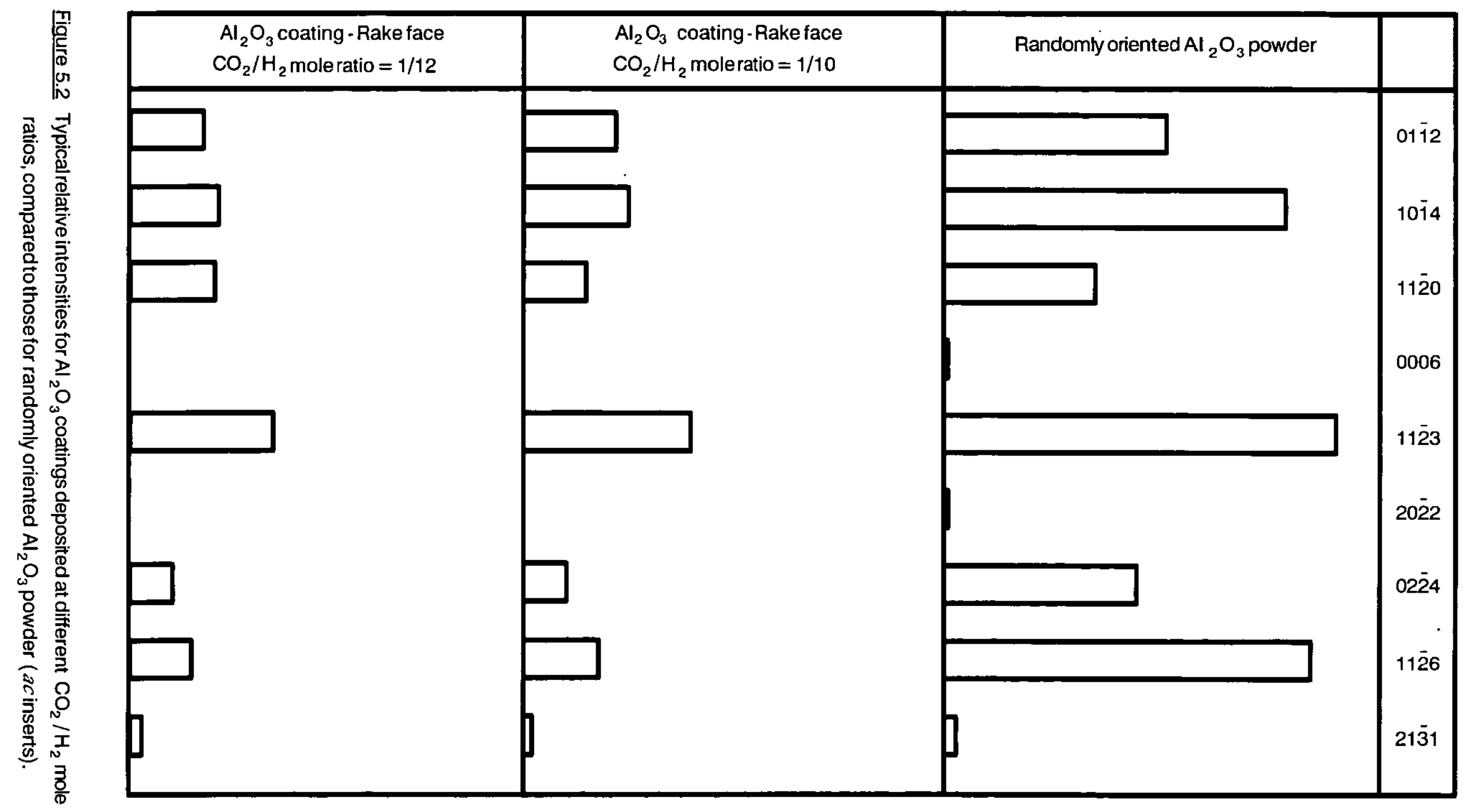




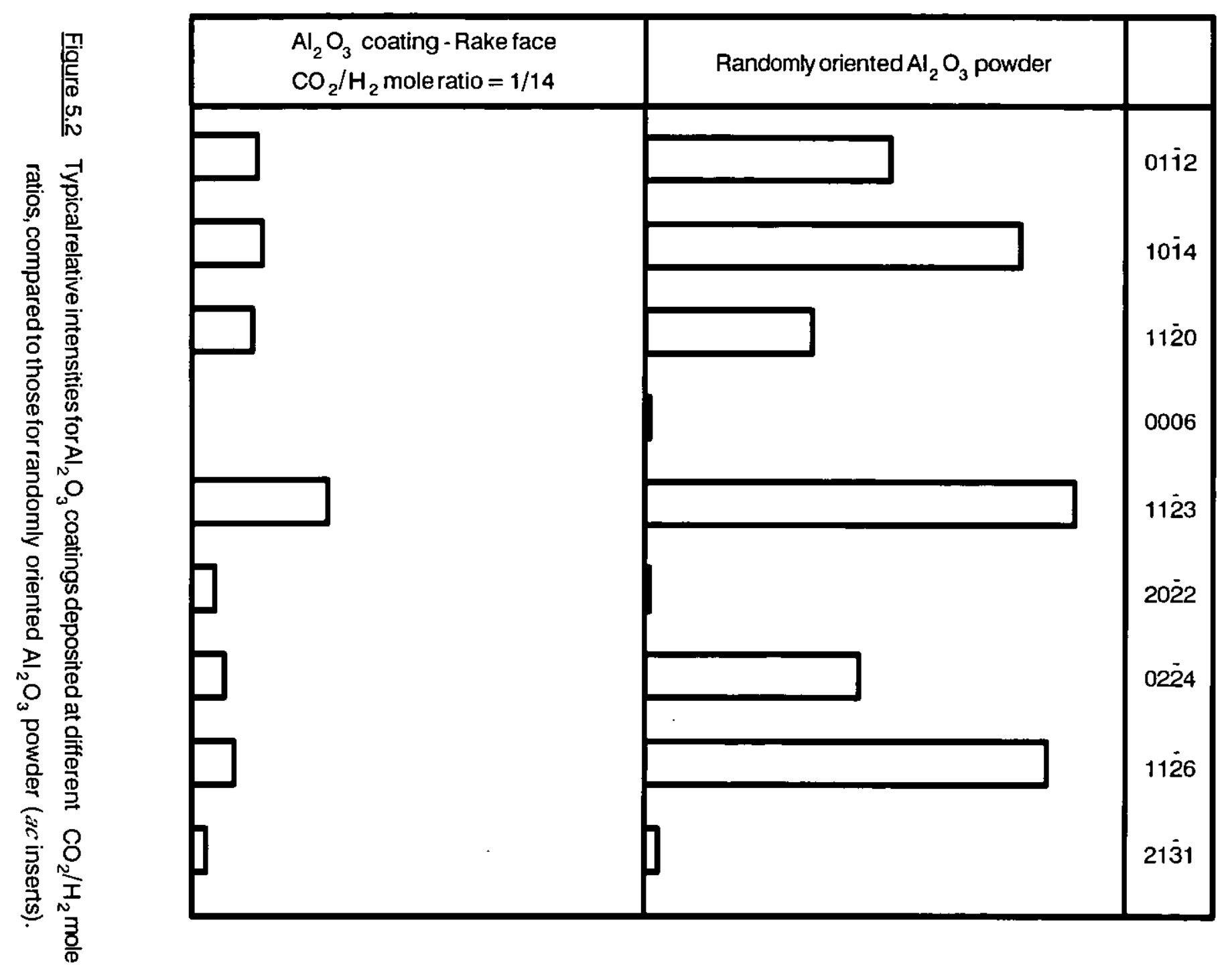




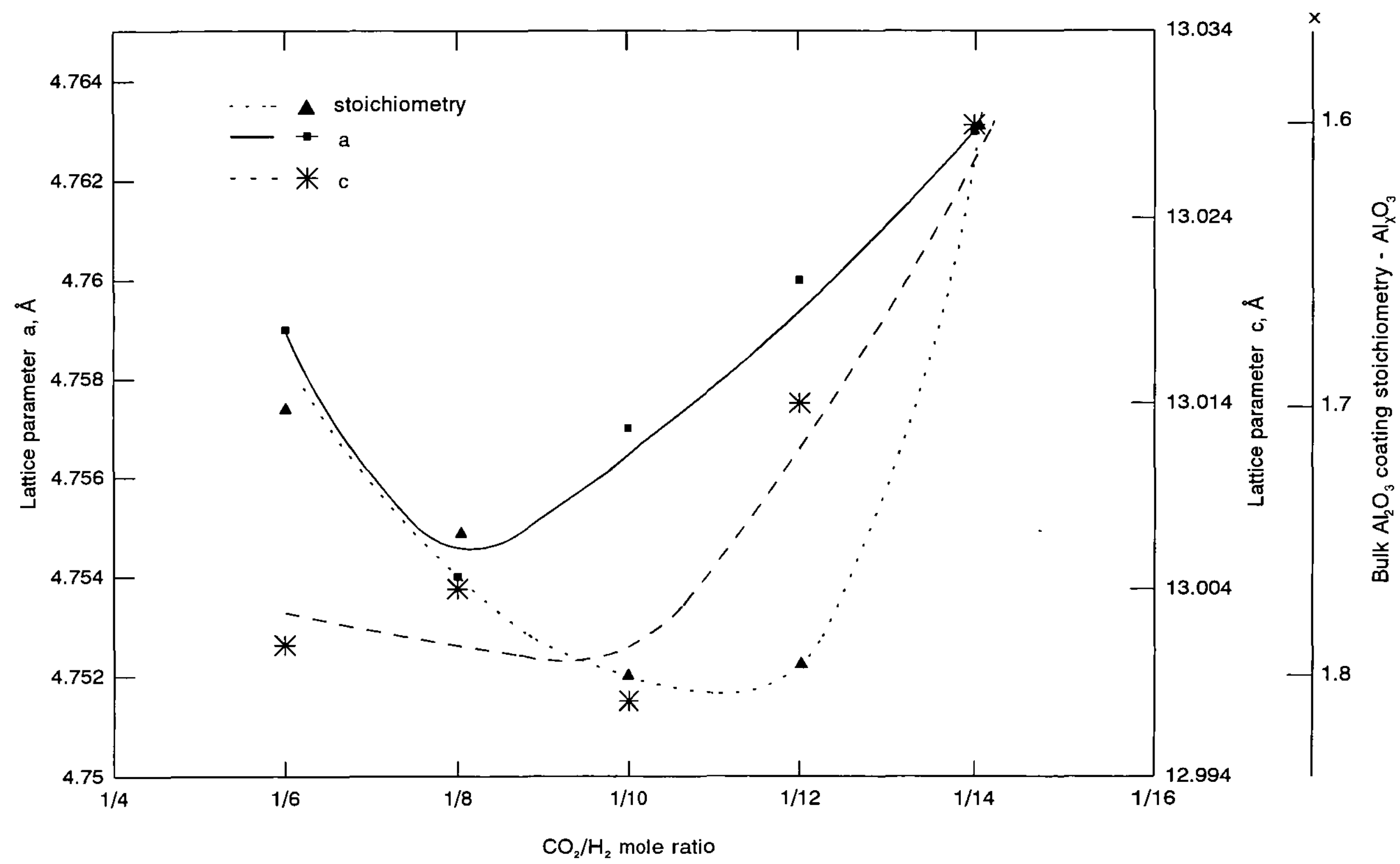

Fiqure 5.3 Effect of $\mathrm{CO}_{2} / \mathrm{H}_{2}$ mole ratio on $\mathrm{Al}_{2} \mathrm{O}_{3}$ coating lattice parameters (superimposed-bulk $\mathrm{Al}_{2} \mathrm{O}_{3}$ coating stoichiometry) 


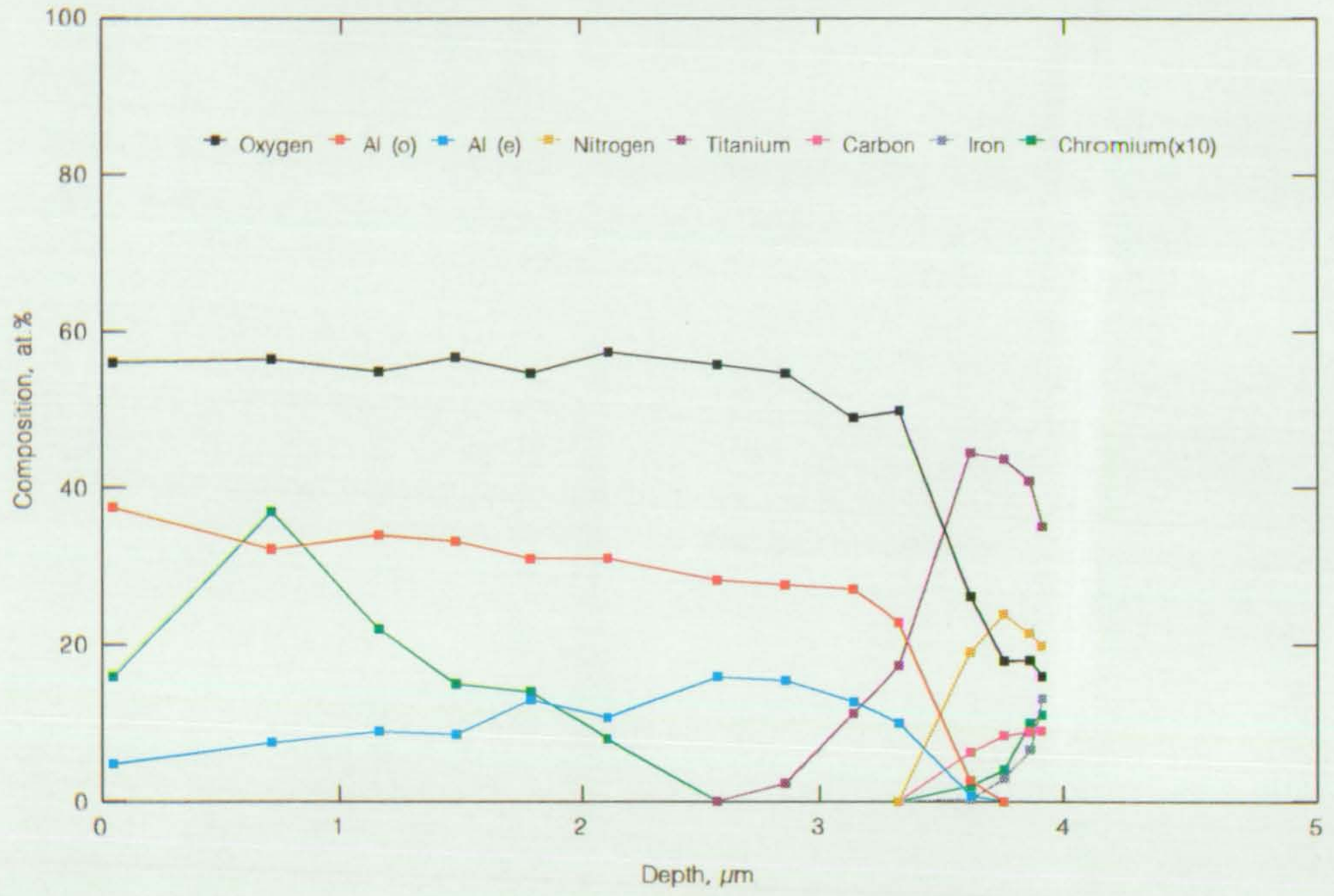

Figure 5.4 Composition-depth profile through $\mathrm{Al}_{2} \mathrm{O}_{3}$ coating and $\mathrm{Al}_{2} \mathrm{O}_{3}$ coating/Ti(C,N) precoating interface (extending through $\mathrm{Ti}(\mathrm{C}, \mathrm{N})$ precoating) for $\mathrm{Al}_{2} \mathrm{O}_{3}$ coated inserts from different $\mathrm{CO}_{2} / \mathrm{H}_{2}$ mole ratio coating runs. (A) $\mathrm{CO}_{2} / \mathrm{H}_{2}$ mole ratio $=1 / 6$ 


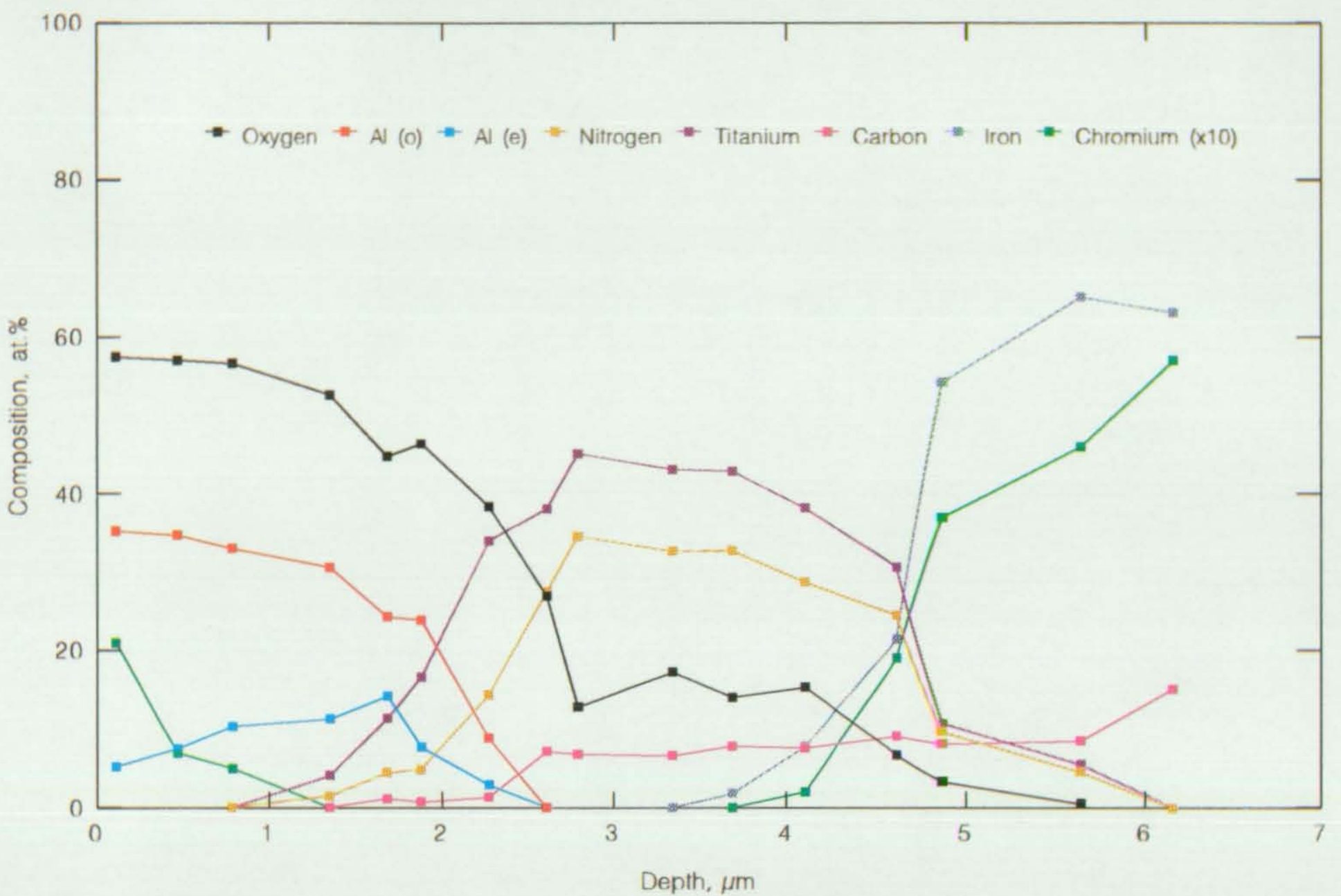

Figure 5.4 Composition-depth profile through $\mathrm{Al}_{2} \mathrm{O}_{3}$ coating and $\mathrm{Al}_{2} \mathrm{O}_{3}$ coating/Ti(C,N) precoating interface (extending through $\mathrm{Ti}(\mathrm{C}, \mathrm{N})$ precoating and $\mathrm{Ti}(\mathrm{C}, \mathrm{N})$ precoating/HSS substrate interface) for $\mathrm{Al}, \mathrm{O}$, coated inserts from different $\mathrm{CO}, / \mathrm{H}$, mole ratio coating runs. (b) $\mathrm{CO}, / \mathrm{H}$, mole ratio $=1 / 8$ 


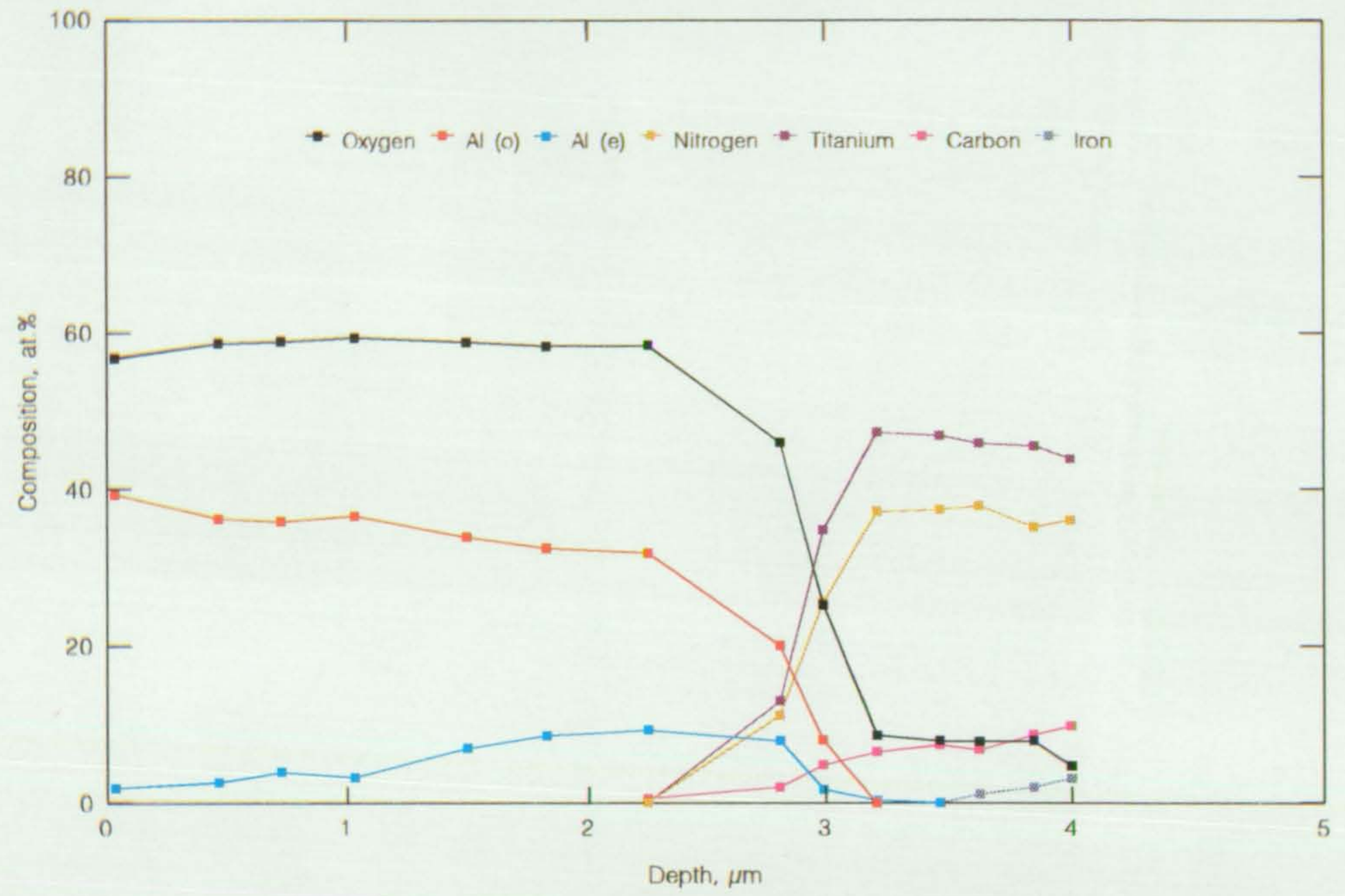

Figure 5.4 Composition-depth profile through $\mathrm{Al}_{2} \mathrm{O}_{3}$ coating and $\mathrm{Al}_{2} \mathrm{O}_{3}$ coating/Ti(C,N) precoating interface (extending through Ti(C,N) precoating and Ti(C,N) precoating/ $\mathrm{HSS}$ substrate interface) for $\mathrm{Al}_{2} \mathrm{O}_{3}$ coated inserts from different $\mathrm{CO}_{2} / \mathrm{H}_{2}$ moleratio coating nuns. (c) $\mathrm{CO}_{2} / \mathrm{H}_{2}$ moleratio $=1 / 10$ 


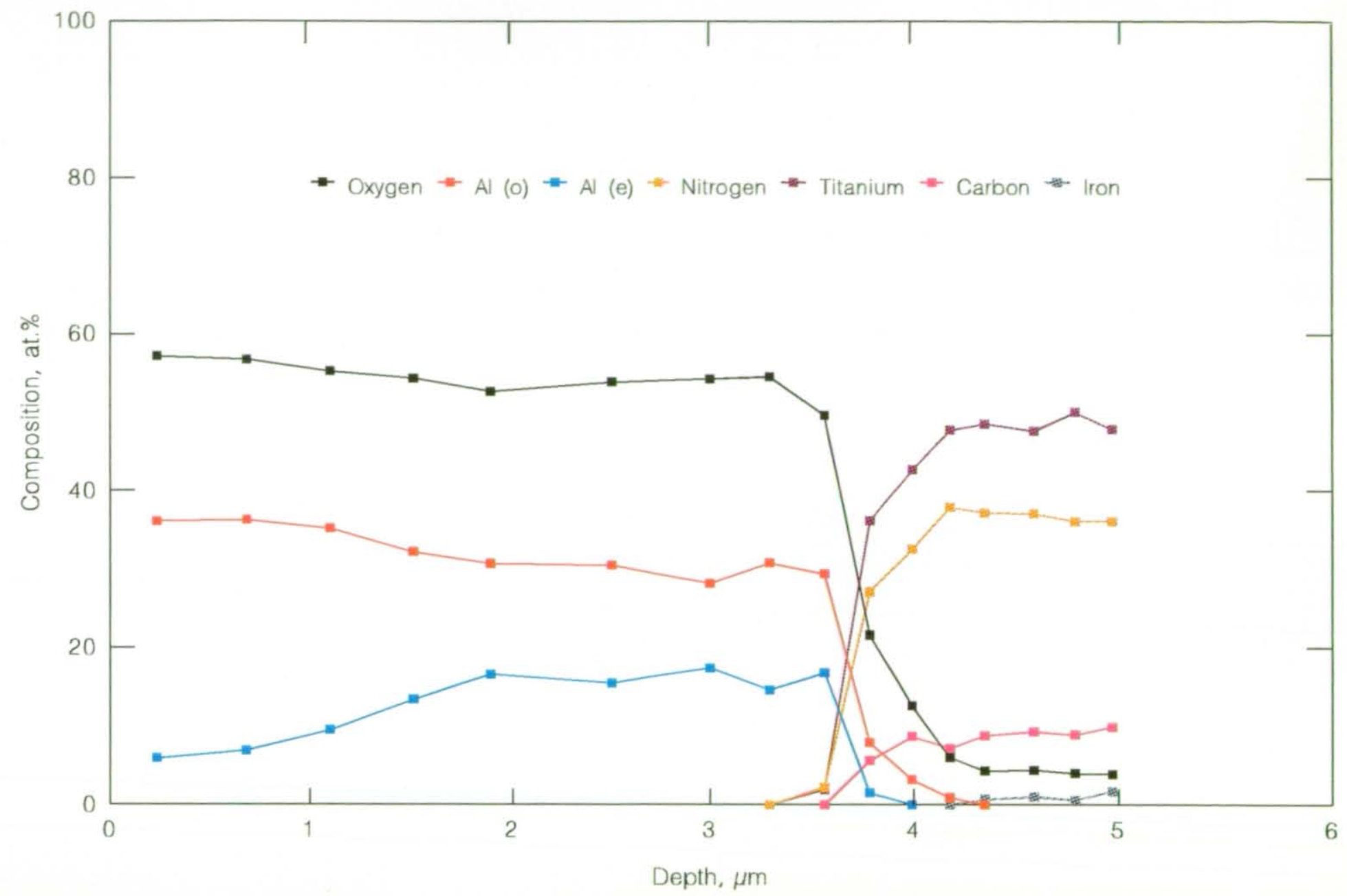

Figure 5.4 Composition-depth profile through $\mathrm{Al}_{2} \mathrm{O}_{3}$ coating and $\mathrm{Al}_{2} \mathrm{O}_{3}$ coating/Ti(C,N) precoating int erface (extending through $\mathrm{Ti}(\mathrm{C}, \mathrm{N})$ precoating and $\mathrm{Ti}(\mathrm{C}, \mathrm{N})$ precoating/ HSS substrate interface) for $\mathrm{Al}_{2} \mathrm{O}_{3}$ coated inserts from different $\mathrm{CO}_{2} / \mathrm{H}_{2}$ mole ratio ceating runs. (d) $\mathrm{CO}_{2} / \mathrm{H}_{2}$ mole ratio $=1 / 12$ 


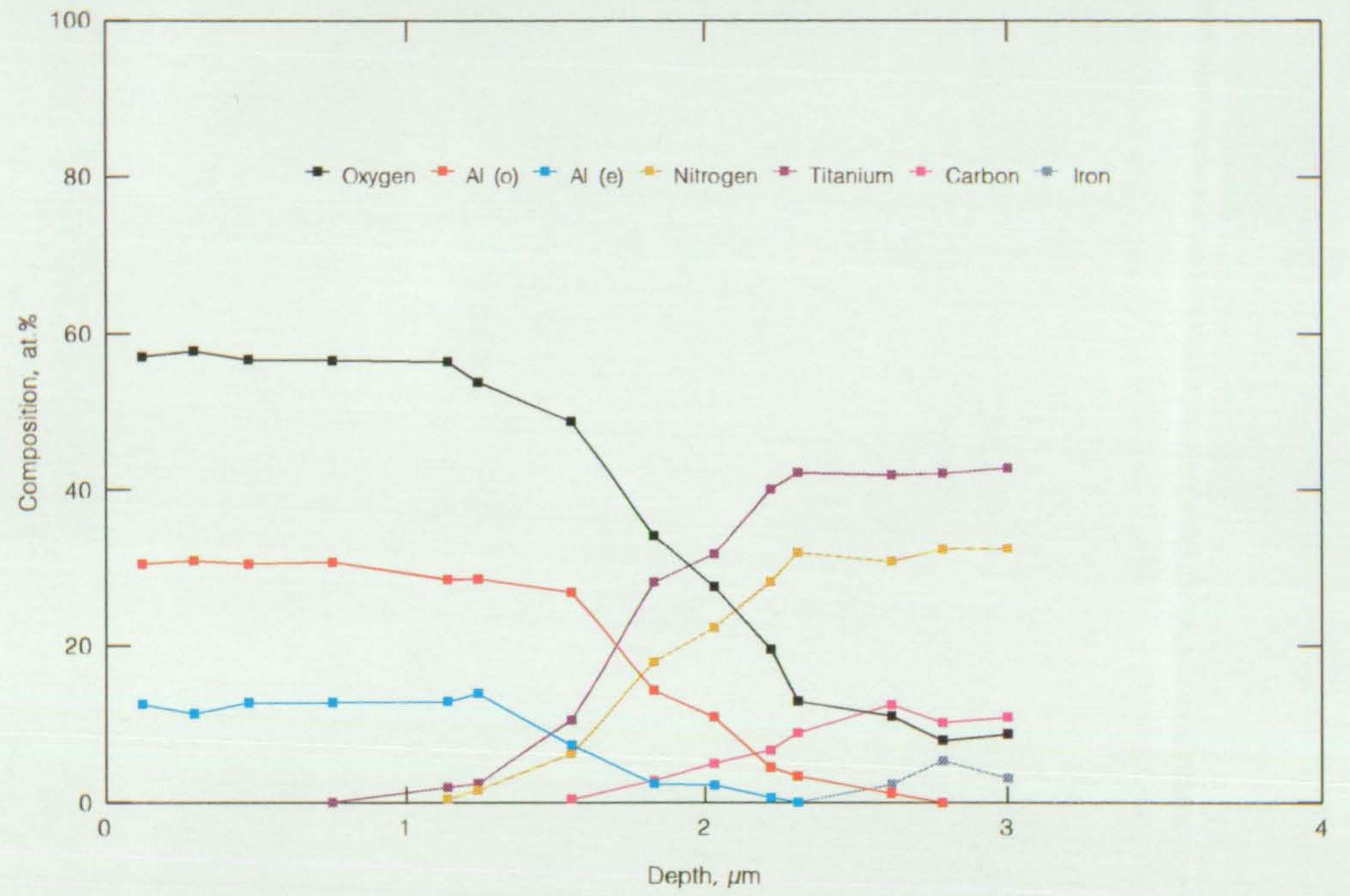

Finure 5.4 Composition-depth profile through $\mathrm{Al}_{2} \mathrm{O}_{3}$ coating and $\mathrm{A}_{2} \mathrm{O}_{3}$ coating/Ti(C,N) precoating interface (extending through $\mathrm{Ti}(\mathrm{C}, \mathrm{N})$ precoating and $\mathrm{Ti}(\mathrm{C}, \mathrm{N})$ precoating/HSS substrate interface) for $\mathrm{A}_{2} \mathrm{O}_{3}$ coated inserts from different $\mathrm{CO}_{2} / \mathrm{H}_{2}$ mole ratio coating runs. (e) $\mathrm{CO}_{2} / \mathrm{H}_{2}$ mole ratio $=1 / 14$ 


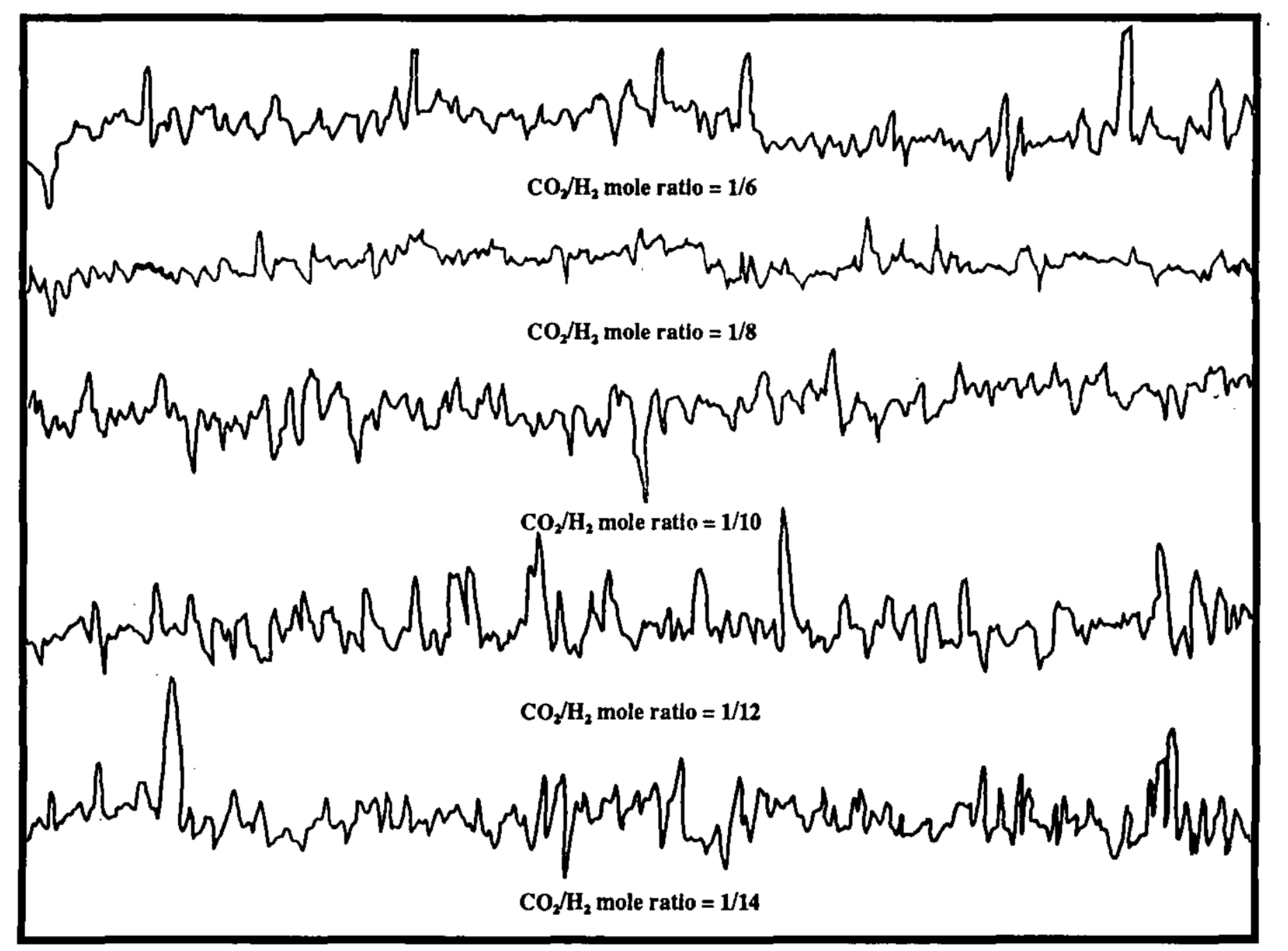
Figure 5.5 Typical Talysurf traces of surface of $\mathrm{Al}_{2} \mathrm{O}_{3}$ coatings deposited at different $\mathrm{CO}_{2} / \mathrm{H}_{2}$ mole
ratios. 


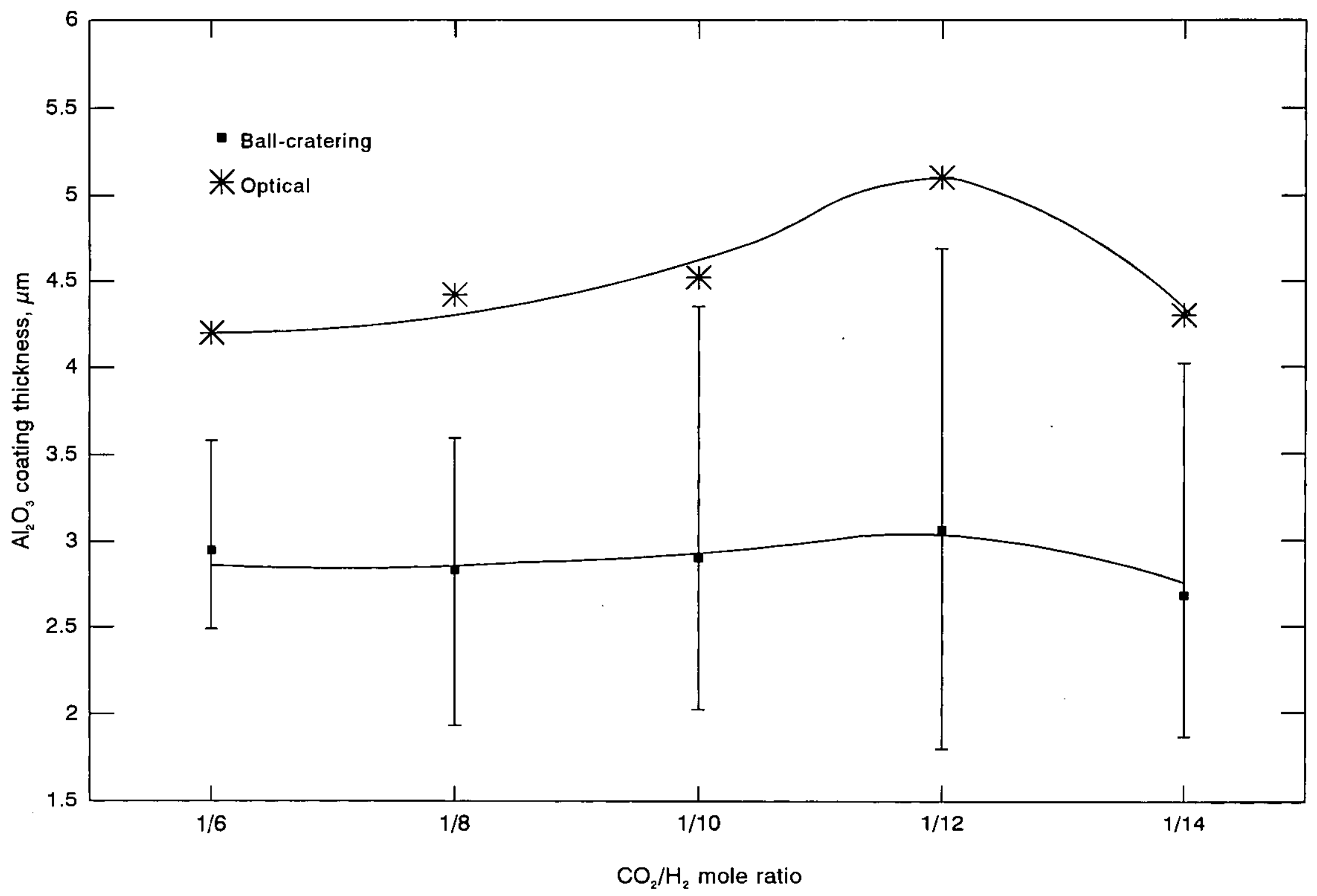

Fiqure 5.6 Effect of $\mathrm{CO}_{2} / \mathrm{H}_{2}$ mole ratio on $\mathrm{Al}_{2} \mathrm{O}_{3}$ coating thickness as determined by ball-cratering and optical measurements. 


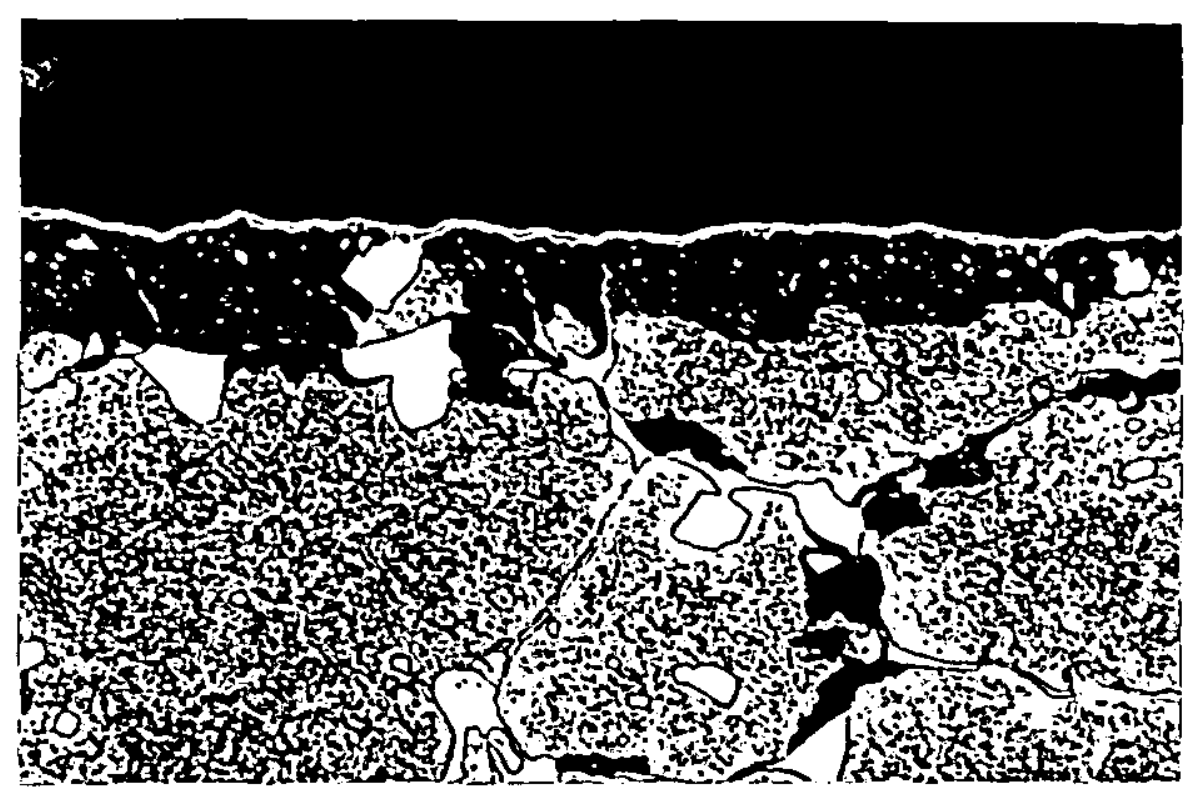

(a) $\mathrm{CO}_{2} / \mathrm{H}_{2}$ mole ratio $=1 / 6$

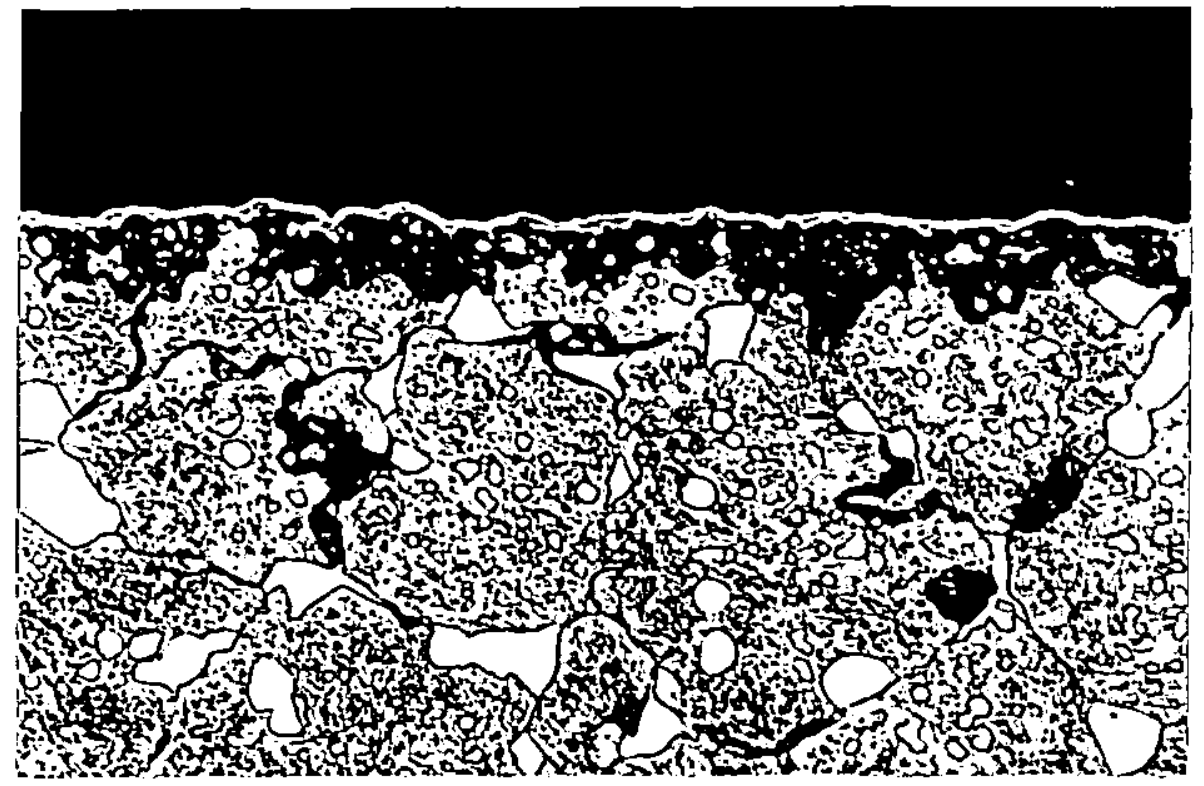

(b) $\mathrm{CO} / \mathrm{H}_{2}$ mole ratio $=1 / 8$

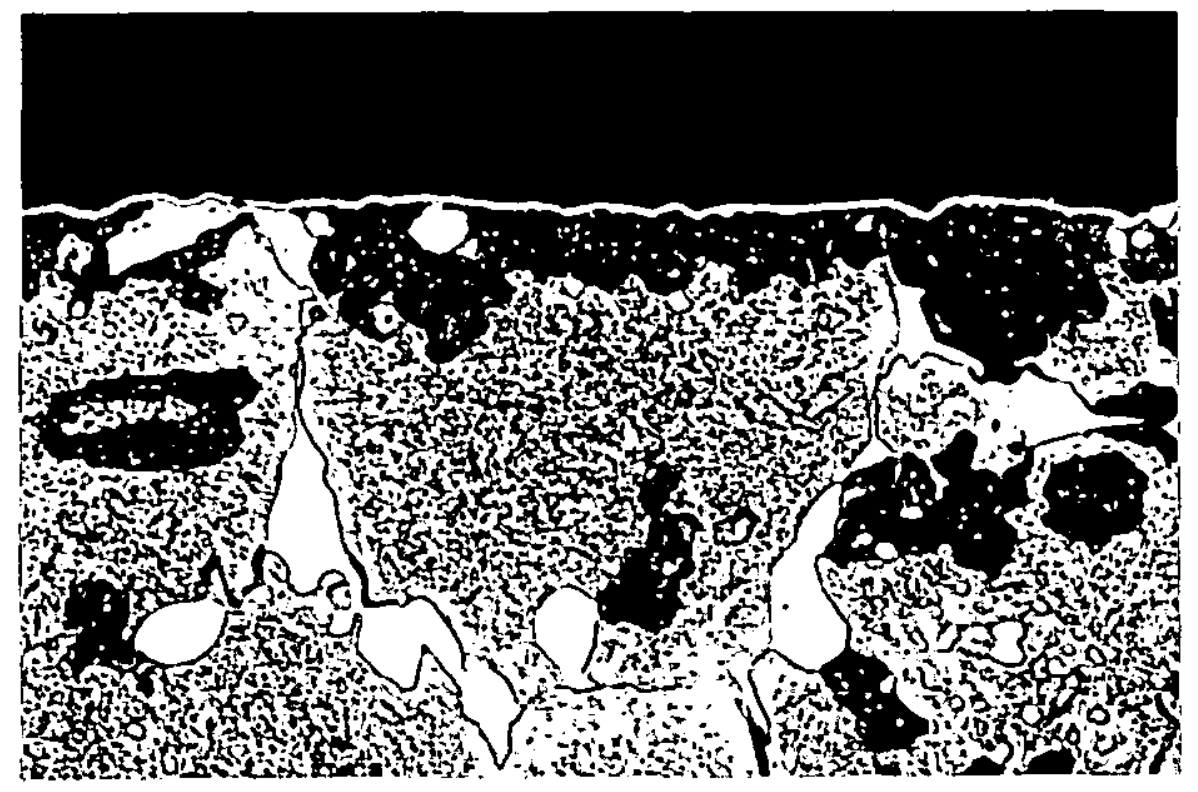

(c) $\mathrm{CO}_{2} / \mathrm{H}_{2}$ mole ratio $=1 / 10$

Figure 5.7 Optical cross-sections through rake face of inserts coated with $\mathrm{Al}_{2} \mathrm{O}_{3}$ at different $\mathrm{CO}_{2} / \mathrm{H}_{2}$ mole ratios. Etchant $2 \%$ nital, $\times 1000$. 


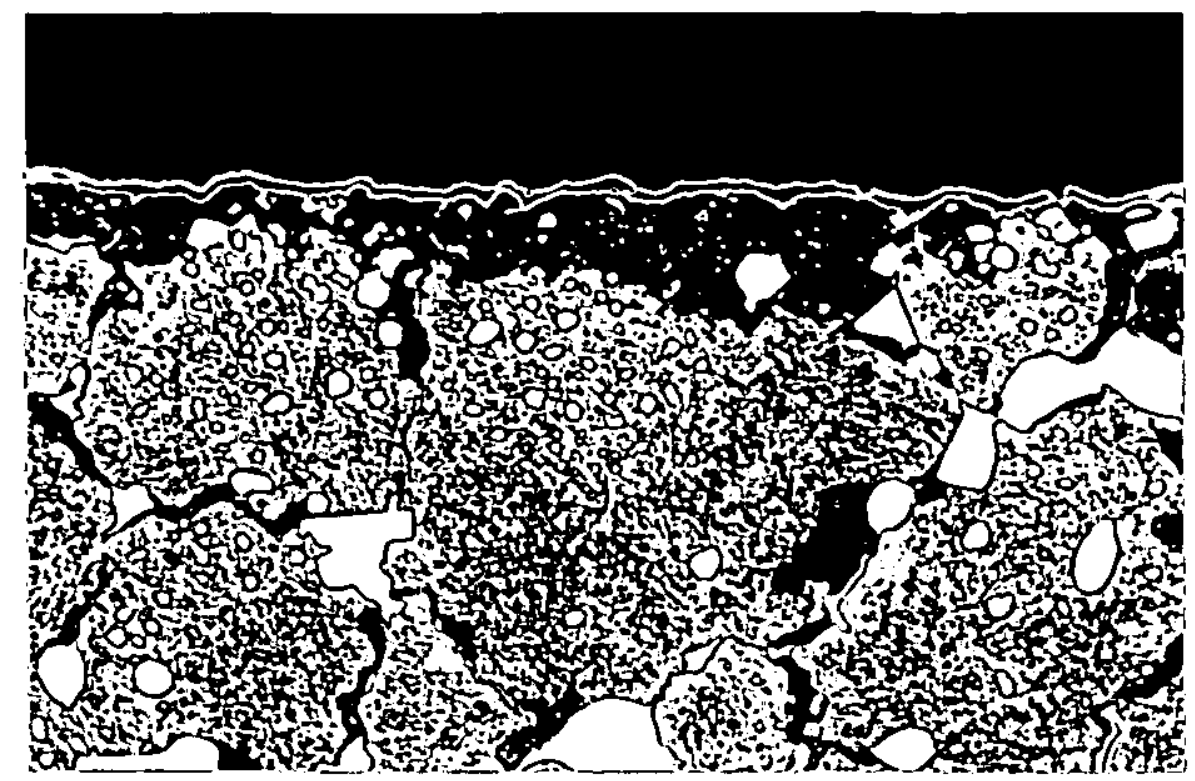

(d) $\mathrm{CO}_{2} / \mathrm{H}_{2}$ mole ratio $=1 / 12$

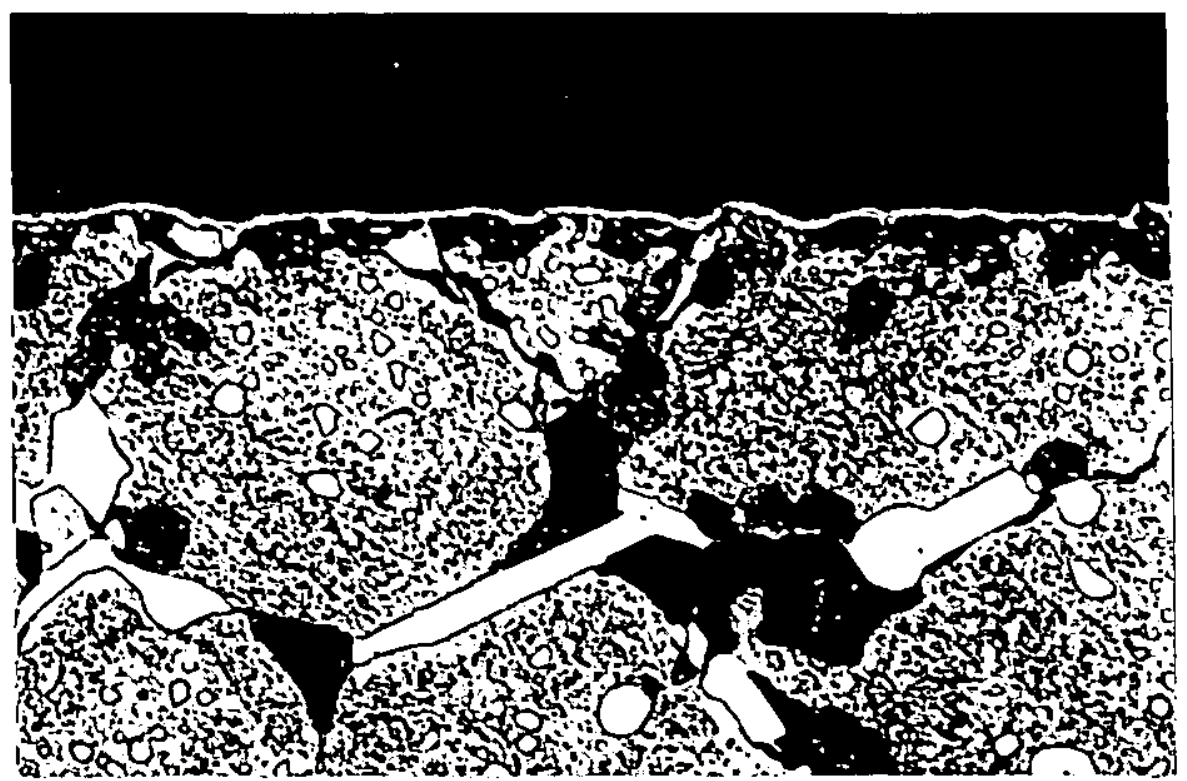

(e) $\mathrm{CO}_{2} / \mathrm{H}_{2}$ mole ratio $=1 / 14$

Eigure 5.7 Optical cross-sections through rake face of inserts coated with $\mathrm{Al}_{2} \mathrm{O}_{3}$ at different $\mathrm{CO}_{2} / \mathrm{H}_{2}$ mole ratios. Etchant $2 \%$ nital, $\mathrm{x} 1000$. 


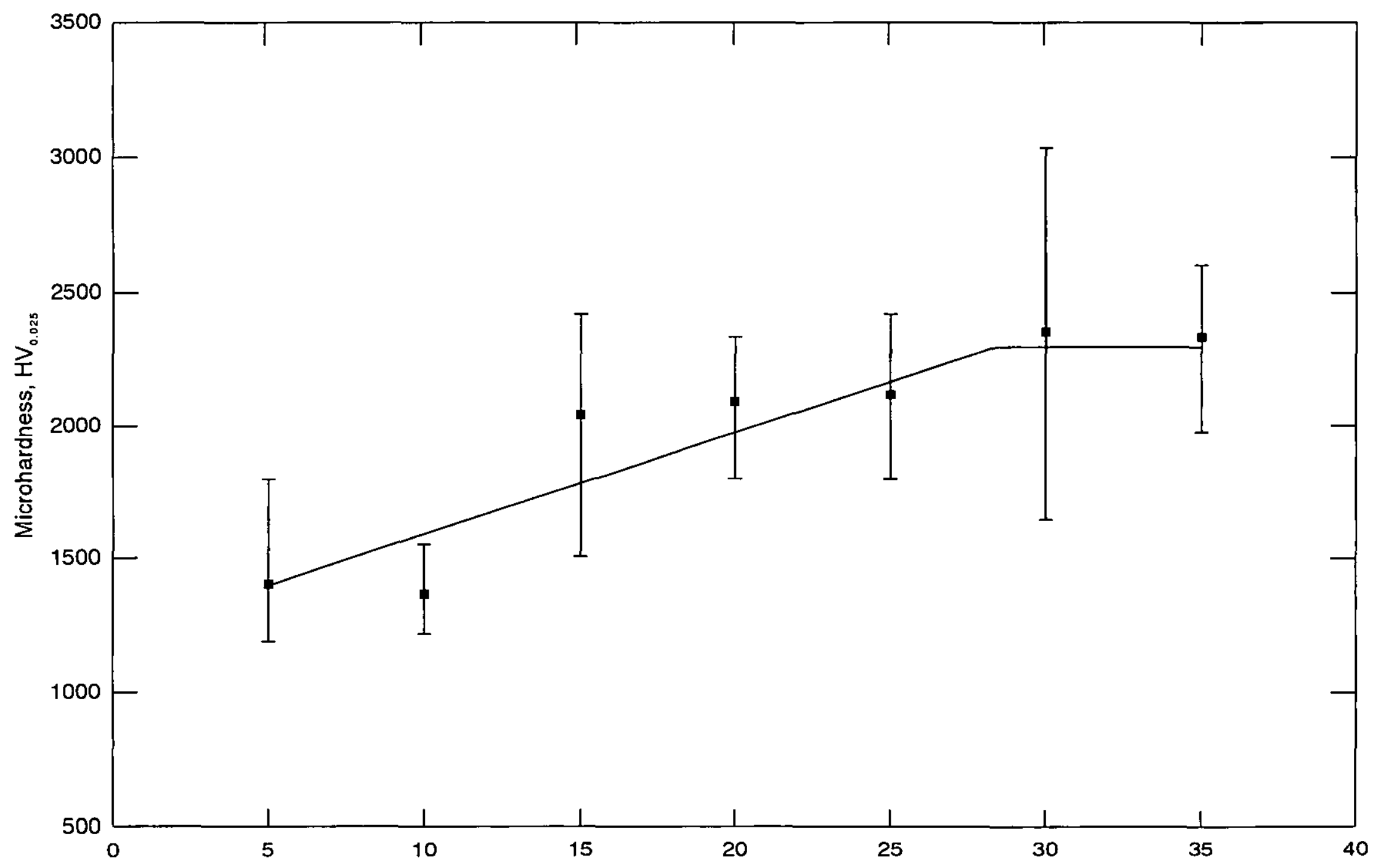

Distance from $\mathrm{Al}_{2} \mathrm{O}_{3}$ coating/Ti(C,N) precoating interface, $\mu \mathrm{m}$

Figure 5.8 Measured variations in microhardness of $\mathrm{Al}_{2} \mathrm{O}_{3}$ coatings deposited at different $\mathrm{CO}_{2} / \mathrm{H}_{2}$ mole ratios with distance from $\mathrm{Al}_{2} \mathrm{O}_{3}$ coating $/ \mathrm{Ti}(\mathrm{C}, \mathrm{N})$ precoating interface on taper- sectioned inserts. $(\mathrm{a}) \mathrm{CO}_{2} / \mathrm{H}_{2}$ mole ratio $=1 / 6$ 


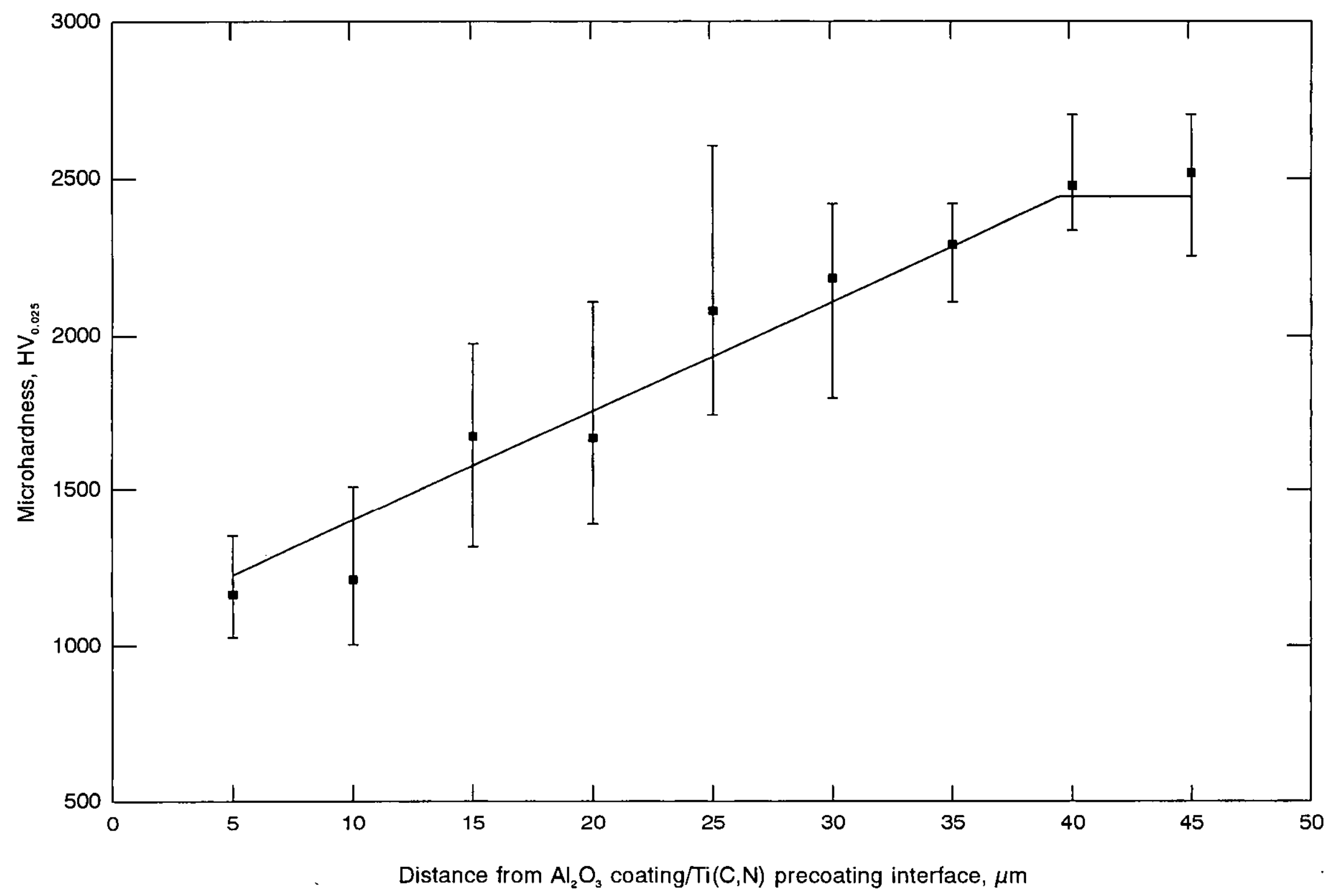

Figure 5.8 Measured variations in microhardness of $\mathrm{Al}_{2} \mathrm{O}_{3}$ coatings deposited at different $\mathrm{CO}_{2} / \mathrm{H}_{2}$ mole ratios with distance from $\mathrm{Al}_{2} \mathrm{O}_{3}$ coating/Ti(C,N) precoating interface on taper-sectioned inserts. (b) $\mathrm{CO}_{2} / \mathrm{H}_{2}$ mole ratio $=1 / 8$ 


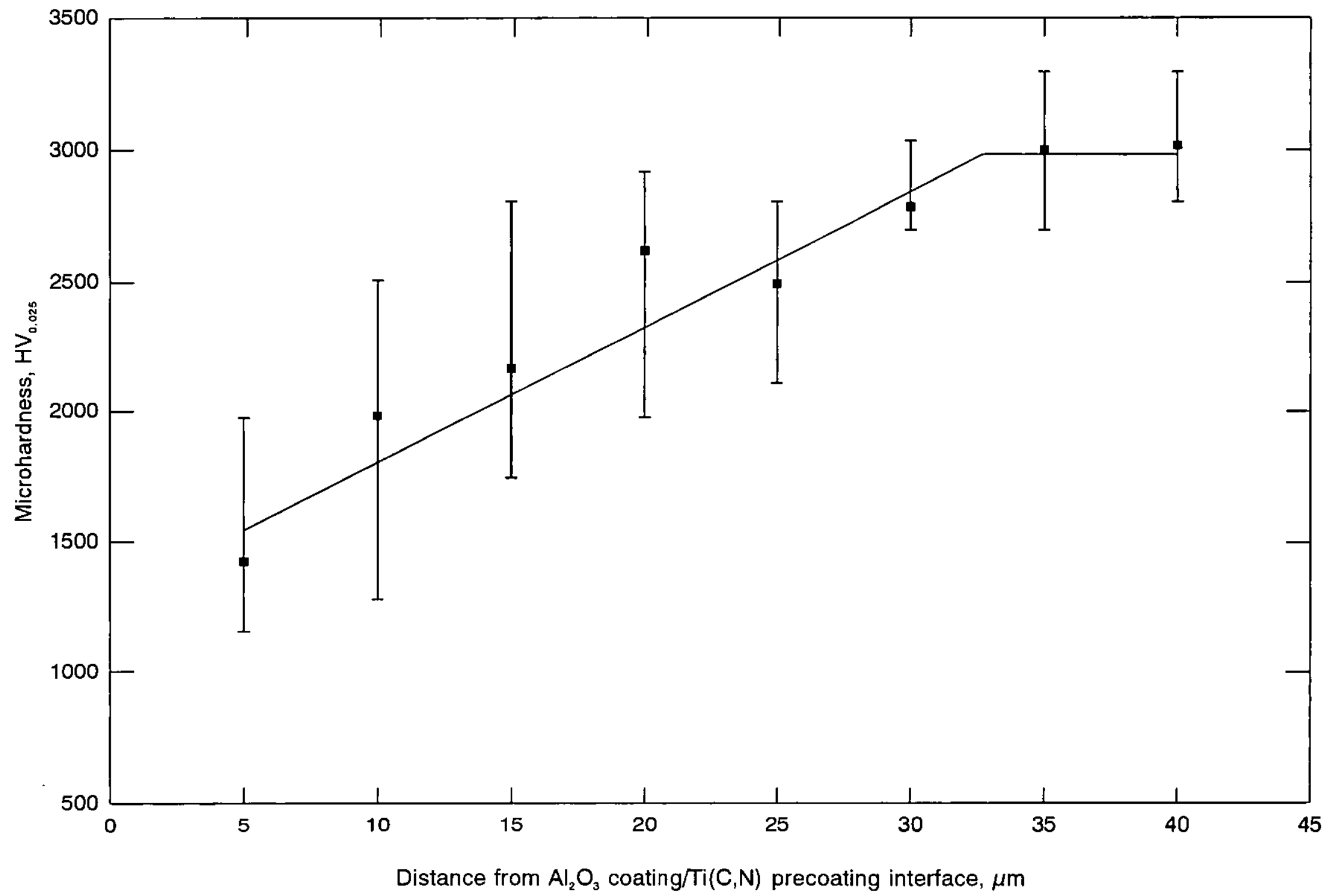

Figure 5.8 Measured variations in microhardness of $\mathrm{Al}_{2} \mathrm{O}_{3}$ coatings deposited at different $\mathrm{CO}_{2} / \mathrm{H}_{2}$ mole ratios with distance from $\mathrm{Al}_{2} \mathrm{O}_{3}$ coating/Ti $(\mathrm{C}, \mathrm{N})$ precoating interface on taper-sectioned inserts. (c) $\mathrm{CO}_{2} / \mathrm{H}_{2}$ mole ratio $=1 / 10$ 


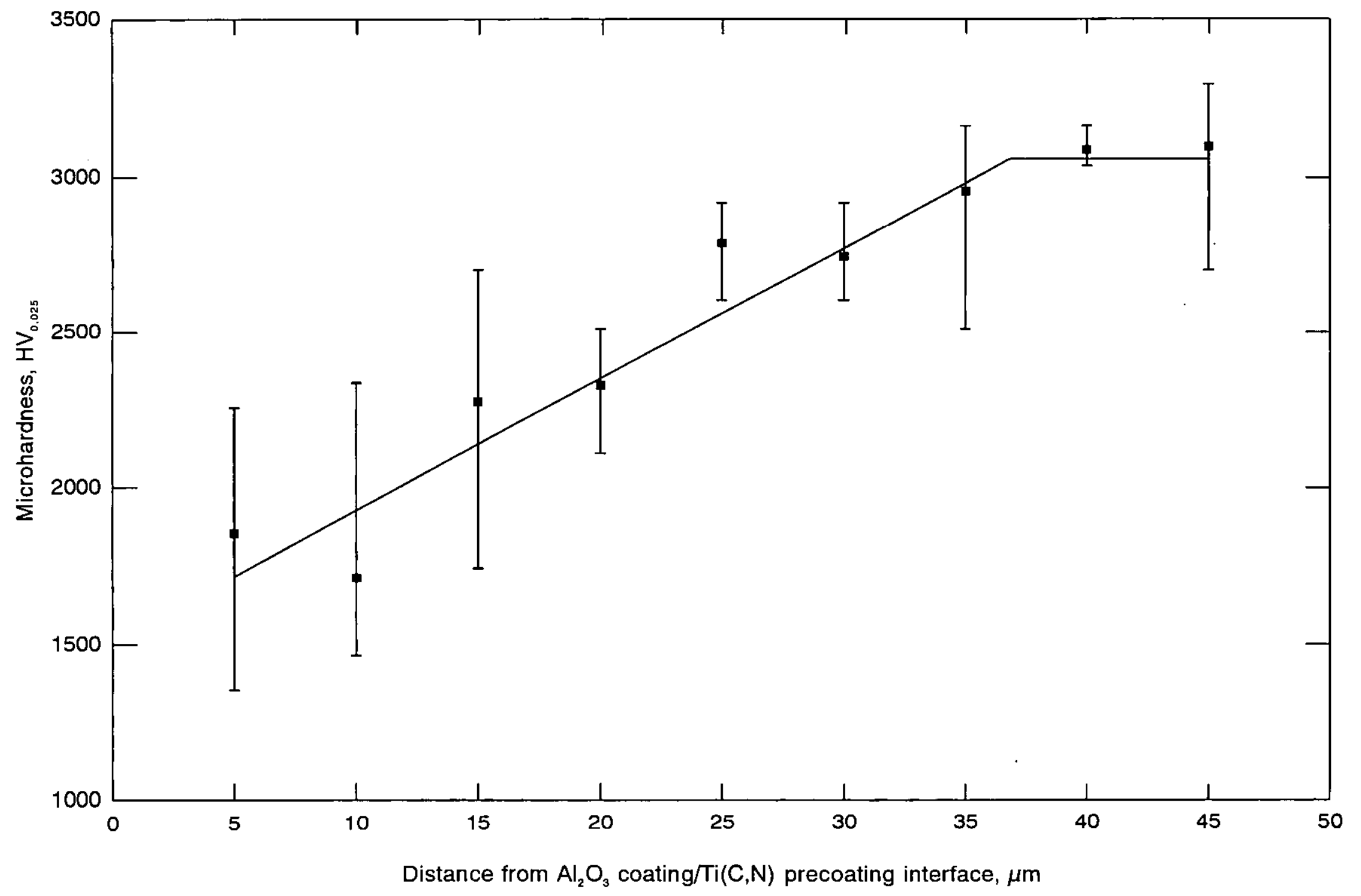

Figure 5.8 Measured variations in microhardness of $\mathrm{Al}_{2} \mathrm{O}_{3}$ coatings deposited at different $\mathrm{CO}_{2} / \mathrm{H}_{2}$ mole ratios with distance from $\mathrm{Al}_{2} \mathrm{O}_{3}$ coating $/ \mathrm{Ti}(\mathrm{C}, \mathrm{N})$ precoating interface on taper-sectioned inserts. (d) $\mathrm{CO}_{2} / \mathrm{H}_{2}$ mole ratio $=1 / 12$ 


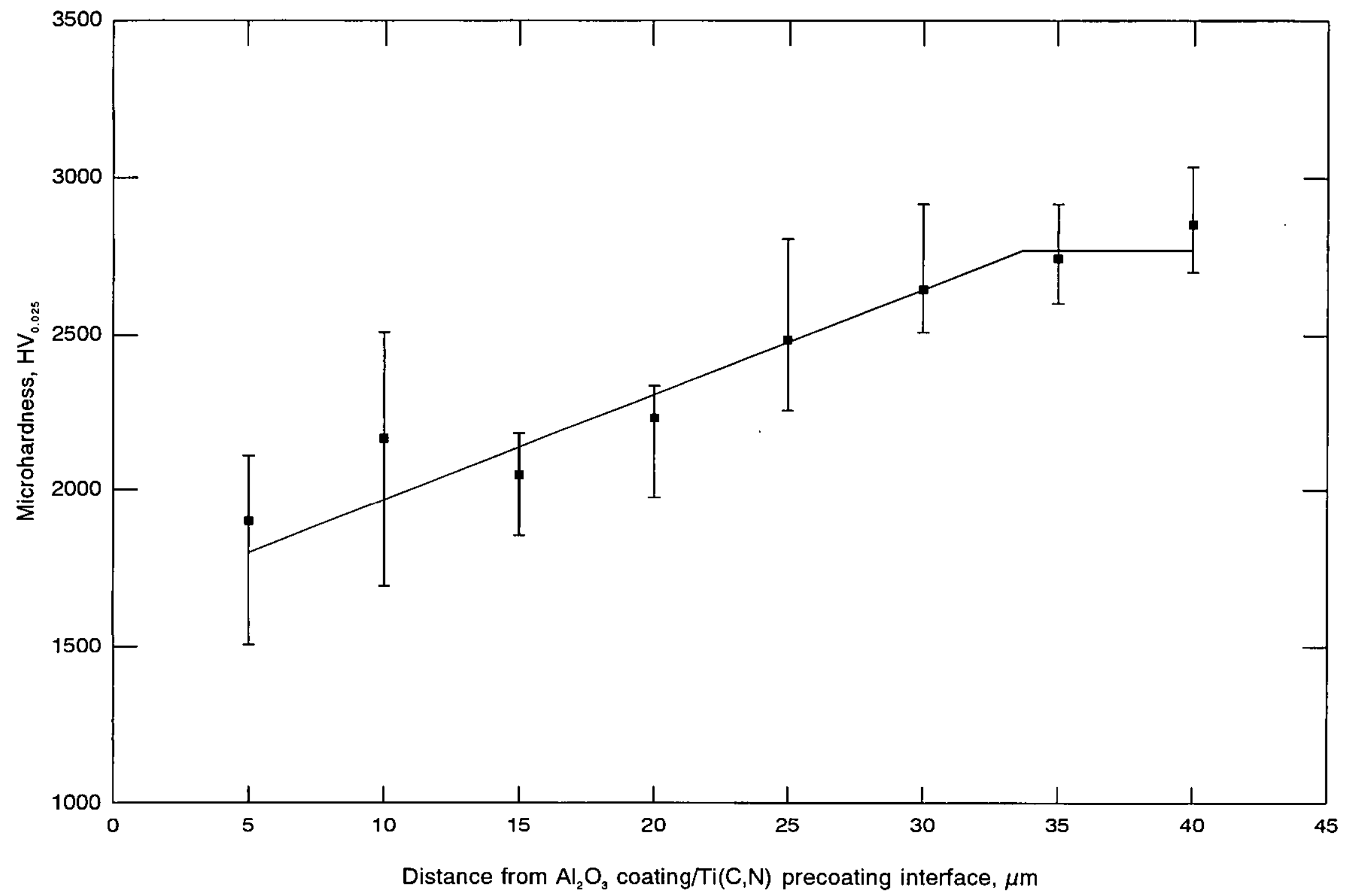

Figure 5.8 Measured variations in microhardness of $\mathrm{Al}_{2} \mathrm{O}_{3}$ coatings deposited at different $\mathrm{CO}_{2} / \mathrm{H}_{2}$ mole ratios with distance from $\mathrm{Al}_{2} \mathrm{O}_{3}$ coating/Ti(C,N) precoating interface on taper-sectioned inserts. (e) $\mathrm{CO}_{2} / \mathrm{H}_{2}$ mole ratio $=1 / 14$ 


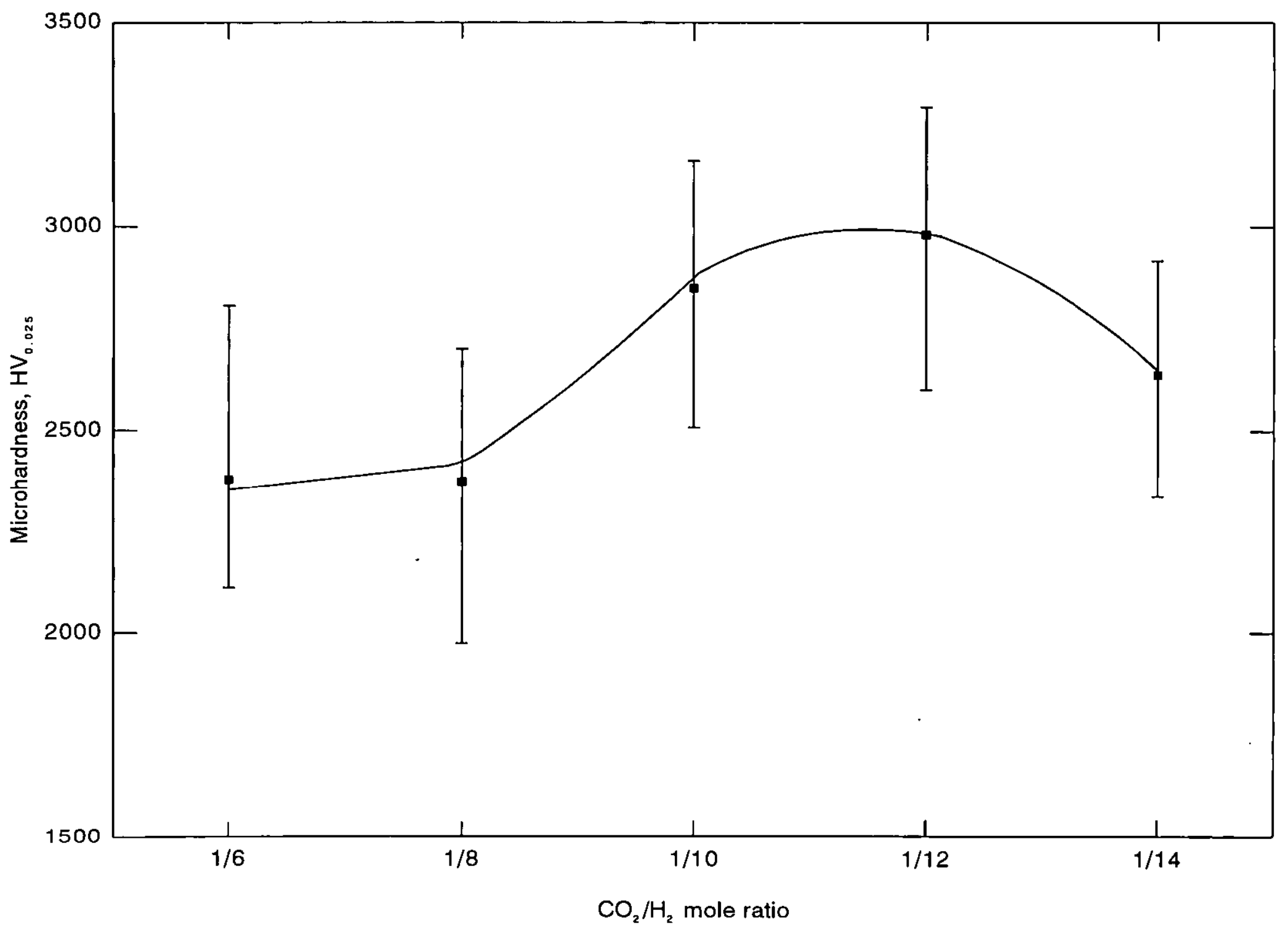

Figure 5.9 Effect of $\mathrm{CO}_{2} / \mathrm{H}_{2}$ mole ratio on $\mathrm{Al}_{2} \mathrm{O}_{3}$ coating microhardness. 


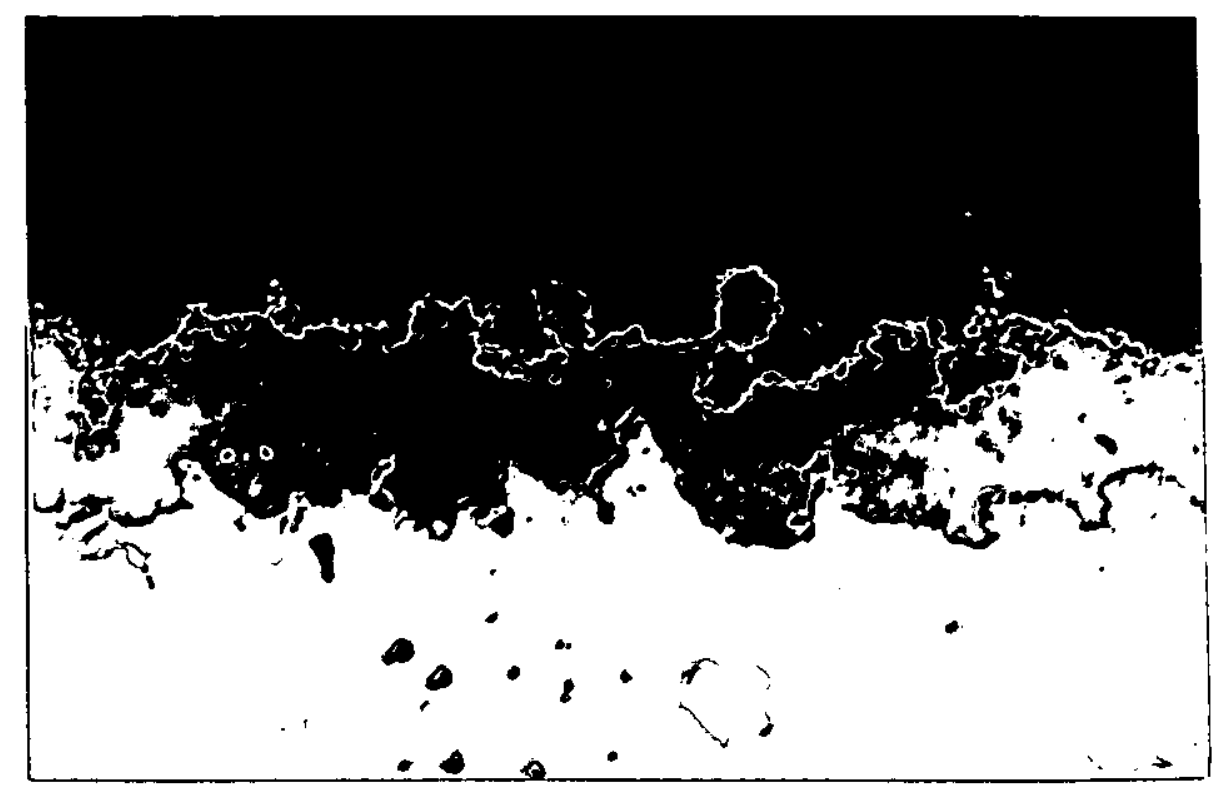

(a) $\mathrm{CO}_{2} / \mathrm{H}_{2}$ mole ratio $=1 / 6$

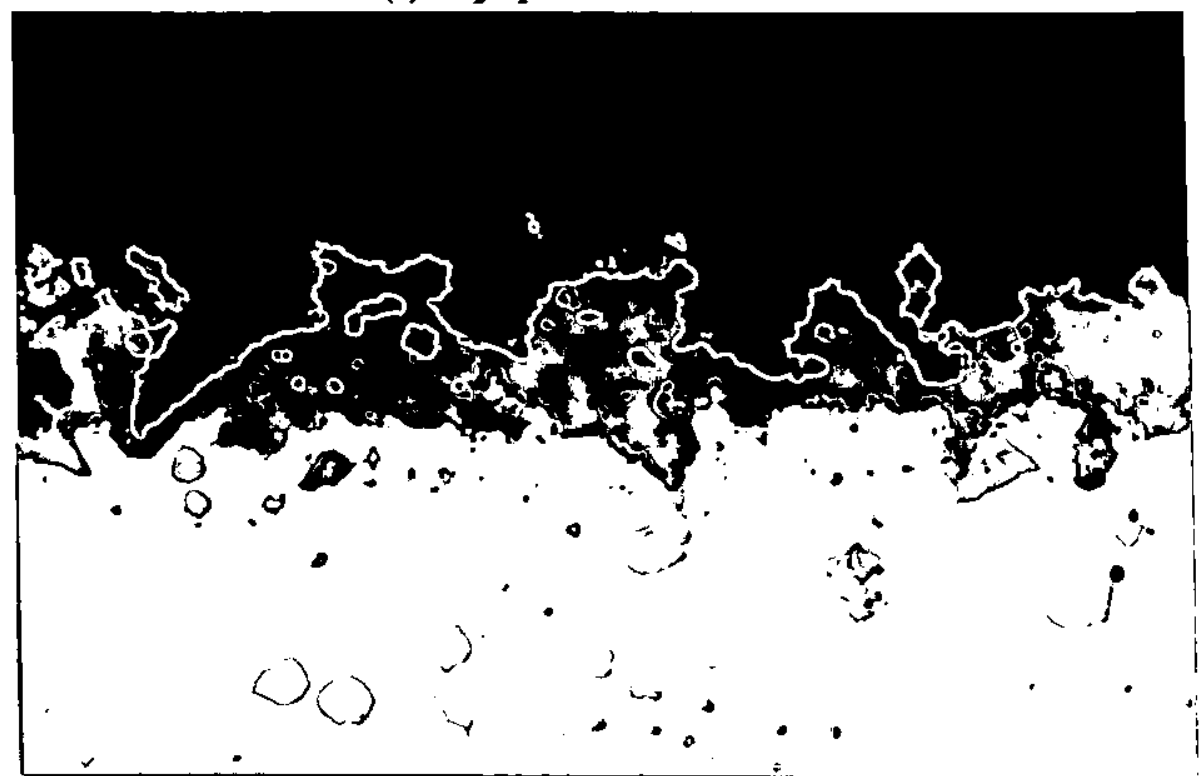

(b) $\mathrm{CO}_{2} / \mathrm{H}_{2}$ mole ratio $=1 / 8$

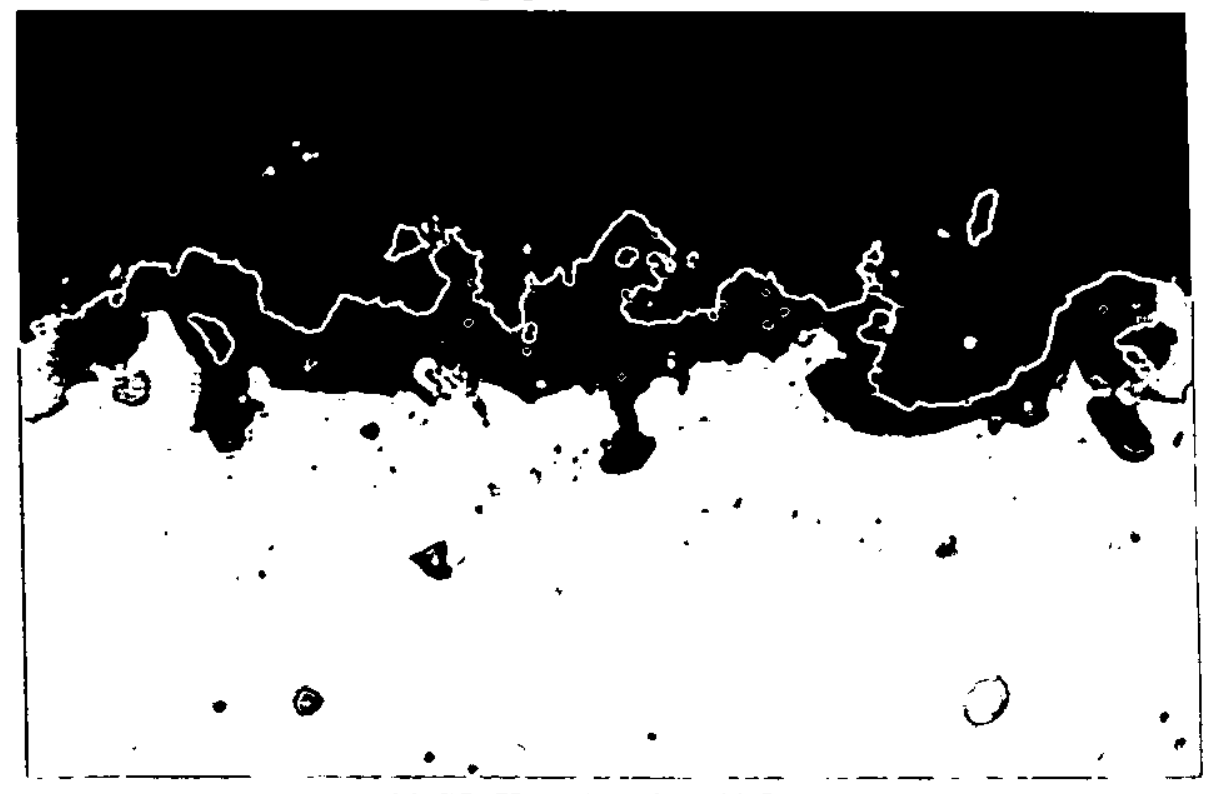

(c) $\mathrm{CO}_{2} / \mathrm{H}_{2}$ mole ratio $=1 / 10$

Figure 5.10 Low-angle $\left(5.6^{\circ}\right)$ optical taper-sections through $\mathrm{Al}_{2} \mathrm{O}_{3}$ coating and $\mathrm{Al}_{2} \mathrm{O}_{3}$ coating/Ti(C,N) precoating interface for $\mathrm{Al}_{2} \mathrm{O}_{3}$ coated inserts from each of the $\mathrm{CO}_{2} / \mathrm{H}_{2}$ mole ratio coating runs. $\mathrm{x} 1000$. 


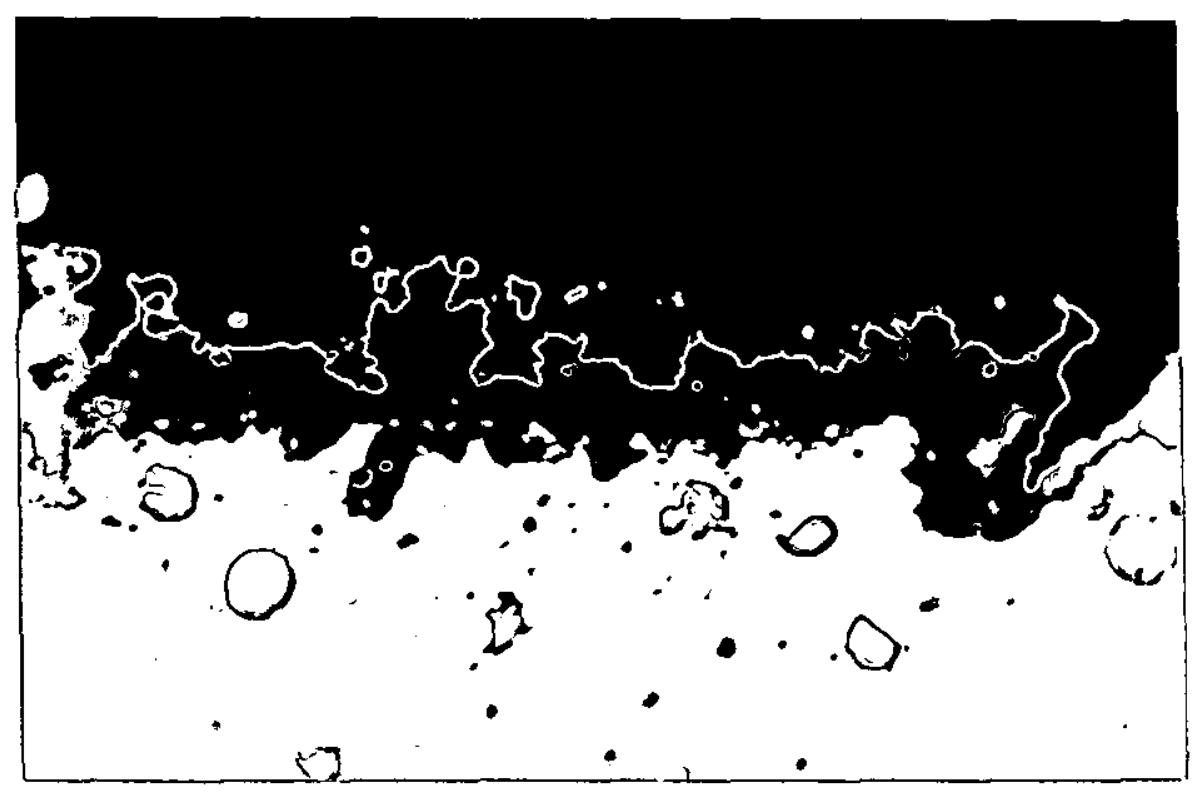

(d) $\mathrm{CO}, / \mathrm{H}_{2}$ mole ratio $=1 / 12$

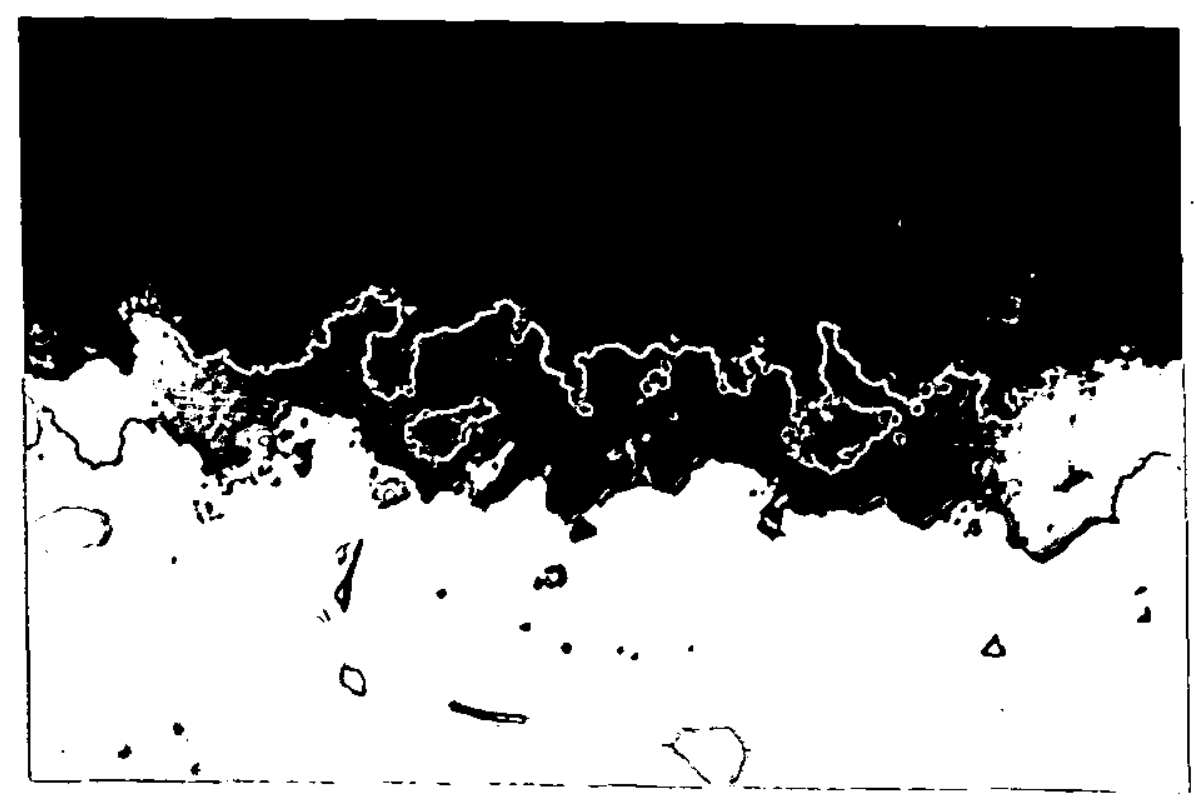

(e) $\mathrm{CO}_{2} / \mathrm{H}_{2}$ mole ratio $=1 / 14$

Figure 5.10 Low-angle $\left(5.6^{\circ}\right)$ optical taper-sections through $\mathrm{Al}_{2} \mathrm{O}_{3}$ coating and $\mathrm{Al}_{2} \mathrm{O}_{3}$ coating/Ti(C,N) precoating interface for $\mathrm{Al}_{2} \mathrm{O}_{3}$ coated inserts from each of the $\mathrm{CO}_{2} / \mathrm{H}_{2}$ mole ratio coating runs. $\times 1000$. 


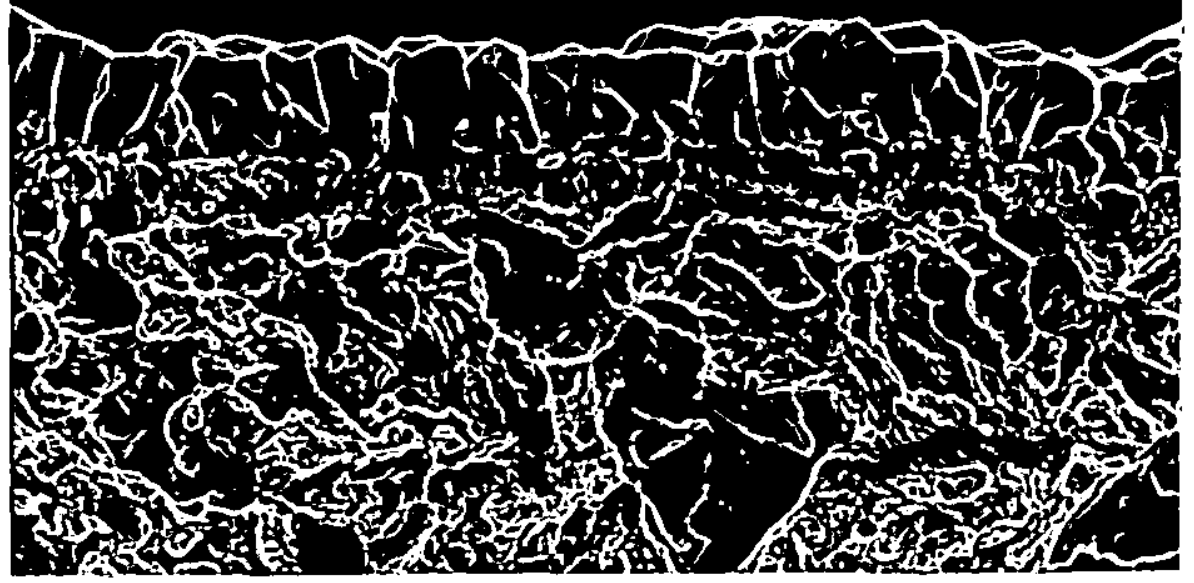

(a) $\mathrm{CO}_{2} / \mathrm{H}_{2}$ mole ratio $=1 / 6$

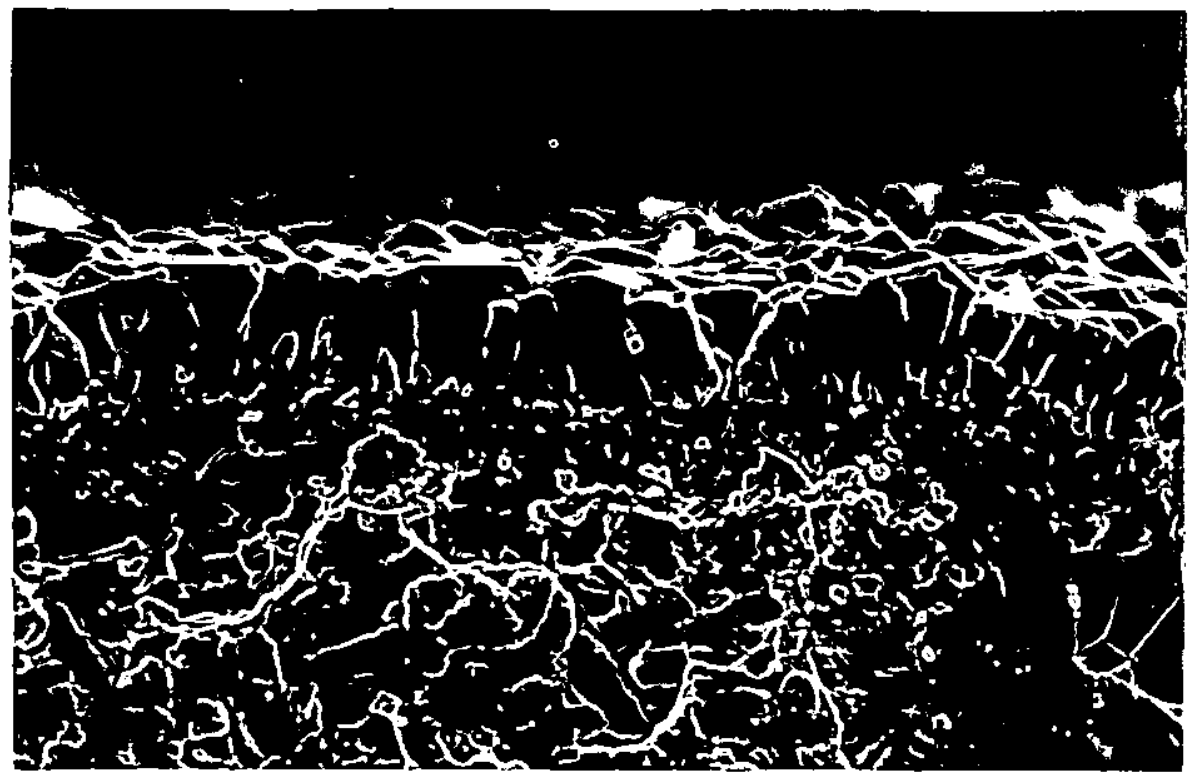

(b) $\mathrm{CO}_{2} / \mathrm{H}_{2}$ mole ratio $=1 / 8$

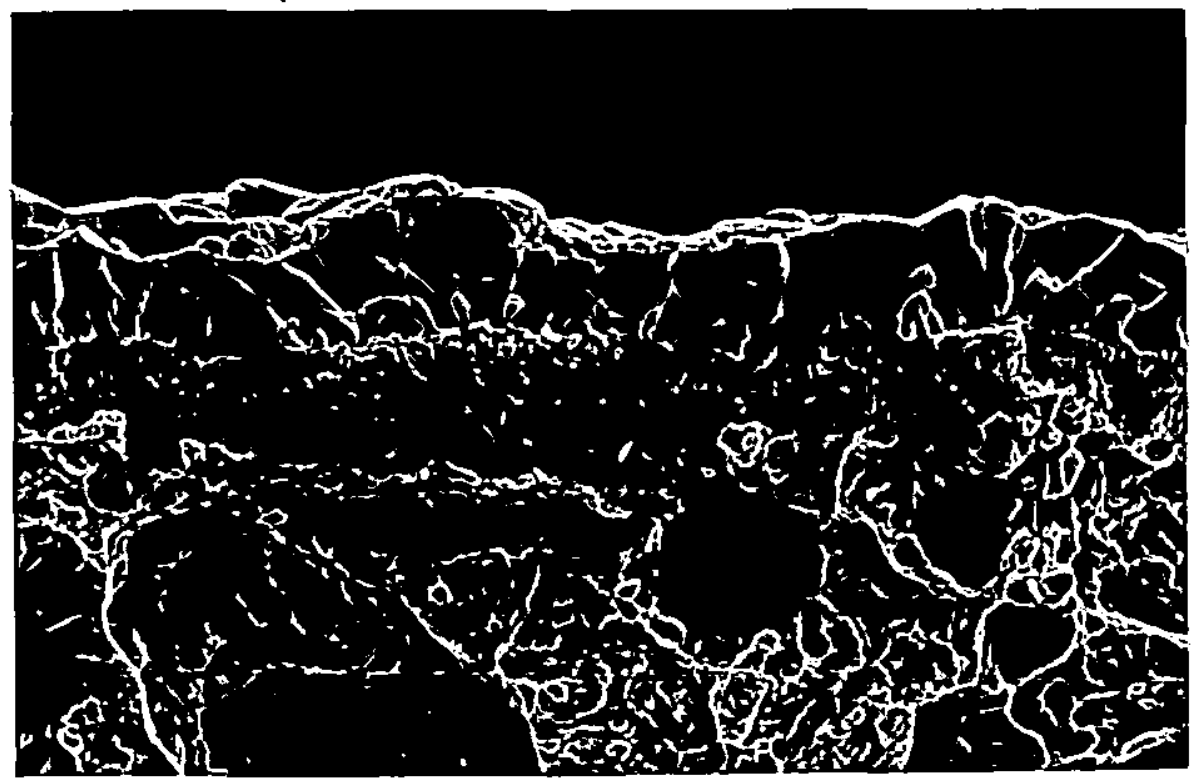

(c) $\mathrm{CO}_{2} / \mathrm{H}_{2}$ mole ratio $=1 / 10$

Figure 5.11 Bulk grain structures of $\mathrm{Al}_{2} \mathrm{O}_{3}$ coatings deposited at different $\mathrm{CO}_{2} / \mathrm{H}_{2}$ mole ratios. $x 5000$. 


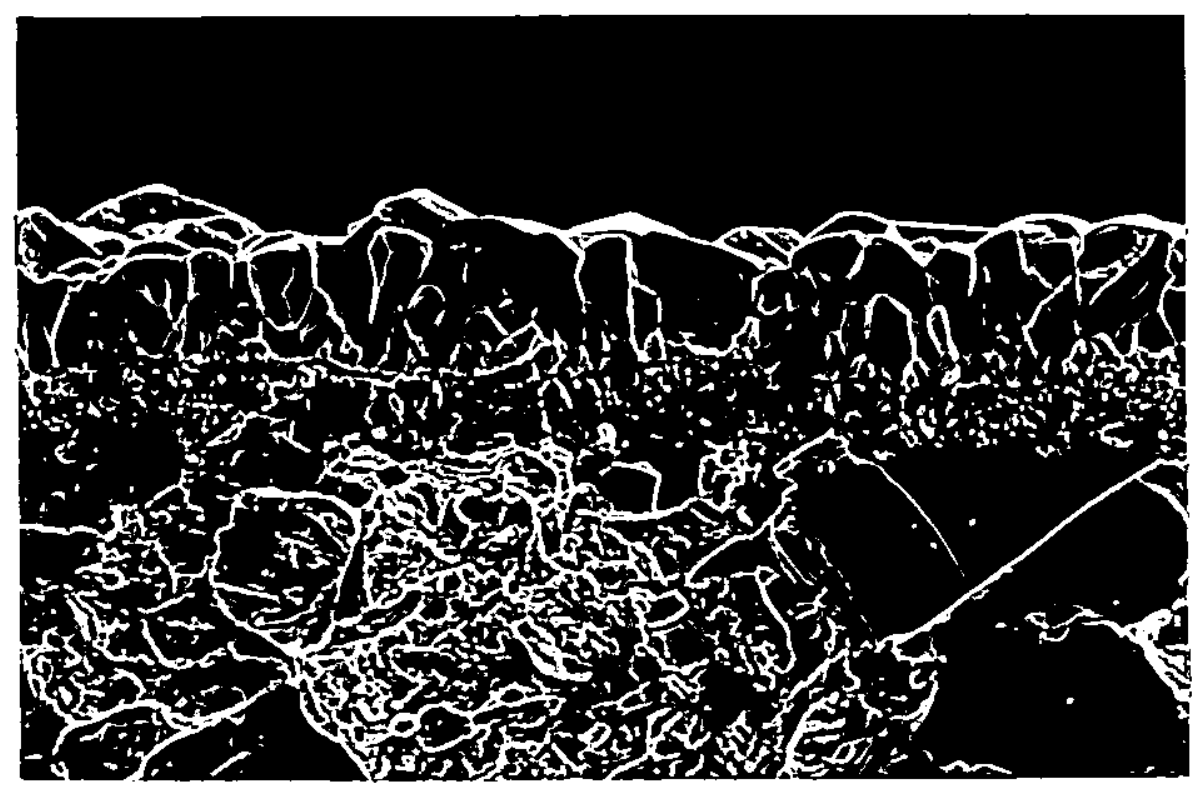

(d) $\mathrm{CO}_{2} / \mathrm{H}_{2}$ mole ratio $=1 / 12$

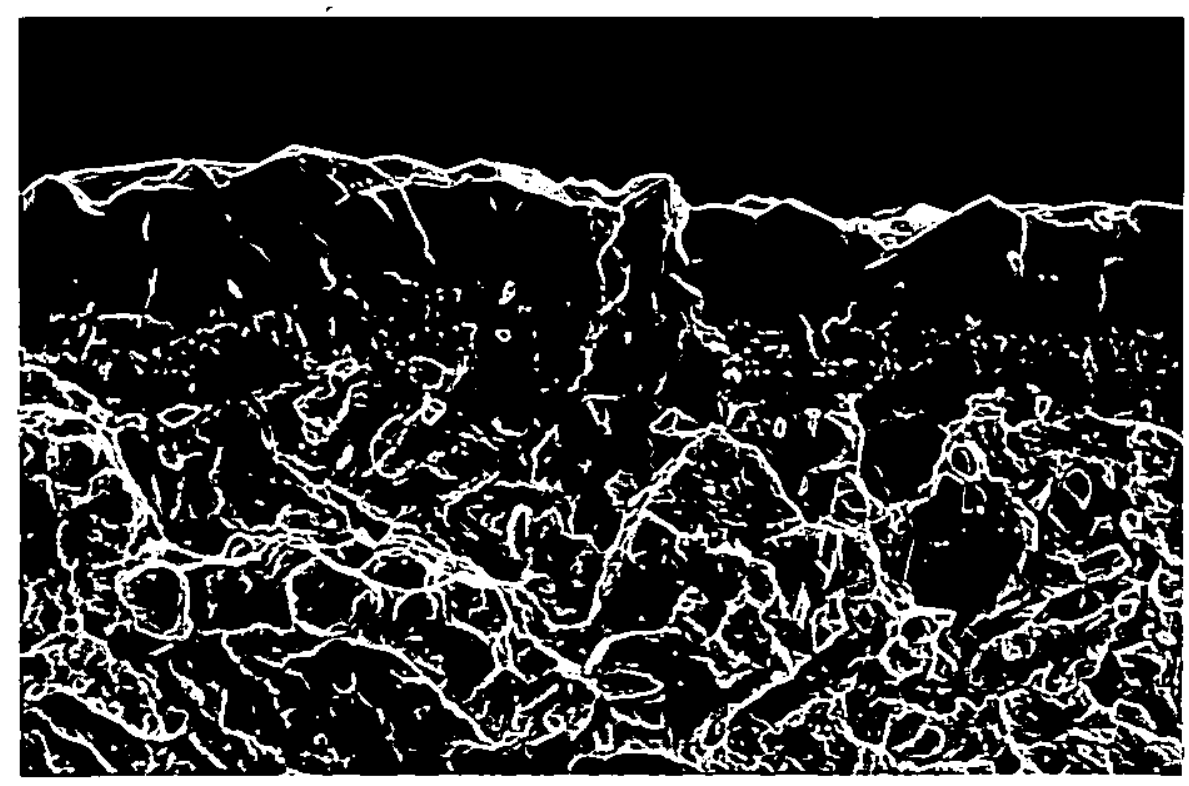

(e) $\mathrm{CO}_{2} / \mathrm{H}_{2}$ mole ratio $=1 / 14$

Figure 5.11 Bulk grain structures of $\mathrm{Al}_{2} \mathrm{O}_{3}$ coatings deposited at different $\mathrm{CO}_{2} / \mathrm{H}_{2}$ mole ratios. $x 5000$. 


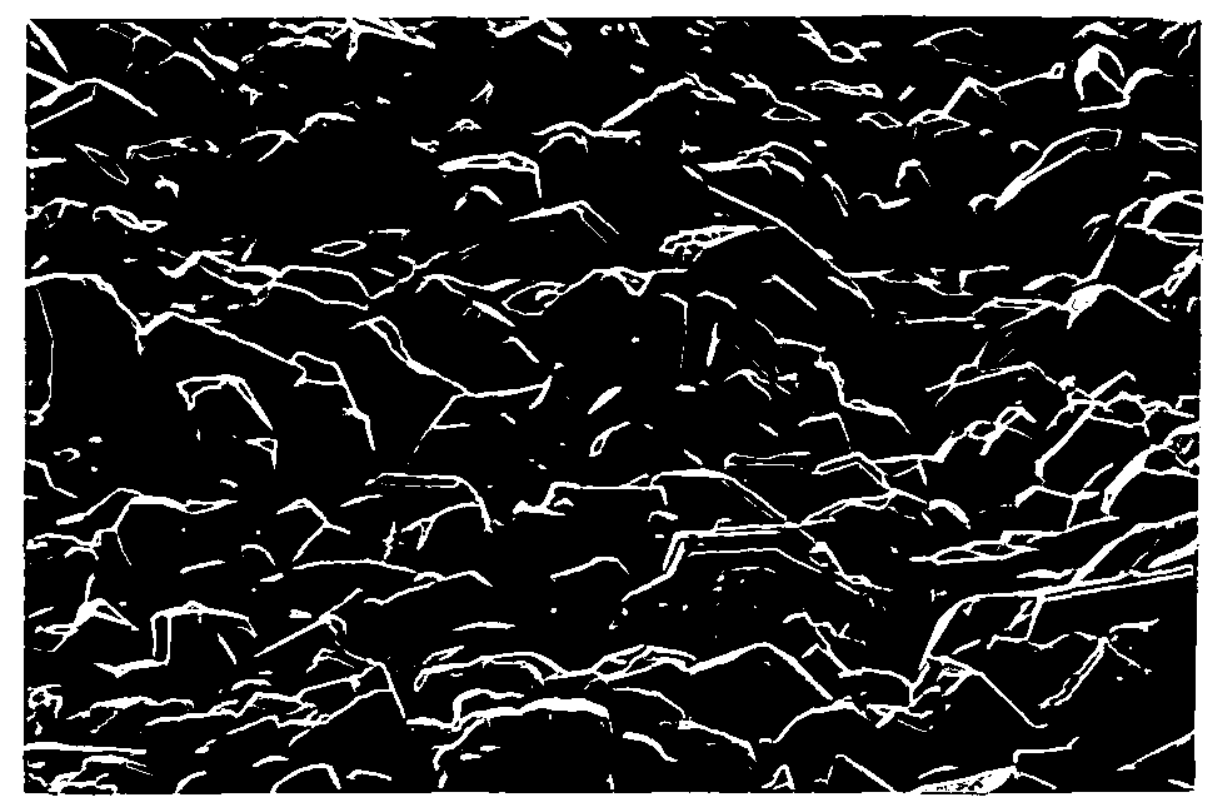

(a) $\mathrm{CO}_{2} / \mathrm{H}_{2}$ mole ratio $=1 / 6$

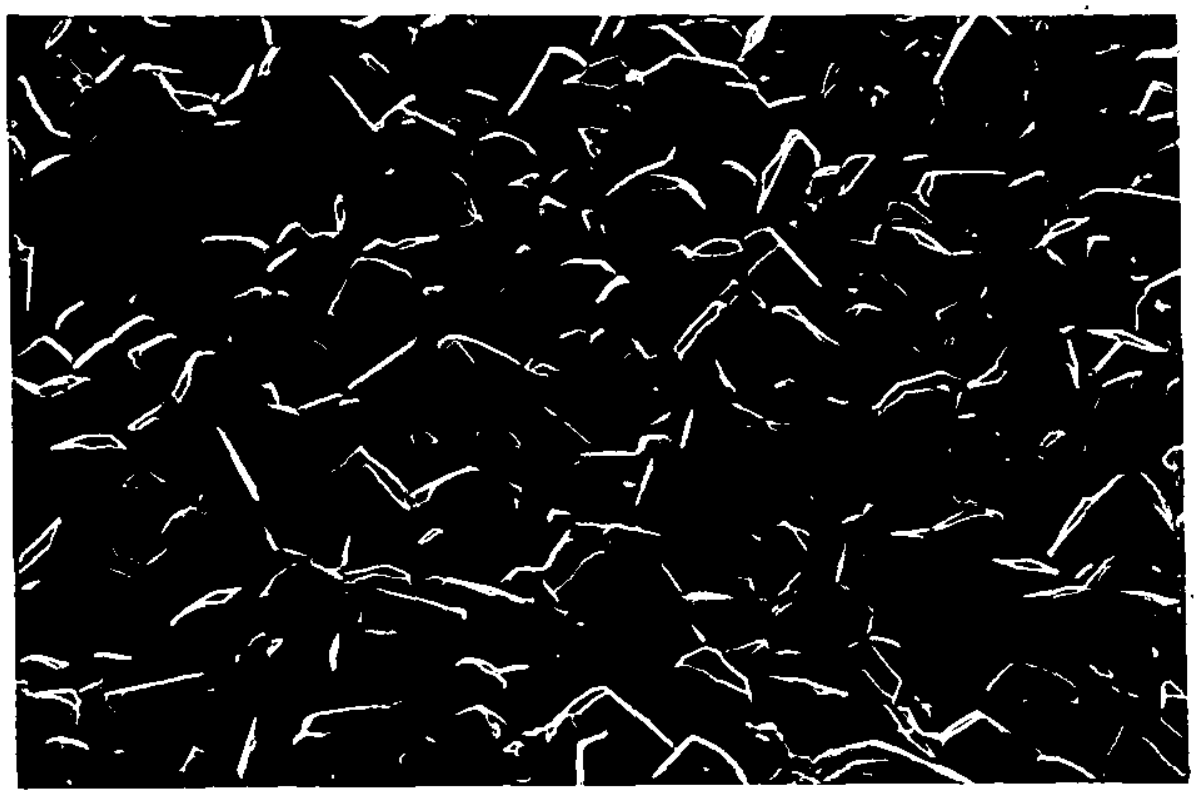

(b) $\mathrm{CO} / \mathrm{H}_{2}$ mole ratio $=1 / 8$

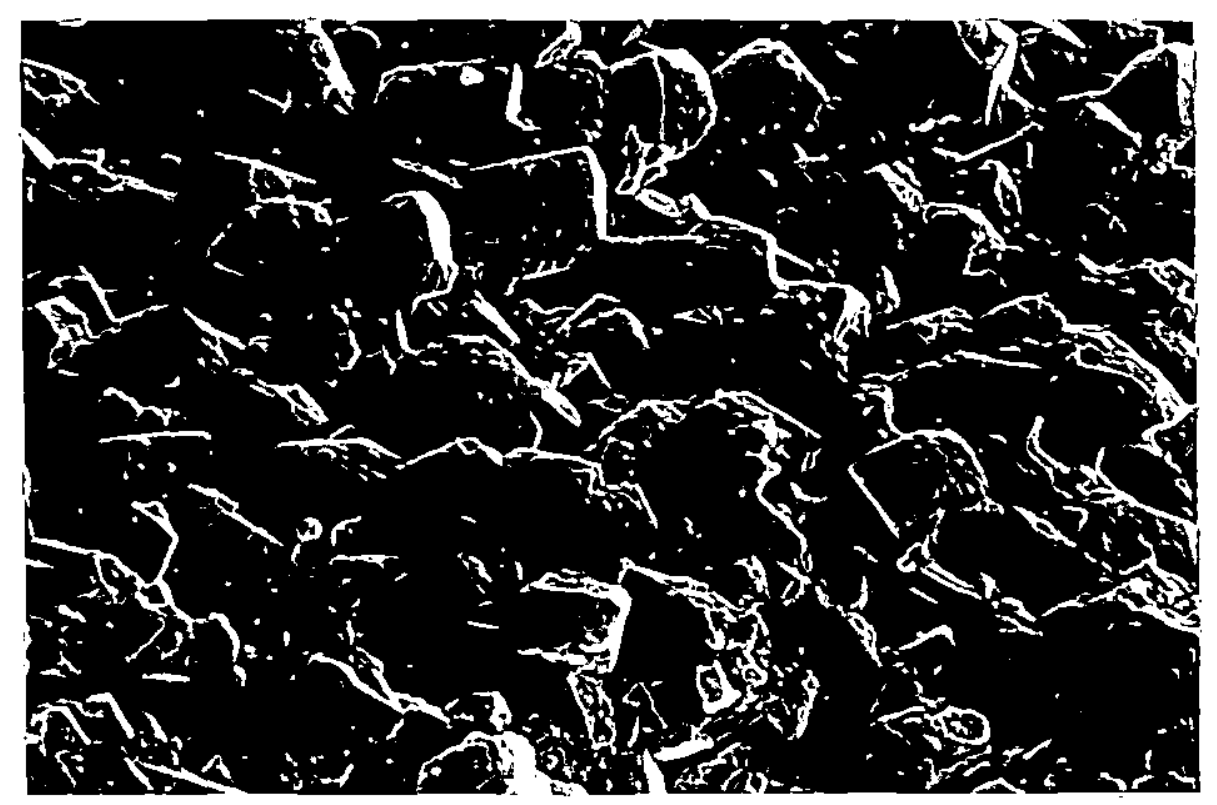

(c) $\mathrm{CO}_{2} / \mathrm{H}_{2}$ mole ratio $=1 / 10$

Figure 5.12 Surface grain structures of $\mathrm{Al}_{2} \mathrm{O}_{3}$ coatings deposited at different $\mathrm{CO}_{2} / \mathrm{H}_{2}$ mole ratios. $\mathrm{x} 5000$. 


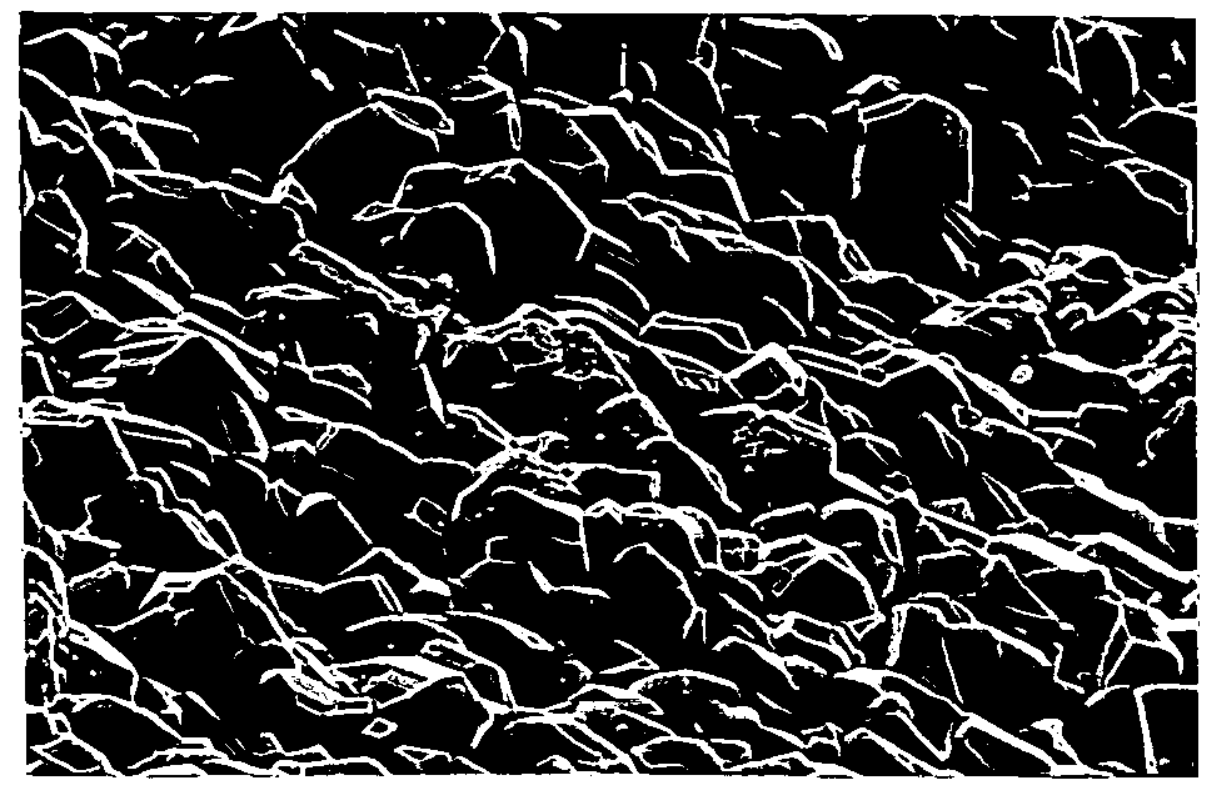

(d) $\mathrm{CO}_{2} / \mathrm{H}_{2}$ mole ratio $=1 / 12$

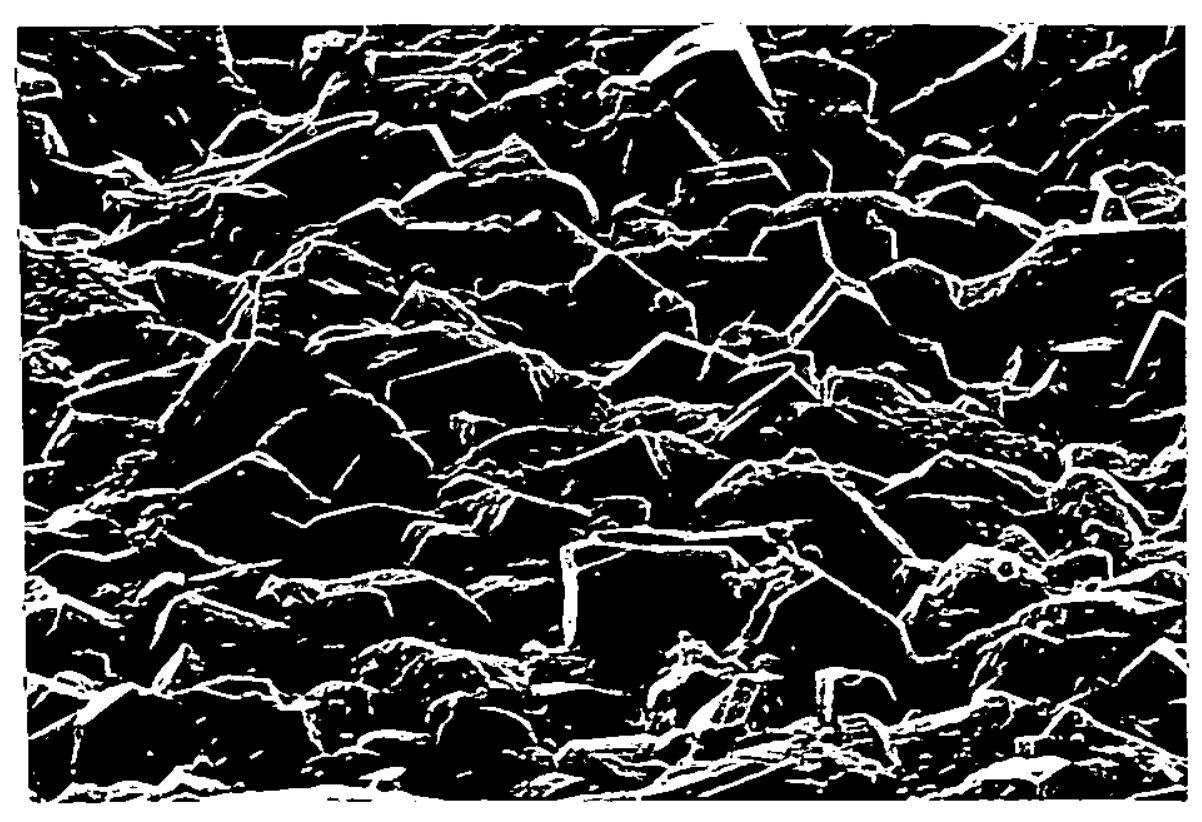

(e) $\mathrm{CO}_{2} / \mathrm{H}_{2}$ mole ratio $=1 / 14$

Eigure 5.12 Surface grain structures of $\mathrm{Al}_{2} \mathrm{O}_{3}$ coatings deposited at different $\mathrm{CO}_{2} / \mathrm{H}_{2}$ mole ratios. $x 5000$. 


\section{(b)}

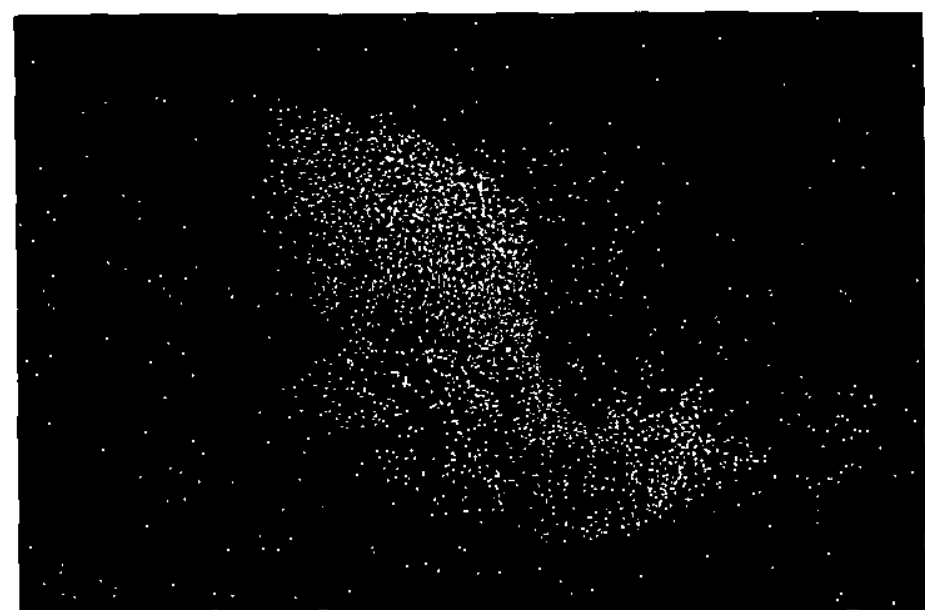

(c)

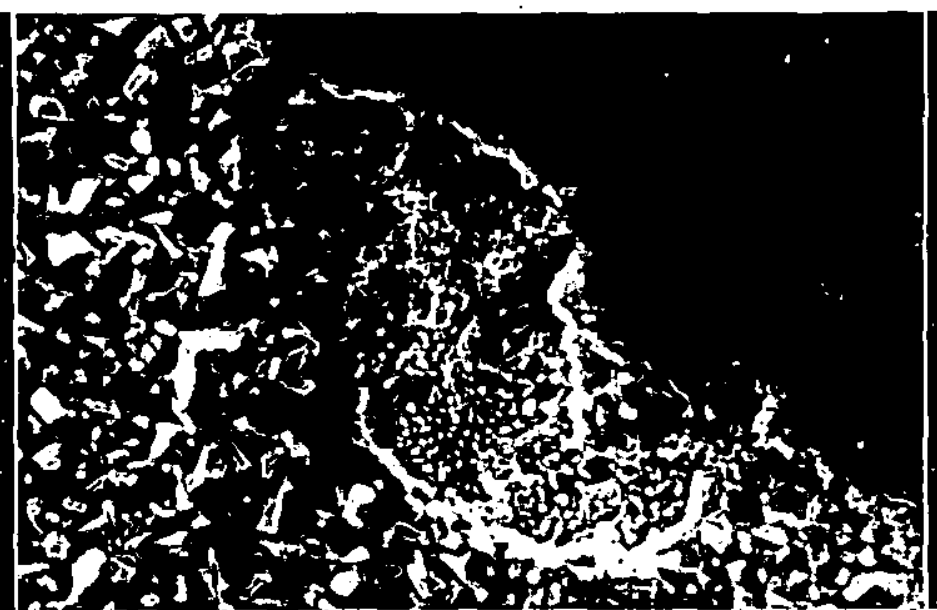

(a)

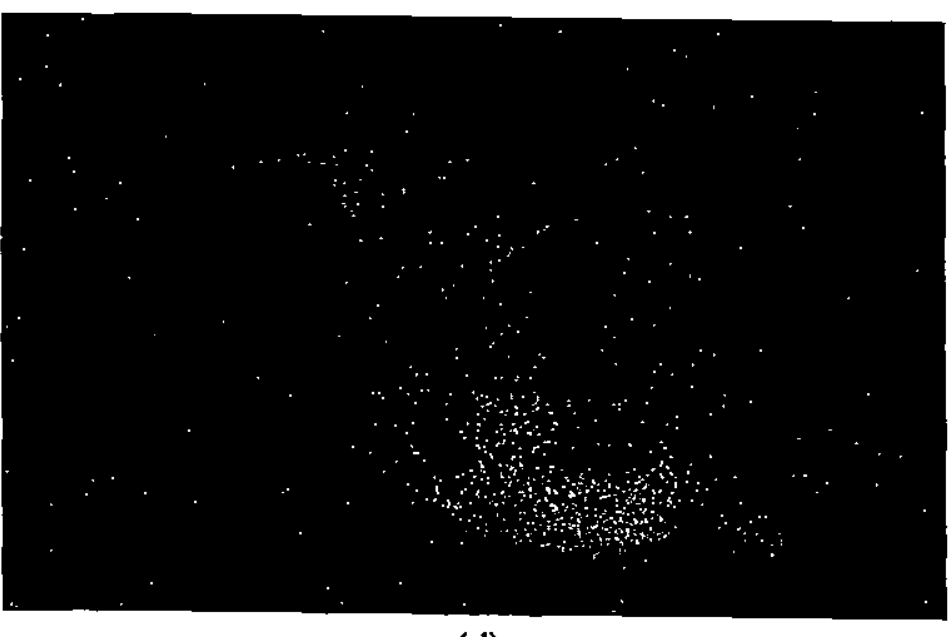

(d)

Figure 5.13 (a) SEM micrograph of flaking at edge of scratch channel on $\mathrm{Al}_{2} \mathrm{O}_{3}$ coated insert from $\mathrm{CO}_{2} / \mathrm{H}_{2}$ mole ratio $=1 / 6$ coating run. Stylus load $=3 \mathrm{~kg} . \times 1200$.

(b) Al $K_{\alpha}$ elemental scan of area shown in (a).

(c) Ti $K_{\alpha}$ elemental scan of area shown in (a).

(d) Fe $K_{\alpha}$ elemental scan of area shown in (a). 
(b)

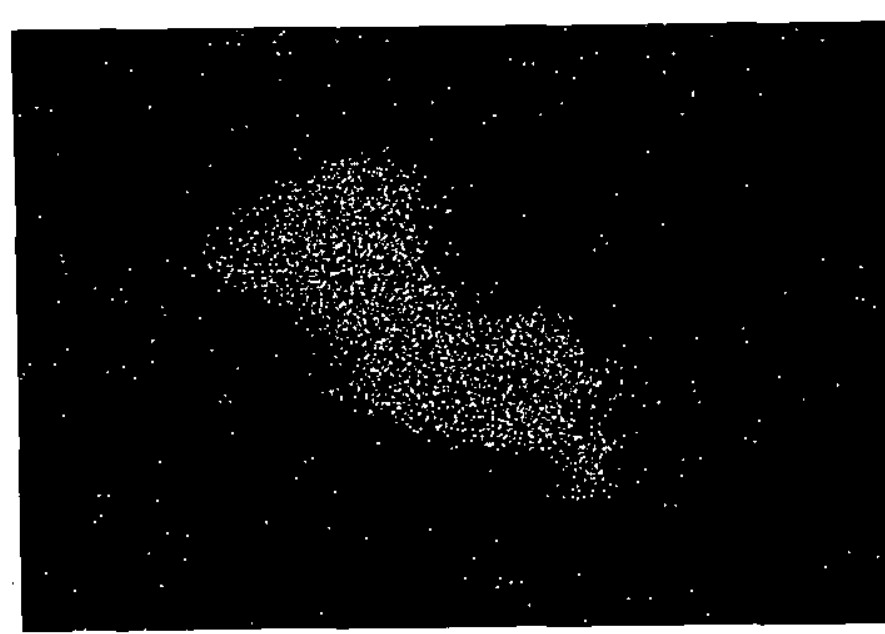

(c)

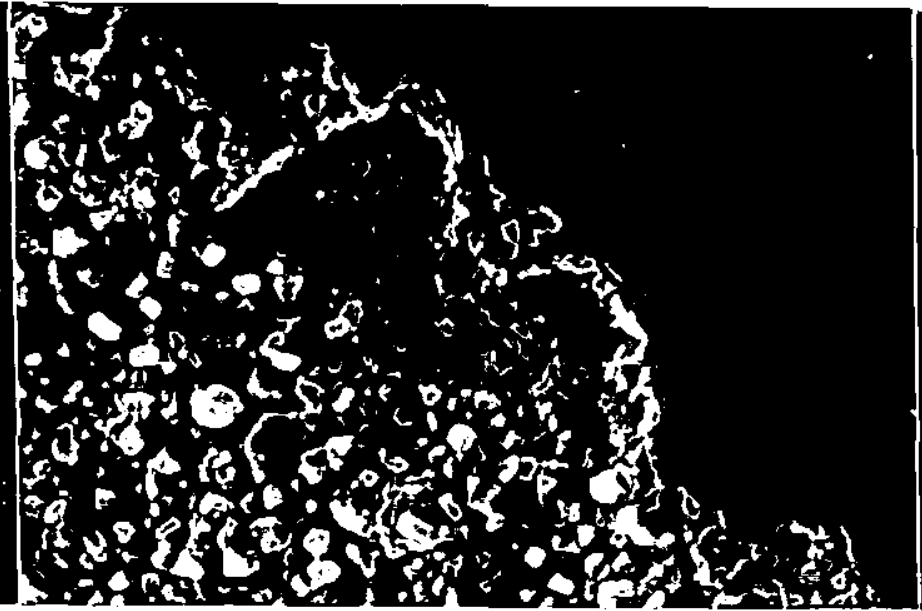

(a)

Figure 5.14 (a) SEM micrograph of flaking at edge of scratch channel on $\mathrm{Al}_{2} \mathrm{O}_{3}$ coated insert from $\mathrm{CO} / \mathrm{H}_{2}$ mole ratio $=1 / 8$ coating run. Stylus load $=3 \mathrm{~kg}$. $\times 1200$.

(b) Al $K_{\alpha}$ elemental scan of area shown in (a).

(c) Ti $K_{\alpha}$ elemental scan of area shown in (a).

(d) Fe $K_{\alpha}$ elemental scan of area shown in (a). 


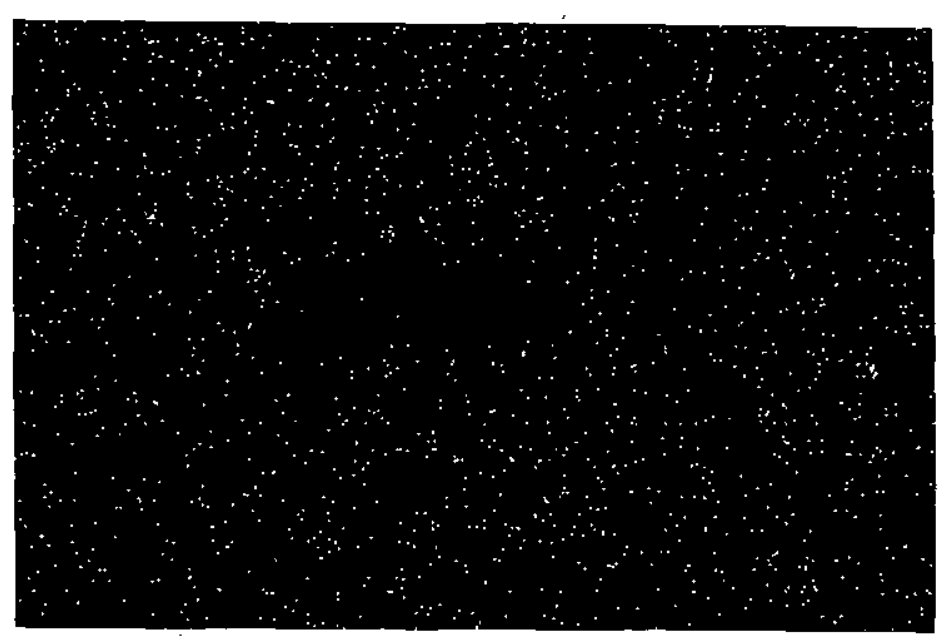

(b)

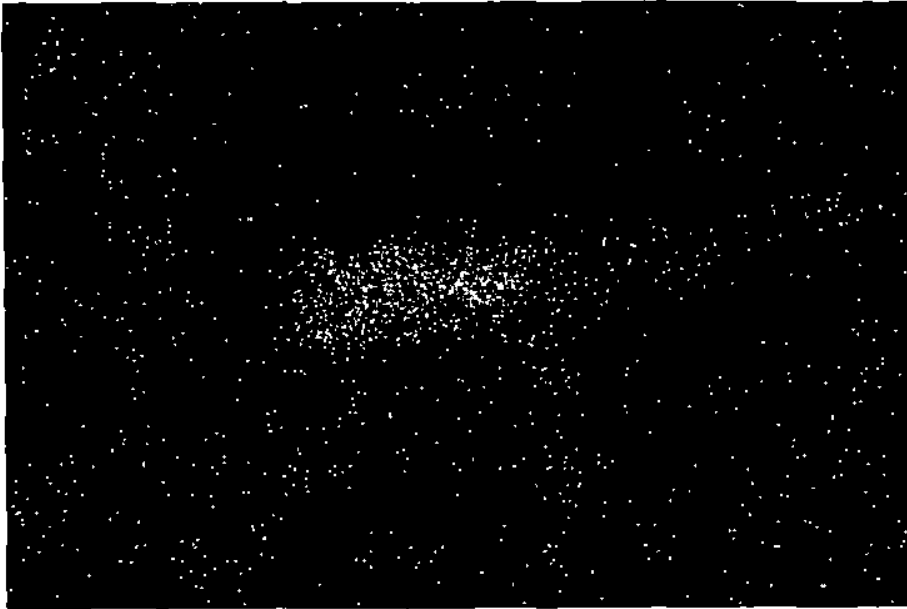

(c)

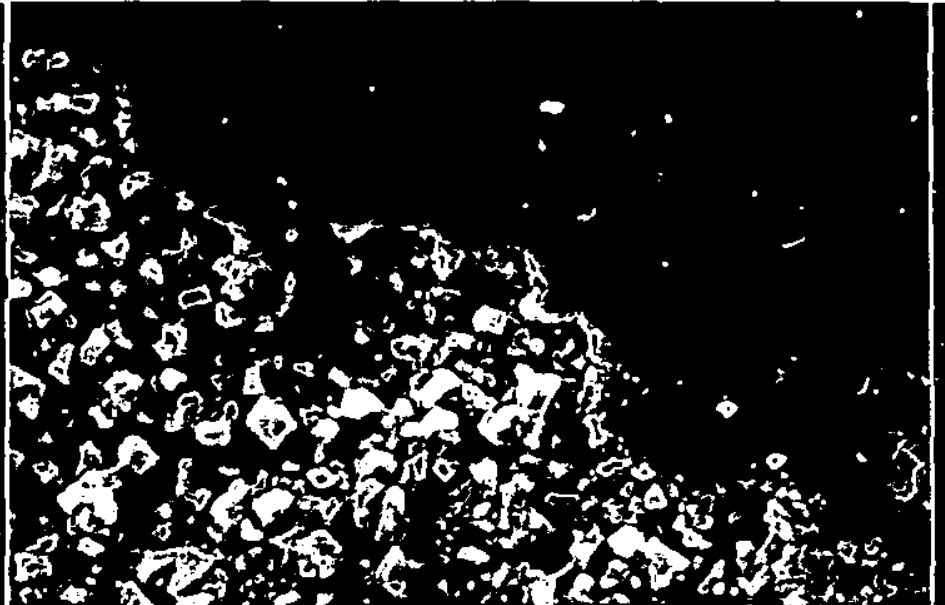

(a)

Figure 5.15 (a) SEM micrograph of flaking at edge of scratch channel on $\mathrm{Al}_{2} \mathrm{O}_{3}$ coated insert from $\mathrm{CO}_{2} / \mathrm{H}_{2}$ mole ratio $=1 / 10$ coating run. Stylus load $=3 \mathrm{~kg}$. $x 1200$.

(b) Al $K_{\alpha}$ elemental scan of area shown in (a).

(c) Ti $K_{a}$ elemental scan of area shown in (a).

(d) Fe $K_{\alpha}$ elemental scan of area shown in (a). 
(b)

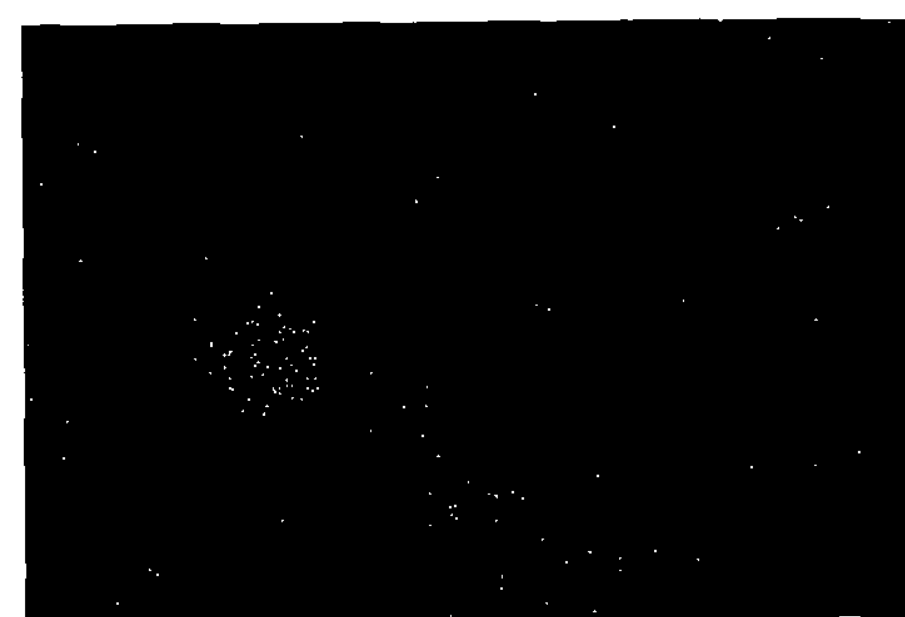

(c)

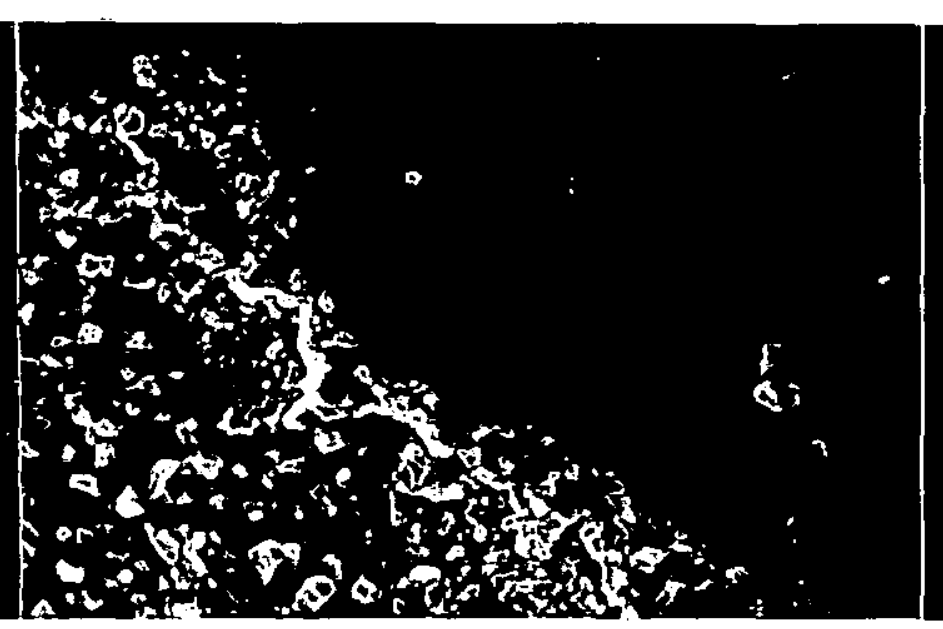

(a) (d)

Eigure 5.16 (a) SEM micrograph of flaking at edge of scratch channel on $\mathrm{Al}_{2} \mathrm{O}_{3}$ coated insert from $\mathrm{CO}_{2} / \mathrm{H}_{2}$ mole ratio $=1 / 12$ coating run. Stylus load $=5 \mathrm{~kg}$. x1200 .

(b) Al $K_{\alpha}$ elemental scan of area shown in (a).

(c) Ti $K_{\alpha}$ elemental scan of area shown in (a).

(d) Fe $K_{\mathrm{a}}$ elemental scan of area shown in (a). 


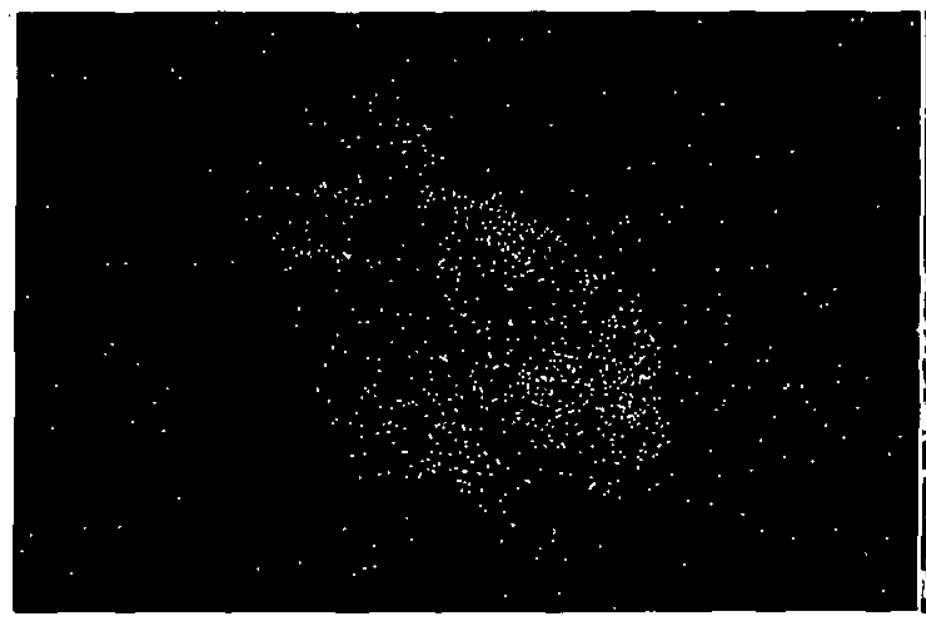

(c)

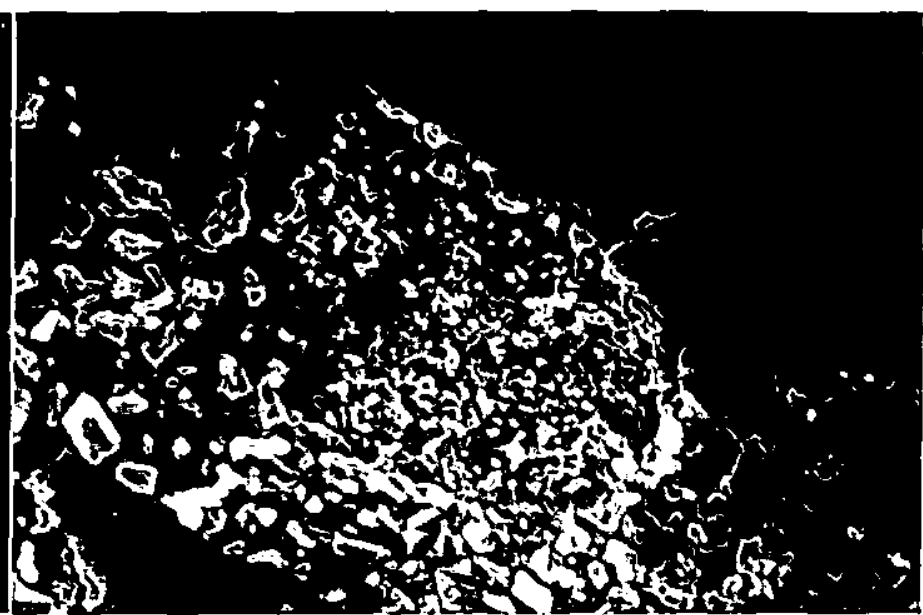

(a)

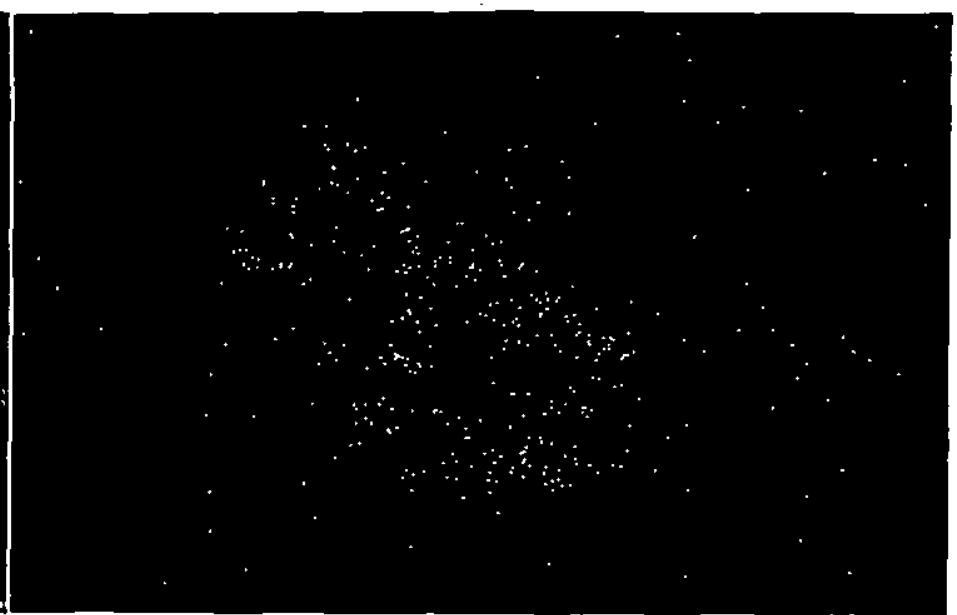

(d)

Figure 5.17 (a) SEM micrograph of flaking at edge of scratch channel on $\mathrm{Al}_{2} \mathrm{O}_{3}$ coated insert from $\mathrm{CO}_{2} / \mathrm{H}_{2}$ mole ratio $=1 / 14$ coating run. Stylus load $=2 \mathrm{~kg}$. $\times 1200$.

(b) Al $K_{a}$ elemental scan of area shown in (a).

(c) Ti $K_{\mathrm{a}}$ elemental scan of area shown in (a).

(d) Fe $K_{\alpha}$ elemental scan of area shown in (a). 
(b)

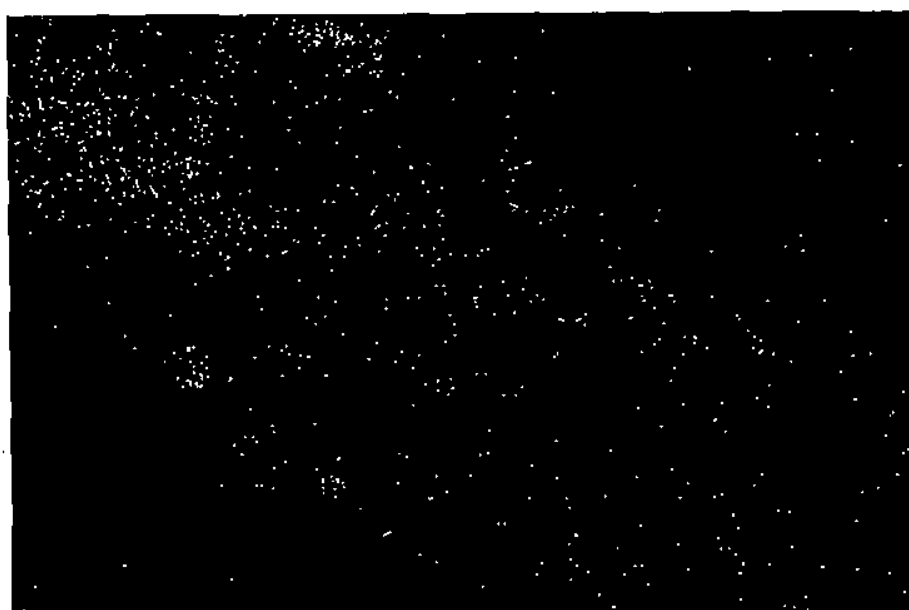

(c)

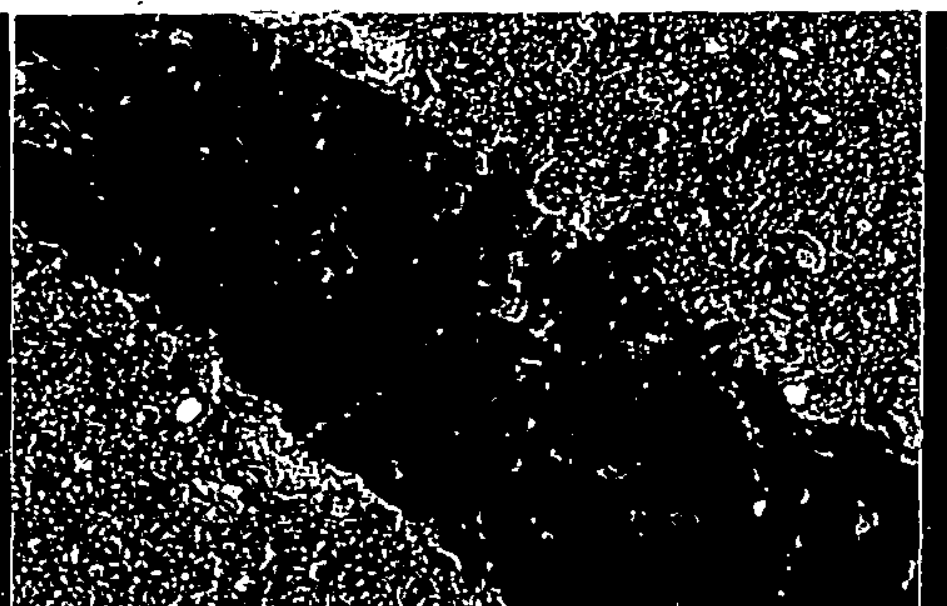

(a) (d)

Eigure 5.18 (a) SEM micrograph of scratch channel on $\mathrm{Al}_{2} \mathrm{O}_{3}$ coated insert from $\mathrm{CO}_{2} / \mathrm{H}_{2}$ mole ratio $=1 / 6$ coating run. Stylus load $=6 \mathrm{~kg} . \times 300$. (b) Al $K_{\alpha}$ elemental scan of area shown in (a).

(c) Ti $K_{\alpha}$ elemental scan of area shown in (a).

(d) Fe $K_{\alpha}$ elemental scan of area shown in (a). 


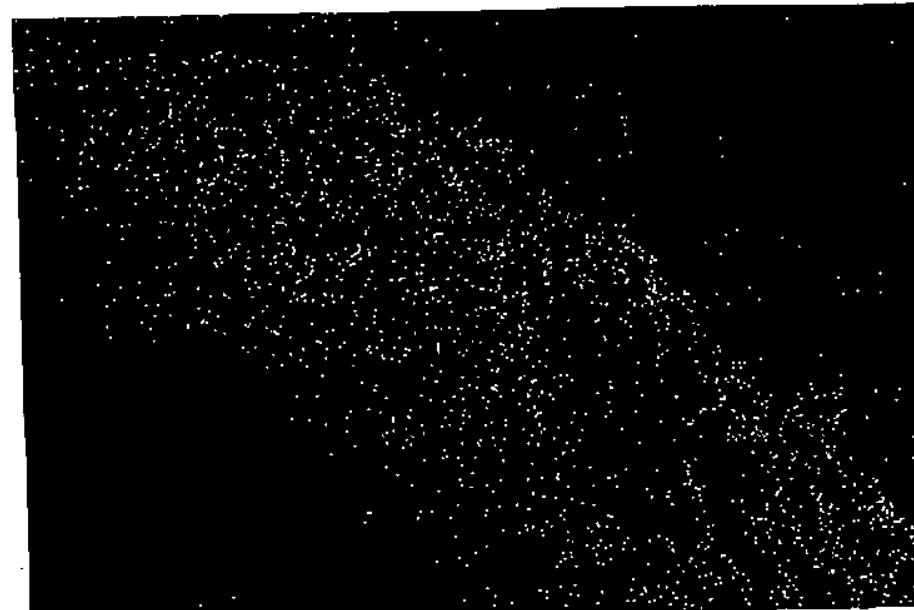

(c)

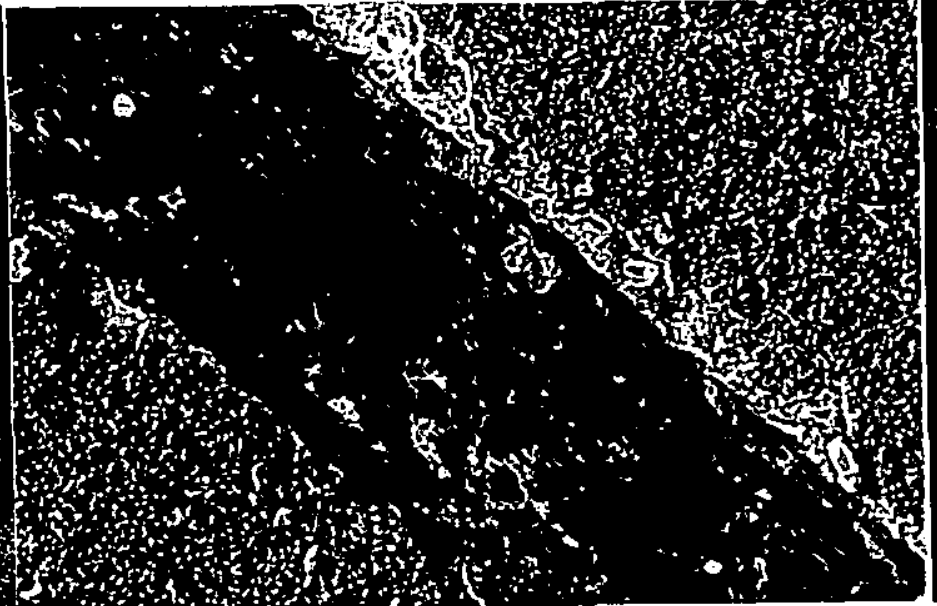

(a)

Figure 5.19 (a) SEM micrograph of scratch channel on $\mathrm{Al}_{2} \mathrm{O}_{3}$ coated insert from $\mathrm{CO}_{2} / \mathrm{H}_{2}$ mole ratio $=1 / 6$ coating run. Stylus load $=7 \mathrm{~kg} . \times 300$. (b) Al $K_{\mathrm{a}}$ elemental scan of area shown in (a).

(c) Ti $K_{\alpha}$ elemental scan of area shown in (a).

(d) Fe $K_{\alpha}$ elemental scan of area shown in (a). 


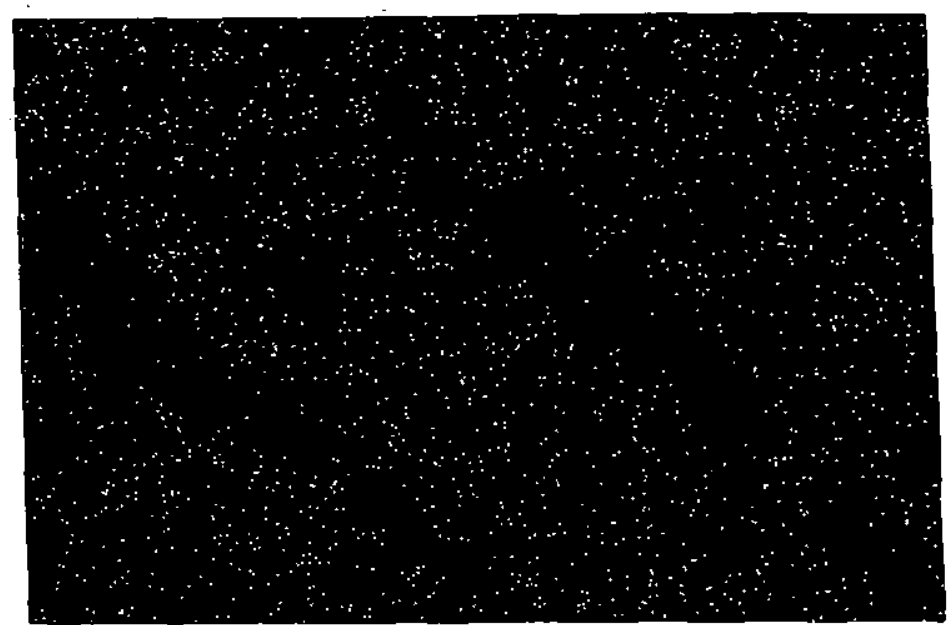

(b)

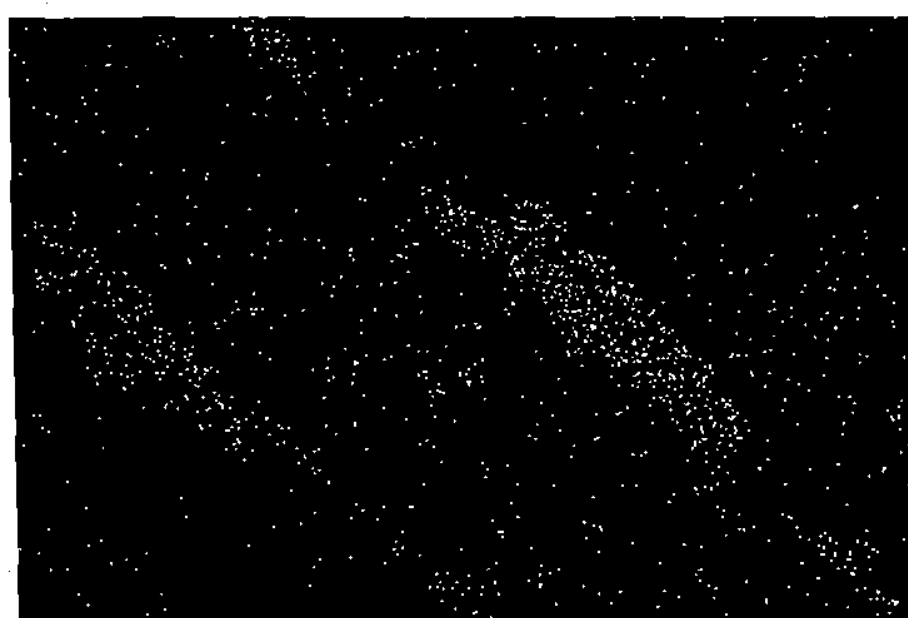

(c)

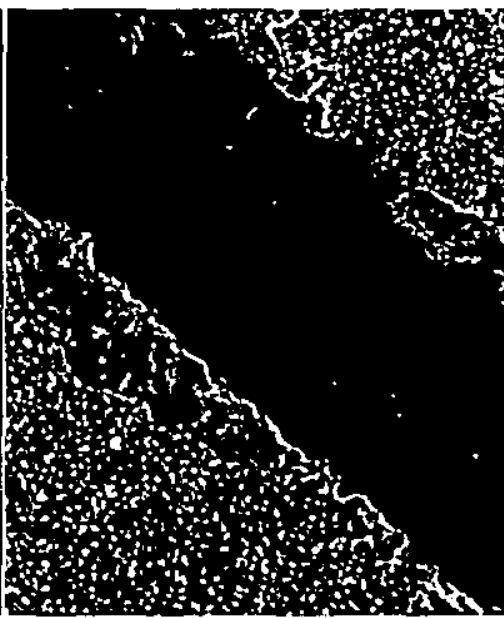

(a)

(d)

Figure 5.20 (a) SEM micrograph of scratch channel on $\mathrm{Al}_{2} \mathrm{O}_{3}$ coated insert from $\mathrm{CO}_{2} / \mathrm{H}_{2}$ mole ratio $=1 / 8$ coating run. Stylus load $=5 \mathrm{~kg}$. $\times 300$.

(b) Al $K_{\alpha}$ elemental scan of area shown in (a).

(c) Ti $K_{\alpha}$ elemental scan of area shown in (a).

(d) Fe $K_{\alpha}$ elemental scan of area shown in (a). 


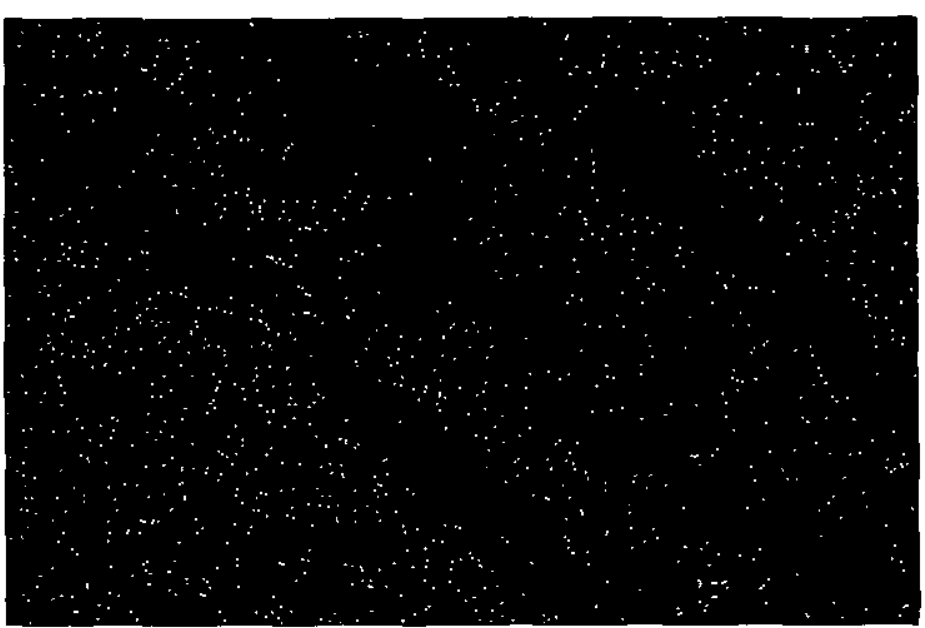

(b)

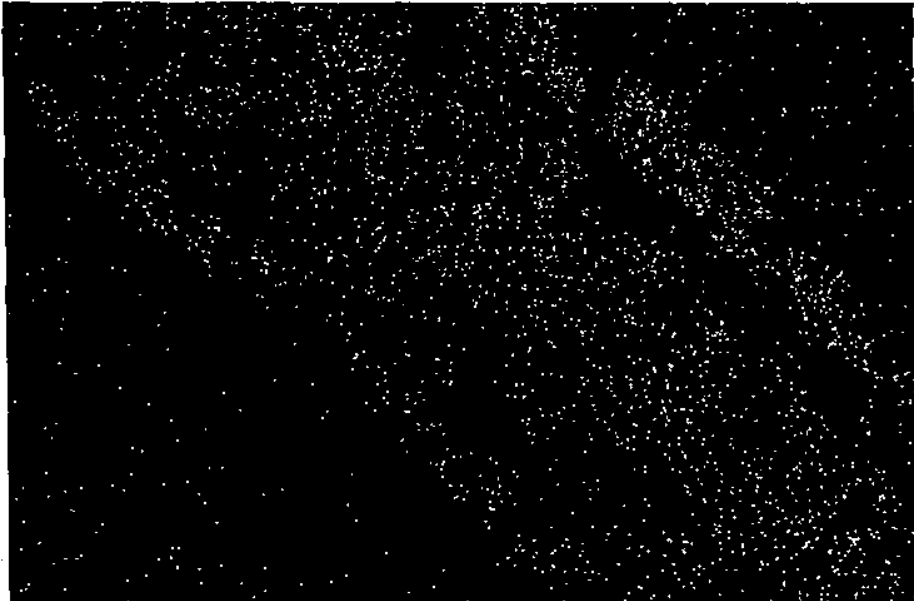

(c)

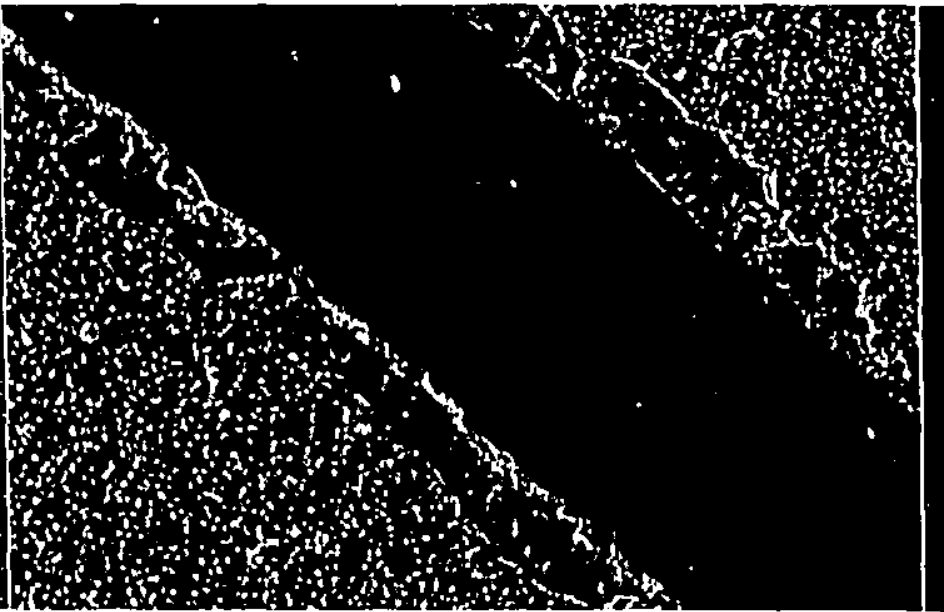

(a) (d)

Eigure 5.21 (a) SEM micrograph of scratch channel on $\mathrm{Al}_{2} \mathrm{O}_{3}$ coated insert from $\mathrm{CO}_{2} / \mathrm{H}_{2}$ mole ratio $=1 / 8$ coating run. Stylus load $=6 \mathrm{~kg} . \times 300$.

(b) Al $K_{\alpha}$ elemental scan of area shown in (a).

(c) Ti $K_{\alpha}$ elemental scan of area shown in (a).

(d) Fe $K_{\alpha}$ elemental scan of area shown in (a). 
(b)

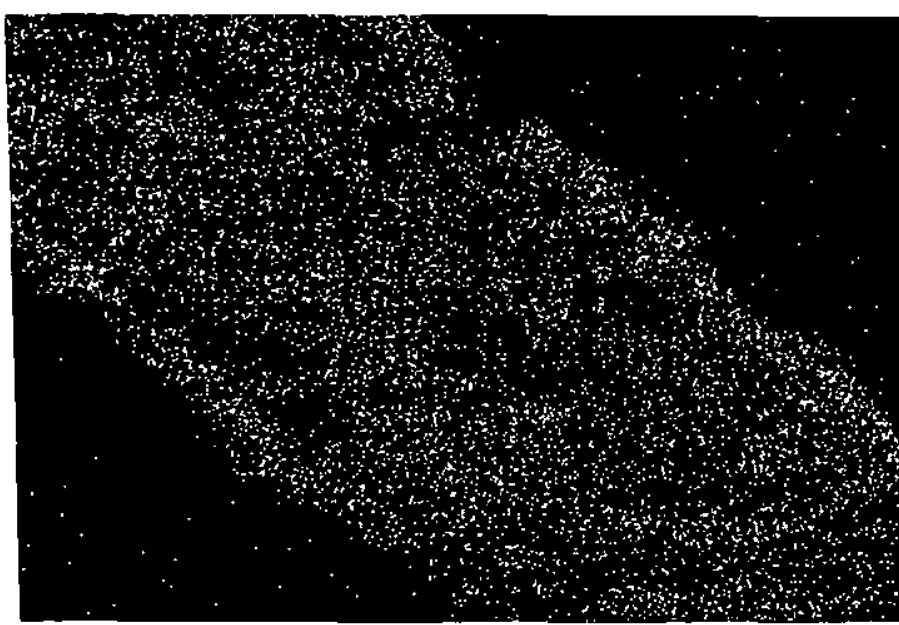

(c)

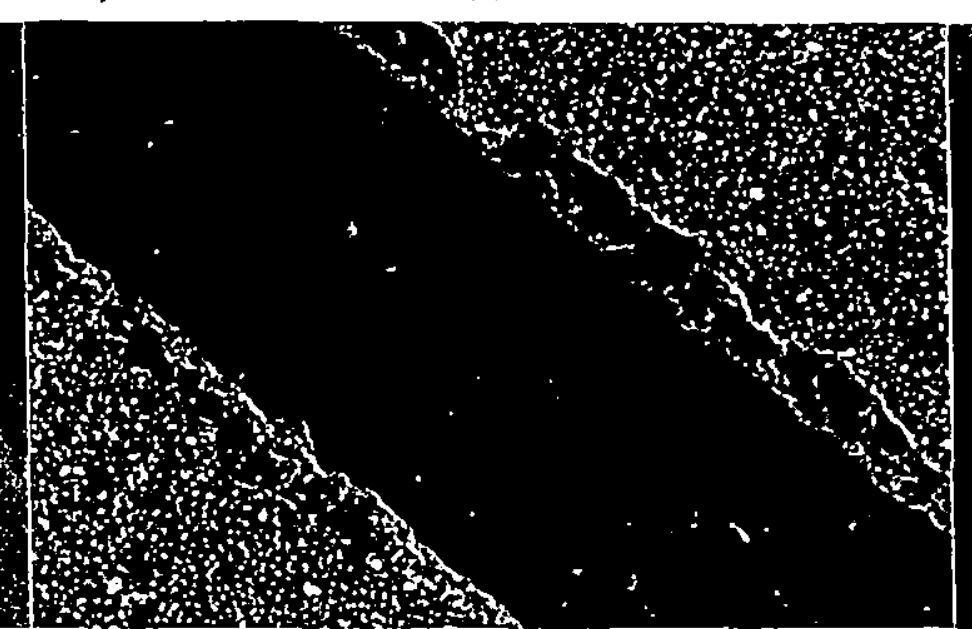

(a) (d)

Figure 5.22 (a) SEM micrograph of scratch channel on $\mathrm{Al}_{2} \mathrm{O}_{3}$ coated insert from $\mathrm{CO}_{2} / \mathrm{H}_{2}$ mole ratio $=1 / 8$ coating run. Stylus load $=7 \mathrm{~kg} . \times 300$. (b) Al $K_{\alpha}$ elemental scan of area shown in (a).

(c) Ti $K_{\alpha}$ elemental scan of area shown in (a).

(d) Fe $K_{\alpha}$ elemental scan of area shown in (a). 


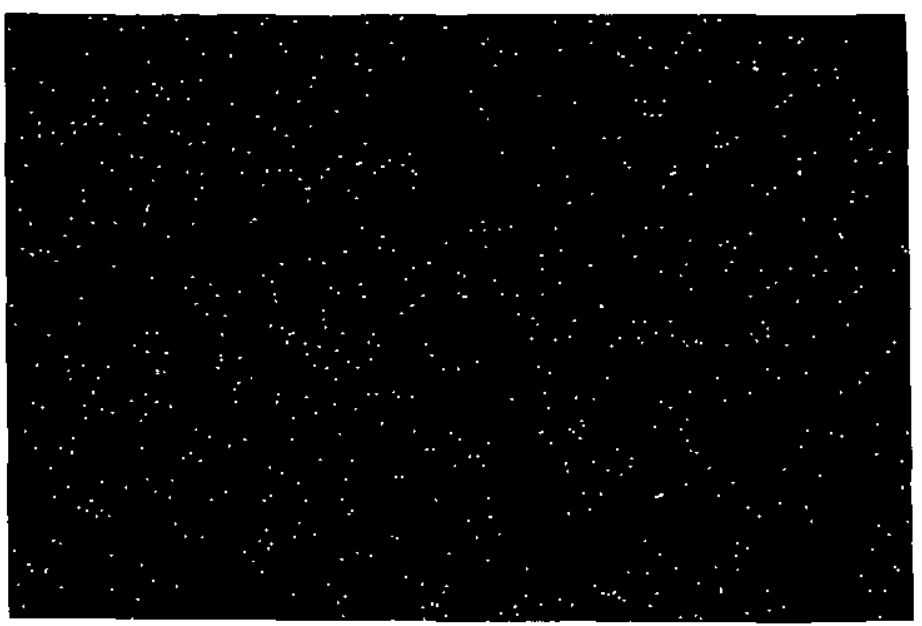

(b)

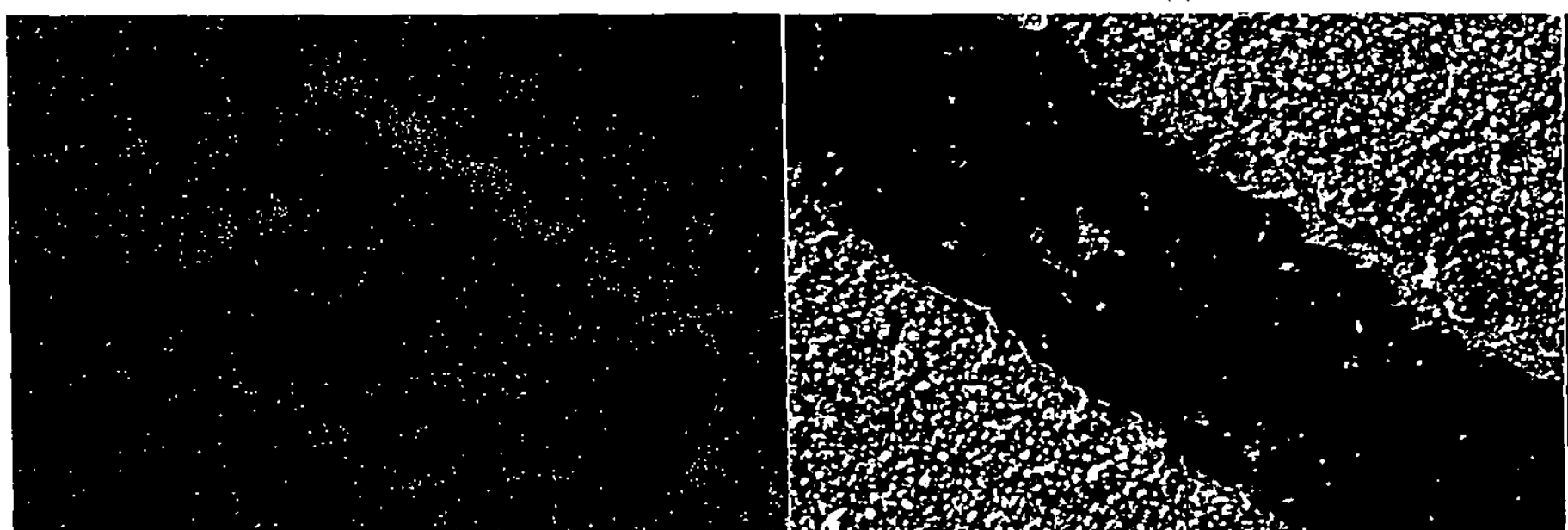

(c)

(a)

(d)

Figure 5.23 (a) SEM micrograph of scratch channel on $\mathrm{Al}_{2} \mathrm{O}_{3}$ coated insert from $\mathrm{CO}_{2} / \mathrm{H}_{2}$ mole ratio $=1 / 10$ coating run. Stylus load $=6 \mathrm{~kg} . \times 300$.

(b) Al $K_{\alpha}$ elemental scan of area shown in (a).

(c) Ti $K_{\alpha}$ elemental scan of area shown in (a).

(d) Fe $K_{\alpha}$ elemental scan of area shown in (a). 
(b)

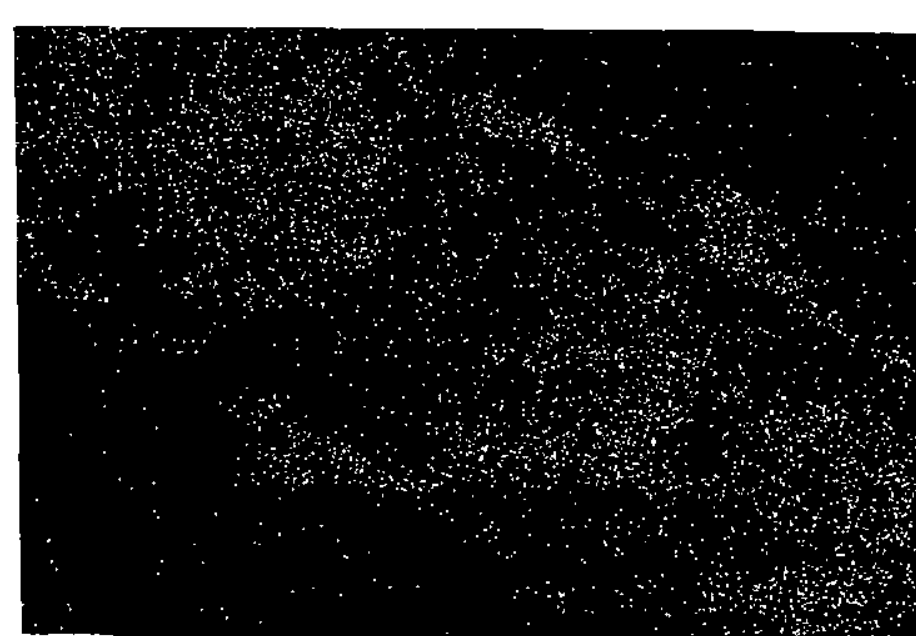

(c)

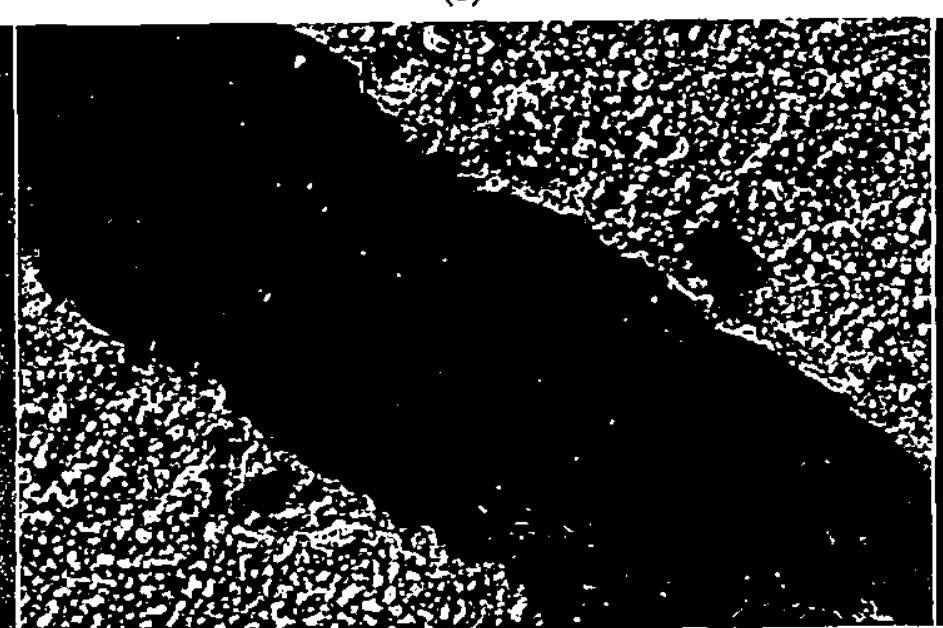

(a) (d)

Eigure 5.24 (a) SEM micrograph of scratch channel on $\mathrm{Al}_{2} \mathrm{O}_{3}$ coated insert from $\mathrm{CO}_{2} / \mathrm{H}_{2}$ mole ratio $=1 / 10$ coating run. Stylus load $=7 \mathrm{~kg} . \times 300$.

(b) Al $K_{\alpha}$ elemental scan of area shown in (a).

(c) Ti $K_{a}$ elemental scan of area shown in (a).

(d) Fe $K_{\mathrm{a}}$ elemental scan of area shown in (a). 


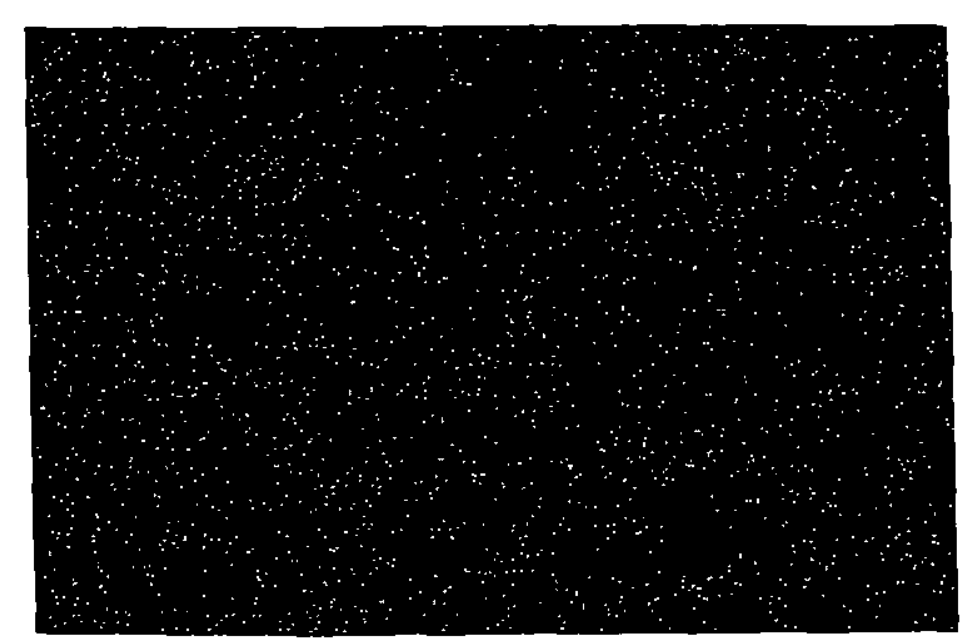

(b)

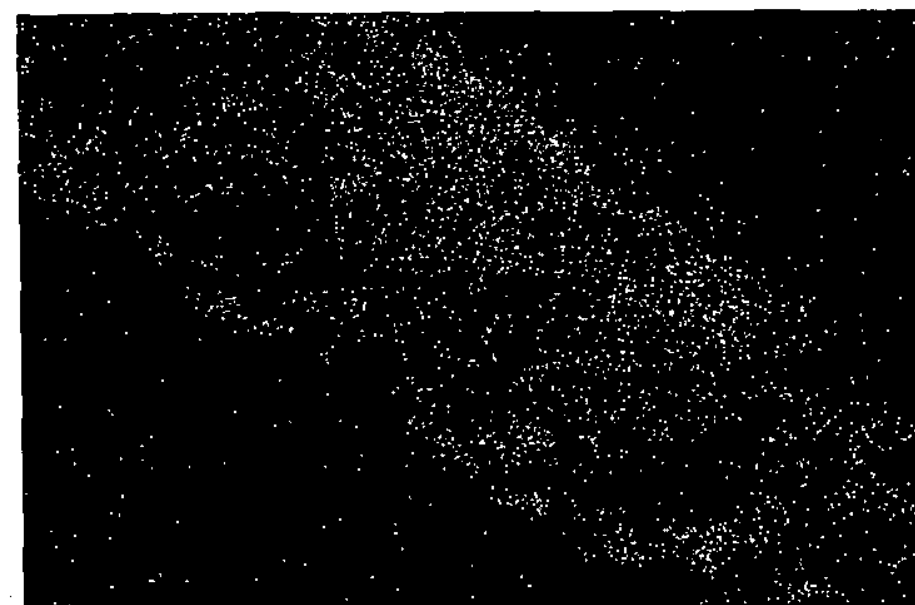

(c)

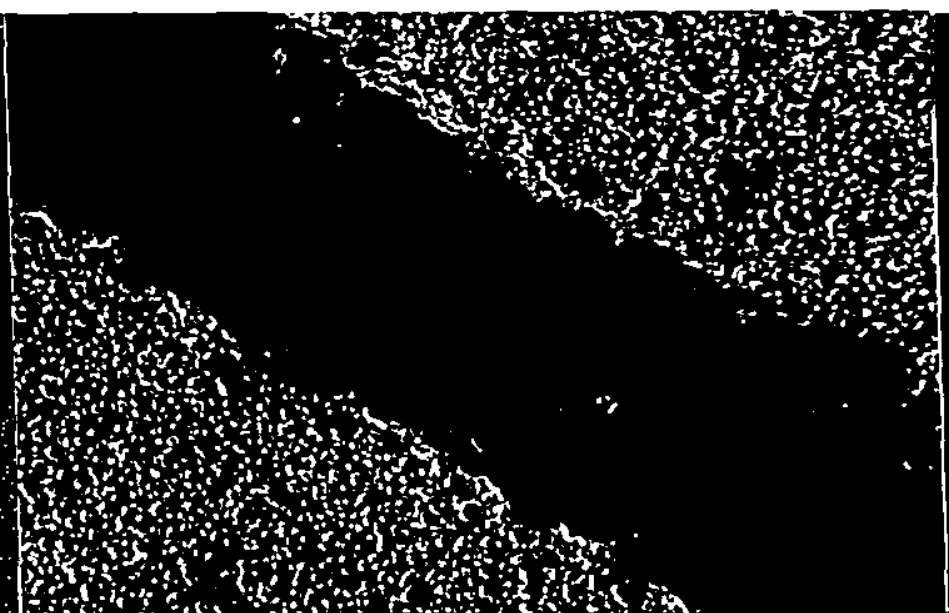

(a) (d)

Eigure 5.25 (a) SEM micrograph of scratch channel on $\mathrm{Al}_{2} \mathrm{O}_{3}$ coated insert from $\mathrm{CO}_{2} / \mathrm{H}_{2}$ mole ratio $=1 / 12$ coating run. Stylus load $=6 \mathrm{~kg}$. $x 300$.

(b) Al $K_{\alpha}$ elemental scan of area shown in (a).

(c) Ti $K_{\alpha}$ elemental scan of area shown in (a).

(d) Fe $K_{\alpha}$ elemental scan of area shown in (a). 


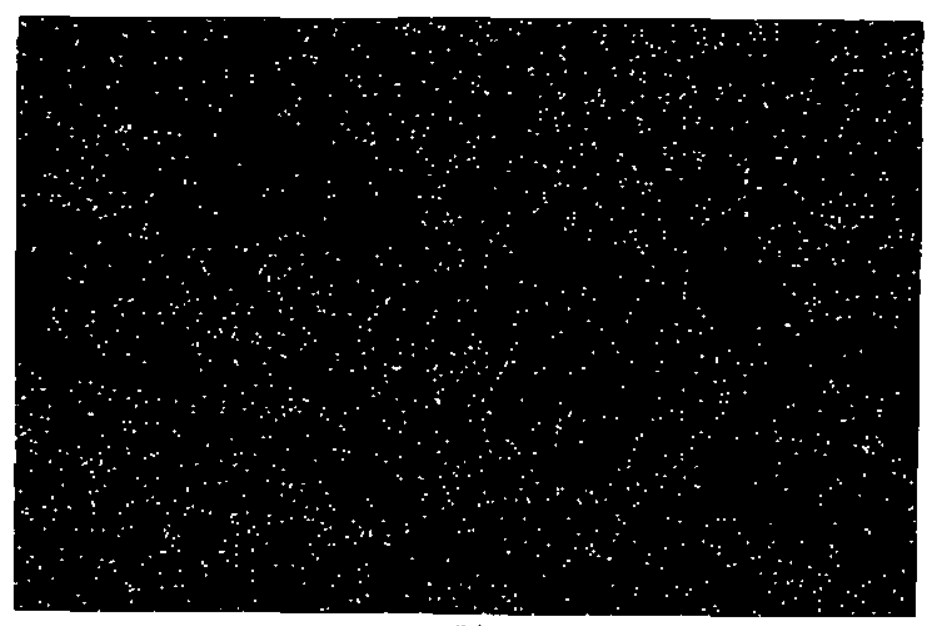

(b)

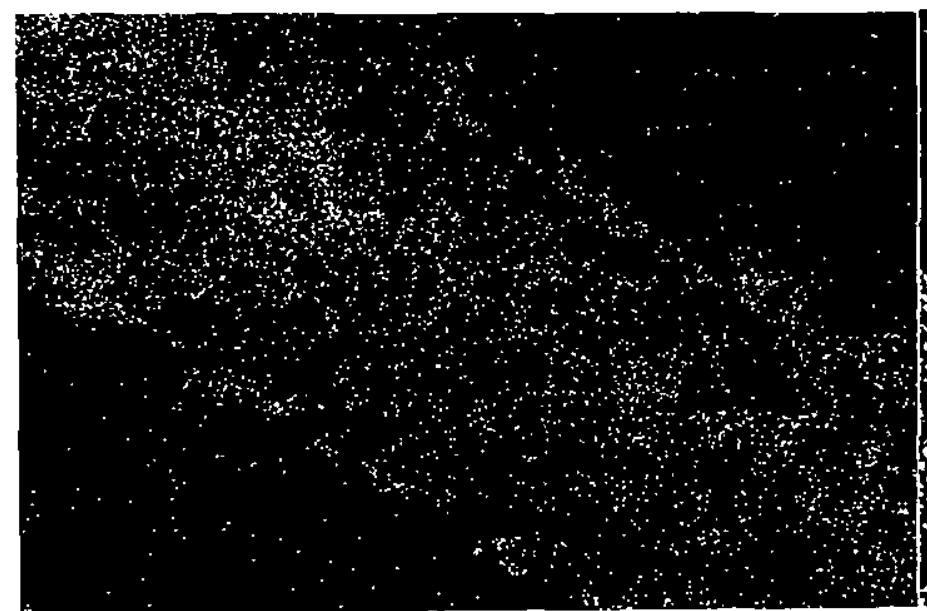

(c)

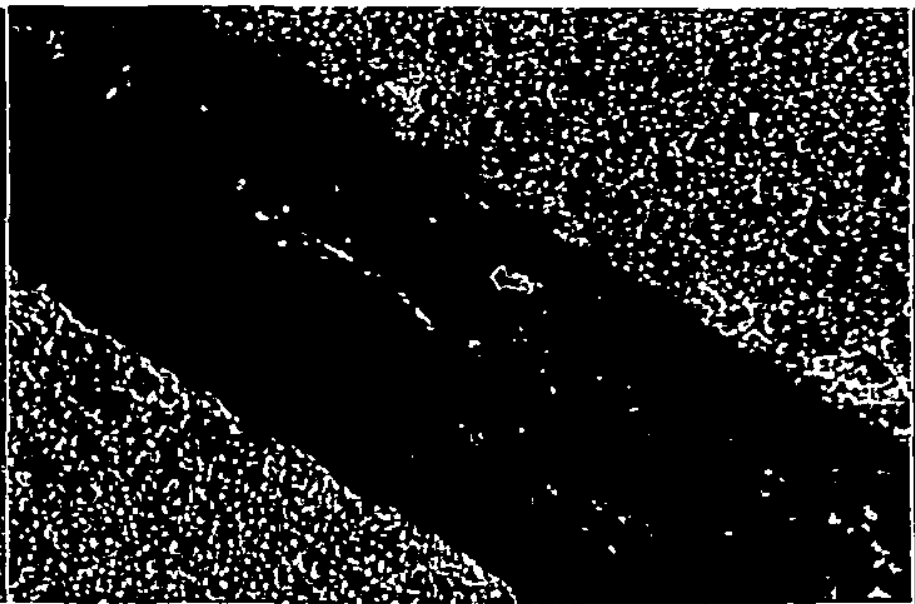

(a) (d)

Figure 5.26 (a) SEM micrograph of scratch channel on $\mathrm{Al}_{2} \mathrm{O}_{3}$ coated insert from $\mathrm{CO}_{2} / \mathrm{H}_{2}$ mole ratio $=1 / 12$ coating run. Stylus load $=7 \mathrm{~kg}$. $\times 300$.

(b) Al $K_{\alpha}$ elemental scan of area shown in (a).

(c) Ti $K_{\alpha}$ elemental scan of area shown in (a).

(d) Fe $K_{\alpha}$ elemental scan of area shown in (a). 
(b)

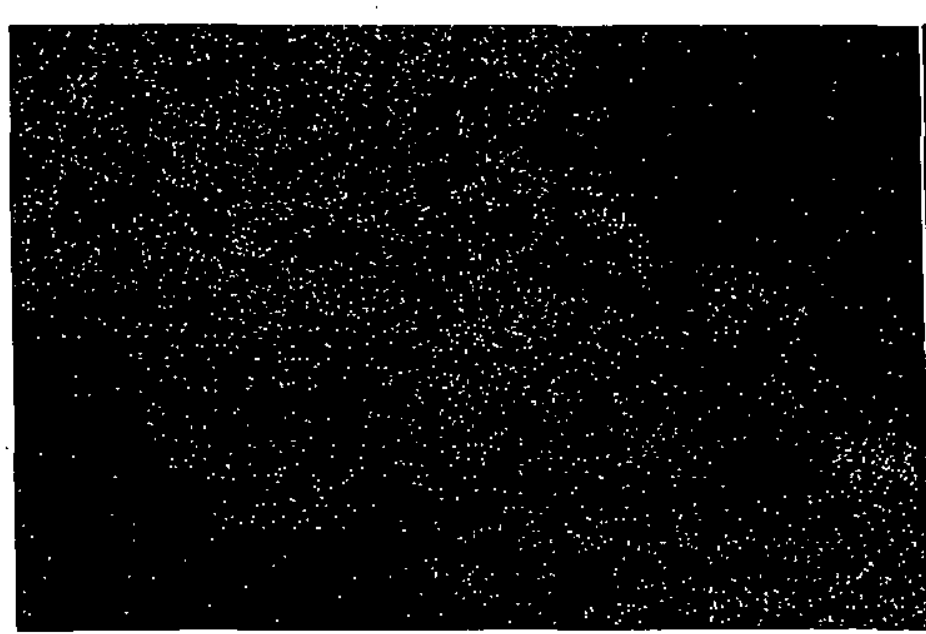

(c)

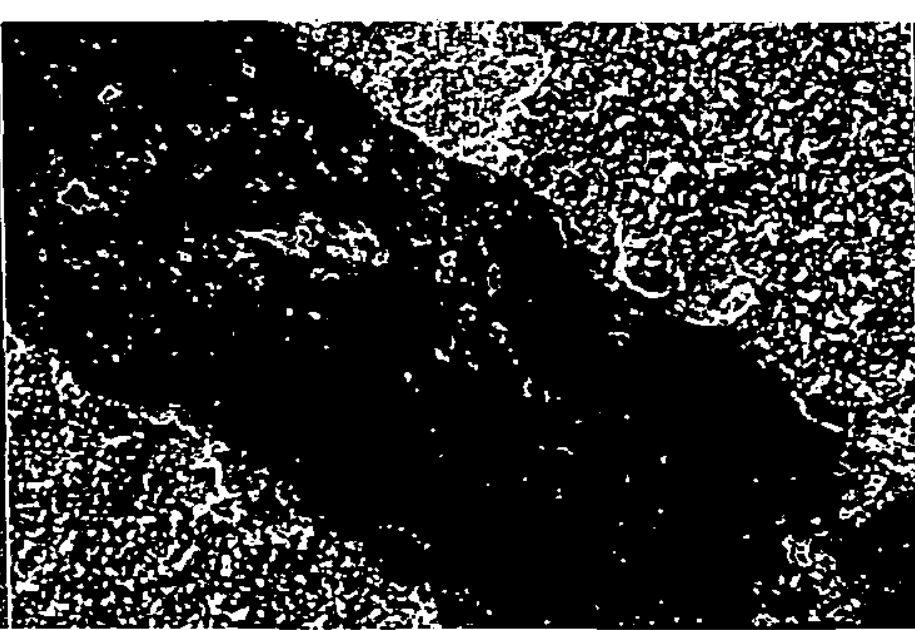

(a) (d)

Figure 5.27 (a) SEM micrograph of scratch channel on $\mathrm{Al}_{2} \mathrm{O}_{3}$ coated insert from $\mathrm{CO} / \mathrm{H}_{2}$ mole ratio $=1 / 14$ coating run. Stylus load $=5 \mathrm{~kg} . \times 300$.

(b) $\mathrm{Al} K_{\alpha}$ elemental scan of area shown in (a).

(c) Ti $K_{\alpha}$ elemental scan of area shown in (a).

(d) Fe $K_{a}$ elemental scan of area shown in (a). 


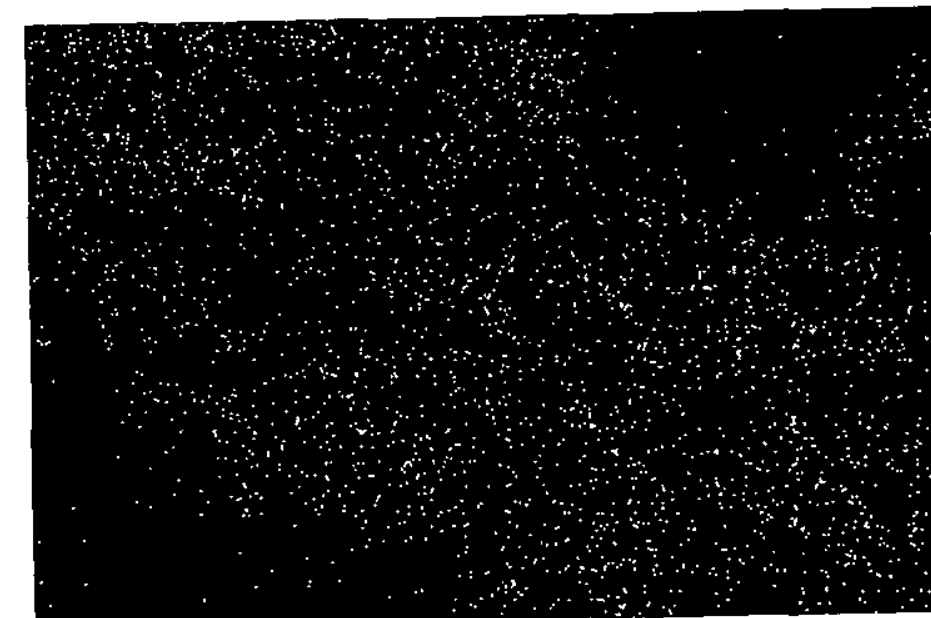

(c)

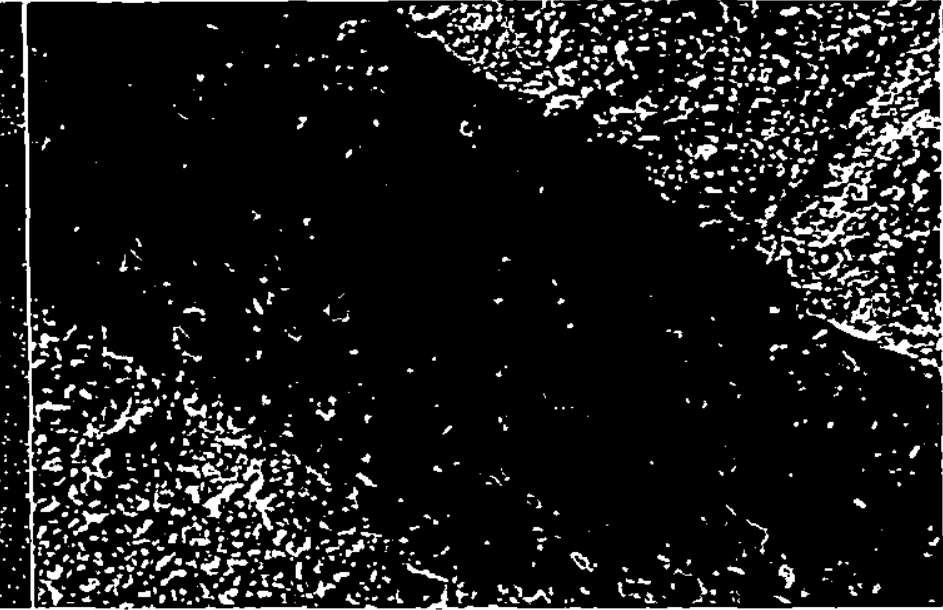

(a)

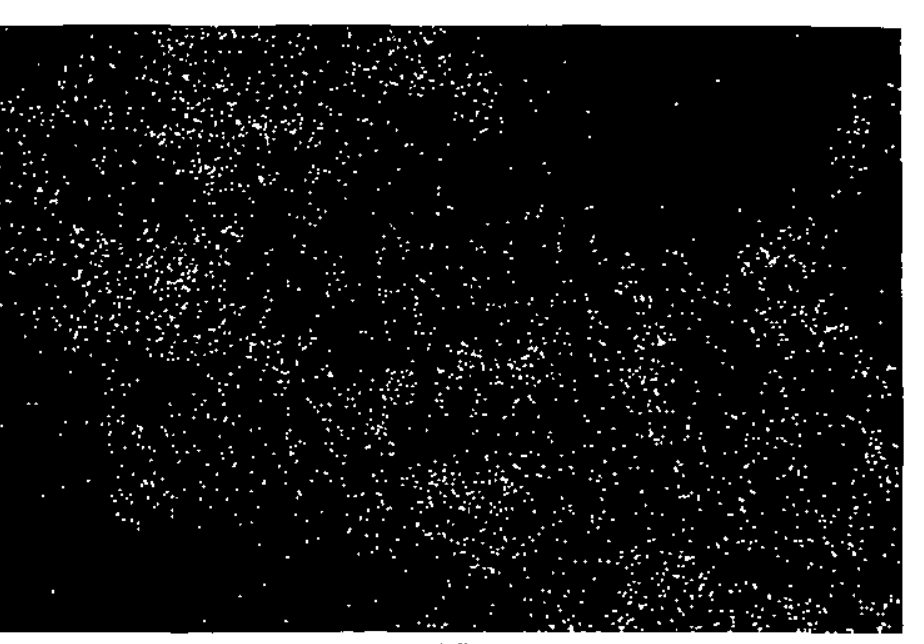

(d)

Figure 5.28 (a) SEM micrograph of scratch channel on $\mathrm{Al}_{2} \mathrm{O}_{3}$ coated insert from $\mathrm{CO}_{2} / \mathrm{H}_{2}$ mole ratio $=1 / 14$ coating run. Stylus load $=6 \mathrm{~kg} . \times 300$. (b) Al $K_{\alpha}$ elemental scan of area shown in (a).

(c) Ti $K_{\alpha}$ elemental scan of area shown in (a).

(d) Fe $K_{\alpha}$ elemental scan of area shown in (a). 


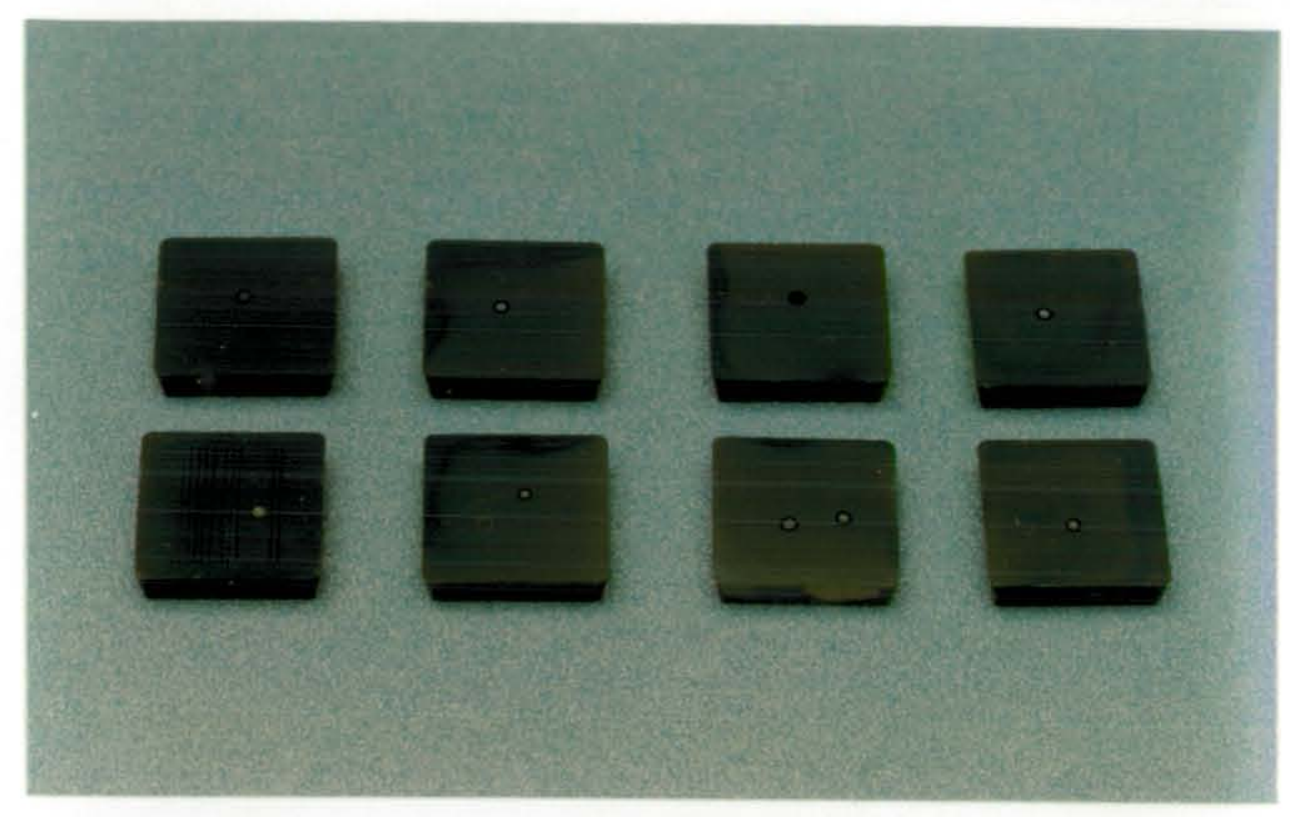

(d) $\mathrm{H}_{2}-1 / \mathrm{AlCl}_{3}$ flow rate $=25 \mathrm{~cm}^{3} \mathrm{~min}^{-1}$

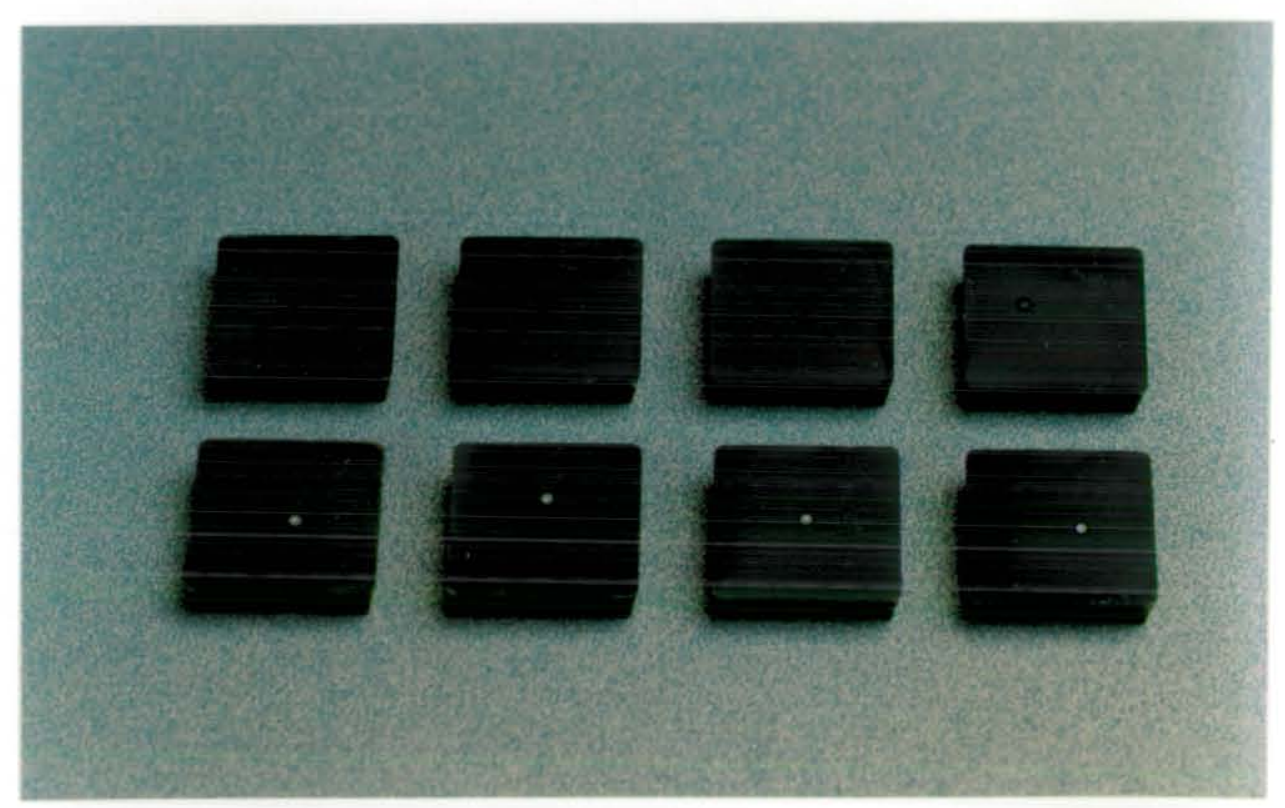

(e) $\mathrm{H}_{2}-1 / \mathrm{AlCl}_{3}$ flow rate $=30 \mathrm{~cm}^{3} \min ^{-1}$

Figure 5.29 External appearance of $a c$ (upper) and $h c$ (lower) inserts from $\mathrm{H}_{2}-1 / \mathrm{AlCl}_{3}$ flow rate coating runs. 


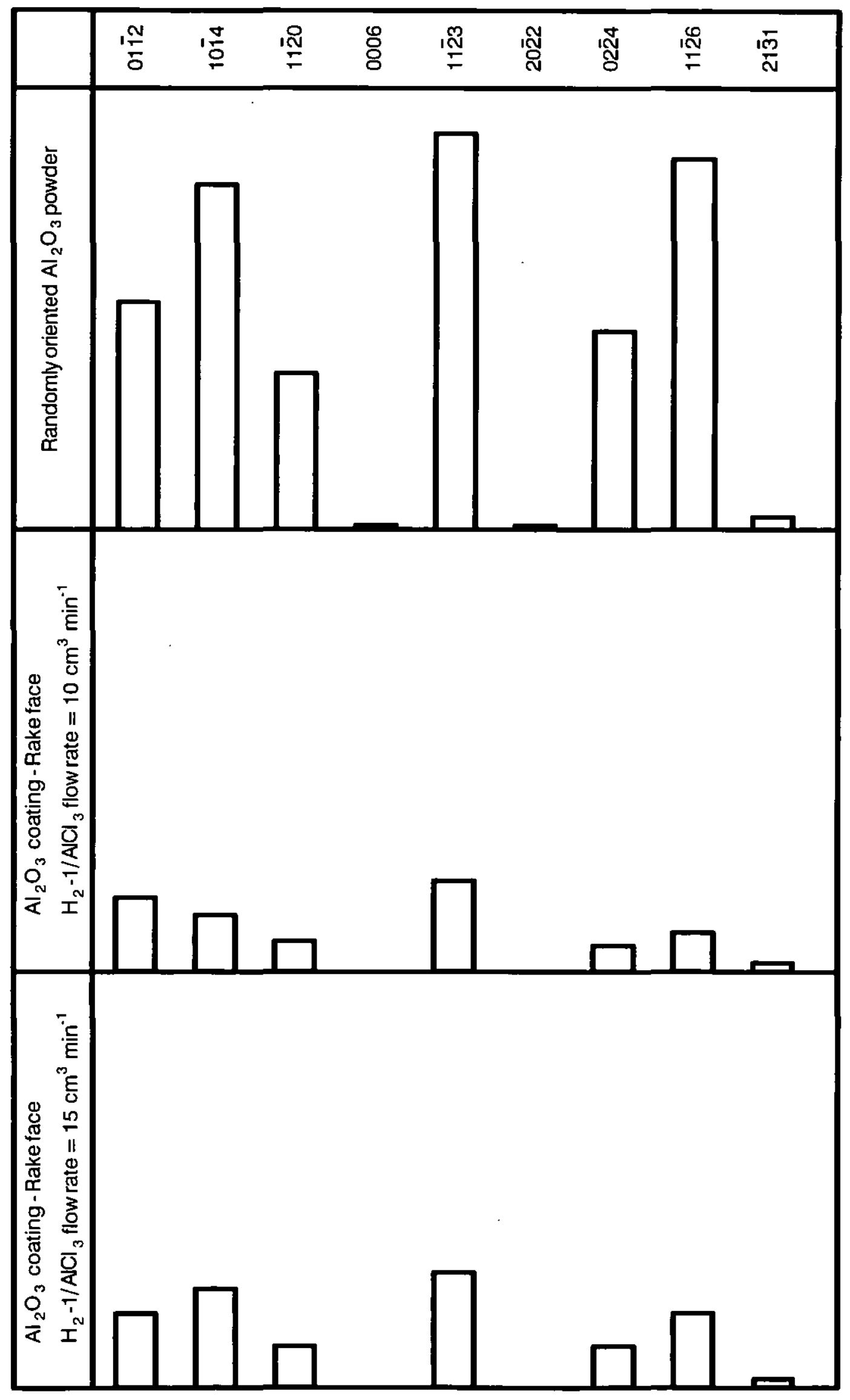

Figure 5.30 Typical relative intensities for $\mathrm{Al}_{2} \mathrm{O}_{3}$ coatings deposited at different $\mathrm{H}_{2}-1 / \mathrm{AlCl}_{3}$ flow rates, compared to those for randomly oriented $\mathrm{Al}_{2} \mathrm{O}_{3}$ powder ( $a c$ inserts). 


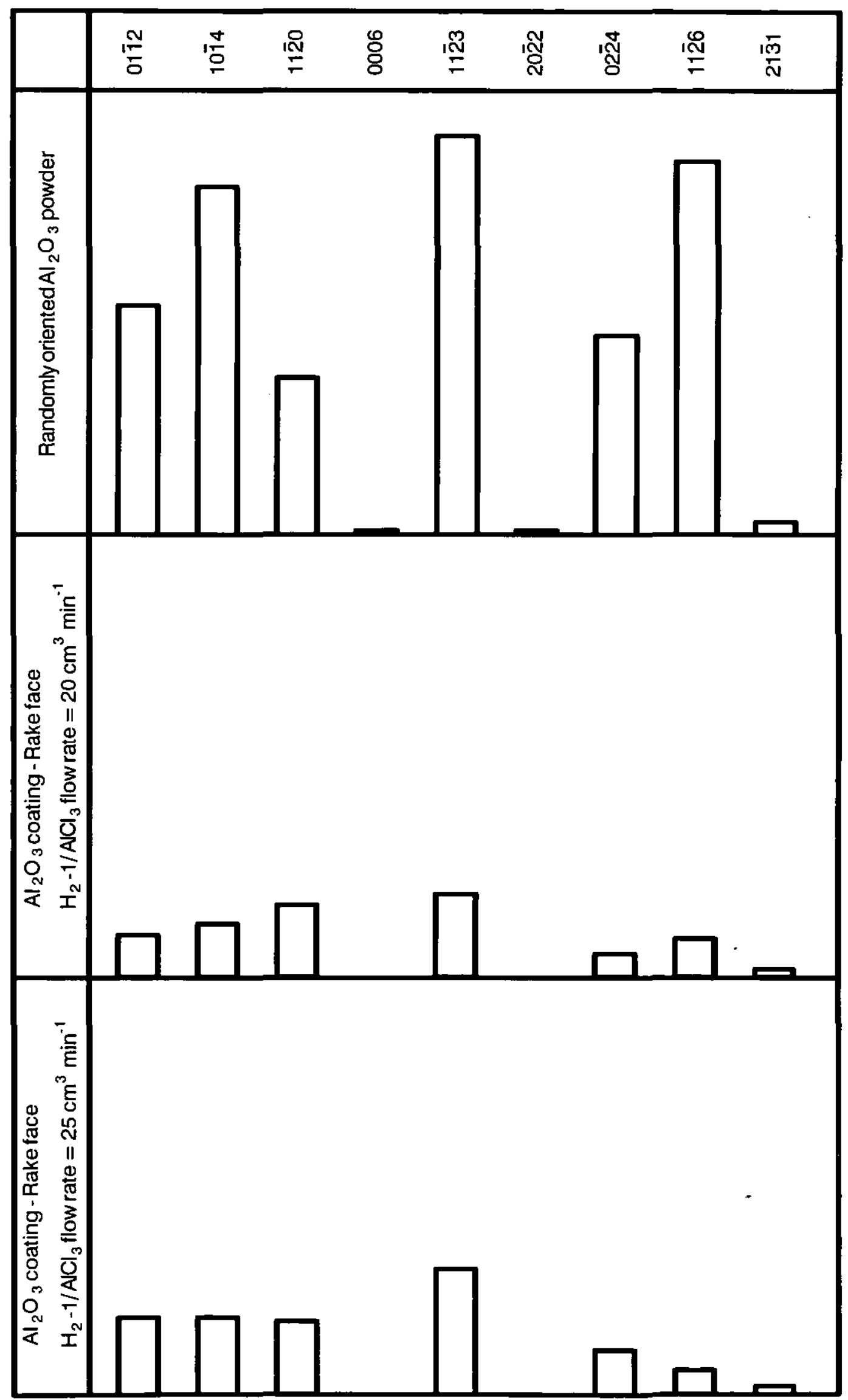

Figure 5.30 Typical relative intensities for $\mathrm{Al}_{2} \mathrm{O}_{3}$ coatings deposited at different $\mathrm{H}_{2}-1 / \mathrm{ACl}_{3}$ flowrates, compared to those for randomly oriented $\mathrm{Al}_{2} \mathrm{O}_{3}$ powder ( $a c$ inserts). 


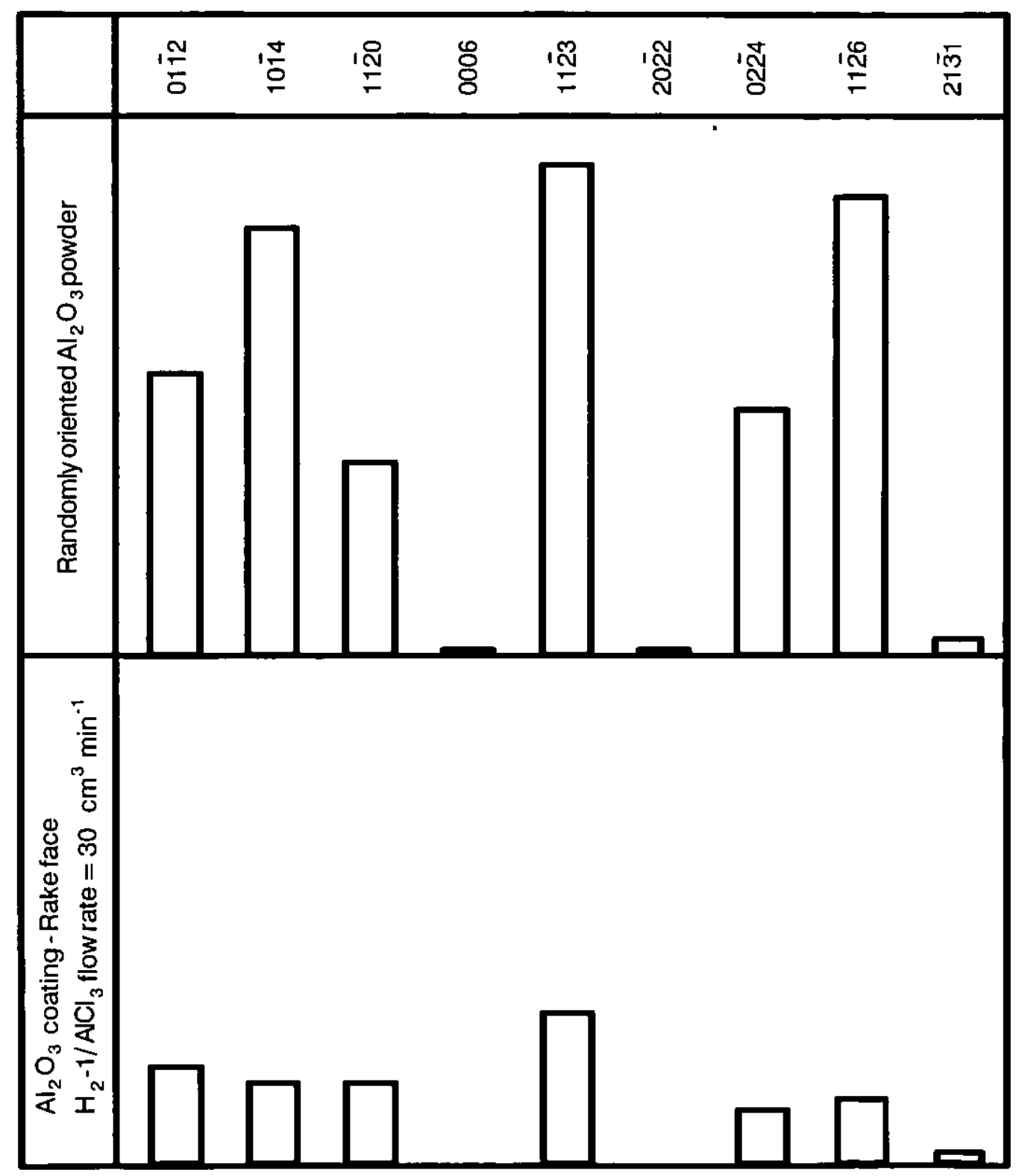

Figure 5.30 Typical relative intensities for $\mathrm{Al}_{2} \mathrm{O}_{3}$ coatings deposited at different $\mathrm{H}_{2}-1 / \mathrm{ACl}_{3}$ flowrates, compared to those for randomly oriented $\mathrm{Al}_{2} \mathrm{O}_{3}$ powder (acinserts). 


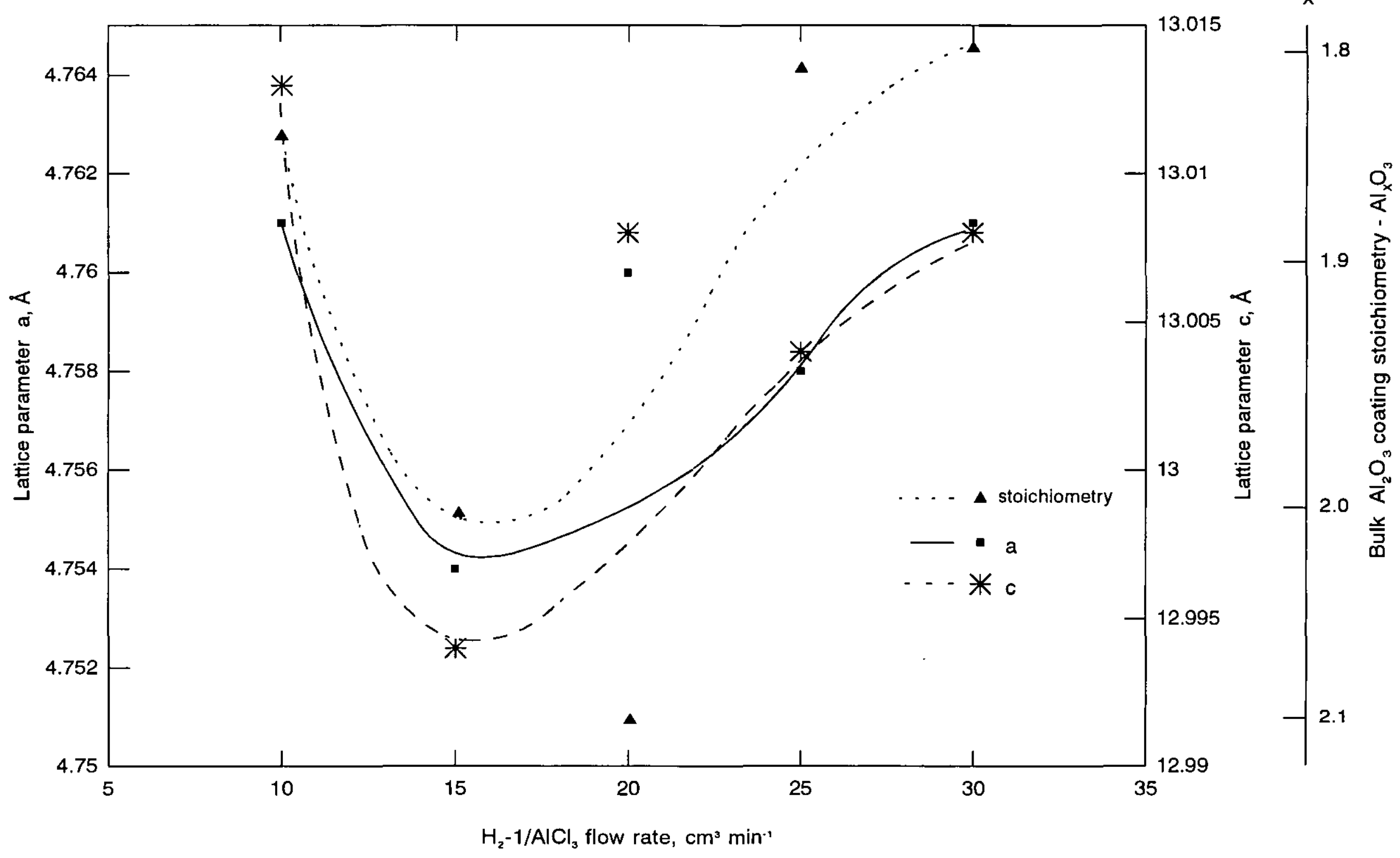

Figure 5.31 Effect of $\mathrm{H}_{2}-1 / \mathrm{AlCl}_{3}$ flow rate on $\mathrm{Al}_{2} \mathrm{O}_{3}$ coating lattice parameters (superimposed - bulk $\mathrm{Al}_{2} \mathrm{O}_{3}$ coating stoichiometry) 


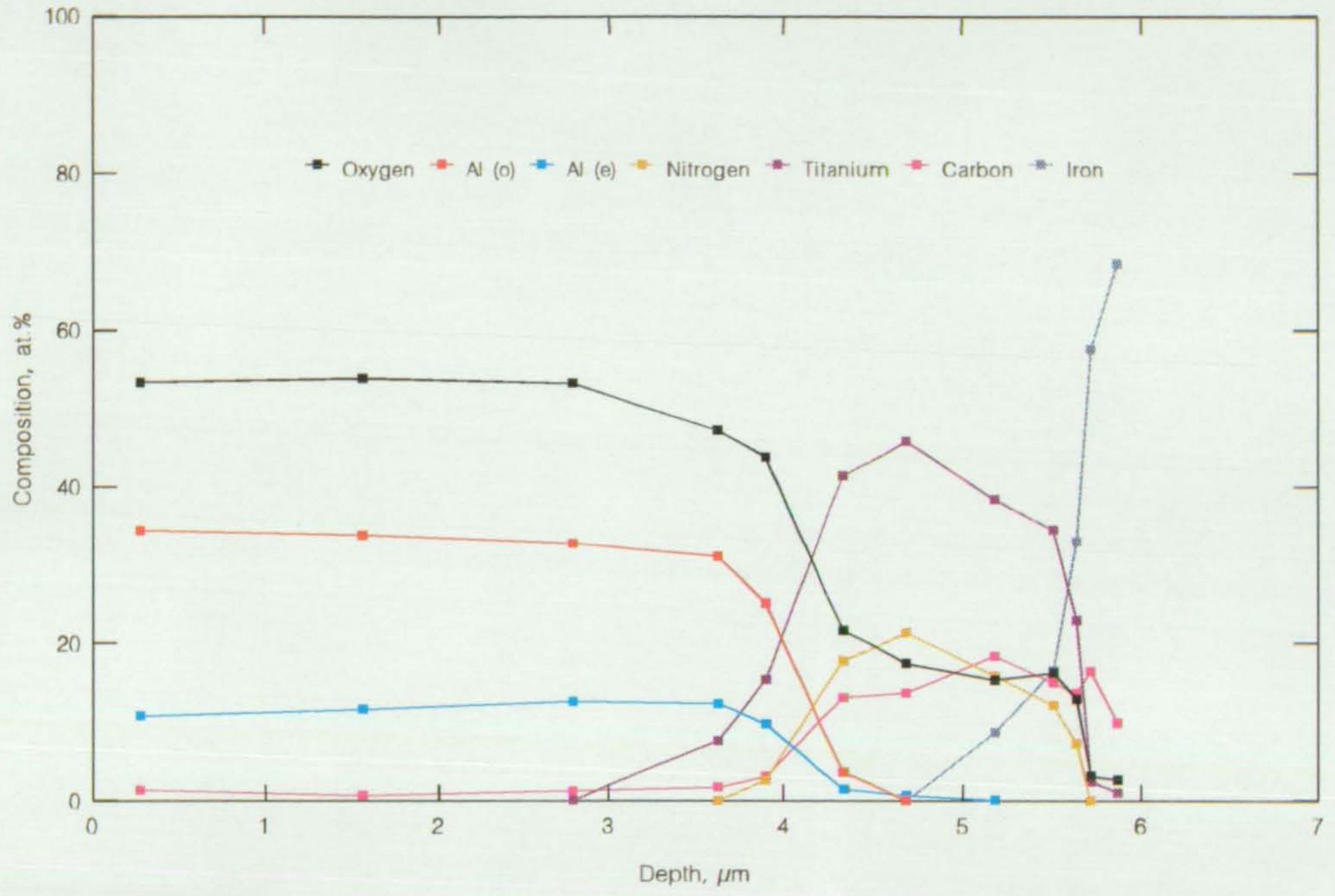

Figure 5.32 Composition-depth profile through $\mathrm{Al}_{2} \mathrm{O}_{3}$ coating and $\mathrm{Al}_{2} \mathrm{O}_{3}$ coating/Ti(C,N) precoating interface (extending through $\mathrm{Ti}(\mathrm{C}, \mathrm{N})$ precoating and $\mathrm{Ti}(\mathrm{C}, \mathrm{N})$ precoating/ $/ \mathrm{SSS}$ substrate interface) for $\mathrm{Al} \mathrm{O}_{3}$ coated inserts from different $\mathrm{H}_{2}-1 / \mathrm{AlCl}_{3}$ flow rate coating runs. (a) $\mathrm{H}_{2}-1 / \mathrm{AlCl}_{3}$ flow rate $=10 \mathrm{~cm}^{3} \mathrm{~min}$ 


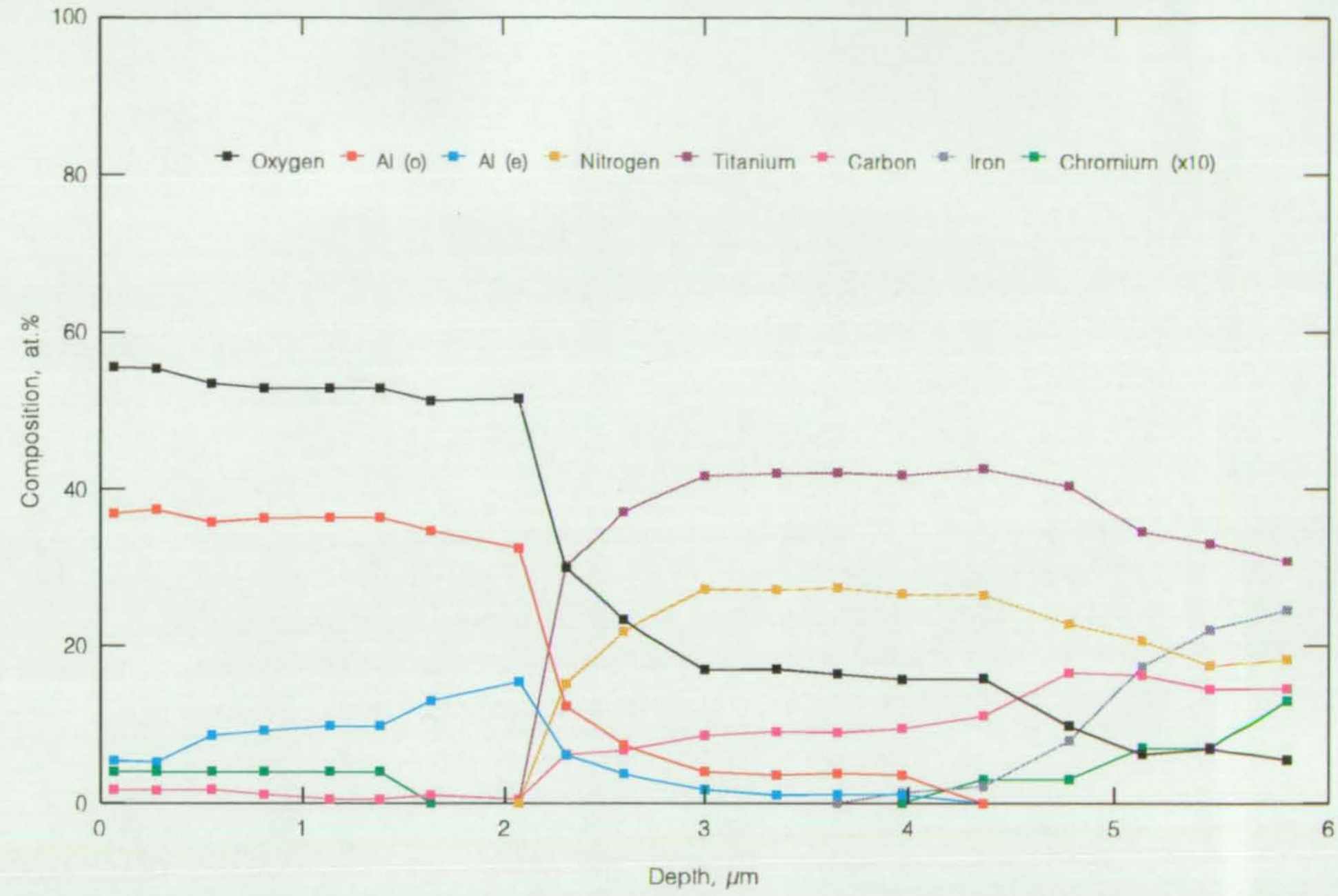

Figure 5.32 Composition-depth profile through $\mathrm{Al}_{2} \mathrm{O}_{3}$ coating and $\mathrm{A}_{2} \mathrm{O}_{3}$ coating/Ti(C,N) precoating interface (extending through $T(C, N)$ precoating and $T(C, N)$ precoating/HSS substrate interface) for $\mathrm{Al}_{2} \mathrm{O}_{3}$ coated inserts from different $\mathrm{H}_{2}-1 / \mathrm{AlCl}_{3}$ flow rate coating runs.(b) $\mathrm{H}_{2}-1 / \mathrm{AlCl}_{3}$ flow rate $=15 \mathrm{~cm}^{3} \mathrm{~min}^{-}$ 


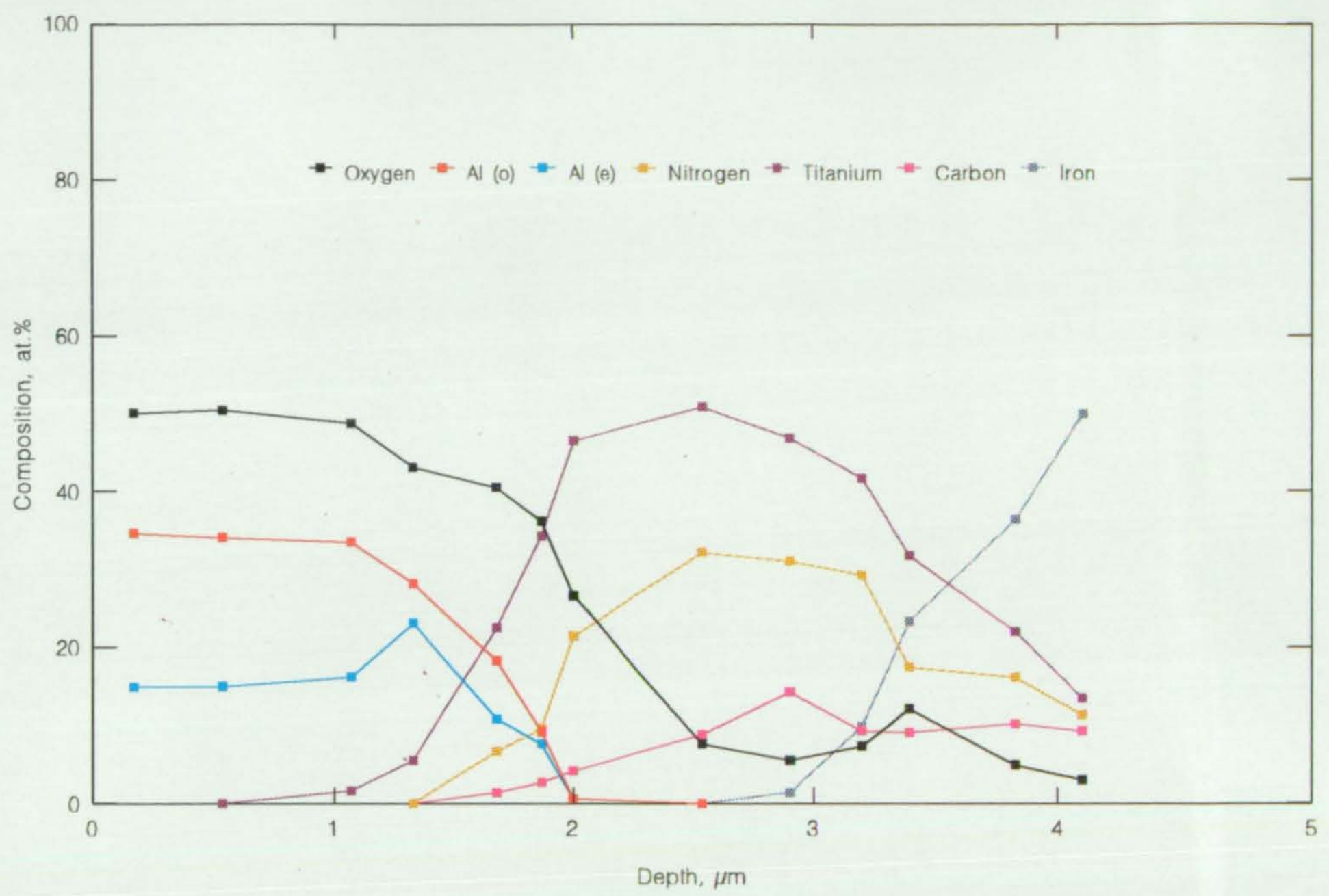

Figure 5.32 Composition-depth profile through $\mathrm{Al}_{2} \mathrm{O}_{3}$ coating and $\mathrm{Al}_{2} \mathrm{O}_{3}$ coating/Ti(C,N) precoating interface (extending through $T_{i}(\mathrm{C}, \mathrm{N})$ precoating and $\mathrm{Ti}(\mathrm{C}, \mathrm{N})$ precoating/HSS substrate interface) for $\mathrm{Al}_{2} \mathrm{O}_{3}$ coated inserts from different $\mathrm{H}_{2}-1 / \mathrm{AlCl}_{3}$ flow rate coating runs. (c) $\mathrm{H}_{2}-1 / \mathrm{AlCl}_{3}$ flow rate $=20 \mathrm{~cm}^{3} \mathrm{~min}^{-1}$ 


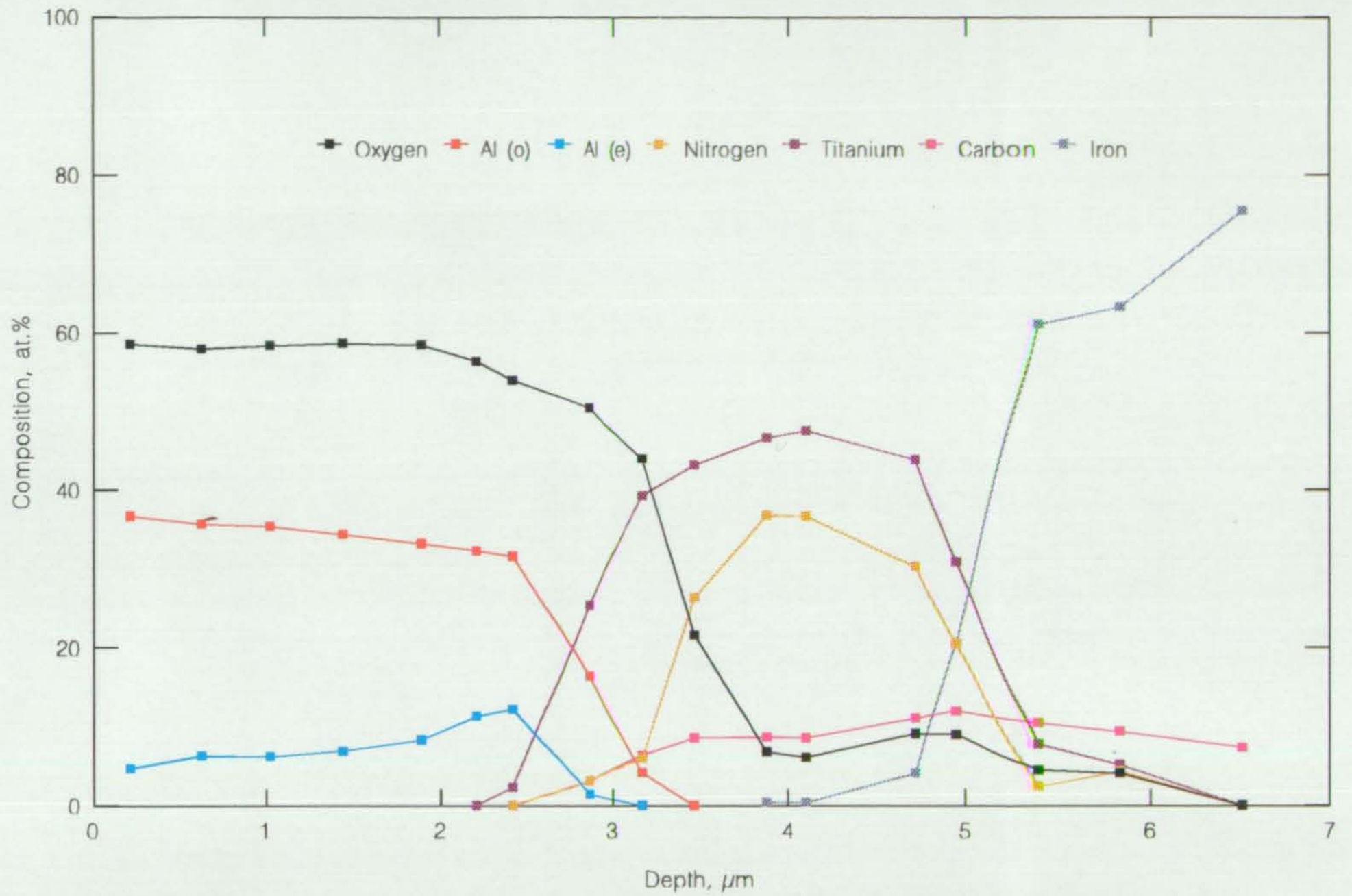

Figure 5.32 Composition-depth profile through $\mathrm{Al}_{2} \mathrm{O}_{3}$ coating and $\mathrm{Al}_{2} \mathrm{O}_{3}$ coating/Ti(C,N) precoating interface (extending through $\mathrm{Ti}(\mathrm{C}, \mathrm{N})$ precoating and $\mathrm{Ti}(\mathrm{C}, \mathrm{N})$ precoating/HSS substrate interface) for $\mathrm{Al}_{2} \mathrm{O}_{3}$ coated inserts from different $\mathrm{H}_{2}-1 / \mathrm{AlCl}_{3}$ flow rate coating runs. (d) $\mathrm{H}_{2}-1 / \mathrm{AlCl}_{3}$ flow rate $=25 \mathrm{~cm}^{3} \mathrm{~min}^{-1}$ 


$$
2
$$




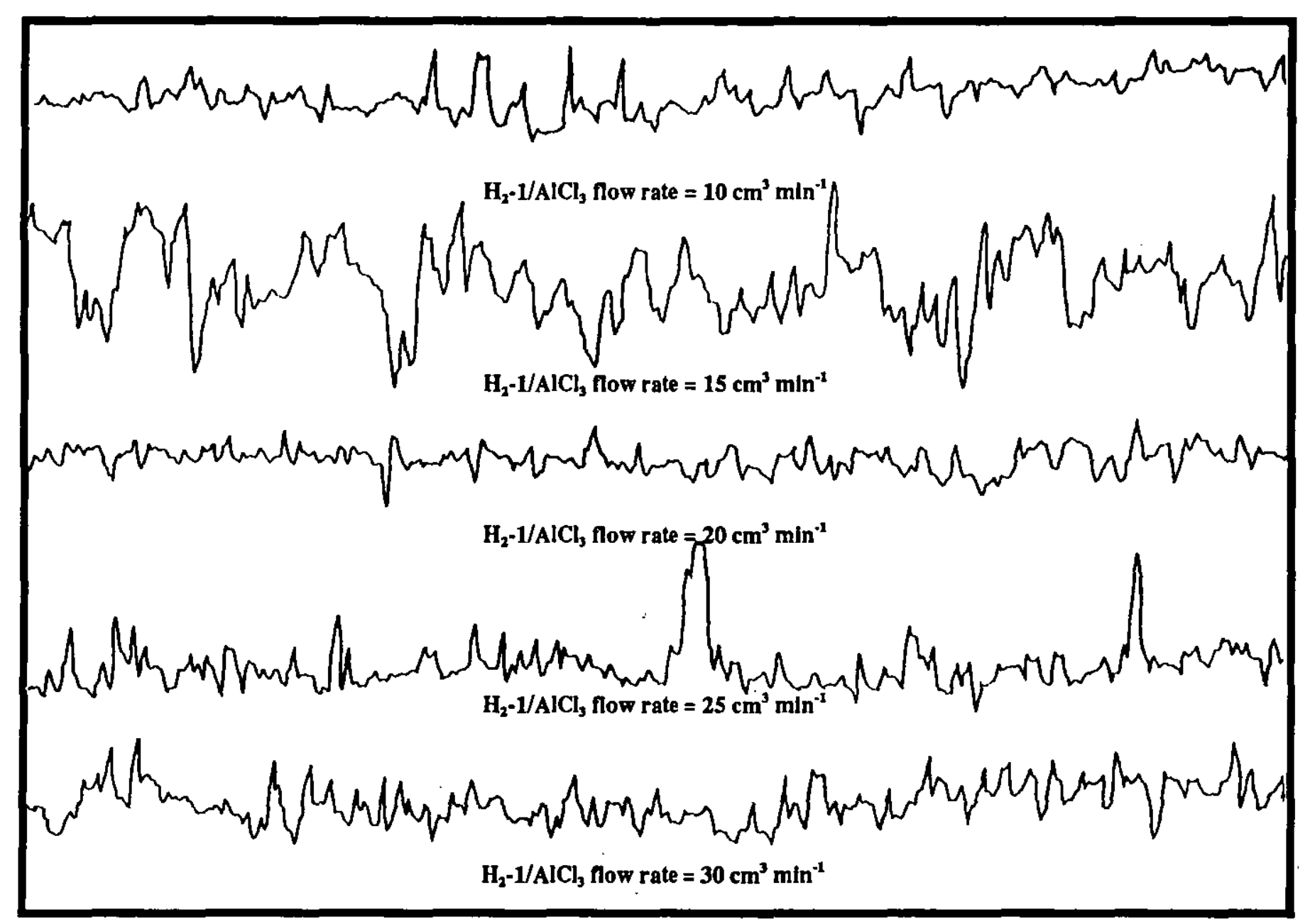

Eigure 5.33 Typical Talysurf traces of surface of $\mathrm{Al}_{2} \mathrm{O}_{3}$ coatings deposited at different $\mathrm{H}_{2}-1 / \mathrm{AlCl}_{3}$ flow rates. 


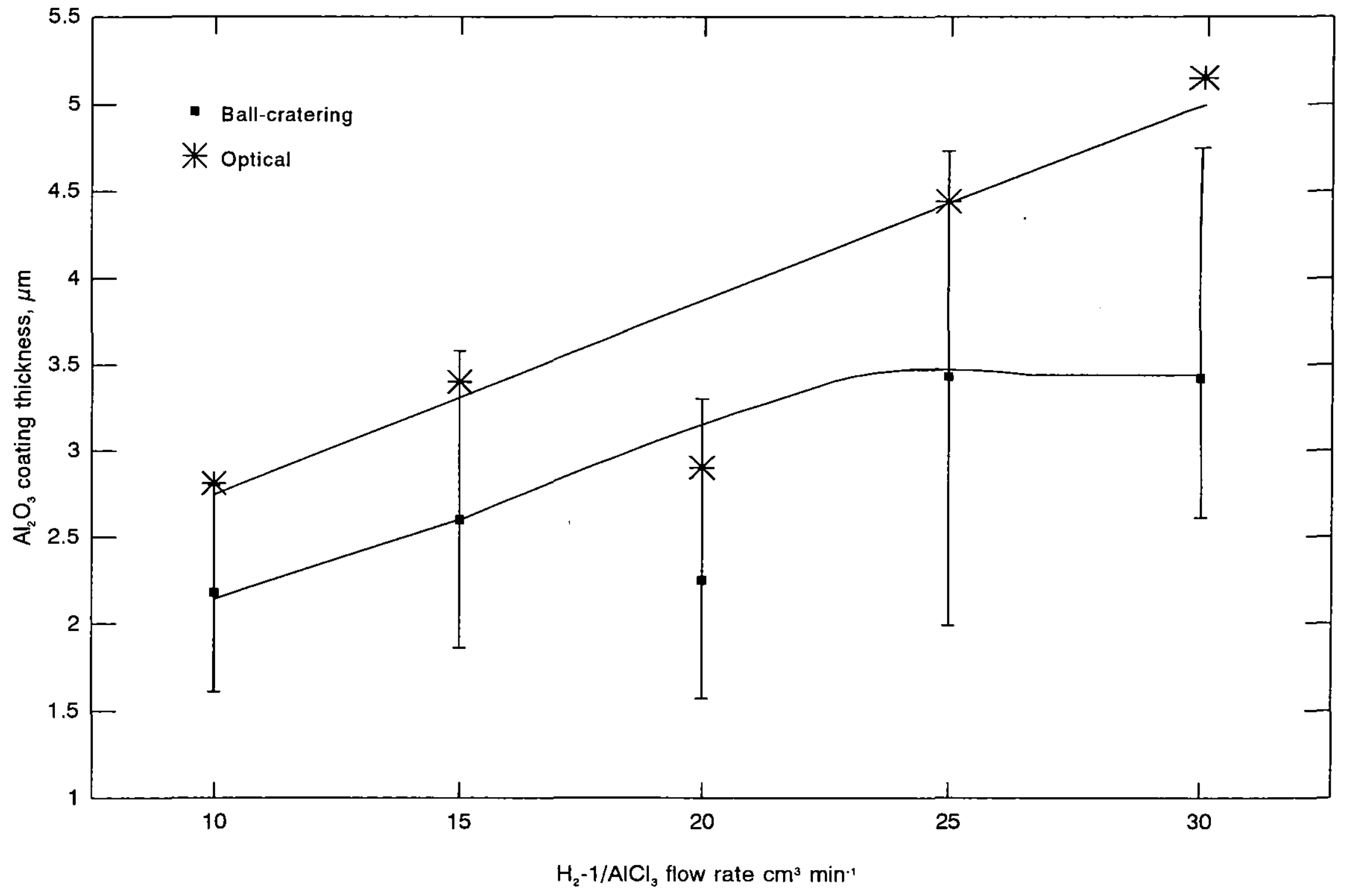

Fiqure 5.34 Effect of $\mathrm{H}_{2}-1 / \mathrm{AlCl}_{3}$ flow rate on $\mathrm{Al}_{2} \mathrm{O}_{3}$ coating thickness as determined by ball-cratering and optical measurements. 


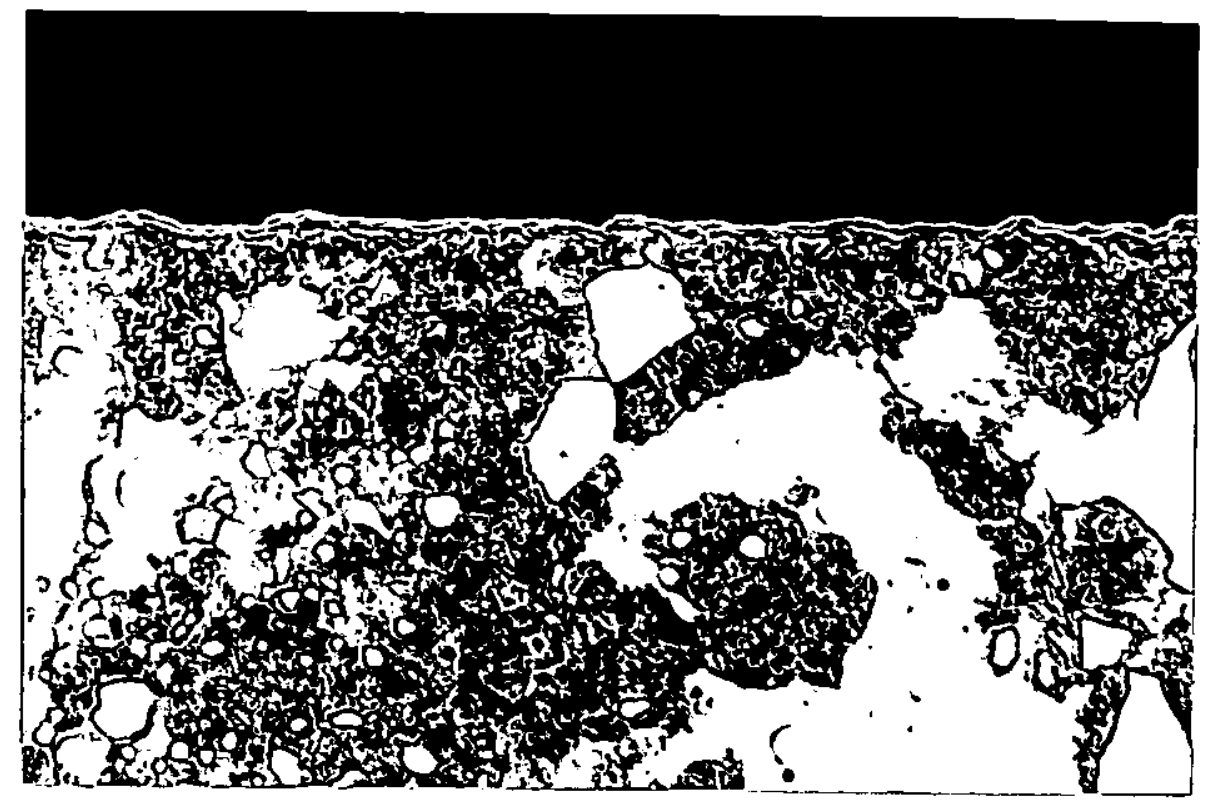

(a) $\mathrm{H}_{2}-1 / \mathrm{AlCl}_{3}$ flow rate $=10 \mathrm{~cm}^{3} \mathrm{~min}^{-1}$

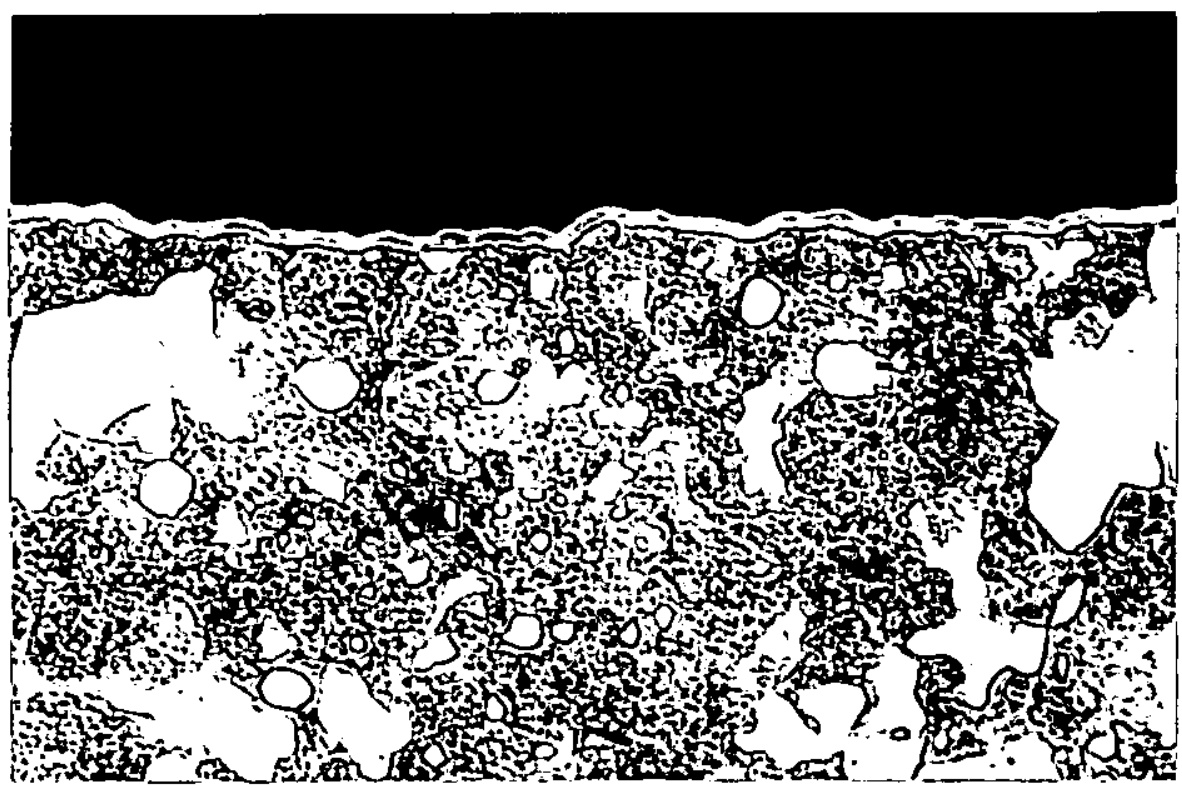

(b) $\mathrm{H}_{2}-1 / \mathrm{AlCl}_{3}$ flow rate $=15 \mathrm{~cm}^{3} \mathrm{~min}^{-1}$

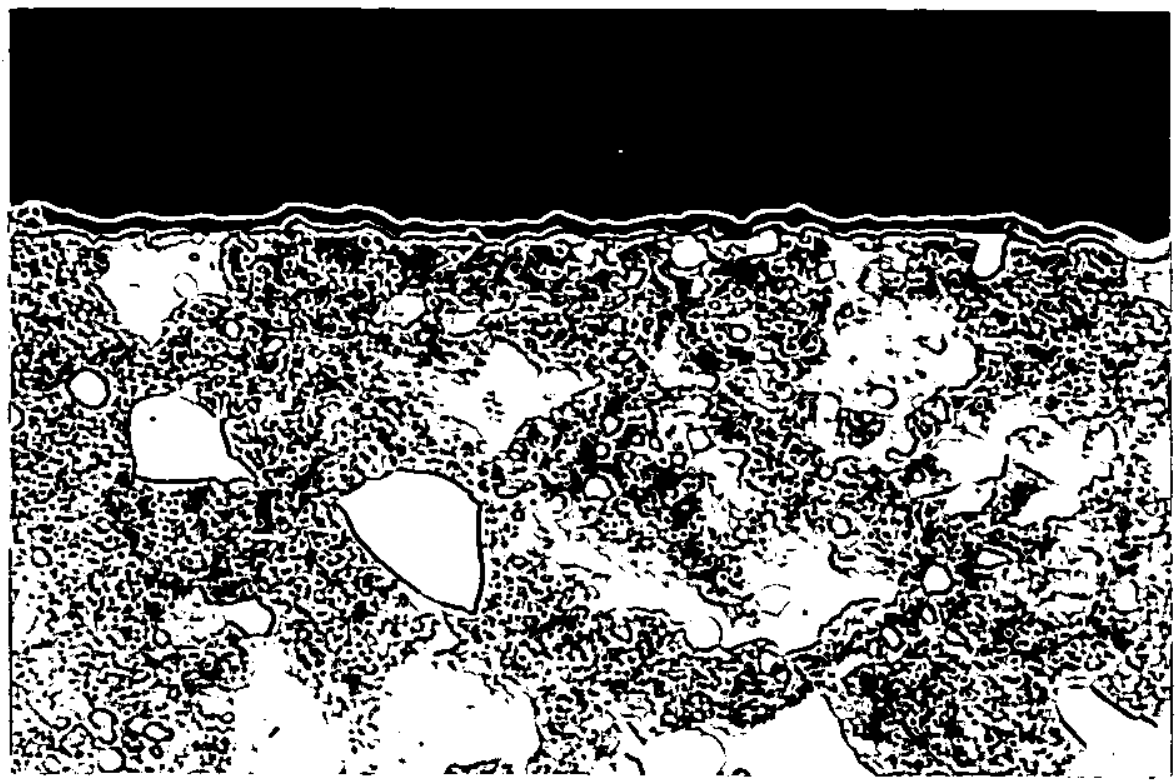

(c) $\mathrm{H}_{2}-1 / \mathrm{AlCl}_{3}$ flow rate $=20 \mathrm{~cm}^{3} \mathrm{~min}^{-1}$

Figure 5.35 Optical cross-sections through rake face of inserts coated with $\mathrm{Al}_{2} \mathrm{O}_{3}$ at different $\mathrm{H}_{2}-1 / \mathrm{AlCl}_{3}$ flow rates. Etchant $2 \%$ nital, $\mathrm{x} 1000$. 


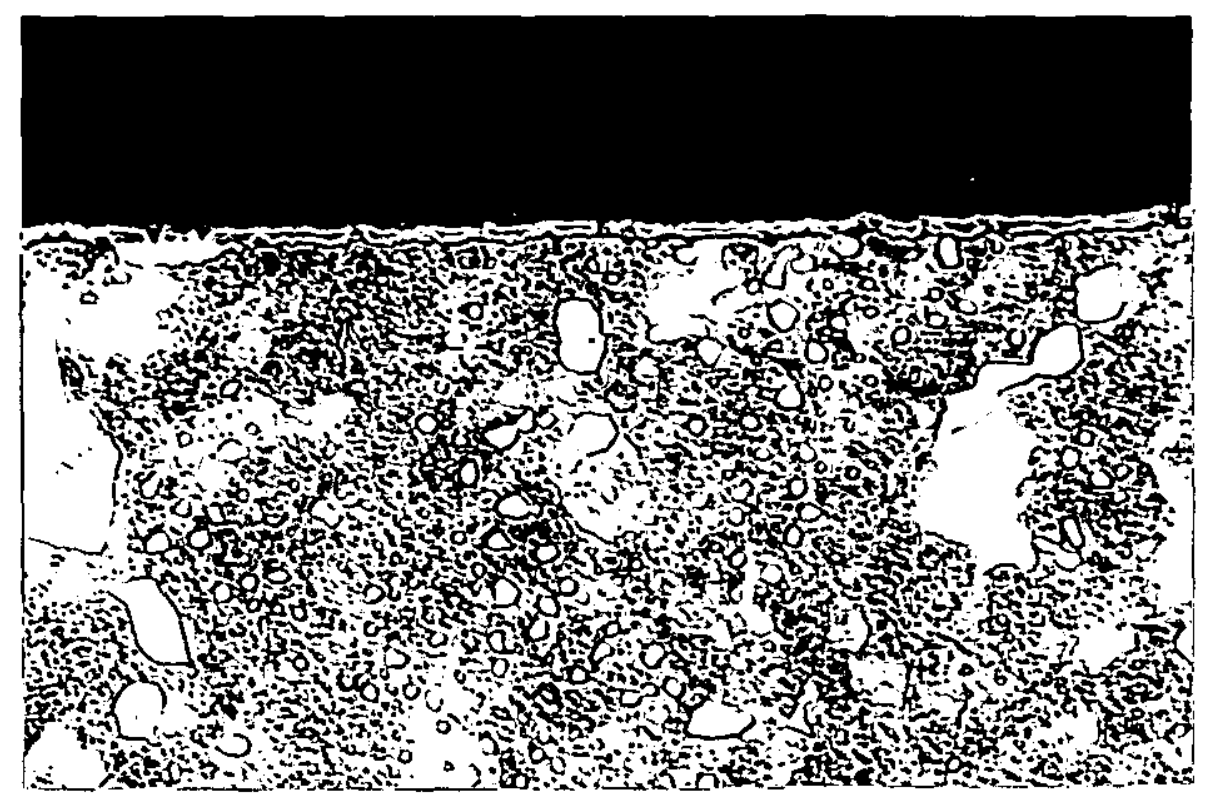

(d) $\mathrm{H}_{2}-1 / \mathrm{AlCl}_{3}$ flow rate $=25 \mathrm{~cm}^{3} \mathrm{~min}^{-1}$

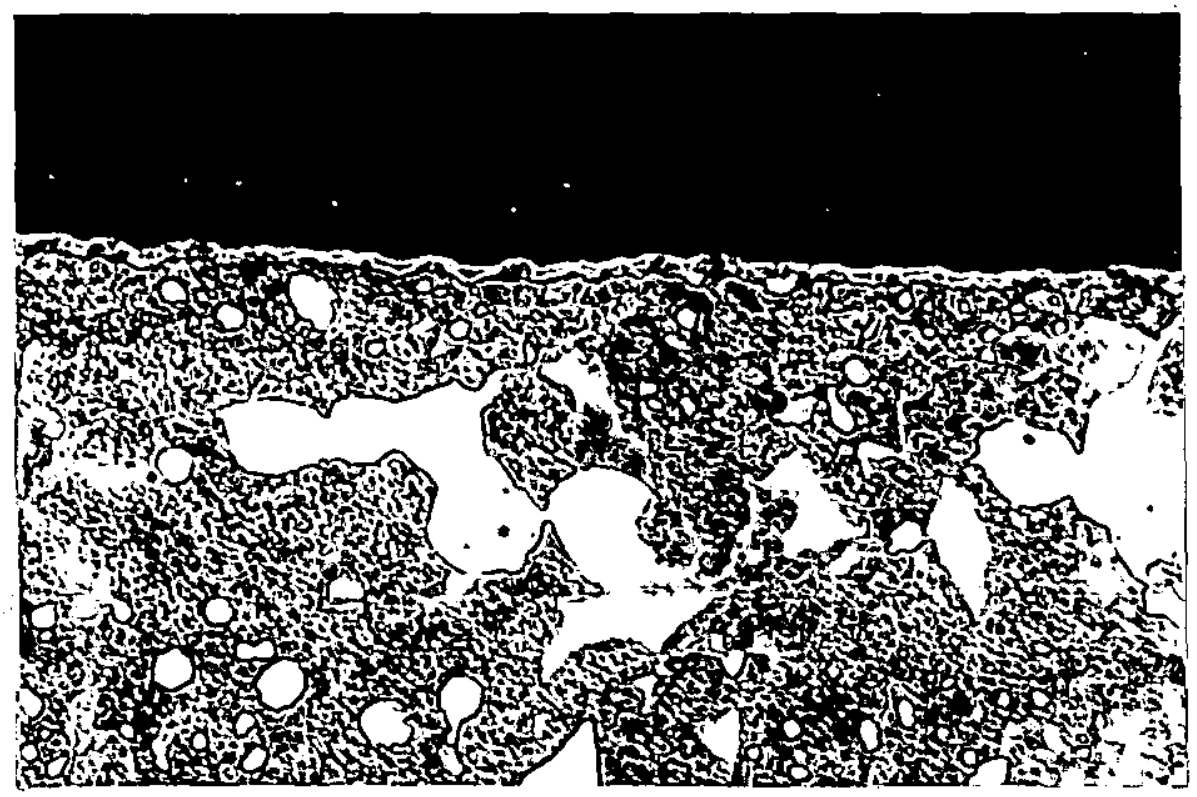

(e) $\mathrm{H}_{2}-1 / \mathrm{AlCl}_{3}$ flow rate $=30 \mathrm{~cm}^{3} \mathrm{~min}^{-1}$

Figure 5.35 Optical cross-sections through rake face of inserts coated with $\mathrm{Al}_{2} \mathrm{O}_{3}$ at different $\mathrm{H}_{2}-1 / \mathrm{AlCl}_{3}$ flow rates. Etchant $2 \%$ nital, $\mathrm{x} 1000$. 


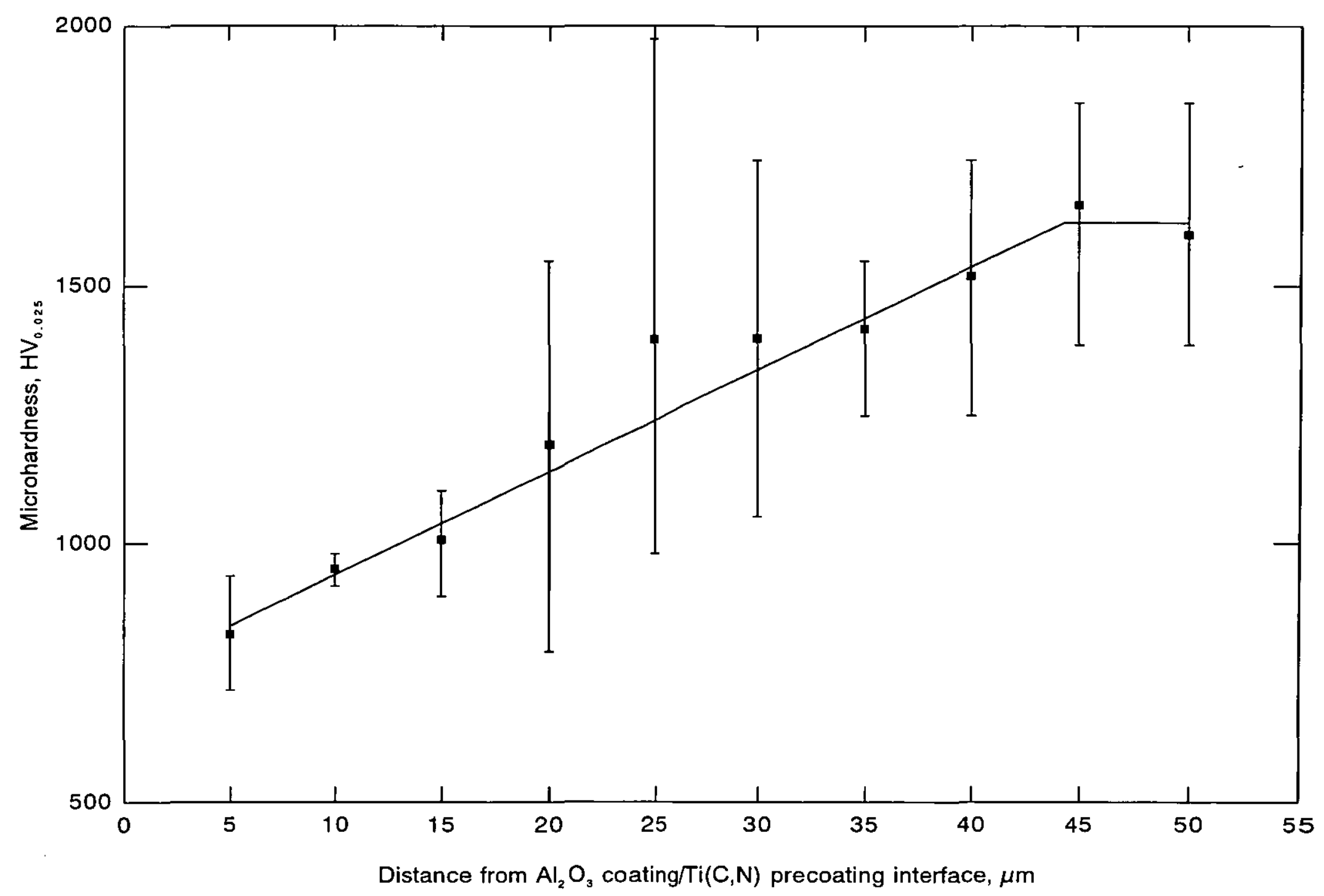

Fiqure 5.36 Measured variations in microhardness of $\mathrm{Al}_{2} \mathrm{O}_{3}$ coatings deposited at different $\mathrm{H}_{2}-1 / \mathrm{AlCl}_{3}$ flow rates with distance from $\mathrm{Al}_{2} \mathrm{O}_{3}$ coating/Ti(C,N) precoating interface on taper-sectioned inserts.

(a) $\mathrm{H}_{2}-1 / \mathrm{AlCl}_{3}$ flow rate $=10 \mathrm{~cm}^{3} \mathrm{~min}^{-1}$ 


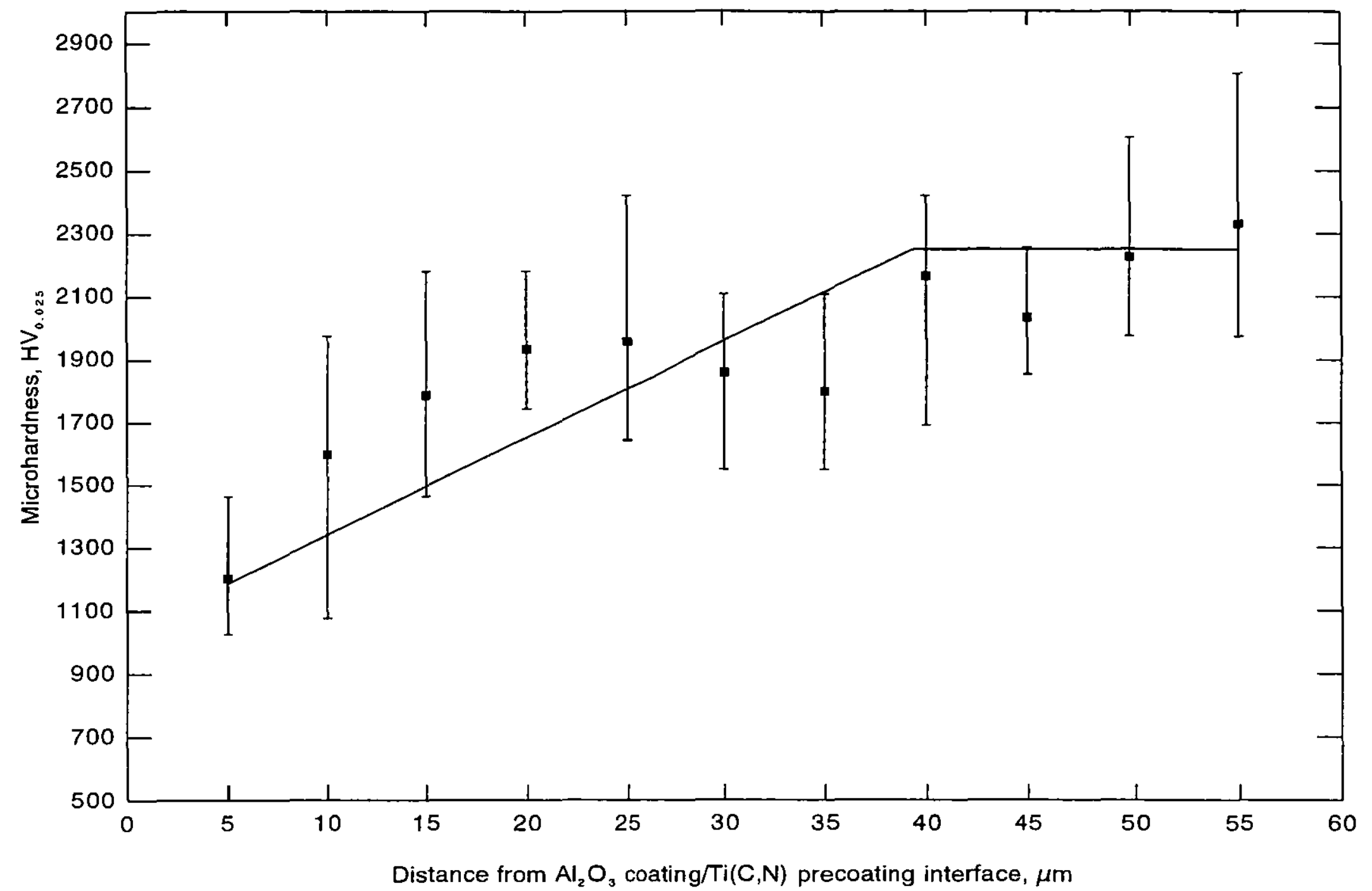

Figure 5.36 Measured variations in microhardness of $\mathrm{Al}_{2} \mathrm{O}_{3}$ coatings deposited at different $\mathrm{H}_{2}-1 / \mathrm{AlCl}_{3}$ flow rates with distance from $\mathrm{Al}_{2} \mathrm{O}_{3}$ coating/Ti(C,N) precoating interface on taper-sectioned inserts.

(b) $\mathrm{H}_{2}-1 / \mathrm{AlCl}_{3}$ flow rate $=15 \mathrm{~cm}^{3} \mathrm{~min}^{-1}$ 


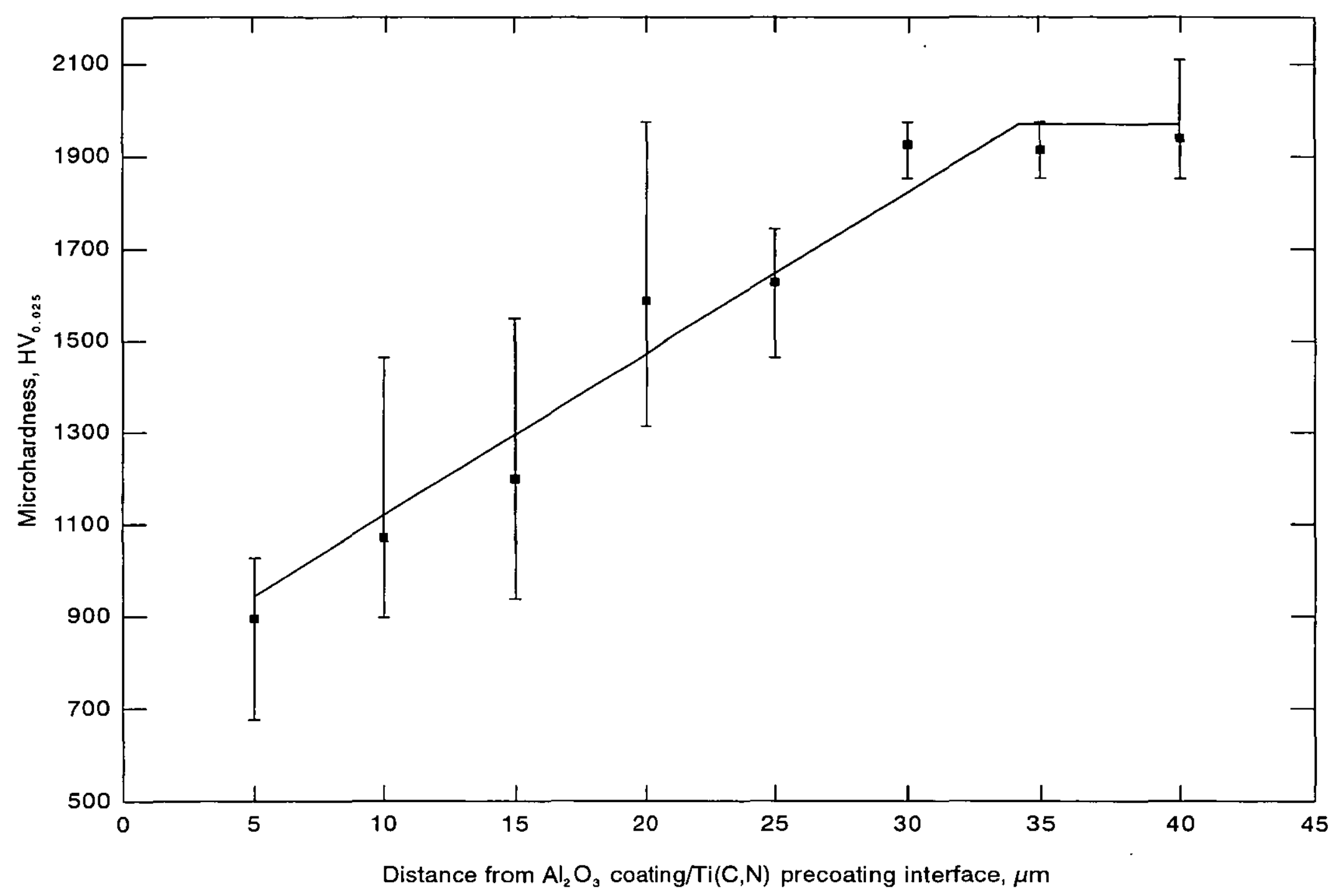

Figure 5.36 Measured variations in microhardness of $\mathrm{Al}_{2} \mathrm{O}_{3}$ coatings deposited at different $\mathrm{H}_{2}-1 / \mathrm{AlCl}_{3}$ flow rates with distance from $\mathrm{Al}_{2} \mathrm{O}_{3}$ coating $/ \mathrm{Ti}(\mathrm{C}, \mathrm{N})$ precoating interface on taper-sectioned inserts.

(c) $\mathrm{H}_{2}-1 / \mathrm{AlCl}_{3}$ flow rate $=20 \mathrm{~cm}^{3} \mathrm{~min}^{-1}$ 


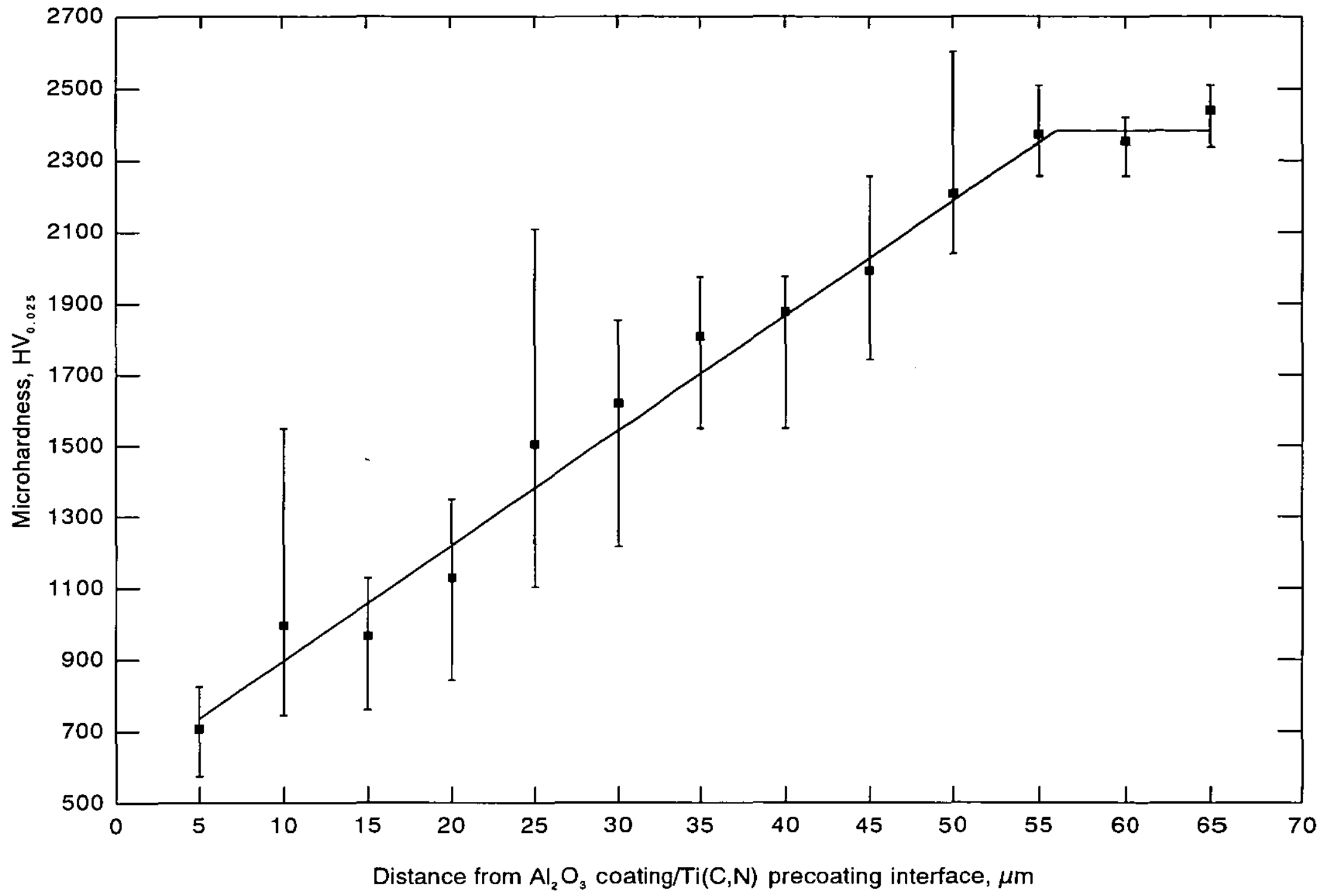

Figure 5.36 Measured variations in microhardness of $\mathrm{Al}_{2} \mathrm{O}_{3}$ coatings deposited at different $\mathrm{H}_{2}-1 / \mathrm{AlCl}_{3}$ flow rates with distance from $\mathrm{Al}_{2} \mathrm{O}_{3}$ coating/Ti(C,N) precoating interface on taper-sectioned inserts.

(d) $\mathrm{H}_{2}-1 / \mathrm{AlCl}_{3}$ flow rate $=25 \mathrm{~cm}^{3} \mathrm{~min}^{-1}$ 


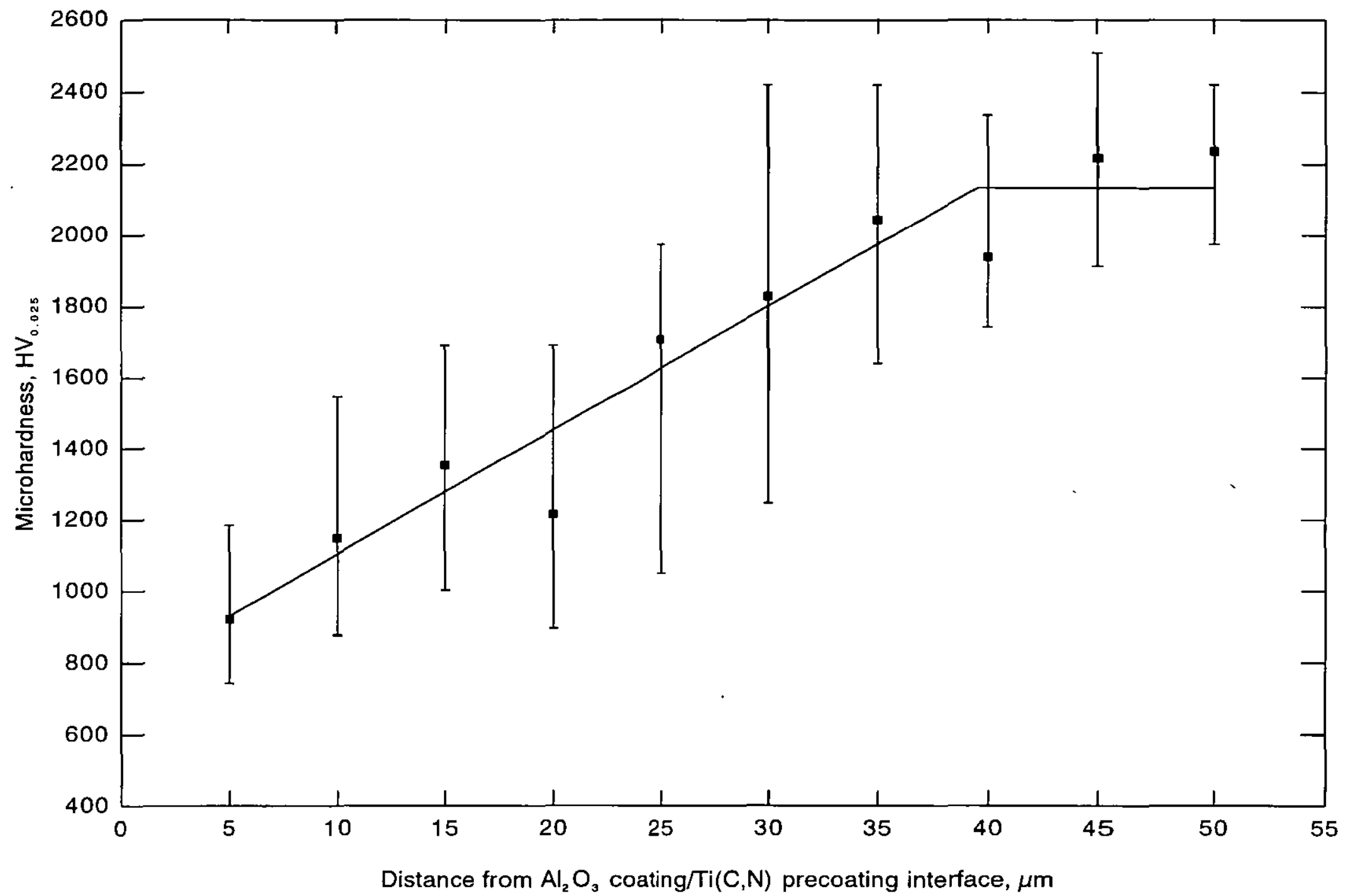

Figure 5.36 Measured variations in microhardness of $\mathrm{Al}_{2} \mathrm{O}_{3}$ coatings deposited at different $\mathrm{H}_{2}-1 / \mathrm{AlCl}_{3}$ flow rates with distance from $\mathrm{Al}_{2} \mathrm{O}_{3}$ coating/Ti( $\left.\mathrm{C}, \mathrm{N}\right)$ precoating interface on taper-sectioned inserts.

(e) $\mathrm{H}_{2}-1 / \mathrm{AlCl}_{3}$ flow rate $=30 \mathrm{~cm}^{3} \mathrm{~min}^{-1}$ 


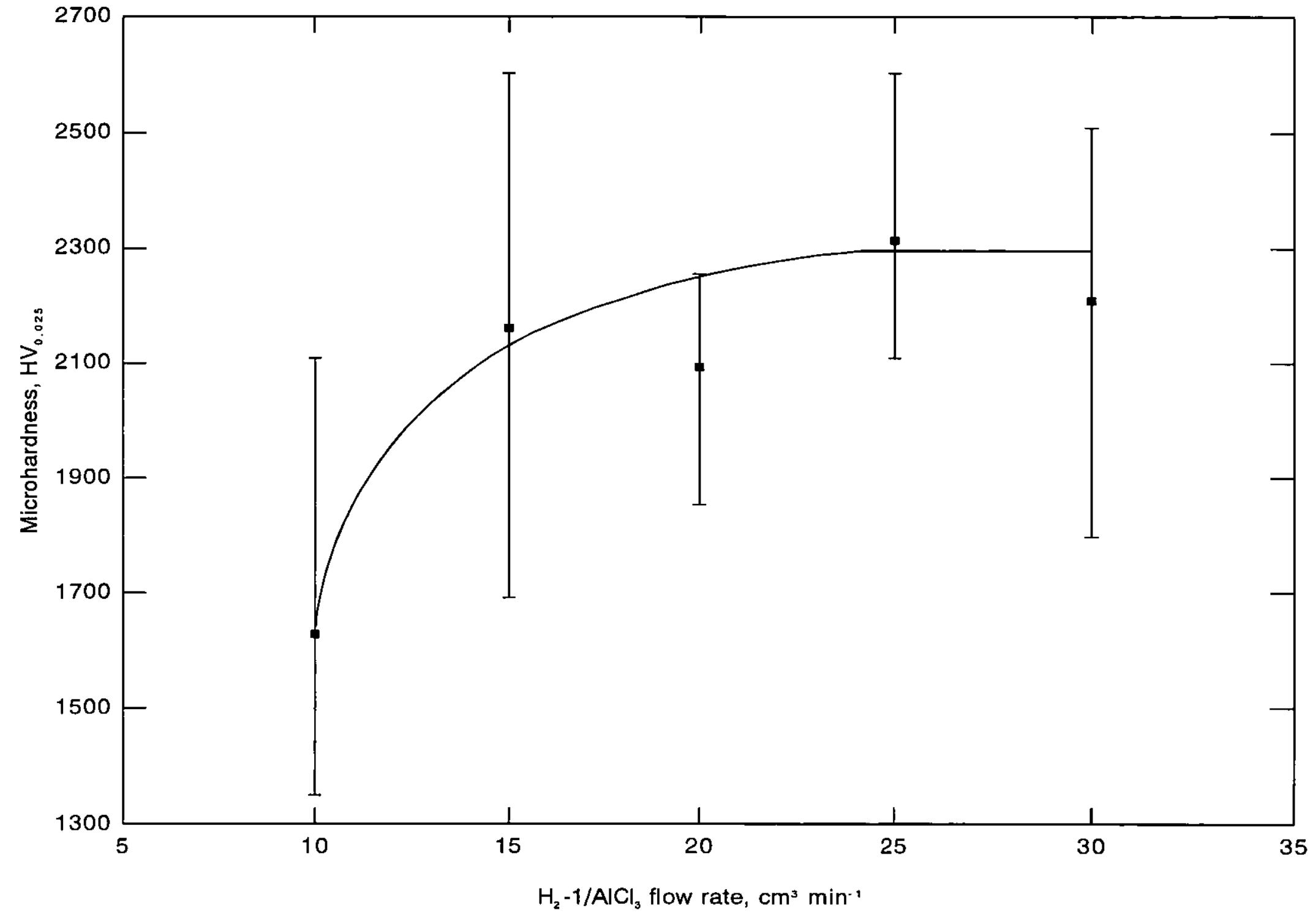

Figure 5.37 Effect of $\mathrm{H}_{2}-1 / \mathrm{AlCl}_{3}$ flow rate on $\mathrm{Al}_{2} \mathrm{O}_{3}$ coating microhardness. 


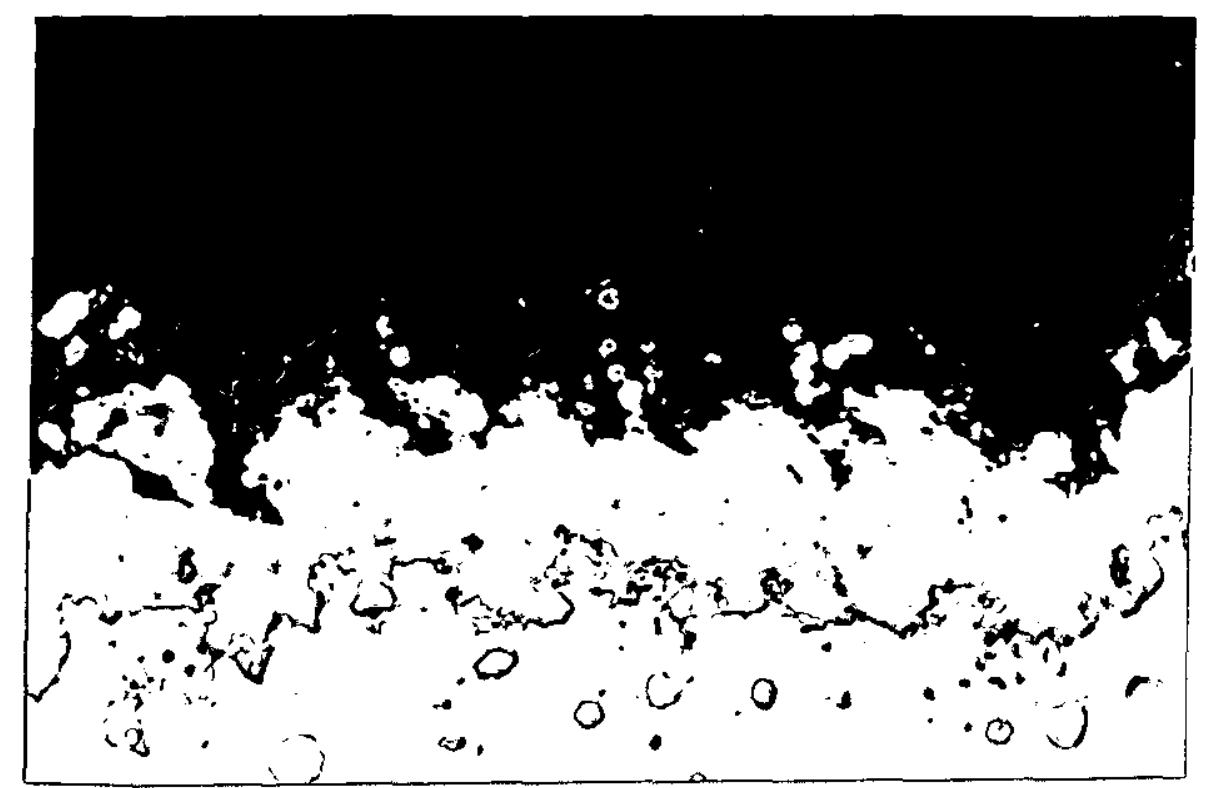

(a) $\mathrm{H}_{2}-1 / \mathrm{AlCl}_{3}$ flow rate $=10 \mathrm{~cm}^{3} \mathrm{~min}^{-1}$

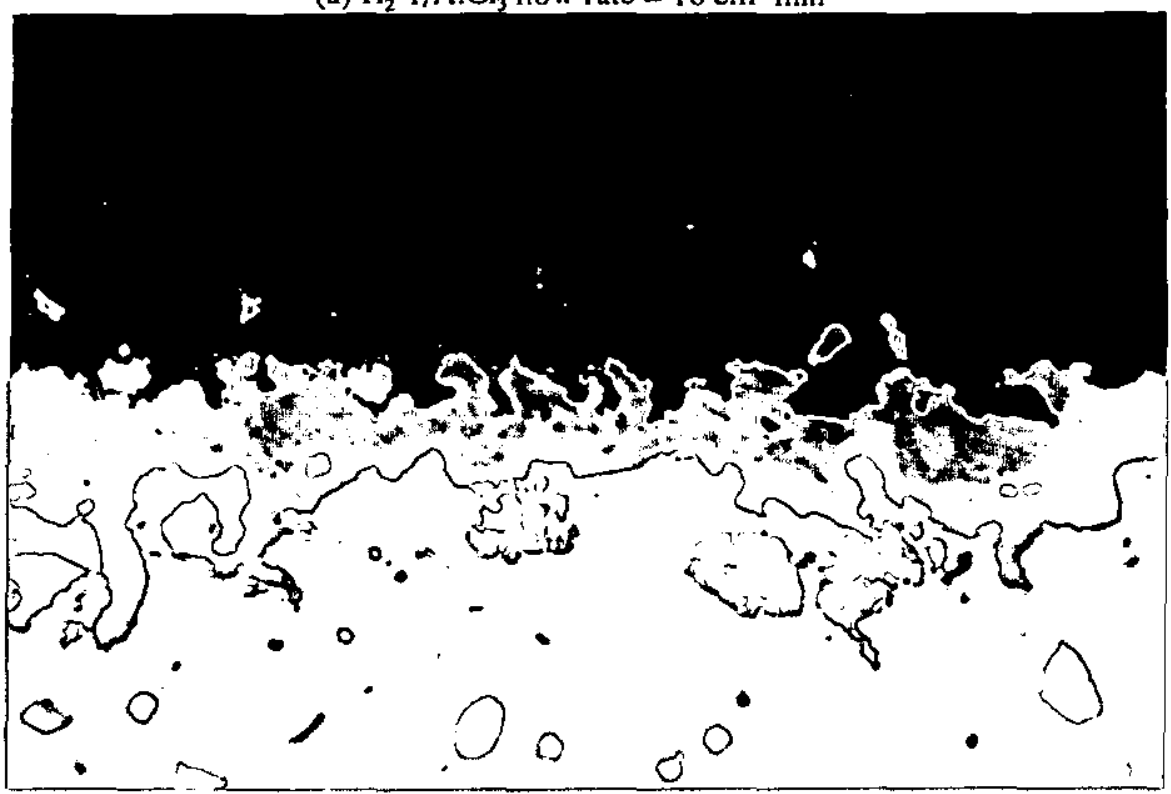

(b) $\mathrm{H}_{2}-1 / \mathrm{AlCl}_{3}$ flow rate $=15 \mathrm{~cm}^{3} \mathrm{~min}^{-1}$

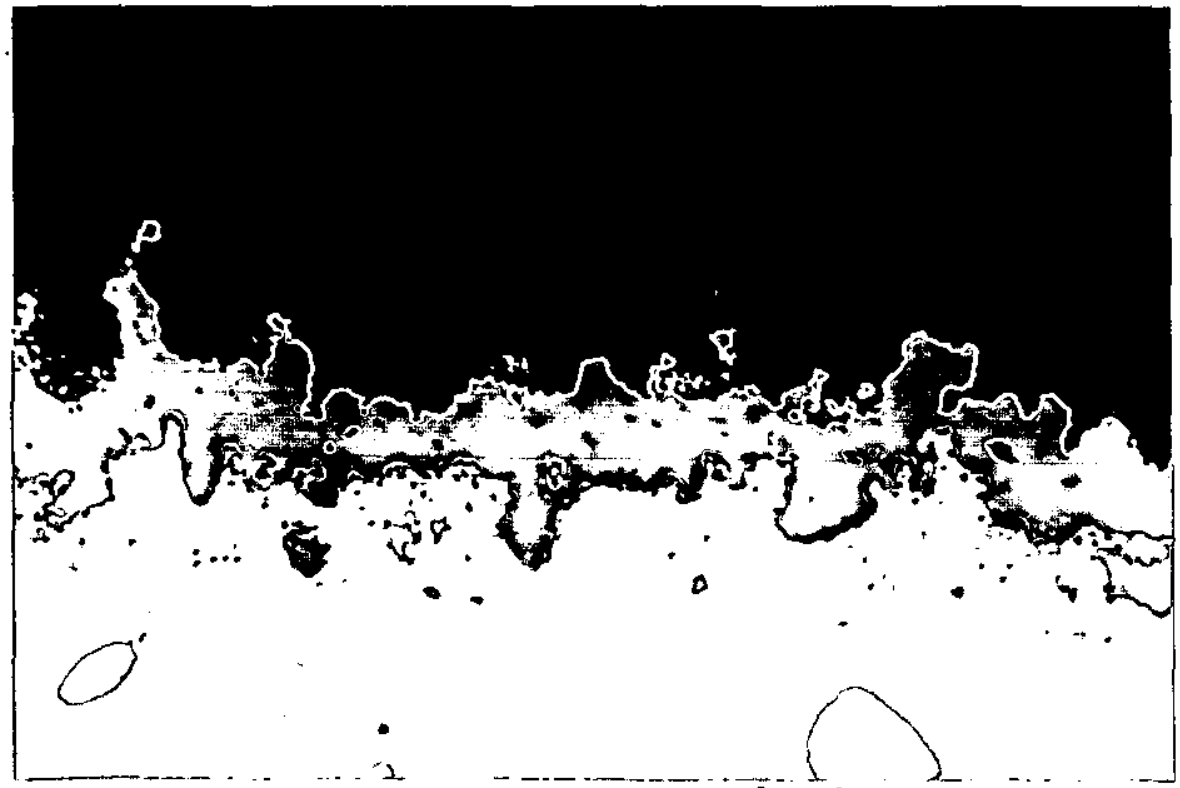

(c) $\mathrm{H}_{2}-1 / \mathrm{AlCl}_{3}$ flow rate $=20 \mathrm{~cm}^{3} \mathrm{~min}^{-1}$

Figure 5.38 Low-angle $\left(5.6^{\circ}\right)$ optical taper-sections through $\mathrm{Al}_{2} \mathrm{O}_{3}$ coating and $\mathrm{Al}_{2} \mathrm{O}_{3}$ coating $/ \mathrm{Ti}(\mathrm{C}, \mathrm{N})$ precoating interface for $\mathrm{Al}_{2} \mathrm{O}_{3}$ coated inserts from each of the $\mathrm{H}_{2}-1 / \mathrm{AlCl}_{3}$ flow rate coating runs. $\times 1000$. 


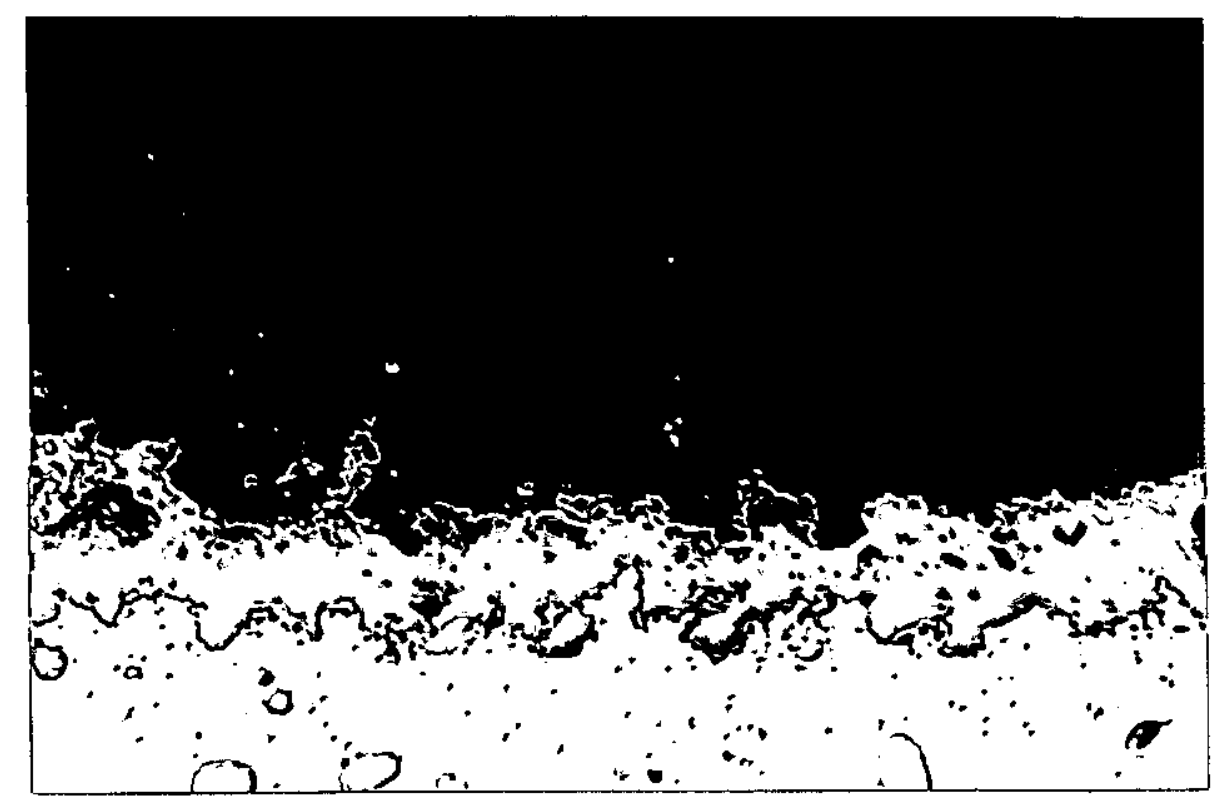

(d) $\mathrm{H}_{2}-1 / \mathrm{AlCl}_{3}$ flow rate $=25 \mathrm{~cm}^{3} \mathrm{~min}^{-1}$

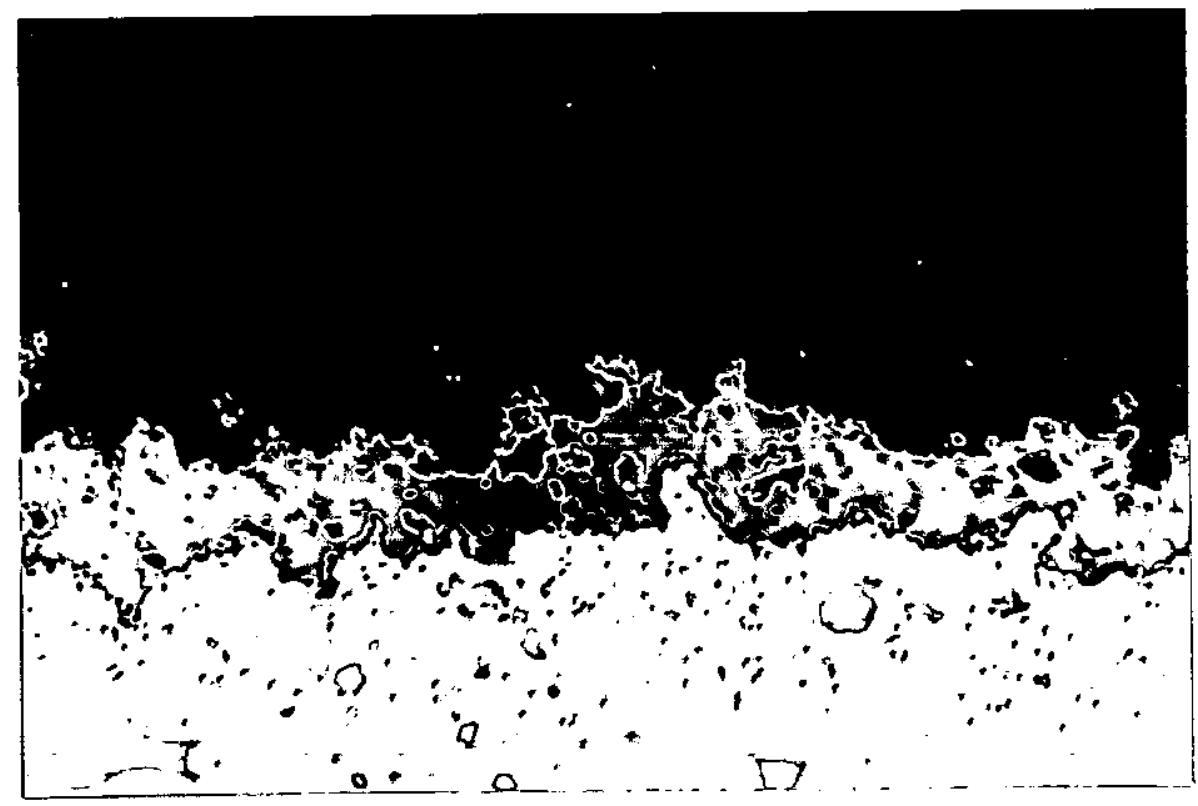

(e) $\mathrm{H}_{2}-1 / \mathrm{AlCl}_{3}$ flow rate $=30 \mathrm{~cm}^{3} \mathrm{~min}^{-1}$

Figure 5.38 Low-angle $\left(5.6^{\circ}\right)$ optical taper-sections through $\mathrm{Al}_{2} \mathrm{O}_{3}$ coating and $\mathrm{Al}_{2} \mathrm{O}_{3}$ coating $/ \mathrm{Ti}(\mathrm{C}, \mathrm{N})$ precoating interface for $\mathrm{Al}_{2} \mathrm{O}_{3}$ coated inserts from each of the $\mathrm{H}_{2}-1 / \mathrm{AlCl}_{3}$ flow rate coating runs. $x 1000$. 


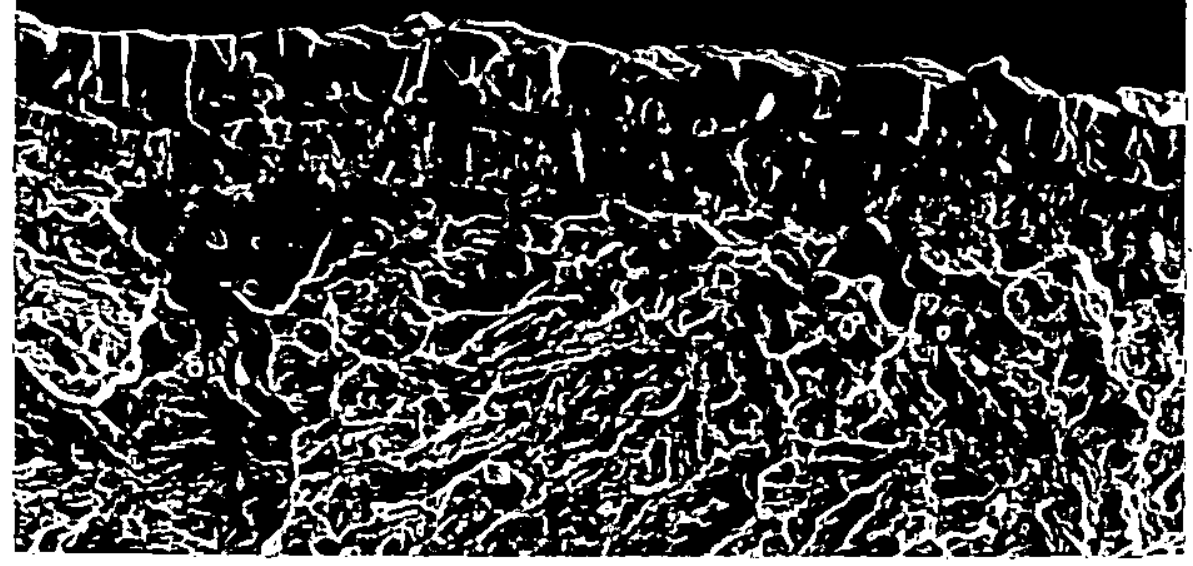

(a) $\mathrm{H}_{2}-1 / \mathrm{AlCl}_{3}$ flow rate $=10 \mathrm{~cm}^{3} \mathrm{~min}^{-1}$

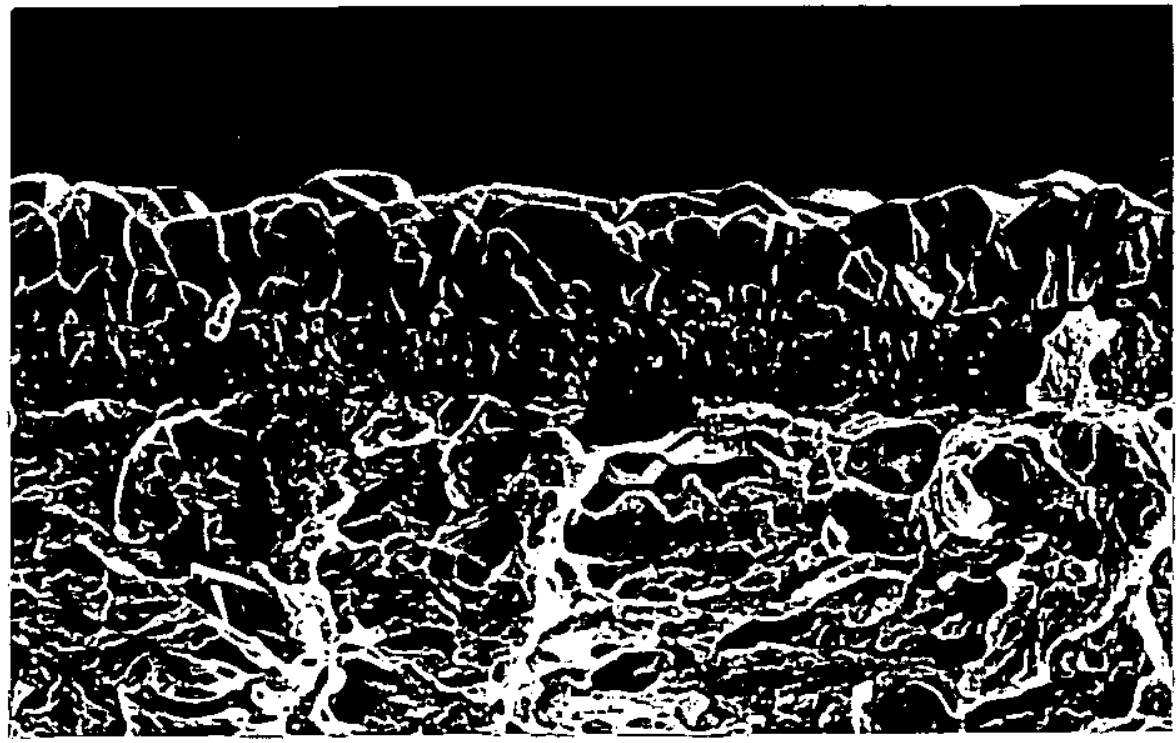

(b) $\mathrm{H}_{2}-1 / \mathrm{AlCl}_{3}$ flow rate $=15 \mathrm{~cm}^{3} \mathrm{~min}^{-1}$

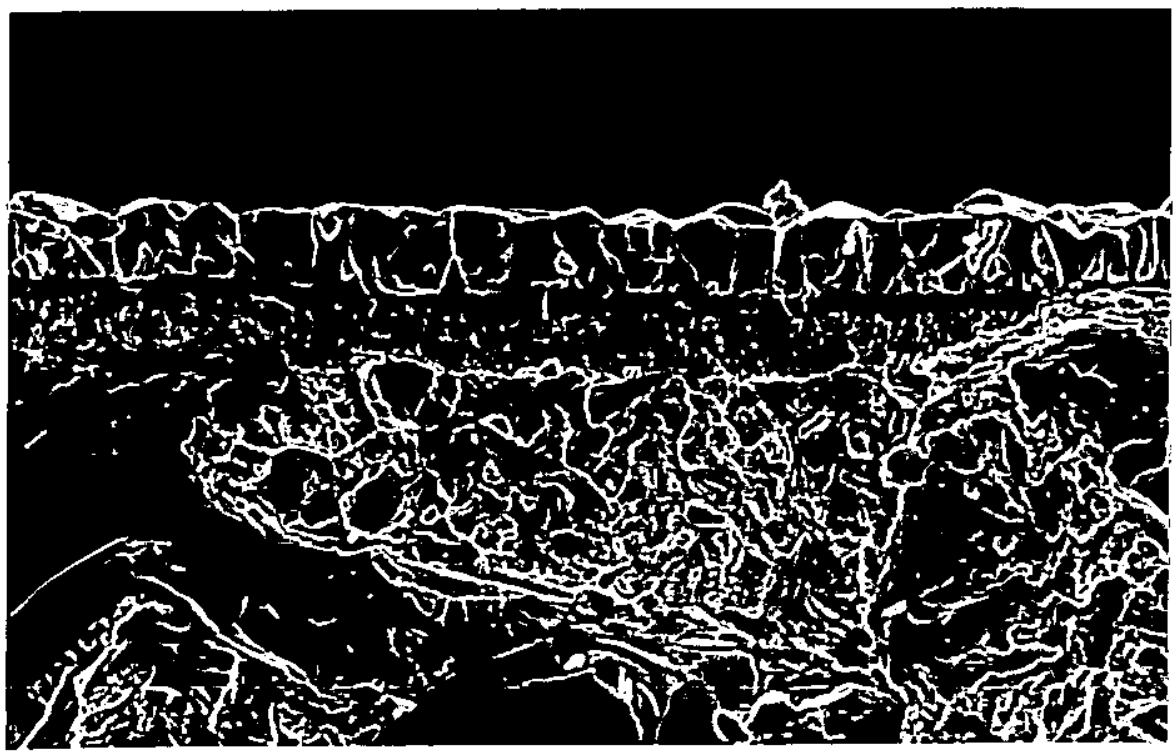

(c) $\mathrm{H}_{2}-1 / \mathrm{AlCl}_{3}$ flow rate $=20 \mathrm{~cm}^{3} \mathrm{~min}^{-1}$

Figure 5.39 Bulk grain structures of $\mathrm{Al}_{2} \mathrm{O}_{3}$ coatings deposited at different $\mathrm{H}_{2}-1 / \mathrm{AlCl}_{3}$ flow rates. $x 5000$. 


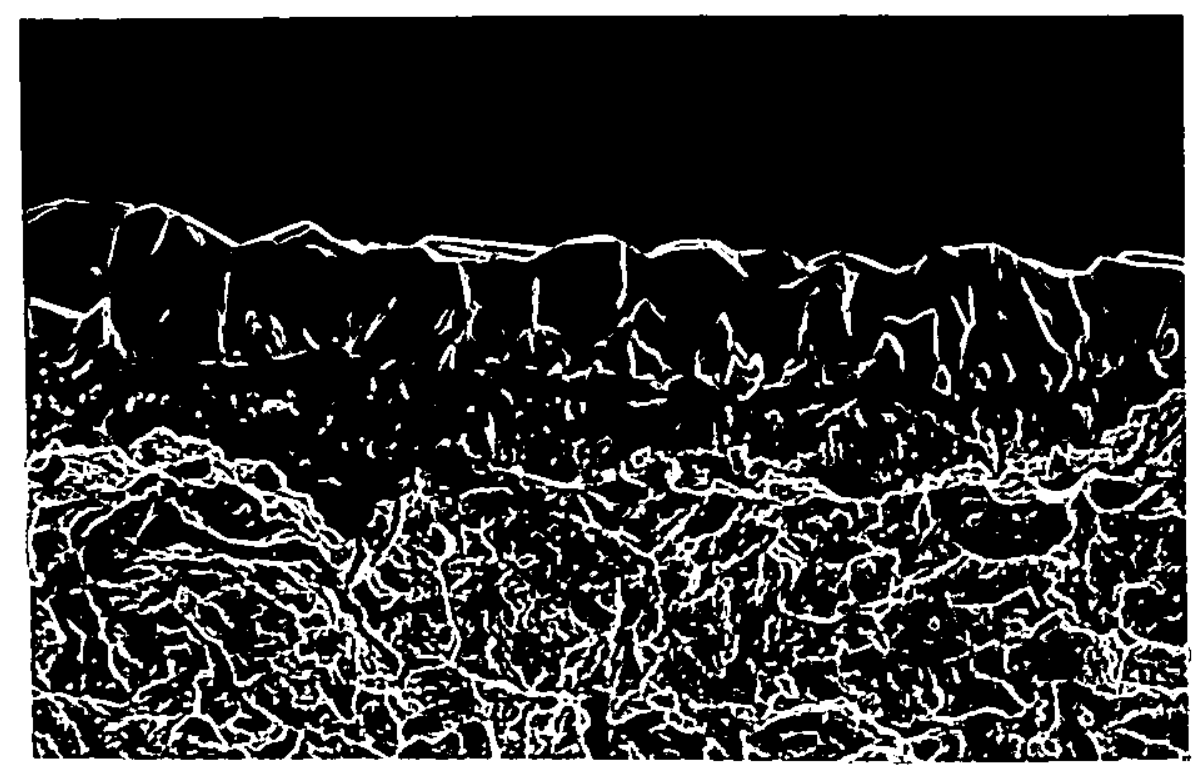

(d) $\mathrm{H}_{2}-1 / \mathrm{AlCl}_{3}$ flow rate $=25 \mathrm{~cm}^{3} \mathrm{~min}^{-1}$

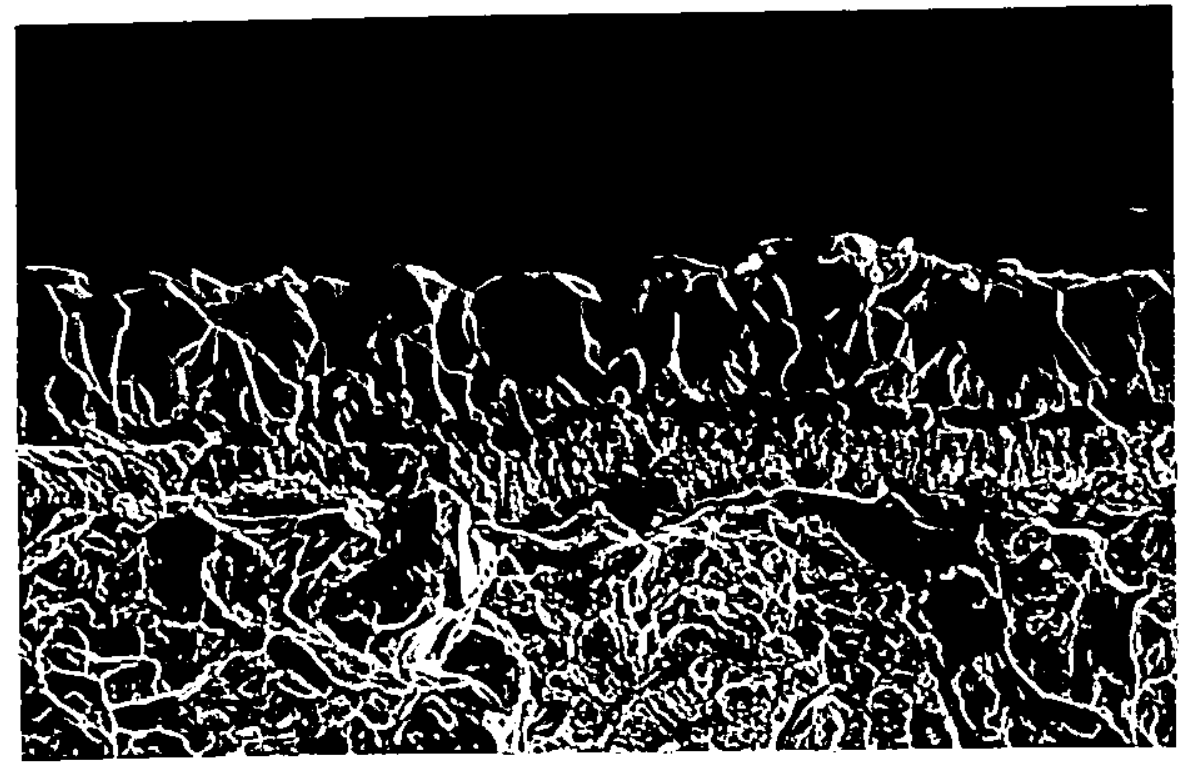

(e) $\mathrm{H}_{2}-1 / \mathrm{AlCl}_{3}$ flow rate $=30 \mathrm{~cm}^{3} \mathrm{~min}^{-1}$

Figure 5.39 Bulk grain structures of $\mathrm{Al}_{2} \mathrm{O}_{3}$ coatings deposited at different $\mathrm{H}_{2}-1 / \mathrm{AlCl}_{3}$ flow rates. $\times 5000$. 


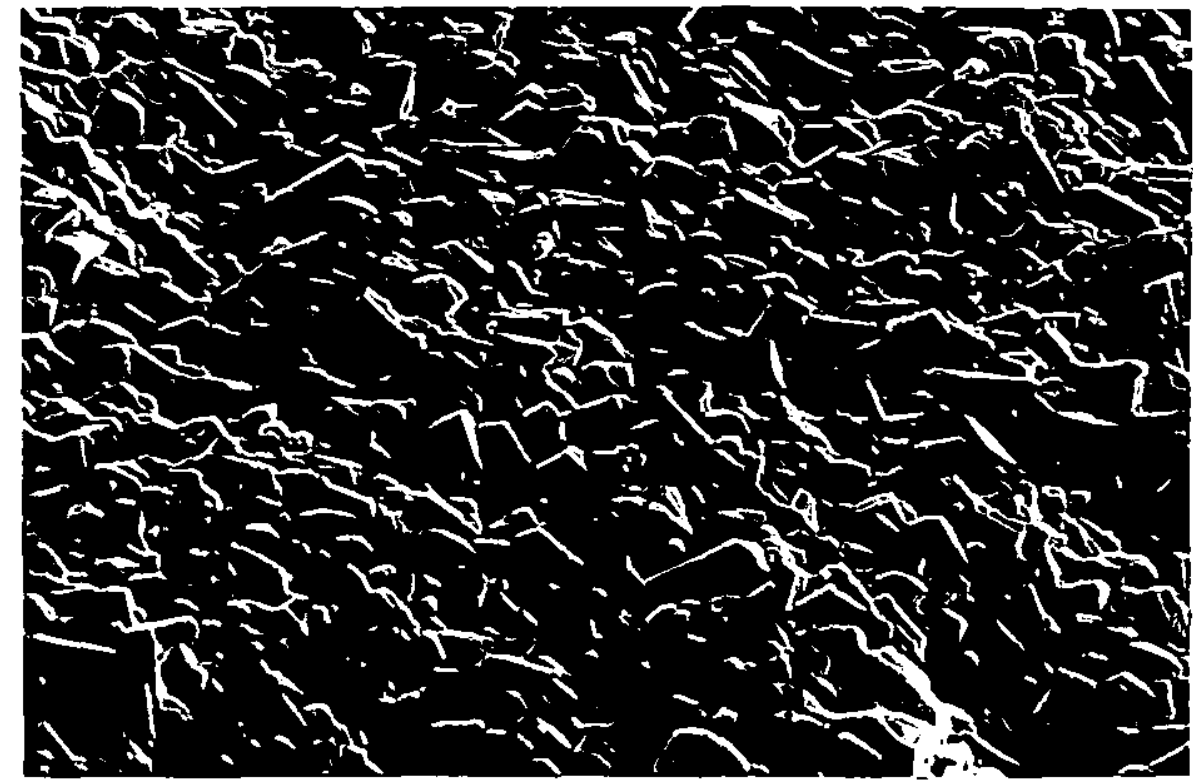

(a) $\mathrm{H}_{2}-1 / \mathrm{AlCl}_{3}$ flow rate $=10 \mathrm{~cm}^{3} \mathrm{~min}^{-1}$

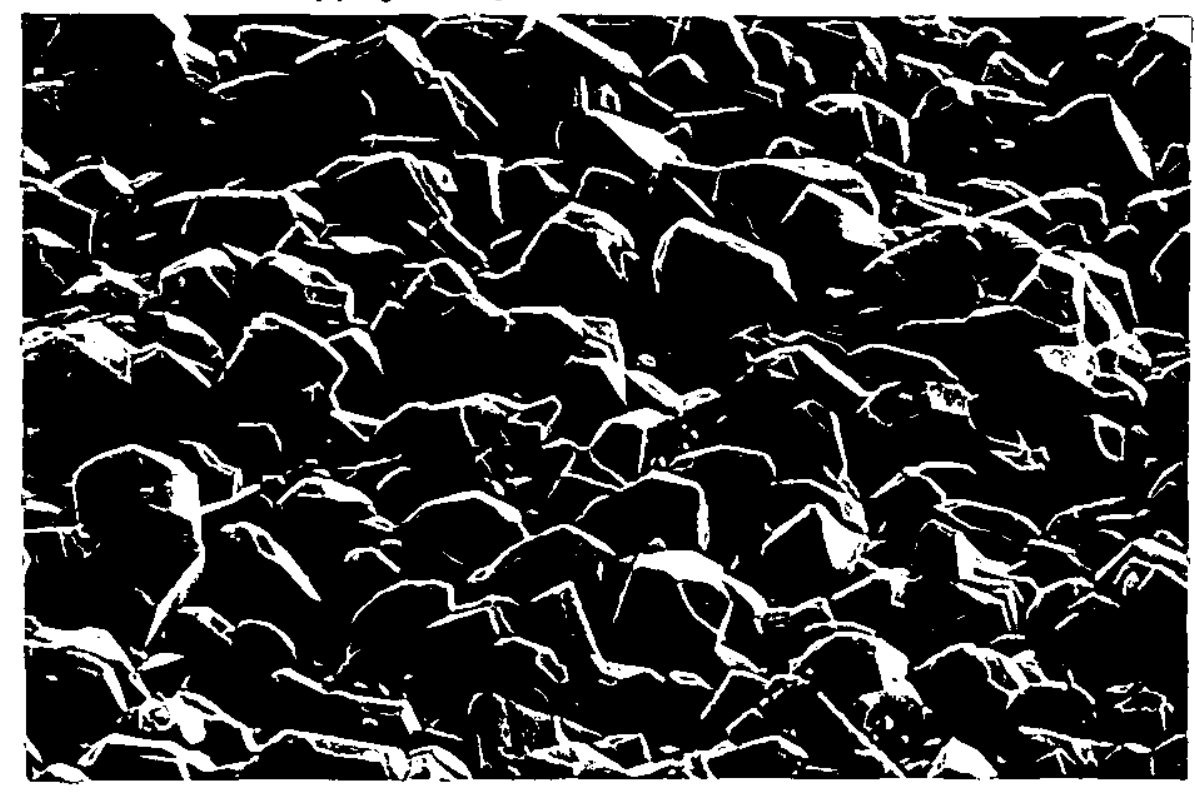

(b) $\mathrm{H}_{2}-1 / \mathrm{AlCl}_{3}$ flow rate $=15 \mathrm{~cm}^{3} \mathrm{~min}^{-1}$

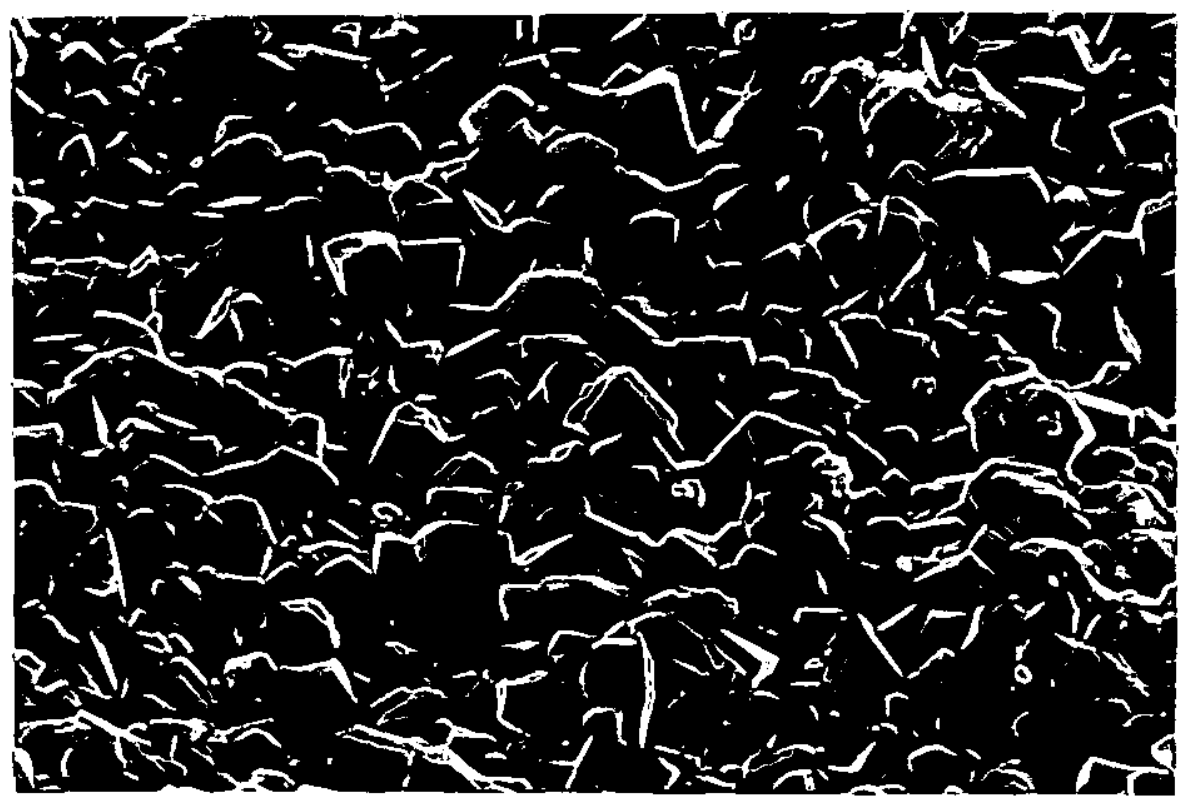

(c) $\mathrm{H}_{2}-1 / \mathrm{AlCl}_{3}$ flow rate $=20 \mathrm{~cm}^{3} \mathrm{~min}^{-1}$

Figure 5,40 Surface grain structures of $\mathrm{Al}_{2} \mathrm{O}_{3}$ coatings deposited at different $\mathrm{H}_{2}-1 / \mathrm{AlCl}_{3}$ flow rates. $\times 5000$. 


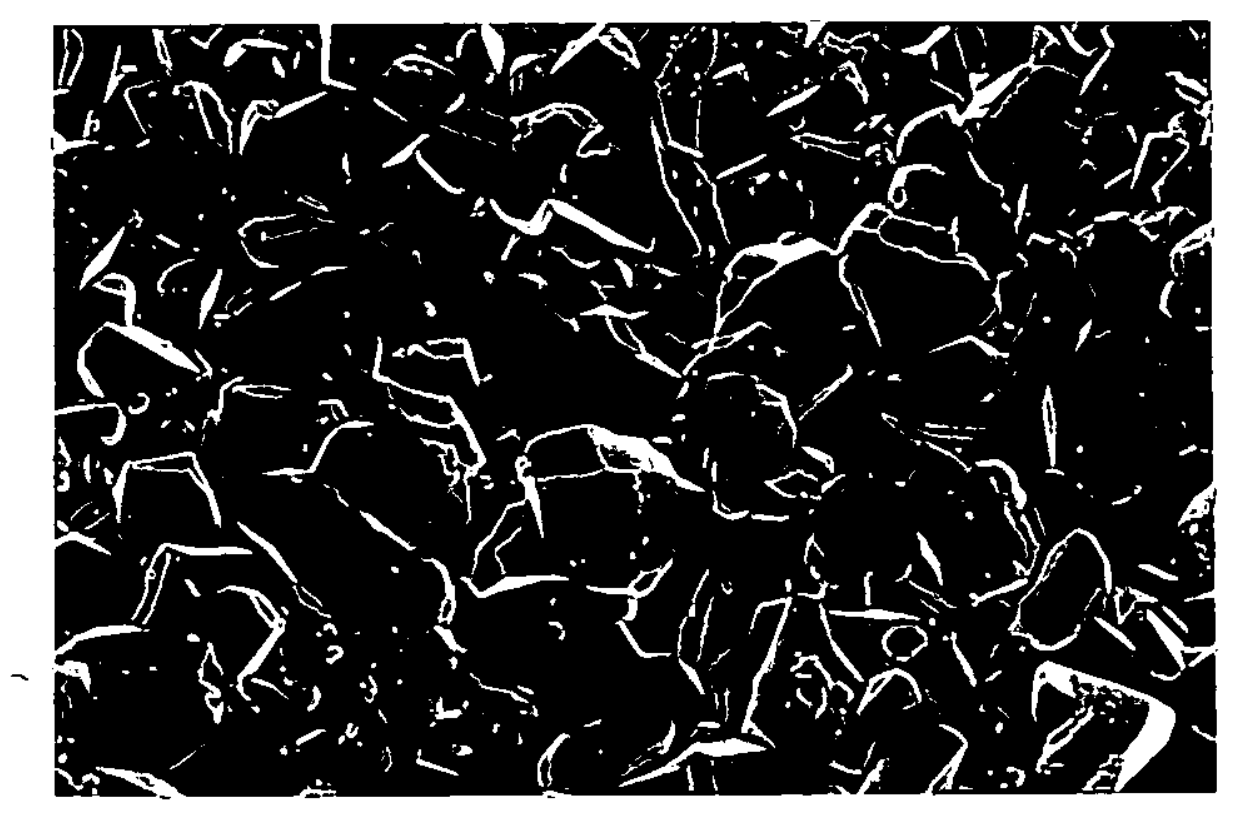

(d) $\mathrm{H}_{2}-1 / \mathrm{AlCl}_{3}$ flow rate $=25 \mathrm{~cm}^{3} \mathrm{~min}^{-1}$

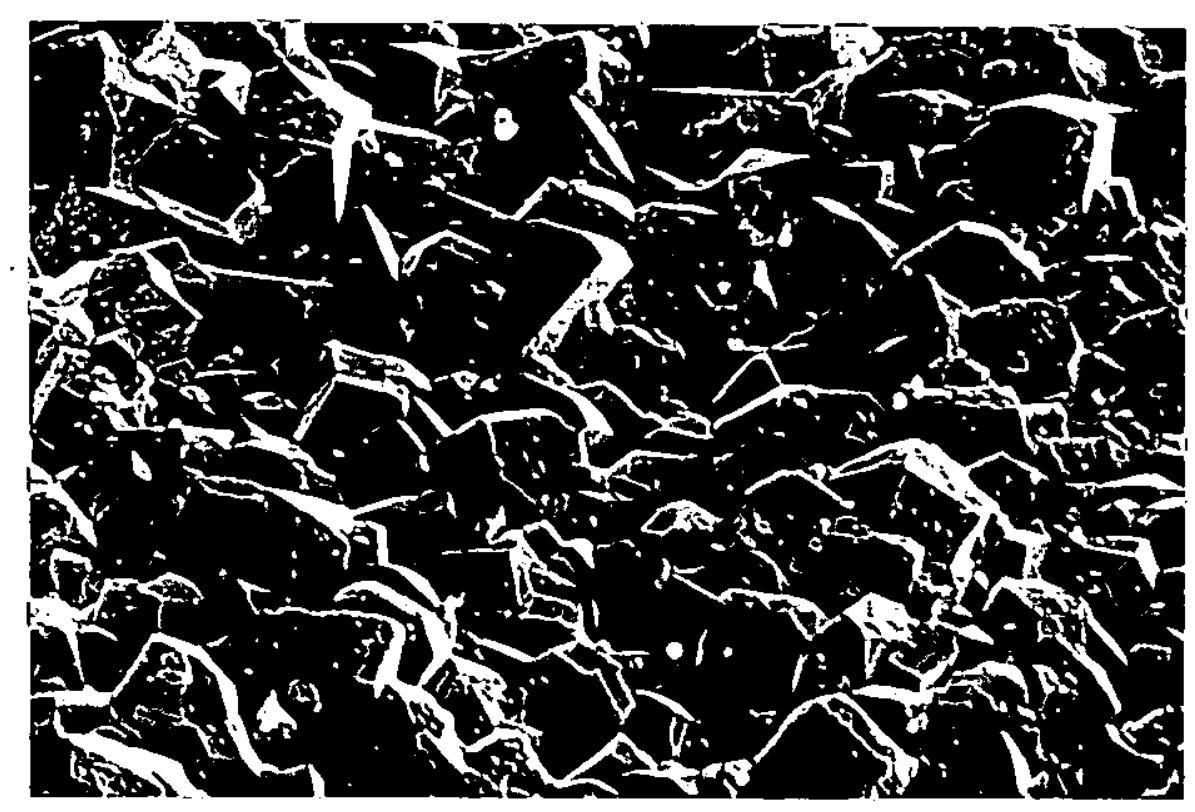

(e) $\mathrm{H}_{2}-1 / \mathrm{AlCl}_{3}$ flow rate $=30 \mathrm{~cm}^{3} \mathrm{~min}^{-1}$

Figure 5.40 Surface grain structures of $\mathrm{Al}_{2} \mathrm{O}_{3}$ coatings deposited at different $\mathrm{H}_{2}-1 / \mathrm{AlCl}_{3}$ flow rates. $\mathrm{x} 5000$. 
(b)

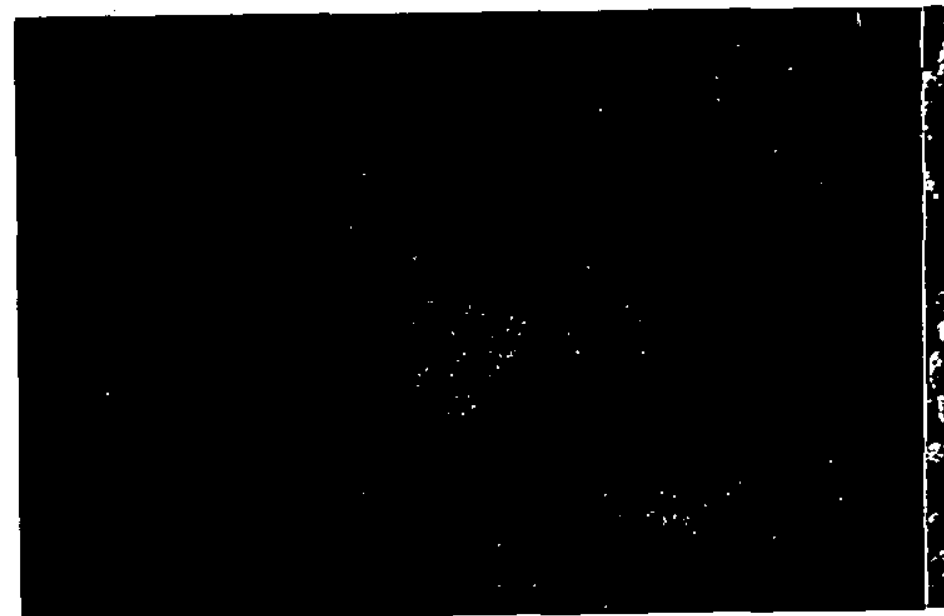

(c)

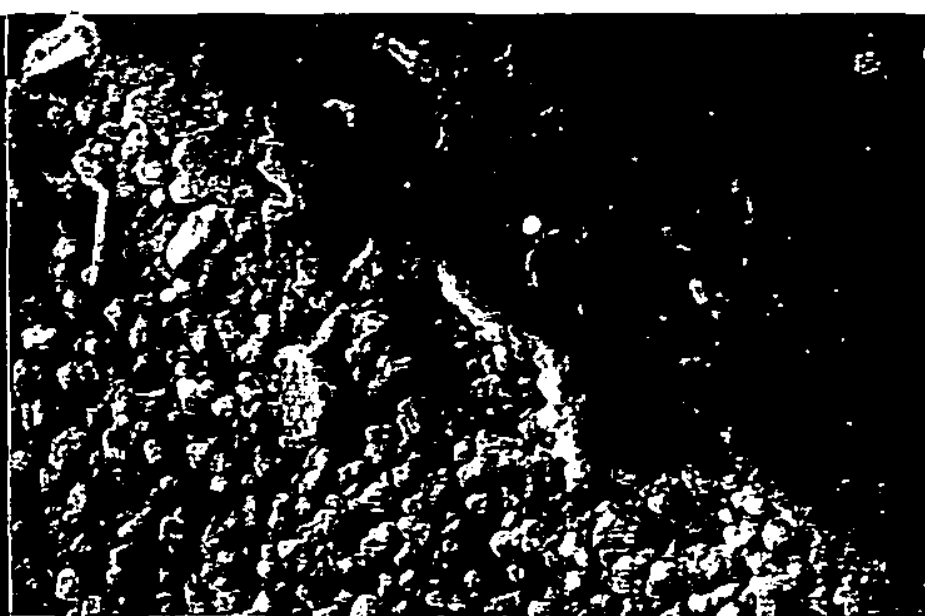

(a)

(d)

Eigure 5.41 (a) SEM micrograph of flaking at edge of scratch channel on $\mathrm{Al}_{2} \mathrm{O}_{3}$ coated insert from $\mathrm{H}_{2}-1 / \mathrm{AlCl}_{3}$ flow rate $=10 \mathrm{~cm}^{3} \mathrm{~min}^{-1}$ coating run. Stylus load $=4 \mathrm{~kg}$. x1200.

(b) Al $K_{\mathrm{a}}$ elemental scan of area shown in (a).

(c) Ti $K_{\alpha}$ elemental scan of area shown in (a).

(d) Fe $K_{\alpha}$ elemental scan of area shown in (a). 


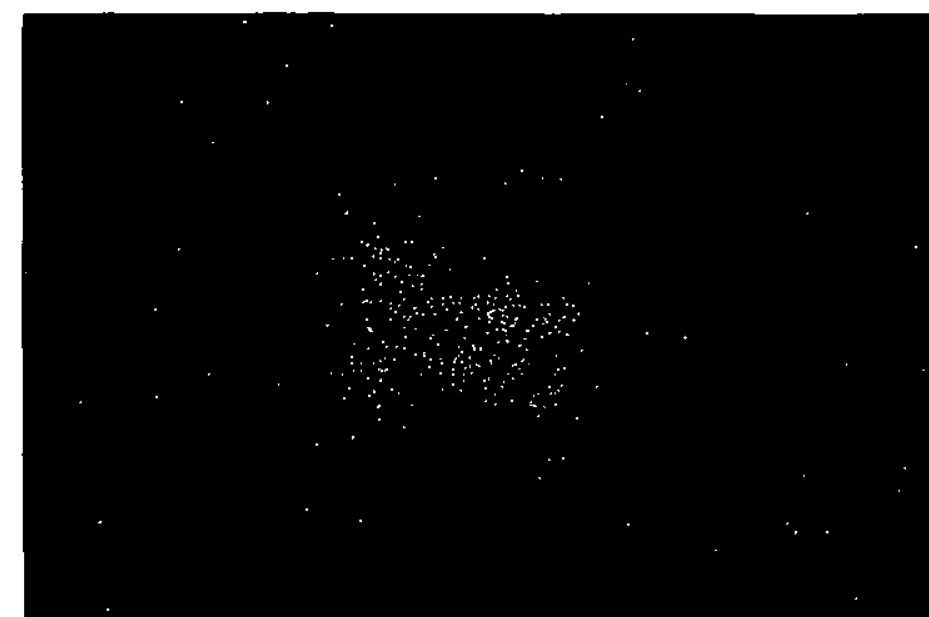

(c)
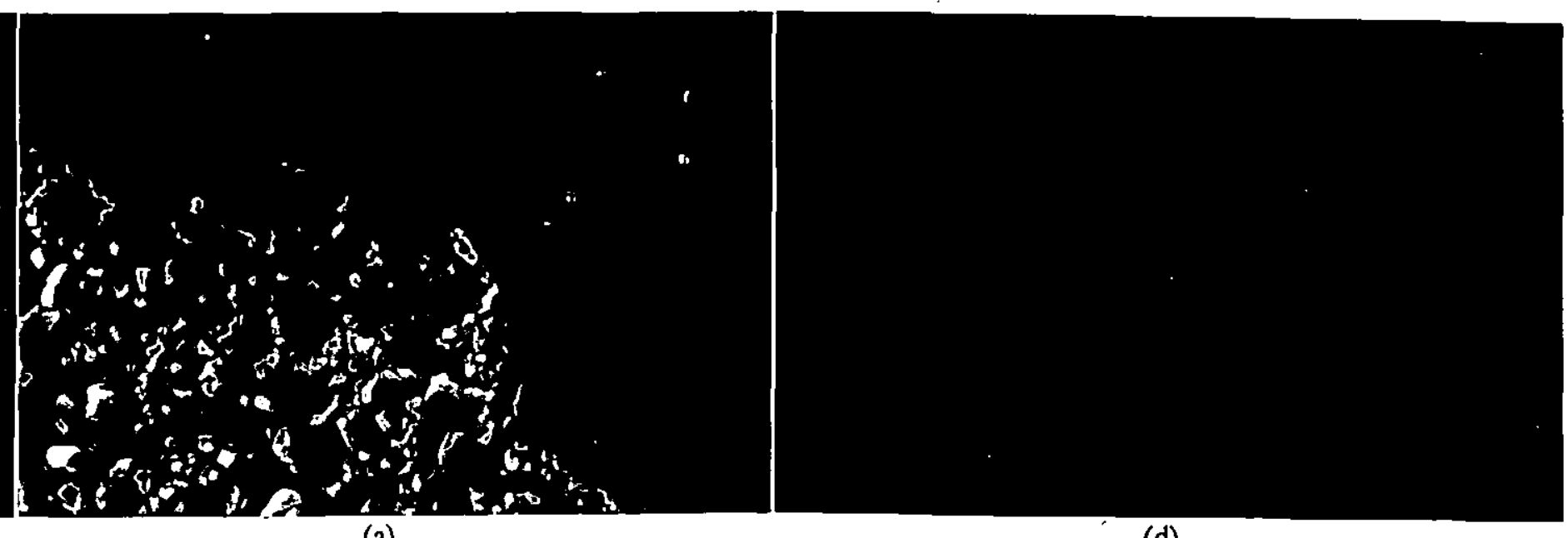

(d)

Figure 5.42 (a) SEM micrograph of flaking at edge of scratch channel on $\mathrm{Al}_{2} \mathrm{O}_{3}$ coated insert from $\mathrm{H}_{2}-1 / \mathrm{AlCl}_{3}$ flow rate $=15 \mathrm{~cm}^{3} \mathrm{~min}^{-1}$ coating run. Stylus load $=4 \mathrm{~kg} . x 1200$. (b) Al $K_{\alpha}$ elemental scan of area shown in (a).

(c) Ti $K_{\alpha}$ elemental scan of area shown in (a).

(d) Fe $K_{\mathrm{a}}$ elemental scan of area shown in (a). 
(b)

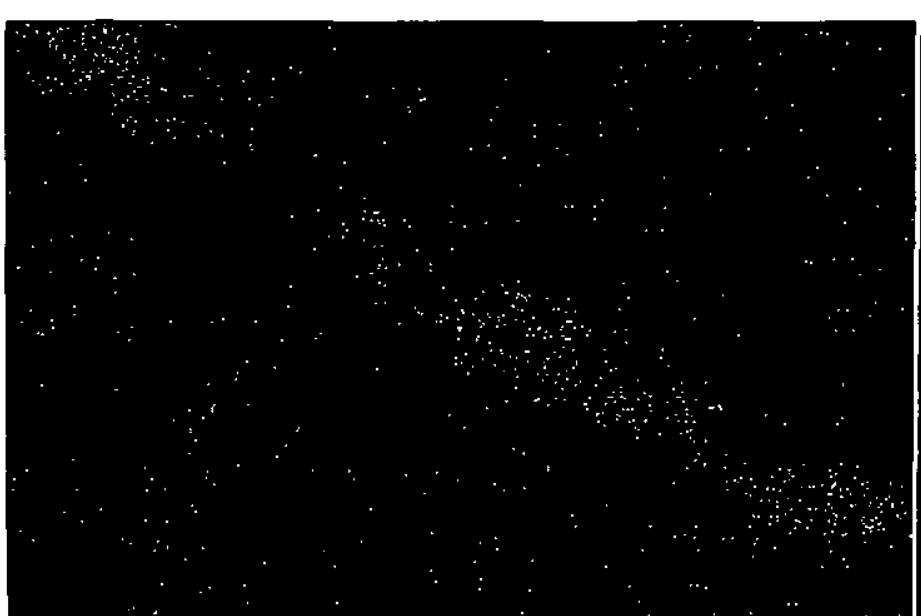

(c)

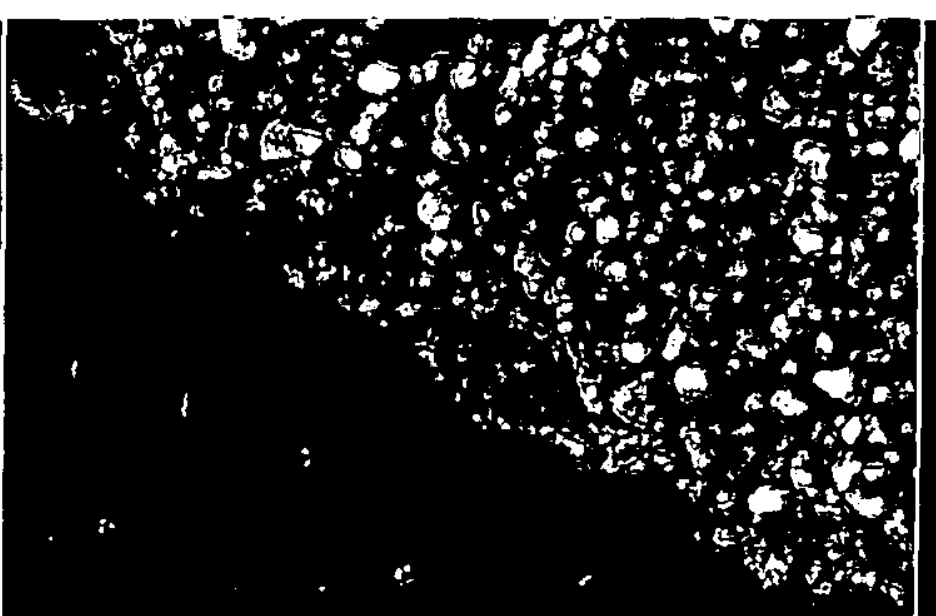

(a) (d)

Eigure 5,43 (a) SEM micrograph of flaking at edge of scratch channel on $\mathrm{Al}_{2} \mathrm{O}_{3}$ coated insert from $\mathrm{H}_{2}-1 / \mathrm{AlCl}_{3}$ flow rate $=20 \mathrm{~cm}^{3} \mathrm{~min}^{-1}$ coating run. Stylus load $=3 \mathrm{~kg}$. $x 1200$. (b) Al $K_{\alpha}$ elemental scan of area shown in (a).

(c) Ti $K_{\alpha}$ elemental scan of area shown in (a).

(d) Fe $K_{\mathrm{a}}$ elemental scan of area shown in (a). 
(b)

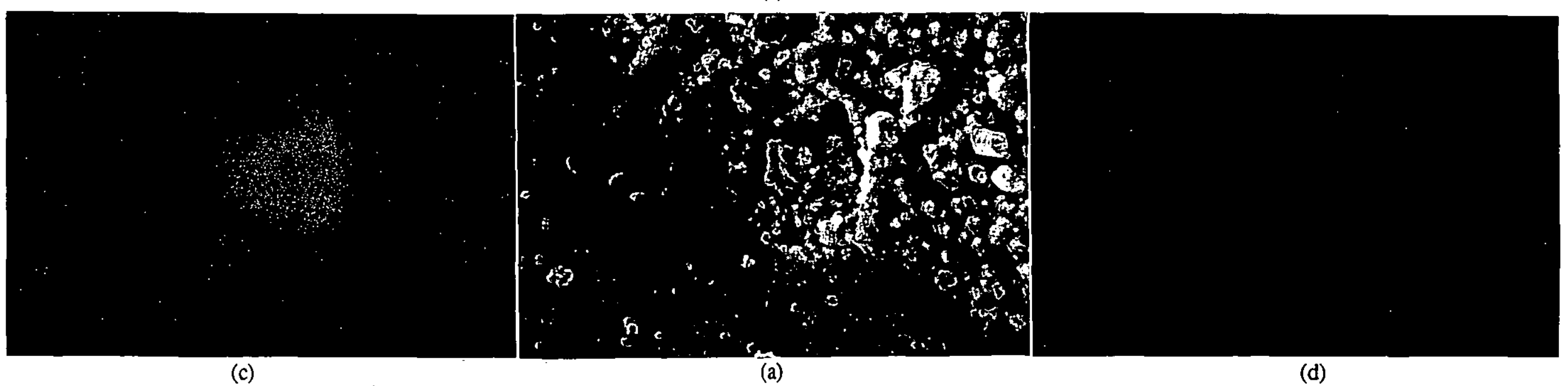

Figure 5.44 (a) SEM micrograph of flaking at edge of scratch channel on $\mathrm{Al}_{2} \mathrm{O}_{3}$ coated insert from $\mathrm{H}_{2^{-1}}-1 / \mathrm{AlCl}_{3}$ flow rate $=25 \mathrm{~cm}^{3} \mathrm{~min}^{-1}$ coating run. Stylus load $=4 \mathrm{~kg}$. $x 1200$. (b) Al $K_{\mathrm{a}}$ elemental scan of area shown in (a).

(c) Ti $K_{a}$ elemental scan of area shown in (a).

(d) Fe $K_{\mathrm{a}}$ elemental scan of area shown in (a). 


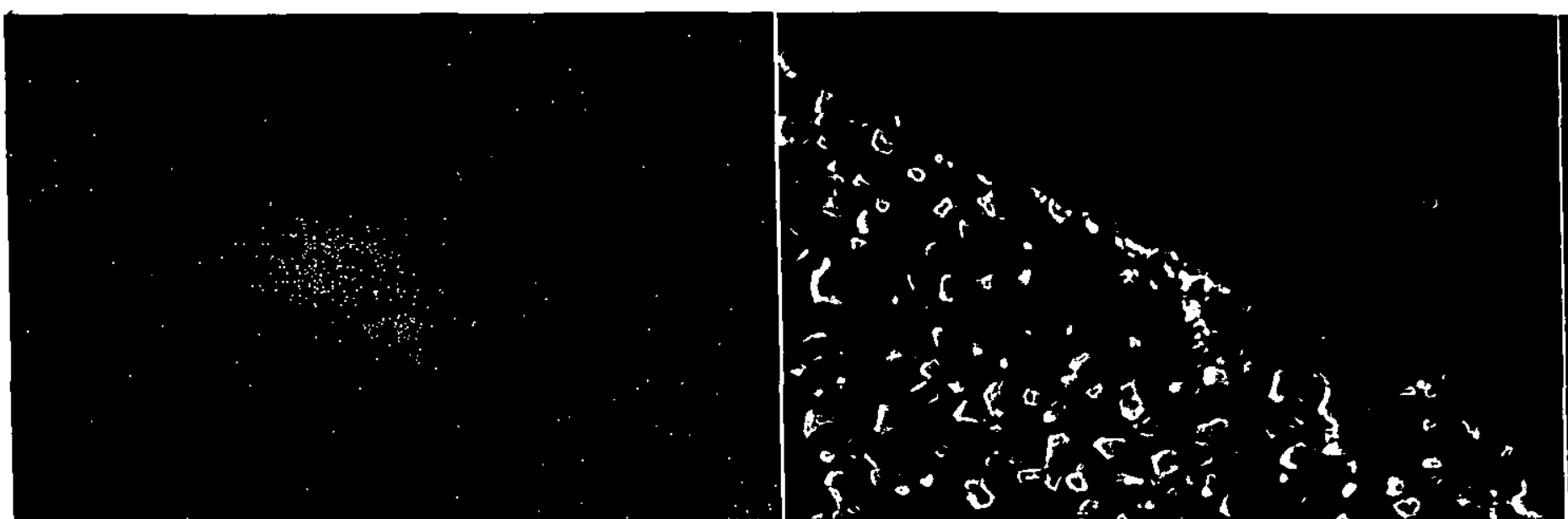

(c)

(a)

(d)

Eigure 5.45 (a) SEM micrograph of flaking at edge of scratch channel on $\mathrm{Al}_{2} \mathrm{O}_{3}$ coated insert from $\mathrm{H}_{2}-1 / \mathrm{AlCl}_{3}$ flow rate $=30 \mathrm{~cm}^{3} \mathrm{~min}^{-1}$ coating run. Stylus load $=4 \mathrm{~kg}$. $x 1200$. (b) Al $K_{\mathrm{a}}$ elemental scan of area shown in (a).

(c) Ti $K_{\alpha}$ elemental scan of area shown in (a).

(d) Fe $K_{a}$ elemental scan of area shown in (a). 


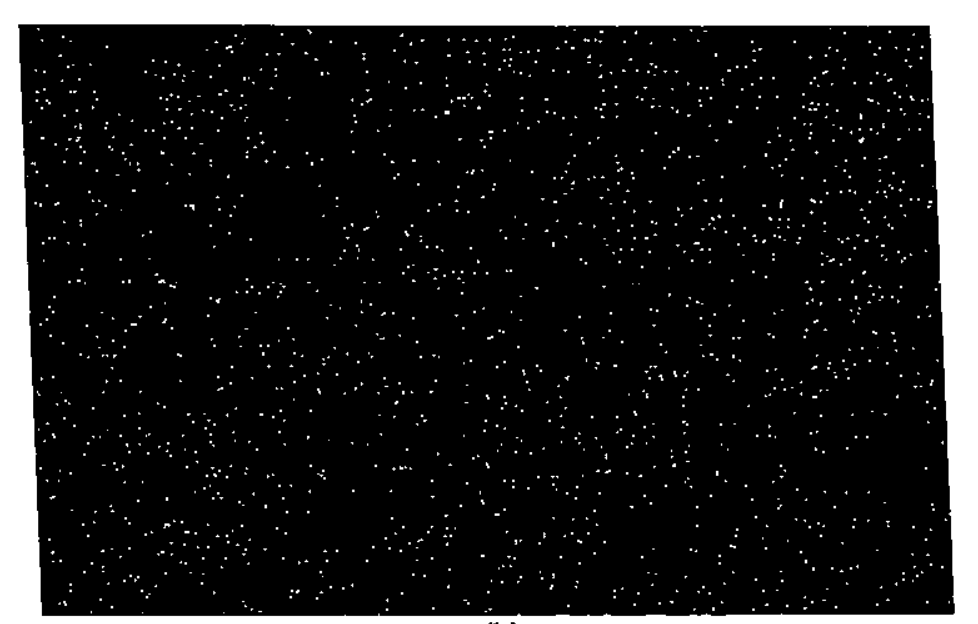

(b)

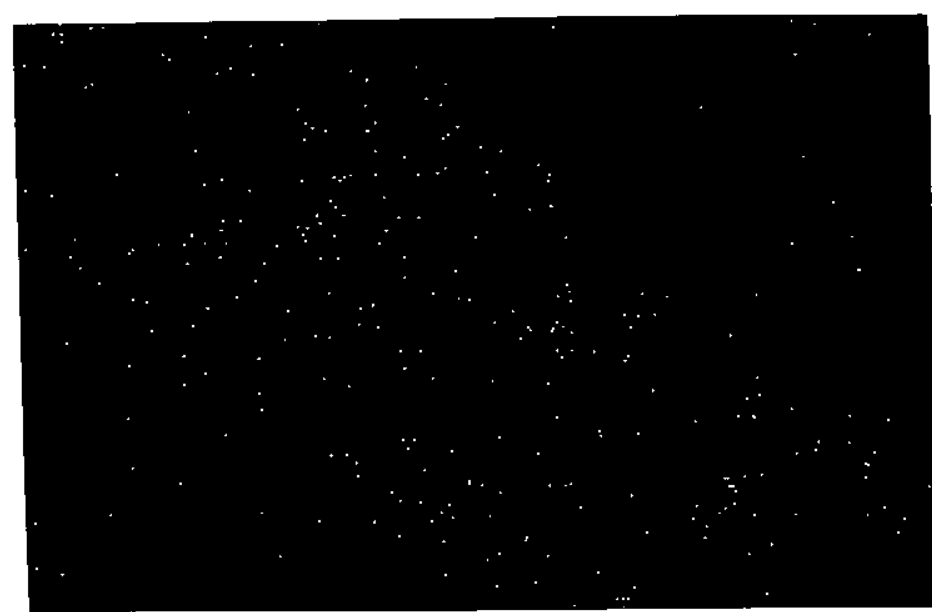

(c)

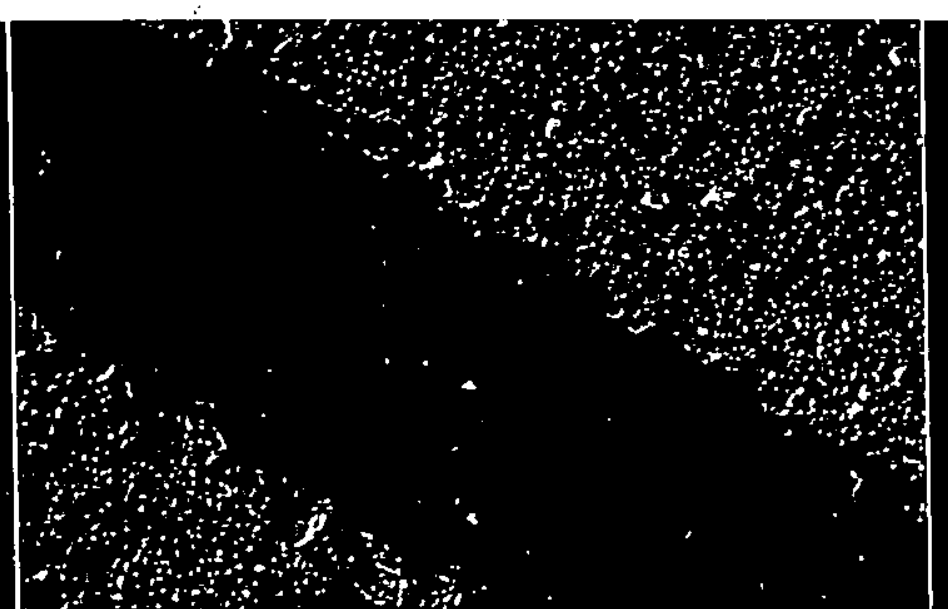

(a)

(d)

Figure 5.46 (a) SEM micrograph of scratch channel on $\mathrm{Al}_{2} \mathrm{O}_{3}$ coated insert from $\mathrm{H}_{2}-1 / \mathrm{AlCl}_{3}$ flow rate $=10 \mathrm{~cm}^{3} \mathrm{~min}^{-1}$ coating run. Stylus load $=7 \mathrm{~kg} . \times 300$.

(b) Al $K_{\alpha}$ elemental scan of area shown in (a).

(c) Ti $K_{\alpha}$ elemental scan of area shown in (a).

(d) Fe $K_{\alpha}$ elemental scan of area shown in (a). 
(b)

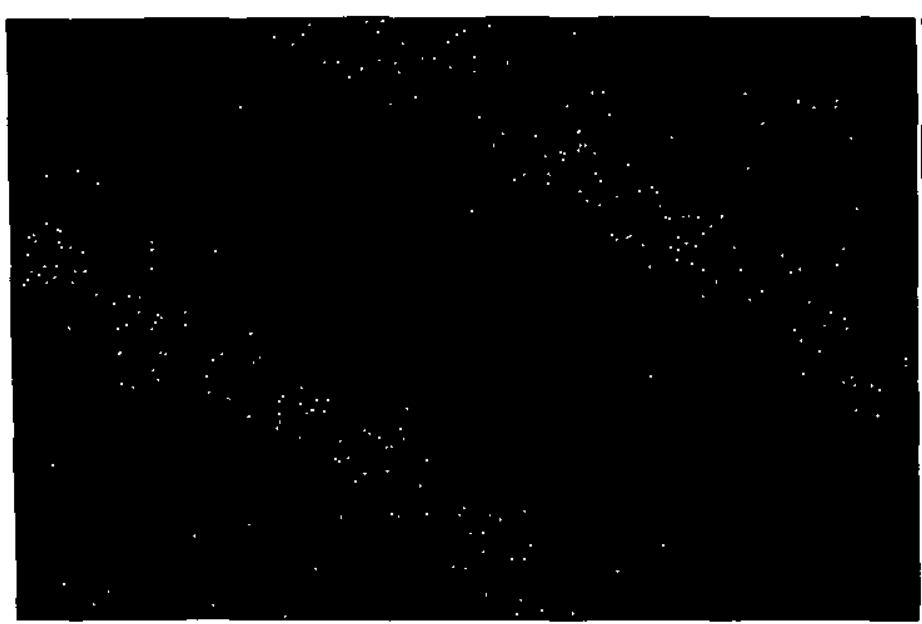

(c)
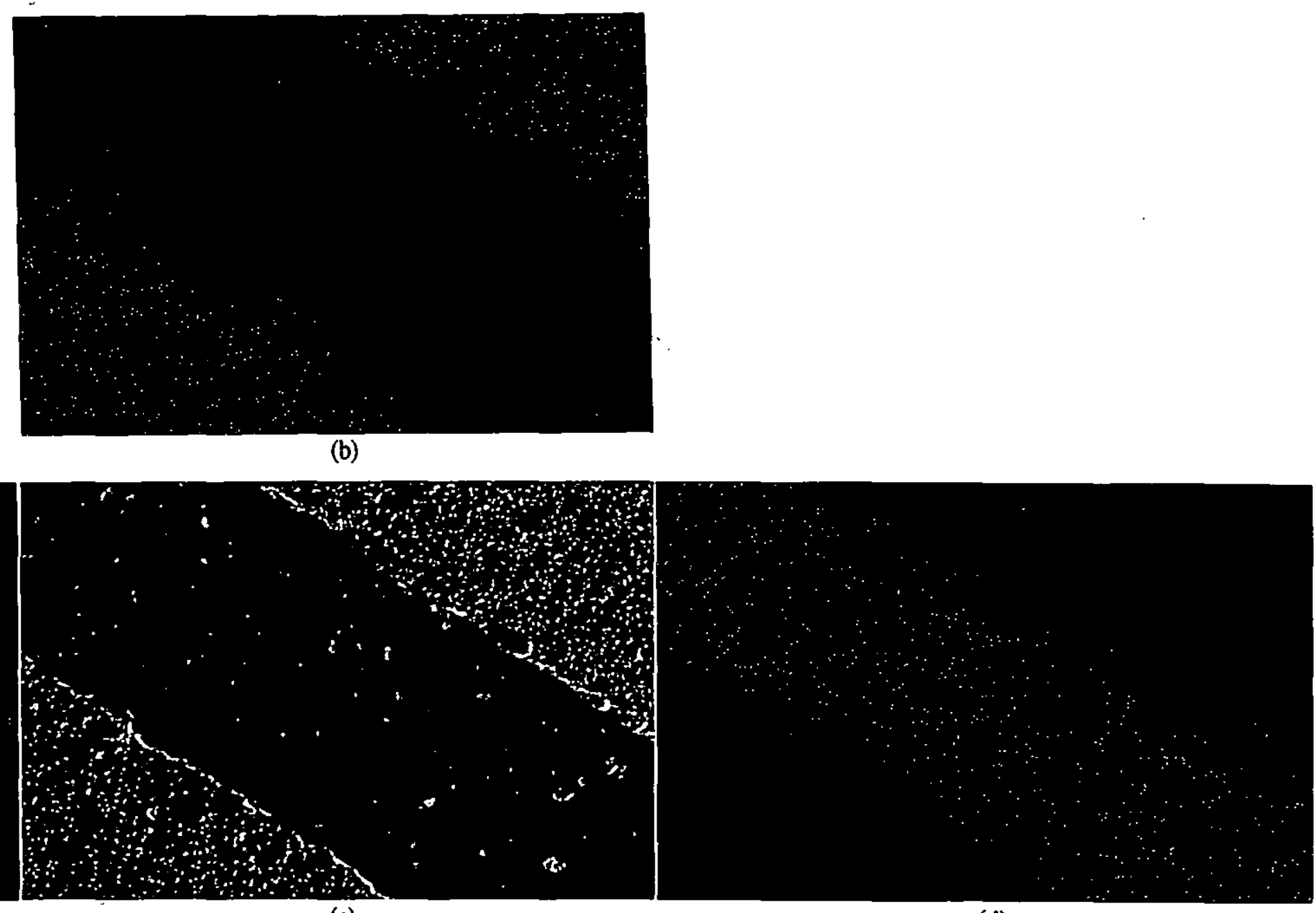

(a)

(d)

Eigure 5.47 (a) SEM micrograph of scratch channel on $\mathrm{Al}_{2} \mathrm{O}_{3}$ coated insert from $\mathrm{H}_{2}-1 / \mathrm{AlCl}_{3}$ flow rate $=10 \mathrm{~cm}^{3} \mathrm{~min}^{-1}$ coating run. Stylus load $=8 \mathrm{~kg}$. $\times 300$.

(b) Al $K_{\alpha}$ elemental scan of area shown in (a).

(c) Ti $K_{\alpha}$ elemental scan of area shown in (a).

(d) Fe $K_{\alpha}$ elemental scan of area shown in (a). 
(b)

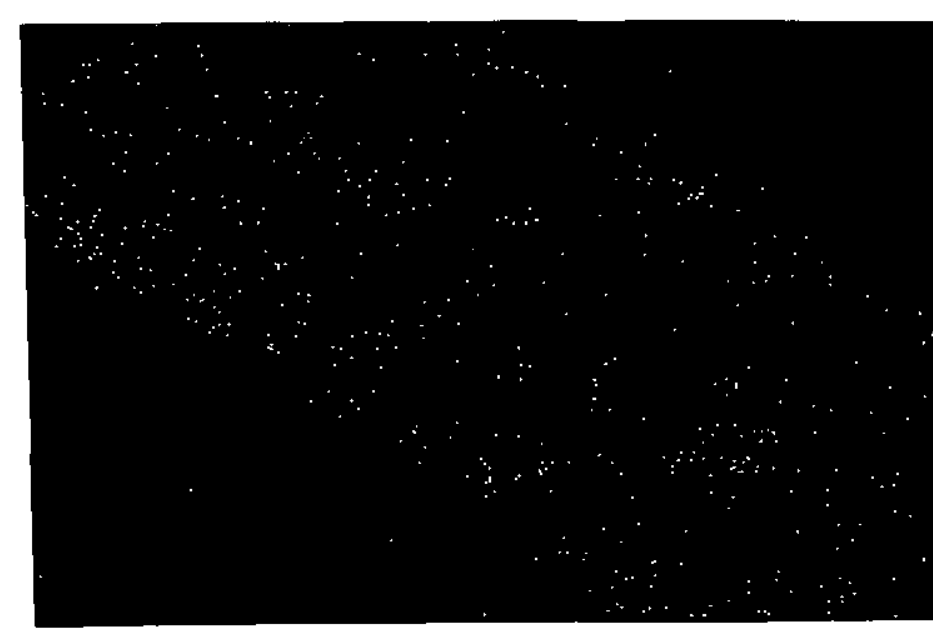

(c)
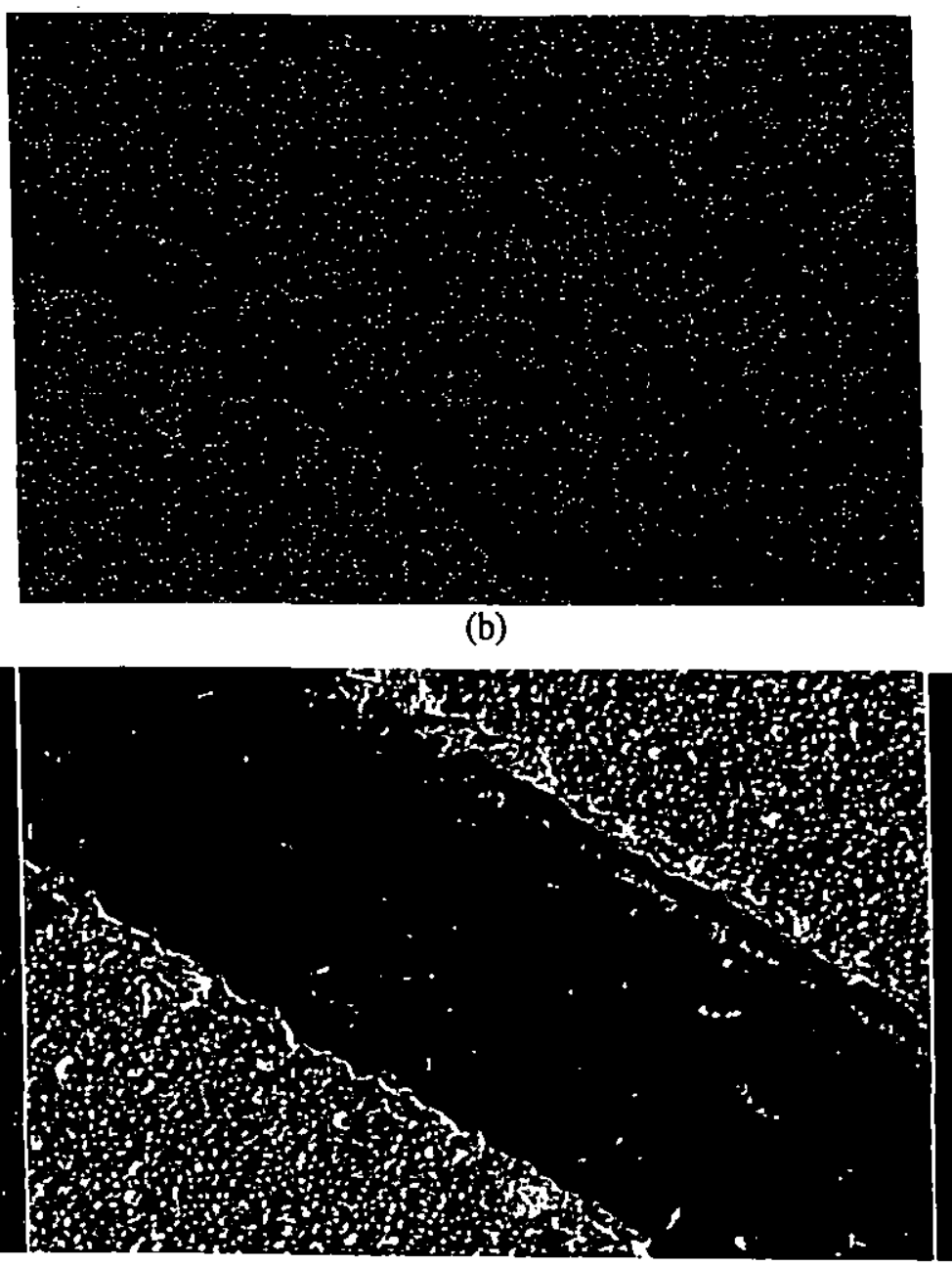

(a)

(d)

Eigure 5.48 (a) SEM micrograph of scratch channel on $\mathrm{Al}_{2} \mathrm{O}_{3}$ coated insert from $\mathrm{H}_{2}-1 / \mathrm{AlCl}_{3}$ flow rate $=15 \mathrm{~cm}^{3} \mathrm{~min}^{-1}$ coating run. Stylus load $=8 \mathrm{~kg} . \times 300$.

(b) Al $K_{a}$ elemental scan of area shown in (a).

(c) Ti $K_{a}$ elemental scan of area shown in (a).

(d) Fe $K_{\mathrm{a}}$ elemental scan of area shown in (a). 


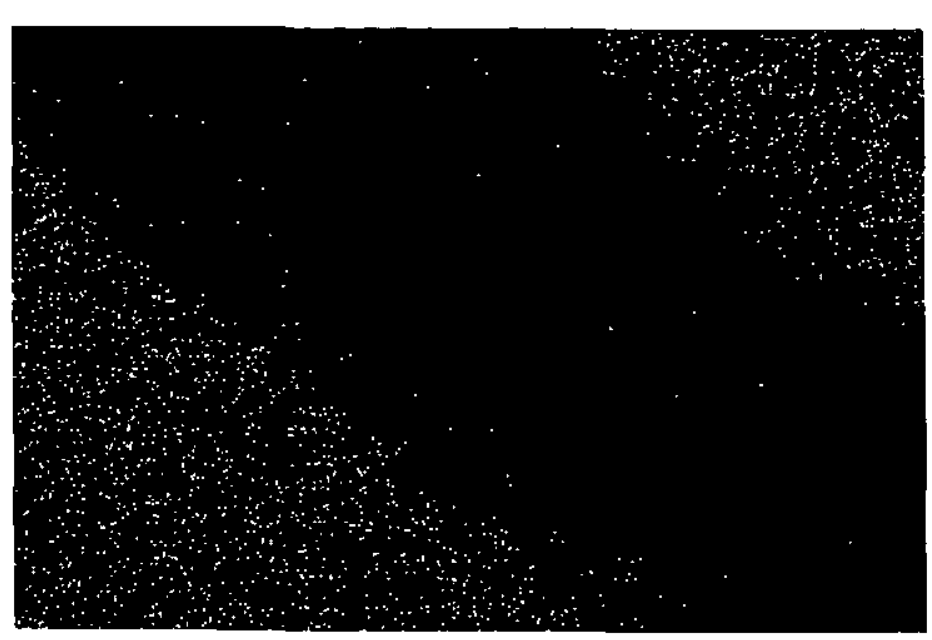

(b)

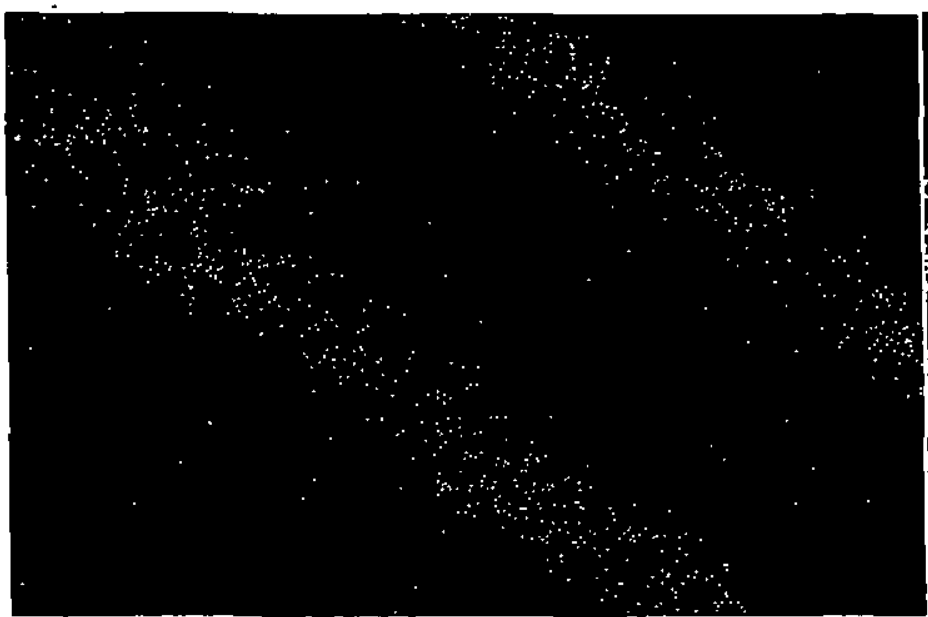

(c)

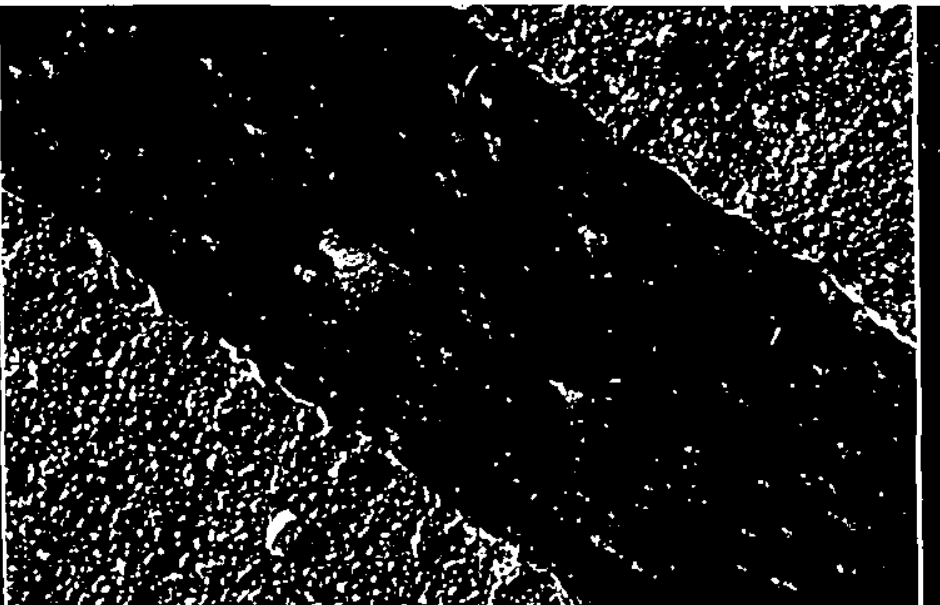

(a)

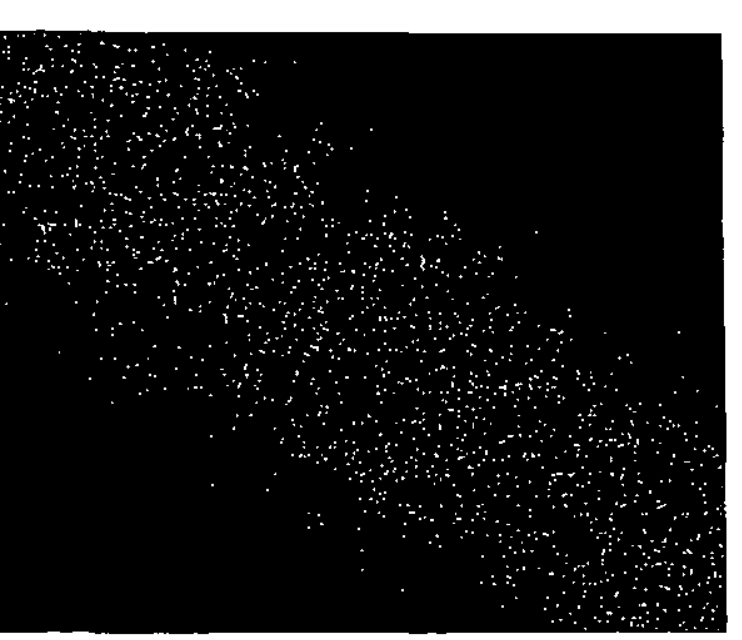

(d)

Figure 5,49 (a) $\mathrm{SEM}$ micrograph of scratch channel on $\mathrm{Al}_{2} \mathrm{O}_{3}$ coated insert from $\mathrm{H}_{2}-1 / \mathrm{AlCl}_{3}$ flow rate $=15 \mathrm{~cm}^{3} \mathrm{~min}^{-1}$ coating run. Stylus load $=9 \mathrm{~kg}$. $\times 300$.

(b) Al $K_{\alpha}$ elemental scan of area shown in (a).

(c) Ti $K_{\alpha}$ elemental scan of area shown in (a).

(d) Fe $K_{\mathrm{\alpha}}$ elemental scan of area shown in (a). 


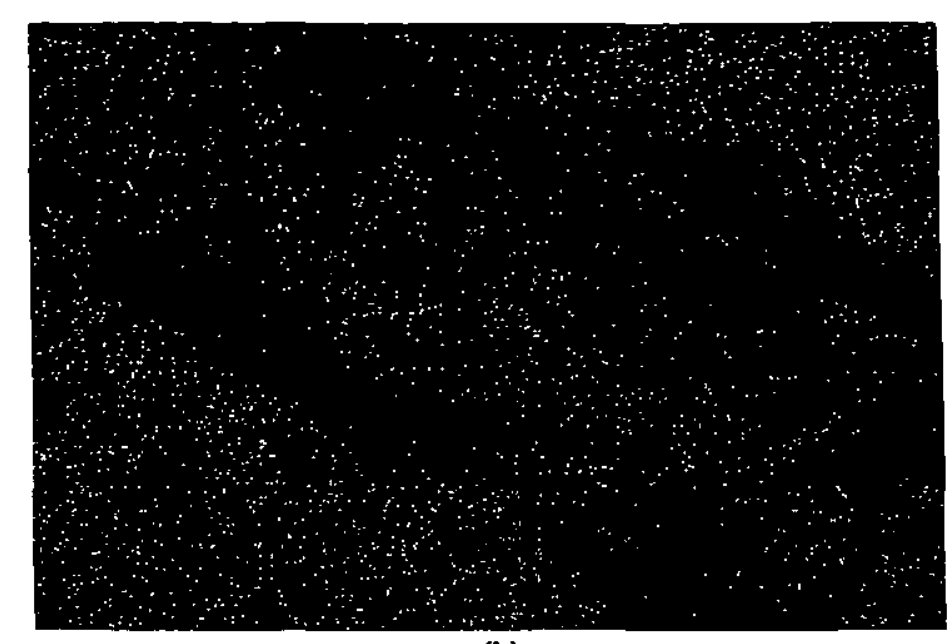

(b)

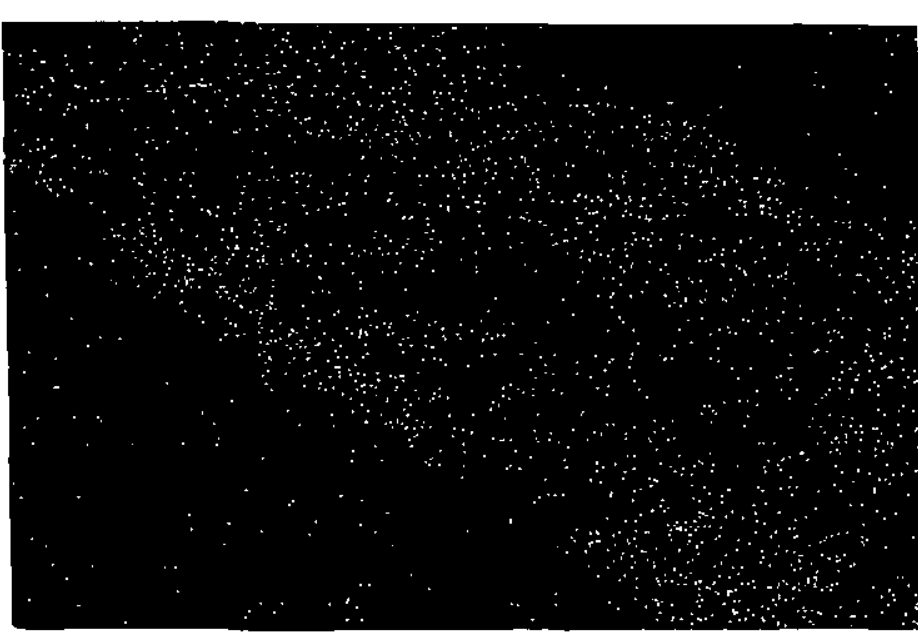

(c)

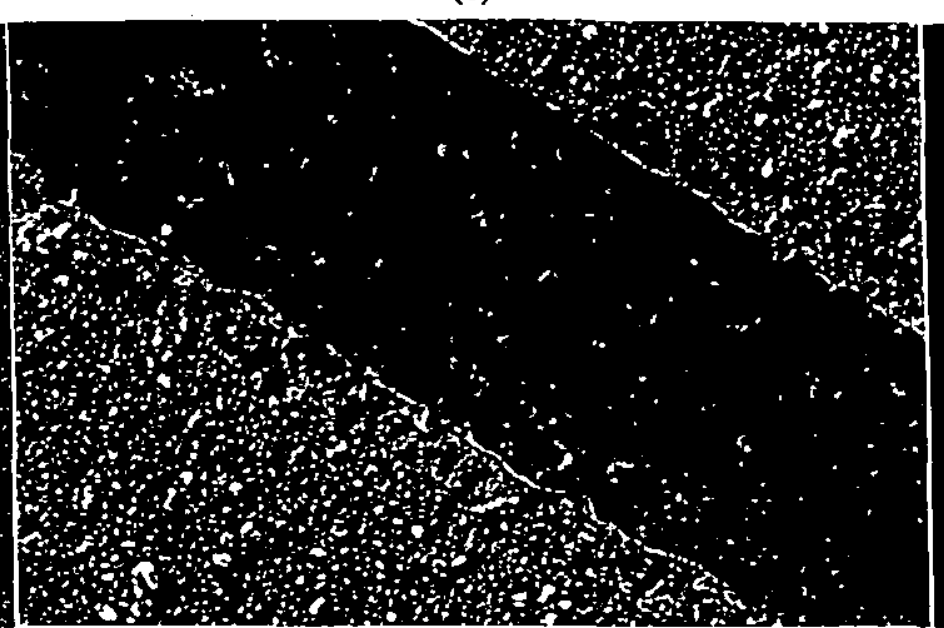

(a)

(d)

Figure 5.50 (a) $\mathrm{SEM}$ micrograph of scratch channel on $\mathrm{Al}_{2} \mathrm{O}_{3}$ coated insert from $\mathrm{H}_{2}-1 / \mathrm{AlCl}_{3}$ flow rate $=20 \mathrm{~cm}^{3} \mathrm{~min}^{-1}$ coating run. Stylus load $=6 \mathrm{~kg} . \times 300$.

(b) Al $K_{\alpha}$ elemental scan of area shown in (a).

(c) Ti $K_{\alpha}$ elemental scan of area shown in (a).

(d) Fe $K_{\alpha}$ elemental scan of area shown in (a). 
(b)

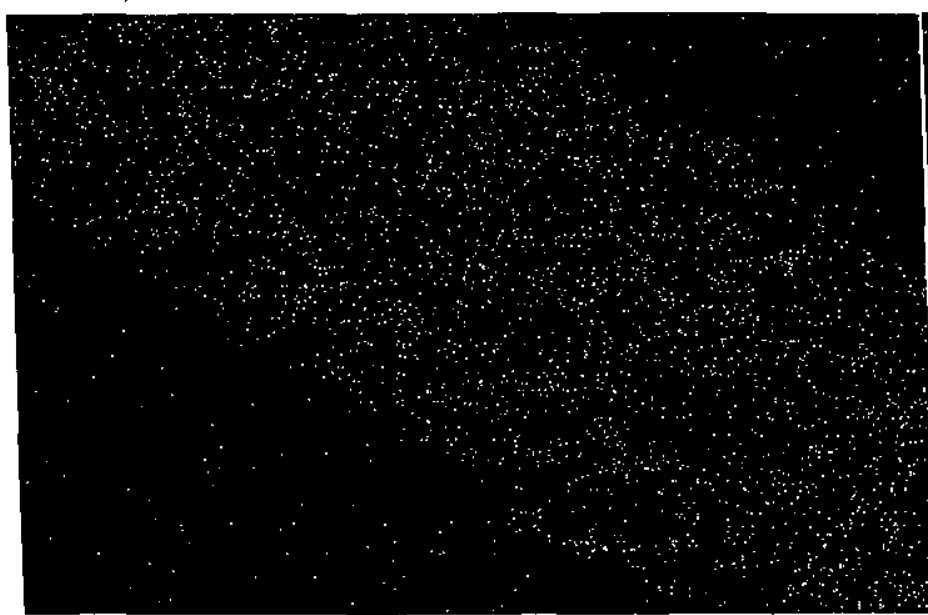

(c)

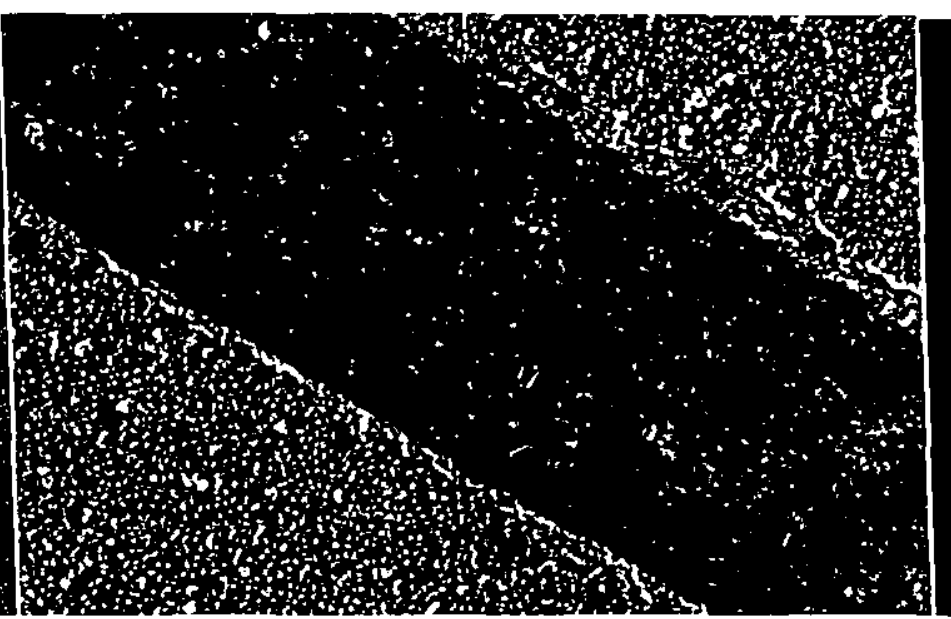

(a)

(d)

Figure 5.51 (a) SEM micrograph of scratch channel on $\mathrm{Al}_{2} \mathrm{O}_{3}$ coated insert from $\mathrm{H}_{2}-1 / \mathrm{AlCl}_{3}$ flow rate $=20 \mathrm{~cm}^{3} \mathrm{~min}^{-1}$ coating run. Stylus load $=7 \mathrm{~kg}$. $x 300$.

(b) Al $K_{\alpha}$ elemental scan of area shown in (a).

(c) Ti $K_{\alpha}$ elemental scan of area shown in (a).

(d) Fe $K_{\alpha}$ elemental scan of area shown in (a). 


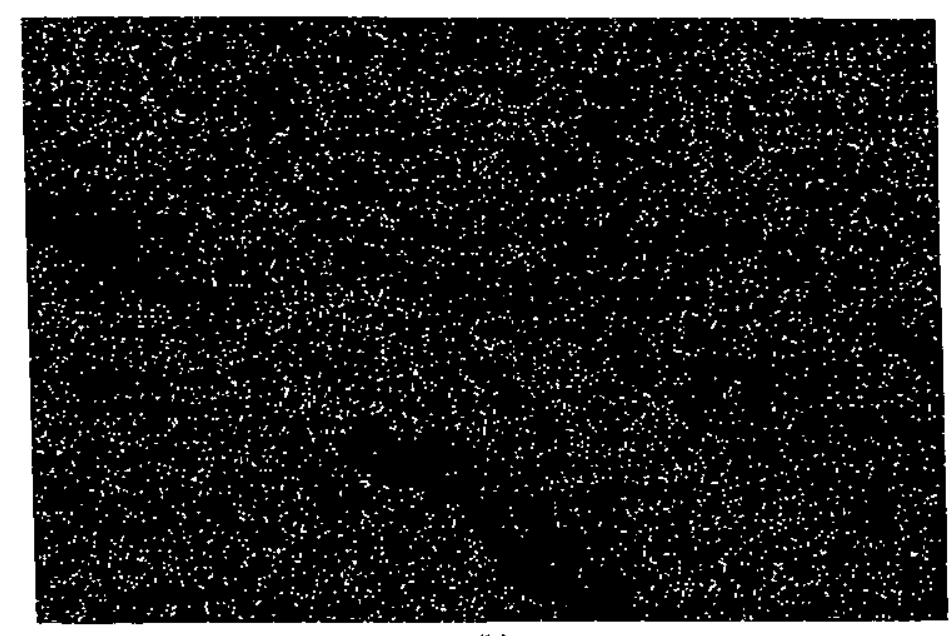

(b)

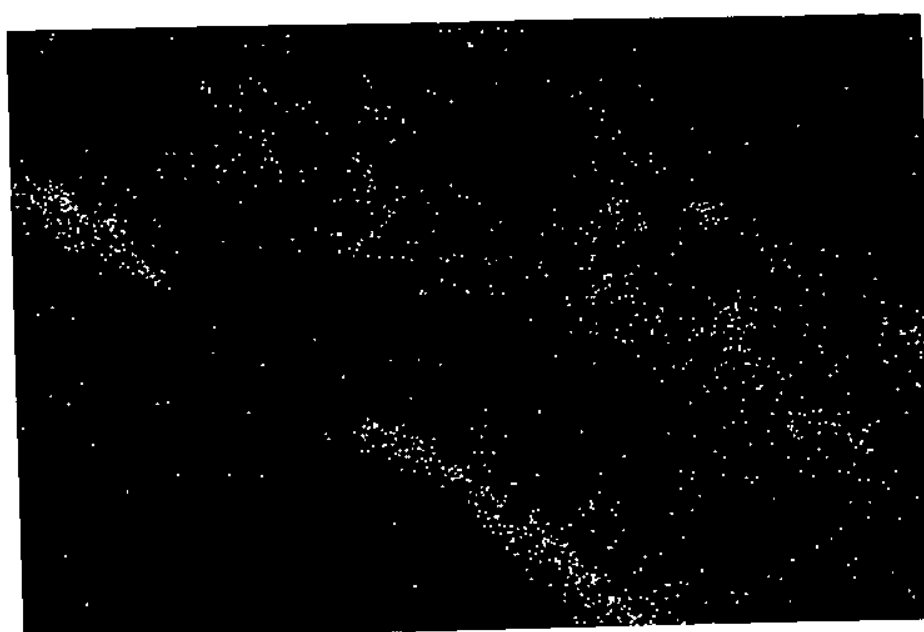

(c)

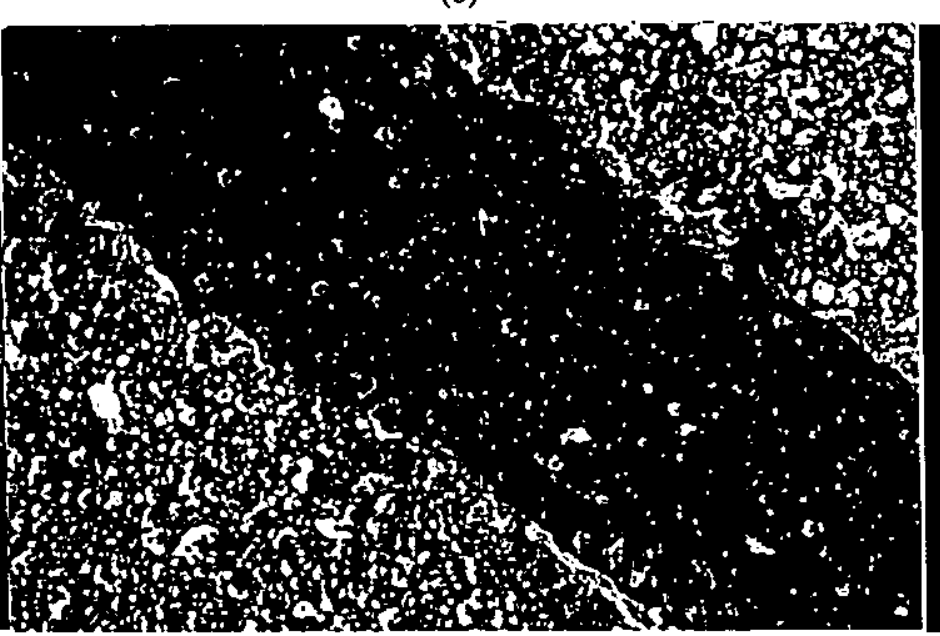

(a) (d)

Figure 5.52 (a) SEM micrograph of scratch channel on $\mathrm{Al}_{2} \mathrm{O}_{3}$ coated insert from $\mathrm{H}_{2}-1 / \mathrm{AlCl}_{3}$ flow rate $=25 \mathrm{~cm}^{3} \mathrm{~min}^{-1}$ coating run. Stylus load $=7 \mathrm{~kg} . \times 300$. (b) Al $K_{\alpha}$ elemental scan of area shown in (a).
(c) Ti $K_{\alpha}$ elemental scan of area shown in (a).
(d) Fe $K_{\alpha}$ elemental scan of area shown in (a). 
(b)

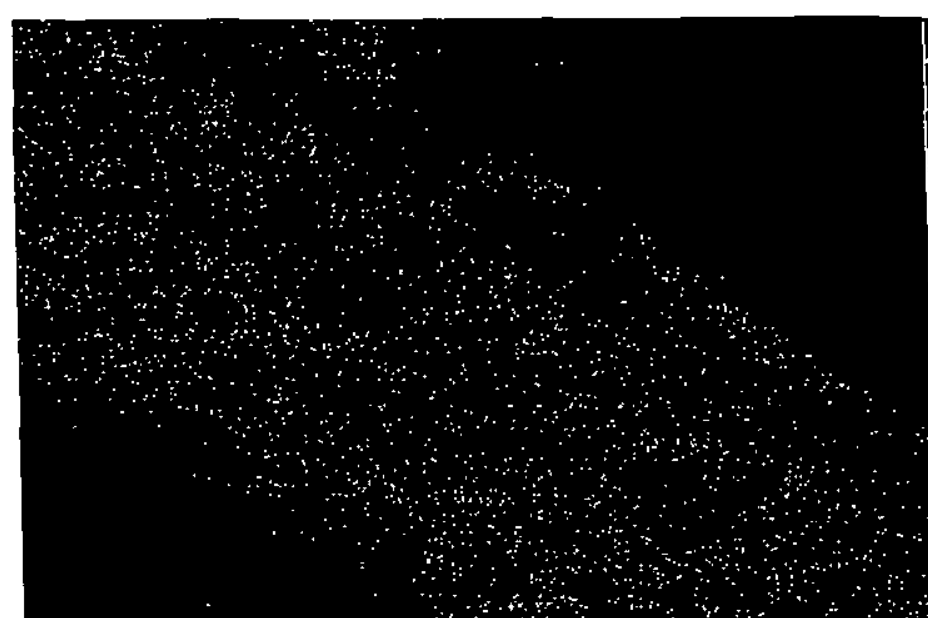

(c)

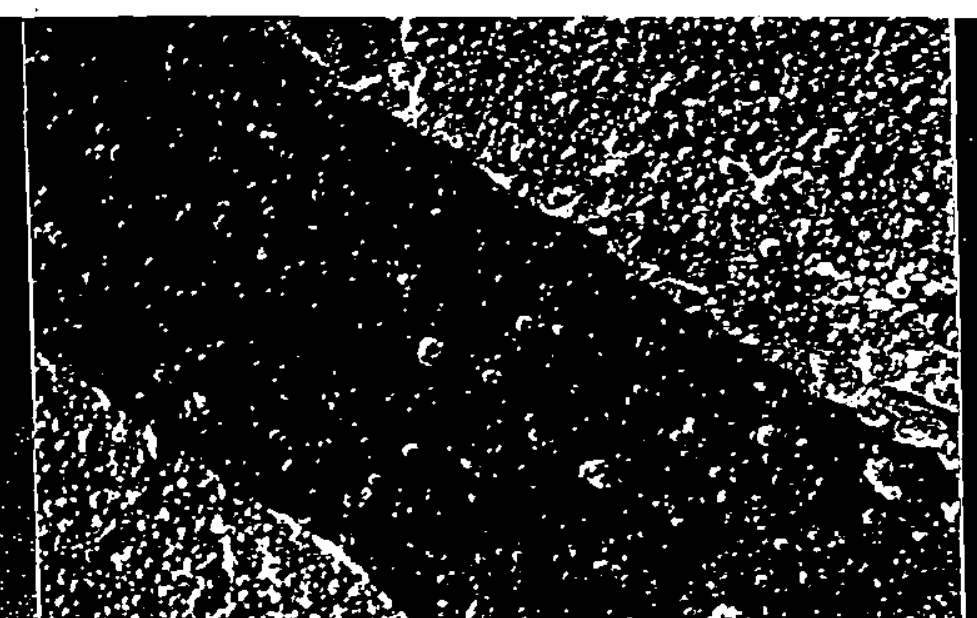

(a) (d)

Eigure 5.53 (a) SEM micrograph of scratch channel on $\mathrm{Al}_{2} \mathrm{O}_{3}$ coated insert from $\mathrm{H}_{2}-1 / \mathrm{AlCl}_{3}$ flow rate $=25 \mathrm{~cm}^{3} \mathrm{~min}^{-1}$ coating run. Stylus load $=8 \mathrm{~kg}$. $\times 300$.

(b) Al $K_{\alpha}$ elemental scan of area shown in (a).

(c) Ti $K_{\alpha}$ elemental scan of area shown in (a).

(d) Fe $K_{\mathrm{a}}$ elemental scan of area shown in (a). 


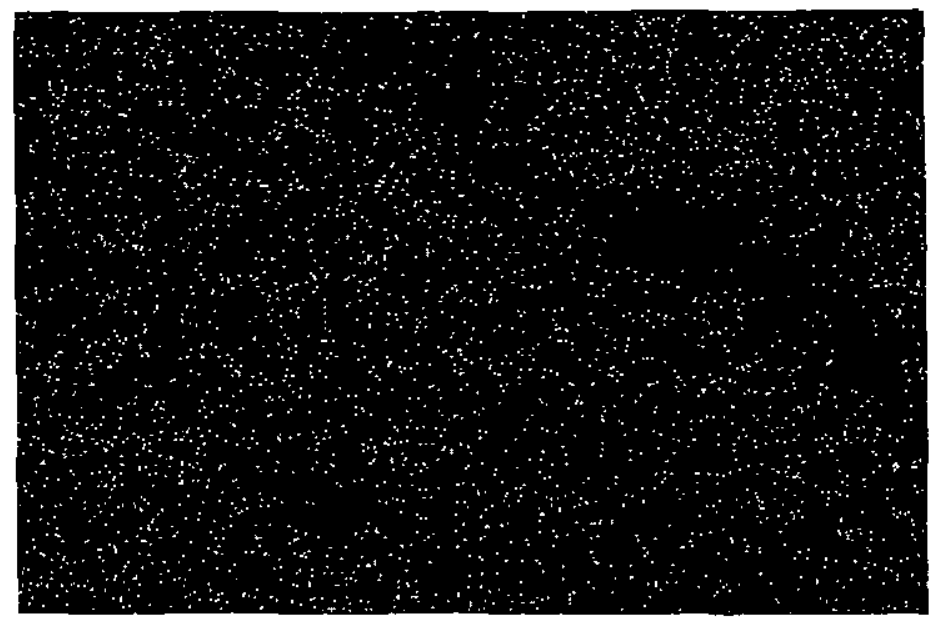

(b)

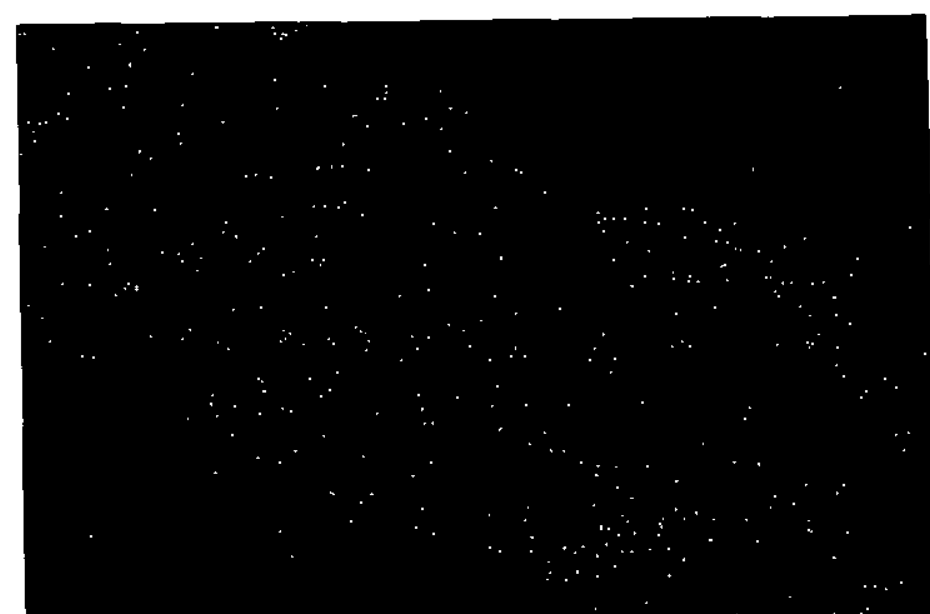

(c)

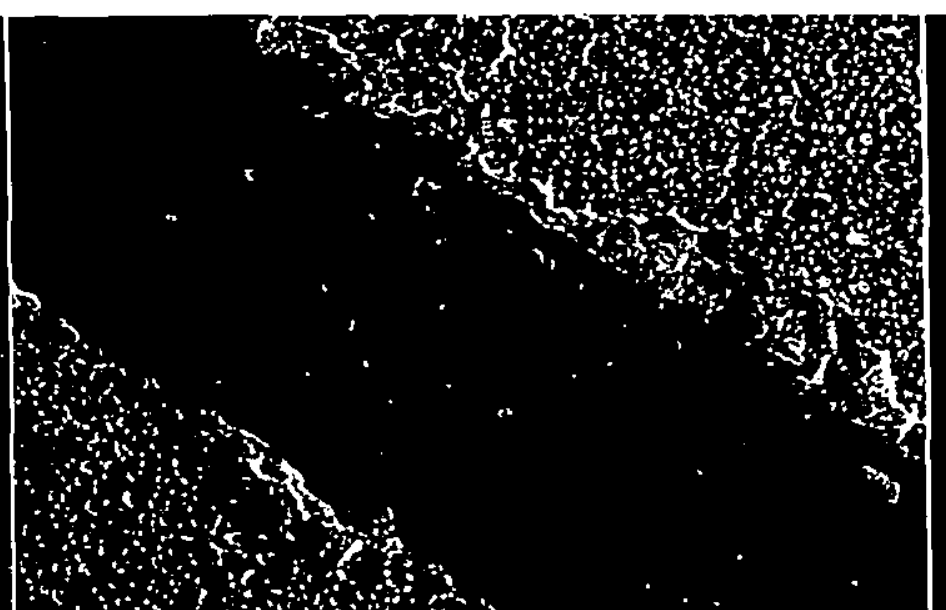

(a)

(d)

Figure 5.54 (a) SEM micrograph of scratch channel on $\mathrm{Al}_{2} \mathrm{O}_{3}$ coated insert from $\mathrm{H}_{2}-1 / \mathrm{AlCl}_{3}$ flow rate $=30 \mathrm{~cm}^{3} \mathrm{~min}^{-1}$ coating run. Stylus load $=8 \mathrm{~kg}$. $x 300$.

(b) Al $K_{\alpha}$ elemental scan of area shown in (a).

(c) Ti $K_{\mathrm{a}}$ elemental scan of area shown in (a).

(d) Fe $K_{\alpha}$ elemental scan of area shown in (a). 


\section{(b)}

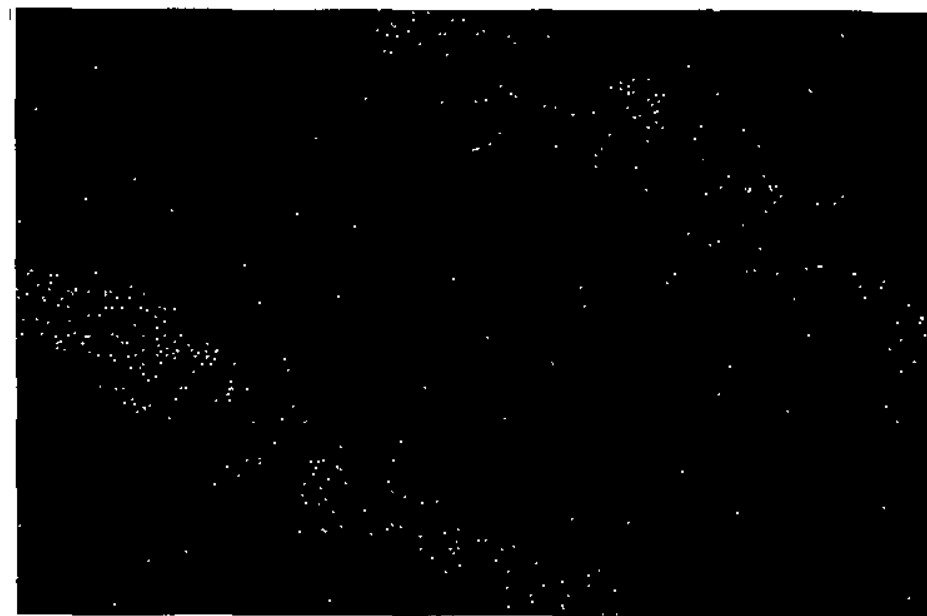

(c)

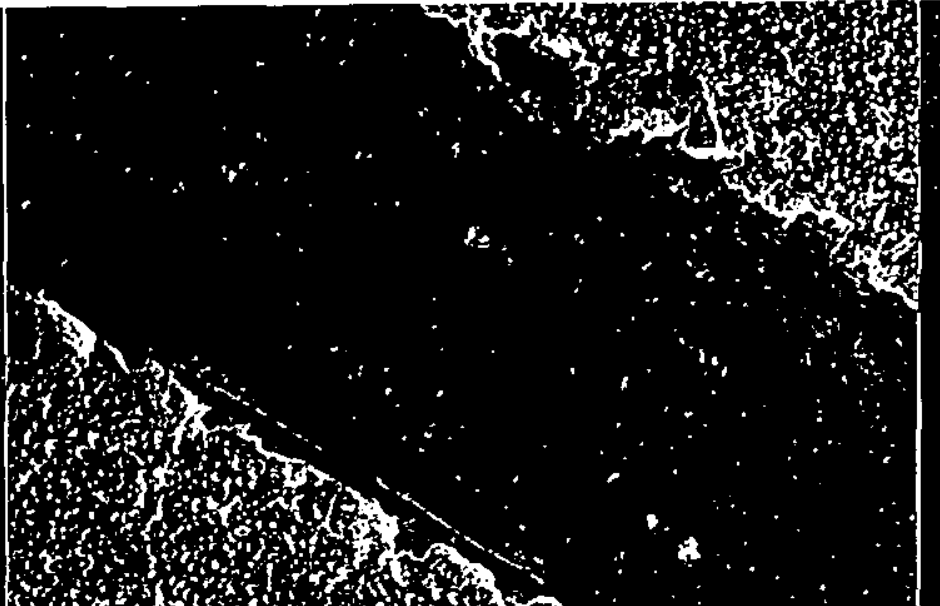

(a) (d)

Figure 5.55 (a) SEM micrograph of scratch channel on $\mathrm{Al}_{2} \mathrm{O}_{3}$ coated insert from $\mathrm{H}_{2}-1 / \mathrm{AlCl}_{3}$ flow rate $=30 \mathrm{~cm}^{3} \mathrm{~min}^{-1}$ coating run. Stylus load $=9 \mathrm{~kg}$. $\times 300$.

(b) Al $K_{\alpha}$ elemental scan of area shown in (a).

(c) Ti $K_{\alpha}$ elemental scan of area shown in (a)

(d) Fe $K_{\alpha}$ elemental scan of area shown in (a). 
Table 5.1 Deposition conditions used for $\mathrm{CO}_{2} / \mathrm{H}_{2}$ mole ratio coating runs.

\begin{tabular}{|c|c|c|c|c|c|c|c|c|c|}
\hline \multirow{2}{*}{$\begin{array}{c}\mathrm{CO}_{2} / \mathrm{H}_{2} \\
\text { mole } \\
\text { ratio }\end{array}$} & \multirow{2}{*}{$\begin{array}{c}\text { Deposition } \\
\text { temperature }{ }^{0} \mathrm{C}\end{array}$} & \multirow{2}{*}{$\begin{array}{l}\mathrm{AlCl}_{3} \\
\text { evap.unit } \\
\text { temp., }{ }^{\circ} \mathrm{C}\end{array}$} & \multicolumn{5}{|c|}{ Gas flow rate, $\mathrm{cm}^{3} \mathrm{~min}^{-1}$} & \multirow[t]{2}{*}{ Time, $\min$} & \multirow{2}{*}{$\begin{array}{c}\text { Amount } \\
\text { of } \mathrm{AlCl}_{3} \\
\text { used, } \mathrm{g}\end{array}$} \\
\hline & & & $\mathrm{CO}_{2}$ & $\begin{array}{l}\mathrm{H}_{2}-1 / \\
\mathrm{AlCl}_{3}\end{array}$ & $\mathrm{H}_{2}-2$ & Ar & Total & & \\
\hline $1 / 6$ & 1050 & 190 & 25 & 25 & 125 & 225 & 400 & 60 & 5.2 \\
\hline $1 / 8$ & 1050 & 190 & 25 & 25 & 175 & 175 & 400 & 60 & 6.8 \\
\hline $1 / 10$ & 1050 & 190 & 25 & 25 & 225 & 125 & 400 & 60 & 8.1 \\
\hline $1 / 12$ & 1050 & 190 & 25 & 25 & 275 & 25 & 400 & 60 & 8.2 \\
\hline $1 / 14$ & 1050 & 190 & 25 & 25 & 325 & 25 & 400 & 60 & 5.3 \\
\hline
\end{tabular}

Table 5.2 Allocation of characterisation techniques to $a c$ and $h c$ inserts from coating runs carried out to investigate effect of $\mathrm{CO}_{2} / \mathrm{H}_{2}$ mole ratio (Insert no. 1 located towards inlet end of reactor coating chamber).

\begin{tabular}{|c|c|c|}
\hline & Left-hand side of insert holder & Right-hand side of insert holder \\
\hline Insert No. & $\begin{array}{l}\text { As-coated } \\
(a c)\end{array}$ & $\begin{array}{l}\text { Heat treated coated } \\
(h c)\end{array}$ \\
\hline 1 & X-ray, Microhardness tests & . \\
\hline 2 & X-ray, Profilometry, Optical & $\begin{array}{c}\mathrm{X} \text {-ray, Fractography, Surface grain } \\
\text { structure }\end{array}$ \\
\hline 3 & X-ray, AES & \\
\hline 4 & $\mathrm{X}$-ray & X-ray, Scratch tests \\
\hline
\end{tabular}

Table 5.3 Thickness of $\mathrm{Al}_{2} \mathrm{O}_{3}$ coatings deposited at different $\mathrm{CO}_{2} / \mathrm{H}_{2}$ mole ratios - determined by ball-cratering (Insert no. 1 located towards inlet end of reactor coating chamber).

\begin{tabular}{|c|c|c|c|c|c|c|c|c|c|c|}
\hline \multirow{3}{*}{$\begin{array}{l}\text { Insert } \\
\text { No. }\end{array}$} & \multicolumn{10}{|c|}{ Coating thickness, $\mu \mathrm{m}$} \\
\hline & \multicolumn{2}{|c|}{$\begin{array}{c}\mathrm{CO}_{2} / \mathrm{H}_{2} \text { mole ratio } \\
=1 / 6\end{array}$} & \multicolumn{2}{|c|}{$\begin{array}{c}\mathrm{CO}_{2} / \mathrm{H}_{2} \text { mole ratio } \\
=1 / 8\end{array}$} & \multicolumn{2}{|c|}{$\begin{array}{c}\mathrm{CO}_{2} / \mathrm{H}_{2} \text { mole ratio } \\
=1 / 10\end{array}$} & \multicolumn{2}{|c|}{$\begin{array}{c}\mathrm{CO}_{2} / \mathrm{H}_{2} \text { mole ratio } \\
=1 / 12\end{array}$} & \multicolumn{2}{|c|}{$\begin{array}{c}\mathrm{CO}_{2} / \mathrm{H}_{2} \text { mole } \\
\text { ratio }=1 / 14\end{array}$} \\
\hline & Left & Right & Left & Right & Left & Right & Left & Right & Left & Right \\
\hline$\overline{1}$ & 3.58 & 3.41 & 3.59 & 3.49 & 4.35 & 4.03 & 4.69 & 3.78 & 4.02 & 3.74 \\
\hline 2 & 3.25 & 2.91 & 3.36 & 2.95 & 3.45 & 2.64 & 3.86 & 3.19 & 3.20 & $\cdot 2.5$ \\
\hline 3 & 2.74 & 2.65 & 2.93 & 2.63 & 2.4 & 2.35 & 2.74 & 2.26 & 2.17 & 1.98 \\
\hline 4 & 2.68 & 2.49 & 2.03 & 1.93 & 2.035 & 2.02 & 2.21 & 1.79 & 1.94 & 1.86 \\
\hline
\end{tabular}


Table 5.4 Lattice parameter values for $\mathrm{Al}_{2} \mathrm{O}_{3}$ coatings deposited at different $\mathrm{CO}_{2} / \mathrm{H}_{2}$ mole ratios.

\begin{tabular}{|c|c|c|c|c|c|c|c|c|c|c|}
\hline \multirow{3}{*}{$\begin{array}{l}\text { Insert } \\
\text { No. }\end{array}$} & \multicolumn{10}{|c|}{ Lattice parameter, $\AA$} \\
\hline & \multicolumn{2}{|c|}{$\begin{array}{c}\mathrm{CO}_{2} / \mathrm{H}_{2} \text { mole ratio } \\
=1 / 6\end{array}$} & \multicolumn{2}{|c|}{$\begin{array}{c}\mathrm{CO}_{2} / \mathrm{H}_{2} \text { mole ratio } \\
=1 / 8\end{array}$} & \multicolumn{2}{|c|}{$\begin{array}{c}\mathrm{CO}_{2} / \mathrm{H}_{2} \text { mole ratio } \\
=1 / 10\end{array}$} & \multicolumn{2}{|c|}{$\begin{array}{c}\mathrm{CO}_{2} / \mathrm{H}_{2} \text { mole ratio } \\
=1 / 12\end{array}$} & \multicolumn{2}{|c|}{$\begin{array}{l}\mathrm{CO}_{2} / \mathrm{H}_{2} \text { mole } \\
\text { ratio }=1 / 14\end{array}$} \\
\hline & a & c & a & c & a & c & $\mathbf{a}$ & c & $\mathbf{a}$ & c \\
\hline $1 \mathrm{~L}$ & 4.759 & 13.014 & 4.757 & 13.004 & 4.754 & 12.977 & 4.760 & 13.006 & 4.751 & 12.993 \\
\hline $2 \mathrm{~L}$ & 4.759 & 13.001 & 4.754 & 13.004 & 4.757 & 12.998 & 4.760 & 13.014 & 4.763 & 13.029 \\
\hline $3 \mathrm{~L}$ & 4.759 & 12.998 & 4.753 & 12.987 & 4.757 & 13.003 & 4.763 & 13.008 & 4.763 & 13.028 \\
\hline $4 \mathrm{~L}$ & 4.758 & 13.000 & 4.752 & 12.983 & 4.763 & 12.882 & 4.755 & 12.988 & 4.758 & 13.011 \\
\hline $2 \mathrm{R}$ & 4.761 & 12.994 & 4.764 & 12.990 & 4.752 & 12.989 & 4.746 & 12.991 & 4.743 & 12.947 \\
\hline $4 \mathrm{R}$ & 4.764 & 13.021 & 4.757 & 12.961 & 4.762 & 12.997 & 4.760 & 13.013 & 4.741 & 12.984 \\
\hline
\end{tabular}

Table 5.5 Surface roughness of $\mathrm{Al}_{2} \mathrm{O}_{3}$ coatings deposited at different $\mathrm{CO}_{2} / \mathrm{H}_{2}$ mole ratios.

\begin{tabular}{|c|c|c|c|c|}
\hline \multirow{2}{*}{$\mathrm{CO}_{2} / \mathrm{H}_{2}$ mole ratio } & \multicolumn{4}{|c|}{ Roughness average $\mathrm{R}_{2}, \mu \mathrm{m}$} \\
\cline { 2 - 5 } & Ave. & Max. & Min. & Standard dev. \\
\hline \hline $1 / 6$ & 0.47 & 0.55 & 0.38 & 0.048 \\
\hline $1 / 8$ & 0.45 & 0.68 & 0.34 & 0.11 \\
\hline $1 / 10$ & 0.45 & 0.54 & 0.39 & 0.044 \\
\hline $1 / 12$ & 0.62 & 0.99 & 0.43 & 0.18 \\
\hline $1 / 14$ & 0.41 & 0.48 & 0.38 & 0.031 \\
\hline
\end{tabular}


Table 5.6 Peripheral thickness variation of $\mathrm{Al}_{2} \mathrm{O}_{3}$ coatings deposited at different $\mathrm{CO}_{2} / \mathrm{H}_{2}$ mole ratios as determined by optical measurement, together with corresponding average rake face coating thicknesses determined by ball-cratering.

\begin{tabular}{|c|c|c|c|c|c|c|}
\hline \multicolumn{6}{|c|}{$\begin{array}{l}\text { Coating thickness } \mu \mathrm{m} \\
\text { (optical) }\end{array}$} & \multirow{2}{*}{$\begin{array}{c}\text { Coating thickness } \\
\mu \mathrm{m} \\
\text { (ball-cratering) }\end{array}$} \\
\hline & & & Average & Maximum & Minimum & \\
\hline \multirow{5}{*}{$\begin{array}{c}\mathrm{CO}_{2} / \mathrm{H}_{2} \text { mole ratio } \\
=1 / 6\end{array}$} & \multicolumn{2}{|l|}{ Rake } & 4.2 & 6.49 & 2.81 & 3.25 \\
\hline & \multirow[t]{2}{*}{ Flank } & 1 & 3.49 & 4.69 & 2.3 & \\
\hline & & 2 & 5.17 & 8.6 & 3.91 & \\
\hline & \multirow[t]{2}{*}{ Corner } & 1 & 8.58 & 9.53 & 7.58 & \\
\hline & & 2 & 4.31 & 4.92 & 3.75 & \\
\hline \multirow{5}{*}{$\begin{array}{c}\mathrm{CO}_{2} / \mathrm{H}_{2} \text { mole ratio } \\
=1 / 8\end{array}$} & \multicolumn{2}{|l|}{ Rake } & 4.42 & 5.31 & 2.03 & 3.36 \\
\hline & \multirow[t]{2}{*}{ Flank } & 1 & 5.41 & 8.67 & 3.59 & \\
\hline & & 2 & $\begin{array}{l}\text { very thin } \\
\text { coating }\end{array}$ & - & - & - \\
\hline & \multirow[t]{2}{*}{ Corner } & 1 & 9.14 & 10.0 & 8.36 & \\
\hline & & 2 & $\begin{array}{l}\text { very thin } \\
\text { coating }\end{array}$ & - & - & \\
\hline \multirow{5}{*}{$\begin{array}{c}\mathrm{CO}_{2} / \mathrm{H}_{2} \text { mole ratio } \\
=1 / 10\end{array}$} & \multicolumn{2}{|l|}{ Rake } & 4.52 & 7.97 & 3.13 & 3.45 \\
\hline & \multirow[t]{2}{*}{ Flank } & 1 & 6.31 & 10.95 & 3.83 & \\
\hline & & 2 & 5.85 & 9.77 & 2.81 & \\
\hline & Corner & 1 & 10.32 & 15.32 & 6.33 & \\
\hline & & 2 & no coating & - & - & \\
\hline \multirow{5}{*}{$\begin{array}{c}\mathrm{CO}_{2} / \mathrm{H}_{2} \text { mole ratio } \\
=1 / 12\end{array}$} & \multicolumn{2}{|l|}{ Rake } & 5.10 & 8.6 & 2.5 & 3.86 \\
\hline & \multirow[t]{2}{*}{ Flank } & 1 & 7.01 & 10.63 & 5.31 & \\
\hline & & 2 & 5.7 & 9.85 & 3.44 & \\
\hline & \multirow[t]{2}{*}{ Corner } & 1 & 8.33 & 9.77 & 6.64 & \\
\hline & & 2 & 8.75 & 10.47 & 4.38 & \\
\hline \multirow{5}{*}{$\begin{array}{c}\mathrm{CO}_{2} / \mathrm{H}_{2} \text { mole ratio } \\
=1 / 14\end{array}$} & \multicolumn{2}{|l|}{ Rake } & 4.3 & 6.2 & 2.97 & 3.20 \\
\hline & \multirow[t]{2}{*}{ Flank } & 1 & 5.56 & 6.3 & 4.2 & \\
\hline & & 2 & 5.26 & 6.72 & 3.99 & \\
\hline & \multirow[t]{2}{*}{ Corner } & 1 & 7.77 & 10.47 & 6.3 & \\
\hline & & 2 & 3.59 & 3.99 & 3.28 & \\
\hline
\end{tabular}


Table 5.7 Microhardness of $\mathrm{Al}_{2} \mathrm{O}_{3}$ coatings deposited at different $\mathrm{CO}_{2} / \mathrm{H}_{2}$ mole ratios.

\begin{tabular}{|c|c|c|c|}
\hline \multirow{2}{*}{$\mathrm{CO}_{2} / \mathrm{H}_{2}$ mole ratio } & \multicolumn{3}{|c|}{ Microhardness, $\mathrm{HV}_{0.025}$} \\
\cline { 2 - 4 } & Ave. & Max. & Min. \\
\hline \hline $1 / 6$ & 2379 & 2807 & 2109 \\
\hline $1 / 8$ & 2374 & 2702 & 2509 \\
\hline $1 / 10$ & 2845 & 3162 & 2603 \\
\hline $1 / 12$ & 2981 & 3295 & 2202 \\
\hline $1 / 14$ & 2620 & 2918 & 2975 \\
\hline
\end{tabular}

Table 5.8 Thickness of $\mathrm{Al}_{2} \mathrm{O}_{3}$ coating and $\mathrm{Ti}(\mathrm{C}, \mathrm{N})$ precoating and hardness of HSS substrate of $h c$ inserts from different $\mathrm{CO}_{2} / \mathrm{H}_{2}$ mole ratio coating runs used in scratch tests.

\begin{tabular}{|c|c|c|c|}
\hline \multirow{2}{*}{$\mathrm{CO}_{2} / \mathrm{H}_{2}$ mole ratio } & \multicolumn{2}{|c|}{ Coating thickness, $\mu \mathrm{m}$} & \multicolumn{2}{c|}{ Substrate hardness, HV30 } \\
\cline { 2 - 4 } & $\mathrm{Al}_{2} \mathrm{O}_{3}$ & $\mathrm{Ti}(\mathrm{C}, \mathrm{N})$ & 927 \\
\hline \hline $1 / 6$ & 2.49 & 1.61 & 912 \\
\hline $1 / 8$ & 1.93 & 1.44 & 942 \\
\hline $1 / 10$ & 2.02 & 1.34 & 916 \\
\hline $1 / 12$ & 1.79 & 1.52 & 916 \\
\hline $1 / 14$ & 1.86 & 1.54 & 9 \\
\hline
\end{tabular}

Table 5.9 Summary of scratch test results for $\mathrm{Al}_{2} \mathrm{O}_{3}$ coated inserts from different $\mathrm{CO}_{2} / \mathrm{H}_{2}$ mole ratio coating runs.

\begin{tabular}{|c|c|c|c|c|}
\hline $\begin{array}{c}\mathrm{CO}_{2} / \mathrm{H}_{2} \\
\text { mole ratio }\end{array}$ & $\begin{array}{c}\text { Stylus load at } \\
\text { which flaking first } \\
\text { observed, kg }\end{array}$ & Type of flaking & Degree of flaking & $\begin{array}{c}\text { Critical stylus load at which } \\
\text { "complete"coating removal } \\
\text { occurred, } \mathrm{kg}\end{array}$ \\
\hline \hline $1 / 6$ & 3 & adhesive & extensive & 6 \\
\hline $1 / 8$ & 3 & adhesive & moderate & 6.5 \\
\hline $1 / 10$ & 3 & adhesive & little & 7 \\
\hline $1 / 12$ & 5 & adhesive & little & 7.5 \\
\hline $1 / 14$ & 2 & adhesive & extensive & 5 \\
\hline
\end{tabular}


Table 5.10 Deposition conditions used for $\mathrm{H}_{2}-1 / \mathrm{AlCl}_{3}$ flow rate coating runs.

\begin{tabular}{|c|c|c|c|c|c|c|c|c|c|}
\hline \multirow{2}{*}{$\begin{array}{l}\mathrm{H}_{2}-1 / \mathrm{AlCl}_{3} \\
\text { flowrate, } \\
\mathrm{cm}^{3} \min ^{-1}\end{array}$} & \multirow{2}{*}{$\begin{array}{c}\text { Deposition } \\
\text { temperature, }{ }^{\circ} \mathrm{C}\end{array}$} & \multirow{2}{*}{$\begin{array}{c}\mathrm{AlCl}_{3} \\
\text { evap.unit } \\
\text { temp., }{ }^{\circ} \mathrm{C}\end{array}$} & \multicolumn{5}{|c|}{ Gas flow rate, $\mathrm{cm}^{3} \mathrm{~min}^{-1}$} & \multirow{2}{*}{$\begin{array}{l}\text { Time, } \\
\min \end{array}$} & \multirow{2}{*}{$\begin{array}{c}\text { Amount } \\
\text { of } \mathrm{AlCl}_{3} \\
\text { used, g }\end{array}$} \\
\hline & & & $\mathrm{CO}_{2}$ & $\begin{array}{l}\mathrm{H}_{2}-1 / \\
\mathrm{AlCl}_{3}\end{array}$ & $\mathrm{H}_{2}-2$ & $\mathrm{Ar}$ & Total & & \\
\hline 10 & 1050 & 190 & 25 & 10 & 240 & 125 & 400 & 60 & 5.8 \\
\hline 15 & 1050 & 190 & 25 & 15 & 235 & 125 & 400 & 60 & 5.5 \\
\hline 20 & 1050 & 190 & 25 & 20 & 230 & 125 & 400 & 60 & 7.3 \\
\hline 25 & 1050 & 190 & 25 & 25 & 225 & 125 & 400 & 60 & 10.1 \\
\hline 30 & 1050 & 190 & 25 & 30 & 220 & 125 & 400 & 60 & 11.6 \\
\hline
\end{tabular}

Table 5.11 Thickness of $\mathrm{Al}_{2} \mathrm{O}_{3}$ coatings deposited at different $\mathrm{H}_{2}-1 / \mathrm{AlCl}_{3}$ flow rates determined by ball-cratering (Insert no. 1 located towards inlet end of reactor coating chamber).

\begin{tabular}{|c|c|c|c|c|c|c|c|c|c|c|}
\hline \multirow[t]{3}{*}{$\begin{array}{l}\text { Insert } \\
\text { No. }\end{array}$} & \multicolumn{10}{|c|}{$\begin{array}{l}\text { Coating thickness, } \mu \mathrm{m} \\
\text { (Ball-cratering) }\end{array}$} \\
\hline & \multicolumn{2}{|c|}{$\begin{array}{c}\mathrm{H}_{2}-1 / \mathrm{AlCl}_{3} \\
\text { flowrate = } \\
10 \mathrm{~cm}^{3} \mathrm{~min}^{-1}\end{array}$} & \multicolumn{2}{|c|}{$\begin{array}{c}\mathrm{H}_{2}-1 / \mathrm{AlCl}_{3} \\
\text { flowrate = } \\
15 \mathrm{~cm}^{3} \mathrm{~min}^{-1}\end{array}$} & \multicolumn{2}{|c|}{$\begin{array}{c}\mathrm{H}_{2}-1 / \mathrm{AlCl}_{3} \\
\text { flowrate = } \\
20 \mathrm{~cm}^{3} \mathrm{~min}^{-1}\end{array}$} & \multicolumn{2}{|c|}{$\begin{array}{c}\mathrm{H}_{2}-1 / \mathrm{AlCl}_{3} \\
\text { flowrate = } \\
25 \mathrm{~cm}^{3} \mathrm{~min}^{-1}\end{array}$} & \multicolumn{2}{|c|}{$\begin{array}{c}\mathrm{H}_{2}-1 / \mathrm{AlCl}_{3} \\
\text { flowrate = } \\
30 \mathrm{~cm}^{3} \mathrm{~min}^{-1}\end{array}$} \\
\hline & Left & Right & Left & Right & Left & Right & Left & Right & Left & Right \\
\hline 1 & 2.8 & 2.59 & 3.58 & 3.41 & 3.30 & 3.12 & 4.73 & 4.48 & 4.75 & 4.05 \\
\hline 2 & 2.56 & 2.22 & 2.96 & 2.54 & 2.31 & 2.22 & 4.12 & 3.61 & 3.58 & 3.50 \\
\hline 3 & 2.05 & 1.61 & 2.35 & 2.08 & 1.91 & 1.88 & 3.34 & 2.84 & 3.23 & 2.94 \\
\hline 4 & 1.87 & 1.73 & 2.04 & 1.86 & 1.67 & 1.57 & 1.99 & 2.32 & 2.61 & 2.66 \\
\hline
\end{tabular}


Table 5.12 Lattice parameter values for $\mathrm{Al}_{2} \mathrm{O}_{3}$ coatings deposited at different $\mathrm{H}_{2}-1 / \mathrm{AlCl}_{3}$ flow rates.

\begin{tabular}{|c|c|c|c|c|c|c|c|c|c|c|}
\hline \multirow{3}{*}{$\begin{array}{c}\text { Insert } \\
\text { No. }\end{array}$} & \multicolumn{10}{|c|}{ Lattice parameter, Å } \\
\hline & \multicolumn{2}{|c|}{$\begin{array}{c}\mathrm{H}_{2}-1 / \mathrm{AICl}_{3} \\
\text { flowrate }= \\
10 \mathrm{~cm}^{3} \mathrm{~min}^{-1}\end{array}$} & \multicolumn{2}{|c|}{$\begin{array}{c}\mathrm{H}_{2}-1 / \mathrm{AlCl}_{3} \\
\text { flowrate }= \\
15 \mathrm{~cm}^{3} \mathrm{~min}^{-1}\end{array}$} & \multicolumn{2}{|c|}{$\begin{array}{c}\mathrm{H}_{2}-1 / \mathrm{AlCl}_{3} \\
\text { flowrate }= \\
20 \mathrm{~cm}^{3} \mathrm{~min}^{-1}\end{array}$} & \multicolumn{2}{|c|}{$\begin{array}{c}\mathrm{H}_{2}-1 / \mathrm{AlCl}_{3} \\
\text { flowrate }= \\
25 \mathrm{~cm}^{3} \mathrm{~min}^{-1}\end{array}$} & \multicolumn{2}{|c|}{$\begin{array}{c}\mathrm{H}_{2}-1 / \mathrm{AlCl}_{3} \\
\text { flowrate }= \\
30 \mathrm{~cm}^{3} \mathrm{~min}^{-1}\end{array}$} \\
\hline & $\mathbf{a}$ & $\mathbf{c}$ & a & $\mathrm{c}$ & a & c & a & $\mathrm{c}$ & a & c \\
\hline $1 \mathrm{~L}$ & 4.758 & 12.993 & 4.753 & 12.982 & 4.758 & 13.001 & 4.764 & 12.990 & 4.762 & 13.007 \\
\hline $2 \mathrm{~L}$ & 4.761 & 13.013 & 4.754 & 12.994 & 4.760 & 13.008 & 4.758 & 13.004 & 4.761 & 13.008 \\
\hline $3 \mathrm{~L}$ & 4.763 & 13.012 & 4.756 & 12.988 & 4.755 & 12.988 & 4.754 & 12.985 & 4.762 & 13.014 \\
\hline $4 \mathrm{~L}$ & 4.765 & 13.014 & 4.761 & 12.994 & 4.761 & 12.964 & 4.758 & 13.001 & 4.752 & 12.980 \\
\hline $2 \mathrm{R}$ & 4.757 & 12.994 & 4.757 & 12.968 & 4.751 & 12.982 & 4.765 & 12.983 & 4.752 & 12.979 \\
\hline $4 \mathrm{R}$ & 4.763 & 13.005 & 4.750 & 12.976 & 4.757 & 13.005 & 4.756 & 12.984 & 4.744 & 12.972 \\
\hline
\end{tabular}

Table 5.13 Surface roughness of $\mathrm{Al}_{2} \mathrm{O}_{3}$ coatings deposited at different $\mathrm{H}_{2}-1 / \mathrm{AlCl}_{3}$ flow rates

\begin{tabular}{|c|c|c|c|c|}
\hline \multirow{2}{*}{$\begin{array}{c}\mathrm{H}_{2}-1 / \mathrm{AlCl}_{3} \text { flow rate, } \\
\mathrm{cm}^{3} \mathrm{~min}^{-1}\end{array}$} & \multicolumn{4}{|c|}{ Roughness average $\mathrm{R}_{\mathrm{a}}, \mu \mathrm{m}$} \\
\cline { 2 - 5 } & Ave. & Max. & Min. & Standard dev. \\
\hline 10 & 0.42 & 0.52 & 0.29 & 0.06 \\
\hline 15 & 0.71 & 1.1 & 0.45 & 0.17 \\
\hline 20 & 0.33 & 0.39 & 0.26 & 0.038 \\
\hline 25 & 0.43 & 0.58 & 0.35 & 0.053 \\
\hline 30 & 0.41 & 0.48 & 0.36 & 0.031 \\
\hline
\end{tabular}


Table 5.14 Peripheral thickness variation of $\mathrm{Al}_{2} \mathrm{O}_{3}$ coatings deposited at different $\mathrm{H}_{2}-1 / \mathrm{AlCl}_{3}$ flow rates as determined by optical measurement, together with corresponding average rake face coating thicknesses determined by ball-cratering.

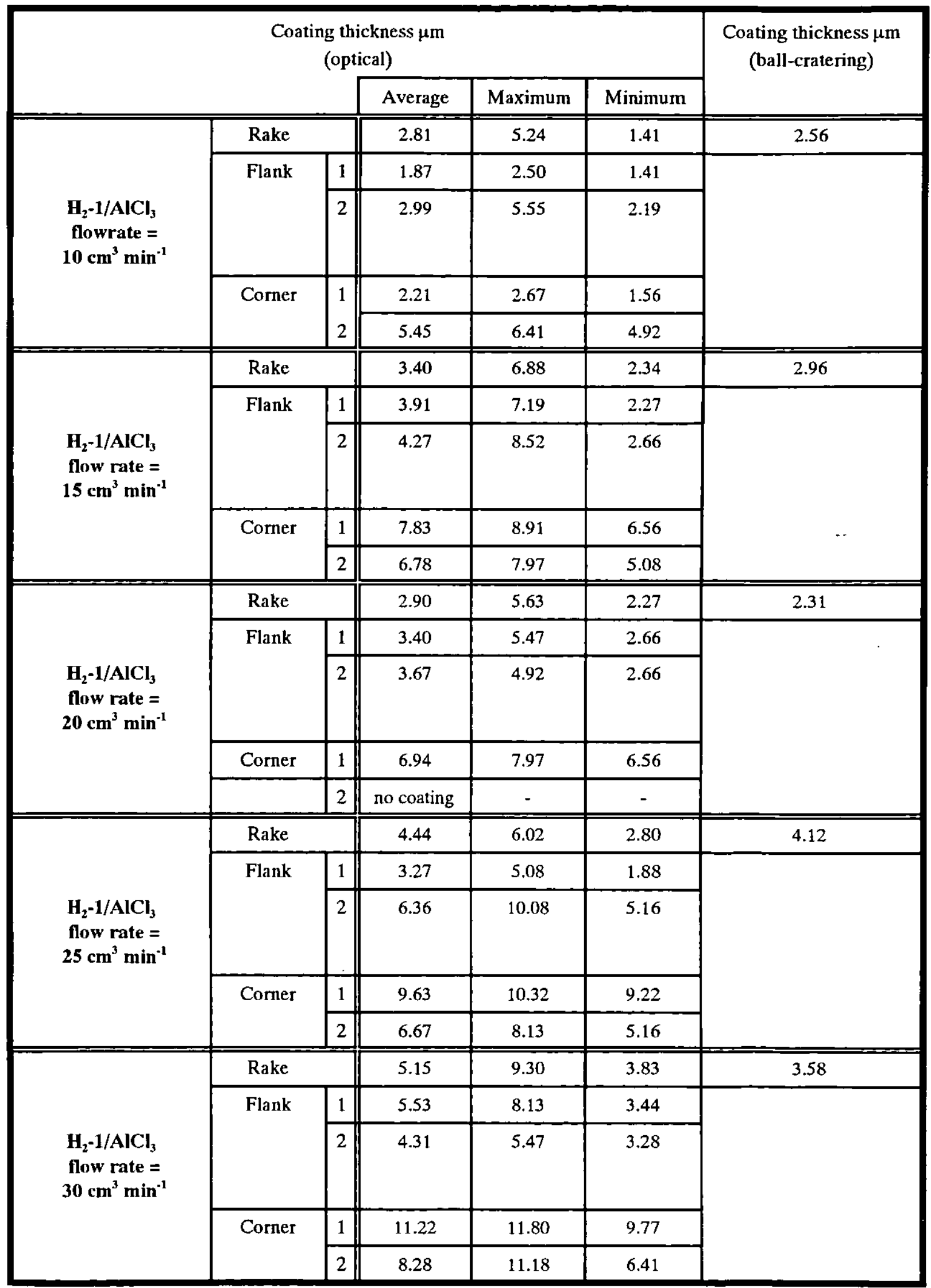


Table 5.15 Microhardness values for $\mathrm{Al}_{2} \mathrm{O}_{3}$ coatings deposited at different $\mathrm{H}_{2}-1 / \mathrm{AlCl}_{3}$ flow rates.

\begin{tabular}{|c|c|c|c|}
\hline \multirow{2}{*}{$\begin{array}{c}\mathrm{H}_{2}-1 / \mathrm{AlCl}_{3} \text { flow rate, } \\
\mathrm{cm}^{3} \mathrm{~min}^{-1}\end{array}$} & \multicolumn{3}{|c|}{ Microbardness, $\mathrm{HV}_{0.025}$} \\
\cline { 2 - 4 } & Ave. & Max. & Min. \\
\hline \hline 10 & 1628 & 2109 & 1349 \\
\hline 15 & 2161 & 2603 & 1691 \\
\hline 20 & 2094 & 2256 & 1853 \\
\hline 25 & 2314 & 2603 & 1853 \\
\hline 30 & 2209 & 2509 & 1797 \\
\hline
\end{tabular}

Table 5.16 Thickness of $\mathrm{Al}_{2} \mathrm{O}_{3}$ coating and $\mathrm{Ti}(\mathrm{C}, \mathrm{N})$ precoating and hardness of HSS substrate of $h c$ inserts from different $\mathrm{H}_{2}-1 / \mathrm{AlCl}_{3}$ flow rate coating runs used in scratch tests.

\begin{tabular}{|c|c|c|c|}
\hline \multirow{2}{*}{$\begin{array}{c}\mathrm{H}_{2}-1 / \mathrm{AlCl}_{3} \\
\text { flowrate, } \mathrm{cm}^{3} \mathrm{~min}^{-1}\end{array}$} & \multicolumn{2}{|c|}{ Coating thickness, $\mu \mathrm{m}$} & \multirow{2}{*}{ Substrate hard ness, HV30 } \\
\cline { 2 - 4 } & $\mathrm{Al}_{2} \mathrm{O}_{3}$ & $\mathrm{Ti}(\mathrm{C}, \mathrm{N})$ & \\
\hline \hline 10 & 1.73 & 1.49 & 934 \\
\hline 15 & 1.86 & 1.42 & 883 \\
\hline 20 & 1.57 & 1.46 & 920 \\
\hline 25 & 2.32 & 1.56 & 935 \\
\hline 30 & 2.66 & 1.49 & 935 \\
\hline
\end{tabular}

Table 5.17 Summary of scratch test results for $\mathrm{Al}_{2} \mathrm{O}_{3}$ coated inserts from different $\mathrm{H}_{2}-1 / \mathrm{AlCl}_{3}$ flow rate coating runs.

\begin{tabular}{|c|c|c|c|c|}
\hline $\begin{array}{c}\mathrm{H}_{2}-1 / \mathrm{AlCl}_{3} \\
\text { flowrate, } \\
\mathrm{cm}^{3} \mathrm{~min}^{-1}\end{array}$ & $\begin{array}{c}\text { Stylus load at } \\
\text { which flaking first } \\
\text { observed, } \mathrm{kg}\end{array}$ & Type of flaking & Degree of flaking & $\begin{array}{c}\text { Critical stylus load at which } \\
\text { "completen coating removal } \\
\text { occurred, } \mathrm{kg}\end{array}$ \\
\hline \hline 10 & 4 & adhesive & little & 7.5 \\
\hline 15 & 4 & adhesive & little & 8.5 \\
\hline 20 & 3 & adhesive & little/moderate & 6.5 \\
\hline 25 & 4 & adhesive & little & 7.5 \\
\hline 30 & 4 & adhesive & little & 8.5 \\
\hline
\end{tabular}




\section{CHAPTER 6}

DISCUSSION OF EXPERIMENTAL RESULTS 


\subsection{DISCUSSION OF EXPERIMENTAL RESULTS}

Since the experimental work carried out for the present study has been described in three parts (see Chapters 3,4 and 5) it was decided that, for clarity, the discussion would be similarly divided. It should be noted, however, that in order to facilitate the most logical explanation of the results obtained in the present work, the discussion will not follow the same order in which the experimental work was originally carried out.

\subsection{Characterisation of Preliminary CVD $\mathrm{Al}_{2} \mathrm{O}_{3}$ Coatings on PM HSS Inserts}

This section is concerned with the characteristics of the preliminary CVD $\mathrm{Al}_{2} \mathrm{O}_{3}$ coatings on the $\mathrm{Ti}(\mathrm{C}, \mathrm{N})$ precoated PM BT42 grade HSS inserts. Not only are these characteristics discussed in detail, in the case of the ac inserts they are also compared to those previously obtained by other investigators for $\mathrm{CVD} \mathrm{Al}_{2} \mathrm{O}_{3}$ coatings on cemented carbide substrates. In addition, the characteristics determined for the preliminary $\mathrm{Al}_{2} \mathrm{O}_{3}$ coatings on the $a c$ and $h c$ inserts in the present work are themselves compared in order to determine the effect (if any) of the post-coating HSS substrate heat treatment on $\mathrm{Al}_{2} \mathrm{O}_{3}$ coating characteristics. In respect of the latter, it is pertinent to point out that the possibility of small variations in coating characteristics arising solely from the different locations of individual $a c$ and $h c$ inserts in the insert holder during CVD of the preliminary $\mathrm{Al}_{2} \mathrm{O}_{3}$ coatings cannot be discounted.

\subsubsection{Auger electron spectroscopy}

From the AES composition-depth profile through the ac insert shown in Figure 4.5, a number of facts are evident. First, the preliminary $\mathrm{Al}_{2} \mathrm{O}_{3}$ coating can be seen to contain two different forms of $\mathrm{Al}$; $\mathrm{Al}$ chemically combined with oxygen $(\mathrm{Al}(\mathrm{o}))$ and elemental $\mathrm{Al}(\mathrm{Al}(\mathrm{e}))$. In an $\alpha$ $-\mathrm{Al}_{2} \mathrm{O}_{3}$ lattice structure, it is known that the oxygen ions form a hexagonally closed packed array and that the $\mathrm{Al}$ ions occupy $2 / 3$ of the octahedral interstitial sites [84]. It is therefore possible that the $\mathrm{Al}(\mathrm{e})$ in the preliminary $\mathrm{Al}_{2} \mathrm{O}_{3}$ coating might occupy some of the vacant octahedral interstitial sites. It can further be seen from Figure 4.5 that whilst the composition of the preliminary $\mathrm{Al}_{2} \mathrm{O}_{3}$ coating clearly changes with depth, with the $\mathrm{Al}(\mathrm{o})$ and oxygen content decreasing and the $\mathrm{Al}(\mathrm{e})$ content initially increasing, its stoichiometry (not including the $\mathrm{Al}(\mathrm{e})$ ) is nonetheless relatively uniform to a depth of $\sim 1.7 \mu \mathrm{m}$ with an approximate formula of $\mathrm{Al}_{1.75} \mathrm{O}_{3}$. Of the order of 2 at.\% $\mathrm{Cr}$ can be seen to be present in the preliminary $\mathrm{Al}_{2} \mathrm{O}_{3}$ coating adjacent to its surface, but this decreases to zero at a depth of $\sim 1.3 \mu \mathrm{m}$. The presence of this $\mathrm{Cr}$ is presumably due to unwanted reaction of the gaseous reactants with the reactor materials during the CVD of the preliminary $\mathrm{Al}_{2} \mathrm{O}_{3}$ coatings. 
It can also be clearly seen from Figure 4.5 that significant intermingling of $\mathrm{Al}_{2} \mathrm{O}_{3}$ coating and $\mathrm{Ti}(\mathrm{C}, \mathrm{N})$ precoating elements has occurred during CVD of the preliminary $\mathrm{Al}_{2} \mathrm{O}_{3}$ coatings, the $\mathrm{Al}_{2} \mathrm{O}_{3}$ coating/Ti(C,N) precoating transition zone (i.e. the zone over which the composition changes from essentially that of the bulk $\mathrm{Ti}(\mathrm{C}, \mathrm{N})$ precoating to that of the bulk $\mathrm{Al}_{2} \mathrm{O}_{3}$ coating) being $\sim 1 \mu \mathrm{m}$ thick. In particular, it can be seen that a small amount of both $\mathrm{Al}(\mathrm{o})$ and $\mathrm{Al}(\mathrm{e})$ are present in the upper part of the $\operatorname{Ti}(C, N)$ precoating, and further that oxygen is not only present in substantial quantities in this location, but also, at a lower level, throughout the $\mathrm{Ti}(\mathrm{C}, \mathrm{N})$ precoating and indeed into the surface of the HSS substrate itself. Similarly, Ti, C and $\mathrm{N}$ can be seen to be present, in substantial quantities in the case of the $\mathrm{Ti}$ and $\mathrm{N}$, in the lower part of the $\mathrm{Al}_{2} \mathrm{O}_{3}$ coating. With reference to the above, it is tentatively suggested that the upper part of the $\mathrm{Ti}(\mathrm{C}, \mathrm{N})$ precoating now consists of titanium oxides (mainly $\mathrm{Ti}_{3} \mathrm{O}_{5}$ or $\mathrm{Ti}_{2} \mathrm{O}_{3}$ and possibly $\mathrm{TiO}_{2}$ ) plus a complex titanium oxycarbonitride $\mathrm{Ti}\left(\mathrm{O}_{\mathrm{x}} \mathrm{C}_{y} \mathrm{~N}_{z}\right)$ compound possibly also containing $\mathrm{Al}$. It is, however, felt to be inappropriate, at this juncture, to make even a tentative suggestion regarding the form in which the $\mathrm{Ti}, \mathrm{C}$ and $\mathrm{N}$ are present in the lower part of the $\mathrm{Al}_{2} \mathrm{O}_{3}$ coating. This will, however, be addressed in Section 6.2.1.

The presence of the oxygen in substantial quantities in the upper part of the $\mathrm{Ti}(\mathrm{C}, \mathrm{N})$ precoating and, at a lower level, throughout its thickness is attributed to a strong "substrate-type" reaction between the $\mathrm{Ti}(\mathrm{C}, \mathrm{N})$ precoating and either the $\mathrm{H}_{2} \mathrm{O}$ formed by the homogeneous gas phase reaction of the $\mathrm{CO}_{2}$ and $\mathrm{H}_{2}$ gaseous reactants or directly with the $\mathrm{CO}_{2}$ reactant gas itself. It.is tempting to suggest that the aforementioned additional presence of the $\mathrm{Al}(\mathrm{O})$ and $\mathrm{Al}(\mathrm{e})$ in the upper part of the $\mathrm{Ti}(\mathrm{C}, \mathrm{N})$ precoating and that of the $\mathrm{Ti}, \mathrm{C}$ and $\mathrm{N}$, in the lower part of the $\mathrm{Al}_{2} \mathrm{O}_{3}$ coating can be attributed solely to interdiffusion between the $\mathrm{Al}_{2} \mathrm{O}_{3}$ coating and $\mathrm{Ti}(\mathrm{C}, \mathrm{N})$ precoating elements at the high temperature $\left(1050^{\circ} \mathrm{C}\right)$ at which CVD of the preliminary $\mathrm{Al}_{2} \mathrm{O}_{3}$ coatings was carried out. However, it can be seen from Figure 4.5 that the depth into the $\mathrm{Al}_{2} \mathrm{O}_{3}$ coating to which the $\mathrm{Ti}$ is present is greater than that of the $\mathrm{C}$ and equal to that of the $\mathrm{N}$. Since $\mathrm{Ti}$ atoms are approximately twice the size of $\mathrm{C}$ and $\mathrm{N}$ atoms [85], then if the presence of the $\mathrm{Ti}$ in the lower part of the $\mathrm{Al}_{2} \mathrm{O}_{3}$ coating was solely or even principally the result of interdiffusion, it would have been expected that it would not have diffused as far into the coating as the $\mathrm{C}$ and $\mathrm{N}$. The fact that this is not the case strongly implies that interdiffusion is not the sole mechanism responsible for the observed intermingling of the $\mathrm{Al}_{2} \mathrm{O}_{3}$ coating and $\mathrm{Ti}(\mathrm{C}, \mathrm{N})$ precoating elements i.e. for the original formation of the $\mathrm{Al}_{2} \mathrm{O}_{3}$ coating/Ti(C,N) precoating transition zone. This matter will be discussed further in Section 6.2.1.

Finally, the stoichiometry of the $\mathrm{Ti}(\mathrm{C}, \mathrm{N})$ precoating can be seen from Figure 4.5 to be reasonably uniform, with a formula of $\sim \operatorname{Ti}\left(\mathrm{C}_{0.2} \mathrm{~N}_{0.8}\right)$, until the $\mathrm{Ti}(\mathrm{C}, \mathrm{N})$ precoating/HSS substrate interface is approached. Significant intermingling can be seen to have occurred between the elemental constituents of the $\mathrm{Ti}(\mathrm{C}, \mathrm{N})$ precoating and the HSS substrate, which this time is attributed solely to interdiffusion at the high temperatures at which the $\operatorname{Ti}(\mathrm{C}, \mathrm{N})$ precoating and the $\mathrm{Al}_{2} \mathrm{O}_{3}$ coating were deposited. 
Comparing the AES composition-depth profile results obtained for the $a c$ insert in the present work with those previously obtained by Layyous and Werthiem [57] and Mehrotro and Quinto [60] for multilayer $\mathrm{Al}_{2} \mathrm{O}_{3} / \mathrm{TiN} / \mathrm{Al}_{2} \mathrm{O}_{3} / \mathrm{TiC}$ (see Figure 2.9) and TiN/Al $\mathrm{O}_{3} / \mathrm{TiC}$ (see Figure 2.10) coatings on cemented carbide substrates, respectively, it must be concluded that either these workers have not distinguished between $\mathrm{Al}(\mathrm{e})$ and $\mathrm{Al}(\mathrm{o})$ or that they did not detect any $\mathrm{Al}(\mathrm{e})$ in their $\mathrm{Al}_{2} \mathrm{O}_{3}$ coatings. With regard to the latter, it is pertinent to note that Smith and Lewus [86] detected a maximum of $\sim 9$ at. $\% \mathrm{Al}(\mathrm{e})$ in the $\mathrm{Al}_{2} \mathrm{O}_{3}$ coating layer of a commercial $\mathrm{Al}_{2} \mathrm{O}_{3} / \mathrm{TiC}$ coated cemented carbide insert. The bulk stoichiometry of the preliminary $\mathrm{Al}_{2} \mathrm{O}_{3}$ coating determined in the present work is lower than that of $\mathrm{Al}_{2.3} \mathrm{O}_{3}$ reported by Mehrotro and Quinto for the $\mathrm{Al}_{2} \mathrm{O}_{3}$ coating which they studied and significantly lower than the range of $\mathrm{Al}_{2} \mathrm{O}_{2}$ to $\mathrm{Al}_{2} \mathrm{O}_{1.5}$ determined by Skogsmo and Norden [61] for $\mathrm{Al}_{2} \mathrm{O}_{3}$ coatings chemically vapour deposited on $\mathrm{TiC}$ coated cemented carbide substrates. The latter may be due in part to the accuracy of the EPMA and AES analysis techniques respectively employed by Skogsmo and Norden and used in the present work to determine $\mathrm{Al}_{2} \mathrm{O}_{3}$ coating composition, and/or to the coatings being deposited under different deposition conditions. It should be noted that although in their work on $\mathrm{Al}_{2} \mathrm{O}_{3}$ coatings chemically vapour deposited on $\mathrm{TiC}$ coated cemented carbide substrates, Lhermitte-Sebire et al $[20,56]$ presented AES composition-depth profile results for the $\mathrm{Al}_{2} \mathrm{O}_{3}$ coating/TiC precoating interface, no comment was made regarding the stoichiometry of the $\mathrm{Al}_{2} \mathrm{O}_{3}$ coatings, in particular the amount of excess $\mathrm{Al}$ clearly present in them. In partial agreement with the present work, in their work both Lhermitte-Sebire et al [20] and Layyous and Werthiem [57] detected substantial intermingling between the elemental constituents of the $\mathrm{Al}_{2} \mathrm{O}_{3}$ coatings and the precoatings which they referred to as interdiffusion. Mehrotro and Quinto [60], however, observed relatively little such interdiffusion. Also in partial agreement with the suggestion made in the present work, Lhermitte-Sebire et al [20] reported the presence of a thin layer of titanium oxides $\left(\mathrm{Ti}_{3} \mathrm{O}_{5}\right.$ and $\left.\mathrm{TiO}_{2}\right)$ and possibly aluminium titanate at the $\mathrm{Al}_{2} \mathrm{O}_{3}$ coating/TiC precoating (oxidised) interface. Finally, with regard to the presence of oxygen all the way through the $\operatorname{Ti}(\mathrm{C}, \mathrm{N})$ precoating and into the surface of the HSS substrate observed in the present work, both Mehrotro and Quinto and Lhermitte-Sebire et al [20] have reported diffusion of oxygen from the $\mathrm{Al}_{2} \mathrm{O}_{3}$ coating through the precoating and into the surface of the cemented carbide substrate.

With regard to the AES results obtained after the obligatory HSS substrate heat treatment in the present work, as can be seen from Figure 4.14 which shows the AES composition-depth profile through the $h c$ insert analysed, broad similarities are evident with the composition-depth profile previously obtained for the $a c$ insert (Figure 4.5). In particular, the $\mathrm{Al}_{2} \mathrm{O}_{3}$ coating on the $h c$ insert again contains $\mathrm{Al}(\mathrm{o})$ and $\mathrm{Al}(\mathrm{e})$, and its stoichiometry (not including the $\mathrm{Al}(\mathrm{e})$ ) is relatively uniform to a depth of $\sim 2 \mu \mathrm{m}$ with an approximate formula of $\mathrm{Al}_{1.8} \mathrm{O}_{3}$. It is further evident from Figure 4.14 that a small amount of $\mathrm{Cr}$ is present in the $\mathrm{Al}_{2} \mathrm{O}_{3}$ coating adjacent to its surface as found for the $a c$ insert. Figure 4.14 also shows that $\mathrm{Al}(\mathrm{e})$ and $\mathrm{Al}(\mathrm{O})$ are again present in the upper part of the $\mathrm{Ti}(\mathrm{C}, \mathrm{N})$ precoating and that oxygen is again not only present in substantial quantities in this location, but also, at a lower level, 
throughout the $\mathrm{Ti}(\mathrm{C}, \mathrm{N})$ precoating and into the HSS substrate. Similarly, $\mathrm{Ti}, \mathrm{C}$ and $\mathrm{N}$ are present, in substantial quantities in the case of the $\mathrm{Ti}$ and $\mathrm{N}$, in the lower part of the $\mathrm{Al}_{2} \mathrm{O}_{3}$ coating as found for the $a c$ insert. With reference to the above, the tentative suggestion made regarding the upper part of the $\mathrm{Ti}(\mathrm{C}, \mathrm{N})$ precoating on the $a c$ insert is clearly still valid in the case of the $h c$ insert. However, it appears from a comparison of Figures 4.14 and 4.5 that the $\mathrm{Al}_{2} \mathrm{O}_{3}$ coating/Ti(C,N) precoating transition zone on the $h c$ insert is $\sim 1.5$ times thicker than that on the $a c$ insert. It is thought likely that this increase in transition zone thickness can be attributed solely to interdiffusion at the elevated austenitisation temperature employed during the post-coating HSS substrate heat treatment. This viewpoint is reinforced by the fact that comparison of Figures 4.14 and 4.5 reveals the interdiffusion between the elemental constituents of the $\operatorname{Ti}(\mathrm{C}, \mathrm{N})$ precoating and the HSS substrate on the $h c$ insert to be more extensive than on the $a c$ insert. Finally, as on the $a c$ insert, the stoichiometry of the $\operatorname{Ti}(C, N)$ precoating on the $h c$ insert can be seen from Figure 4.14 to be relatively uniform, with a formula of $\sim \operatorname{Ti}\left(\mathrm{C}_{0.2} \mathrm{~N}_{0.8}\right)$, until the $\mathrm{Ti}(\mathrm{C}, \mathrm{N})$ precoating/HSS substrate interface is approached.

Overall it is therefore concluded that the heat treatment used to harden the HSS substrate has not significantly affected the bulk composition of the preliminary $\mathrm{Al}_{2} \mathrm{O}_{3}$ coating but that it has caused an increase in the thickness of the $\mathrm{Al}_{2} \mathrm{O}_{3}$ coating/Ti(C,N) precoating transition zone (and in the interdiffusion between the $\mathrm{Ti}(\mathrm{C}, \mathrm{N})$ precoating and the HSS substrate) as a result of the elevated austenitisation temperature employed during the post-coating heat treatment.

\subsubsection{X-ray diffraction}

As previously described in Section 4.1.1 and shown in Figure 4.1, the $\alpha-\mathrm{Al}_{2} \mathrm{O}_{3}$ powder used in the present work for comparison purposes was found to exhibit relative $\mathrm{X}$-ray intensities which correspond very well indeed with those quoted for $\alpha-\mathrm{Al}_{2} \mathrm{O}_{3}$ in the ASTM powder diffraction file (card no. 10-173 [82]). Consequently, as desired, the $\mathrm{Al}_{2} \mathrm{O}_{3}$ powder sample can be classified as being randomly oriented. However, the lattice parameter values of a $4.747 \AA$ and $\mathrm{c}-12.956 \AA$ determined for the $\mathrm{Al}_{2} \mathrm{O}_{3}$ powder (see Table 4.2) are substantially lower than the values of a $-4.758 \AA$ and $\mathrm{c}-12.991 \AA$ reported for $\mathrm{Al}_{2} \mathrm{O}_{3}$ in the ASTM powder diffraction file.

As is evident from Figure 4.2, the magnitudes of the relative X-ray intensities obtained for the preliminary $\mathrm{Al}_{2} \mathrm{O}_{3}$ coating on the rake face of the $a c$ inserts characterised in the present work are considerably smaller than those obtained for the $\alpha-\mathrm{Al}_{2} \mathrm{O}_{3}$ powder. As previously described in Section 4.1.1, these low relative intensities are related to preliminary $\mathrm{Al}_{2} \mathrm{O}_{3}$ coating thickness. It is, however, further evident from Figure 4.2 that the coating on the $a c$ inserts is $\alpha-\mathrm{Al}_{2} \mathrm{O}_{3}$, but that it exhibits preferred orientation of the $\{11 \overline{2} 3\}$ planes. The latter is somewhat different to $\mathrm{X}$-ray diffraction results for $\mathrm{Al}_{2} \mathrm{O}_{3}$ coatings obtained by other workers 
$[24,44,43]$. Kuo et al [24] reported that $\mathrm{Al}_{2} \mathrm{O}_{3}$ coatings chemically vapour deposited on steel substrates exhibited preferred orientations of the $\{10 \overline{1} 4\}$ and $\{03 \overline{3} 0\}$ planes. In the case of cemented carbide substrates, whilst Park et al [44] found that $\mathrm{Al}_{2} \mathrm{O}_{3}$ coatings chemically vapour deposited on TiN coated cemented carbide substrates exhibited preferred orientations of the $\{10 \overline{1} 4\}$ and $\{11 \overline{2} 6\}$ planes, $\mathrm{Kim}$ et al [43] found that $\mathrm{Al}_{2} \mathrm{O}_{3}$ coatings deposited on similar substrates exhibited preferred orientation of the $\{10 \overline{1} 4\}$ planes. Since it has previously been established by the latter workers that the crystallographic structure of $\mathrm{Al}_{2} \mathrm{O}_{3}$ coatings changes with increasing deposition temperature, it seems reasonable to suggest that the different $\mathrm{Al}_{2} \mathrm{O}_{3}$ coating preferred orientations observed in the present work and in that carried out by Kuo et al [24], can be partially attributed to the different deposition temperatures employed $\left(1050^{\circ} \mathrm{C}\right.$ in the present work c.f. 860 to $970^{\circ} \mathrm{C}$ in the work of Kuo et al - see Section 2.1).

The lattice parameter values, particularly the $c$ values, obtained for the preliminary $\mathrm{Al}_{2} \mathrm{O}_{3}$ coatings on the rake face of the $a c$ inserts in the present work can be seen from Table 4.2 to be higher than those determined for the $\mathrm{Al}_{2} \mathrm{O}_{3}$ powder in the present work, but do correspond very well with the values quoted for $\mathrm{Al}_{2} \mathrm{O}_{3}$ in the ASTM powder diffraction file. The latter is compatible with the composition of the $\mathrm{Al}_{2} \mathrm{O}_{3}$ coating on the ac inserts having been found to be relatively close to stoichiometric (see Section 6.1.1). With reference to Table 4.2, it should be noted that although there is a slight decrease in the lattice parameter values in going from $a c$ insert 1 (located towards the inlet end of the reactor coating chamber) to ac insert 4 (located towards the outlet end of the reactor coating chamber), such a slight decrease is not considered to be significant. Surprisingly, no lattice parameter values for $\mathrm{Al}_{2} \mathrm{O}_{3}$ coatings were found in the literature to permit comparison with the results of the present work.

With regard to the X-ray results obtained for the $h c$ inserts in the present work, it can be seen from Figure 4.13 that, as with the $a c$ inserts and for the same reason, the magnitudes of the relative $\mathrm{X}$-ray intensities obtained for the preliminary $\mathrm{Al}_{2} \mathrm{O}_{3}$ coatings on the rake face of the $h c$ inserts are considerably smaller than those obtained for the $\alpha-\mathrm{Al}_{2} \mathrm{O}_{3}$ powder. It is, however, further evident from Figure 4.13 that the coating is still of the $\alpha-\mathrm{Al}_{2} \mathrm{O}_{3}$ crystal form and exhibits essentially the same degree and type of preferred orientation (of the $\{11 \overline{2} 3\}$ planes) as found for the $a c$ inserts (see Figure 4.2). As can be seen from Table 4.6, the lattice parameter values, particularly the $\mathrm{c}$ values, obtained for the $\mathrm{Al}_{2} \mathrm{O}_{3}$ coatings on the rake face of the $h c$ inserts are slightly lower than those obtained for the $\mathrm{Al}_{2} \mathrm{O}_{3}$ coatings on the ac inserts (see Table 4.2), but do not exhibit a slight decrease in going from insert 1 to insert 4 as observed with the $a c$ inserts, substantiating the suggestion made earlier in this section that the latter is not significant. Given that, as described in Section 6.1.1, the bulk preliminary $\mathrm{Al}_{2} \mathrm{O}_{3}$ coating on the $h c$ insert had an approximate formula of $\mathrm{Al}_{1.8} \mathrm{O}_{3}$ as compared to $\mathrm{Al}_{1.75} \mathrm{O}_{3}$ in the case of the $a c$ insert, it seems unlikely that the slightly lower $\mathrm{Al}_{2} \mathrm{O}_{3}$ coating lattice parameter values obtained for the $h c$ as compared to the $a c$ inserts can be accounted for in terms of coating stoichiometries. Similar, but significantly larger reductions in coating lattice parameter values 
as a result of post-coating HSS substrate heat treatment, have previously been observed by Whittle [6] and Lewus [11] for CVD TiN and TiC coated PM BT42 HSS inserts respectively. In both cases, these reductions have been suggested to be due to a reduction in the level of internal strain in the coatings caused by cracking during post-coating HSS substrate heat treatment. Given the cracks observed in the preliminary $\mathrm{Al}_{2} \mathrm{O}_{3}$ coating in the present work following post-coating HSS substrate heat treatment (see Section 6.1.3), it is thought likely that this suggestion is also applicable to the present work.

Notwithstanding the slightly lower $\mathrm{Al}_{2} \mathrm{O}_{3}$ coating lattice parameter values obtained for the $h c$ inserts as compared to the $a c$ inserts in the present work, it is concluded that, overall, the heat treatment used to harden the HSS substrate has had no significant effect on the crystal structure of the $\mathrm{Al}_{2} \mathrm{O}_{3}$ coatings.

\subsubsection{Optical microscopy - cross-section}

Optical examination of the polished and etched cross-section through one of the $a c$ inserts characterised in the present work revealed that the preliminary $\mathrm{Al}_{2} \mathrm{O}_{3}$ coating extended all round the periphery of the $\mathrm{Ti}(\mathrm{C}, \mathrm{N})$ precoated PM HSS insert. However, it was also observed that although the thickness of the $\mathrm{Al}_{2} \mathrm{O}_{3}$ coating was fairly uniform on the rake face of the $a c$ insert, on one flank face and corresponding corner of the insert the $\mathrm{Al}_{2} \mathrm{O}_{3}$ coating was very thin, whilst on the other flank face and corresponding comer, particularly the latter, it was significantly thicker than on the rake face. This is also evident from the preliminary $\mathrm{Al}_{2} \mathrm{O}_{3}$ coating thickness values presented in Table 4.4, and could be due to the location of the flank faces of the insert relative to the reactant gas flow and/or to the gas flow conditions inside the CVD reactor during deposition of the preliminary $\mathrm{Al}_{2} \mathrm{O}_{3}$ coatings. Similar variations in coating thickness have been observed by Funk et al [31] and Pauer et al [55] in the case of $\mathrm{Al}_{2} \mathrm{O}_{3}$ coatings chemically vapour deposited on uncoated and $\mathrm{TiC}$ coated cemented carbide substrates respectively. In partial agreement with the suggestion made above, it has been suggested by the latter workers that the increase in $\mathrm{Al}_{2} \mathrm{O}_{3}$ coating thickness at the edges (i.e. corners) of the substrates could be attributed to the nature of the gas flow conditions and the rapid decomposition of the reactants leading to high local supersaturation.

From the optical cross-sections through the rake and flank faces of the $a c$ insert in the present work, shown in Figure 4.7, it can also be seen that the surface of the preliminary $\mathrm{Al}_{2} \mathrm{O}_{3}$ coating on the flank face of the insert in particular is rather uneven. Whilst, in some regions, Figure 4.7 clearly shows this unevenness to be an inherent feature of the $\mathrm{Al}_{2} \mathrm{O}_{3}$ coating, in others it can be attributed to the underlying $\mathrm{Ti}(\mathrm{C}, \mathrm{N})$ precoating. As is also evident from Figure 4.7, with the exception of isolated porosity, no major defects are visible in the preliminary $\mathrm{Al}_{2} \mathrm{O}_{3}$ coating and the $\mathrm{Al}_{2} \mathrm{O}_{3}$ coating/Ti(C,N) precoating interface appears to be continuous. From a closer examination of these optical cross-sections, particularly that through the flank face 
of the $a c$ insert, it is possible to just discern a thin band in the upper part of the $\operatorname{Ti}(\mathrm{C}, \mathrm{N})$ precoating immediately adjacent to its interface with the $\mathrm{Al}_{2} \mathrm{O}_{3}$ coating. The presence of this band will be discussed in Section 6.1.4. In contrast to the present work, optical cross-sections presented in the literature by Funk et al [31] and Kalish and Peters [16] for $\mathrm{Al}_{2} \mathrm{O}_{3}$ coated cemented carbide and $\mathrm{Ti}(\mathrm{C}, \mathrm{N})$ precoated cemented carbide substrates, respectively, show a smooth $\mathrm{Al}_{2} \mathrm{O}_{3}$ coating surface, with no evidence of a thin band in the upper part of the $\operatorname{Ti}(\mathrm{C}, \mathrm{N})$ precoating immediately adjacent to its interface with the $\mathrm{Al}_{2} \mathrm{O}_{3}$ coating.

The $\mathrm{Ti}(\mathrm{C}, \mathrm{N})$ precoating/HSS substrate interface on the rake and the flank faces of the ac insert characterised in the present work also appears from Figure 4.7 to be continuous, although there is some isolated porosity in the $\mathrm{Ti}(\mathrm{C}, \mathrm{N})$ precoating adjacent to this interface. It is also evident from Figure 4.7 that the microstructure of the PM HSS substrate consists of relatively large angular carbides in a coarse-grained, semi-martensitic matrix, with a small amount of a dark etching phase, previously identified as pearlite [87], evenly distributed throughout the microstructure at the grain boundaries. A continuous band of pearlite can also be seen to be present in the HSS substrate adjacent to the Ti(C,N) precoating/HSS substrate interface on both the rake and flank faces. A similar substrate microstructural feature has previously been observed by Abbas [9] and Lewus [11] for CVD TiN and TiC coated PM HSS inserts, respectively. These workers could not explain its presence. In their work on chromium carbide coated steel substrates, however, Perry and Hovarth $[88,89]$ observed a similar band of pearlite and accounted for its presence in terms of compositional shifts on the iron-chromium-carbon ternary phase diagram.

Optical examination of the polished and etched cross-section through one of the $h c$ inserts characterised in the present work revealed that the preliminary $\mathrm{Al}_{2} \mathrm{O}_{3}$ coating was still present all around the periphery of the insert. It was also observed that although the thickness of the $\mathrm{Al}_{2} \mathrm{O}_{3}$ coating was fairly uniform on the rake face of the $h c$ insert, on one flank face and corresponding corner of the insert the $\mathrm{Al}_{2} \mathrm{O}_{3}$ coating was very thin, whilst on the other flank face and corresponding corner its thickness was comparable to that on the rake face. This is also evident from the preliminary $\mathrm{Al}_{2} \mathrm{O}_{3}$ coating thickness values presented in Table 4.8, but is somewhat different to the results previously obtained for the $a c$ insert, where it was found that on one flank face and corresponding corner, particularly the latter, the $\mathrm{Al}_{2} \mathrm{O}_{3}$ coating was significantly thicker than on the rake face. This difference, also evident from a comparison of the $\mathrm{Al}_{2} \mathrm{O}_{3}$ coating thickness values presented in Tables 4.8 and 4.4 for the $h c$ and $a c$ inserts respectively, is principally attributed to the different location of the $a c$ and $h c$ inserts in question in the insert holder during CVD of the preliminary $\mathrm{Al}_{2} \mathrm{O}_{3}$ coatings.

The optical cross-sections through the rake and flank faces of the $h c$ insert, shown in Figure 4.16, exhibit some common features with those through the rake and flank faces of the $a c$ insert. In particular, it can be seen that preliminary $\mathrm{Al}_{2} \mathrm{O}_{3}$ coating on the flank face of the $h c$ insert is again rather uneven, isolated porosity is present in the $\mathrm{Al}_{2} \mathrm{O}_{3}$ coating, the $\mathrm{Al}_{2} \mathrm{O}_{3}$ 
coating/Ti(C,N) precoating interface appears to be still continuous, the thin band is still just discernible in the upper part of the $\mathrm{Ti}(\mathrm{C}, \mathrm{N})$ precoating immediately adjacent to its interface with the $\mathrm{Al}_{2} \mathrm{O}_{3}$ coating, the $\mathrm{Ti}(\mathrm{C}, \mathrm{N})$ precoating/HSS substrate interface appears to be still continuous and there is again some isolated porosity in the precoating adjacent to this interface. However, one major difference observed between the $\mathrm{Al}_{2} \mathrm{O}_{3}$ coating on the $h c$ insert and that on the $a c$ insert is the presence of cracks in the coating at the cutting edge and in some adjacent areas on the rake face of the former (not evident in Figure 4.16) which were not observed in the case of the latter. Similar cracks have previously been observed in CVD TiN [6] and TiC [11] coatings on PM HSS substrates following post-coating HSS substrate heat treatment, and have been attributed to the coatings not being able to expand enough to accommodate the $\sim 4 \%$ volumetric expansion of the substrate accompanying the austenite to martensite transformation during this heat treatment. It is thought that this is also the reason for the observed presence of the cracks in the preliminary $\mathrm{Al}_{2} \mathrm{O}_{3}$ coating on the $h c$ insert in the present work. It is also evident from Figure 4.16 that the microstructure of the PM HSS substrate of the $h c$ insert in the present work can generally be seen to consist of relatively large angular carbides in a rather coarse martensitic matrix. This is typical of the microstructure of vacuum sintered HSS hardened and tempered without an intermediate anneal. Figure 4.16 also reveals that on both the rake and the flank faces of the $h c$ insert, a band $\sim 15 \mu \mathrm{m}$ wide is present in the HSS substrate adjacent to its interface with the $\mathrm{Ti}(\mathrm{C}, \mathrm{N})$ precoating, in which the prior austenite grains are significantly smaller, and the martensite significantly finer, than in the bulk of the substrate. It is almost certain that this band in the $h c$ insert originates from the band of pearlite found in the same position on the rake and flank faces of the ac insert (see Figure 4.7). The same substrate microstructural feature has previously been noted for CVD TiN and TiC coated PM HSS inserts $[6,11]$.

Overall, it can be concluded that the only effect of the post-coating HSS substrate heat treatment on the preliminary $\mathrm{Al}_{2} \mathrm{O}_{3}$ coating, evident on the optical cross-sections, is cracking of the coating at the cutting edge and in some adjacent areas on the insert rake face.

\subsubsection{Optical microscopy - taper section}

As previously described in Section 6.1.3 and shown in Figures 4.7 and 4.16, on the optical cross-sections through the rake and flank faces, particularly the latter, of one of the $a c$ and $h c$ inserts respectively, a thin band was just discernible in the upper part of the $\operatorname{Ti}(\mathrm{C}, \mathrm{N})$ precoating immediately adjacent to its interface with the $\mathrm{Al}_{2} \mathrm{O}_{3}$ coating. As described earlier in Section 4.1.6 (and intimated in Section 4.2), the $a c$ and $h c$ taper-sectioned inserts were respectively employed to facilitate a proper, relatively high magnification optical examination of this band. From the optical taper sections through the rake face of the $a c$ and $h c$ inserts shown in Figures 4.10 and 4.18 respectively, a thin layer can quite clearly be seen to be present in the upper part of the $\mathrm{Ti}(\mathrm{C}, \mathrm{N})$ precoating directly adjacent to its interface with the $\mathrm{Al}_{2} \mathrm{O}_{3}$ 
coating. Unexpectedly, it can also be seen that the lower part of the $\mathrm{Al}_{2} \mathrm{O}_{3}$ coating immediately adjacent to this interface has a "mottled" appearance. From the AES composition-depth profile results obtained for the preliminary $\mathrm{Al}_{2} \mathrm{O}_{3}$ coated $a c$ and $h c$ inserts, it was tentatively suggested (see Section 6.1.1) that the upper part of the $\mathrm{Ti}(\mathrm{C}, \mathrm{N})$ precoating now consists $\mathrm{Ti}_{3} \mathrm{O}_{5}$ or $\mathrm{Ti}_{2} \mathrm{O}_{3}$ and possibly $\mathrm{TiO}_{2}$ plus a complex $\mathrm{Ti}\left(\mathrm{O}_{\mathrm{x}} \mathrm{C}_{\mathrm{y}} \mathrm{N}_{z}\right)$ compound. It seems reasonable to assume that the thin layer observed in the upper part of the $\mathrm{Ti}(\mathrm{C}, \mathrm{N})$ precoating on the optical taper sections through the rake face of the $a c$ and $h c$ inserts corresponds to this. The AES composition-depth profile results for the preliminary $\mathrm{Al}_{2} \mathrm{O}_{3}$ coated $a c$ and $h c$ inserts also revealed the presence of $\mathrm{Ti}, \mathrm{C}$ and $\mathrm{N}$ in the lower part of the $\mathrm{Al}_{2} \mathrm{O}_{3}$ coating. Although it was felt inappropriate in Section 6.1.1 to make even a tentative suggestion regarding the form in which these elements are present in this location, it does, nonetheless, seem reasonable to now tentatively suggest that the "mottled" appearance of the lower part of the preliminary $\mathrm{Al}_{2} \mathrm{O}_{3}$ coating on the optical taper sections through the rake face of the $a c$ and $h c$ inserts may well be associated in some way with the presence of the $\mathrm{Ti}, \mathrm{C}$ and $\mathrm{N}$ there.

It was, however, also found (see Section 6.1.1) from the AES composition-depth profile results that the $\mathrm{Al}_{2} \mathrm{O}_{3}$ coating/Ti(C,N) precoating transition zone on the hc insert was approximately 1.5 times as thick as that on the $a c$ insert. It was suggested that this increase can be attributed solely to interdiffusion at the elevated austenitisation temperature employed during HSS substrate heat treatment, but that interdiffusion was not the sole mechanism responsible for the original formation of the $\mathrm{Al}_{2} \mathrm{O}_{3}$ coating/Ti(C,N) precoating transition zone. The fact that the increase in thickness of this zone on the $h c$ insert relative to the $a c$ insert, evident from the AES composition-depth profile results, does not appear to be reflected in the extent of either the thin layer in the upper part of the Ti(C,N) precoating or of the "mottled" region of the lower part of the $\mathrm{Al}_{2} \mathrm{O}_{3}$ coating on the optical taper sections through the $a c$ and $h c$ inserts shown in Figures 4.10 and 4.18 respectively, is seen as adding weight to this suggestion. However, it is evident from these figures that both of these microstructural features are more clearly defined in the case of the $h c$ insert than in that of the $a c$ insert.

\subsubsection{Fractography}

As previously described in Section 4.1.7, it was found from the fractography work carried out on the $a c$ insert in the present work that, in general, the bulk grain structure of the preliminary $\mathrm{Al}_{2} \mathrm{O}_{3}$ coating (and of the $\mathrm{Ti}(\mathrm{C}, \mathrm{N})$ precoating) was relatively uniform along its length, with the fractograph presented in Figure 4.11 being representative of the grain structure(s) most often observed. As can be seen from this figure, the structure of the $\mathrm{Al}_{2} \mathrm{O}_{3}$ coating consists mainly of coarse grains (much coarser than those of the $\mathrm{Ti}(\mathrm{C}, \mathrm{N})$ precoating), exhibiting a slight tendency towards columnar growth. Directly adjacent to its interface with the $\mathrm{Ti}(\mathrm{C}, \mathrm{N})$ precoating, however, some much finer grains are evident in the $\mathrm{Al}_{2} \mathrm{O}_{3}$ coating. Also just discernible in some regions in Figure 4.11 is the presence of a thin layer in the upper 
part of the $\mathrm{Ti}(\mathrm{C}, \mathrm{N})$ precoating directly adjacent to its interface with the $\mathrm{Al}_{2} \mathrm{O}_{3}$ coating. Clearly, this must correspond to the thin layer observed optically in this location on the cross-section (Figure 4.7) and the taper section (Figure 4.10) through an $a c$ insert, which, it was stated in Section 6.1.4, it was reasonable to assume corresponds to the $\mathrm{Ti}_{3} \mathrm{O}_{5}$ or $\mathrm{Ti}_{2} \mathrm{O}_{3}$ and possibly $\mathrm{TiO}_{2}$ plus the complex $\mathrm{Ti}\left(\mathrm{O}_{x} \mathrm{C}_{y} \mathrm{~N}_{z}\right)$ compound, referred to initially in Section 6.1.1. The bulk grain structure of the preliminary $\mathrm{Al}_{2} \mathrm{O}_{3}$ coating observed in the present work is comparable with those presented in the literature (see Section 2.8) for $\mathrm{Al}_{2} \mathrm{O}_{3}$ coatings chemically vapour deposited on uncoated/precoated cemented carbide substrates $[16,18,63-65]$, although the latter are generally finer, having been deposited at reduced total pressures.

It was similarly found from the fractography work carried out on the $h c$ insert in the present work (see Section 4.2), that the bulk grain structure of the preliminary $\mathrm{Al}_{2} \mathrm{O}_{3}$ coating (and of the $\mathrm{Ti}(\mathrm{C}, \mathrm{N})$ precoating) was relatively uniform along its length, with the fractograph presented in Figure 4.19 being representative of the grain structure(s) most often observed. It is evident from this figure (by comparison with Figure 4.11) that the bulk grain structure of the $\mathrm{Al}_{2} \mathrm{O}_{3}$ coating is much more clearly delineated in the case of the $h c$ insert than in that of the ac insert. The structure of the preliminary $\mathrm{Al}_{2} \mathrm{O}_{3}$ coating on the $h c$ insert can clearly be seen to consist mainly of coarse grains (much coarser than those of the $\mathrm{Ti}(\mathrm{C}, \mathrm{N})$ precoating), exhibiting a distinct tendency towards columnar growth; some of the these grains apparently almost extending throughout the thickness of the $\mathrm{Al}_{2} \mathrm{O}_{3}$ coating. Directly adjacent to its interface with the $\mathrm{Ti}(\mathrm{C}, \mathrm{N})$ precoating, however, some much finer grains are clearly evident in the $\mathrm{Al}_{2} \mathrm{O}_{3}$ coating. The thin layer in the upper part of the $\mathrm{Ti}(\mathrm{C}, \mathrm{N})$ precoating directly adjacent to its interface with the $\mathrm{Al}_{2} \mathrm{O}_{3}$ coating, which was just discernible in some regions of the fractograph for the $a c$ insert, is also much more clearly defined in the case of the $h c$ insert. It is pertinent to note, however, that even in the case of the $h c$ insert, no grains are evident in this thin layer and there is no evidence of the "mottled" appearance of the lower part of the $\mathrm{Al}_{2} \mathrm{O}_{3}$ coating adjacent to its interface with the $\mathrm{Ti}(\mathrm{C}, \mathrm{N})$ precoating observed optically (see Section 6.1.4). Whether there is any correspondence between the much finer grains present in this location in the $\mathrm{Al}_{2} \mathrm{O}_{3}$ coating and its "mottled" optical appearance, which it has been tentatively suggested in Section 6.1.4 may well be associated in some way with the presence of the $\mathrm{Ti}$, $\mathrm{C}$ and $\mathrm{N}$ in the lower part of the $\mathrm{Al}_{2} \mathrm{O}_{3}$ coating, will be considered further in Section 6.2.1.

It might be concluded from the comments above concerning the typical bulk grain structures of the preliminary $\mathrm{Al}_{2} \mathrm{O}_{3}$ coatings on the $a c$ and $h c$ inserts, that the post-coating heat treatment of the HSS substrate of the inserts has caused a change in the grain structure of the $\mathrm{Al}_{2} \mathrm{O}_{3}$ coatings. This is, however, not thought to be the case. Rather it is suggested that the increase in HSS substrate hardness caused by the post-coating heat treatment has caused a change in the fracture mode of the $\mathrm{Al}_{2} \mathrm{O}_{3}$ coatings from predominantly transgranular in the case of the $a c$ insert, to predominantly intergranular in the case of the $h c$ insert, and that it is this change in fracture mode rather than a change in the structure of the $\mathrm{Al}_{2} \mathrm{O}_{3}$ coating itself, which is responsible for the differences in the structure of the $\mathrm{Al}_{2} \mathrm{O}_{3}$ coating on the $a c$ and $h c$ inserts 
evident in Figures 4.11 and 4.19. In support of this suggestion, the sharp edges of the grains in the $\mathrm{Al}_{2} \mathrm{O}_{3}$ coating on the $h c$ insert visible in Figure 4.19, which are typical of intergranular fracture, are not present in the $\mathrm{Al}_{2} \mathrm{O}_{3}$ coating on the $a c$ insert (Figure 4.11). The same effect has previously been noted for CVD TiN coatings on PM HSS inserts [6], with essentially the same explanation advanced to account for it as in the present work. The much more distinct thin layer in the upper part of the $\mathrm{Ti}(\mathrm{C}, \mathrm{N})$ precoating immediately adjacent to its interface with the $\mathrm{Al}_{2} \mathrm{O}_{3}$ coating in the case of the $h c$ insert in the present work is entirely consistent with the similar observation made regarding the optical taper sections through the $a c$ and $h c$ inserts - see Section 6.1.4.

Figure 4.12 shows an SEM micrograph of a typical region of the surface of the preliminary $\mathrm{Al}_{2} \mathrm{O}_{3}$ coating on the rake face of one of the ac inserts characterised in the present work. As is evident from this figure, the surface grain structure of the $\mathrm{Al}_{2} \mathrm{O}_{3}$ coating can be seen to consist of coarse, pyramidal grains. Similar surface grain structures have previously been observed for $\mathrm{Al}_{2} \mathrm{O}_{3}$ coatings chemically vapour deposited on $\mathrm{TiN}$ and $\mathrm{TiC}$ coated cemented carbide substrates $[43,44]$ (see Section 2.5), although the latter are generally finer, having been deposited at reduced total pressures. With regard to the surface grain structure of the preliminary $\mathrm{Al}_{2} \mathrm{O}_{3}$ coating observed in the present work after the HSS substrate heat treatment, it can be seen by comparison of Figure 4.20 for the $h c$ insert with Figure 4.12 for the $a c$ insert that the surface grain structures of the preliminary $\mathrm{Al}_{2} \mathrm{O}_{3}$ coating on the $h c$ and $a c$ inserts are essentially the same. This corroborates the earlier suggestion regarding the bulk grain structure of the $\mathrm{Al}_{2} \mathrm{O}_{3}$ coating on the $h c$ and $a c$ inserts, that it is the change in fracture mode of the inserts rather than a change in the structure of the $\mathrm{Al}_{2} \mathrm{O}_{3}$ coating itself, which is responsible for the more distinct $\mathrm{Al}_{2} \mathrm{O}_{3}$ coating bulk grain structure observed in the case of the $h c$ insert.

Overall, it is concluded that the HSS substrate heat treatment has not affected either the bulk or the surface grain structures of the preliminary $\mathrm{Al}_{2} \mathrm{O}_{3}$ coating. This conclusion is compatible with that derived earlier regarding the effect of post-coating heat treatment on the crystal structure of the preliminary $\mathrm{Al}_{2} \mathrm{O}_{3}$ coating (see Section 6.1.2).

\subsubsection{Surface roughness assessment}

As shown in Table 4.3, the average surface roughness value determined for the preliminary $\mathrm{Al}_{2} \mathrm{O}_{3}$ coating on the rake face of the $a c$ insert characterised in the present work was $0.45 \mu \mathrm{m}$ $\mathrm{R}_{\mathrm{a}}$. No corresponding surface roughness values for CVD $\mathrm{Al}_{2} \mathrm{O}_{3}$ coatings were found in the literature to permit comparison with the results of the present work. With regard to the surface roughness of the preliminary $\mathrm{Al}_{2} \mathrm{O}_{3}$ coating in the present work after the post-coating $\mathrm{HSS}$ substrate heat treatment, it can be seen from Table 4.7 that the surface roughness value of $0.45 \mu \mathrm{m} \mathrm{R}$ abtained for the preliminary $\mathrm{Al}_{2} \mathrm{O}_{3}$ coating on the $h c$ insert is identical to that for the $a c$ insert. This is also reflected in the typical Talysurf traces for the $\mathrm{Al}_{2} \mathrm{O}_{3}$ coating on the 
$h c$ and $a c$ inserts shown in Figures 4.15 and 4.6 respectively. It should be noted that the sharp peaks present on the Talysurf trace for the $h c$ insert are thought to be a consequence of unusually deep grinding marks on the rake surface of the insert prior to coating. It is therefore concluded that the post-coating HSS substrate heat treatment has had no effect on the surface roughness of the preliminary $\mathrm{Al}_{2} \mathrm{O}_{3}$ coating. This conclusion is completely consistent with those regarding the effect of this heat treatment on the surface grain structure of the preliminary $\mathrm{Al}_{2} \mathrm{O}_{3}$ coating and the surface appearance of the coating on the optical cross-sections through the $a c$ and $h c$ inserts.

\subsubsection{Microhardness tests}

From Figure 4.9, it can be seen that the microhardness of the preliminary $\mathrm{Al}_{2} \mathrm{O}_{3}$ coating on the taper-sectioned $a c$ insert characterised in the present work initially increases with increasing distance from the $\mathrm{Al}_{2} \mathrm{O}_{3}$ coating/Ti(C,N) precoating interface and then reaches a plateau, the latter indicating the region of valid microhardness determination. As shown in Table 4.5, the average microhardness value thus determined for the $\mathrm{Al}_{2} \mathrm{O}_{3}$ coating on the rake face of the ac insert was $2374 \mathrm{HV}_{0.025}$. Whilst the microhardness of chemically vapour deposited $\mathrm{Al}_{2} \mathrm{O}_{3}$ coatings (predominantly on cemented carbide substrates) has been determined by many researchers (see Chapter 2), it is not possible to make a detailed comparison between most of the $\mathrm{Al}_{2} \mathrm{O}_{3}$ coating microhardnesses quoted in the literature and that obtained in the present work, due to the different loads employed during microhardness testing. Nonetheless, it is clear that the microhardness value obtained for the preliminary $\mathrm{Al}_{2} \mathrm{O}_{3}$ coating on the $a c$ insert in the present work lies just below the range of microhardness values of $2400 \mathrm{~kg} \mathrm{~mm}^{-2}$ [60] to $3000 \mathrm{~kg} \mathrm{~mm}^{-2}$ [31] quoted for $\mathrm{Al}_{2} \mathrm{O}_{3}$ in the literature.

From Figure 4.17, it can similarly be seen that the microhardness of the preliminary $\mathrm{Al}_{2} \mathrm{O}_{3}$ coating on the taper-sectioned $h c$ insert characterised in the present work initially increases with increasing distance from the $\mathrm{Al}_{2} \mathrm{O}_{3}$ coating/Ti(C,N) precoating interface and then reaches a plateau. The average microhardness value of $2333 \mathrm{HV}_{0.025}$ thus determined for the $\mathrm{Al}_{2} \mathrm{O}_{3}$ coating on the rake face of the $h c$ insert (see Table 4.9) is obviously very close indeed to that determined for the $\mathrm{Al}_{2} \mathrm{O}_{3}$ coating on the ac insert. To determine whether there was in fact any significant difference between the mean microhardness values obtained for the $a c$ and $h c$ inserts, a statistical 2 sided t-test [90] was carried out. It was thus established, at a 95\% confidence level, that no significant difference exists between the two mean microhardness values, and it is therefore concluded that the substrate heat treatment has not affected the microhardness of the preliminary $\mathrm{Al}_{2} \mathrm{O}_{3}$ coating.

A salient feature of Figures 4.9 and 4.17 not so far addressed is the microhardness value corresponding to zero distance from the $\mathrm{Al}_{2} \mathrm{O}_{3}$ coating/Ti(C,N) precoating interface. By extrapolating the sloping line on Figures 4.9 and 4.17 to intersect the microhardness axis, 
microhardness values of $\sim 1000$ and $1500 \mathrm{HV}_{0.025}$ are obtained at this location for the $a c$ and $h c$ inserts respectively. Theoretically, these should correspond to the microhardness of the $\mathrm{Ti}(\mathrm{C}, \mathrm{N})$ precoating, which, for a stoichiometry of $\sim \mathrm{Ti}\left(\mathrm{C}_{0.2} \mathrm{~N}_{0.8}\right)$, should be of the order of $2400 \mathrm{HV}_{0.025}[76]$. However, it is likely, given the thickness of the $\mathrm{Ti}(\mathrm{C}, \mathrm{N})$ precoating employed in the present work, that the hardness of the underlying HSS substrate would still be affecting the microhardness value obtained for the $\mathrm{Ti}(\mathrm{C}, \mathrm{N})$ precoating, even adjacent to its surface. Given that the hardness of the HSS substrate of the $h c$ insert is considerably greater than that of the HSS substrate of the $a c$ insert (see Table 4.11), this explains why the microhardness value at the point in question is considerably greater on the $h c$ insert than on the $a c$ insert. Nonetheless, even on the $h c$ insert, this microhardness value is still much lower than the value which would have been expected for the $\mathrm{Ti}(\mathrm{C}, \mathrm{N})$ precoating. Since it is known that titanium oxides have much lower hardness than $\mathrm{Ti}(\mathrm{C}, \mathrm{N})$ [91], then this result is, however, completely consistent with, and adds considerable weight to the suggestion made in Section 6.1.1 (and permeating throughout this section of the discussion) that the upper part of the $\mathrm{Ti}(\mathrm{C}, \mathrm{N})$ precoating on the preliminary $\mathrm{Al}_{2} \mathrm{O}_{3}$ coated inserts consists of $\mathrm{Ti}_{3} \mathrm{O}_{5}$ or $\mathrm{Ti}_{2} \mathrm{O}_{3}$ and possibly $\mathrm{TiO}_{2}$ plus a complex $\mathrm{Ti}\left(\mathrm{O}_{\mathrm{x}} \mathrm{C}_{\mathrm{y}} \mathrm{N}_{\mathrm{z}}\right)$ compound.

\subsubsection{Adhesion test}

As previously noted in Section 4.2, scratch tests were carried out in the present work only on the $h c$ inserts and not on the $a c$ inserts, since the lower HSS substrate hardness of the latter (see Table 4.11) and the known effect of substrate hardness on critical stylus load would preclude comparison of results for the $a c$ and $h c$ inserts.

It was found from the scratch tests carried out on the $h c$ inserts that flaking occurred at the edges of the scratch channels at pre-critical stylus loads. The lowest load at which such flaking occurred was established to be $3 \mathrm{~kg}$. An SEM micrograph showing a typical example of the flaking observed at this stylus load, together with the corresponding $\mathrm{Al}, \mathrm{Ti}$ and $\mathrm{Fe} K_{\alpha} \mathrm{X}$-ray maps, is shown in Figure 4.21. Correlation of the $\mathrm{X}$-ray maps in this figure with the region of flaking at the edge of the scratch channel on the $\mathrm{Al}_{2} \mathrm{O}_{3}$ coated insert, suggests that the flaking is of the adhesive type; testified by the complete absence of $\mathrm{Al} /$ presence of $\mathrm{Ti}$ throughout the whole region of flaking. This adhesive flaking of the preliminary $\mathrm{Al}_{2} \mathrm{O}_{3}$ coating at pre-critical stylus loads is apparently comparable with that presented in the literature (see Section 2.8) for $\mathrm{Al}_{2} \mathrm{O}_{3}$ coatings chemically vapour deposited on $\mathrm{TiC}$ coated cemented carbide substrates $[73,56]$, although in the work cited pre-critical load flaking occurred at a considerably higher stylus load $(6 \mathrm{~kg})$ than that in the present work, but of course cemented carbide is much harder than HSS. 
As previously described in Section 4.2, optical examination of the scratch channels on the $h c$ insert tested in the present work revealed that the scratch channels produced at stylus loads up to and including $5 \mathrm{~kg}$ were of a uniform dark purple appearance but that at a stylus load of $6 \mathrm{~kg}$ some orange/silvery areas were visible. At stylus loads of $7 \mathrm{~kg}$ and above, however, virtually the whole of the scratch channels was silvery in appearance. For the stylus load of $5 \mathrm{~kg}$ it appears from Figure 4.22 that the preliminary $\mathrm{Al}_{2} \mathrm{O}_{3}$ coating is still present in the scratch channel; there being some evidence of smoothing/smearing of the coating but no coating breakthrough. This is revealed by the presence of $\mathrm{Al}$ in the scratch channel in the relevant X-ray map shown in Figure 4.22. As is evident from Figure 4.23, however, increasing the stylus load to $6 \mathrm{~kg}$ appears to have resulted in partial removal of the coating from the middle of the scratch channel; evinced by the absence of $\mathrm{Al} /$ presence of $\mathrm{Ti}$ in this region of the scratch channel in the $\mathrm{X}$-ray maps shown in this figure. Increasing the stylus load further to $7 \mathrm{~kg}$ can be seen from Figure 4.24 to have resulted in the preliminary $\mathrm{Al}_{2} \mathrm{O}_{3}$ coating and the $\mathrm{Ti}(\mathrm{C}, \mathrm{N})$ precoating being virtually completely removed from the scratch channel, witnessed by the absence of $\mathrm{Al}$ and $\mathrm{Ti} /$ presence of $\mathrm{Fe}$ in the region of the scratch channel in the X-ray maps shown in this figure. It may therefore be concluded from the results above that the critical stylus load for the preliminary $\mathrm{Al}_{2} \mathrm{O}_{3}$ coating, corresponding to extensive removal from the scratch channel, occurs at a load of between 6 and $7 \mathrm{~kg}$. It may also be concluded from the above, that optical examination of the scratch channels gives a reasonable indication of the stylus load at which $\mathrm{Al}_{2} \mathrm{O}_{3}$ coating removal begins to occur, the purple, orange and silver appearances in the scratch channels obviously corresponding to the $\mathrm{Al}_{2} \mathrm{O}_{3}$ coating, the $\mathrm{Ti}(\mathrm{C}, \mathrm{N})$ precoating and the HSS substrate respectively. However, it should be noted that $\alpha-\mathrm{Al}_{2} \mathrm{O}_{3}$ is transparent [92] and thus the colour of the $\mathrm{Al}_{2} \mathrm{O}_{3}$ coating observed in the present work should have been orange reflecting the $\mathrm{Ti}(\mathrm{C}, \mathrm{N})$ precoating underneath it. The fact this was not the case but that the $\mathrm{Al}_{2} \mathrm{O}_{3}$ coating was purple in appearance is suggested to reflect and further endorse the suggestion initially made in Section 6.1.1, that the upper part of the $\mathrm{Ti}(\mathrm{C}, \mathrm{N})$ precoating on the preliminary $\mathrm{Al}_{2} \mathrm{O}_{3}$ coated inserts consists of $\mathrm{Ti}_{3} \mathrm{O}_{5}$ or $\mathrm{Ti}_{2} \mathrm{O}_{3}$ and possibly $\mathrm{TiO}_{2}$ plus a $\mathrm{Ti}\left(\mathrm{O}_{\mathrm{x}} \mathrm{C}_{\mathrm{y}} \mathrm{N}_{\mathrm{z}}\right)$ compound. This is so since it is known that $\mathrm{Ti}_{3} \mathrm{O}_{5}$ is a blue/black material and that $\mathrm{Ti}_{2} \mathrm{O}_{3}$ is a purple material [93].

Although, for the reasons given earlier in this section, valid comparisons between the scratch tests results for the $\mathrm{Al}_{2} \mathrm{O}_{3}$ coated PM HSS insert obtained in the present work and those reported in the literature for $\mathrm{Al}_{2} \mathrm{O}_{3}$ coated cemented carbides cannot be made (since cemented carbide has a significantly higher hardness than HSS), it is interesting to note that the critical stylus load range of 3 to $9 \mathrm{~kg}[16,56]$ determined for $\mathrm{Al}_{2} \mathrm{O}_{3}$ coatings chemically vapour deposited on $\mathrm{TiC}$ precoated cemented carbide substrates encompasses the critical stylus load of between 6 and $7 \mathrm{~kg}$ determined in the present work. 
It is clear from the characterisation results obtained for the preliminary $\mathrm{Al}_{2} \mathrm{O}_{3}$ coating on the $\mathrm{Ti}(\mathrm{C}, \mathrm{N})$ precoated PM HSS inserts in the present work, that considerable scope for improvement exists. In particular it is necessary to decrease the amount of $\mathrm{Al}(\mathrm{e})$ in the $\mathrm{Al}_{2} \mathrm{O}_{3}$ coating, to reduce peripheral coating thickness variability and the inherent unevenness of the $\mathrm{Al}_{2} \mathrm{O}_{3}$ coating surface, to substantially refine the coating grain structure and to improve adhesion: some of these features are thought to be interrelated. It is also evident that the obligatory post-coating HSS substrate heat treatment has not materially affected the characteristics of the preliminary $\mathrm{Al}_{2} \mathrm{O}_{3}$ coatings. In order, ultimately, to improve upon the characteristics of the preliminary $\mathrm{Al}_{2} \mathrm{O}_{3}$ coating, the afore-described (see Chapter 5) major studies of the effect of $\mathrm{CO}_{2} / \mathrm{H}_{2}$ mole ratio and $\mathrm{AlCl}_{3}$ concentration on the characteristics of $\mathrm{Al}_{2} \mathrm{O}_{3}$ coatings chemically vapour deposited on $\mathrm{Ti}(\mathrm{C}, \mathrm{N})$ precoated PM BT42 grade HSS inserts were carried out. The results of this work are discussed in the following section.

\subsection{Effect of $\mathrm{CO}_{2} / \mathrm{H}_{2}$ mole ratio and $\mathrm{H}_{2}-1 / \mathrm{AlCl}_{3}$ flow rate on characteristics of CVD $\underline{\mathrm{Al}}_{2} \underline{\mathrm{O}}_{3}$ coatings}

In this section, the results obtained from the experimental studies of the effect of $\mathrm{CO}_{2} / \mathrm{H}_{2}$ mole ratio and $\mathrm{AlCl}_{3}$ concentration on the characteristics of $\mathrm{Al}_{2} \mathrm{O}_{3}$ coatings chemically vapour deposited on the Ti(C,N) precoated PM BT42 grade HSS inserts are discussed in detail and related, where possible, to the results of previous work (surveyed in Chapter 2). It should be noted, however, that in order to facilitate the most logical explanation of the results obtained in the present work, this discussion will follow the reverse of the order in which the two experimental studies were originally carried out (see Chapter 5).

\subsubsection{Effect of $\mathrm{H}_{2}-1 / \mathrm{AlCl}_{3}$ flow rate (AICl${ }_{3}$ concentration)}

As described earlier in Section 5.2, $\mathrm{H}_{2}-1 / \mathrm{AlCl}_{3}$ flow rates of $10,15,20,25$ and $30 \mathrm{~cm}^{3} \mathrm{~min}^{-1}$ were employed in the present work (at a constant $\mathrm{CO}_{2} / \mathrm{H}_{2}$ mole ratio of $1 / 10$ ) to investigate the effect of $\mathrm{AlCl}_{3}$ concentration on the characteristics of the $\mathrm{Al}_{2} \mathrm{O}_{3}$ coatings. In contrast, previous work on the effect of $\mathrm{AlCl}_{3}$ concentration on the characteristics of $\mathrm{Al}_{2} \mathrm{O}_{3}$ coatings (deposited on uncoated/precoated cemented carbide substrates) has been carried out in terms of either $\mathrm{AlCl}_{3}$ partial pressures or mole fractions (see Section 2.5). To facilitate comparison between the results of the present and previous work, it is therefore necessary, first of all, to convert the $\mathrm{AlCl}_{3}$ concentration in terms of $\mathrm{H}_{2}-1 / \mathrm{AlCl}_{3}$ flow rates, employed in the present work, to partial pressures. This conversion can be readily achieved using the values of the amount of $\mathrm{AlCl}_{3}$ used during each of the $\mathrm{H}_{2}-1 / \mathrm{AlCl}_{3}$ flow rate coating runs, shown in Table 5.10. When this is done, it is found that the $\mathrm{H}_{2}-1 / \mathrm{AlCl}_{3}$ flow rate range of 10 to $30 \mathrm{~cm}^{3} \mathrm{~min}^{-1}$ employed in the present work corresponds to an $\mathrm{AlCl}_{3}$ partial pressure range of $3.7 \times 10^{-2}$ to $7.5 \times 10^{-2}$ atm. However, these values of $\mathrm{AlCl}_{3}$ partial pressure must be treated with a certain amount of caution. As previously described in Section 3.3.3, the amount of $\mathrm{AlCl}_{3}$ used during 
each coating run was determined by weighing the glass evaporation vessel ( $p l u s \mathrm{AlCl}_{3}$ ) before and after the run and then subtracting the amount of $\mathrm{AlCl}_{3}$ by-passed during the heating-up of the evaporation unit prior to the start of coating deposition. However, it was observed after each coating run that $\mathrm{AlCl}_{3}$ (or a transformation product of it) was present in the reaction coating chamber and the exhaust gas pipes. Therefore the amount of $\mathrm{AlCl}_{3}$ which was actually used in the deposition reaction must be lower than the value determined by weighing and hence the actual values of $\mathrm{AlCl}_{3}$ partial pressure must also be lower than those calculated, although it is unfortunately not known by how much.

Having calculated the range of $\mathrm{AlCl}_{3}$ partial pressures employed in the present work, there is still a problem in comparing the results of the present and previous work on the effect of $\mathrm{AlCl}_{3}$ concentration. The previous work referred to was carried out at reduced total deposition pressures, whereas atmospheric pressure was employed in the present work. Consequently the $\mathrm{AlCl}_{3}$ partial pressures employed in previous work are much lower than those employed in the present work. To facilitate meaningful comparisons, therefore, these will be made in terms of $\mathrm{AlCl}_{3}$ partial pressure expressed as a percentage of the total pressure. This quantity, which is of course equal to the mole percent of $\mathrm{AlCl}_{3}$, will be given the symbol $\phi$. Since one atmosphere total deposition pressure was employed in the present work then, of course, the range of $\phi$ values is simply that of $\mathrm{AlCl}_{3}$ partial pressure multiplied by 100 , giving a $\phi$ value range of 3.7 to 7.5 .

An overview of the results obtained from the study of the effect of $\mathrm{AlCl}_{3}$ concentration on $\mathrm{Al}_{2} \mathrm{O}_{3}$ coating characteristics carried out in the present work, suggests that there was a problem (of unknown origin) with the coating run carried out at the $\mathrm{H}_{2}-1 / \mathrm{AlCl}_{3}$ flow rate of $20 \mathrm{~cm}^{3}$ $\min ^{-1}$. Consequently, the results obtained from this coating run have been treated as suspect in identifying graphical trends, and will be similarly treated in the discussion of the effect of $\mathrm{AlCl}_{3}$ concentration in this section.

\subsubsection{Effect of $\mathrm{H}_{2}-1 / \mathrm{AlCl}$ flow rate on composition of $\mathrm{Al}_{2} \mathrm{O}_{3}$ coating and $\mathrm{Al}_{2} \mathrm{O}_{3}$ coating/Ti(C,N) precoating interface}

As previously described in Section 5.2, the AES composition-depth profiles through one of the $a c$ inserts (left 3, Table 5.2) from each of the $\mathrm{H}_{2}-1 / \mathrm{AlCl}_{3}$ flow rate coating runs are shown in Figure 5.32. Correlating these profiles with the thickness, as measured by ball-cratering, of the $\mathrm{Al}_{2} \mathrm{O}_{3}$ coating on $a c$ insert left 3 from each of the $\mathrm{H}_{2}-1 / \mathrm{AlCl}_{3}$ flow rate coating runs, as shown in Table 5.11, the location of the bottom of each $\mathrm{Al}_{2} \mathrm{O}_{3}$ coating on its respective AES composition-depth profile can be (approximately) fixed. With one inexplicable exception $\left(\mathrm{H}_{2}-1 / \mathrm{AlCl}_{3}\right.$ flow rate $\left.=10 \mathrm{~cm}^{3} \mathrm{~min}^{-1}\right)$, this can be seen to correspond (not surprisingly perhaps) to the point at which the $\mathrm{Al}$ content begins to increase rapidly/substantially. This point will, 
hereafter, be assumed to locate the bottom of the $\mathrm{Al}_{2} \mathrm{O}_{3}$ coating on all the AES composition-depth profiles in Figure 5.32. Various observations about coating composition can now be made.

Overall, the major characteristics of each of the AES composition-depth profiles shown in Figure 5.32 are compatible with those of the AES composition-depth profile for the preliminary $\mathrm{Al}_{2} \mathrm{O}_{3}$ coated insert shown in Figure 4.5 and previously described and discussed in Section 6.1.1. In particular, it can be clearly seen from Figure 5.32 that each of the $\mathrm{Al}_{2} \mathrm{O}_{3}$ coatings from the $\mathrm{H}_{2}-1 / \mathrm{AlCl}_{3}$ flow rate coating runs contains both $\mathrm{Al}(\mathrm{o})$ and $\mathrm{Al}(\mathrm{e})$, and that whilst the composition of each $\mathrm{Al}_{2} \mathrm{O}_{3}$ coating changes with depth, with the $\mathrm{Al}(\mathrm{o})$ and oxygen content decreasing and the $\mathrm{Al}(\mathrm{e})$ initially increasing, the stoichiometry of each coating (not including the $\mathrm{Al}(\mathrm{e})$ ) is nonetheless relatively uniform until the $\mathrm{Al}_{2} \mathrm{O}_{3}$ coating/Ti(C,N) precoating interface is approached. It can also be clearly seen from Figure 5.32 that significant intermingling of $\mathrm{Al}_{2} \mathrm{O}_{3}$ coating and $\mathrm{Ti}(\mathrm{C}, \mathrm{N})$ precoating elements has occurred during CVD of the $\mathrm{Al}_{2} \mathrm{O}_{3}$ coatings. In particular, both $\mathrm{Al}(\mathrm{o})$ and $\mathrm{Al}(\mathrm{e})$ can be seen to be present in the upper part of the $\operatorname{Ti}(\mathrm{C}, \mathrm{N})$ precoating and further it can be seen that oxygen is not only present in substantial quantities in this location, but also, at a lower level, throughout the $\mathrm{Ti}(\mathrm{C}, \mathrm{N})$ precoating. Similarly $\mathrm{Ti}, \mathrm{C}$ and $\mathrm{N}$ can be seen to be present, in substantial quantities in the case of the $\mathrm{Ti}$ and $\mathrm{N}$, in the lower part of the $\mathrm{Al}_{2} \mathrm{O}_{3}$ coatings, the depth into the $\mathrm{Al}_{2} \mathrm{O}_{3}$ coatings to which the $\mathrm{Ti}$ is present being either greater than or equal to that of the $\mathrm{N}$. It follows from the above that the tentative suggestion made in Section 6.1.1 in regard to the preliminary $\mathrm{Al}_{2} \mathrm{O}_{3}$ coated inserts in their $a c$ condition, i.e. that the upper part of the $\mathrm{Ti}(\mathrm{C}, \mathrm{N})$ precoating consists of $\mathrm{Ti}_{3} \mathrm{O}_{5}$ or $\mathrm{Ti}_{2} \mathrm{O}_{3}$ and possibly $\mathrm{TiO}_{2}$ plus a complex $\mathrm{Ti}\left(\mathrm{O}_{x} \mathrm{C}_{y} \mathrm{~N}_{z}\right)$ compound possibly also containing $\mathrm{Al}$, is still valid in the case of the $a c$ insert from each of the $\mathrm{H}_{2}-1 / \mathrm{AlCl}_{3}$ flow rate coating runs. It also follows that in discussing the AES composition-depth profiles for the latter inserts it is necessary to consider three regions: the bulk of the $\mathrm{Ti}(\mathrm{C}, \mathrm{N})$ precoating, the upper part of the $\mathrm{Ti}(\mathrm{C}, \mathrm{N})$ precoating and the lower part of the $\mathrm{Al}_{2} \mathrm{O}_{3}$ coating, which together comprise the $\mathrm{Al}_{2} \mathrm{O}_{3}$ coating/Ti(C,N) precoating transition zone, and finally the bulk of the $\mathrm{Al}_{2} \mathrm{O}_{3}$ coating.

Consideration will now be given to the effect of $\mathrm{H}_{2}-1 / \mathrm{AlCl}_{3}$ flow rate on the above defined three regions, beginning with the bulk of the $\mathrm{Ti}(\mathrm{C}, \mathrm{N})$ precoating. As previously intimated it can be seen from Figure 5.32 that oxygen is present throughout the thickness of each of the $\mathrm{Ti}(\mathrm{C}, \mathrm{N})$ precoatings, but that the average level of oxygen present in the bulk of each precoating is not the same. With increase in $\mathrm{H}_{2}-1 / \mathrm{AlCl}_{3}$ flow rate from 10 to $15 \mathrm{~cm}^{3} \mathrm{~min}^{-1}$ the average level of oxygen present in the bulk of the $\mathrm{Ti}(\mathrm{C}, \mathrm{N})$ precoating appears to remain substantially unchanged. Further increase in $\mathrm{H}_{2}-1 / \mathrm{AlCl}_{3}$ flow rate to $25 \mathrm{~cm}^{3} \mathrm{~min}^{-1}$, however, can be seen to have resulted in a substantial decrease in this average level of oxygen, which then appears to remain essentially unchanged with additional increase in $\mathrm{H}_{2}-1 / \mathrm{AlCl}_{3}$ flow rate to $30 \mathrm{~cm}^{3}$ $\min ^{-1}$. 
Turning now to the $\mathrm{Al}_{2} \mathrm{O}_{3}$ coating/Ti(C,N) precoating transition zone; it is evident from Figure 5.32 that the distance over which the oxygen content increases from the average level present in the $\mathrm{Ti}(\mathrm{C}, \mathrm{N})$ precoating to a level representative of the $\mathrm{Al}_{2} \mathrm{O}_{3}$ coating, decreases noticeably and continuously with increase in $\mathrm{H}_{2}-1 / \mathrm{AlCl}_{3}$ flow rate from 10 to $30 \mathrm{~cm}^{3} \mathrm{~min}^{-1}$. The concurrent change in the composition of the upper part of the $\operatorname{Ti}(\mathrm{C}, \mathrm{N})$ precoating with increasing $\mathrm{H}_{2}$-1/AlCl${ }_{3}$ flow rate can, however, be seen from Figure 5.32 to be rather more complex. It appears that increase in $\mathrm{H}_{2}-1 / \mathrm{AlCl}_{3}$ flow rate from 10 to $30 \mathrm{~cm}^{3} \mathrm{~min}^{-1}$ has resulted in a marked decrease in the amount of oxygen present in the upper part of the $\mathrm{Ti}(\mathrm{C}, \mathrm{N})$ precoating but that the situation with regard to $\mathrm{Al}(\mathrm{o})$ and $\mathrm{Al}(\mathrm{e})$ is different. Increase in $\mathrm{H}_{2}-1 / \mathrm{AlCl}_{3}$ flow rate from 10 to $15 \mathrm{~cm}^{3} \mathrm{~min}^{-1}$ can be seen to have resulted in a dramatic increase in the depth to which $\mathrm{Al}(\mathrm{O})$ and $\mathrm{Al}(\mathrm{e})$ are present in the $\mathrm{Ti}(\mathrm{C}, \mathrm{N})$ precoating. With further increase in $\mathrm{H}_{2}-1 / \mathrm{AlCl}_{3}$ flow rate, however, the depth of presence of $\mathrm{Al}(\mathrm{o})$ and $\mathrm{Al}(\mathrm{e})$ decreases dramatically, until at the $\mathrm{H}_{2}-1 / \mathrm{AlCl}_{3}$ flow rate of $30 \mathrm{~cm}^{3} \mathrm{~min}^{-1}$ little $\mathrm{Al}(\mathrm{o})$ and $\mathrm{Al}(\mathrm{e})$ are present in the upper part of the $\mathrm{Ti}(\mathrm{C}, \mathrm{N})$ precoating. Turning now to the presence of $\mathrm{Ti}, \mathrm{C}$ and $\mathrm{N}$ in the lower part of the $\mathrm{Al}_{2} \mathrm{O}_{3}$ coatings, it is clear from Figure 5.32 that the depth to which these elements are present in this location differs substantially with $\mathrm{H}_{2}-1 / \mathrm{AlCl}_{3}$ flow rate. Comparison of Figures 5.32 (a) and (b) clearly reveals that, with increase in $\mathrm{H}_{2}-1 / \mathrm{AlCl}_{3}$ flow rate from 10 to $15 \mathrm{~cm}^{3}$ $\mathrm{min}^{-1}$, the depth of presence of the $\mathrm{Ti}, \mathrm{C}$ and $\mathrm{N}$, particularly the former, in the lower part of the $\mathrm{Al}_{2} \mathrm{O}_{3}$ coating decreases significantly. Further increase in $\mathrm{H}_{2}-1 / \mathrm{AlCl}_{3}$ flow rate from 15 to $25 \mathrm{~cm}^{3} \mathrm{~min}^{-1}$, however, can be seen from Figures 5.32 (b) and (d) to have resulted in a significant increase in the depth of presence of the $\mathrm{Ti}, \mathrm{C}$ and $\mathrm{N}$, which then appears from Figure 5.32 (e) to increase further by only a small amount with additional increase in $\mathrm{H}_{2}-1 / \mathrm{AlCl}_{3}$ flow rate to $30 \mathrm{~cm}^{3} \mathrm{~min}^{-1}$. It also appears from Figure 5.32 (a) to (e), that the decrease in $\mathrm{Ti}$ with increasing distance into the lower part of the $\mathrm{Al}_{2} \mathrm{O}_{3}$ coating and the corresponding increase in $\mathrm{Al}(\mathrm{e})$ may be related; the $\mathrm{Al}(\mathrm{e})$ content reaching a maximum as the Ti content approaches/reaches zero.

Finally, with regard to the bulk of the $\mathrm{Al}_{2} \mathrm{O}_{3}$ coating; the bulk stoichiometry of the $\mathrm{Al}_{2} \mathrm{O}_{3}$ coatings deposited at the $\mathrm{H}_{2}-1 / \mathrm{AlCl}_{3}$ flow rates of $10,15,(20), 25$ and $30 \mathrm{~cm}^{3} \mathrm{~min}^{-1}$ can respectively, with reference to Figure 5.32, be expressed by the following formulae: $\mathrm{Al}_{1.84} \mathrm{O}_{3}$, $\mathrm{Al}_{2} \mathrm{O}_{3},\left(\mathrm{Al}_{2.1} \mathrm{O}_{3}\right), \mathrm{Al}_{1.81} \mathrm{O}_{3}$ and $\mathrm{Al}_{1.8} \mathrm{O}_{3}$. With respect to the $\mathrm{Al}(\mathrm{e})$ present in the bulk of each of the $\mathrm{Al}_{2} \mathrm{O}_{3}$ coatings, it appears from Figure 5.32 that initial increase in $\mathrm{H}_{2}-1 / \mathrm{AlCl}_{3}$ flow rate from 10 to $15 \mathrm{~cm}^{3} \mathrm{~min}^{-1}$ has resulted in a slight increase in the average amount of $\mathrm{Al}(\mathrm{e})$ present. However, the amount of $\mathrm{Al}(\mathrm{e})$ present then appears to decrease with further increase in $\mathrm{H}_{2}-1 / \mathrm{AlCl}_{3}$ flow rate to $25 \mathrm{~cm}^{3} \mathrm{~min}^{-1}$ and then increases slightly with increase in $\mathrm{H}_{2}-1 / \mathrm{AlCl}_{3}$ flow rate to $30 \mathrm{~cm}^{3} \mathrm{~min}^{-1}$. It can also be seen from Figure 5.32 that $\mathrm{C}$ is present throughout the bulk of the $\mathrm{Al}_{2} \mathrm{O}_{3}$ coatings deposited at the $\mathrm{H}_{2}-1 / \mathrm{AlCl}_{3}$ flow rates of 10,15 , and $30 \mathrm{~cm}^{3}$ $\mathrm{min}^{-1}$, but not, apparently, in the coatings deposited at the flow rates of 20 and $25 \mathrm{~cm}^{3} \mathrm{~min}^{-1}$. 
It is evident from the preceding three paragraphs that, in general, the effect of increasing $\mathrm{H}_{2}-1 / \mathrm{AlCl}_{3}$ flow rate on the three previously defined regions of the $\mathrm{Al}_{2} \mathrm{O}_{3}$ coated inserts do not mirror each other. This is attributed to three different reactions or combinations of reactions being responsible for the presence/formation of these three regions. Before these reactions are discussed, it is instructive to consider the previously described work of Lhermitte-Sebire et al [20] in more detail.

As part of their work, Lhermitte-Sebire et al carried out a theoretical thermodynamic study of the CVD of $\mathrm{Al}_{2} \mathrm{O}_{3}$ coatings on $\mathrm{TiC}$ coated cemented carbide substrates from an $\mathrm{AlCl}_{3}-\mathrm{H}_{2}-\mathrm{CO}_{2}$ gas mixture, at a deposition temperature of $1300 \mathrm{~K}\left(1027^{\circ} \mathrm{C}\right)$ and a total pressure of $0.05 \mathrm{~atm}$, as a function of initial reactant gas composition characterised by the ratio between the $\mathrm{H}_{2}$ and $\mathrm{CO}_{2}$ partial pressures $\left(P_{\mathrm{H}_{2 i \mathrm{n}}} / P_{\mathrm{CO}_{2 \mathrm{in}}}=\alpha\right)$ and by the partial pressure of $\mathrm{AlCl}_{3}\left(P_{\mathrm{AlCl}_{3 i \mathrm{n}}}\right)$. Basically, they concluded from their study that the initial chemical behaviour of the TiC precoating during $\mathrm{Al}_{2} \mathrm{O}_{3}$ coating deposition was dependent on the initial gas composition. For $\mathrm{CO}_{2}$-rich initial gas compositions or for $P_{A I C l_{3 i n}}$ values below a critical value, chemical reactions, some involving the $\mathrm{TiC}$ precoating, were predicted to occur as detailed below:

(i) Oxidation of both $\mathrm{H}_{2}$ and $\mathrm{TiC}$ by $\mathrm{CO}_{2}$ :

$$
\begin{aligned}
& 3 \mathrm{H}_{2(g)}+3 \mathrm{CO}_{2_{(g)}} \rightarrow 3 \mathrm{H}_{2} \mathrm{O}_{(g)}+3 \mathrm{CO}_{(g)} \\
& 6 \mathrm{TiC}_{(s)}+5 \mathrm{CO}_{2(g)} \rightarrow 2 \mathrm{Ti}_{3} \mathrm{O}_{5_{(s)}}+11 C_{(s)}
\end{aligned}
$$$$
\left[\delta G_{1300 K}=-774.6 \mathrm{~kJ}\right]
$$

(ii) Oxidation of $\mathrm{AlCl}_{3}$ by $\mathrm{H}_{2} \mathrm{O}$ or $\mathrm{Ti}_{3} \mathrm{O}_{5}$ resulting from reaction (1) and/or reaction (2)

$$
\begin{aligned}
& 2 \mathrm{AlCl}_{3(\mathrm{~g})}+3 \mathrm{H}_{2} \mathrm{O}_{(\mathrm{g})} \rightarrow \mathrm{Al}_{2} \mathrm{O}_{3_{(s)}}+6 \mathrm{HCl}_{(\mathrm{g})} \\
& 10 \mathrm{AlCl}_{3(\mathrm{~g})}+3 \mathrm{Ti}_{3} \mathrm{O}_{5_{(s)}}+6 \mathrm{HCl}_{(\mathrm{g})} \rightarrow 5 \mathrm{Al}_{2} \mathrm{O}_{3_{(s)}}+9 \mathrm{TiCl}_{4(\mathrm{~g})}+3 \mathrm{H}_{2(\mathrm{~g})} \\
& {\left[\delta G_{1300 \mathrm{~K}}=-409.7 \mathrm{~kJ}\right]}
\end{aligned}
$$

For initial gas compositions containing excess $\mathrm{H}_{2}$ or $\mathrm{AlCl}_{3}$, the $\mathrm{TiC}$ precoating was predicted to be chemically inert towards the gaseous reactants and the chemical reactions detailed below were predicted:

Reaction (1) from above plus reaction (5) below

$$
3 \mathrm{H}_{2(g)}+3 \mathrm{CO}_{(g)} \rightarrow 3 \mathrm{H}_{2} \mathrm{O}_{(g)}+3 \mathrm{C}_{(s)}
$$

plus reaction (3) from above combining to give the overall reaction:

$$
4 \mathrm{AlCl}_{3(g)}+6 \mathrm{H}_{2(g)}+3 \mathrm{CO}_{2_{(g)}} \rightarrow 2 \mathrm{Al}_{2} \mathrm{O}_{3_{(s)}}+3 \mathrm{C}_{(s)}+12 \mathrm{HCl}_{(g)}
$$


Returning now to the present work; the presence of the oxygen in the bulk of the $\mathrm{Ti}(\mathrm{C}, \mathrm{N})$ precoating and in the upper part of the precoating of the preliminary $\mathrm{Al}_{2} \mathrm{O}_{3}$ ac inserts in the present work has previously been attributed to a strong "substrate-type" reaction between the $\mathrm{Ti}(\mathrm{C}, \mathrm{N})$ precoating and either the $\mathrm{H}_{2} \mathrm{O}$ formed by the homogeneous gas phase reaction of the $\mathrm{CO}_{2}$ and $\mathrm{H}_{2}$ gaseous reactants or directly with the $\mathrm{CO}_{2}$ reactant gas itself. It has also been suggested for these inserts (Section 6.1.1) that, as a result of this reaction, the upper part of the $\mathrm{Ti}(\mathrm{C}, \mathrm{N})$ precoating consists of $\mathrm{Ti}_{3} \mathrm{O}_{5}$ or $\mathrm{Ti}_{2} \mathrm{O}_{3}$ and possibly $\mathrm{TiO}_{2}$ plus a complex $\operatorname{Ti}\left(\mathrm{O}_{\mathrm{x}} \mathrm{C}_{\mathrm{y}} \mathrm{N}_{z}\right)$ compound possibly also containing $\mathrm{Al}$. The continuing validity of this suggestion in the case of the $a c$ inserts from each of the $\mathrm{H}_{2}-1 / \mathrm{AlCl}_{3}$ flow rate coating runs has already been noted earlier in the present section. This being the case, since the free energy for the oxidation of $\mathrm{TiC}$ by $\mathrm{H}_{2} \mathrm{O}$ has been calculated by the author, using data from thermodynamic tables [94], to be $\delta G_{1300 K}=-496 \mathrm{~kJ}$, i.e. less negative than that calculated by Lhermitte-Sebire et al for the oxidation of $\mathrm{TiC}$ by $\mathrm{CO}_{2}$, the presence of oxygen in the bulk and in the upper part of the $\mathrm{Ti}(\mathrm{C}, \mathrm{N})$ precoating of the $a c$ inserts from the $\mathrm{H}_{2}-1 / \mathrm{AlCl}_{3}$ flow rate (and the preliminary) coating runs, and the formation of the titanium oxides in the upper part of the $\operatorname{Ti}(\mathrm{C}, \mathrm{N})$ precoating, is now firmly attributed to a strong "substrate-type" reaction (hereafter referred to as the first "substrate-type" reaction) between the $\mathrm{TiC}$ phase of the $\mathrm{Ti}(\mathrm{C}, \mathrm{N})$ precoating and the $\mathrm{CO}_{2}$ reactant gas (Lhermitte-Sebire et al reaction (2)). The strength of this reaction and the fact that it precedes other possible reactions, can be accounted for in terms of its high negative free energy in comparison to those of the other possible reactions. With regard to the effect of $\mathrm{H}_{2}-1 / \mathrm{AlCl}_{3}$ flow rate, as described earlier the average level of oxygen present in the bulk of each of the $\mathrm{Ti}(\mathrm{C}, \mathrm{N})$ precoatings was found to show an overall decrease and the amount of oxygen present in the upper part of the $\mathrm{Ti}(\mathrm{C}, \mathrm{N})$ precoating to show a marked decrease with increase in $\mathrm{H}_{2}-1 / \mathrm{AlCl}_{3}$ flow rate from 10 to $30 \mathrm{~cm}^{3} \mathrm{~min}^{-1}$. Given the firm attribution above, since the $\mathrm{CO}_{2}$ flow rate remained constant $\left(25 \mathrm{~cm}^{3} \mathrm{~min}^{-1}\right)$ with increasing $\mathrm{H}_{2}-1 / \mathrm{AlCl}_{3}$ flow rate, the decrease in the oxygen present in the bulk and upper part of the $\mathrm{Ti}(\mathrm{C}, \mathrm{N})$ precoatings with increasing $\mathrm{H}_{2}-1 / \mathrm{AlCl}_{3}$ flow rate is attributed to the concomitant decrease in $\mathrm{CO}_{2} / \mathrm{AlCl}_{3}$ mole ratio.

Turning now to the $\mathrm{Al}_{2} \mathrm{O}_{3}$ coating/Ti $(\mathrm{C}, \mathrm{N})$ precoating transition zone; the presence of the titanium oxides in the upper part of the Ti(C,N) precoating has already been attributed to the first "substrate-type" reaction. It is now further suggested that, following this reaction, the original formation of the $\mathrm{Al}_{2} \mathrm{O}_{3}$ coating/Ti(C,N) precoating transition zone, and thus the observed intermingling of the $\mathrm{Al}_{2} \mathrm{O}_{3}$ coating and $\mathrm{Ti}(\mathrm{C}, \mathrm{N})$ precoating elements, is due to interdiffusion in concert with the combination of a second "substrate-type" reaction between the titanium oxides in the upper part of the $\mathrm{Ti}(\mathrm{C}, \mathrm{N})$ precoating and the $\mathrm{AlCl}_{3}$ reactant gas (Lhermitte-Sebire et al reaction (4)) and either the overall reaction between $\mathrm{AlCl}_{3}$ and $\mathrm{H}_{2} \mathrm{O}$ (Lhermitte-Sebire et al reaction (3) - free energy calculated by the author, $\delta G_{1300 K}=-325 \mathrm{~kJ}$ ) or between $\mathrm{AlCl}_{3}, \mathrm{H}_{2}$ and $\mathrm{CO}_{2}$ (Lhermitte-Sebire et al reaction (6) - free energy calculated by the author, $\delta G_{1300 K}=-520 \mathrm{~kJ}$ ), but modified in either case by the presence of $\mathrm{TiCl}_{4}$ resulting from the "substrate-type" reaction between the titanium oxides in the upper part of the $\mathrm{Ti}(\mathrm{C}, \mathrm{N})$ 
precoating and the $\mathrm{AlCl}_{3}$ reactant gas (Lhermitte-Sebire et al reaction (4)). It is suggested that the second "substrate-type" reaction in combination with the modified overall reactions between $\mathrm{AlCl}_{3}, \mathrm{H}_{2} \mathrm{O}$ and $\mathrm{TiCl}_{4}$ or between $\mathrm{AlCl}_{3}, \mathrm{H}_{2}, \mathrm{CO}_{2}$ and $\mathrm{TiCl}_{4}$ leads initially to the codeposition of oxygen deficient $\mathrm{Al}_{2} \mathrm{O}_{3}$ (hence the initial increase in $\mathrm{Al}(\mathrm{e})$ in the lower part of the $\mathrm{Al}_{2} \mathrm{O}_{3}$ coatings) and some form of titanium oxide (hence the greater depth of presence of $\mathrm{Ti}$ in the lower part of the $\mathrm{Al}_{2} \mathrm{O}_{3}$ coatings than can be accounted for in terms of diffusion) which is then transformed to $\mathrm{Ti}\left(\mathrm{O}_{x} \mathrm{C}_{y} \mathrm{~N}_{z}\right)$ by the diffusion of $\mathrm{C}$ and $\mathrm{N}$ from the $\mathrm{Ti}(\mathrm{C}, \mathrm{N})$ precoating. In support of this suggestion, it should be noted that the deliberate codeposition of $\mathrm{Al}_{2} \mathrm{O}_{3}$ and titanium oxycarbide $\mathrm{Ti}\left(\mathrm{C}_{\mathrm{x}} \mathrm{O}_{\mathrm{y}}\right)$ on $\mathrm{TiC}$ precoated/uncoated cemented carbides from an $\mathrm{AlCl}_{3}-\mathrm{H}_{2}-\mathrm{CO}_{2}-\mathrm{TiCl}_{4}$ gas mixture has previously been reported by Colombier and $\mathrm{Lux}$ [54]. It should be noted that, in the present work, the "substrate-type" reaction between the titanium oxides in the upper part of the $\mathrm{Ti}(\mathrm{C}, \mathrm{N})$ precoating and the $\mathrm{AlCl}_{3}$ reactant gas cannot occur in isolation of the (modified) overall reaction(s) since the $\mathrm{HCl}$ by-product from the (modified) overall reaction(s) is required for the "substrate-type" reaction to take place. It is further suggested that as access by the $\mathrm{AlCl}_{3}$ reactant gas to the titanium oxides in the upper part of the $\mathrm{Ti}(\mathrm{C}, \mathrm{N})$ precoating diminishes with increasing deposition, the contribution of the "substrate-type" reaction correspondingly diminishes, accompanied by a concomitant decrease in the amount of $\mathrm{TiCl}_{4}$ generated by it, whilst that of the modified overall reaction(s) increases, but with the modification caused by the presence of the $\mathrm{TiCl}_{4}$ diminishing as the amount of $\mathrm{TiCl}_{4}$ decreases, until the influence of the overall reaction(s), no longer modified by $\mathrm{TiCl}_{4}$, eventually becomes total.

Given the complexity of the reactions suggested to be responsible for the formation of the $\mathrm{Al}_{2} \mathrm{O}_{3}$ coating/Ti(C,N) precoating transition zone in the present work, it is very difficult to account for the observed effects of increasing $\mathrm{H}_{2}-1 / \mathrm{AlCl}_{3}$ flow rate on the compositional changes in this region without substantial further work.

In view of the above suggestions, it is pertinent to note that, as described earlier, Lhermitte-Sebire et al predicted the chemical reactions involving their TiC precoating only for $\mathrm{CO}_{2}$-rich initial gas compositions or for $P_{A I C l_{3 i n}}$ values below a critical value. For initial gas compositions containing excess $\mathrm{H}_{2}$ or $\mathrm{AlCl}_{3}$, the TiC precoating was predicted to be chemically inert towards the gaseous reactants. Since the investigation of the effect of $\mathrm{H}_{2}-1 / \mathrm{AlCl}_{3}$ flow rate in the present work was carried out at a constant $\mathrm{CO}_{2} / \mathrm{H}_{2}$ mole ratio of $1 / 10$, i.e. under conditions of apparent excess $\mathrm{H}_{2}$, the suggested occurrence of the two "substrate-type" reactions in the present work implies that the range of $\mathrm{AlCl}_{3}$ partial pressures used must have been below the critical value referred to by Lhermitte-Sebire et al. This is completely consistent with the fact that, as described earlier, the average level of oxygen present in the bulk of each of the $\operatorname{Ti}(\mathrm{C}, \mathrm{N})$ precoatings was found to show an overall decrease and the amount of oxygen present in the upper part of the $\operatorname{Ti}(\mathrm{C}, \mathrm{N})$ precoatings to show a marked decrease with increase in $\mathrm{H}_{2}-1 / \mathrm{AlCl}_{3}$ flow rate from 10 to $30 \mathrm{~cm}^{3} \mathrm{~min}^{-1}$ in the present work, i.e. a decrease in the extent of the "substrate-type" reaction as the partial pressure of 
$\mathrm{AlCl}_{3}$ in the present work got nearer to the critical value referred to by Lhermitte-Sebire et al. There is also other experimental evidence which indirectly supports this. In very recent work carried out by Smith [95] using the same CVD reactor as employed in the present work, an attempt was made to $\mathrm{CVD}$ an $\mathrm{Al}_{2} \mathrm{O}_{3}$ coating onto previously aluminised PM BT42 grade HSS inserts, using an $\mathrm{AlCl}_{3}-\mathrm{H}_{2}-\mathrm{CO}_{2}$ gas mixture and the same deposition conditions as employed for the preliminary $\mathrm{Al}_{2} \mathrm{O}_{3}$ coatings in the present work. No $\mathrm{Al}_{2} \mathrm{O}_{3}$ coating was found to have been deposited on the inserts. It is suggested that the reason for this is that the first "substrate-type" reaction identified in the present work, led, in the work carried out by Smith, to the formation of a thin film of aluminium oxide (not necessarily $\mathrm{Al}_{2} \mathrm{O}_{3}$ ) on the surface of the aluminised HSS inserts. This made the inserts chemically inert towards the gaseous reactants, thus preventing $\mathrm{Al}_{2} \mathrm{O}_{3}$ coating deposition under the particular deposition conditions employed.

Finally, considering the bulk of the $\mathrm{Al}_{2} \mathrm{O}_{3}$ coatings in the present work; it is, not surprisingly, suggested that deposition of the bulk of the $\mathrm{Al}_{2} \mathrm{O}_{3}$ coatings occurs either by the overall reaction between $\mathrm{AlCl}_{3}$ and $\mathrm{H}_{2} \mathrm{O}$ (Lhermitte-Sebire et al reaction (3)) and/or between $\mathrm{AlCl}_{3}, \mathrm{H}_{2}$ and $\mathrm{CO}_{2}$ (Lhermitte-Sebire et al reaction (6)), once the influence of these overall reactions over the second "substrate-type" reaction has become total and they are no longer modified by the presence of $\mathrm{TiCl}_{4}$ resulting from the second "substrate-type" reaction. With regard to the effect of $\mathrm{H}_{2}-1 / \mathrm{AlCl}_{3}$ flow rate on the bulk of the $\mathrm{Al}_{2} \mathrm{O}_{3}$ coatings, as described earlier, the bulk stoichiometry of the $\mathrm{Al}_{2} \mathrm{O}_{3}$ coatings was found to initially increase from $\mathrm{Al}_{1.84} \mathrm{O}_{3}$ to $\mathrm{Al}_{2} \mathrm{O}_{3}$ with increase in $\mathrm{H}_{2}-1 / \mathrm{AlCl}_{3}$ flow rate from 10 to $15 \mathrm{~cm}^{3} \mathrm{~min}^{-1}$, but then to deteriorate to values of $\mathrm{Al}_{1.81} \mathrm{O}_{3}$ and $\mathrm{Al}_{1.8} \mathrm{O}_{3}$ at $\mathrm{H}_{2}-1 / \mathrm{AlCl}_{3}$ flow rates of 25 and $30 \mathrm{~cm}^{3} \mathrm{~min}^{-1}$. Given the aforementioned concomitant decrease in $\mathrm{CO}_{2} / \mathrm{AlCl}_{3}$ mole ratio in the present work with increasing $\mathrm{H}_{2}-1 / \mathrm{AlCl}_{3}$ flow rate, it might have been anticipated that the $\mathrm{Al}(\mathrm{o})$ content of the bulk of the coatings would have simply increased relative to that of the oxygen with increasing $\mathrm{H}_{2}-1 / \mathrm{AlCl}_{3}$ flow rate. The reason why this was not found to be the case may be connected with the fact that, as described earlier, $\mathrm{C}$ was found to be present in the bulk of the $\mathrm{Al}_{2} \mathrm{O}_{3}$ coatings deposited at the $\mathrm{H}_{2}-1 / \mathrm{AlCl}_{3}$ flow rates of 10,15 and $30 \mathrm{~cm}^{3} \mathrm{~min}^{-1}$ but not in the coatings deposited at the flow rates of 20 and $25 \mathrm{~cm}^{3} \mathrm{~min}^{-1}$. The fact that codeposition of $\mathrm{Al}_{2} \mathrm{O}_{3}$ and $\mathrm{C}$ can occur by the overall reaction between $\mathrm{AlCl}_{3}, \mathrm{H}_{2}$ and $\mathrm{CO}_{2}$ (Lhermitte-Sebire et al reaction (6)), but not by the overall reaction between $\mathrm{AlCl}_{3}$ and, $\mathrm{H}_{2} \mathrm{O}$ (Lhermitte-Sebire et al reaction (3)), suggests that the controlling/predominant overall reaction responsible for the CVD of the bulk of $\mathrm{Al}_{2} \mathrm{O}_{3}$ coatings in the present work might have been influenced by increasing $\mathrm{H}_{2}-1 / \mathrm{AlCl}_{3}$ flow rate, and that this, together with the concomitant decrease in $\mathrm{CO}_{2} / \mathrm{AlCl}_{3}$ mole ratio, might have been responsible for the observed effect of $\mathrm{H}_{2}-1 / \mathrm{AlCl}_{3}$ flow rate on the bulk $\mathrm{Al}_{2} \mathrm{O}_{3}$ coating stoichiometry and also the amount of $\mathrm{Al}(\mathrm{e})$ in the bulk of the $\mathrm{Al}_{2} \mathrm{O}_{3}$ coatings. Clearly, further, detailed work is required in this area. 
From Figure 5.34, which shows the effect of $\mathrm{H}_{2}-1 / \mathrm{AlCl}_{3}$ flow rate on the thickness of the $\mathrm{Al}_{2} \mathrm{O}_{3}$ coatings on the rake face of the inserts in the present work (as determined by optical measurements and ball-cratering), it can be seen that, according to the optical measurements, an increase in $\mathrm{H}_{2}-1 / \mathrm{AlCl}_{3}$ flow rate from 10 to $30 \mathrm{~cm}^{3} \mathrm{~min}^{-1}$ has simply caused a linear increase in $\mathrm{Al}_{2} \mathrm{O}_{3}$ coating thickness. However, the ball-cratering results suggest that although $\mathrm{Al}_{2} \mathrm{O}_{3}$ coating thickness initially increases linearly with increase in $\mathrm{H}_{2}-1 / \mathrm{AlCl}_{3}$ flow rate from 10 to $\sim 20 \mathrm{~cm}^{3} \mathrm{~min}^{-1}$, with further increase in $\mathrm{H}_{2}-1 / \mathrm{AlCl}_{3}$ flow rate the rate of increase in coating thickness begins to decrease until, at $\mathrm{H}_{2}-1 / \mathrm{AlCl}_{3}$ flow rates of $\sim 25 \mathrm{~cm}^{3} \mathrm{~min}^{-1}$ and above, $\mathrm{Al}_{2} \mathrm{O}_{3}$ coating thickness becomes sensibly constant. As described in Section 5.2.5, the optical measurements in Figure 5.34 correspond to the average of twenty readings on the rake face of a polished and etched cross-section through one of the ac inserts from each of the $\mathrm{H}_{2}-1 / \mathrm{AlCl}_{3}$ flow rate coating runs, whereas, as described in Section 5.2.1, the ball-cratering results in Figure 5.34 reflect measurements on the rake face of all eight inserts from each of the coating runs. It is therefore felt that the trend in $\mathrm{Al}_{2} \mathrm{O}_{3}$ coating thickness with increasing $\mathrm{H}_{2}-1 / \mathrm{AlCl}_{3}$ flow rate suggested by the ball-cratering results is likely to be more representative than that suggested by the optical measurements, and will hence be adopted.

As is evident from Sections 2.5.1 and 2.5.2, in previous work the effect of $\mathrm{AlCl}_{3}$ concentration on $\mathrm{Al}_{2} \mathrm{O}_{3}$ coating deposition rate rather than coating thickness has been investigated. However, it is also clear from these two sections that, despite similar $\phi$ value ranges having been previously investigated, significantly different effects of $\mathrm{AlCl}_{3}$ concentration on $\mathrm{Al}_{2} \mathrm{O}_{3}$ coating deposition rate have been observed. In their work on $\mathrm{Al}_{2} \mathrm{O}_{3}$ coatings chemically vapour deposited on cemented carbide substrates, Funk et al [31] found that increasing $P_{\mathrm{AlCl}_{3}}$ from 0.2 to 1.5 torr (i.e increasing $\phi$ from 0.4 to 3) caused a decrease in $\mathrm{Al}_{2} \mathrm{O}_{3}$ deposition rate. In contrast, Park et al [42] found, for $\mathrm{Al}_{2} \mathrm{O}_{3}$ coatings chemically vapour deposited on TiN coated cemented carbide substrates, that increasing the $\mathrm{AlCl}_{3}$ mole fraction from close to 0 to $3 \times 10^{-3}$ (i.e increasing $\phi$ from close to 0 to 0.3 ) caused an increase in $\mathrm{Al}_{2} \mathrm{O}_{3}$ deposition rate but that further increase in $\mathrm{AlCl}_{3}$ mole fraction to $1 \times 10^{-2}$ (i.e. increase in $\phi$ to 1) resulted in a slight decrease in the deposition rate. The same basic trend observed by Park et al was also noted by Chun et al [36] (see Figure 2.7) and Kim et al [43] in their work on the effect of $P_{\mathrm{AICl}_{3}}$ on the deposition rate of $\mathrm{Al}_{2} \mathrm{O}_{3}$ coatings chemically vapour deposited on $\mathrm{TiC}$ and $\mathrm{TiN}$ coated cemented carbide substrates respectively. With increase in $P_{\mathrm{AlCl}_{3}}$ from close to 0 to 1 torr (i.e increase in $\phi$ from close to 0 to 1 ), they observed an increase in $\mathrm{Al}_{2} \mathrm{O}_{3}$ deposition rate but further increase in $P_{\mathrm{AlCl}_{3}}$ to 3 torr (i.e increase in $\phi$ to 3) was found to result in a decrease in the deposition rate which was more marked than that observed by Park et al. Conversely, in their work on $\mathrm{Al}_{2} \mathrm{O}_{3}$ coatings chemically vapour deposited on uncoated cemented carbide substrates, Colmet et al [37] found (see Figure 2.4) that the $\mathrm{Al}_{2} \mathrm{O}_{3}$ deposition rate initially increased rapidly with increase in $P_{\mathrm{AlCl}_{3}}$ from $0.5 \times 10^{-3}$ to $0.8 \times 10^{-3} \mathrm{~atm}$ (i.e. increase in $\phi$ from $\sim 0.83$ to $\sim 1.3$ ), but then reached a limit above which no further increase in deposition 
rate took place with additional increase in $P_{\mathrm{ALCl}_{3}}$. Silvestri et al [38] investigated the effect of $\mathrm{CO}_{2}$ and $\mathrm{AlCl}_{3}$ mole fractions (expressed in terms of mole flow rates) on the deposition rate of $\mathrm{Al}_{2} \mathrm{O}_{3}$ coatings chemically vapour deposited on Si substrates. They found that if the $\mathrm{AlCl}_{3}$ mole flow rate was increased from close to 0 to $1 \times 10^{-4}$ moles $\min ^{-1}$ at a constant $\mathrm{CO}_{2}$ mole flow rate, i.e. a decrease in $\mathrm{CO}_{2} / \mathrm{AlCl}_{3}$ mole ratio, it caused an initial increase in the $\mathrm{Al}_{2} \mathrm{O}_{3}$ deposition rate, but at higher $\mathrm{AlCl}_{3}$ mole flow rates, the deposition rate reached a limit, governed by the $\mathrm{CO}_{2}$ mole flow rate. These findings are in agreement with those of Colmet et al [37] with regard to the effect of $P_{\mathrm{AlCl}_{3}}$ on the deposition rate of $\mathrm{Al}_{2} \mathrm{O}_{3}$ coatings.

If it is assumed that $\mathrm{Al}_{2} \mathrm{O}_{3}$ coating thickness is directly proportional to $\mathrm{Al}_{2} \mathrm{O}_{3}$ coating deposition rate (a not unreasonable assumption), then clearly the effect of $\mathrm{AlCl}_{3}$ concentration on $\mathrm{Al}_{2} \mathrm{O}_{3}$ coating thickness observed in the present work is in agreement with that on deposition rate determined by Colmet et al and Silvestri et al, despite the different range of $\phi$ values employed in the present work and by the former, but is in partial disagreement with the effects observed by the other workers cited above. It is interesting to note that none of these workers have given a coherent explanation for the effect of $\mathrm{AlCl}_{3}$ concentration on $\mathrm{Al}_{2} \mathrm{O}_{3}$ deposition rate which they observed. Park et al [42] reported that the deposition rate is affected by the variation of the relative contents of the $\mathrm{Al}$ and $\mathrm{O}$ donors $\left(\mathrm{AlCl}_{3}\right.$ and $\mathrm{H}_{2} \mathrm{O}$ respectively): at low $\mathrm{AlCl}_{3}$ mole fractions (i.e low $\mathrm{Al}$ donor to $\mathrm{O}$ donor ratio) the deposition rate increases with increasing $\mathrm{AlCl}_{3}$ mole fraction, whereas at higher $\mathrm{AlCl}_{3}$ mole fractions (i.e $\mathrm{O}$ donor is less than $\mathrm{Al}$ donor) the deposition rate is mainly affected by the $\mathrm{H}_{2} \mathrm{O}$-forming reaction between $\mathrm{H}_{2}$ and $\mathrm{CO}_{2}$. Conversely, Kim et al [43] simply commented that the decrease in deposition rate at higher $P_{\mathrm{AlCl}_{3}}$ which they observed might be due to $\mathrm{HCl}$ gas or to the nature of the adsorption of the reactants on the substrate surface.

The rate of coating deposition (and hence coating thickness) is of course a matter of kinetics. It is well established that the rate limiting step of a CVD reaction, i.e. the step which controls the deposition rate, can be determined either singularly or in combination by surface reaction kinetics, mass transport (of the reactants/products through the gas boundary layer) or, more uncommonly, by gas-phase kinetics i.e. homogeneous reactions in the gas phase. When the deposition temperature and pressure are high, as in the present work, the rate of deposition is normally controlled by mass transport. It is self evident that, in the present work, despite the existence of the $\mathrm{Al}_{2} \mathrm{O}_{3}$ coating/Ti(C,N) precoating transition zone, the $\mathrm{Al}_{2} \mathrm{O}_{3}$ coating thickness measurements principally relate to the bulk of the $\mathrm{Al}_{2} \mathrm{O}_{3}$ coatings. Therefore, with reference to Section 6.2.1.1, the CVD reactions of predominant importance with regard to the observed effect of $\mathrm{H}_{2}-1 / \mathrm{AlCl}_{3}$ flow rate on $\mathrm{Al}_{2} \mathrm{O}_{3}$ coating thickness are the overall reaction(s) between $\mathrm{AlCl}_{3}$ and $\mathrm{H}_{2} \mathrm{O}$ (reaction (3), page 93) and/or between $\mathrm{AlCl}_{3}, \mathrm{H}_{2}$ and $\mathrm{CO}_{2}$ (reaction (6), page 93). This being the case, and given the preceding remarks, the initial, linear increase in $\mathrm{Al}_{2} \mathrm{O}_{3}$ coating thickness with increase in $\mathrm{H}_{2}-1 / \mathrm{AlCl}_{3}$ flow rate from 10 to $20 \mathrm{~cm}^{3}$ $\mathrm{min}^{-1}$ observed in the present work, typical of mass transport control, can be rationalised in terms of the corresponding increase in the concentration of $\mathrm{AlCl}_{3}$ in the bulk gas stream. 
However, as described earlier in this section, with further increase in $\mathrm{H}_{2}-1 / \mathrm{AlCl}_{3}$ flow rate in the present work, the rate of increase in $\mathrm{Al}_{2} \mathrm{O}_{3}$ coating thickness began to decrease until, at $\mathrm{H}_{2}-1 / \mathrm{AlCl}_{3}$ flow rates of $\sim 25 \mathrm{~cm}^{3} \mathrm{~min}^{-1}$ and above, the $\mathrm{Al}_{2} \mathrm{O}_{3}$ coating thickness became sensibly constant. In explanation of this it is suggested that although there is initially mass transport control, the concomitant decrease in $\mathrm{CO}_{2} / \mathrm{AlCl}_{3}$ mole ratio with increasing $\mathrm{H}_{2}-1 / \mathrm{AlCl}_{3}$ flow rate eventually leads to a relative shortage of $\mathrm{O}$-donors with the result that there is a transition between $\mathrm{H}_{2}-1 / \mathrm{AlCl}_{3}$ flow rates of $\sim 20$ and $\sim 25 \mathrm{~cm}^{3} \mathrm{~min}^{-1}$ from mass transport control to control by the homogeneous reaction between $\mathrm{H}_{2}$ and $\mathrm{CO}_{2}$ in the gas phase (which occurs in both reactions (3) and (6), page 93) and that at $\mathrm{H}_{2}-1 / \mathrm{AlCl}_{3}$ flow rates of $25 \mathrm{~cm}^{3} \mathrm{~min}^{-1}$ and above, the latter becomes rate limiting, in agreement with the work of Silvestri et al.

\subsubsection{Effect of $\mathrm{H}_{2}-1 / \mathrm{AlCl}_{3}$ flow rate on bulk and surface grain structures of $\mathrm{Al}_{2} \underline{\mathrm{O}}_{3}$ coatings}

From Figure 5.40, which shows typical surface grain structures determined for the $\mathrm{Al}_{2} \mathrm{O}_{3}$ coatings deposited at the five different $\mathrm{H}_{2}-1 / \mathrm{AlCl}_{3}$ flow rates in the present work, it can be seen that increasing the $\mathrm{H}_{2}-1 / \mathrm{AlCl}_{3}$ flow rate has had no effect on the morphology of the grains on the surface of the $\mathrm{Al}_{2} \mathrm{O}_{3}$ coatings, the grains remaining pyramidal/faceted in form. It is, however, also evident from this figure that increase in $\mathrm{H}_{2}-1 / \mathrm{AlCl}_{3}$ flow rate from 10 to $25 \mathrm{~cm}^{3} \mathrm{~min}^{-1}$ has caused a sustained increase in $\mathrm{Al}_{2} \mathrm{O}_{3}$ coating surface grain size, which is particularly marked with increase in flow rate from 10 to $15 \mathrm{~cm}^{3} \mathrm{~min}^{-1}$, but that the grain size appears to remain sensibly constant when the $\mathrm{H}_{2}-1 / \mathrm{AlCl}_{3}$ flow rate is further increased to 30 $\mathrm{cm}^{3} \mathrm{~min}^{-1}$. Not surprisingly, given the above findings, it can be seen from Figure 5.39, which shows typical bulk grain structures for the $\mathrm{Al}_{2} \mathrm{O}_{3}$ coatings deposited at the five different $\mathrm{H}_{2}-1 / \mathrm{AlCl}_{3}$ flow rates, that increasing the $\mathrm{H}_{2}-1 / \mathrm{AlCl}_{3}$ flow rate has had no effect on the morphology of the grains in the bulk of the $\mathrm{Al}_{2} \mathrm{O}_{3}$ coatings, these grains exhibiting a distinct tendency towards columnar growth and being noticeably coarser than those of the $\operatorname{Ti}(\mathrm{C}, \mathrm{N})$ precoating in each case. It is also evident from Figure 5.39 that, as with $\mathrm{Al}_{2} \mathrm{O}_{3}$ coating surface grain size, increase in $\mathrm{H}_{2}-1 / \mathrm{AlCl}_{3}$ flow rate from 10 to $25 \mathrm{~cm}^{3} \mathrm{~min}^{-1}$ has caused a sustained increase in $\mathrm{Al}_{2} \mathrm{O}_{3}$ coating bulk grain size, which is particularly marked with increase in flow rate from 10 to $15 \mathrm{~cm}^{3} \mathrm{~min}^{-1}$, but that the bulk grain size appears to remain sensibly constant when the $\mathrm{H}_{2}-1 / \mathrm{AlCl}_{3}$ flow rate is further increased to $30 \mathrm{~cm}^{3} \mathrm{~min}^{-1}$. Surprisingly, no work on the effect of $\mathrm{AlCl}_{3}$ concentration on $\mathrm{Al}_{2} \mathrm{O}_{3}$ coating bulk grain structure was found in the literature to permit comparison with the results of the present work, but, as described in Section 2.5.1, work has previously been carried out on the effect of $\mathrm{AlCl}_{3}$ concentration on $\mathrm{Al}_{2} \mathrm{O}_{3}$ coating surface grain structure. Since, in the present work, as described above, the effects of $\dot{\mathrm{H}}_{2}-1 / \mathrm{AlCl}_{3}$ flow rate on $\mathrm{Al}_{2} \mathrm{O}_{3}$ coating bulk and surface grain structure are completely consistent, discussion will proceed with reference to $\mathrm{Al}_{2} \mathrm{O}_{3}$ coating surface grain structures. 
The overall effect of $\mathrm{AlCl}_{3}$ concentration on $\mathrm{Al}_{2} \mathrm{O}_{3}$ coating surface grain size observed in the present work is partially comparable with that observed by Park et al [44] for $\mathrm{Al}_{2} \mathrm{O}_{3}$ coatings chemically vapour deposited on TiN coated cemented carbide substrates. As previously described in Section 2.5.2, Park et al found that increasing the $\mathrm{AlCl}_{3}$ mole fraction from $1 \mathrm{x}$ $10^{-3}$ to $1 \times 10^{-2}$ (i.e increasing $\phi$ from 0.1 to 1 ) caused the $\mathrm{Al}_{2} \mathrm{O}_{3}$ coating surface grain structure to become coarser, but that, in contrast to the present work, further increase in $\mathrm{AlCl}_{3}$ mole fraction to $3 \times 10^{-2}$ (i.e increase in $\phi$ to 3 ) resulted in finer surface grains. In their work on the effect of $\mathrm{AlCl}_{3}$ concentration on the surface grain size of $\mathrm{Al}_{2} \mathrm{O}_{3}$ coatings chemically vapour deposited on TiN coated cemented carbide substrates Kim et al [43] (see Section 2.5.1) found that increase in $P_{\mathrm{AlCl}_{3}}$ over the range from 0.5 to 3 torr (i.e increase in $\phi$ over the range from 0.5 to 3), caused a slight decrease in $\mathrm{Al}_{2} \mathrm{O}_{3}$ coating surface grain size. Both Kim et al [43] and Park et al [44] associated the nucleation rate of $\mathrm{Al}_{2} \mathrm{O}_{3}$ coatings, and hence coating surface grain size, with supersaturation of the reactants but not in a concordant manner. Park et al suggested that at low $\mathrm{AlCl}_{3}$ concentration the supersaturation of the $\mathrm{Al}$ donor decreases with increase in $\mathrm{AlCl}_{3}$ concentration whilst that of the $\mathrm{H}_{2} \mathrm{O}$ increases and hence that the $\mathrm{Al}_{2} \mathrm{O}_{3}$ coating surface morphology is controlled by the supersaturation of the Al-donor, but that with further increase in $\mathrm{AlCl}_{3}$ concentration the nucleation of $\mathrm{Al}_{2} \mathrm{O}_{3}$ becomes limited by the $\mathrm{O}$-donor. Conversely, $\mathrm{Kim}$ et al suggested that the nucleation rate of $\mathrm{Al}_{2} \mathrm{O}_{3}$ coatings might be independent of the supersaturation of the Al-donor and controlled by the supersaturation of $\mathrm{H}_{2} \mathrm{O}$.

It is clearly evident that the effect of increasing $\mathrm{H}_{2}-1 / \mathrm{AlCl}_{3}$ flow rate on $\mathrm{Al}_{2} \mathrm{O}_{3}$ coating bulk and surface grain size observed in the present work, closely matches that on $\mathrm{Al}_{2} \mathrm{O}_{3}$ coating thickness dealt with in the previous section. This is to be expected since it has been argued in the previous section that the $\mathrm{Al}_{2} \mathrm{O}_{3}$ coating thickness measurements principally relate to the bulk of the $\mathrm{Al}_{2} \mathrm{O}_{3}$ coatings. As with $\mathrm{Al}_{2} \mathrm{O}_{3}$ coating thickness, therefore, the CVD reactions of predominant importance with regard to the observed effect of $\mathrm{H}_{2}-1 / \mathrm{AlCl}_{3}$ flow rate on $\mathrm{Al}_{2} \mathrm{O}_{3}$ coating bulk and hence surface grain size are the overall reaction(s) between $\mathrm{AlCl}_{3}$ and $\mathrm{H}_{2} \mathrm{O}$ (reaction (3), page 93) and/or between $\mathrm{AlCl}_{3}, \mathrm{H}_{2}$ and $\mathrm{CO}_{2}$ (reaction (6), page 93). This being the case, and with reference to the work of Park et al, it is suggested that the sustained increase in $\mathrm{Al}_{2} \mathrm{O}_{3}$ coating grain size with increase in $\mathrm{H}_{2}-1 / \mathrm{AlCl}_{3}$ flow rate from 10 to $25 \mathrm{~cm}^{3}$ $\mathrm{min}^{-1}$ observed in the present work is due to the corresponding increase in the concentration of $\mathrm{AlCl}_{3}$ in the bulk gas stream causing a decrease in the supersaturation of $\mathrm{AlCl}_{3}$ and thereby a decrease in the nucleation rate, i.e. a decrease in the number of $\mathrm{Al}_{2} \mathrm{O}_{3}$ nuclei, and thus an increase in grain size. The fact that, as described earlier in this section, the $\mathrm{Al}_{2} \mathrm{O}_{3}$ coating grain size appeared to remain sensibly constant with further increase in $\mathrm{H}_{2}-1 / \mathrm{AlCl}_{3}$ flow rate to $30 \mathrm{~cm}^{3} \mathrm{~min}^{-1}$, is attributed to the aforementioned concomitant decrease in $\mathrm{CO}_{2} / \mathrm{AlCl}_{3}$ mole ratio with increasing $\mathrm{H}_{2}-1 / \mathrm{AlCl}_{3}$ flow rate eventually leading to a relative shortage of $\mathrm{O}$-donors with the result that at $\mathrm{H}_{2}-1 / \mathrm{AlCl}_{3}$ flow rates above $25 \mathrm{~cm}^{3} \mathrm{~min}^{-1}$, the nucleation of $\mathrm{Al}_{2} \mathrm{O}_{3}$ is limited by the $\mathrm{O}$-donor. This explanation is completely consistent with that for the effect of $\mathrm{H}_{2}-1 / \mathrm{AlCl}_{3}$ flow rate on $\mathrm{Al}_{2} \mathrm{O}_{3}$ coating thickness. 
Returning to the bulk grain structures of the $\mathrm{Al}_{2} \mathrm{O}_{3}$ coatings deposited at the five different $\mathrm{H}_{2}-1 / \mathrm{AlCl}_{3}$ flow rates shown in Figure 5.39, it can also be seen for each flow rate that a thin layer is present in the upper part of the $\mathrm{Ti}(\mathrm{C}, \mathrm{N})$ precoating directly adjacent to the $\mathrm{Al}_{2} \mathrm{O}_{3}$ coating/Ti(C,N) precoating interface, and that the lower part of the $\mathrm{Al}_{2} \mathrm{O}_{3}$ coating directly adjacent to this interface contains grains which are much finer than those in the bulk of the $\mathrm{Al}_{2} \mathrm{O}_{3}$ coating. Similar features were also observed in the case of the preliminary $h c$ inserts (see Figure 4.19, and Section 6.1.5). Given the comments made regarding these features in the case of the latter inserts, and the conclusions reached in Section 6.2.1.1 regarding the ac inserts from the $\mathrm{H}_{2}-1 / \mathrm{AlCl}_{3}$ flow rate coating runs, it seems certain that the thin layer observed in the upper part of the $\mathrm{Ti}(\mathrm{C}, \mathrm{N})$ precoating directly adjacent to the $\mathrm{Al}_{2} \mathrm{O}_{3}$ coating/Ti(C,N) precoating interface on the $h c$ inserts from the $\mathrm{H}_{2}-1 / \mathrm{AlCl}_{3}$ flow rate (and preliminary) coating runs is the titanium oxides caused by the first "substrate-type" reaction (reaction (2), page 93). It is also strongly felt that the finer grains in the lower part of the $\mathrm{Al}_{2} \mathrm{O}_{3}$ coating directly adjacent to this interface are due to the combination of the second "substrate-type" reaction between the titanium oxides in the upper part of the $\mathrm{Ti}(\mathrm{C}, \mathrm{N})$ precoating and the $\mathrm{AlCl}_{3}$ reactant gas (reaction (4), page 93) with either the modified overall reaction between $\mathrm{AlCl}_{3}, \mathrm{H}_{2} \mathrm{O}$ and $\mathrm{TiCl}_{4}$ or between $\mathrm{AlCl}_{3}, \mathrm{H}_{2}, \mathrm{CO}_{2}$ and $\mathrm{TiCl}_{4}$. There is, in fact, some evidence from the work of Colombier and Lux [54] on the deliberate codeposition of $\mathrm{Al}_{2} \mathrm{O}_{3}$ and $\mathrm{Ti}\left(\mathrm{C}_{\mathrm{x}} \mathrm{O}_{\mathrm{y}}\right)$ from an $\mathrm{AlCl}_{3}-\mathrm{H}_{2}-\mathrm{CO}_{2}-\mathrm{TiCl}_{4}$ gas mixture to substantiate this. Given the complexity of the reactions suggested in Section 6.2.1.1 to be responsible for the formation of the $\mathrm{Al}_{2} \mathrm{O}_{3}$ coating/Ti(C,N) precoating transition zone, and hence the thin layer of titanium oxides in the upper part of the $\mathrm{Ti}(\mathrm{C}, \mathrm{N})$ precoating and the finer grains in the lower part of $\mathrm{Al}_{2} \mathrm{O}_{3}$ coating, it is very difficult to account for the observed effects of increasing $\mathrm{H}_{2}-1 / \mathrm{AlCl}_{3}$ flow rate on both of these features without more detailed work.

\subsubsection{Effect of $\mathrm{H}_{2}-1 / \mathrm{AlCl}_{3}$ flow rate on preferred orientation and lattice parameter of $\mathrm{Al}_{2} \underline{\mathrm{O}}_{3}$ coatings}

A number of facts are evident from Figure 5.30, which shows typical relative X-ray intensities for the $\mathrm{Al}_{2} \ddot{\mathrm{O}}_{3}$ coatings deposited at the five different $\mathrm{H}_{2}-1 / \mathrm{AlCl}_{3}$ flow rates, compared to the random intensities for the $\alpha-\mathrm{Al}_{2} \mathrm{O}_{3}$ powder. First, it is evident that, overall, the magnitudes of the relative intensities obtained for the $\mathrm{Al}_{2} \mathrm{O}_{3}$ coatings are considerably smaller than those obtained for the $\alpha-\mathrm{Al}_{2} \mathrm{O}_{3}$ powder. In the case of the preliminary $\mathrm{Al}_{2} \mathrm{O}_{3}$ coatings, as previously described in Section 4.1.1, similarly low relative intensities were attributed to preliminary $\mathrm{Al}_{2} \mathrm{O}_{3}$ coating thickness. This explanation is, of course, also of general validity for the $\mathrm{Al}_{2} \mathrm{O}_{3}$ coatings deposited at the different $\mathrm{H}_{2}-1 / \mathrm{AlCl}_{3}$ flow rates. It can also be seen from Figure 5.30 that all the $\mathrm{Al}_{2} \mathrm{O}_{3}$ coatings from the $\mathrm{H}_{2}-1 / \mathrm{AlCl}_{3}$ flow rate coating runs are of the $\alpha-\mathrm{Al}_{2} \mathrm{O}_{3}$ crystal form and that all exhibit preferred orientation of the $\{11 \overline{2} 3\}$ planes. It is, however, also evident that increase in $\mathrm{H}_{2}-1 / \mathrm{AlCl}_{3}$ flow rate from 10 to $25 \mathrm{~cm}^{3} \mathrm{~min}^{-1}$ has caused a sustained increase in the intensity of the $\{11 \overline{2} 3\}$ reflections, but that this then appears to remain sensibly 
constant with further increase in $\mathrm{H}_{2}-1 / \mathrm{AlCl}_{3}$ flow rate to $30 \mathrm{~cm}^{3} \mathrm{~min}^{-1}$. This effect is consistent with the effect of $\mathrm{H}_{2}-1 / \mathrm{AlCl}_{3}$ flow rate on $\mathrm{Al}_{2} \mathrm{O}_{3}$ coating thickness observed earlier (see Section 6.2.1.2). Given the preceding comments regarding the low magnitudes of the relative intensities obtained for the $\mathrm{Al}_{2} \mathrm{O}_{3}$ coatings, it is suggested that the observed effect of increasing $\mathrm{H}_{2}-1 / \mathrm{AlCl}_{3}$ flow rate on the intensity of the $\{11 \overline{2} 3\}$ reflections from the $\mathrm{Al}_{2} \mathrm{O}_{3}$ coatings can be directly attributed to the concomitant effect of $\mathrm{H}_{2}-1 / \mathrm{AlCl}_{3}$ flow rate on $\mathrm{Al}_{2} \mathrm{O}_{3}$ coating thickness. This, of course, implies that there has been no change in the degree preferred orientation of the $\mathrm{Al}_{2} \mathrm{O}_{3}$ coatings with increasing $\mathrm{H}_{2}-1 / \mathrm{AlCl}_{3}$ flow rate, which is completely consistent with the observation (see Section 6.2.1.3) that increasing $\mathrm{H}_{2}-1 / \mathrm{AlCl}_{3}$ flow rate had no effect on the morphology of the grains in the bulk of the $\mathrm{Al}_{2} \mathrm{O}_{3}$ coatings.

In contrast to the results of the present work, Park et al [44] found for $\mathrm{Al}_{2} \mathrm{O}_{3}$ coatings chemically vapour deposited on TiN coated cemented carbide substrates, that an increase in $\mathrm{AlCl}_{3}$ mole fraction from $1 \times 10^{-3}$ to $1 \times 10^{-2}$ (i.e increase in $\phi$ from 0.1 to 1 ) caused the $\mathrm{Al}_{2} \mathrm{O}_{3}$ coating grains to become coarser and to exhibit preferred orientations of the $\{10 \overline{1} 4\}$ and $\{11 \overline{2} 6\}$ planes, but that further increase in $\mathrm{AlCl}_{3}$ mole fraction resulted in a finer grain size and a reduction in preferred orientation. It seems reasonable to suggest that the different $\mathrm{Al}_{2} \mathrm{O}_{3}$ coating preferred orientations observed in the present work and in that carried out by Park et al, may be due to a difference in the deposition conditions employed, including the $\phi$ values ( $\phi$. value range of 3.7 to 7.5 in the present work c.f. range of 0.1 to 1 in the work of Park et al).

From Figure 5.31, which shows the effect of $\mathrm{H}_{2}-1 / \mathrm{AlCl}_{3}$ flow rate on the "a" and "c" lattice parameters of the $\mathrm{Al}_{2} \mathrm{O}_{3}$ coatings in the present work, it can be seen that with initial increase in $\mathrm{H}_{2}-1 / \mathrm{AlCl}_{3}$ flow rate from 10 to $\sim 15 \mathrm{~cm}^{3} \mathrm{~min}^{-1}$ there is a marked decrease in the lattice parameters, but that further increase in $\mathrm{H}_{2}-1 / \mathrm{AlCl}_{3}$ flow rate from $\sim 15$ to $30 \mathrm{~cm}^{3} \mathrm{~min}^{-1}$ has caused their sustained increase. Superimposed on Figure 5.31 are the bulk stoichiometries of the $\mathrm{Al}_{2} \mathrm{O}_{3}$ coatings deposited at the different $\mathrm{H}_{2}-1 / \mathrm{AlCl}_{3}$ flow rates, and it is immediately evident that there is a very good correlation between the effect of increasing $\mathrm{H}_{2}-1 / \mathrm{AlCl}_{3}$ flow rate on the bulk stoichiometry and lattice parameters of the $\mathrm{Al}_{2} \mathrm{O}_{3}$ coatings. It is therefore, not surprisingly, suggested that the observed effect of $\mathrm{H}_{2}-1 / \mathrm{AlCl}_{3}$ flow rate on $\mathrm{Al}_{2} \mathrm{O}_{3}$ coating lattice parameters is a reflection of its effect on the bulk stoichiometry of the $\mathrm{Al}_{2} \mathrm{O}_{3}$ coatings, previously discussed in Section 6.2.1.1.

Surprisingly, no previous work on the effect of $P_{\mathrm{AlCl}_{3}}$ on the lattice parameters of $\mathrm{Al}_{2} \mathrm{O}_{3}$ coatings was found in the literature to permit comparison with the results of the present work.

\subsubsection{Effect of $\mathrm{H}_{2}-1 / \mathrm{AlCl}_{3}$ flow rate on $\mathrm{Al}_{2} \underline{\mathrm{O}}_{3}$ coating microhardness}

From Figure 5.37, which shows the effect of $\mathrm{H}_{2}-1 / \mathrm{AlCl}_{3}$ flow rate on the microhardness of the $\mathrm{Al}_{2} \mathrm{O}_{3}$ coatings, it can be seen that increase in $\mathrm{H}_{2}-1 / \mathrm{AlCl}_{3}$ flow rate from 10 to $\sim 25 \mathrm{~cm}^{3}$ 
$\min ^{-1}$ has caused a sustained increase in the microhardness of the $\mathrm{Al}_{2} \mathrm{O}_{3}$ coatings, which is particularly marked with increase in flow rate from 10 to $15 \mathrm{~cm}^{3} \mathrm{~min}^{-1}$, but that the microhardness then appears to remain sensibly constant with further increase in $\mathrm{H}_{2}-1 / \mathrm{AlCl}_{3}$ flow rate from $\sim 25$ to $30 \mathrm{~cm}^{3} \mathrm{~min}^{-1}$. This effect mirrors that of increasing $\mathrm{H}_{2}-1 / \mathrm{AlCl}_{3}$ flow rate on $\mathrm{Al}_{2} \mathrm{O}_{3}$ coating bulk grain size discussed in Section 6.2.1.3. Given the well-known inverse relationship between the hardness of bulk polycrystalline materials and their grain size (exemplified by the Hall-Petch equation [84]), it might appear strange that an association is being made in the present work between increasing microhardness and increasing grain size of the $\mathrm{Al}_{2} \mathrm{O}_{3}$ coatings. However, in previous work on CVD TiC and TiN coatings on PM BT42 grade HSS inserts, Lewus [11] and Abbas [9] respectively observed an increase in coating microhardness with increasing grain size. In both cases, it was suggested to be associated with a concomitant increase in crystal defect concentration. Similarly, therefore, in the present work, it is suggested that the effect of $\mathrm{H}_{2}-1 / \mathrm{AlCl}_{3}$ flow rate on $\mathrm{Al}_{2} \mathrm{O}_{3}$ coating microhardness is associated with, but not directly caused by, the concomitant effect of $\mathrm{H}_{2}-1 / \mathrm{AlCl}_{3}$ flow rate on $\mathrm{Al}_{2} \mathrm{O}_{3}$ coating bulk grain size. Whether the direct cause is a corresponding increase in crystal defect concentration requires further work using transmission electron microscopy techniques.

With regard to the microhardness values in Figures 5.36(a) - (e) corresponding to zero distance from the $\mathrm{Al}_{2} \mathrm{O}_{3}$ coating/Ti(C,N) precoating interface; by extrapolating the sloping line on each figure to intersect the microhardness axis, it is evident that the microhardness value obtained in each case is considerably lower than that of the $\mathrm{Ti}(\mathrm{C}, \mathrm{N})$ precoating to which it should correspond $\left(\sim 2400 \mathrm{HV}_{0.025}\right.$ for $\mathrm{Ti}\left(\mathrm{C}_{0.2} \mathrm{~N}_{0.8}\right)$ - see Section 6.1.7). The same feature was observed in the case of the preliminary $\mathrm{Al}_{2} \mathrm{O}_{3}$ coated inserts, and attributed to the lower hardness of the thin layer of titanium oxides in the upper part of the $\mathrm{Ti}(\mathrm{C}, \mathrm{N})$ precoating directly adjacent to its interface with the $\mathrm{Al}_{2} \mathrm{O}_{3}$ coating (see Section 6.1.7). Obviously, given the remarks made earlier in this section of the discussion (i.e. Section 6.2.1), this explanation is also applicable to the $\mathrm{Al}_{2} \mathrm{O}_{3}$ coated inserts from the $\mathrm{H}_{2}-1 / \mathrm{AlCl}_{3}$ flow rate coating runs.

\subsubsection{Effect of $\mathrm{H}_{2}-1 / \mathrm{AlCl}_{3}$ flow rate on peripheral thickness variation (and other features) of $\mathrm{Al}_{2} \underline{\mathrm{O}}_{3}$ coatings}

Optical examination of the polished and etched cross-section through one of the ac inserts from each of the five $\mathrm{H}_{2}-1 / \mathrm{AlCl}_{3}$ flow rate coating runs characterised in the present work, revealed that, in each case, the $\mathrm{Al}_{2} \mathrm{O}_{3}$ coating extended all round the periphery of the $\mathrm{Ti}(\mathrm{C}, \mathrm{N})$ precoated PM HSS insert. However, it was also observed that although, in general, the $\mathrm{Al}_{2} \mathrm{O}_{3}$ coating was of fairly uniform thickness on the rake and flank faces of the ac inserts, it was significantly thicker on the comers. This is exemplified by the $\mathrm{Al}_{2} \mathrm{O}_{3}$ coating thickness values presented in Table 5.14. It would appear from this table that the increased thickness of the $\mathrm{Al}_{2} \mathrm{O}_{3}$ coating on the corners of the $a c$ inserts, relative to that on the rake and flank faces, is 
not materially affected by $\mathrm{H}_{2}-1 / \mathrm{AlCl}_{3}$ flow rate, remaining approximately constant at a level in the region of two times. This increased thickness is thought to be due, as previously suggested in Section 6.1.3, to the location of the inserts relative to the reactant gas flow and/or to the gas flow conditions inside the CVD reactor during deposition.

From the optical cross-sections through the rake face of the $a c$ inserts from each of the $\mathrm{H}_{2}-1 / \mathrm{AlCl}_{3}$ flow rate coating runs, shown in Figure 5.35, it can be seen that the surface of the $\mathrm{Al}_{2} \mathrm{O}_{3}$ coating on the rake face of the inserts is rather uneven. Whilst, at each $\mathrm{H}_{2}-1 / \mathrm{AlCl}_{3}$ flow rate, this unevenness can be at least partially attributed to the underlying $\mathrm{Ti}(\mathrm{C}, \mathrm{N})$ precoating, Figure 5.35 clearly shows that at the $\mathrm{H}_{2}-1 / \mathrm{AlCl}_{3}$ flow rates of 15 and $25 \mathrm{~cm}^{3} \mathrm{~min}^{-1}$ in particular, some of the unevenness is an inherent feature of the $\mathrm{Al}_{2} \mathrm{O}_{3}$ coating itself. As is also evident from Figure 5.35, with the exception of isolated porosity, no major defects are visible in the $\mathrm{Al}_{2} \mathrm{O}_{3}$ coatings and the $\mathrm{Al}_{2} \mathrm{O}_{3}$ coating/Ti(C,N) precoating interface appears to be continuous in each case, as also does the $\mathrm{Ti}(\mathrm{C}, \mathrm{N})$ precoating/HSS substrate interface, although there is some porosity in the $\mathrm{Ti}(\mathrm{C}, \mathrm{N})$ precoating adjacent to the latter interface. Also just discernible from these optical cross-sections, particularly those through the rake face of the inserts corresponding to $\mathrm{H}_{2}-1 / \mathrm{AlCl}_{3}$ flow rates of 25 and $30 \mathrm{~cm}^{3} \mathrm{~min}^{-1}$, is the presence of a thin band in the $\mathrm{Ti}(\mathrm{C}, \mathrm{N})$ precoating immediately adjacent to its interface with the $\mathrm{Al}_{2} \mathrm{O}_{3}$ coating. The presence of this thin band will be discussed in Section 6.2.1.8.

\subsubsection{Effect of $\mathrm{H}_{2}=1 / \mathrm{AlCl}{ }_{3}$ flow rate on surface roughness of $\underline{\mathrm{Al}}_{2} \underline{\mathrm{O}}_{3}$ coatings}

From Table 5.13, which shows the surface roughness values for the $\mathrm{Al}_{2} \mathrm{O}_{3}$ coatings deposited in the five $\mathrm{H}_{2}-1 / \mathrm{AlCl}_{3}$ flow rate coating runs, and from Figure 5.33 which shows the corresponding typical Talysurf traces obtained for the coatings, it is evident that increasing $\mathrm{H}_{2}-1 / \mathrm{AlCl}_{3}$ flow rate has not had a sustained, identifiable effect on the surface roughness of the $\mathrm{Al}_{2} \mathrm{O}_{3}$ coatings. This is attributed to the fact that the surface roughness of the $\mathrm{Al}_{2} \mathrm{O}_{3}$ coatings is influenced by three factors: the surface roughness of the underlying $\mathrm{Ti}(\mathrm{C}, \mathrm{N})$ precoating, which is not influenced by $\mathrm{H}_{2}-1 / \mathrm{AlCl}_{3}$ flow rate; the inherent unevenness of the surface of the $\mathrm{Al}_{2} \mathrm{O}_{3}$ coating itself, which, as described in Section 6.2.1.6, was affected by $\mathrm{H}_{2}-1 / \mathrm{AlCl}_{3}$ flow rate but not in a systematic way, and the surface grain size of the $\mathrm{Al}_{2} \mathrm{O}_{3}$ coatings which, as described in Section 6.2.1.3, was also affected by $\mathrm{H}_{2}-1 / \mathrm{AlCl}_{3}$ flow rate but in a systematic way. The significantly greater surface roughness of the $\mathrm{Al}_{2} \mathrm{O}_{3}$ coatings deposited at the $\mathrm{H}_{2}-1 / \mathrm{AlCl}_{3}$ flow rates of 15 and $25 \mathrm{~cm}^{3} \mathrm{~min}^{-1}$, evident in both Table 5.13 and Figure 5.33, is attributed primarily to the inherent marked unevenness of the surface of the $\mathrm{Al}_{2} \mathrm{O}_{3}$ coating itself, referred to previously in Section 6.2.1.6, and visible in Figure 5.35 (b) and (d). 


\subsubsection{Effect of $\mathrm{H}_{2}=1 / \mathrm{AlCl}_{3}$ flow rate on microstructure of $\mathrm{Al}_{2} \mathrm{O}_{3}$ coating adjacent to interface with $\mathrm{Ti}(\mathrm{C}, \mathrm{N})$ precoating}

As previously described in Section 6.2.1.6 and shown in Figure 5.35, on the optical cross-sections through the rake face of some of the ac inserts from the $\mathrm{H}_{2}-1 / \mathrm{AlCl}_{3}$ flow rate coating runs, a thin band was just discernible in the upper part of the Ti(C,N) precoating immediately adjacent to its interface with the $\mathrm{Al}_{2} \mathrm{O}_{3}$ coating. As described earlier in Section 5.2.7, the ac taper-sectioned inserts from each of the $\mathrm{H}_{2}-1 / \mathrm{AlCl}_{3}$ flow rate coating runs were employed to facilitate a proper, relatively high magnification optical examination of this band. From the optical taper sections through the rake face of each of these $a c$ inserts, shown in Figure 5.38, a thin layer can quite clearly be seen to be present in the upper part of the $\operatorname{Ti}(\mathrm{C}, \mathrm{N})$ precoating directly adjacent to its interface with the $\mathrm{Al}_{2} \mathrm{O}_{3}$ coating. Manifestly, this must correspond to the thin layer observed in this location on the fractographs (Figure 5.39) of the $h c$ inserts from each of the $\mathrm{H}_{2}-1 / \mathrm{AlCl}_{3}$ flow rate coating runs, which, it was stated in Section 6.2.1.3, is the titanium oxides caused by the first "substrate-type" reaction (reaction (2), page 93), referred to initially in Section 6.2.1.1.

It is further evident from Figure 5.38 that, for each $\mathrm{H}_{2}-1 / \mathrm{AlCl}_{3}$ flow rate, the lower part of the $\mathrm{Al}_{2} \mathrm{O}_{3}$ coating immediately adjacent to its interface with the $\mathrm{Ti}(\mathrm{C}, \mathrm{N})$ precoating has a "mottled" appearance. This feature was also observed in the case of the preliminary ac and $h c$ inserts (see Figures 4.10 and 4.18, respectively and Section 6.1.4). Given the comments made regarding this feature in the case of the preliminary $a c$ and $h c$ inserts, and more particularly the conclusions reached in Section 6.2.1.1 regarding the $a c$ inserts from the $\mathrm{H}_{2}-1 / \mathrm{AlCl}_{3}$ flow rate coating runs, it seems certain that the "mottled" appearance observed in the lower part of the $\mathrm{Al}_{2} \mathrm{O}_{3}$ coating on the ac inserts from the $\mathrm{H}_{2}-1 / \mathrm{AlCl}_{3}$ flow rate (and preliminary) coating runs, results from the combination of the second "substrate-type" reaction between the titanium oxides in the upper part of the $\mathrm{Ti}(\mathrm{C}, \mathrm{N})$ precoating and the $\mathrm{AlCl}_{3}$ reactant gas (reaction (4), page 93) with either the modified overall reaction between $\mathrm{AlCl}_{3}, \mathrm{H}_{2} \mathrm{O}$ and $\mathrm{TiCl}_{4}$ or between $\mathrm{AlCl}_{3}, \mathrm{H}_{2}, \mathrm{CO}_{2}$ and $\mathrm{TiCl}_{4}$. It was suggested in Section 6.2.1.1, that this combination leads initially to the codeposition of oxygen deficient $\mathrm{Al}_{2} \mathrm{O}_{3}$ and some form of titanium oxide, which is then transformed to $\operatorname{Ti}\left(\mathrm{O}_{x} \mathrm{C}_{\mathrm{y}} \mathrm{N}_{z}\right)$ by the diffusion of $\mathrm{C}$ and $\mathrm{N}$ from the $\operatorname{Ti}(\mathrm{C}, \mathrm{N})$ precoating. It is now further suggested that the speckles which are evident in the "mottled" region are this $\operatorname{Ti}\left(\mathrm{O}_{\mathrm{x}} \mathrm{C}_{\mathrm{y}} \mathrm{N}_{\mathrm{z}}\right)$. In support of this suggestion, it can be seen from Figure 5.38 that their shade matches that of the thin layer in the upper part of the $\mathrm{Ti}(\mathrm{C}, \mathrm{N})$ precoating.

As mentioned earlier in Section 6.2.1.1, given the complexity of the reactions suggested to be responsible for the formation of the $\mathrm{Al}_{2} \mathrm{O}_{3}$ coating/Ti(C,N) precoating transition zone, and hence the thin layer of titanium oxides in the upper part of the $\operatorname{Ti}(\mathrm{C}, N)$ precoating and the "mottled" appearance of the lower part of $\mathrm{Al}_{2} \mathrm{O}_{3}$ coating, it is very difficult to account for the observed effects of increasing $\mathrm{H}_{2}-1 / \mathrm{AlCl}_{3}$ flow rate on both of these features without more detailed work. 


\subsubsection{Effect of $\mathrm{H}_{2}-1 / \mathrm{AlCl}_{3}$ flow rate on $\mathrm{Al}_{2} \mathrm{O}_{3}$ coating adhesion}

As mentioned earlier in Section 5.2.9 the scratch test was used to investigate the effect of $\mathrm{H}_{2}-1 / \mathrm{AlCl}_{3}$ flow rate on the adhesion of the $\mathrm{Al}_{2} \mathrm{O}_{3}$ coatings to the Ti(C,N) precoated PM HSS inserts. For the reasons previously explained in Section 5.2.9, prior to scratch testing of the $h c$ inserts from the different $\mathrm{H}_{2}-1 / \mathrm{AlCl}_{3}$ flow rate coating runs, the thickness of the $\mathrm{Al}_{2} \mathrm{O}_{3}$ coating (and of the Ti(C,N) precoating) and the hardness of the PM HSS substrate of each of the $h c$ inserts to be employed were determined. These values are shown in Table 5.16.

Turning now to the scratch test results obtained; several points are evident from Table 5.17 which summarises the results of the scratch tests carried out on the $h c$ insert from each of the $\mathrm{H}_{2}-1 / \mathrm{AlCl}_{3}$ flow rate coating runs. First, it can be seen that at each flow rate pre-critical stylus load flaking of the $\mathrm{Al}_{2} \mathrm{O}_{3}$ coating occurred at the edges of the scratch channels. It is further evident that increase in $\mathrm{H}_{2}-1 / \mathrm{AlCl}_{3}$ flow rate from 10 to $30 \mathrm{~cm}^{3} \mathrm{~min}^{-1}$ has had no effect on the stylus load at which this flaking was first observed nor on the type or degree of flaking. As can be seen, the lowest load at which such flaking occurred was established to be $4 \mathrm{~kg}$. An SEM micrograph showing a typical example of the flaking observed at this stylus load, together with the corresponding $\mathrm{Al}$, Ti and $\mathrm{Fe} K_{\alpha} \mathrm{X}$-ray maps, is shown for each $\mathrm{H}_{2}-1 / \mathrm{AlCl}_{3}$ flow rate in Figures 5.41 to 5.45. Correlation of the X-ray maps in each figure with the region of flaking at the edge of the scratch channel on the $\mathrm{Al}_{2} \mathrm{O}_{3}$ coated insert, suggests that the flaking is of the adhesive type; witnessed by the absence of $\mathrm{Al} /$ presence of Ti throughout the whole region of flaking. The fact that there appears to be no change in either the type or degree of flaking nor in the stylus load at which it was first was observed, is rather surprising. Although the $\mathrm{Al}_{2} \mathrm{O}_{3}$ coating/Ti(C,N) precoating transition zone was of the same form at each $\mathrm{H}_{2}-1 / \mathrm{AlCl}_{3}$ flow rate: i.e a thin layer of titanium oxides in the upper part of the $\mathrm{Ti}(\mathrm{C}, \mathrm{N})$ precoating, adjoining the lower part of the $\mathrm{Al}_{2} \mathrm{O}_{3}$ coating consisting of oxygen deficient $\mathrm{Al}_{2} \mathrm{O}_{3}$ containing speckles of $\operatorname{Ti}\left(\mathrm{O}_{x} \mathrm{C}_{y} \mathrm{~N}_{z}\right)$ - see Section 6.2.1.8, increasing $\mathrm{H}_{2}-1 / \mathrm{AlCl}_{3}$ flow rate did have an effect on both the upper part of the $\mathrm{Ti}(\mathrm{C}, \mathrm{N})$ precoating and the lower part of the $\mathrm{Al}_{2} \mathrm{O}_{3}$ coating (see Section 6.2.1.1) and it is therefore surprising that this has not, apparently, had an effect on pre-critical load flaking of the $\mathrm{Al}_{2} \mathrm{O}_{3}$ coating.

To attempt to determine the critical stylus load corresponding to extensive removal of the $\mathrm{Al}_{2} \mathrm{O}_{3}$ coating from the scratch channel, the scratch channel on each of the $h c$ inserts corresponding to the optically determined stylus load at which virtually the whole of the channel became silvery in appearance, together with channels produced by stylus loads lower than this, had been examined on an SEM. SEM micrographs of a typical region of the relevant scratch channels on each of the $h c$ inserts, together with the corresponding $\mathrm{Al}$, Ti and $\mathrm{Fe} K_{\mathrm{a}}$ $\mathrm{X}$-ray maps are shown in Figures 5.46 to 5.55. In each case it can be seen from the X-ray maps that for the scratch channels corresponding to the lower of the two stylus loads presented, $\mathrm{Al}$ (i.e. $\mathrm{Al}_{2} \mathrm{O}_{3}$ ) is present throughout the region of the scratch channels and there is little or no evidence of $\mathrm{Ti}$ or $\mathrm{Fe}$ (indicative of $\mathrm{Ti}(\mathrm{C}, \mathrm{N})$ ) or HSS respectively) in the region of the 
scratch channels. Conversely, for the scratch channels corresponding to the higher of the two stylus loads presented, it can be seen from each of the figures that the $\mathrm{Al}_{2} \mathrm{O}_{3}$ coating has been virtually completely removed from the scratch channels, as witnessed by the absence of $\mathrm{Al}$ in the region of the scratch channel in the X-ray map accompanying each of the SEM micrographs. Closer examination of these accompanying $\mathrm{X}$-ray maps, however, reveals that at $\mathrm{H}_{2}-1 / \mathrm{AlCl}_{3}$ flow rates of 10,15 and $30 \mathrm{~cm}^{3} \mathrm{~min}^{-1}$ (Figures $5.47,5.49$ and 5.55 respectively) not only is the $\mathrm{Al}$ absent from the area of the scratch channel but also there is little or no evidence of $\mathrm{Ti}$ and $\mathrm{Fe}$ is present throughout most of the scratch channel region. Obviously, this is indicative of the $\mathrm{Ti}(\mathrm{C}, \mathrm{N})$ precoating and the $\mathrm{Al}_{2} \mathrm{O}_{3}$ coating having been removed. Conversely, at the $\mathrm{H}_{2}-1 / \mathrm{AlCl}_{3}$ flow rate of $25 \mathrm{~cm}^{3} \mathrm{~min}^{-1}$, as evident from Figure 5.53 , the absence of $\mathrm{Al}$ from the region of the scratch channel is accompanied by the presence of $\mathrm{Ti}$ but not that of $\mathrm{Fe}$, indicative that in this case only the $\mathrm{Al}_{2} \mathrm{O}_{3}$ coating has been removed. This being the case, then only at the $\mathrm{H}_{2}-1 / \mathrm{AlCl}_{3}$ flow rate of $25 \mathrm{~cm}^{3} \mathrm{~min}^{-1}$ does the critical stylus load quoted in Table 5.17 actually correspond to adhesion of the $\mathrm{Al}_{2} \mathrm{O}_{3}$ coating to the $\mathrm{Ti}(\mathrm{C}, \mathrm{N})$ precoating. For each of the other $\mathrm{H}_{2}-1 / \mathrm{AlCl}_{3}$ flow rates, the "critical" stylus load corresponds to the adhesion of the $\mathrm{Ti}(\mathrm{C}, \mathrm{N})$ precoating to the HSS substrate. Obviously, this precludes identification of the real effect of $\mathrm{H}_{2}-1 / \mathrm{AlCl}_{3}$ flow rate on the adhesion of the $\mathrm{Al}_{2} \mathrm{O}_{3}$ coating proper.

Surprisingly, no previous work on the effect of $P_{A l C l}$ on the adhesive character of $\mathrm{Al}_{2} \mathrm{O}_{3}$ coatings was found in the literature to permit comparison with the results of the present work.

\subsubsection{Effect of $\mathrm{CO}_{2} / \mathrm{H}_{2}$ mole ratio}

$\mathrm{CO}_{2} / \mathrm{H}_{2}$ mole ratios of $1 / 6,1 / 8,1 / 10,1 / 12$ and $1 / 14$ were employed in the present work (at a constant $\mathrm{H}_{2}-1 / \mathrm{AlCl}_{3}$ flow rate of $25 \mathrm{~cm}^{3} \mathrm{~min}^{-1}$ ) to investigate the effect of $\mathrm{CO}_{2} / \mathrm{H}_{2}$ mole ratio on the characteristics of $\mathrm{Al}_{2} \mathrm{O}_{3}$ coatings deposited on the Ti(C,N) precoating PM BT42 grade HSS inserts. As previously pointed out in the introduction to Section 5.1, the $\mathrm{Al}_{2} \mathrm{O}_{3}$ coating deposited at the $\mathrm{CO}_{2} / \mathrm{H}_{2}$ mole ratio of $1 / 8$ was, in fact, the preliminary $\mathrm{Al}_{2} \mathrm{O}_{3}$ coating, the characteristics of which have already been discussed in Section 6.1. These characteristics will, however, be reconsidered in this section, in the context of those of the $\mathrm{Al}_{2} \mathrm{O}_{3}$ coatings deposited at the other $\mathrm{CO}_{2} / \mathrm{H}_{2}$ mole ratios, in order to initially identify and subsequently discuss the effects of $\mathrm{CO}_{2} / \mathrm{H}_{2}$ mole ratio on $\mathrm{Al}_{2} \mathrm{O}_{3}$ coating characteristics.

Prior to this, it is pertinent to redraw attention to a matter first addressed in the introduction to Section 5.2. The deposition conditions $\mathrm{CO}_{2} / \mathrm{H}_{2}$ mole ratio $=1 / 10$ and $\mathrm{H}_{2}-1 / \mathrm{AlCl}_{3}$ flow rate $=25 \mathrm{~cm}^{3} \mathrm{~min}^{-1}$ were common to both the study of the effect of $\mathrm{CO}_{2} / \mathrm{H}_{2}$ mole ratio and of $\mathrm{AlCl}_{3}$ concentration on $\mathrm{Al}_{2} \mathrm{O}_{3}$ coating characteristics. As described in the introduction to Section 5.2 , however, separate coating runs under these deposition conditions were performed for the two studies. This was done because a new batch of Ti(C,N) precoated PM HSS inserts had 
to be prepared for the $\mathrm{AlCl}_{3}$ concentration study and it was thought that there may be a minor compositional difference between the $\mathrm{Ti}(\mathrm{C}, \mathrm{N})$ precoating on these inserts and that on the inserts previously used for the $\mathrm{CO}_{2} / \mathrm{H}_{2}$ mole ratio study. It was to guard against any possible effects of this on $\mathrm{Al}_{2} \mathrm{O}_{3}$ coating characteristics that separate coating runs at a $\mathrm{CO}_{2} / \mathrm{H}_{2}$ mole ratio of $1 / 10$ and an $\mathrm{H}_{2}-1 / \mathrm{AlCl}_{3}$ flow rate of $25 \mathrm{~cm}^{3} \mathrm{~min}^{-1}$ were performed for the studies of the effect of $\mathrm{CO}_{2} / \mathrm{H}_{2}$ mole ratio and $\mathrm{AlCl}_{3}$ concentration. This being the case, caution must be exercised in making any detailed comparison of the characteristics of the $\mathrm{Al}_{2} \mathrm{O}_{3}$ coatings deposited in those two runs.

\subsubsection{Effect of $\mathrm{CO}_{2} / \mathrm{H}_{2}$ mole ratio on composition of $\mathrm{Al}_{2} \underline{\mathrm{O}}_{3}$ coating and $\mathrm{Al}_{2} \underline{\mathrm{O}}_{3}$ coating/Ti(C,N) precoating interface}

As previously described in Section 5.1, the AES composition-depth profiles through one of the $a c$ inserts (left 3, Table 5.2) from each of the $\mathrm{CO}_{2} / \mathrm{H}_{2}$ mole ratio coating runs are shown in Figure 5.4. Correlating these profiles with the thickness, as measured by ball-cratering, of the $\mathrm{Al}_{2} \mathrm{O}_{3}$ coating on ac insert left 3 from each of the $\mathrm{CO}_{2} / \mathrm{H}_{2}$ mole ratio coating runs, as shown in Table 5.3, reveals significant, inexplicable discrepancies. Notwithstanding this, overall, the major characteristics of each of these AES composition-depth profiles are compatible with those of the AES composition-depth profiles for the $\mathrm{Al}_{2} \mathrm{O}_{3}$ coated inserts from the $\mathrm{H}_{2}-1 / \mathrm{AlCl}_{3}$ flow rate study, shown in Figure 5.32 and previously described and discussed in Section 6.2.1.1. In particular, it can be clearly seen from Figure 5.4 that each of the $\mathrm{Al}_{2} \mathrm{O}_{3}$ coatings from the $\mathrm{CO}_{2} / \mathrm{H}_{2}$ mole ratio coating runs contains both $\mathrm{Al}(\mathrm{o})$ and $\mathrm{Al}(\mathrm{e})$, and that whilst the composition of each $\mathrm{Al}_{2} \mathrm{O}_{3}$ coating changes with depth, the stoichiometry of each coating (not including the $\mathrm{Al}(\mathrm{e})$ ) is nonetheless relatively uniform until the $\mathrm{Al}_{2} \mathrm{O}_{3}$ coating/Ti(C,N) precoating interface is approached. It can also be clearly seen from Figure 5.4 that significant intermingling of $\mathrm{Al}_{2} \mathrm{O}_{3}$ coating and $\mathrm{Ti}(\mathrm{C}, \mathrm{N})$ precoating elements has occurred during CVD of the $\mathrm{Al}_{2} \mathrm{O}_{3}$ coatings. In particular, both $\mathrm{Al}(\mathrm{o})$ and $\mathrm{Al}(\mathrm{e})$ can be seen to be present in the upper part of the $\mathrm{Ti}(\mathrm{C}, \mathrm{N})$ precoating and further it can be seen that oxygen is not only present in substantial quantities in this location, but also, at a lower level, throughout the $\mathrm{Ti}(\mathrm{C}, \mathrm{N})$ precoating. Similarly $\mathrm{Ti}, \mathrm{C}$ and $\mathrm{N}$ can be seen to be present, in substantial quantities in the case of the $\mathrm{Ti}$ and $\mathrm{N}$, in the lower part of the $\mathrm{Al}_{2} \mathrm{O}_{3}$ coatings, the depth into the $\mathrm{Al}_{2} \mathrm{O}_{3}$ coatings to which the $\mathrm{Ti}$ is present being either greater than or equal to that of the $\mathrm{N}$. It follows from the above that, as with the $\mathrm{Al}_{2} \mathrm{O}_{3}$ coated inserts from the $\mathrm{H}_{2}-1 / \mathrm{AlCl}_{3}$ flow rate coating runs, in discussing the AES composition-depth profiles for the inserts from the $\mathrm{CO}_{2} / \mathrm{H}_{2}$ mole ratio coating runs it is necessary to consider three regions: the bulk of the $\mathrm{Ti}(\mathrm{C}, \mathrm{N})$ precoating, the upper part of the $\mathrm{Ti}(\mathrm{C}, \mathrm{N})$ precoating and the lower part of the $\mathrm{Al}_{2} \mathrm{O}_{3}$ coating, which together comprise the $\mathrm{Al}_{2} \mathrm{O}_{3}$ coating/Ti(C,N) precoating transition zone, and finally the bulk of the $\mathrm{Al}_{2} \mathrm{O}_{3}$ coating. It also follows that the three different reactions/combinations of reactions suggested in Section 6.2.1 to be responsible for the presence/formation of these three regions in the case of the $\mathrm{Al}_{2} \mathrm{O}_{3}$ coated inserts from the $\mathrm{H}_{2}-1 / \mathrm{AlCl}_{3}$ flow rate study, are equally applicable to the $\mathrm{Al}_{2} \mathrm{O}_{3}$ coated inserts from the $\mathrm{CO}_{2} / \mathrm{H}_{2}$ mole ratio coating runs being 
considered here. It is not proposed to repeat the description of these three different reactions/combinations of reactions here as they have been dealt with at length in Section 6.2.1.

Consideration will now be given to the effect of $\mathrm{CO}_{2} / \mathrm{H}_{2}$ mole ratio on the above defined three regions, beginning with the bulk of the $\mathrm{Ti}(\mathrm{C}, \mathrm{N})$ precoating. As previously intimated it can be seen from Figure 5.4 that oxygen is present throughout the thickness of each of the $\operatorname{Ti}(\mathrm{C}, \mathrm{N})$ precoatings, but that the average level of oxygen present in the bulk of each precoating is not the same. With decrease in $\mathrm{CO}_{2} / \mathrm{H}_{2}$ mole ratio from $1 / 6$ to $1 / 8$ the average level of oxygen present in the bulk of the $\mathrm{Ti}(\mathrm{C}, \mathrm{N})$ precoating appears to remain substantially unchanged. Further decrease in $\mathrm{CO}_{2} / \mathrm{H}_{2}$ mole ratio to $1 / 12$, however, can be seen to have resulted in a dramatic decrease in this average level of oxygen which then increases with decrease in $\mathrm{CO}_{2} / \mathrm{H}_{2}$ mole ratio to $1 / 14$. Turning now to the $\mathrm{Al}_{2} \mathrm{O}_{3}$ coating/Ti(C,N) precoating transition zone; it is evident from Figure 5.4 that the distance over which the oxygen content increases from the average level present in the $\mathrm{Ti}(\mathrm{C}, \mathrm{N})$ precoating to a level representative of the $\mathrm{Al}_{2} \mathrm{O}_{3}$ coating, decreases noticeably and continuously with decrease in $\mathrm{CO}_{2} / \mathrm{H}_{2}$ mole ratio from $1 / 6$ to $1 / 12$. Further decrease in $\mathrm{CO}_{2} / \mathrm{H}_{2}$ mole ratio to $1 / 14$, however, can be seen to have resulted in an increase in this distance. With regard to the concurrent change in the composition of the upper part of the $\mathrm{Ti}(\mathrm{C}, \mathrm{N})$ precoating with decreasing $\mathrm{CO}_{2} / \mathrm{H}_{2}$ mole ratio, it appears from Figure 5.4 that decrease in $\mathrm{CO}_{2} / \mathrm{H}_{2}$ mole ratio from $1 / 6$ to $1 / 12$ has resulted in a marked decrease in the amount of oxygen present in the upper part of the $\operatorname{Ti}(\mathrm{C}, \mathrm{N})$ precoating but that this then appears to increase with further decrease in $\mathrm{CO}_{2} / \mathrm{H}_{2}$ mole ratio to $1 / 14$. Similarly, decrease in $\mathrm{CO}_{2} / \mathrm{H}_{2}$ mole ratio from $1 / 6$ to $1 / 12$ can be seen to have resulted in a dramatic decrease in the depth to which $\mathrm{Al}(\mathrm{o})$ and $\mathrm{Al}(\mathrm{e})$ are present in the $\mathrm{Ti}(\mathrm{C}, \mathrm{N})$ precoating, but with further decrease in $\mathrm{CO}_{2} / \mathrm{H}_{2}$ mole ratio to $1 / 14$ the depth of presence of $\mathrm{Al}(\mathrm{o})$ and $\mathrm{Al}(\mathrm{e})$ increases. Turning now to the presence of $\mathrm{Ti}, \mathrm{C}$ and $\mathrm{N}$ in the lower part of the $\mathrm{Al}_{2} \mathrm{O}_{3}$ coatings, Figure 5.4 clearly reveals that, with decrease in $\mathrm{CO}_{2} / \mathrm{H}_{2}$ mole ratio from $1 / 6$ to $1 / 12$, the depth of presence of the $\mathrm{Ti}, \mathrm{C}$ and $\mathrm{N}$, particularly the former, in the lower part of the $\mathrm{Al}_{2} \mathrm{O}_{3}$ coating decreases significantly. Further decrease in $\mathrm{CO}_{2} / \mathrm{H}_{2}$ mole ratio to $1 / 14$, however, can be seen to have resulted in a significant increase in the depth of presence of the $\mathrm{Ti}, \mathrm{C}$ and $\mathrm{N}$. It also appears from Figure 5.4 that, as with the $\mathrm{Al}_{2} \mathrm{O}_{3}$ coated inserts from the $\mathrm{H}_{2}-1 / \mathrm{AlCl}_{3}$ flow rate coating runs, the decrease in $\mathrm{Ti}$ with increasing distance into the lower part of the $\mathrm{Al}_{2} \mathrm{O}_{3}$ coating and the corresponding increase in $\mathrm{Al}(\mathrm{e})$ may be related; the $\mathrm{Al}(\mathrm{e})$ content reaching a maximum as the $\mathrm{Ti}$ content approaches/reaches zero. Finally, with regard to the bulk of the $\mathrm{Al}_{2} \mathrm{O}_{3}$ coating; the bulk stoichiometry of the $\mathrm{Al}_{2} \mathrm{O}_{3}$ coatings deposited at the $\mathrm{CO}_{2} / \mathrm{H}_{2}$ mole ratios of $1 / 6,1 / 8,1 / 10,1 / 12$ and $1 / 14$ can respectively, with reference to Figure 5.4 , be expressed by the following formulae: $\mathrm{Al}_{1.7} \mathrm{O}_{3}, \mathrm{Al}_{1.75} \mathrm{O}_{3}, \mathrm{Al}_{1.8} \mathrm{O}_{3}, \mathrm{Al}_{1.79} \mathrm{O}_{3}$ and $\mathrm{Al}_{1.6} \mathrm{O}_{3}$. With respect to the $\mathrm{Al}(\mathrm{e})$ present in the bulk of each of the $\mathrm{Al}_{2} \mathrm{O}_{3}$ coatings, it appears from Figure 5.4 that initial decrease in $\mathrm{CO}_{2} / \mathrm{H}_{2}$ mole ratio from $1 / 6$ to $1 / 10$ has resulted in a dramatic decrease in the average amount of $\mathrm{Al}(\mathrm{e})$ present. However, the amount of $\mathrm{Al}(\mathrm{e})$ present then appears to increase with further decrease in $\mathrm{CO}_{2} / \mathrm{H}_{2}$ mole ratio to $1 / 12$ and then decreases 
slightly with decrease in $\mathrm{CO}_{2} / \mathrm{H}_{2}$ mole ratio to $1 / 14$. It can also be seen from Figure 5.4 that $\mathrm{C}$ is not present in the bulk of any of the $\mathrm{Al}_{2} \mathrm{O}_{3}$ coatings deposited at the five different $\mathrm{CO}_{2} / \mathrm{H}_{2}$ mole ratios. The latter suggests that the overall reaction responsible for the deposition of the bulk of each of the $\mathrm{Al}_{2} \mathrm{O}_{3}$ coatings in the $\mathrm{CO}_{2} / \mathrm{H}_{2}$ mole ratio coating runs is that between $\mathrm{AlCl}_{3}$ and $\mathrm{H}_{2} \mathrm{O}$ (Lhermitte-Sebire et al reaction (3) - see Section 6.2.1.1) rather than that between $\mathrm{AlCl}_{3}, \mathrm{H}_{2}$ and $\mathrm{CO}_{2}$ (Lhermitte-Sebire et al reaction (6) - see Section 6.2.1.1), since the latter results in the codeposition of $\mathrm{Al}_{2} \mathrm{O}_{3}$ and $\mathrm{C}$.

The aforementioned (dramatic/marked) decrease in the average level of oxygen present in the bulk and in the upper part of the Ti(C,N) precoatings of the $a c$ inserts with decrease in $\mathrm{CO}_{2} / \mathrm{H}_{2}$ mole ratio from $1 / 6$ to $1 / 12$, is indicative of a concurrent decrease in the first "substrate-type" reaction between the $\mathrm{TiC}$ phase of the $\mathrm{Ti}(\mathrm{C}, \mathrm{N})$ precoating and the $\mathrm{CO}_{2}$ reactant gas. By reducing the formation of the titanium oxides in the upper part of the $\operatorname{Ti}(\mathrm{C}, \mathrm{N})$ precoating, such a decrease would also have reduced the extent of the second "substrate-type" reaction between these titanium oxides and the $\mathrm{AlCl}_{3}$ reactant gas. Such a reduction would have been expected to have decreased the distance over which the oxygen content increased from the average level present in the $\mathrm{Ti}(\mathrm{C}, \mathrm{N})$ precoating to a level representative of the $\mathrm{Al}_{2} \mathrm{O}_{3}$ coating, to have reduced the depth to which $\mathrm{Al}(\mathrm{O})$ and $\mathrm{Al}(\mathrm{e})$ are present in the $\operatorname{Ti}(\mathrm{C}, \mathrm{N})$ precoating and to have reduced the depth of presence of $\mathrm{Ti}, \mathrm{C}$ and $\mathrm{N}$ in the lower part of the $\mathrm{Al}_{2} \mathrm{O}_{3}$ coating. As described earlier in this section, it can be seen from Figure 5.4 that decrease in $\mathrm{CO}_{2} / \mathrm{H}_{2}$ mole ratio from $1 / 6$ to $1 / 12$ in the present work had exactly these effects. It is therefore concluded that there was indeed a decrease in the first "substrate-type" reaction between the $\mathrm{TiC}$ phase of the $\mathrm{Ti}(\mathrm{C}, \mathrm{N})$ precoating and the $\mathrm{CO}_{2}$ reactant gas in the present work with decrease in $\mathrm{CO}_{2} / \mathrm{H}_{2}$ mole ratio from $1 / 6$ to approximately $1 / 12$. The question which must now be addressed is how this decrease could have occurred when the $\mathrm{CO}_{2} / \mathrm{H}_{2}$ mole ratio coating runs were carried out at a constant $\mathrm{CO}_{2}$ flow rate of $25 \mathrm{~cm}^{3} \mathrm{~min}^{-1}$ (and a constant $\mathrm{H}_{2}-1 / \mathrm{AlCl}_{3}$ flow rate of $25 \mathrm{~cm}^{3} \mathrm{~min}^{-1}$ ). In answer to this, it is suggested that the use of atmospheric total deposition pressure in the present work, in comparison to the significantly reduced total deposition pressures employed in previous work on the $\mathrm{CVD}$ of $\mathrm{Al}_{2} \mathrm{O}_{3}$ coatings (see Chapter 2), caused an increase in the ratio of $\mathrm{H}_{2}$ to $\mathrm{CO}_{2}$ necessary to produce the maximum amount of $\mathrm{H}_{2} \mathrm{O}$ via their homogeneous gas phase reaction, from a value close to unity inferred by Kim et al [43] from their work at reduced pressure (see Section 2.5.1) and also evident in Figure 2.6 [37], to a $\mathrm{CO}_{2} / \mathrm{H}_{2}$ mole ratio value of approximately $1 / 12$ in the present work. In support of this suggestion, total pressure is well known to exert a significant effect on the thermodynamics of chemical reactions [96]. Assuming this to be the case, then at the highest $\mathrm{CO}_{2} / \mathrm{H}_{2}$ mole ratio of $1 / 6$ employed in the present work, there would have been insufficient $\mathrm{H}_{2}$ to convert all the $\mathrm{CO}_{2}$ into $\mathrm{H}_{2} \mathrm{O}$, the excess $\mathrm{CO}_{2}$ reacting with the TiC phase of the $\mathrm{Ti}(\mathrm{C}, \mathrm{N})$ precoating in the first "substrate-type" reaction. With decrease in $\mathrm{CO}_{2} / \mathrm{H}_{2}$ mole ratio from $1 / 6$ to $1 / 12$, however, the amount of excess $\mathrm{CO}_{2}$ would have decreased, leading to the postulated decrease in the first "substrate-type" reaction, with its attendant, aforementioned effects. Concurrently, there would, of course, have been an increase in the amount of $\mathrm{H}_{2} \mathrm{O}$ formed by 
the reaction between the $\mathrm{H}_{2}$ and $\mathrm{CO}_{2}$ (and hence in the overall reaction between the $\mathrm{AlCl}_{3}$ and $\mathrm{H}_{2} \mathrm{O}$ suggested earlier to be responsible for deposition of the bulk of the $\mathrm{Al}_{2} \mathrm{O}_{3}$ coatings in the $\mathrm{CO}_{2} / \mathrm{H}_{2}$ mole ratio coating runs), and it is suggested that this is the reason for the observed effect on bulk $\mathrm{Al}_{2} \mathrm{O}_{3}$ coating stoichiometry of the decrease in $\mathrm{CO}_{2} / \mathrm{H}_{2}$ mole ratio from $1 / 6$ to approximately $1 / 12$ observed in the present work.

As described earlier in this section, however, further decrease in $\mathrm{CO}_{2} / \mathrm{H}_{2}$ mole ratio from $1 / 12$ to $1 / 14$ led to a complete reversal of the trends evident with decrease in $\mathrm{CO}_{2} / \mathrm{H}_{2}$ mole ratio from $1 / 6$ to $1 / 12$. With decrease in $\mathrm{CO}_{2} / \mathrm{H}_{2}$ mole ratio from $1 / 12$ to $1 / 14$, the average level of oxygen present in the bulk and in the upper part of the $\mathrm{Ti}(\mathrm{C}, \mathrm{N})$ precoating increased, the distance over which the oxygen content increased from the average level present in the $\operatorname{Ti}(\mathrm{C}, \mathrm{N})$ precoating to a level representative of the $\mathrm{Al}_{2} \mathrm{O}_{3}$ coating became larger, the depth to which $\mathrm{Al}(\mathrm{O})$ and $\mathrm{Al}(\mathrm{e})$ were present in the $\mathrm{Ti}(\mathrm{C}, \mathrm{N})$ precoating increased, the depth of presence of $\mathrm{Ti}, \mathrm{C}$ and $\mathrm{N}$ in the lower part of the $\mathrm{Al}_{2} \mathrm{O}_{3}$ coating increased and the bulk stoichiometry of the $\mathrm{Al}_{2} \mathrm{O}_{3}$ coating deteriorated. These effects are indicative of a sudden, marked increase in the first "substrate-type" reaction between the $\mathrm{TiC}$ phase of the $\mathrm{Ti}(\mathrm{C}, \mathrm{N})$ precoating and the $\mathrm{CO}_{2}$ reactant gas, and hence in the extent of the second "substrate-type" reaction between the titanium oxides in the upper part of the $\mathrm{Ti}(\mathrm{C}, \mathrm{N})$ precoating and the $\mathrm{AlCl}_{3}$ reactant gas. It is suggested that these effects occurred because the excess $\mathrm{H}_{2}$ which would have been present at the $\mathrm{CO}_{2} / \mathrm{H}_{2}$ mole ratio of $1 / 14$ in the present work, partly reduced the $\mathrm{AlCl}_{3}$ reactant into aluminium subchlorides (i.e. $\mathrm{AlCl}_{2}$ and $\mathrm{AlCl}$ ). Such an effect of excess $\mathrm{H}_{2}$ in the CVD of $\mathrm{Al}_{2} \mathrm{O}_{3}$ coatings from an $\mathrm{AlCl}_{3}-\mathrm{CO}_{2}-\mathrm{H}_{2}$ gas mixture has previously been suggested by Lhermitte-Sebire et al [20]. In the present work, it is further suggested that this partial reduction of $\mathrm{AlCl}_{3}$ by the excess $\mathrm{H}_{2}$ present caused an abrupt decrease in $\mathrm{AlCl}_{3}$ concentration, and that it was this decrease which was responsible for the observed effects of decreasing the $\mathrm{CO}_{2} / \mathrm{H}_{2}$ mole ratio from $1 / 12$ to $1 / 14$ in the present work. In support of this suggestion, it is evident from the $\mathrm{H}_{2}-1 / \mathrm{AlCl}_{3}$ flow rate study carried out in the present work, that decrease in $\mathrm{H}_{2}-1 / \mathrm{AlCl}_{3}$ flow rate does, overall, cause the same effects as those observed in the present work with decrease in $\mathrm{CO}_{2} / \mathrm{H}_{2}$ mole ratio from $1 / 12$ to $1 / 14$.

\subsubsection{Effect of $\mathrm{CO}_{2} / \mathrm{H}_{2}$ mole ratio on $\mathrm{Al}_{2} \underline{\mathrm{O}}_{3}$ coating thickness}

From Figure 5.6, which shows the effect of $\mathrm{CO}_{2} / \mathrm{H}_{2}$ mole ratio on the thickness of the $\mathrm{Al}_{2} \mathrm{O}_{3}$ coatings on the rake face of the inserts in the present work (as determined by optical measurements and ball-cratering), it can be seen that according to both the optical measurements and the ball-cratering results, decrease in $\mathrm{CO}_{2} / \mathrm{H}_{2}$ mole ratio from $1 / 6$ to approximately $1 / 12$ has caused a sustained increase in $\mathrm{Al}_{2} \mathrm{O}_{3}$ coating thickness, but that with further decrease in $\mathrm{CO}_{2} / \mathrm{H}_{2}$ mole ratio to $1 / 14$ there is a decrease in $\mathrm{Al}_{2} \mathrm{O}_{3}$ coating thickness. This trend is more marked in the case of the optical measurements than in the case of the ball-cratering results. 
As with $\mathrm{AlCl}_{3}$ concentration, the effect of $\mathrm{CO}_{2} / \mathrm{H}_{2}$ mole ratio on $\mathrm{Al}_{2} \mathrm{O}_{3}$ coating deposition rate rather than coating thickness has been investigated in previous work (see Sections 2.5.1 and 2.5.2). In their work on $\mathrm{Al}_{2} \mathrm{O}_{3}$ coatings chemically vapour deposited on TiN coated cemented carbide substrates, Park et al [42] established that $\mathrm{Al}_{2} \mathrm{O}_{3}$ coating deposition rate initially increased with increase in $\mathrm{CO}_{2} / \mathrm{H}_{2}$ mole ratio from close to 0 to 1 , in agreement with the findings of Funk et al [31] (see Figure 2.3) and Colmet et al [37] (see Figure 2.5), but then decreased with further increase in $\mathrm{CO}_{2} / \mathrm{H}_{2}$ mole ratio, in disagreement with the findings of Funk et al and Colmet et al in their work on the effect of $P_{\mathrm{CO}_{2}} / P_{\mathrm{H}_{2}}$ ratio on the deposition rate of $\mathrm{Al}_{2} \mathrm{O}_{3}$ coatings. The trend obtained by Park et al, however, is in agreement with that obtained by $\mathrm{Kim}$ et al [43], in their work on the effect of $P_{\mathrm{H}_{2}} / \mathrm{P}_{\mathrm{CO}_{2}}$ ratio on the deposition rate of $\mathrm{Al}_{2} \mathrm{O}_{3}$ coatings (see Figure 2.8). Kim et al established that increase in $P_{\mathrm{H}_{2}} / P_{\mathrm{CO}_{2}}$ ratio from 0.02 to 1 initially caused an increase in deposition rate, but that with further increase in $\mathrm{P}_{2} / \mathrm{P}_{\mathrm{CO}_{2}}$ ratio the deposition rate decreased. It is interesting to note that none of these workers have given a coherent explanation for the effect of $\mathrm{CO}_{2} / \mathrm{H}_{2}$ mole ratio (or $P_{\mathrm{CO}_{2}} / P_{\mathrm{H}_{2}}$ ratio) on $\mathrm{Al}_{2} \mathrm{O}_{3}$ deposition rate which they observed. If it is assumed that $\mathrm{Al}_{2} \mathrm{O}_{3}$ coating thickness is directly proportional to $\mathrm{Al}_{2} \mathrm{O}_{3}$ deposition rate (a not unreasonable assumption), then the effect of $\mathrm{CO}_{2} / \mathrm{H}_{2}$ mole ratio at a total deposition pressure of one atmosphere observed in the present work, is comparable to that observed at reduced deposition pressures by Park et al [42] and Kim et al [43], but with one important difference. In their work, both Park et al and Kim et al found that the maximum $\mathrm{Al}_{2} \mathrm{O}_{3}$ coating deposition rate occurred at a $\mathrm{CO}_{2} / \mathrm{H}_{2}$ mole ratio of (close to) unity, whereas in the present work maximum $\mathrm{Al}_{2} \mathrm{O}_{3}$ coating thickness occurred at a $\mathrm{CO}_{2} / \mathrm{H}_{2}$ mole ratio of approximately $1 / 12$. This shift is totally compatible with, and is seen as adding considerable weight to, the suggestion made earlier in Section 6.2.2.1 that the use of atmospheric total deposition pressure in the present work, in comparison to the significantly reduced total deposition pressures employed in previous work on the CVD of $\mathrm{Al}_{2} \mathrm{O}_{3}$ coatings (see Chapter 2), caused an increase in the ratio of $\mathrm{H}_{2}$ to $\mathrm{CO}_{2}$ necessary to produce the maximum amount of $\mathrm{H}_{2} \mathrm{O}$, from a value of (close to) unity in the previous work cited to a $\mathrm{CO}_{2} / \mathrm{H}_{2}$ mole ratio value of approximately $1 / 12$ in the present work.

It is self evident that, in the present work, despite the existence of the $\mathrm{Al}_{2} \mathrm{O}_{3}$ coating/Ti(C,N) precoating transition zone, the $\mathrm{Al}_{2} \mathrm{O}_{3}$ coating thickness measurements principally relate to the bulk of the $\mathrm{Al}_{2} \mathrm{O}_{3}$ coatings. Thus, with reference to Section 6.2.2.1, the CVD reaction of predominant importance with regard to the observed effect of $\mathrm{CO}_{2} / \mathrm{H}_{2}$ mole ratio on $\mathrm{Al}_{2} \mathrm{O}_{3}$ coating thickness is the overall reaction between $\mathrm{AlCl}_{3}$ and $\mathrm{H}_{2} \mathrm{O}$ (Lhermitte-Sebire et al reaction (3) - see Section 6.2.1.1). This being the case, then with regard to the above paragraph, and taking into account that at the constant $\mathrm{H}_{2}-1 / \mathrm{AlCl}_{3}$ flow rate of $25 \mathrm{~cm}^{3} \mathrm{~min}^{-1}$ used in the $\mathrm{CO}_{2} / \mathrm{H}_{2}$ mole ratio study, it has been suggested earlier in Section 6.2.1.2 that the rate of $\mathrm{Al}_{2} \mathrm{O}_{3}$ coating deposition was limited by the homogeneous gas phase water reaction between $\mathrm{H}_{2}$ and $\mathrm{CO}_{2}$, the observed increase in $\mathrm{Al}_{2} \mathrm{O}_{3}$ coating thickness in the present work with decrease in $\mathrm{CO}_{2} / \mathrm{H}_{2}$ mole ratio from $1 / 6$ to approximately $1 / 12$ may be simply accounted for as follows. At the highest $\mathrm{CO}_{2} / \mathrm{H}_{2}$ mole ratio of $1 / 6$, there would have been insufficient $\mathrm{H}_{2}$ to convert all 
the $\mathrm{CO}_{2}$ into $\mathrm{H}_{2} \mathrm{O}$. With decrease in $\mathrm{CO}_{2} / \mathrm{H}_{2}$ mole ratio from $1 / 6$ to approximately $1 / 12$, however, due to the increase in $\mathrm{H}_{2}$, there would have been an increase in the amount of $\mathrm{H}_{2} \mathrm{O}$ formed by the reaction between the $\mathrm{H}_{2}$ and $\mathrm{CO}_{2}$, and, since this reaction is rate limiting, this increase would have caused an increase in the overall reaction between $\mathrm{AlCl}_{3}$ and $\mathrm{H}_{2} \mathrm{O}$ and hence the increase in $\mathrm{Al}_{2} \mathrm{O}_{3}$ coating thickness observed. As will be immediately evident, this explanation is completely consistent with that of the effect on bulk $\mathrm{Al}_{2} \mathrm{O}_{3}$ coating stoichiometry of decrease in $\mathrm{CO}_{2} / \mathrm{H}_{2}$ mole ratio from $1 / 6$ to approximately $1 / 12$, advanced in the preceding section. The decrease in $\mathrm{Al}_{2} \mathrm{O}_{3}$ coating thickness with further decrease in $\mathrm{CO}_{2} / \mathrm{H}_{2}$ mole ratio from 1/12 to $1 / 14$ evident in Figure 5.6 and described earlier (as with the concurrent change in coating composition discussed in the preceding section), is attributed to the excess $\mathrm{H}_{2}$ which would have been present at the $\mathrm{CO}_{2} / \mathrm{H}_{2}$ mole ratio of $1 / 14$, partly reducing the $\mathrm{AlCl}_{3}$ reactant into aluminium subchlorides and thus causing an abrupt decrease in $\mathrm{AlCl}_{3}$ concentration. In support of the latter, it is clear from the $\mathrm{H}_{2}-1 / \mathrm{AlCl}_{3}$ flow rate study carried out in the present work, that decrease in $\mathrm{H}_{2}-1 / \mathrm{AlCl}_{3}$ flow rate below a value of $25 \mathrm{~cm}^{3} \mathrm{~min}^{-1}$ does cause a decrease in $\mathrm{Al}_{2} \mathrm{O}_{3}$ coating thickness (see Figure 5.34) as observed with decrease in $\mathrm{CO}_{2} / \mathrm{H}_{2}$ mole ratio from $1 / 12$ to $1 / 14$.

\subsubsection{Effect of $\mathrm{CO}_{2} / \mathrm{H}_{2}$ mole ratio on bulk and surface grain structures of $\mathrm{Al}_{2} \underline{\mathrm{O}}_{3}$ coatings}

From Figure 5.12, which shows typical surface grain structures determined for the $\mathrm{Al}_{2} \mathrm{O}_{3}$ coatings deposited at the five different $\mathrm{CO}_{2} / \mathrm{H}_{2}$ mole ratios in the present work, it can be seen that decreasing the $\mathrm{CO}_{2} / \mathrm{H}_{2}$ mole ratio has had no effect on the morphology of the grains on the surface of the $\mathrm{Al}_{2} \mathrm{O}_{3}$ coatings, the grains remaining pyramidal/faceted in form. It is, however, also evident from this figure that decrease in $\mathrm{CO}_{2} / \mathrm{H}_{2}$ mole ratio from $1 / 6$ to $1 / 10$ has caused a gradual increase in $\mathrm{Al}_{2} \mathrm{O}_{3}$ coating surface grain size. However, the $\mathrm{Al}_{2} \mathrm{O}_{3}$ coating surface grain size then appears to, if anything, decrease slightly with further decrease in $\mathrm{CO}_{2} / \mathrm{H}_{2}$ mole ratio to $1 / 12$ and then to increase again with additional decrease in $\mathrm{CO}_{2} / \mathrm{H}_{2}$ mole ratio to 1/14. From Figure 5.11, which shows typical bulk grain structures for the $\mathrm{Al}_{2} \mathrm{O}_{3}$ coatings deposited at the five different $\mathrm{CO}_{2} / \mathrm{H}_{2}$ mole ratios, it can be seen that the grains in the bulk of the $\mathrm{Al}_{2} \mathrm{O}_{3}$ coatings exhibit a tendency towards columnar grow th and are noticeably coarser than those of the $\mathrm{Ti}(\mathrm{C}, \mathrm{N})$ precoating in each case. It is also evident from Figure 5.11 that, in general agreement with $\mathrm{Al}_{2} \mathrm{O}_{3}$ coating surface grain size, decrease in $\mathrm{CO}_{2} / \mathrm{H}_{2}$ mole ratio from $1 / 6$ to $1 / 10$ has caused a gradual increase in $\mathrm{Al}_{2} \mathrm{O}_{3}$ coating bulk grain size, which then appears to remain constant with further decrease in $\mathrm{CO}_{2} / \mathrm{H}_{2}$ mole ratio to $1 / 12$ and then to increase again with additional decrease in $\mathrm{CO}_{2} / \mathrm{H}_{2}$ mole ratio to $1 / 14$. As with $\mathrm{AlCl}_{3}$ concentration, no work on the effect of $\mathrm{CO}_{2} / \mathrm{H}_{2}$ mole ratio on $\mathrm{Al}_{2} \mathrm{O}_{3}$ coating bulk grain structure was found in the literature to permit comparison with the results of the present work, but, as 
described in Section 2.5.1, work has previously been carried out on the effect of $\mathrm{CO}_{2} / \mathrm{H}_{2}$ mole ratio on $\mathrm{Al}_{2} \mathrm{O}_{3}$ coating surface grain structure. Discussion will therefore proceed with reference to this.

The overall effect of $\mathrm{CO}_{2} / \mathrm{H}_{2}$ mole ratio on $\mathrm{Al}_{2} \mathrm{O}_{3}$ coating surface grain size observed in the present work is only partially comparable with that observed in previous work on $\mathrm{Al}_{2} \mathrm{O}_{3}$ coatings (chemically vapour deposited on TiN coated cemented carbide substrates) carried out by Kim et al [43] and Park et al [44]. As previously described in Section 2.5.1, Kim et al investigated the effect on the surface morphology of $\mathrm{Al}_{2} \mathrm{O}_{3}$ coatings of increasing the $P_{\mathrm{H}_{2}} / \mathrm{P}_{\mathrm{CO}_{2}}$ ratio over the range from 0.05 to 24 . They found that the surface grains of the $\mathrm{Al}_{2} \mathrm{O}_{3}$ coatings deposited at the $P_{\mathrm{H}_{2}} / P_{\mathrm{CO}_{2}}$ ratios of 1 and 2 were coarser than those deposited at the other $P_{\mathrm{H}_{2}} / P_{\mathrm{CO}_{2}}$ values. Since this result corresponded closely to their calculated $\mathrm{H}_{2} \mathrm{O}$ supersaturation values, Kim et al concluded that the surface grain size of $\mathrm{Al}_{2} \mathrm{O}_{3}$ coatings is mainly affected by $\mathrm{H}_{2} \mathrm{O}$ supersaturation, i.e. an increase in $\mathrm{H}_{2} \mathrm{O}$ supersaturation results in a decrease in $\mathrm{Al}_{2} \mathrm{O}_{3}$ coating surface grain size. Also, as previously described in Section 2.5.2, Park et al studied the effect on the surface morphology of $\mathrm{Al}_{2} \mathrm{O}_{3}$ coatings of increasing the $\mathrm{CO}_{2} / \mathrm{H}_{2}$ mole ratio from 0.1 to 24 . They found that the surface grains of the $\mathrm{Al}_{2} \mathrm{O}_{3}$ coatings deposited at a $\mathrm{CO}_{2} / \mathrm{H}_{2}$ mole ratio of 2 were coarser than those of the $\mathrm{Al}_{2} \mathrm{O}_{3}$ coatings deposited at the other $\mathrm{CO}_{2} / \mathrm{H}_{2}$ mole ratios. Since this corresponded closely to their calculated supersaturations of the $\mathrm{O}$-donor values, they concluded that the surface grain size of $\mathrm{Al}_{2} \mathrm{O}_{3}$ coatings is mainly affected by O-donor supersaturation.

It is evident that the effect of decrease in $\mathrm{CO}_{2} / \mathrm{H}_{2}$ mole ratio from $1 / 6$ to $1 / 12$ on $\mathrm{Al}_{2} \mathrm{O}_{3}$ coating bulk and surface grain size observed in the present work resembles, although is not identical to, that on $\mathrm{Al}_{2} \mathrm{O}_{3}$ coating thickness dealt with in the previous section. This resemblance is as would have been expected since it has been argued in the previous section that the $\mathrm{Al}_{2} \mathrm{O}_{3}$ coating thickness measurements principally relate to the bulk of the $\mathrm{Al}_{2} \mathrm{O}_{3}$ coatings. As with $\mathrm{Al}_{2} \mathrm{O}_{3}$ coating thickness, therefore, the CVD reaction of predominant importance with regard to the observed effect of $\mathrm{CO}_{2} / \mathrm{H}_{2}$ mole ratio on $\mathrm{Al}_{2} \mathrm{O}_{3}$ coating bulk and hence surface grain size is the overall reaction between $\mathrm{AlCl}_{3}$ and $\mathrm{H}_{2} \mathrm{O}$ (Lhermitte-Sebire et al reaction (3) - see Section 6.2.1.1). It is therefore suggested that the explanation for the observed effect of decrease in $\mathrm{CO}_{2} / \mathrm{H}_{2}$ mole ratio from $1 / 6$ to $1 / 12$ on $\mathrm{Al}_{2} \mathrm{O}_{3}$ coating bulk and hence surface grain size is basically the same as that for its effect on $\mathrm{Al}_{2} \mathrm{O}_{3}$ coating thickness. Namely, that at the highest $\mathrm{CO}_{2} / \mathrm{H}_{2}$ mole ratio of $1 / 6$ there would have been insufficient $\mathrm{H}_{2}$ to convert all the $\mathrm{CO}_{2}$ to $\mathrm{H}_{2} \mathrm{O}$, but that with decrease in $\mathrm{CO}_{2} / \mathrm{H}_{2}$ mole ratio from $1 / 6$ to approximately $1 / 12$, due to the increase in $\mathrm{H}_{2}$, there would have been an increase in the amount of $\mathrm{H}_{2} \mathrm{O}$ formed by the reaction between $\mathrm{H}_{2}$ and $\mathrm{CO}_{2}$. With reference to the work by Kim et al [43] and Park et al [44], it is further suggested that this increase in $\mathrm{H}_{2} \mathrm{O}$ concentration in the present work caused a decrease in the supersaturation of $\mathrm{H}_{2} \mathrm{O}$ and thereby a decrease in the nucleation rate of the $\mathrm{Al}_{2} \mathrm{O}_{3}$ coatings and thus the observed increase in their grain size. It is thought that the latter additional factor may account for the relatively slight difference between the observed effect 
of decrease in $\mathrm{CO}_{2} / \mathrm{H}_{2}$ mole ratio from $1 / 6$ to $1 / 12$ on $\mathrm{Al}_{2} \mathrm{O}_{3}$ coating bulk and surface grain size and $\mathrm{Al}_{2} \mathrm{O}_{3}$ coating thickness, grain size being more sensitive to increase in the amount of $\mathrm{H}_{2} \mathrm{O}$ formed by the homogeneous gas phase reaction between $\mathrm{CO}_{2}$ and $\mathrm{H}_{2}$ than is coating thickness. The discontinuity in the effect of decreasing $\mathrm{CO}_{2} / \mathrm{H}_{2}$ mole ratio on $\mathrm{Al}_{2} \mathrm{O}_{3}$ coating bulk and surface grain size with further decrease in $\mathrm{CO}_{2} / \mathrm{H}_{2}$ mole ratio from $1 / 12$ to $1 / 14$ observed in the present work, as with the corresponding decrease in $\mathrm{Al}_{2} \mathrm{O}_{3}$ coating thickness, is attributed to the accompanying abrupt decrease in $\mathrm{AlCl}_{3}$ concentration, caused as described previously in Section 6.2.2.1.

Considering further the bulk grain structures of the $\mathrm{Al}_{2} \mathrm{O}_{3}$ coatings deposited at the five different $\mathrm{CO}_{2} / \mathrm{H}_{2}$ mole ratios, shown in Figure 5.11, it can be seen, particularly at the $\mathrm{CO}_{2} / \mathrm{H}_{2}$ mole ratios of $1 / 8$ and $1 / 12$, that a thin layer is present in the upper part of the $\operatorname{Ti}(\mathrm{C}, \mathrm{N})$ precoating directly adjacent to the $\mathrm{Al}_{2} \mathrm{O}_{3}$ coating/Ti(C,N) precoating interface. It is also evident from this figure that for each $\mathrm{CO}_{2} / \mathrm{H}_{2}$ mole ratio from $1 / 6$ to $1 / 12$, the lower part of the $\mathrm{Al}_{2} \mathrm{O}_{3}$ coating directly adjacent to this interface contains grains which are much finer than those in the bulk of the $\mathrm{Al}_{2} \mathrm{O}_{3}$ coating. Corresponding features were also seen in the case of the $\mathrm{Al}_{2} \mathrm{O}_{3}$ coated inserts from the $\mathrm{H}_{2}-1 / \mathrm{AlCl}_{3}$ flow rate coating runs (see Figure 5.39). Since their origins have already been discussed at some length in Section 6.2.1.3, there seems little point in duplicating that discussion here.

\subsubsection{Effect of $\mathrm{CO}_{2} / \mathrm{H}_{2}$ mole ratio on preferred orientation and lattice parameter of}

\section{$\mathrm{Al}_{2} \underline{O}_{3}$ coatings}

A number of facts are evident from Figure 5.2, which shows typical relative $\mathrm{X}$-ray intensities for the $\mathrm{Al}_{2} \mathrm{O}_{3}$ coatings deposited at the five different $\mathrm{CO}_{2} / \mathrm{H}_{2}$ mole ratios, compared to the random intensities for the $\alpha-\mathrm{Al}_{2} \mathrm{O}_{3}$ powder. First, as with the $\mathrm{Al}_{2} \mathrm{O}_{3}$ coated inserts from the $\mathrm{H}_{2}$-1/AICl${ }_{3}$ flow rate coating runs, it is evident that, overall, the magnitudes of the relative intensities obtained for the $\mathrm{Al}_{2} \mathrm{O}_{3}$ coatings from the $\mathrm{CO}_{2} / \mathrm{H}_{2}$ mole ratio coating runs are considerably smaller than those obtained for the $\alpha-\mathrm{Al}_{2} \mathrm{O}_{3}$ powder. This is again attributed, in general, to the low thickness of the $\mathrm{Al}_{2} \mathrm{O}_{3}$ coatings. It can also be seen from Figure 5.2 that all the $\mathrm{Al}_{2} \mathrm{O}_{3}$ coatings from the $\mathrm{CO}_{2} / \mathrm{H}_{2}$ mole ratio coating runs are of the $\alpha-\mathrm{Al}_{2} \mathrm{O}_{3}$ crystal form and that all exhibit preferred orientation of the $\{11 \overline{2} 3\}$ planes. It is, however, also evident that decrease in $\mathrm{CO}_{2} / \mathrm{H}_{2}$ mole ratio from $1 / 6$ to $1 / 10$ has caused a gradual increase in the intensity of the $\{11 \overline{2} 3\}$ reflections, but that the intensity of the $\{11 \overline{2} 3\}$ reflections then decreases slightly with further decrease in $\mathrm{CO}_{2} / \mathrm{H}_{2}$ mole ratio from $1 / 10$ to $1 / 12$, and decreases more substantially with additional decrease in $\mathrm{CO}_{2} / \mathrm{H}_{2}$ mole ratio from $1 / 12$ to $1 / 14$. The effect of decrease in $\mathrm{CO}_{2} / \mathrm{H}_{2}$ mole ratio from $1 / 6$ to $1 / 12$ on the intensity of the $\{11 \overline{2} 3\}$ reflections from the $\mathrm{Al}_{2} \mathrm{O}_{3}$ coatings is consistent with that observed on $\mathrm{Al}_{2} \mathrm{O}_{3}$ coating grain size, discussed in Section 6.2.2.3. It is therefore suggested that they are associated. Notwithstanding this, given the preceding comments regarding the low magnitudes of the relative intensities 
obtained for all the $\mathrm{Al}_{2} \mathrm{O}_{3}$ coatings from the $\mathrm{CO}_{2} / \mathrm{H}_{2}$ mole ratio coating runs, it is possible that the effect of decrease in $\mathrm{CO}_{2} / \mathrm{H}_{2}$ mole ratio from $1 / 6$ to $1 / 12$ on the intensity of the $\{11 \overline{2} 3\}$ reflections from the $\mathrm{Al}_{2} \mathrm{O}_{3}$ coatings could have also been influenced by the concomitant effect on $\mathrm{Al}_{2} \mathrm{O}_{3}$ coating thickness, discussed earlier in Section 6.2.2.2. The suggested association between the preferred orientation of the $\mathrm{Al}_{2} \mathrm{O}_{3}$ coatings deposited at the $\mathrm{CO}_{2} / \mathrm{H}_{2}$ mole ratios in the range $1 / 6$ to $1 / 12$ and their grain size, is corroborated to a certain extent by previous work on $\mathrm{Al}_{2} \mathrm{O}_{3}$ coatings chemically vapour deposited on TiN coated cemented carbide substrates, carried out by Park et al [44] (see Section 2.5.2). In this work, it was established that as the $\mathrm{Al}_{2} \mathrm{O}_{3}$ coating surface grain structure became coarser the coating was found to exhibit preferred orientations of the $\{10 \overline{1} 4\}$ and $\{11 \overline{2} 6\}$ planes, and that as the $\mathrm{Al}_{2} \mathrm{O}_{3}$ coating surface grain structure became finer there was a reduction in preferred orientations. It seems reasonable to suggest that the different $\mathrm{Al}_{2} \mathrm{O}_{3}$ coating preferred orientations observed in the present work and in that carried out by Park et al, may be due to a difference in the deposition conditions employed. Finally, the more substantial decrease in the intensity of the $\{11 \overline{2} 3\}$ reflections from the $\mathrm{Al}_{2} \mathrm{O}_{3}$ coatings in the present work with additional decrease in $\mathrm{CO}_{2} / \mathrm{H}_{2}$ mole ratio from $1 / 12$ to $1 / 14$, is attributed to the accompanying abrupt decrease in $\mathrm{AlCl}_{3}$ concentration, caused as described previously in Section 6.2.2.1. In support of the latter, it is clear from the $\mathrm{H}_{2}-1 / \mathrm{AlCl}_{3}$ flow rate study carried out in the present work, that decrease in $\mathrm{H}_{2}-1 / \mathrm{AlCl}_{3}$ flow rate below a value of $25 \mathrm{~cm}^{3} \mathrm{~min}^{-1}$ does cause a decrease in the intensity of the $\{11 \overline{2} 3\}$ reflections from the $\mathrm{Al}_{2} \mathrm{O}_{3}$ coatings (see Figure 5.30) as observed with decrease in $\mathrm{CO}_{2} / \mathrm{H}_{2}$ mole ratio from $1 / 12$ to $1 / 14$.

From Figure 5.3, which shows the effect of $\mathrm{CO}_{2} / \mathrm{H}_{2}$ mole ratio on the "a" and "c" lattice parameters of the $\mathrm{Al}_{2} \mathrm{O}_{3}$ coatings in the present work, it can be seen that there is a disparity between the effect of $\mathrm{CO}_{2} / \mathrm{H}_{2}$ mole ratio on the " $\mathrm{a}$ " and "c" lattice parameters. Furthermore, superimposed on Figure 5.3 are the bulk stoichiometries of the $\mathrm{Al}_{2} \mathrm{O}_{3}$ coatings deposited at the different $\mathrm{CO}_{2} / \mathrm{H}_{2}$ mole ratios, and it is immediately evident that there is a further disparity between the effect of decreasing $\mathrm{CO}_{2} / \mathrm{H}_{2}$ mole ratio on the bulk stoichiometry and on the "a" and "c" lattice parameters of the $\mathrm{Al}_{2} \mathrm{O}_{3}$ coatings. Clearly then, in contrast to the situation with the $\mathrm{Al}_{2} \mathrm{O}_{3}$ coatings from the $\mathrm{H}_{2}-1 / \mathrm{AlCl}_{3}$ flow rate study, it would appear that the effect of $\mathrm{CO}_{2} / \mathrm{H}_{2}$ mole ratio on $\mathrm{Al}_{2} \mathrm{O}_{3}$ coating lattice parameters cannot be attributed to its concurrent effect on the bulk stoichiometry of the $\mathrm{Al}_{2} \mathrm{O}_{3}$ coatings. Further work is needed to ascertain the reason for the disparities evident in Figure 5.3.

Surprisingly, no previous work on the effect of $\mathrm{CO}_{2} / \mathrm{H}_{2}$ mole ratio on the lattice parameters of $\mathrm{Al}_{2} \mathrm{O}_{3}$ coatings was found in the literature to permit comparison with the results of the present work. 


\subsubsection{Effect of $\mathrm{CO}_{2} / \mathrm{H}_{2}$ mole ratio on $\mathrm{Al}_{2} \mathrm{O}_{3}$ coating microhardness}

From Figure 5.9, which shows the effect of $\mathrm{CO}_{2} / \mathrm{H}_{2}$ mole ratio on the microhardness of the $\mathrm{Al}_{2} \mathrm{O}_{3}$ coatings, it can be seen that decrease in $\mathrm{CO}_{2} / \mathrm{H}_{2}$ mole ratio from $1 / 6$ to approximately $1 / 10$ has caused a noticeable increase in the microhardness of the $\mathrm{Al}_{2} \mathrm{O}_{3}$ coatings, but that the microhardness then appears to remain almost constant with further decrease in $\mathrm{CO}_{2} / \mathrm{H}_{2}$ mole ratio from approximately $1 / 10$ to $1 / 12$, but then decreases substantially with additional decrease in $\mathrm{CO}_{2} / \mathrm{H}_{2}$ mole ratio from $1 / 12$ to $1 / 14$. The effect of decrease in $\mathrm{CO}_{2} / \mathrm{H}_{2}$ mole ratio from $1 / 6$ to $1 / 12$ on $\mathrm{Al}_{2} \mathrm{O}_{3}$ coating microhardness is consistent with that on $\mathrm{Al}_{2} \mathrm{O}_{3}$ coating bulk grain size discussed in Section 6.2.2.3. As with the $\mathrm{Al}_{2} \mathrm{O}_{3}$ coated inserts from the $\mathrm{H}_{2}-1 / \mathrm{AlCl}_{3}$ flow rate coating runs, it is thus suggested that the effect of $\mathrm{CO}_{2} / \mathrm{H}_{2}$ mole ratio on $\mathrm{Al}_{2} \mathrm{O}_{3}$ coating microhardness is associated with, but not directly caused by, the concomitant effect of $\mathrm{CO}_{2} / \mathrm{H}_{2}$ mole ratio on $\mathrm{Al}_{2} \mathrm{O}_{3}$ coating bulk grain size. The substantial decrease in $\mathrm{Al}_{2} \mathrm{O}_{3}$ coating microhardness with additional decrease in $\mathrm{CO}_{2} / \mathrm{H}_{2}$ mole ratio from $1 / 12$ to $1 / 14$ is attributed to the accompanying abrupt decrease in $\mathrm{AlCl}_{3}$ concentration, caused as described previously in Section 6.2.2.1. In support of the latter, it is clear from the $\mathrm{H}_{2}-1 / \mathrm{AlCl}_{3}$ flow rate study carried out in the present work, that decrease in $\mathrm{H}_{2}-1 / \mathrm{AlCl}_{3}$ flow rate below a value of $25 \mathrm{~cm}^{3} \mathrm{~min}^{-1}$ does cause a decrease in $\mathrm{Al}_{2} \mathrm{O}_{3}$ coating microhardness (see Figure 5.37) as observed with decrease in $\mathrm{CO}_{2} / \mathrm{H}_{2}$ mole ratio from $1 / 12$ to $1 / 14$.

With regard to the microhardness values in Figures 5.8 (a) - (e) corresponding to zero distance from the $\mathrm{Al}_{2} \mathrm{O}_{3}$ coating/Ti(C,N) precoating interface; by extrapolating the sloping line on each figure to intersect the microhardness axis, it is evident that the microhardness value obtained in each case is considerably lower than that of the $\mathrm{Ti}(\mathrm{C}, \mathrm{N})$ precoating to which it should correspond ( $2400 \mathrm{HV}_{0.025}$ for $\mathrm{Ti}\left(\mathrm{C}_{0.2} \mathrm{~N}_{0.8}\right)$ - see Section 6.1.7). The same feature was observed in the case of the $\mathrm{Al}_{2} \mathrm{O}_{3}$ coated inserts from the $\mathrm{H}_{2}-1 / \mathrm{AlCl}_{3}$ flow rate (and preliminary) coating runs and was attributed to the lower hardness of the thin layer of titanium oxides in the upper part of the $\mathrm{Ti}(\mathrm{C}, \mathrm{N})$ precoating directly adjacent to its interface with the $\mathrm{Al}_{2} \mathrm{O}_{3}$ coating (see Section 6.1.7). This explanation is obviously also applicable to the $\mathrm{Al}_{2} \mathrm{O}_{3}$ coated inserts from the $\mathrm{CO}_{2} / \mathrm{H}_{2}$ mole ratio coating runs.

\subsubsection{Effect of $\mathrm{CO}_{2} / \mathrm{H}_{2}$ mole ratio on peripheral thickness variation (and other features) of $\mathrm{Al}_{2} \underline{\mathrm{O}}_{3}$ coatings}

Optical examination of the polished and etched cross-section through one of the $a c$ inserts from each of the five $\mathrm{CO}_{2} / \mathrm{H}_{2}$ mole ratio coating runs characterised in the present work, revealed that, in each case, the $\mathrm{Al}_{2} \mathrm{O}_{3}$ coating extended all round the periphery of the $\mathrm{Ti}(\mathrm{C}, \mathrm{N})$ precoated PM HSS insert. However, it was also observed that although, in general, the $\mathrm{Al}_{2} \mathrm{O}_{3}$ coating was of fairly uniform thickness on the rake and flank faces of the $a c$ inserts, it was significantly thicker on the corners. This is exemplified by the $\mathrm{Al}_{2} \mathrm{O}_{3}$ coating thickness values 
presented in Table 5.6. It would appear from this table that the increased thickness of the $\mathrm{Al}_{2} \mathrm{O}_{3}$ coating on the corners of the $a c$ inserts, relative to that on the rake and flank faces, is not materially affected by $\mathrm{CO}_{2} / \mathrm{H}_{2}$ mole ratio, remaining approximately constant at a level in the region of two times. The same feature was observed in the case of the $\mathrm{Al}_{2} \mathrm{O}_{3}$ coated inserts from the $\mathrm{H}_{2}-1 / \mathrm{AlCl}_{3}$ flow rate coating runs and was attributed to the location of the inserts relative to the reactant gas flow and/or to the gas flow conditions inside the CVD reactor during deposition. This explanation is also thought to be applicable to the $\mathrm{Al}_{2} \mathrm{O}_{3}$ coated inserts from the $\mathrm{CO}_{2} / \mathrm{H}_{2}$ mole ratio coating runs.

From the optical cross-sections through the rake face of the $a c$ inserts from each of the $\mathrm{CO}_{2} / \mathrm{H}_{2}$ mole ratio coating runs, shown in Figure 5.7, it can be seen that the surface of the $\mathrm{Al}_{2} \mathrm{O}_{3}$ coating on the rake face of the inserts is rather uneven. Whilst, at each $\mathrm{CO}_{2} / \mathrm{H}_{2}$ mole ratio, this unevenness can be at least partially attributed to the underlying $\mathrm{Ti}(\mathrm{C}, \mathrm{N})$ precoating, Figure 5.7 clearly shows that at the $\mathrm{CO}_{2} / \mathrm{H}_{2}$ mole ratio of $1 / 12$ in particular, some of the unevenness is an inherent feature of the $\mathrm{Al}_{2} \mathrm{O}_{3}$ coating itself. As is also evident from Figure 5.7, with the exception of isolated porosity, no major defects are visible in the $\mathrm{Al}_{2} \mathrm{O}_{3}$ coatings and the $\mathrm{Al}_{2} \mathrm{O}_{3}$ coating/ $\mathrm{Ti}(\mathrm{C}, \mathrm{N})$ precoating interface appears to be continuous in each case, as also does the $\mathrm{Ti}(\mathrm{C}, \mathrm{N})$ precoating/HSS substrate interface, although there is some porosity in the $\mathrm{Ti}(\mathrm{C}, \mathrm{N})$ precoating adjacent to the latter interface. Also just discernible from these optical cross-sections, particularly those through the rake face of the inserts corresponding to $\mathrm{CO}_{2} / \mathrm{H}_{2}$ mole ratios of $1 / 6,1 / 8$ and $1 / 12$, is the presence of a thin band in the $\operatorname{Ti}(\mathrm{C}, \mathrm{N})$ precoating immediately adjacent to its interface with the $\mathrm{Al}_{2} \mathrm{O}_{3}$ coating. The presence of this thin band will be discussed in Section 6.2.2.8.

\subsubsection{Effect of $\mathrm{CO}_{2} / \mathrm{H}_{2}$ mole ratio on surface roughness of $\underline{\mathrm{Al}}_{2} \underline{\mathrm{O}}_{3} \underline{\text { coatings }}$}

From Table 5.5, which shows the surface roughness values for the $\mathrm{Al}_{2} \mathrm{O}_{3}$ coatings deposited in the five $\mathrm{CO}_{2} / \mathrm{H}_{2}$ mole ratio coating runs, and from Figure 5.5 which shows the corresponding typical Talysurf traces obtained for the coatings, it is evident that decreasing $\mathrm{CO}_{2} / \mathrm{H}_{2}$ mole ratio has not had a sustained, identifiable effect on the surface roughness of the $\mathrm{Al}_{2} \mathrm{O}_{3}$ coatings. As with the $\mathrm{Al}_{2} \mathrm{O}_{3}$ coated inserts from the $\mathrm{H}_{2}-1 / \mathrm{AlCl}_{3}$ flow rate coating runs (see Section 6.2.1.7), this is attributed to the fact that the surface roughness of the $\mathrm{Al}_{2} \mathrm{O}_{3}$ coatings is influenced by three factors: the surface roughness of the underlying $\mathrm{Ti}(\mathrm{C}, \mathrm{N})$ precoating, which is not influenced by $\mathrm{CO}_{2} / \mathrm{H}_{2}$ mole ratio; the inherent unevenness of the surface of the $\mathrm{Al}_{2} \mathrm{O}_{3}$ coating itself, which, as described in Section 6.2.2.6, was affected by $\mathrm{CO}_{2} / \mathrm{H}_{2}$ mole ratio but not in a systematic way, and the surface grain size of the $\mathrm{Al}_{2} \mathrm{O}_{3}$ coatings which, as described in Section 6.2.2.3, was also affected by $\mathrm{CO}_{2} / \mathrm{H}_{2}$ mole ratio but in a systematic way. The significantly greater surface roughness of the $\mathrm{Al}_{2} \mathrm{O}_{3}$ coating deposited at the $\mathrm{CO}_{2} / \mathrm{H}_{2}$ mole 
ratio of $1 / 12$, evident in both Table 5.5 and Figure 5.5, is attributed primarily to the inherent marked unevenness of the surface of the $\mathrm{Al}_{2} \mathrm{O}_{3}$ coating itself, referred to previously in Section 6.2.2.6, and visible in Figure 5.7 (d).

\subsubsection{Effect of $\mathrm{CO}_{2} / \mathrm{H}_{2}$ mole ratio on microstructure of $\mathrm{Al}_{2} \underline{\mathrm{O}}_{3}$ coating adjacent to interface with $\mathrm{Ti}(\mathrm{C}, \mathrm{N})$ precoating}

As previously described in Section 6.2.2.6 and shown in Figure 5.7, on the optical cross-sections through the rake face of some of the $a c$ inserts from the $\mathrm{CO}_{2} / \mathrm{H}_{2}$ mole ratio coating runs, a thin band was just discernible in the upper part of the $\mathrm{Ti}(\mathrm{C}, \mathrm{N})$ precoating immediately adjacent to its interface with the $\mathrm{Al}_{2} \mathrm{O}_{3}$ coating. As described earlier in Section 5.1.7, the ac taper-sectioned inserts from each of the $\mathrm{CO}_{2} / \mathrm{H}_{2}$ mole ratio coating runs were employed to facilitate a proper, relatively high magnification optical examination of this band. From the optical taper sections through the rake face of these ac inserts, shown in Figure 5.10 , a thin layer can be seen, particularly at the $\mathrm{CO}_{2} / \mathrm{H}_{2}$ mole ratios of $1 / 6,1 / 8$ and $1 / 14$, to be present in the upper part of the $\operatorname{Ti}(\mathrm{C}, \mathrm{N})$ precoating directly adjacent to its interface with the $\mathrm{Al}_{2} \mathrm{O}_{3}$ coating. It is also evident from this figure that, for each $\mathrm{CO}_{2} / \mathrm{H}_{2}$ mole ratio, the lower part of the $\mathrm{Al}_{2} \mathrm{O}_{3}$ coating immediately adjacent to its interface with the $\operatorname{Ti}(\mathrm{C}, \mathrm{N})$ precoating has a "mottled" appearance. Corresponding features were also seen in the case of the $\mathrm{Al}_{2} \mathrm{O}_{3}$ coated inserts from the $\mathrm{H}_{2}-1 / \mathrm{AlCl}_{3}$ flow rate coating runs (see Figure 5.38). Since their origins have already been discussed at some length in Section 6.2.1.8, there seems little point in duplicating that discussion here.

\subsubsection{Effect of $\mathrm{CO}_{2} / \mathrm{H}_{2}$ mole ratio on $\underline{\mathrm{Al}}_{2} \underline{\mathrm{O}}_{3}$ coating adhesion}

As mentioned earlier in Section 5.1.9 the scratch test was used to investigate the effect of $\mathrm{CO}_{2} / \mathrm{H}_{2}$ mole ratio on the adhesion of the $\mathrm{Al}_{2} \mathrm{O}_{3}$ coatings to the $\mathrm{Ti}(\mathrm{C}, \mathrm{N})$ precoated PM HSS inserts. For the reasons previously explained in Section 5.1.9, prior to scratch testing of the $h c$ inserts from the different $\mathrm{CO}_{2} / \mathrm{H}_{2}$ mole ratio coating runs, the thickness of the $\mathrm{Al}_{2} \mathrm{O}_{3}$ coating (and of the Ti(C,N) precoating) and the hardness of the PM HSS substrate of each of the $h c$ inserts to be employed were determined. These values are shown in Table 5.8.

Turning now to the scratch test results obtained; several points are evident from Table 5.9 which summarises the results of the scratch tests carried out on the $h c$ insert from each of the $\mathrm{CO}_{2} / \mathrm{H}_{2}$ mole ratio coating runs. First, it can be seen that at each mole ratio pre-critical stylus load flaking of the $\mathrm{Al}_{2} \mathrm{O}_{3}$ coating occurred at the edges of the scratch channels. It is further evident that the stylus load at which this flaking was first observed initially remained constant with decrease in $\mathrm{CO}_{2} / \mathrm{H}_{2}$ mole ratio from $1 / 6$ to $1 / 10$, although there was a progressive reduction in the degree of flaking. Further decrease in $\mathrm{CO}_{2} / \mathrm{H}_{2}$ mole ratio to $1 / 12$ can be seen to have caused an increase in the stylus load at which flaking was first observed, but additional 
decrease in mole ratio to $1 / 14$ has clearly caused an abrupt decrease in this load together with an abrupt increase in the degree of flaking. An SEM micrograph showing a typical example of the flaking at the pre-critical stylus load at which it was first observed, together with the corresponding $\mathrm{Al}, \mathrm{Ti}$ and $\mathrm{Fe} K_{\alpha}$ maps, is shown for each $\mathrm{CO}_{2} / \mathrm{H}_{2}$ mole ratio in Figures 5.13 to 5.17. Correlation of the $\mathrm{X}$-ray maps in each figure with the region of flaking at the edge of the scratch channel on the $\mathrm{Al}_{2} \mathrm{O}_{3}$ coated insert, suggests that, at each $\mathrm{CO}_{2} / \mathrm{H}_{2}$ mole ratio, the flaking is of the adhesive type, witnessed by the absence of $\mathrm{Al} /$ presence of Ti throughout the whole region of flaking.

As with the $\mathrm{Al}_{2} \mathrm{O}_{3}$ coated inserts from the $\mathrm{H}_{2}-1 / \mathrm{AlCl}_{3}$ flow rate coating runs (see Section 6.2.1.9), the relevant scratch channels on the $h c$ insert from each $\mathrm{CO}_{2} / \mathrm{H}_{2}$ mole ratio coating run were then examined, in order to attempt to determine the critical stylus load corresponding to extensive removal of the $\mathrm{Al}_{2} \mathrm{O}_{3}$ coating from the scratch channel. SEM micrographs of a typical region of the relevant scratch channels on each of the $h c$ inserts, together with the corresponding $\mathrm{Al}, \mathrm{Ti}$ and $\mathrm{Fe} K_{\alpha} \mathrm{X}$-ray maps are shown in Figures 5.18 to 5.28. In each case it can be seen from the X-ray maps that for the scratch channel corresponding to the lower of the two stylus loads presented (lowest of the three stylus loads presented in the case of $\mathrm{CO}_{2} / \mathrm{H}_{2}$ mole ratio $1 / 8$ ), $\mathrm{Al}$ (i.e. $\mathrm{Al}_{2} \mathrm{O}_{3}$ ) is present throughout most of the region of the scratch channel. Conversely, for the scratch channel corresponding to the higher of the two stylus loads presented (highest of the three stylus loads presented in the case of $\mathrm{CO}_{2} / \mathrm{H}_{2}$ mole ratio $1 / 8$ ), it can be seen from each of the figures that the $\mathrm{Al}_{2} \mathrm{O}_{3}$ coating has been virtually completely removed from the $\mathrm{Ti}(\mathrm{C}, \mathrm{N})$ precoating in the scratch channel, as witnessed by the absence of $\mathrm{Al} /$ presence of $\mathrm{Ti}$ in the region of the scratch channel in the X-ray maps accompanying each of the SEM micrographs. It is further evident from Table 5.9 that the critical stylus load corresponding to extensive removal of the $\mathrm{Al}_{2} \mathrm{O}_{3}$ coating from the scratch channel initially increases from 6 to $7.5 \mathrm{~kg}$ with decrease in $\mathrm{CO}_{2} / \mathrm{H}_{2}$ mole ratio from $1 / 6$ to $1 / 12$, but then deteriorates to a value of $5 \mathrm{~kg}$ with further decrease in $\mathrm{CO}_{2} / \mathrm{H}_{2}$ mole ratio to $1 / 14$.

As may be deducted from the foregoing discussion of the scratch test results for the $\mathrm{Al}_{2} \mathrm{O}_{3}$ coated inserts from the $\mathrm{CO}_{2} / \mathrm{H}_{2}$ mole ratio coating runs, there is a (surprisingly) good correlation between the effect of $\mathrm{CO}_{2} / \mathrm{H}_{2}$ mole ratio on the adhesion of the $\mathrm{Al}_{2} \mathrm{O}_{3}$ coatings as assessed in terms of pre-critical load flaking (stylus load at which first observed plus degree of flaking) - the so called "threshold adhesion value" [97] - and as assessed in terms of the critical stylus load (corresponding to extensive removal of the $\mathrm{Al}_{2} \mathrm{O}_{3}$ coating from the scratch channel). This effect of $\mathrm{CO}_{2} / \mathrm{H}_{2}$ mole ratio on $\mathrm{Al}_{2} \mathrm{O}_{3}$ coating adhesion is consistent with and is attributed to its effect on the upper part of the $\mathrm{Ti}(\mathrm{C}, \mathrm{N})$ precoating and the lower part of the $\mathrm{Al}_{2} \mathrm{O}_{3}$ coating, i.e. on the $\mathrm{Al}_{2} \mathrm{O}_{3}$ coating/Ti(C,N) precoating transition zone, described, discussed and accounted for earlier in Section 6.2.2.1. 
Surprisingly, no previous work on the effect of $\mathrm{CO}_{2} / \mathrm{H}_{2}$ mole ratio on the adhesive character of $\mathrm{Al}_{2} \mathrm{O}_{3}$ coatings was found in the literature to permit comparison with the results of the present work.

As stipulated in Section 4.3 and reiterated at the end of Section 6.1, the major studies of the effect of $\mathrm{CO}_{2} / \mathrm{H}_{2}$ mole ratio and $\mathrm{AlCl}_{3}$ concentration on the characteristics of $\mathrm{Al}_{2} \mathrm{O}_{3}$ coatings chemically vapour deposited on the Ti(C,N) precoated PM BT42 grade HSS inserts, were carried out in order, ultimately, to improve upon the characteristics of the preliminary $\mathrm{Al}_{2} \mathrm{O}_{3}$ coating obtained in the present work. This being the case, it was thought pertinent, at this juncture, to review the results obtained in order to ascertain whether such an improvement had actually been achieved. It was stated at the end of Section 6.1, in regard to the preliminary $\mathrm{Al}_{2} \mathrm{O}_{3}$ coating from the present work, that it was necessary, in particular, to decrease the amount of $\mathrm{Al}(\mathrm{e})$ in the $\mathrm{Al}_{2} \mathrm{O}_{3}$ coating, to reduce peripheral coating thickness variability and the inherent unevenness of the $\mathrm{Al}_{2} \mathrm{O}_{3}$ coating surface, to substantially refine the coating grain structure and to improve adhesion; implicitly, without detriment to the other $\mathrm{Al}_{2} \mathrm{O}_{3}$ coating characteristics. Comparison of the characteristics of the preliminary $\mathrm{Al}_{2} \mathrm{O}_{3}$ coating (see Chapter 4) and those of the $\mathrm{Al}_{2} \mathrm{O}_{3}$ coatings from the $\mathrm{CO}_{2} / \mathrm{H}_{2}$ mole ratio and $\mathrm{AlCl}_{3}$ concentration coating runs (see Chapter 5), reveals that whilst some improvement over each of the aforementioned characteristics of the preliminary $\mathrm{Al}_{2} \mathrm{O}_{3}$ coating was achieved in the $\mathrm{CO}_{2} / \mathrm{H}_{2}$ mole ratio and $\mathrm{AlCl}_{3}$ concentration studies, these were not attained under a single set of deposition conditions and, in the case of refinement of $\mathrm{Al}_{2} \mathrm{O}_{3}$ coating grain structure, not without detriment to $\mathrm{Al}_{2} \mathrm{O}_{3}$ coating microhardness. It must, therefore, be concluded that, in this respect, the major studies of the effect of $\mathrm{CO}_{2} / \mathrm{H}_{2}$ mole ratio and $\mathrm{AlCl}_{3}$ concentration on $\mathrm{Al}_{2} \mathrm{O}_{3}$ coating characteristics have not been successful. Indeed, it appears to be the case that the undesirable characteristics of the $\mathrm{Al}_{2} \mathrm{O}_{3}$ coatings deposited at atmospheric total deposition pressure in the present work, originally identified in the case of the preliminary $\mathrm{Al}_{2} \mathrm{O}_{3}$ coating, as compared to those of $\mathrm{Al}_{2} \mathrm{O}_{3}$ coatings chemically vapour deposited on cemented carbide substrates at reduced total deposition pressures (see Chapter 2), are an inevitable consequence of the use of atmospheric total deposition pressure. This must not, however, be interpreted as implying that the use of atmospheric total deposition pressure to chemically vapour deposit $\mathrm{Al}_{2} \mathrm{O}_{3}$ coatings on (precoated) $\mathrm{PM}$ HSS inserts is untenable, rather, that in addition to the advantages of its use (identified earlier in Section 3.2.1) there are also some apparent disadvantages with regard to $\mathrm{Al}_{2} \mathrm{O}_{3}$ coating characteristics, the consequence of which, on the cutting performance of the $\mathrm{Al}_{2} \mathrm{O}_{3}$ coated inserts, have yet to be ascertained. 


\subsection{Trial $\mathrm{Al}_{2} \mathrm{O}_{3}$ Coating Runs}

Having established and accounted for the effects of $\mathrm{CO}_{2} / \mathrm{H}_{2}$ mole ratio and $\mathrm{AlCl}_{3}$ concentration on the CVD and on the characteristics of the $\mathrm{Al}_{2} \mathrm{O}_{3}$ coatings on the Ti(C,N) precoated $\mathrm{PM}$ HSS inserts, the major effects observed during the trial $\mathrm{Al}_{2} \mathrm{O}_{3}$ coating runs can now be explained.

The results obtained from the trial $\mathrm{Al}_{2} \mathrm{O}_{3}$ coating runs, previously described in detail in Section 3.3, are summarised in Table 3.2. As is evident from these two sources, two major effects were observed during the trial $\mathrm{Al}_{2} \mathrm{O}_{3}$ coating runs. First, at a $\mathrm{CO}_{2} / \mathrm{H}_{2}$ mole ratio of 1 (trial coating runs 1 and 3 ) the Ti-base precoatings were either completely removed or damaged through their thickness. Decrease in $\mathrm{CO}_{2} / \mathrm{H}_{2}$ mole ratio to $1 / 2$ (trial coating run 4), however, led to a small improvement, in the sense that there was some evidence of intact Ti-base precoatings, but with further decrease in $\mathrm{CO}_{2} / \mathrm{H}_{2}$ mole ratio to $1 / 8$ (trial coating run 5) the Ti-base precoatings were found to still be present on the PM HSS inserts, although the TiC precoating exhibited some evidence of damage. These results are not only completely consistent with, but are seen as adding considerable further weight to several of the principal suggestions advanced during the discussion of the effect of $\mathrm{AlCl}_{3}$ concentration and $\mathrm{CO}_{2} / \mathrm{H}_{2}$ mole ratio on the CVD of the $\mathrm{Al}_{2} \mathrm{O}_{3}$ coatings in the present work (Section 6.2). In particular, it was suggested in Section 6.2.2.1 that the use of atmospheric total deposition pressure in the present work, in comparison to the significantly reduced total deposition pressures employed in previous work on the CVD of $\mathrm{Al}_{2} \mathrm{O}_{3}$ coatings, caused an increase in the ratio of $\mathrm{H}_{2}$ to $\mathrm{CO}_{2}$ necessary to produce the maximum amount of $\mathrm{H}_{2} \mathrm{O}$ via their homogeneous gas phase reaction, from a value close to unity at significantly reduced total deposition pressures to a $\mathrm{CO}_{2} / \mathrm{H}_{2}$ mole ratio of $1 / 12$ at atmospheric total deposition pressure in the present work. It was additionally argued that at the highest $\mathrm{CO}_{2} / \mathrm{H}_{2}$ mole ratio of $1 / 6$ employed in the $\mathrm{CO}_{2} / \mathrm{H}_{2}$ mole ratio study in the present work, there would have been insufficient $\mathrm{H}_{2}$ to convert all the $\mathrm{CO}_{2}$ into $\mathrm{H}_{2} \mathrm{O}$, the excess $\mathrm{CO}_{2}$ reacting with the TiC phase of the $\mathrm{Ti}(\mathrm{C}, \mathrm{N})$ precoating in the first "substrate-type" reaction and thus causing the observed oxidation of the bulk of the precoating. With decrease in $\mathrm{CO}_{2} / \mathrm{H}_{2}$ mole ratio from $1 / 6$ to $1 / 12$, however, it was further suggested that the amount of excess $\mathrm{CO}_{2}$ would have decreased, leading to a decrease in the first "substrate-type" reaction and hence in the oxidation of the bulk of the precoating. The removal/damage through the thickness of the Ti-base precoatings ( $\mathrm{TiC}, \mathrm{Ti}(\mathrm{C}, \mathrm{N})$ and $\mathrm{TiN})$ in trial coating runs 1 and 3 can thus be accounted for in terms of the significant excess of $\mathrm{CO}_{2}$ which would have been present at this $\mathrm{CO}_{2} / \mathrm{H}_{2}$ mole ratio, leading to a marked increase in the first "substrate-type" reaction thereby causing gross oxidation of the Ti-base precoatings. The small improvement in the state of the Ti-base precoatings with decrease in $\mathrm{CO}_{2} / \mathrm{H}_{2}$ mole ratio to $1 / 2$ (trial coating run 4 ) and the fact that with further decrease in $\mathrm{CO}_{2} / \mathrm{H}_{2}$ mole ratio to $1 / 8$ (trial coating run 5) the Ti-base precoatings were found to still be present on the PM HSS 
inserts, can, of course, be explained in terms of the accompanying reduction in the amount of excess $\mathrm{CO}_{2}$ and hence in the oxidation of the precoatings resulting from the first "substrate-type" reaction.

The second major effect observed during the trial $\mathrm{Al}_{2} \mathrm{O}_{3}$ coating runs was that, of the PM HSS inserts employed (uncoated and $\mathrm{Ti}(\mathrm{C}, \mathrm{N}), \mathrm{TiN}$ and $\mathrm{TiC}$ precoated), the best results were obtained with the $\mathrm{Ti}(\mathrm{C}, \mathrm{N})$ precoated inserts. This is attributed to the fact that, at any given $\mathrm{CO}_{2} / \mathrm{H}_{2}$ mole ratio, the susceptibility to oxidation of the different inserts during the first "substrate-type" reaction was not the same. The worst results were obtained with the uncoated PM HSS inserts, which is hardly surprising, their susceptibility to oxidation being the greatest. It is considered likely that in the case of these inserts the first "substrate-type" reaction would have resulted in the formation of a brittle, low strength layer of iron oxide on the surface of the inserts, causing poor adhesion and ultimately $\mathrm{Al}_{2} \mathrm{O}_{3}$ coating detachment. Of the precoated PM HSS inserts, the worst results were obtained with the TiC precoating, the next best with the TiN precoating and, as stated earlier, the best results were obtained with the Ti(C,N) precoating. It is known that the susceptibility of $\mathrm{TiC}$ to oxidation is greater than that of $\mathrm{TiN}$ [98], and it is presumed that $\mathrm{Ti}(\mathrm{C}, \mathrm{N})$ will occupy an intermediate position in this respect. Clearly, this explains why, of the three precoatings, the worst results were obtained with the $\mathrm{TiC}$, although it does not account for the fact that the best results were obtained with the $\mathrm{Ti}(\mathrm{C}, \mathrm{N})$ precoating and not with the TiN. This is considered likely to be associated with a difference in the nature of the oxide layer formed on the surface of the Ti(C,N) and TiN precoatings during the first "substrate-type" reaction. 


\section{CHAPTER 7}

MAJOR CONCLUSIONS AND SUGGESTIONS FOR FURTHER WORK 


\subsection{MAJJOR CONCLUSIONS AND SUGGESTIONS FOR FURTHER WORK}

The major conclusions arising from the work of this thesis are as detailed below.

1. An $\alpha-\mathrm{Al}_{2} \mathrm{O}_{3}$ coating can be successfully chemically vapour deposited on PM BT42 grade HSS inserts at atmospheric pressure, and retained during the obligatory post-coating HSS substrate heat treatment, but a precoating is required on the HSS inserts to facilitate this. Of the three Ti-base precoatings studied in the present work ( $\mathrm{TiC}, \mathrm{TiN}$ and $\mathrm{Ti}(\mathrm{C}, \mathrm{N})$ ), the best results have been obtained with the $\mathrm{Ti}(\mathrm{C}, \mathrm{N})$ precoating, which had a composition of $\sim \mathrm{Ti}\left(\mathrm{C}_{0.2} \mathrm{~N}_{0.8}\right)$.

2. The $\mathrm{Al}_{2} \mathrm{O}_{3}$ coatings successfully chemically vapour deposited on the $\mathrm{Ti}(\mathrm{C}, \mathrm{N})$ precoated PM HSS inserts at atmospheric total deposition pressure in the present work exhibit some undesirable characteristics compared to $\mathrm{Al}_{2} \mathrm{O}_{3}$ coatings chemically vapour deposited on uncoated/precoated cemented carbide inserts at significantly reduced total deposition pressures. These include the amount of $\mathrm{Al}(\mathrm{e})$ in the $\mathrm{Al}_{2} \mathrm{O}_{3}$ coatings, variability in peripheral coating thickness, the inherent unevenness of the surface of the $\mathrm{Al}_{2} \mathrm{O}_{3}$ coatings and coarse coating grain size, and are thought to be an inevitable consequence of the use of atmospheric total deposition pressure.

3. A markedly lower $\mathrm{CO}_{2} / \mathrm{H}_{2}$ mole ratio is required to successfully chemically vapour deposit $\mathrm{Al}_{2} \mathrm{O}_{3}$ coatings on $\mathrm{Ti}(\mathrm{C}, \mathrm{N})$ precoated $\mathrm{PM}$ HSS inserts at atmospheric pressure, than the value of approximately unity normally employed to deposit such coatings on uncoated/precoated cemented carbide inserts at significantly reduced total deposition pressures.

4. The obligatory post-coating heat treatment used to harden and temper the HSS substrate of the $\mathrm{Al}_{2} \mathrm{O}_{3}$ coated PM HSS inserts does not significantly affect the characteristics of the $\mathrm{Al}_{2} \mathrm{O}_{3}$ coating. As a result of the volume expansion accompanying the austenite to martensite transformation of the HSS, however, it does cause localised cracking of the $\mathrm{Al}_{2} \mathrm{O}_{3}$ coating at the insert cutting edges and on immediately adjacent areas of the insert rake face.

5. Some common features were found to be exhibited by all the $\mathrm{Al}_{2} \mathrm{O}_{3}$ coated $(\mathrm{Ti}(\mathrm{C}, \mathrm{N})$ precoated) PM HSS inserts fully characterised in the present work. Oxygen was present in the bulk and in the upper part of the $\operatorname{Ti}(\mathrm{C}, \mathrm{N})$ precoating, the latter being thought to consist of a thin layer of titanium oxides $\left(\mathrm{Ti}_{3} \mathrm{O}_{5}\right.$ or $\mathrm{Ti}_{2} \mathrm{O}_{3}$ and possibly $\left.\mathrm{TiO}_{2}\right)$ plus a complex $\operatorname{Ti}\left(\mathrm{O}_{x} \mathrm{C}_{y} \mathrm{~N}_{z}\right)$ compound possibly also containing Al. This layer was revealed by both optical microscopy and fractography. The lower part of the $\mathrm{Al}_{2} \mathrm{O}_{3}$ coating, which together with the upper part of the $\mathrm{Ti}(\mathrm{C}, \mathrm{N})$ precoating constitutes the $\mathrm{Al}_{2} \mathrm{O}_{3}$ 
coating/Ti(C,N) precoating transition zone, had a "mottled" optical appearance, due, it is suggested, to it being composed of oxygen deficient $\mathrm{Al}_{2} \mathrm{O}_{3}$ containing speckles of $\mathrm{Ti}\left(\mathrm{O}_{\mathrm{x}} \mathrm{C}_{\mathrm{y}} \mathrm{N}_{z}\right)$. The bulk of the $\mathrm{Al}_{2} \mathrm{O}_{3}$ coating consisted of $\alpha-\mathrm{Al}_{2} \mathrm{O}_{3}$, but contained $\mathrm{Al}(\mathrm{e})$. It had a structure made up of coarse grains, exhibiting a distinct tendency towards columnar growth, with finer grains present in the lower part of the $\mathrm{Al}_{2} \mathrm{O}_{3}$ coating, and exhibited preferred orientation of the $\{11 \overline{2} 3\}$ planes. The grains on the surface of the $\mathrm{Al}_{2} \mathrm{O}_{3}$ coating were pyramidal/faceted in form.

6. When assessing the characteristics of the $\mathrm{Al}_{2} \mathrm{O}_{3}$ coated ( $\mathrm{Ti}(\mathrm{C}, \mathrm{N})$ precoated) PM HSS inserts it is necessary to consider three regions: the (oxidised) bulk of the $\mathrm{Ti}(\mathrm{C}, \mathrm{N})$ precoating, the $\mathrm{Al}_{2} \mathrm{O}_{3}$ coating/Ti(C,N) precoating transition zone (made up of the upper part of the $\mathrm{Ti}(\mathrm{C}, \mathrm{N})$ precoating and the lower part of the $\mathrm{Al}_{2} \mathrm{O}_{3}$ coating) and the bulk of the $\mathrm{Al}_{2} \mathrm{O}_{3}$ coating.

7. The following reactions/combinations of reactions are suggested to be responsible for the presence/formation of the above-defined three regions:

- The presence of the oxygen in the bulk and in the upper part of the Ti(C,N) precoating, and hence the presence of the thin layer of titanium oxides in the latter location, is attributed to a first "substrate-type" reaction between the $\operatorname{Ti}(\mathrm{C}, \mathrm{N})$ precoating and the $\mathrm{CO}_{2}$ reactant gas.

- Following the first "substrate-type" reaction, the original formation of the $\mathrm{Al}_{2} \mathrm{O}_{3}$ coating/Ti(C,N) precoating transition zone, and thus the observed intermingling of the $\mathrm{Al}_{2} \mathrm{O}_{3}$ coating and $\mathrm{Ti}(\mathrm{C}, \mathrm{N})$ precoating elements, is due to interdiffusion in concert with the combination of a second "substrate-type" reaction between the titanium oxides in the upper part of the $\mathrm{Ti}(\mathrm{C}, \mathrm{N})$ precoating and the $\mathrm{AlCl}_{3}$ reactant gas, and either the overall reaction between $\mathrm{AlCl}_{3}$ and $\mathrm{H}_{2} \mathrm{O}$ or between $\mathrm{AlCl}_{3}, \mathrm{H}_{2}$ and $\mathrm{CO}_{2}$, but modified in either case by the presence of $\mathrm{TiCl}_{4}$ resulting from the "substrate-type" reaction between the titanium oxides in the upper part of the $\mathrm{Ti}(\mathrm{C}, \mathrm{N})$ precoating and the $\mathrm{AlCl}_{3}$ reactant gas. It is suggested that the second "substrate-type" reaction in combination with the modified overall reactions between $\mathrm{AlCl}_{3}, \mathrm{H}_{2} \mathrm{O}$ and $\mathrm{TiCl}_{4}$ or between $\mathrm{AlCl}_{3}, \mathrm{H}_{2}, \mathrm{CO}_{2}$ and $\mathrm{TiCl}_{4}$ leads initially to the codeposition of oxygen deficient $\mathrm{Al}_{2} \mathrm{O}_{3}$ and some form of titanium oxide which is then transformed to $\mathrm{Ti}\left(\mathrm{O}_{\mathrm{x}} \mathrm{C}_{\mathrm{y}} \mathrm{N}_{\mathrm{z}}\right)$ by the diffusion of $\mathrm{C}$ and $\mathrm{N}$ from the $\mathrm{Ti}(\mathrm{C}, \mathrm{N})$ precoating.

- The deposition of the bulk of the $\mathrm{Al}_{2} \mathrm{O}_{3}$ coatings occurs either by the overall reaction between $\mathrm{AlCl}_{3}$ and $\mathrm{H}_{2} \mathrm{O}$ and/or between $\mathrm{AlCl}_{3}, \mathrm{H}_{2}$ and $\mathrm{CO}_{2}$, once the influence of these overall reactions over the second "substrate-type" reaction has become total and they are no longer modified by the presence of $\mathrm{TiCl}_{4}$ resulting from the second "substrate-type" reaction. 
8. The fact that the Ti(C,N) precoating on the PM HSS inserts in the present work was not chemically inert towards the gaseous reactants is due to two factors: the range of $\mathrm{AlCl}_{3}$ partial pressures employed being below the critical value referred to by Lhermitte-Sebire et al [20], and the use of atmospheric total deposition pressure causing an increase in the ratio of $\mathrm{H}_{2}$ to $\mathrm{CO}_{2}$ necessary to produce the maximum amount of $\mathrm{H}_{2} \mathrm{O}$ via their homogeneous gas phase reaction, from a value close to unity at significantly reduced total deposition pressures, to a $\mathrm{CO}_{2} / \mathrm{H}_{2}$ mole ratio of approximately $1 / 12$ at atmospheric pressure in the present work.

The following six major conclusions relate specifically to the investigation of the effect of $\mathrm{AlCl}_{3}$ concentration $\left(\mathrm{H}_{2}-1 / \mathrm{AlCl}_{3}\right.$ flow rate) on the CVD of $\mathrm{Al}_{2} \mathrm{O}_{3}$ coatings on the $\mathrm{Ti}(\mathrm{C}, \mathrm{N})$ precoated PM BT42 grade HSS inserts, carried out at a constant $\mathrm{CO}_{2} / \mathrm{H}_{2}$ mole ratio of $1 / 10$ in the present work.

9. The average level of oxygen present in the bulk of the Ti(C,N) precoatings shows an overall decrease and the amount of oxygen present in the upper part of the precoating exhibits a marked decrease with increase in $\mathrm{H}_{2}-1 / \mathrm{AlCl}_{3}$ flow rate from 10 to $30 \mathrm{~cm}^{3}$ $\min ^{-1}$. This is attributed to the concomitant decrease in $\mathrm{CO}_{2} / \mathrm{AlCl}_{3}$ mole ratio. It is very difficult to account for the observed effects of increasing $\mathrm{H}_{2}-1 / \mathrm{AlCl}_{3}$ flow rate on the compositional features of the $\mathrm{Al}_{2} \mathrm{O}_{3}$ coating/Ti(C,N) precoating transition zone. The bulk stoichiometry of the $\mathrm{Al}_{2} \mathrm{O}_{3}$ coatings increases from $\mathrm{Al}_{1.84} \mathrm{O}_{3}$ to $\mathrm{Al}_{2} \mathrm{O}_{3}$ with increase in $\mathrm{H}_{2}-1 / \mathrm{AlCl}_{3}$ flow rate from 10 to $15 \mathrm{~cm}^{3} \mathrm{~min}^{-1}$, but then deteriorates to $\mathrm{Al}_{1.81} \mathrm{O}_{3}$ and further to $\mathrm{Al}_{1.8} \mathrm{O}_{3}$ at $\mathrm{H}_{2}-1 / \mathrm{AlCl}_{3}$ flow rates of 25 and $30 \mathrm{~cm}^{3} \mathrm{~min}^{-1}$ respectively. The reason for this is not known, but it may be that the controlling/predominant overall reaction responsible for the CVD of the bulk of the $\mathrm{Al}_{2} \mathrm{O}_{3}$ coatings was influenced by increasing $\mathrm{H}_{2}-1 / \mathrm{AlCl}_{3}$ flow rate and that this, together with the concomitant decrease in $\mathrm{CO}_{2} / \mathrm{AlCl}_{3}$ mole ratio, might have been responsible for the observed effect of $\mathrm{H}_{2}-1 / \mathrm{AlCl}_{3}$ flow rate on bulk $\mathrm{Al}_{2} \mathrm{O}_{3}$ coating stoichiometry. The latter is reflected in, and is responsible for, the observed effect of $\mathrm{H}_{2}-1 / \mathrm{AlCl}_{3}$ flow rate on $\mathrm{Al}_{2} \mathrm{O}_{3}$ coating lattice parameters.

10. $\mathrm{Al}_{2} \mathrm{O}_{3}$ coating thickness initially increases linearly with increase in $\mathrm{H}_{2}-1 / \mathrm{AlCl}_{3}$ flow rate from 10 to $\sim 20 \mathrm{~cm}^{3} \mathrm{~min}^{-1}$, but with further increase in $\mathrm{H}_{2}-1 / \mathrm{AlCl}_{3}$ flow rate the rate of increase in coating thickness begins to decrease until, at $\mathrm{H}_{2}-1 / \mathrm{AlCl}_{3}$ flow rates of $\sim 25$ $\mathrm{cm}^{3} \mathrm{~min}^{-1}$ and above, $\mathrm{Al}_{2} \mathrm{O}_{3}$ coating thickness becomes sensibly constant. The initial linear increase in $\mathrm{Al}_{2} \mathrm{O}_{3}$ coating thickness with increase in $\mathrm{H}_{2}-1 / \mathrm{AlCl}_{3}$ flow rate from 10 to $\sim 20 \mathrm{~cm}^{3} \mathrm{~min}^{-1}$ is typical of mass transport control and can be rationalised in terms of the corresponding increase in the concentration of $\mathrm{AlCl}_{3}$ in the bulk gas stream. The concomitant decrease in $\mathrm{CO}_{2} / \mathrm{AlCl}_{3}$ mole ratio with increasing $\mathrm{H}_{2}-1 / \mathrm{AlCl}_{3}$ flow rate 
eventually leads to a relative shortage of $\mathrm{O}$-donors with the result that there is a transition between $\mathrm{H}_{2}-1 / \mathrm{AlCl}_{3}$ flow rates of $\sim 20$ and $\sim 25 \mathrm{~cm}^{3} \mathrm{~min}^{-1}$ from mass transport control to control by the homogeneous reaction between $\mathrm{H}_{2}$ and $\mathrm{CO}_{2}$ in the gas phase and that, at $\mathrm{H}_{2}-1 / \mathrm{AlCl}_{3}$ flow rates of $\sim 25 \mathrm{~cm}^{3} \mathrm{~min}^{-1}$ and above, the latter becomes rate limiting. The observed effect of increasing $\mathrm{H}_{2}-1 / \mathrm{AlCl}_{3}$ flow rate on $\mathrm{Al}_{2} \mathrm{O}_{3}$ coating thickness is reflected in, and is responsible for, the accompanying effect on the intensity of the $\{11 \overline{2} 3\}$ reflections from the $\mathrm{Al}_{2} \mathrm{O}_{3}$ coatings. There is, therefore, no change in $\mathrm{Al}_{2} \mathrm{O}_{3}$ coating preferred orientation with increasing $\mathrm{H}_{2}-1 / \mathrm{AlCl}_{3}$ flow rate.

11. Increasing $\mathrm{H}_{2}-1 / \mathrm{AlCl}_{3}$ flow rate has no effect on the morphology of the grains at the surface and in the bulk of the $\mathrm{Al}_{2} \mathrm{O}_{3}$ coatings. The effect of increasing $\mathrm{H}_{2}-1 / \mathrm{AlCl}_{3}$ flow rate on $\mathrm{Al}_{2} \mathrm{O}_{3}$ coating bulk and surface grain size closely matches that on $\mathrm{Al}_{2} \mathrm{O}_{3}$ coating thickness. The sustained increase in $\mathrm{Al}_{2} \mathrm{O}_{3}$ coating grain size with increase in $\mathrm{H}_{2}-1 / \mathrm{AlCl}_{3}$ flow rate from 10 to $25 \mathrm{~cm}^{3} \mathrm{~min}^{-1}$ is due to the corresponding increase in the concentration of $\mathrm{AlCl}_{3}$ in the bulk gas stream causing a decrease in the supersaturation of $\mathrm{AlCl}_{3}$ and thereby a decrease in the nucleation rate and thus an increase in grain size. The $\mathrm{Al}_{2} \mathrm{O}_{3}$ coating grain size remaining sensibly constant with further increase in $\mathrm{H}_{2}-1 / \mathrm{AlCl}_{3}$ flow rate to $30 \mathrm{~cm}^{3} \mathrm{~min}^{-1}$ is attributed to the concomitant decrease in $\mathrm{CO}_{2} / \mathrm{AlCl}_{3}$ mole ratio with increasing $\mathrm{H}_{2}-1 / \mathrm{AlCl}_{3}$ flow rate eventually leading to a relative shortage of O-donors, with the result that at $\mathrm{H}_{2}-1 / \mathrm{AlCl}_{3}$ flow rates of $25 \mathrm{~cm}^{3} \mathrm{~min}^{-1}$ and above, the nucleation of $\mathrm{Al}_{2} \mathrm{O}_{3}$ is limited by the $\mathrm{O}$-donor.

12. The effect of increasing $\mathrm{H}_{2}-1 / \mathrm{AlCl}_{3}$ flow rate on $\mathrm{Al}_{2} \mathrm{O}_{3}$ coating microhardness mirrors that on $\mathrm{Al}_{2} \mathrm{O}_{3}$ coating bulk grain size. It is thus suggested that the effect of $\mathrm{H}_{2}-1 / \mathrm{AlCl}_{3}$ flow rate on $\mathrm{Al}_{2} \mathrm{O}_{3}$ coating microhardness is associated with, but not directly caused by, its concomitant effect on $\mathrm{Al}_{2} \mathrm{O}_{3}$ coating bulk grain size.

13. Increasing $\mathrm{H}_{2}-1 / \mathrm{AlCl}_{3}$ flow rate did not have a sustained, identifiable effect on the surface roughness of the $\mathrm{Al}_{2} \mathrm{O}_{3}$ coatings nor did it materially affect the increased thickness of the $\mathrm{Al}_{2} \mathrm{O}_{3}$ coating on the corners of the Ti(C,N) precoated PM HSS inserts relative to that on the rake and flank faces.

14. All the $\mathrm{Al}_{2} \mathrm{O}_{3}$ coated inserts exhibited pre-critical stylus load adhesive flaking at the edges of the scratch channels during scratch adhesion testing. Increasing $\mathrm{H}_{2}-1 / \mathrm{AlCl}_{3}$ flow rate does not affect either the stylus load at which this flaking is first observed nor the degree of flaking, due, it is suggested, to the $\mathrm{Al}_{2} \mathrm{O}_{3}$ coating/Ti(C,N) precoating transition zone being of the same form at each $\mathrm{H}_{2}-1 / \mathrm{AlCl}_{3}$ flow rate. It is not possible to assess the effect of $\mathrm{H}_{2}-1 / \mathrm{AlCl}_{3}$ flow rate on the adhesion of the $\mathrm{Al}_{2} \mathrm{O}_{3}$ coating to the $\mathrm{Ti}(\mathrm{C}, \mathrm{N})$ precoating as measured in terms of the critical stylus load corresponding to extensive removal of the $\mathrm{Al}_{2} \mathrm{O}_{3}$ coating from the scratch channel. This is so because at all but one $\mathrm{H}_{2}-1 / \mathrm{AlCl}_{3}$ flow rate $\left(25 \mathrm{~cm}^{3} \mathrm{~min}^{-1}\right)$, this was preceded by removal of the $\mathrm{Al}_{2} \mathrm{O}_{3}$ coating and the $\mathrm{Ti}(\mathrm{C}, \mathrm{N})$ precoating from the scratch channel. 
The following eight major conclusions relate specifically to the investigation of the effect of $\mathrm{CO}_{2} / \mathrm{H}_{2}$ mole ratio on the CVD of $\mathrm{Al}_{2} \mathrm{O}_{3}$ coatings on the Ti(C,N) precoated PM BT42 grade HSS inserts, carried out at a constant $\mathrm{H}_{2}-1 / \mathrm{AlCl}_{3}$ flow rate of $25 \mathrm{~cm}^{3} \mathrm{~min}^{-1}$ in the present work.

15. Decrease in $\mathrm{CO}_{2} / \mathrm{H}_{2}$ mole ratio from $1 / 6$ to $1 / 12$ causes a decrease in the first "substrate-type" reaction between the Ti(C,N) precoating and the $\mathrm{CO}_{2}$ reactant gas, and thus results in a dramatic/marked decrease in the average level of oxygen present in the bulk and in the upper part of the $\mathrm{Ti}(\mathrm{C}, \mathrm{N})$ precoating, causing a reduction in the formation of the thin layer of titanium oxides in the latter location. This, in turn, causes a reduction in the extent of the second "substrate-type" reaction between this titanium oxide and the $\mathrm{AlCl}_{3}$ reactant gas and, by so doing, decreases the distance over which the oxygen content increases from the average level present in the $\operatorname{Ti}(\mathrm{C}, N)$ precoating to a level representative of the $\mathrm{Al}_{2} \mathrm{O}_{3}$ coating, reduces the depth to which $\mathrm{Al}(\mathrm{o})$ and $\mathrm{Al}(\mathrm{e})$ are present in the $\mathrm{Ti}(\mathrm{C}, \mathrm{N})$ precoating and diminishes the depth of presence of $\mathrm{Ti}, \mathrm{C}$ and $\mathrm{N}$ in the lower part of the $\mathrm{Al}_{2} \mathrm{O}_{3}$ coating. This effect of $\mathrm{CO}_{2} / \mathrm{H}_{2}$ mole ratio is suggested to be due to the use of atmospheric total deposition pressure causing an increase in the ratio of $\mathrm{H}_{2}$ to $\mathrm{CO}_{2}$ necessary to produce the maximum amount of $\mathrm{H}_{2} \mathrm{O}$ via their homogeneous gas phase reaction, from a value close to unity at reduced total deposition pressures to a $\mathrm{CO}_{2} / \mathrm{H}_{2}$ mole ratio of approximately $1 / 12$. Thus, at the $\mathrm{CO}_{2} / \mathrm{H}_{2}$ mole ratio of $1 / 6$ there is insufficient $\mathrm{H}_{2}$ to convert all the $\mathrm{CO}_{2}$ into $\mathrm{H}_{2} \mathrm{O}$, the excess $\mathrm{CO}_{2}$ reacting with the $\mathrm{Ti}(\mathrm{C}, \mathrm{N})$ precoating in the first "substrate-type" reaction. With decrease in $\mathrm{CO}_{2} / \mathrm{H}_{2}$ mole ratio from $1 / 6$ to $1 / 12$ the amount of excess $\mathrm{CO}_{2}$ decreases, leading to the decrease in the first "substrate-type" reaction with its attendant effects. The concurrent increase in the amount of $\mathrm{H}_{2} \mathrm{O}$ formed by the reaction between $\mathrm{H}_{2}$ and $\mathrm{CO}_{2}$ is suggested to be responsible for the increase in bulk stoichiometry of the $\mathrm{Al}_{2} \mathrm{O}_{3}$ coatings from $\mathrm{Al}_{1.7} \mathrm{O}_{3}$ to $\mathrm{Al}_{1.79} \mathrm{O}_{3}$ with decrease in $\mathrm{CO}_{2} / \mathrm{H}_{2}$ mole ratio from $1 / 6$ to approximately $1 / 12$.

16. Further decrease in $\mathrm{CO}_{2} / \mathrm{H}_{2}$ mole ratio from $1 / 12$ to $1 / 14$ leads to a complete reversal of the trends evident with decrease in $\mathrm{CO}_{2} / \mathrm{H}_{2}$ mole ratio from $1 / 6$ to $1 / 12$. It is suggested that this is due to the excess $\mathrm{H}_{2}$ present at the $\mathrm{CO}_{2} / \mathrm{H}_{2}$ mole ratio of $1 / 14$ partially reducing the $\mathrm{AlCl}_{3}$ reactant into aluminium subchlorides, causing an abrupt decrease in $\mathrm{AlCl}_{3}$ reactant concentration.

17. Decrease in $\mathrm{CO}_{2} / \mathrm{H}_{2}$ mole ratio from $1 / 6$ to $1 / 12$ causes a sustained increase in $\mathrm{Al}_{2} \mathrm{O}_{3}$ coating thickness, but with further decrease in $\mathrm{CO}_{2} / \mathrm{H}_{2}$ mole ratio to $1 / 14$ there is a decrease in $\mathrm{Al}_{2} \mathrm{O}_{3}$ coating thickness. Since, at the constant $\mathrm{H}_{2}-1 / \mathrm{AlCl}_{3}$ flow rate of 25 $\mathrm{cm}^{3} \mathrm{~min}^{-1}$ used in the $\mathrm{CO}_{2} / \mathrm{H}_{2}$ mole ratio study, the rate of $\mathrm{Al}_{2} \mathrm{O}_{3}$ coating deposition is limited by the homogeneous gas phase water reaction between $\mathrm{H}_{2}$ and $\mathrm{CO}_{2}$ (see conclusion 10), the former effect is attributed to the increased amount of $\mathrm{H}_{2} \mathrm{O}$ formed by the reaction between the $\mathrm{H}_{2}$ and the $\mathrm{CO}_{2}$ with decrease in $\mathrm{CO}_{2} / \mathrm{H}_{2}$ mole ratio from 
$1 / 6$ to $1 / 12$, referred to in conclusion 15 . The latter effect is attributed to the abrupt decrease in $\mathrm{AlCl}_{3}$ concentration with further decrease in $\mathrm{CO}_{2} / \mathrm{H}_{2}$ mole ratio from $1 / 12$ to $1 / 14$, referred to in conclusion 16 .

18. Decreasing $\mathrm{CO}_{2} / \mathrm{H}_{2}$ mole ratio has no effect on the morphology of the grains at the surface and in the bulk of the $\mathrm{Al}_{2} \mathrm{O}_{3}$ coatings. The effect of decrease in $\mathrm{CO}_{2} / \mathrm{H}_{2}$ mole ratio from $1 / 6$ to $1 / 12$ on $\mathrm{Al}_{2} \mathrm{O}_{3}$ coating bulk and surface grain size resembles, but is not identical to that on $\mathrm{Al}_{2} \mathrm{O}_{3}$ coating thickness. The explanation for the former is thus, basically, thought to be the same as that for the latter, except that, in the case of the former, it is further suggested that the increase in the amount of $\mathrm{H}_{2} \mathrm{O}$ formed with decrease in $\mathrm{CO}_{2} / \mathrm{H}_{2}$ mole ratio from $1 / 6$ to $1 / 12$ causes a decrease in the supersaturation of $\mathrm{H}_{2} \mathrm{O}$ and thereby a decrease in the nucleation rate of the $\mathrm{Al}_{2} \mathrm{O}_{3}$ coatings and thus the observed increase in their grain size. The discontinuity in the effect of decreasing $\mathrm{CO}_{2} / \mathrm{H}_{2}$ mole ratio on $\mathrm{Al}_{2} \mathrm{O}_{3}$ coating bulk and surface grain size with further decrease in $\mathrm{CO}_{2} / \mathrm{H}_{2}$ mole ratio from $1 / 12$ to $1 / 14$ is attributed to the accompanying abrupt decrease in $\mathrm{AlCl}_{3}$ concentration.

19. Decrease in $\mathrm{CO}_{2} / \mathrm{H}_{2}$ mole ratio from $1 / 6$ to $1 / 10$ causes a gradual increase in the intensity of the $\{11 \overline{2} 3\}$ reflections from the $\mathrm{Al}_{2} \mathrm{O}_{3}$ coatings, but this intensity then decreases slightly with further decrease in $\mathrm{CO}_{2} / \mathrm{H}_{2}$ mole ratio from $1 / 10$ to $1 / 12$. This effect is essentially consistent with that observed on $\mathrm{Al}_{2} \mathrm{O}_{3}$ coating grain size and it is therefore suggested that they are associated. The more substantial decrease in the intensity of the $\{11 \overline{2} 3\}$ reflections from the $\mathrm{Al}_{2} \mathrm{O}_{3}$ coatings with additional decrease in $\mathrm{CO}_{2} / \mathrm{H}_{2}$ mole ratio from $1 / 12$ to $1 / 14$ is attributed to the accompanying abrupt decrease in $\mathrm{AlCl}_{3}$ concentration. In contrast to the situation with $\mathrm{H}_{2}-1 / \mathrm{AlCl}_{3}$ flow rate, the effect of $\mathrm{CO}_{2} / \mathrm{H}_{2}$ mole ratio on $\mathrm{Al}_{2} \mathrm{O}_{3}$ coating lattice parameters cannot be attributed to its concurrent effect on the bulk stoichiometry of the $\mathrm{Al}_{2} \mathrm{O}_{3}$ coatings.

20. The microhardness of the $\mathrm{Al}_{2} \mathrm{O}_{3}$ coatings increases noticeably with decrease in $\mathrm{CO}_{2} / \mathrm{H}_{2}$ mole ratio from $1 / 6$ to approximately $1 / 10$, but with further decrease in $\mathrm{CO}_{2} / \mathrm{H}_{2}$ mole ratio from approximately $1 / 10$ to $1 / 12$ the microhardness remains almost constant and then decreases substantially with additional decrease in $\mathrm{CO}_{2} / \mathrm{H}_{2}$ mole ratio to $1 / 14$. The effect of decrease in $\mathrm{CO}_{2} / \mathrm{H}_{2}$ mole ratio from $1 / 6$ to $1 / 12$ on $\mathrm{Al}_{2} \mathrm{O}_{3}$ coating microhardness is consistent with that on $\mathrm{Al}_{2} \mathrm{O}_{3}$ coating bulk grain size. It is thus suggested that the former is associated with, but not directly caused by, the latter. The substantial decrease in $\mathrm{Al}_{2} \mathrm{O}_{3}$ coating microhardness with additional decrease in $\mathrm{CO}_{2} / \mathrm{H}_{2}$ mole ratio from $1 / 12$ to $1 / 14$ is attributed to the accompanying abrupt decrease in $\mathrm{AlCl}_{3}$ concentration.

21. Decreasing $\mathrm{CO}_{2} / \mathrm{H}_{2}$ mole ratio did not have a sustained effect on the surface roughness of the $\mathrm{Al}_{2} \mathrm{O}_{3}$ coatings nor did it materially affect the increased thickness of the $\mathrm{Al}_{2} \mathrm{O}_{3}$ coating on the corners of the $\mathrm{Ti}(\mathrm{C}, \mathrm{N})$ precoated HSS inserts relative to that on the rake and flank faces. 
22. All the $\mathrm{Al}_{2} \mathrm{O}_{3}$ coated inserts exhibited pre-critical stylus load adhesive flaking at the edges of the scratch channels during scratch adhesion testing. The stylus load at which this flaking is first observed initially remains constant with decrease in $\mathrm{CO}_{2} / \mathrm{H}_{2}$ mole ratio from $1 / 6$ to $1 / 10$, although there is a progressive reduction in the degree of flaking. Further decrease in $\mathrm{CO}_{2} / \mathrm{H}_{2}$ mole ratio to $1 / 12$ causes an increase in the stylus load at which flaking is first observed, but additional decrease in mole ratio to $1 / 14$ causes an abrupt decrease in this load together with an abrupt increase in the degree of flaking. The critical stylus load corresponding to extensive removal of the $\mathrm{Al}_{2} \mathrm{O}_{3}$ coating from the scratch channel initially increases from 6 to $7.5 \mathrm{~kg}$ with decrease in $\mathrm{CO}_{2} / \mathrm{H}_{2}$ mole ratio from $1 / 6$ to $1 / 12$, but then deteriorates to a value of $5 \mathrm{~kg}$ with further decrease in $\mathrm{CO}_{2} / \mathrm{H}_{2}$ mole ratio to $1 / 14$. The effect of $\mathrm{CO}_{2} / \mathrm{H}_{2}$ mole ratio on the adhesion of the $\mathrm{Al}_{2} \mathrm{O}_{3}$ coatings as assessed in terms of both pre-critical load flaking (stylus load at which first observed plus degree of flaking) and the critical stylus load is consistent with and is attributed to its effect on the upper part of the $\mathrm{Ti}(\mathrm{C}, \mathrm{N})$ precoating and the lower part of the $\mathrm{Al}_{2} \mathrm{O}_{3}$ coating, i.e. on the $\mathrm{Al}_{2} \mathrm{O}_{3}$ coating/Ti(C,N) precoating transition zone.

23. Overall, it is concluded that in the limited cases where it is possible to make a comparison between the observed effects of $\mathrm{AlCl}_{3}$ concentration and $\mathrm{CO}_{2} / \mathrm{H}_{2}$ mole ratio on the CVD of $\mathrm{Al}_{2} \mathrm{O}_{3}$ coatings on the $\mathrm{Ti}(\mathrm{C}, \mathrm{N})$ precoated $\mathrm{PM}$ HSS inserts at atmospheric total deposition pressure in the present work and on the CVD of $\mathrm{Al}_{2} \mathrm{O}_{3}$ coatings on uncoated/precoated cemented carbide inserts at significantly reduced total deposition pressures in previous work reported in the literature, there is, perhaps not surprisingly, only partial agreement.

The following suggestions for further work are advanced:

(i). The effects of $\mathrm{AlCl}_{3}$ concentration on bulk $\mathrm{Al}_{2} \mathrm{O}_{3}$ coating stoichiometry, the compositional features of the $\mathrm{Al}_{2} \mathrm{O}_{3}$ coating/Ti(C,N) precoating transition zone and $\mathrm{Al}_{2} \mathrm{O}_{3}$ coating adhesion requires further study. Further work is also required on the effect of $\mathrm{CO}_{2} / \mathrm{H}_{2}$ mole ratio and $\mathrm{AlCl}_{3}$ concentration on the amount of $\mathrm{Al}(\mathrm{e})$ in the bulk of the $\mathrm{Al}_{2} \mathrm{O}_{3}$ coatings, $\mathrm{Al}_{2} \mathrm{O}_{3}$ coating lattice parameters and $\mathrm{Al}_{2} \mathrm{O}_{3}$ coating microhardness. In respect of the latter, whether the direct cause of the effect observed is a corresponding increase in crystal defect concentration requires investigation using transmission electron microscopy techniques. The difficulties associated with preparing the required thin sections of the $\mathrm{Al}_{2} \mathrm{O}_{3}$ coated inserts are recognised.

(ii). The effect of total flow rate, deposition temperature and precoating stoichiometry on the characteristics of $\mathrm{Al}_{2} \mathrm{O}_{3}$ coatings chemically vapour deposited on $\mathrm{Ti}(\mathrm{C}, \mathrm{N})$ precoated PM BT42 grade HSS inserts should be additionally studied. This would aid in establishing the reactions suggested in the present work to be responsible for the 
presence/formation of the three regions of the $\mathrm{Al}_{2} \mathrm{O}_{3}$ coated (Ti(C,N) precoated) PM HSS inserts and allow identification of optimum $\mathrm{Al}_{2} \mathrm{O}_{3}$ coating deposition conditions with regard to coating characteristics.

(iii). A detailed study of the effect of different deposition conditions on the cutting performance of $\mathrm{Al}_{2} \mathrm{O}_{3}$ coated ( $\mathrm{Ti}(\mathrm{C}, \mathrm{N})$ precoated) PM BT42 grade HSS inserts should be carried out. Once the cutting performance of these inserts has been optimised, it can then be compared to that exhibited by CVD TiN coated PM BT42 grade HSS inserts.

(iv). The use of evaporated $\mathrm{AlCl}_{3}$ powder as the donor $\mathrm{Al}$ source in the $\mathrm{CVD}$ of $\mathrm{Al}$-containing coatings, pioneered and developed in the present work, should be extended to other applications, such as the CVD aluminising of iron-base substrates and nickel-base and cobalt-base superalloy substrates.

(v). Further work should be carried out on the CVD aluminising of PM BT42 grade HSS inserts as an alternative to $\mathrm{Ti}(\mathrm{C}, \mathrm{N})$ precoating of the inserts to facilitate atmospheric pressure CVD of $\mathrm{Al}_{2} \mathrm{O}_{3}$ coatings. This should be followed by an investigation of the use of different deposition conditions to those employed in the present work, to ascertain if $\mathrm{Al}_{2} \mathrm{O}_{3}$ coatings can be chemically vapour deposited on these aluminised PM HSS inserts at atmospheric pressure. If successful, the effect on $\mathrm{Al}_{2} \mathrm{O}_{3}$ coating characteristics and the cutting performance of the $\mathrm{Al}_{2} \mathrm{O}_{3}$ coated PM HSS inserts of using the aluminising precoating treatment as opposed to a $\mathrm{Ti}(\mathrm{C}, \mathrm{N})$ precoating, should be determined. 
CHAPTER 8

REFERENCES 


\subsection{REFERENCES}

1. Jagger, F.L. and Price, W.J.C.: UK Patent 1466249, 1977.

2. Jagger, F.L. and Price, W.J.C., Walker, P.I. and Smith, P.: Powder Metall., 1977, $\underline{20}$, (3), 151.

3. Dickinson, E.A., Walker, P.I. and Jagger, F.L.: Proc. 10th Plansee Seminar, (ed. Ortner, H.M.), 439; 1981, Reutte, Metallwerk Plansee.

4. Dickinson, E.A. and Walker, P.I.: Metal Powder Report, 1980, 35, (1), 18.

5. Delphic Forecast: Powder Metall., 1982, 25, (4), i.

6. Whittle, N.C.: Ph.D. Thesis, Loughborough University of Technology, 1987.

7. Smith, A.B. and Whittle, N.C.: Proc. 25th Int. Machine Tool Design and Research Conf., (ed. Tobias, S.A.), 261; 1985, London, Macmillan.

8. Smith, A.B. and Whittle, N.C.: "Proc. of 6th European Conf. on CVD", (ed. Porat, R.), 77; 1987, Jerusalem.

9. Abbas, F.M.H.: Ph.D. Thesis, Loughborough University of Technology, 1990.

10. Smith, A.B., Abbas, F.M.H. and Lamsehchi, M.: Proc. 1st Int. High Speed Steel Conf., (eds. Hackl, G. And Hribernik, B.), 282; 1990, Weiz, Klampfer GmbH.

11. Lewus, M.O.: Ph.D. Thesis, Loughborough University of Technology, 1987.

12. Smith, A.B. and Lewus, M.O.: Horizons of Powder Metallurgy Part 1, (eds. Kaysser, W.A. and Huppmann, W.J.), 245; 1986, Verlag Schmid GmbH., Freiburg.

13. Smith, A.B. and Williams, R.: Powder Metall., 1988, 31, (2), 846.

14. Lamsehchi, M.: Ph.D. Thesis, Loughborough University of Technology, 1992.

15. Snell, P.O.: Jernkonterets Ann., 1970, 154, 413.

16. Kalish, H.S. and Peters, L.: Metal Powder Report, 1989, 44, (12), 846.

17. Graham, D.E. and Hale, T.E.: Carbide and Tool Journal, 1982, May/June, 34.

18. Wertheim, R., Sivan, R., Porat, R. and Ber, A.: Annals CIRP, 1982, 31, (1), 7.

19. Bunshah, R.F. and Schramm, R.J.: Thin Solid Films, 1977, 40, 211.

20. Lhermitte-Sebire, I., Colmet, R., Naslain, R., Desmaison, J. and Gladel, G.: Thin Solid Films, 1986, 138, 221.

21. Matthews, A. and Valli, J.: Proc. 3rd Int. Congress for Surface Technology, (eds. Czichos, H., Steinhardt, H. and Volk, K.E.), 627; 1985. Berlin, VDE-Verlag.

22. Matthews, A.: J. Vac. Sci. Technol. A, 1985, ㄱ, (6), 2354.

23. Shieh, F.C.: M.S. Thesis, National Chiao Tung University, Taiwan, 1987.

24. Kuo, C.T., Chen, W.W. and Shieh, F.C.: Chin. J. Mater. Sci., 1989, 21, (2), 86.

25. Kuo, C.T., Shieh, F.C. and Chen, W.W.: Chin. J. Mater. Sci., 1989, 21, (1), 38.

26. Hale, T.E.: US Patent 3914473, 1975.

27. Colmet, R. and Naslain, R.: Wear, 1982, 무, 221.

28. Colombier, C., Lux, B. and Lindstrom, L.: Refactory and Hard Materials, 1986, Dec., 222.

29. Lindstrom, J. N. and Johannesson, R.T.: J. Electrochem. Soc., 1976, 123, (4), 555.

30. Lindstrom, J.N., Jonsson, B.F. and Ohlsson, F.J.O.W.: US Patent 29420, 1977. 
31. Funk, R., Schachner, H., Triquet, C., Kornmann, M. and Lux, B.: J. Electrochem. Soc., $1976,123,(2), 285$.

32. Kornmann, M., Schachner, H., Funk, R. and Lux, B.: J. Cryst. Growth, 1975, 28, 259.

33. Schachner, H., Funk, R. and Tannenberger, H.: Proc. 5th Int. Conf. on 'Chemical vapour deposition', (eds. Blocher, J.M. Jr., Hintermann, H.E. and Hall, L.H.), 485; 1975, Electrochemical Society.

34. Schmitt, T., Altena, H. and Lux, B.: Proc. 4th European Conf. on 'Chemical vapour deposition', (ed. Bloem. J., Verspui, G. and Wolff, L.R.), 421; 1983, Eindhoven, Philips Ctr. Manuf. Tech.

35. Altena, H., Colombier, Ch. and Lux, B.: Proc. 4th European Conf. on 'Chemical vapour deposition', (ed. Bloem. J., Verspui, G. and Wolff, L.R.), 435; 1983, Eindhoven, Philips Ctr. Manuf. Tech.

36. Chun, S.S., Kim, J.G. and Park, C.S.: J. Korean Inst. Met., 1981, 19, (9), 752.

37. Colmet, R., Naslain, R., Hagenmuller, P. and Bernard, C.: Proc. 8th Int. Conf. on 'Chemical vapour deposition', (eds. Blocher, J.M. Jr., Vulliard, G.S. and Wahl, G.), 17; 1981, Electrochemical Society, Pennington, NJ.

38. Silvestri, V.J., Osburn, C.M. and Ormond, D.W.: J. Electrochem. Soc., 1978, 125, (6), 902.

39. Fredriksson, E. and Carlsson, J. O.: Journal De Physique, 1989, 50, (C5), 391.

40. Blocher, J.M. Jr.: J. Vac. Sci. Technol., 1974, 11, (4), 680.

41. Johannesson, T.R. and Lindstrom, J.N.: J. Vac. Sci. Technol., 1975, 12, (4), 854.

42. Park, C.S., Kim, J.G. and Chun, J.S.: Proc. 4th European Conf. on 'Chemical vapour deposition', (ed. Bloem. J., Verspui, G. and Wolff, L.R.), 401; 1983, Eindhoven, Philips Ctr. Manuf. Tech.

43. Kim, J.G., Park, C.S. and Chun, J.S.: Thin Solid Films, 1982, 97, 97.

44. Park, C.S., Kim, J.G., and Chun, J.S.: J. Electrochem. Soc., 1983, 130, (7), 1607.

45. Schaffer, P.: J. Am. Ceram. Soc., 1965, 48, (10), 508.

46. Wong, P. and Robinson, M.: J. Am. Ceram. Soc., 1970, 53, (11), 617.

47. Iida, K. and Tsujide, T.: Jap. J. App. Phys., 1972, 11, (6), 840.

48. Mantyla, T., Telma, A., Vuoristo, P. and Kettunen, P.: Proc. 5th European Conf. on 'Chemical vapour deposition', (ed. Carlsson, J.O. and Lindstrom, J.), 381; 1985, Uppsala, Sweden.

49. Altena, H., Colombier, Ch. and Lux, B.: Proc. 4th European Conf. on 'Chemical vapour deposition', (ed. Bloem. J., Verspui, G. and Wolff, L.R.), 451; 1983, Eindhoven, Philips Ctr. Manuf. Tech.

50. Altena, H., Colombier, Ch., Lebl, A., Lindstrom, J. and Lux, B.: Proc. 4th European Conf. on 'Chemical vapour deposition', (ed. Bloem. J., Verspui, G. and Wolff, L.R.), 428; 1983, Eindhoven, Philips Ctr. Manuf. Tech.

51. Colombier, C., Peng, J., Altena, H. and Lux, B.: Refactory and Hard Materials, 1986, June, 82. 
52. Altena, H., Stjernberg, J. and Lux, B.: Proc. 5th European Conf. on 'Chemical vapour deposition', (ed. Carlsson, J.O. and Lindstrom, J.), 381; 1985, Uppsala, Sweden.

53. Altena, H., Pauer, G., Wilhartitz, P. and Lux, B.: Proc. 5th European Conf. on 'Chemical vapour deposition', (ed. Carlsson, J.O. and Lindstrom, J.), 334; 1985, Uppsala, Sweden.

54. Colombier, C. and Lux, B.: J. Mater. Sci., 1989, 24, 462.

55. Pauer, G., Altena, H. and Lux, B.: Refactory and Hard Materials, 1986, Sept., 165.

56. Lhermitte-Sebire, I., Lahaye, M., Colmet, R., Naslain, R. and Chevreir, M.: Thin Solid Films, 1986, 138, 209.

57. Layyous, A. and Wertheim, R.: Journal De Physique, 1989, $\underline{50}$, (C5), 423.

58. Minni, E. and Vuorinen, S.: Proc. 5th European Conf. on 'Chemical vapour deposition', (ed. Carlsson, J.O. and Lindstrom, J.), 428; 1985, Uppsala, Sweden.

59. Jacobson, B. E.: Thin Solid Films, 1980, 73 , 331.

60. Mehrotro, P.K. and Quinto, D.T., Proc. Conf. 11th Int. Plansee Seminar, Vol 1, 20-24 May; 1985, Reutte, Austria.

61. Skogsmo, J. and Norden, H.:Proc. 5th European Conf. on 'Chemical vapour deposition', (ed. Carlsson, J.O. and Lindstrom, J.), 364; 1985, Uppsala, Sweden.

62. Lhermitte-Sebire, I., Colmet, R., Naslain, R. and Bernard, C.: Journal of the Less-Common Metals, 1986, 118, 83.

63. Lux, B. and Schachner, H.: High temperatures-High pressures, 1978, 10, 315.

64. Layyous, A. A., Freinkel, D. M. and Israel, R.: Surface and Coatings Technology, 1992, $\underline{56}, 89$.

65. Ellis, R. C., Jr.: Chemical Vapour Deposition, Raythean Co.

66. Hazra, J.: Manufac. Eng., Jan. 1978.

67. Bryant, W. A., Battagalia, F. B., Downey, B. K. and Undercoffer, K. E.: Proc. 12th Plansee Seminar, (eds. Bildstein, H. and Ortner, H.M.), Vol 3, 187 - 201; Reutte, Metallwerk Plansee.

68. Heavens, O. S.: J.Phys. Radiat., 1950, 11, 355.

69. Benjamin, P. and Weaver, C.: Proc. R. Soc., 1960, A254, 163.

70. Hummer, E. and Perry, A. J.: Thin Solid Films, 1983, 101, 243.

71. Perry, A. J.: Thin Solid Films, 1983, 107, 167.

72. Laeng, P. and Steinmann, P. A.: Proc. 8th Int. Conf. on 'Chemical vapour deposition', (eds. Blocher, J.M. Jr., Vulliard, G.S. and Wahl, G.), 723; 1981, Electrochemical Society, Pennington, NJ.

73. Boving, H. J., Hintermann, H. E. and Julia C.: Adv. Mats. Tech. Int., 1992, 81.

74. ISO 1832: Indexable (throwaway) inserts for cutting tools, Designation-code of symbolization, 1977.

75. BS 4659: British Standard Specification for Tool Steels, 1971.

76. Obray, J.: Undergraduate B.Sc. Project, Loughborough University of Technology, 1986.

77. Lux, B.: Proc. 4th European Conf. on 'Chemical vapour deposition', (ed. Bloem. J., Verspui, G. and Wolff, L.R.), 379; 1983, Eindhoven, Philips Ctr. Manuf. Tech.

78. Hale, T.E.: French Patent 72.19060-26.5, 1972. 
79. Smith, A. B.: Private Communication.

80. Walls, J. M., Hall, D. D. and Sykes, D. E.: Surf. Interface Anal., 1979, 1, (6), 204.

81. Schafer, H.: "Chemical Transport Reactions", 1964, New York, Academic Press.

82. ASTM Powder Diffraction File.

83. Cullity, B. D.: "Elements of X-Ray Diffraction", 1978, Addison Wesley.

84. Askeland, D. R.: "The Science and Engineering of Materials", 1990, Chapman and Hall.

85. Van Vlack, L. H.: "Elements of Materials Science", second edition, 1970, Addison Wesley.

86. Smith, A. B. and Lewus, M. O.: Private Communication.

87. Wright, L. S.: Ph.D. Thesis, University of Bradford, 1983.

88. Perry, A. J. and Horvarth, E.: Journal of Materials Science, 1978, 13, 1303.

89. Perry, A. J. and Horvarth, E.: Thin Solid Films, 1979, 62, 133.

90. Kennedy, J. B. and Neville, A. M.: "Basic statistical Methods for Engineers and Scientists", 1976, Harper and Row.

91. Ohring, M.: "The Materials Science of Thin Films", 1992, Academic Press MC, Harcourt Brace Jovanovich Publishers.

92. Messier, D. R. and Wong, P.: J. Electrochem. Soc., 1971, 118, (5), 772.

93. Greenwood, N. N. and Earnshaw, A.: "Chemistry of the Elements", 1986, second edition, Pergamon Press.

94. Barin, I. and Knacke, O.: "Thermochemical Properties of Inorganic Substances", 1973, Springer-Verlag Berlin Heidelberg New York. Verlag Stahleisen m.b.h. Dusseldorf.

95. Smith, A. B.: Private Communication.

96. Moore, J. J.: "Chemical Metallurgy", 1981, Butterworth \& Co. Limited.

97. Orshnik, J. and Kroll, W. K.: Adhesion Measurement of Thin Films, A.S.T.M. Spec. Tech. Publ., 1978, $\underline{640}, 158$.

98. Hintermann, H .E.: Private Communication. 
APPENDIX 1

USING THE IDEAL GAS LAW TO OBTAIN THE RELATION BETWEEN GAS PARTIAL PRESSURE AND CONCENTRATION 


\section{A1.0 USING THE IDEAL GAS LAW TO OBTAIN THE RELATION BETWEEN GAS PARTIAL PRESSURE AND CONCENTRATION}

For a mixture of two ideal gases $\mathrm{A}$ and $\mathrm{B}$

$$
P_{A}=\frac{n_{A}}{V} R T=[A] \cdot R T
$$

and,

$$
P_{B}=\frac{n_{B}}{V} R T=[B] \cdot R T
$$

where,

$\mathrm{P}_{\mathrm{A}}$ and $\mathrm{P}_{\mathrm{B}} \quad$ partial pressures of gases in the mixture;

$P \quad$ pressure;

$\mathrm{n} \quad$ number of moles of gas;

V volume;

R gas constant, and

T Temperature.

The partial pressure is proportional to the number of moles of the gas present i.e. concentration of the gas, (gas]

$$
\therefore \quad P \propto[\text { gas }]
$$

According to Dalton's law of partial pressures, the total pressure, $P_{v}$, is the sum of the partial pressures and only depends on $n_{1}$ the total number of moles.

$$
\therefore \quad P_{t}=P_{A}+P_{B}=\left(n_{A}+n_{B}\right)\left(\frac{R T}{V}\right)=n_{t} \frac{R T}{V}
$$

Dividing eqs. (1) by (2) and simplifying

$$
\begin{aligned}
& \frac{P_{A}}{P_{t}}=\frac{n_{A}}{n_{t}}=X_{A} \\
& \therefore P_{A}=P_{t} X_{A}
\end{aligned}
$$

As is evident the partial pressure of any gas, such as gas $A$, is the $P_{t}$ of the mixture multiplied by $X_{A}$, the fraction of the total moles of gas $A$. Therefore at constant pressure:

$$
P_{A}=X_{A}
$$


APPENDIX 2

HANDLING/TRANSFERRING OF $\mathrm{AICl}_{3}$ 


\section{A2.0 HANDLING/TRANSFERRING OF $\mathrm{AlCl}_{3}$}

\section{A2.1 Placement of $\mathrm{AlCl}_{3}$ in Glass Evaporation Vessel}

Handle $\mathrm{AlCl}_{3}$ with care.

Read instructions on bottle.

Due to the reaction of $\mathrm{AlCl}_{3}$ with air the chemical has to be handled under an inert atmosphere.

1. Assemble reaction flask. (see Appendix 3.5.2)

2. Gently place the flask in the evaporator unit - keeping the cord and plug to one side. The flask must rest on the parallel bars in the oil.

3. Slide the flask towards the fitting.

4. Position the 3 fittings on the glass tubes and the stainless steel (s.s.) tube with the fittings on the s.s. pipes.

5. Gently clamp the flask.

6. Hold the body of the fitting on the $\mathrm{H}_{2} .1$ inlet glass tube and insert into the s.s. fitting until the front ferrule seats in fitting.

7. Tighten nut by hand. Follow same procedure for $\mathrm{Ar}$ inlet and $\mathrm{H}_{2} \cdot 1+\mathrm{AlCl}_{3}$ tubes.

8. Using a spanner, tighten slightly the nut on the Ar inlet line.

9. Close all the valves on the reaction flask.

10. Increase Ar flow rate to absolute maximum.

11. Open Ar green valve (No.1).

12. Open Ar blue valve - fill reaction flask with Ar.

13. When there is a decrease in the flow rate, open Ar bypass green valve to release gas mixture.

14. Close Ar bypass green valve.

Whilst flask is under Ar....

15. Fill reaction flask with Ar. Place a tissue in the cupboard.

16. Calibrate the scales.

17. Place the following equipment in the atmosbag/inertmosphere: plastic and nickel spatulas, insulating tape scissors, funnel, $\mathrm{AlCl}_{3} \mathrm{jar}$ and a tissue. 
18. When Ar flow rate is at/or near zero - close Ar blue valve.

19. Close Ar green valve (No.1).

20. Completely open the nuts of the three fittings.

21. Hold the flask and open the clamp.

22. Gently remove the flask - keep the flask at an angle so that the oil can drip back into the tank.

23. Place the tissue under the flask and remove from fume cupboard.

24. Thoroughly clean the outside of the flask with acetone. Place flask in holder.

25. Place the flask + holder in the atmosbag/inertmosphere.

(to use the atmosbag - follow instructions below).

(to use the inertmosphere - follow instructions in manual and then follow on from No. 31).

26. Seal atmosbag.

27. Switch on vacuum pump... 1

Deflate the bag completely

Switch off vacuum.

Open nitrogen $(\mathrm{N})$ valve ( 5 p.s.i )...1

Inflate bag - (approx. $3 / 4$ of its maximum capacity)

Switch on vacuum pump...2

Close nitrogen valve.

28. Open $\mathrm{N}$ valve...2

29. Switch on vacuum pump...3

30. Open $\mathrm{N}$ valve...3 - Decrease pressure to 1 p.s.i.

31. Using the gloves in the bag open the plastic cap on the Ar port and remove Ar tube.

32. Place the funnel in the port.

33. Open the $\mathrm{AlCl}_{3}$ bottle and carefully add the desired amount of $\mathrm{AlCl}_{3}$ powder into the plastic spatula using the Ni spatula ( 4 scoops).

34. Close $\mathrm{AlCl}_{3}$ jar. Seal with tape.

35. Pour $\mathrm{AlCl}_{3}$ into the flask. Remove funnel.

36. Place Ar tube in the port and tighten cap. 
37. Make sure all valves are closed.

38. Open seal of atmosbag. Remove flask.

39. Quickly but carefully transfer flask to tank. Make sure the flask is in position and all the nuts are finger - tight.

40. Tighten slightly the nut on the $\mathbf{H}_{2} .1$ line, with a spanner.

41. Increase $\mathrm{H}_{2} .1$ flow rate to absolute maximum.

42. Open $\mathrm{H}_{2} .1$ green valve (No.5)

43. Open $\mathrm{H}_{2} .1$ red valve. When there is a decrease in the flow rate, open Ar bypass green valve and release the gaseous mixture.

44. Close Ar bypass green valve.

45. Fill flask with $\mathrm{H}_{2}$ until flow is at/near to zero.

46. Remove flask.

47. Weigh flask - fill in sheet No.

48. Place flask back in tank. Tighten all nuts with a spanner.

49. Fill with Ar. 
APPENDIX 3

EXPERIMENTAL PROCEDURE FOR C.V.D OF $\mathrm{Al}_{2} \mathrm{O}_{3}$ 


\section{A3.0 EXPERIMENTAL PROCEDURE FOR C.V.D OF Al ${ }_{2} \underline{0}_{3}$}

\section{A3.1 Day Before Coating Run}

Date:

Run:

\section{Inserts in reactor chamber}

Identify inserts using indentation marks

Clean inserts in $\mathrm{CCl}_{4}$

Place inserts in reactor

\section{$\underline{\mathrm{AlCl}_{3} \text { in evaporator unit }}$}

Wt. of $\mathrm{AlCl}_{3}+$ evaporator unit (before run)

Wt. of $\mathrm{AlCl}_{3}+$ evaporator unit (after run)

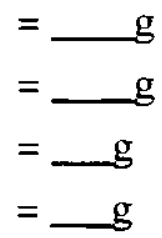

Wt. of $\mathrm{AlCl}_{3}$ used during bypass

Total wt. of $\mathrm{AlCl}_{3}$ used

Preset pressures and flow rates

Ar pressure 5 p.s.i.

C.F. $=0.987$

Desired flow rate $=$ $\mathrm{cm}^{3} \min ^{-1}$

Chart flow rate $=$ Desired flow rate $/$ C.F. $=$

Reading on flowmeter (from graph 3 g. ball) $=$

$\mathrm{H}_{2} .1$ pressure 5 p.s.i.

C.F. $=4.384$

Desired flow rate $=$ $\mathrm{cm}^{3} \min ^{-1}$

Chart flowrate $=$ Desired flowrate $/$ C.F. $=$

Reading on flowmeter (from graph $1 \mathrm{~g}$. ball) $=$

$\mathrm{CO}_{2}$ pressure 5 p.s.i.

C.F. $=0.9346$

Desired flowrate $=$ $\mathrm{cm}^{3} \min ^{-1}$

Chart flowrate $=$ Desired flowrate $/$ C.F.$=$

Reading on flowmeter (from graph 2 s.s. ball) $=$ 
$\mathrm{H}_{2} .2$ pressure 5 p.s.i.

C.F. $=4.384$

Desired flowrate $=$ $\mathrm{cm}^{3} \min ^{-1}$

Chart flowrate $=$ Desired flowrate $/$ C.F. $=$

Reading on flowmeter (from graph $1 \mathrm{~g}$. ball) =

Level of oil $=$ $\left(5 \frac{3}{8}{ }^{\prime \prime}\right)$

Gas ballast

Set flow rates 


\section{A3.1.1 Setting flow rates}

Pressures should be set

\section{$\underline{\mathrm{CO}}_{2}$ Flowrate}

Set $\mathrm{CO}_{2}$ flowrate on flowmeter to maximum

Open $\mathrm{CO}_{2}$ green valve (No.3)

Close vacuum green bar valve (No.8)

Open m.g.d pipe green valve (No.7)

Watch pressure gauge until reading is 0.25

Immediately open $\mathrm{H}_{2} .2$ flame green exhaust gas valve (No.10)

Set $\mathrm{CO}_{2}$ flowrate on flowmeter to -150 (the s.s.ball just touching the g. ball)

\section{Leave $\mathrm{CO}_{2}$ flowing}

Watch $\mathrm{CO}_{2}$ pressure gauge (on cylinder outside) until pressure is 5 p.s.i.

Keep $\mathrm{CO}_{2}$ flowing whilst setting $\mathrm{H}_{2}$ flow rates

Increase the setting on heat gun (No. 3) to 3.5

\section{$\underline{\mathrm{H}}_{2} . \underline{2}$ Flowrate}

Keep $\mathrm{H}_{2} .2$ flowrate low

Open $\mathrm{H}_{2} .2$ green valve (No.4)

Light $\mathrm{H}_{2}$

Set $\mathrm{H}_{2} .2$ flowrate on flowmeter to -150 (the s.s. ball just touching the g. ball)

Set $\mathrm{CO}_{2}$ flowrate at desired value

\section{$\underline{\mathrm{H}}_{2} \cdot \underline{1}$ Flowrate}

Keep $\mathrm{H}_{2} .1$ flowrate low

Open $\mathrm{H}_{2} .1$ green valve (No.5)

Close Ar blue valve

Open $\mathrm{H}_{2} .1$ red valve

Close Ar green valve (No.1)

Open $\mathrm{H}_{2} \cdot 1+\mathrm{AlCl}_{3}$ green valve

Use a cloth and open $\mathrm{H}_{2} \cdot 1+\mathrm{AlCl}_{3}$ green valve (No.6) (watch flame) 
Increase $\mathrm{H}_{2} .1$ flowrate to -150 (the s.s. ball just touching the g. ball)

Watch $\mathrm{H}_{2} .1$ pressure until 5 p.s.i.

Close $\mathrm{CO}_{2}$ green valve (No.3)

Set $\mathrm{H}_{2} .1$ flowrate to 5 (g.ball)

\section{$\underline{\text { Ar flowrate }}$}

Keep Ar flowrate low

Open Ar green valve (No.2)

Increase Ar flowrate to - 150 (the s.s ball just touching the g. ball)

Set $\mathrm{H}_{2} .2$ flowrate to 140 (s.s ball)

Close $\mathrm{H}_{2} .2$ green valve (No.4)

$\mathrm{H}_{2}$ flame will eventually go out

\section{REMEMBER $\mathrm{H}_{2} .1$ IS STILL FLOWING}

Switch off heat gun (No. 3)

Close $\mathrm{H}_{2} \cdot 1+\mathrm{AlCl}_{3}$ green valve (No.6)

Close $\mathrm{H}_{2} \cdot 1+\mathrm{AlCl}_{3}$ green valve

Watch Ar pressure until 5 p.s.i.

Set $\mathrm{Ar}$ and $\mathrm{H}_{2} .2$ flow rates during coating run.

To switch off and divert Ar to evaporator unit

Close $\mathrm{H}_{2} .2$ exhaust gas green valve (No.10)

Close m.g.d. pipe green valve (No.7)

Open vacuum green bar valve (No.8)

Close Ar green valve (No.2)

Open Ar green valve (No.1)

Close $\mathrm{H}_{2} .1$ red valve

Open Ar blue valve

Close $\mathrm{H}_{2} .1$ green valve (No.5)

Set $\mathrm{Ar}$ flowrate to maximum

Open Ar bypass green valve to release $\mathrm{H}_{2}$

Close Ar bypass green valve

Leave unit under Ar. 


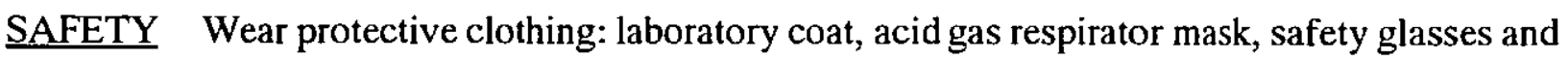
gloves.

Date:

Run:

\begin{tabular}{|c|c|l|}
\hline $\begin{array}{c}\text { Elapsed } \\
\text { Time }\end{array}$ & $\begin{array}{c}\text { Actual } \\
\text { Time }\end{array}$ & \\
\hline 0 & $\begin{array}{l}\text { Adjust plastic caps on evaporation unit. Loosen each cap in turn - } \\
\text { Argon (Ar) flow indicated on flowmeter. Then tighten slightly - Ar } \\
\text { flow near zero. }\end{array}$ \\
$\begin{array}{l}\text { Carefully put lid on unit. } \\
\text { Fix metal box on } \mathrm{H}_{2} .1+\mathrm{AlCl}_{3} \text { tube fitting. } \\
\text { Position heat guns (No.2 and No.3) }\end{array}$ \\
$\begin{array}{l}\text { Check leak rate Time to } 2 x 10^{-1}= \\
\text { Back fill with Ar }-1 \\
\text { Increase Ar flowrate to absolute maximum } \\
\text { Close Ar green valve (No.1) to evaporator unit } \\
\text { Open Ar green valve (No.2) to furnace } \\
\text { Close green bar valve (No.8) to vacuum pump } \\
\text { Open green valve (No.7) along mixed gas delivery (m.g.d) pipe } \\
\text { Back fill with Ar until pressure gauge reading is } 0.25 \text { bar }\end{array}$ \\
\hline
\end{tabular}




\begin{tabular}{|c|c|c|}
\hline $\begin{array}{c}\text { Elapsed } \\
\text { Time }\end{array}$ & $\begin{array}{l}\text { Actual } \\
\text { Time }\end{array}$ & Procedure \\
\hline $30 \mathrm{~min}$ & & $\begin{array}{l}\text { Evacuate - } 1 \\
\text { Close green valve (No.7) along m.g.d pipe } \\
\text { Open green bar valve (No.8) to vacuum pump } \\
\text { Close Ar green valve (No.2) to furnace } \\
\text { Open Ar green valve (No.1) to evaporator unit } \\
\text { Evacuate to }= \\
\text { Back fill with Ar - } 2 \\
\text { Evacuate - } 2 \\
\text { Back fill with Ar - } 3 \\
\text { When pressure gauge reading is } 0.25 \text { bar } \\
\text { Open exhaust gas green valve (No.10) to } \mathrm{H}_{2} \text { flame } \\
\text { Ar flow through tube - reduce flowrate to } 117.5 \text { (glass ball tube } 3 \text { ) } \\
\text { Open } \mathrm{H}_{2} .2 \text { green valve (No.4) } \\
\text { Adjust } \mathrm{H}_{2} .2 \text { flowrate through tube to } 150+\text { (s.s ball) } \\
\text { Light } \mathrm{H}_{2} \text { flame } \\
\text { Close Ar green valve (No.2) to furnace } \\
\text { Open Ar green valve (No.1) to evaporator unit } \\
\text { Increase Ar flowrate to evaporator unit to absolute maximum } \\
\text { Temperature setting } \\
\text { Switch on digital thermometer } \\
\text { away from end cap as possible } \\
\text { Switch on furnace }\end{array}$ \\
\hline
\end{tabular}




\begin{tabular}{|c|c|c|}
\hline $\begin{array}{c}\text { Elapsed } \\
\text { Time }\end{array}$ & $\begin{array}{c}\text { Actual } \\
\text { Time }\end{array}$ & Procedure \\
\hline $\begin{array}{c}1 \mathrm{hr} 30 \mathrm{~min} \\
2 \mathrm{hrs}\end{array}$ & & 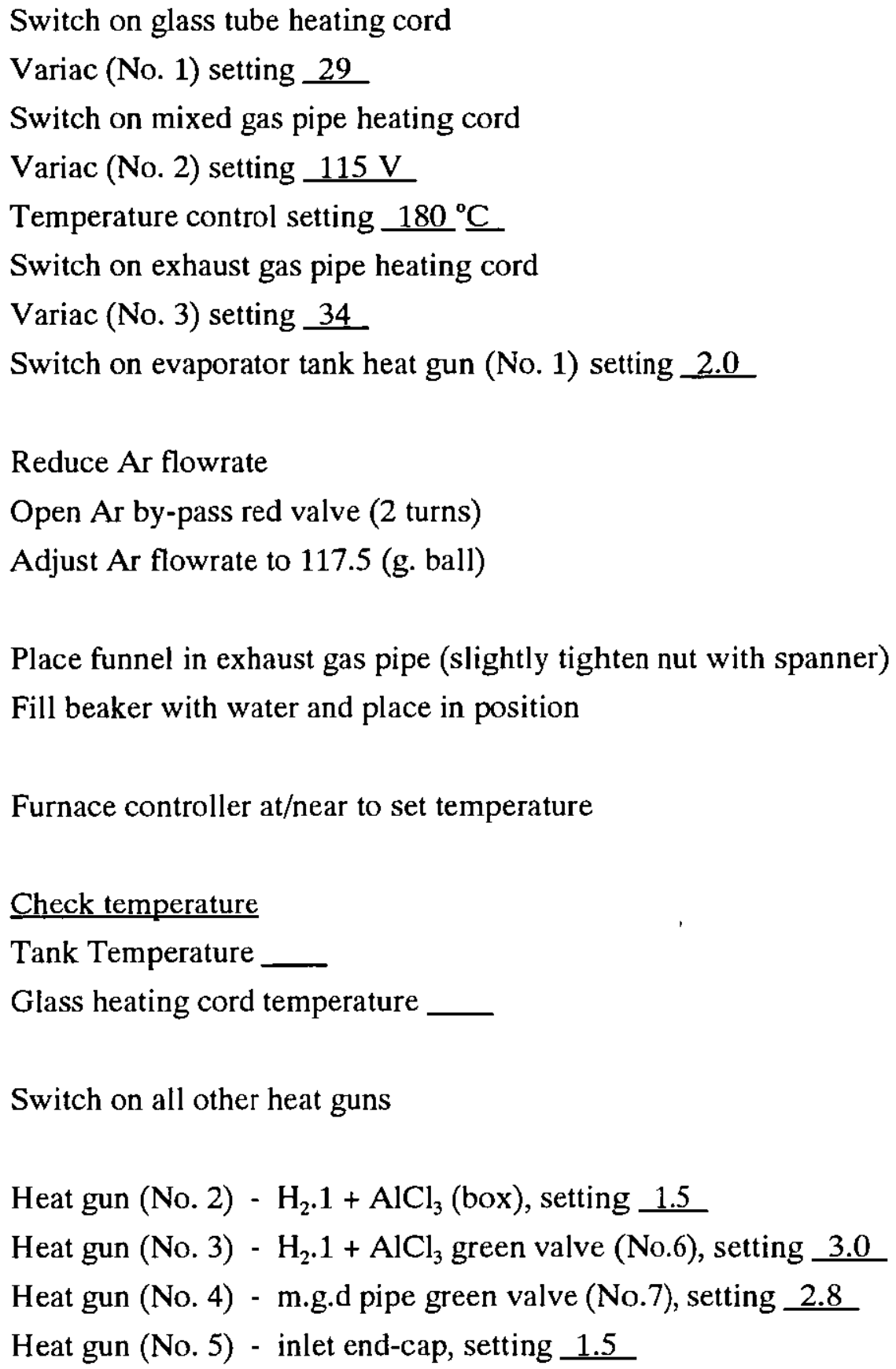 \\
\hline
\end{tabular}




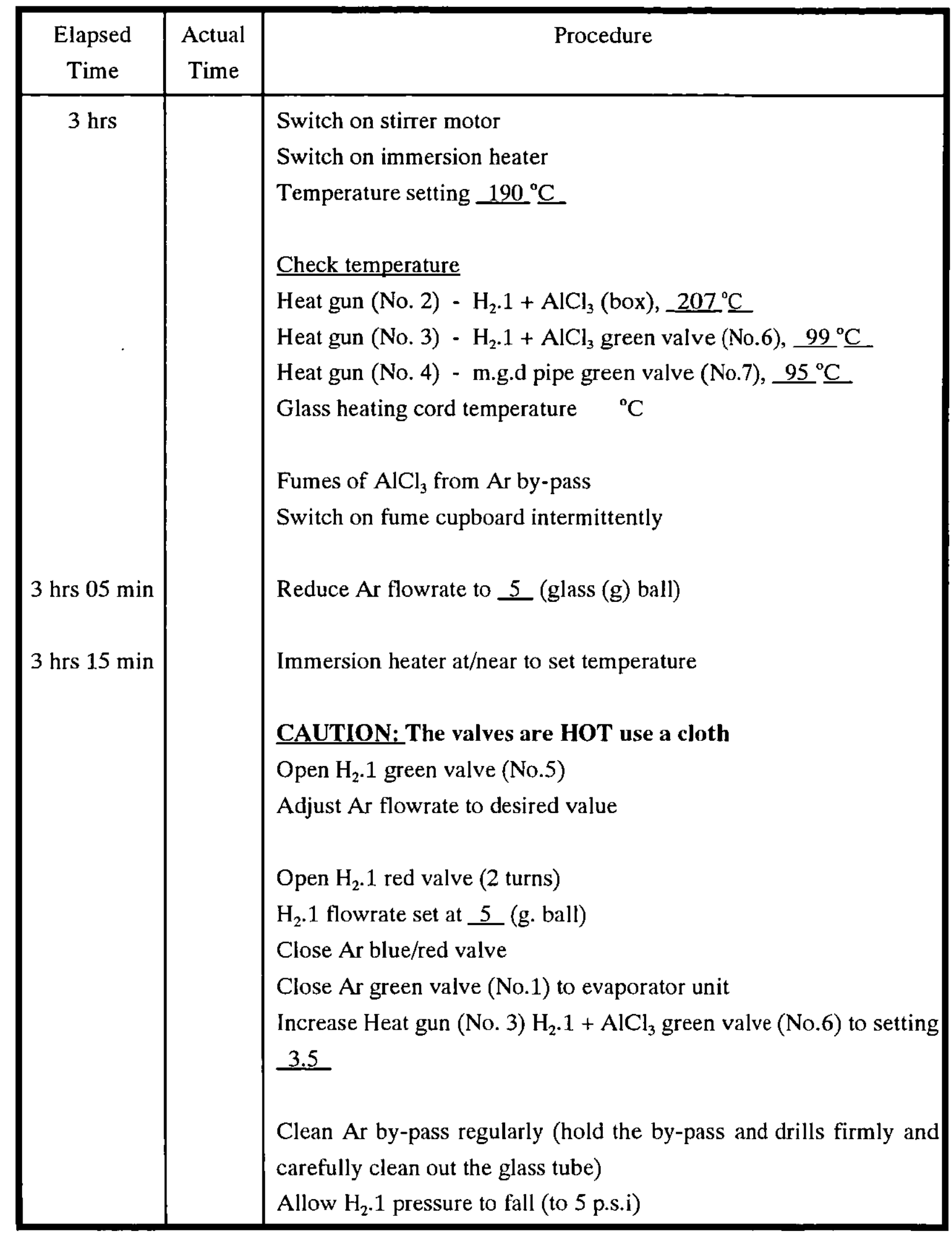




\begin{tabular}{|c|c|c|}
\hline $\begin{array}{c}\text { Elapsed } \\
\text { Time }\end{array}$ & $\begin{array}{l}\text { Actual } \\
\text { Time }\end{array}$ & Procedure \\
\hline $3 \mathrm{hrs} 30 \mathrm{~min}$ & & 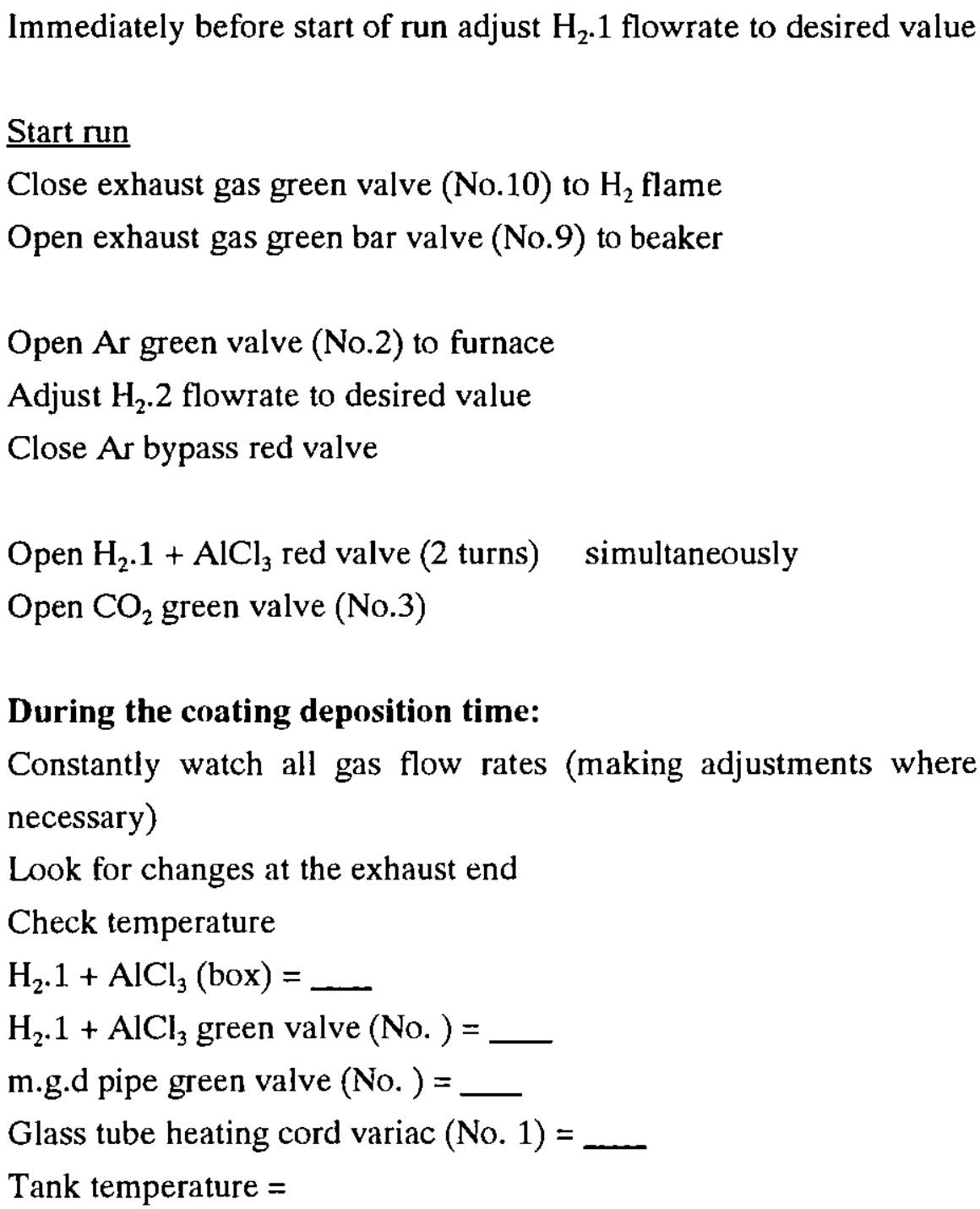 \\
\hline
\end{tabular}




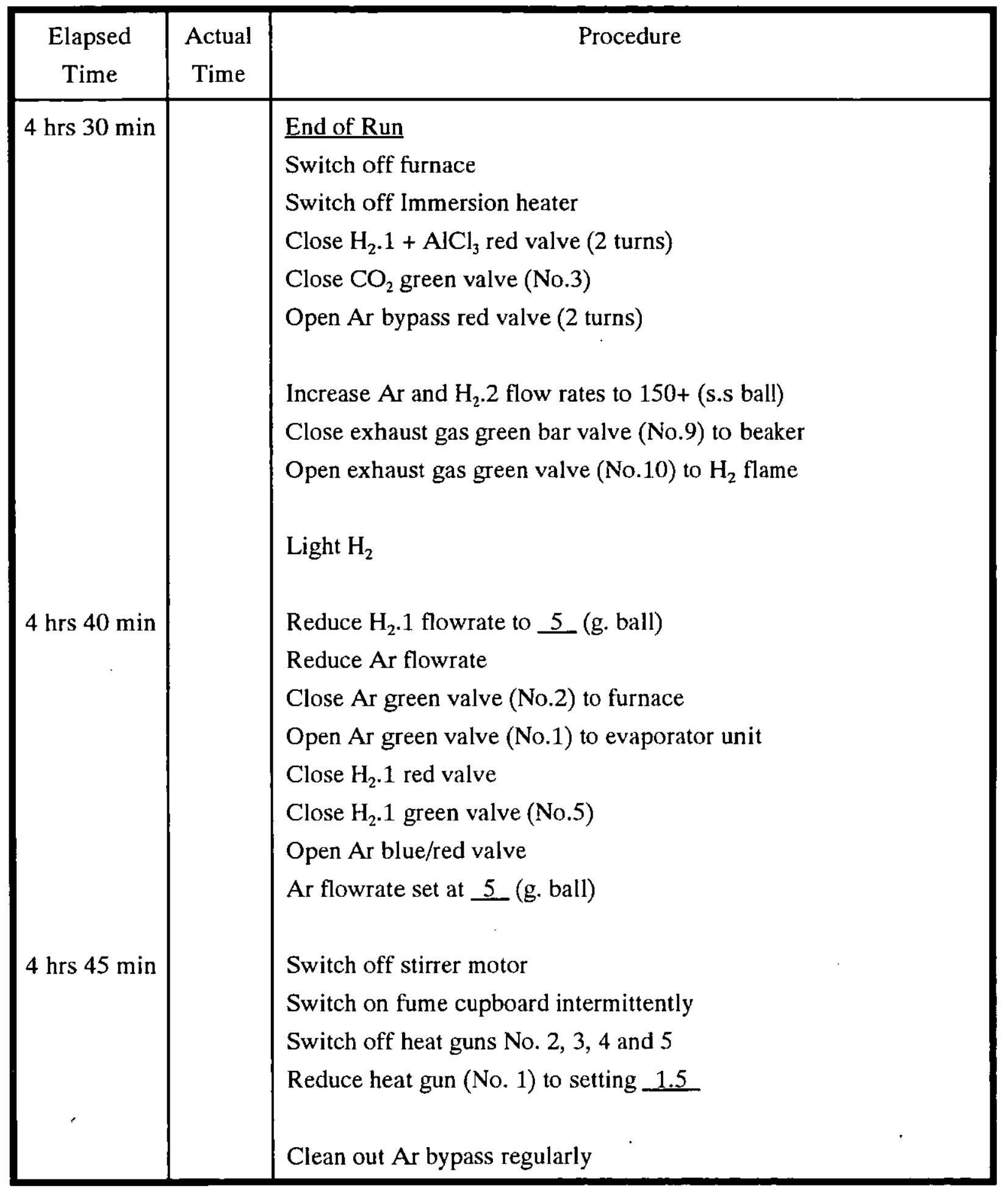




\begin{tabular}{|c|c|c|}
\hline $\begin{array}{c}\text { Elapsed } \\
\text { Time }\end{array}$ & $\begin{array}{c}\text { Actual } \\
\text { Time }\end{array}$ & Procedure \\
\hline & & $\begin{array}{l}\text { Back fill evaporator unit with } \mathbf{H}_{2} \\
\text { Quickly open the Argon fitting } \\
\text { Turn the glass Ar side arm to one side } \\
\text { Reduce } \mathrm{H}_{2} \cdot 1 \text { flowrate } \\
\text { Open Ar blue valve to release the gaseous mixture } \\
\text { Adjust } \mathrm{H}_{2} \cdot 1 \text { flowrate to } 150 \text { (g.ball) } \\
\text { Close Ar blue valve } \\
\text { Increase } \mathrm{H}_{2} \cdot 1 \text { flowrate to absolute maximum } \\
\text { Fill flask with } \mathrm{H}_{2} \\
\text { When } \mathrm{H}_{2} .1 \text { flowrate is at or near to zero } \\
\text { Close } \mathrm{H}_{2} .1 \text { red valve } \\
\text { Close } \mathrm{H}_{2} .1 \text { green valve (No.5) } \\
\text { Quickly open the fitting on the } \mathrm{H}_{2} .1 \text { and } \mathrm{AlCl}_{3} \text { bypass tubes. } \\
\text { Gently slide back the flask and remove from tank (clean oil with } \\
\text { acetone) } \\
\text { Weigh vessel and note reading } \\
\text { Follow instructions on disposal of chemicals (see Appendix } 3.7 \text { ) }\end{array}$ \\
\hline
\end{tabular}




\section{A3.3 Reactor Coating Chamber Apparatus}

\section{A3.3.1 Inserts}

Eight inserts can be placed in the holder during each coating run. Each insert must be marked so that its position in the holder can be identified after each coating run.

1. Mark each insert on the bottom face using the Vickers hardness machine $(50 \mathrm{~kg})$.

An example of the marking system used is shown below
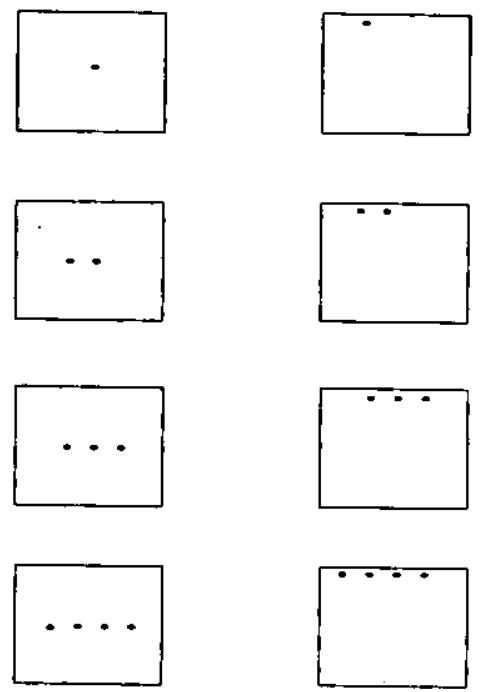

2. Pour $75-100 \mathrm{ml} \mathrm{CCl}_{4}$ in a clean beaker.

3. Place the inserts in the beaker and put the beaker in the ultrasonic cleaner for 20 mins. (the apparatus should be in a fume cupboard).

4. Using a pair of clean tongs take out the inserts and dry them using a drier.

5. Position the inserts in the holder.

6. Using the holder rod place the holder in the furnace until the mark on the rod is level with the ceramic tube. Remove rod.

7. Assemble furnace. 


\section{A3.4 Assembly of Reactor Coating Chamber Apparatus}

1. Carefully place exhaust end cap in the reactor chamber. If the cones inside the chamber are in the correct position then the end cap should touch the O-ring.

2. Loosely place the screws in the end cap.

3. Place the bracket on the end cap. If this does not fit place the bracket on the $\mathrm{H}_{2} .2$ green valve and tighten screws (this ensures the tube is vertical).

$N B$ : Make sure this bracket is fitted at right angles and the side arm is greased.

4. Slightly tighten screws on the end cap.

5. Open green bar valve (No. 8) to vacuum (this ensures the cones inside are pulled together).

6. Tighten screws - make sure the gap at the top and the bottom of the end cap is the same.

7. Place the end cap bracket in position and tighten the screws.

8. Measure distance A.

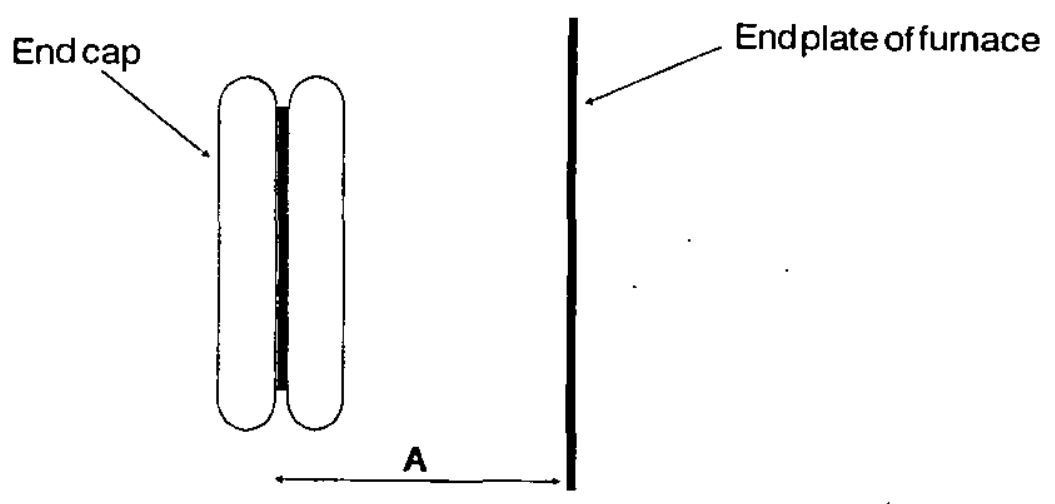

$A=$ Distance from end plate of furnace to inner end cap plate $=1 \frac{5}{8} "$

9. Place perspex plates in position. 


\section{A3.5 Glass Evaporation Vessel}

\section{A3.5.1 Cleaning}

Thoroughly clean all glassware with Decon 90 (follow instructions on bottle).

Rinse with alcohol.

Dry glassware with drier.

\section{i) $\mathrm{H}_{2} .1+\mathrm{AlCl}_{3}$ tube and Bypass tube}

Handle both tubes with care.

Always hold the tubes together.

Do not allow the bypass tube to twist or swing freely.

Keep all insulated and exposed heating cord surfaces dry.

Clean all valve seats and ferrules with a moist (soaked in alcohol) cloth.

Dry valves and ferrules with a clean, dry cloth.

Wash swagelok fittings with hot water.

Rinse with alcohol. If necessary use cotton buds to remove any solid deposits in the body of the fitting and in the nut.

Dry with a drier.

\section{ii) Swagelok fitting}

Follow these instructions for connecting fittings to $\mathrm{H}_{2} \cdot 1$ inlet, $\mathrm{Ar}$ inlet and $\mathrm{H}_{2} \cdot 1+\mathrm{AlCl}_{3}$ tubes.

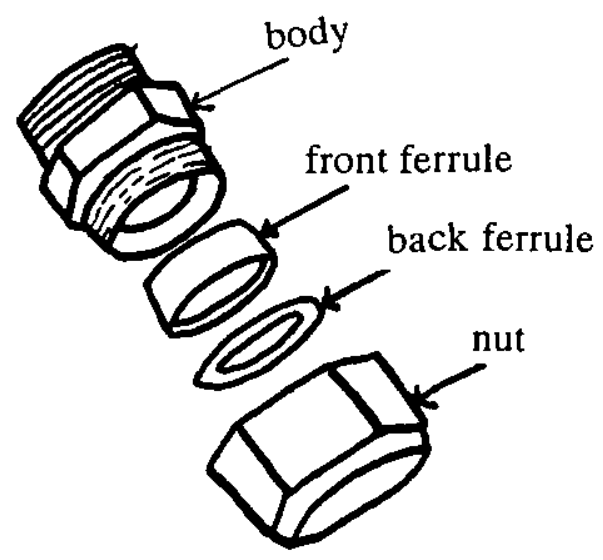

or ștainless steel

1. Place back p.t.f.e. ferrule and then front ferrule into the nut, as shown in the illustration.

2. Insert body into nut and turn nut 1-2 turns.

3. Insert glass/stainless steel (s.s.) tube into fitting, making sure that the tubing rests firmly on the shoulder of the fitting and that the nut is finger-tight. 


\section{iii) $\underline{\text { Ar and } \mathrm{H}_{2} .1 \text { inlet tubes }}$}

Place fitting and tube on bench.

Hold the body of the fitting with a spanner and tighten nut slightly.

\section{iv) $\underline{\mathrm{H}}_{2} . \mathbf{1}+\mathrm{AlCl}_{3}$ tube}

Tighten fitting after the tubes have been placed in the flask.

(for further information see swagelok tube fitting catalogue)

\section{v) $\underline{\text { Seals }}$}

Follow these instructions for $\mathrm{Ar}$ and $\mathrm{H}_{2} .1$ glass tubings and $\mathrm{H}_{2} .1+\mathrm{AlCl}_{3}$ and $\mathrm{Ar}$ bypass s.s. tubings.

1. Insert tubing into plastic cap.

2. Fit the silicone rubber at the correct seal distance (see table of tubing/seal distance) as shown in Figure 1.

3. Fit the p.t.f.e. washer. It is important that the washer is fitted carefully and correctly. This is achieved by opening out the washer with a tapered former. Fit each component separately to the fitting which is to be held, as shown in Figure 1. To obtain a better seal in this system fit the washer the other way round, as shown in Figure 2.

N.B. When fitting the seal on the $\mathrm{H}_{2} \cdot 1+\mathrm{AlCl}_{3}$ s.s. tube, hold the green valve on the tube and gently push the rubber and washer along the tube. Follow the same procedure for the Ar bypass s.s. tube but hold the top end of the tube.

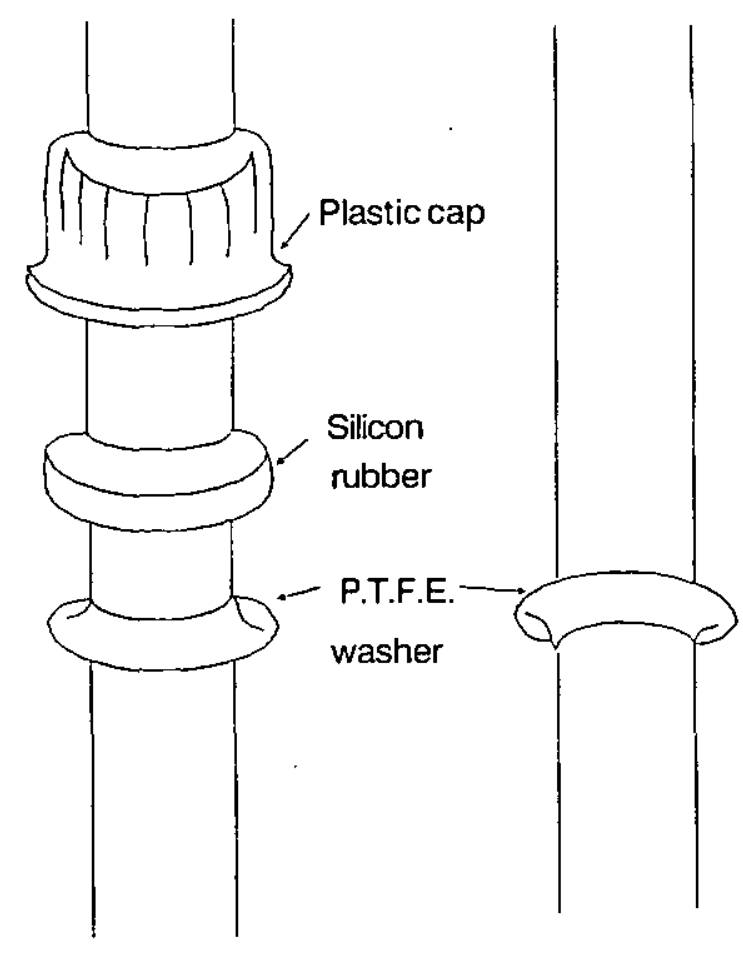

Figure 1 


\section{vi) Valves}

Fit the white safety lock on the Ar inlet tube and screw the blue valve on the thread. Follow the same procedure for $\mathrm{H}_{2} .1$ inlet tube.

To ensure the lock is fastened, close the valve until it just seals. Open the valve completely. The lock should remain fastened to the valve. 


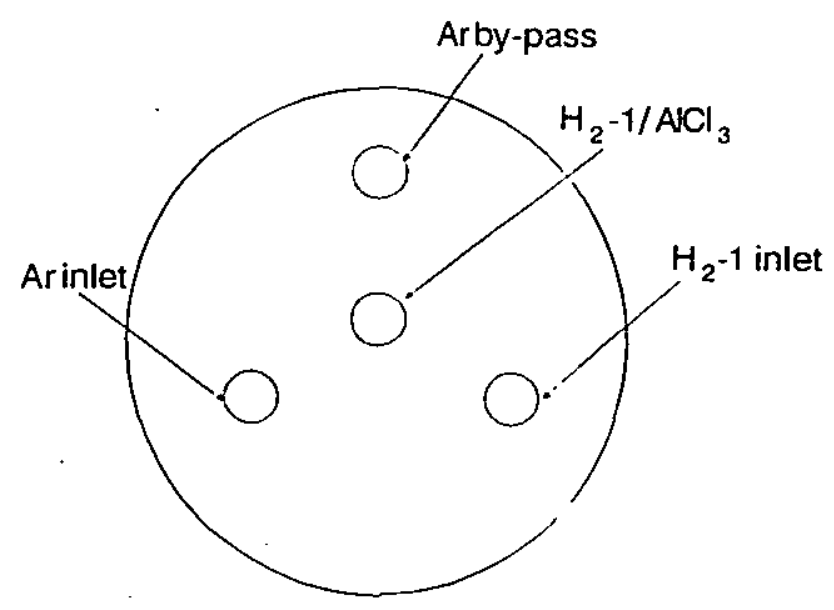

1. Place $\mathrm{H}_{2} .1$ inlet tube in the correct port on the flask shown in Figure 3.

2. Hold the side arm of the tube and screw the cap on the thread - making sure the tube is in the centre of the port.

3. Position the side arm towards the front.

4. Hold the $\mathrm{H}_{2} \cdot 1+\mathrm{AlCl}_{3}$ and the Ar bypass s.s. tubes together and insert them in the appropriate ports.

5. Gently screw the cap on the thread.

6. Hold the side arm of the $\mathrm{H}_{2} \cdot 1+\mathrm{AlCl}_{3}$ tube and tighten cap.

7. Hold the Ar bypass and tighten cap.

SEAL DISTANCES

\begin{tabular}{|l|l|}
\hline \multicolumn{1}{|c|}{ Tube } & Distance (inches) \\
\hline Argon inlet & \\
\hline $\mathrm{H}_{2} \cdot 1$ inlet & \\
\hline $\mathrm{H}_{2} \cdot 1+\mathrm{AlCl}_{3}$ & \\
\hline Argon bypass & \\
\hline
\end{tabular}




\section{A3.6 Dismantling Reactor Coating Chamber After Coating Run}

1. Close exhaust gas green valve (No. 10) to $\mathrm{H}_{2} .2$ flame.

2. Place tube under $\mathrm{Ar}$ at 0.25 bar.

3. Close green valve along m.g.d. pipe (No. 7).

4. Close Ar green valve (No. 2).

5. Remove perspex.

6. Remove bracket on outlet end-cap.

7. Remove the screws on the bracket holding the $\mathrm{H}_{2} .2$ flame green valve (No. 10 ).

8. Remove the screws on the end cap.

9. Release pressure by opening the $\mathrm{H}_{2} .2$ flame green valve (No. 10).

10. Slowly pull out the end cap - do not put weight on the ceramic tube.

11. Carefully take out insert holder.

12. Remove O-ring and end cap plate.

\section{A3.6.1 Cleaning apparatus}

1. Insert the long brush in the reactor chamber and slowly clean around the inside of the tube, removing as much of the debris as possible.

2. Clean the tube with industrial vacuum cleaner.

3. Wrap a tissue/cloth around the rod. Dampen tissue with Alcohol. Insert the rod into the chamber and clean the tube.

4. Clean the tube with the vacuum again.

5. Dampen cloth with Alcohol and clean the inside and outside of the ceramic tube (at the position of the O-ring and end plate).

6. Clean the O-ring and end plate with a cloth dampened with alcohol and place them in position on the ceramic tube.

7. Wash insert holder with hot water.

8. Rinse with alcohol. Dry with a drier. 


\section{A3.6.2 Exhaust end apparatus}

1. At the point of the cross piece (near valve No. 10) carefully remove the exhaust pipe and pressure gauge.

2. Dismantle the green valves (Nos. 9 \& 10)

3. Clean the inside of all valves and tubes with hot water and then clean with a pipe cleaner. (NB. Fold in the cut end of the cleaner)

4. Wash with hot water again and rinse in alcohol.

5. Thoroughly dry all the insides of tubes and valves with a drier.

6. Assemble furnace.

7. Close green valves Nos. 9 and 10. 


\section{A3.7 Disposal of Chemicals}

SAFETY: Always wear protective clothing.

1. After the coating run remove flask from evaporator tank.

2. Carefully remove all glass tubes from the flask and place them on a cloth on the bench.

3. Place flask in the large fume-cupboard.

4. Switch on fume-cupboard.

5. Squirt hot water into the flask. Do not stand too near the flask.

6. When all the $\mathrm{AlCl}_{3}$ has been dissolved and the $\mathrm{HCl}$ fumes have disappeared, remove the flask and pour the solution in the waste bottle labelled $\mathrm{AlCl}_{3}$ solution.

7. See Appendix 3.5 for cleaning rest of the glassware.

Carbon TetraChloride $\left(\mathrm{CCl}_{4}\right)$

After cleaning the inserts pour $\mathrm{CCl}_{4}$ in the waste bottle. 
APPENDIX 4

$\mathrm{AlCl}_{3} \mathrm{BY}$-PASS RUNS 


\section{A4.0 AlCl $_{3}$ BY-PASS RUNS}

\section{A4.1 Experimental Procedure for $\mathrm{AlCl}_{3} \mathrm{By}_{\text {-pass }} \mathrm{Runs}$}

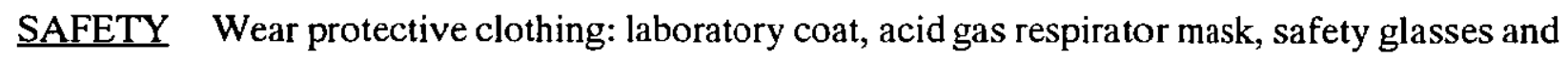
gloves.

Date:

Run:

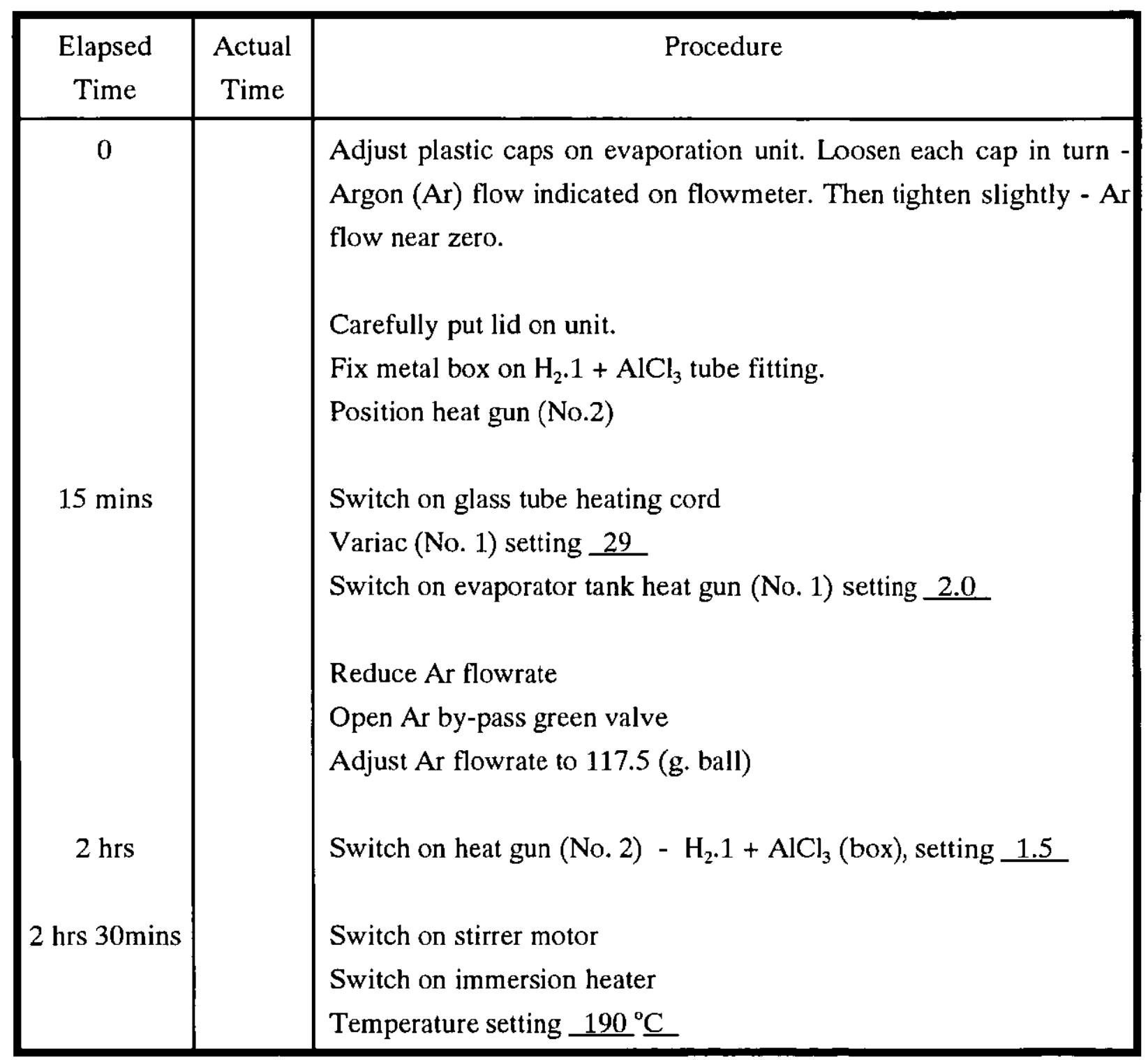




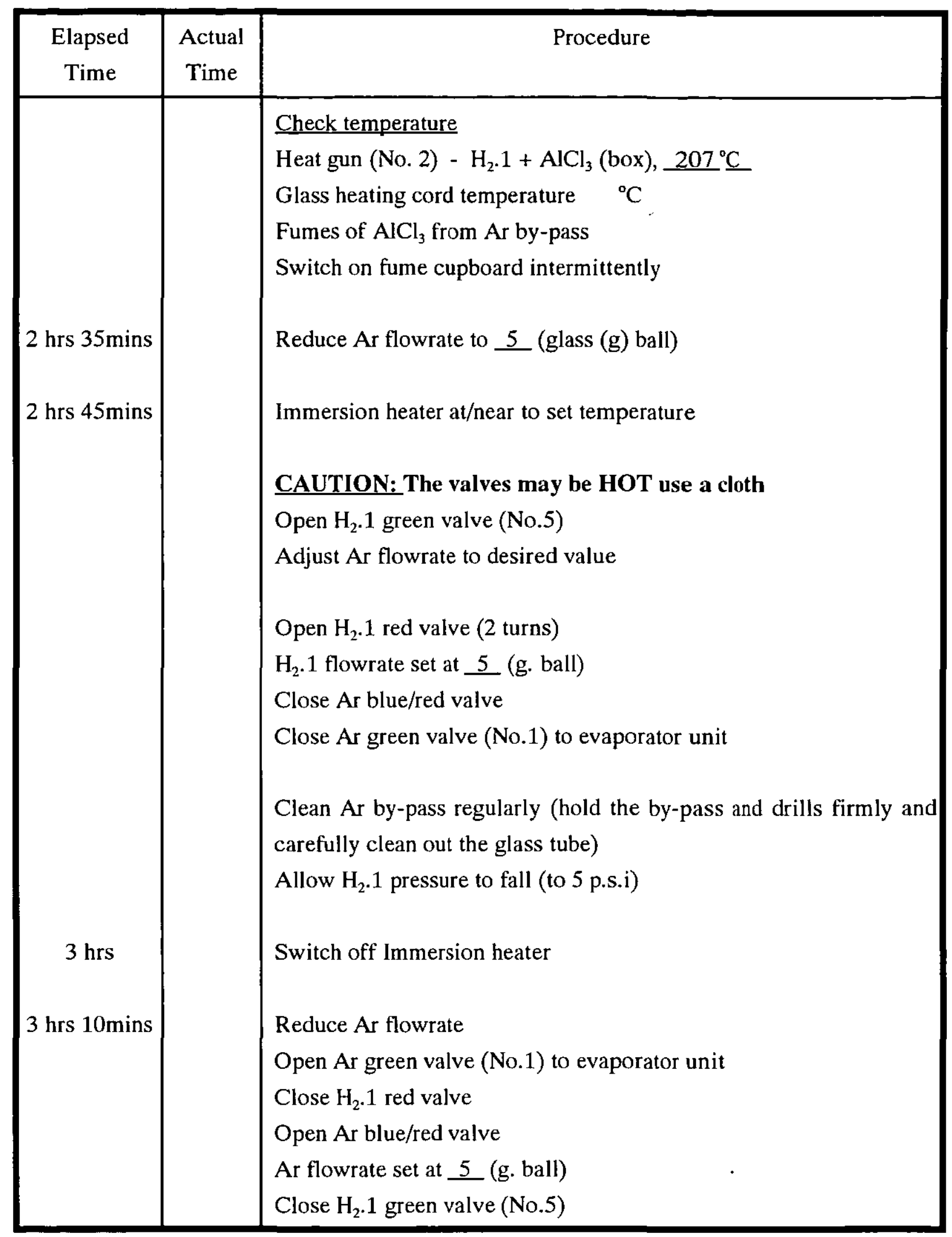




\begin{tabular}{|c|l|l|}
\hline $\begin{array}{c}\text { Elapsed } \\
\text { Time }\end{array}$ & $\begin{array}{c}\text { Actual } \\
\text { Time }\end{array}$ & \multicolumn{1}{|c|}{ Procedure } \\
\hline 3 hrs 15mins & $\begin{array}{l}\text { Switch off stirrer motor } \\
\text { Switch off heat gun No. 2 } \\
\text { Reduce heat gun (No. 1) to setting 1.5 } \\
\text { Switch on fume cupboard intermittently }\end{array}$ \\
4 hrs 15mins & $\begin{array}{l}\text { Clean out Ar bypass regularly } \\
\text { Switch off glass tube heating cord variac (No. 1) } \\
\text { Switch off evaporator tank heat gun (No. 1) } \\
\text { Close Ar bypass red valve } \\
\text { Leave evaporator unit under Ar (flowrate 25 ) for an hour } \\
\text { Increase Ar flowrate to absolute maximum }\end{array}$ \\
\hline
\end{tabular}


APPENDIX 5

DETERMINATION OF LATTICE PARAMETERS FOR HEXAGONAL SYSTEMS 


\section{A5.0 DETERMINATION OF LATTICE PARAMETERS FOR HEXAGONAL SYSTEMS}

Patterns of hexagonal crystals can be indexed by graphical methods, since the hexagonal unit cell is characterised by two variable parameters, a and $c$. The plane-spacing equation [83] is:

$$
d=\left[\frac{4}{3 a^{2}}\left(h^{2}+k^{2}+h k\right)+\frac{l^{2}}{c^{2}}\right]^{\frac{-1}{2}}
$$

rearrange eqn(1):

$$
\frac{1}{d^{2}}=\frac{4}{3 a^{2}}\left(h^{2}+k^{2}+h k\right)+\frac{l^{2}}{c^{2}}
$$

if

$e=\frac{4}{3}\left(h^{2}+k^{2}+h k\right)$

$f=l^{2}$

Both $e$ and $f$ vary depending on family of planes $(h, k, l)$ being considered

$$
\frac{1}{d^{2}}=\frac{e}{a^{2}}+\frac{f}{c^{2}}
$$

$\mathrm{d}$ varies similarly, but $\mathrm{c}$ and a should be constant

Multiply eqn (3) by $\quad d^{2}$

$$
\begin{gathered}
1=\frac{e d^{2}}{a^{2}}+\frac{f d^{2}}{c^{2}} \\
\therefore \quad \frac{f d^{2}}{c^{2}}=1-\frac{e d^{2}}{a^{2}} \\
\therefore \quad f d^{2}=c^{2}-\frac{c^{2}}{a^{2}} e d^{2}
\end{gathered}
$$

Plot $f d^{2}$ vs $e d^{2}$-obtain straight line graph 
The value of $c$ may be obtained by determining the intersection of the line at the $f d^{2}$ axis i.e. $e d^{2}=0$

$$
\therefore \quad \text { When } e d^{2}=0 \quad f d^{2}=c^{2}
$$

Also, the slope of the line is given by

Slope $\quad=\frac{-c^{2}}{a^{2}}$

which can be used to determine 'a'. 
